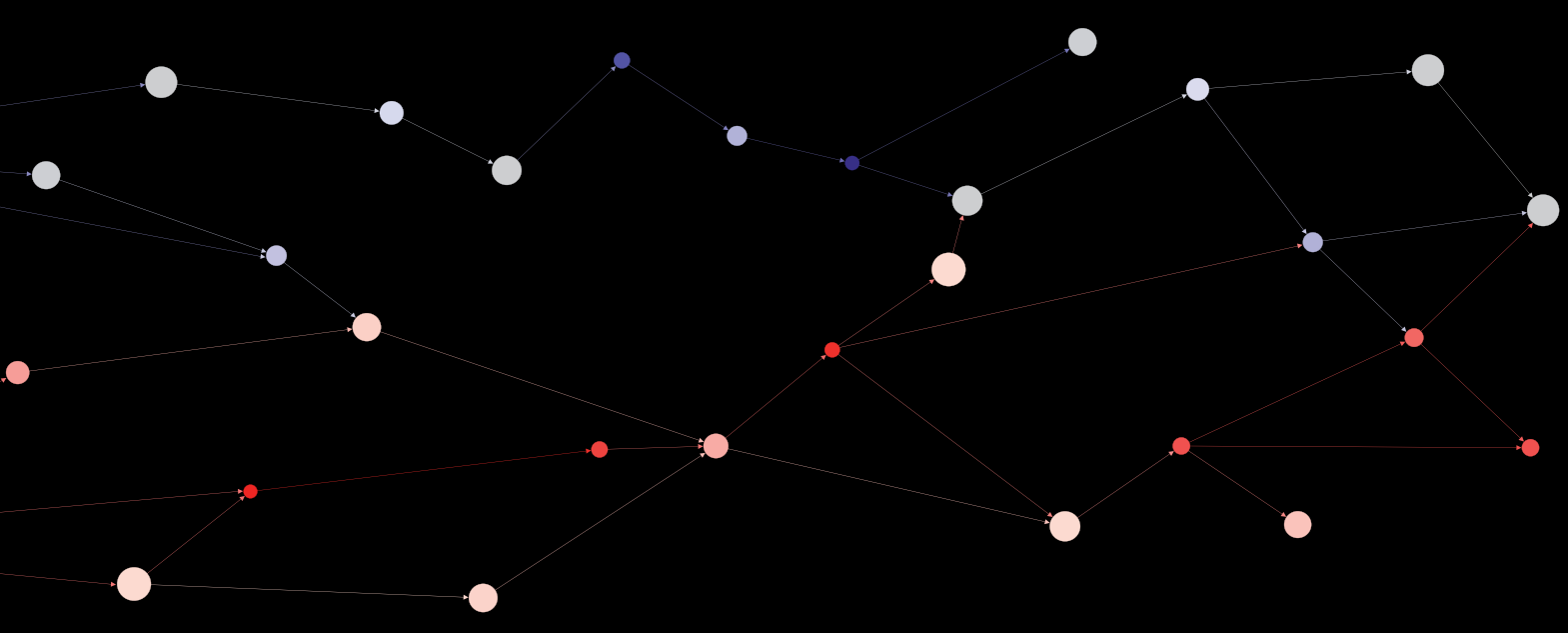

\title{
Industrial Symbiosis as a Social Process
}

DEVELOPING THEORY AND METHODS FOR THE LONGITUDINAL INVESTIGATION OF SOCIAL DYNAMICS IN THE EMERGENCE AND DEVELOPMENT OF INDUSTRIAL SYMBIOSIS 



\section{INDUSTRIAL SYMBIOSIS AS A SOCIAL PROCESS}

Developing theory and methods for the longitudinal investigation of social dynamics in the emergence and development of industrial symbiosis

Wouter Spekkink 
Copyright @ 2015 Wouter Spekkink

All rights reserved. No part of this thesis may be reproduced or transmitted in any form or by any means, electronic or mechanical, including photocopy, without prior permission of the publisher and copyright owner, or where appropriate, the publisher of the articles.

ISBN 978-94-6169-785-1

Cover Design Wouter Spekkink

Lay-out and printing Optima Grafische Communicatie, Rotterdam, The Netherlands

Place of Publication Rotterdam, the Netherlands 


\section{Industrial Symbiosis as a Social Process; \\ Developing theory and methods for the longitudinal investigation of social dynamics in the emergence and development of industrial symbiosis \\ Industriële symbiose als een sociaal proces; \\ Over het ontwikkelen van theorie en methoden voor longitudinaal onderzoek naar sociale dynamiek in de emergentie en ontwikkeling van industriële symbiose}

\section{Thesis}

To obtain the degree of Doctor from the

Erasmus University Rotterdam

by command of the Rector Magnificus

Prof.dr. H.A.P. Pols

and in accordance with the decision of the Doctorate Board.

The public defence shall be held on

Thursday, the $4^{\text {th }}$ of February 2016 at 11.30 hours

Wouter Spekkink

born in Zelhem 
DOCTORAL COMMITTEE:

Promotors: $\quad$ Prof.dring G.R. Teisman

Prof.dr. F.A.A. Boons

Other members: Prof.dr. E.H. Klijn

Prof.dr. J. Edelenbos

Prof.dr. R. Torenvlied 


\section{TABLE OF CONTENTS}

$\begin{array}{ll}\text { Acknowledgements } & 7\end{array}$

$\begin{array}{lll}\text { Chapter } 1 . & 11\end{array}$

$\begin{array}{lll}\text { Chapter } 2 . & \text { Literature review }\end{array}$

Intermezzo 1: Developing the conceptual framework 41

Chapter 3. Conceptual framework 45

Intermezzo 2: Changing the scope of the research 59

Chapter 4. Methods: Event Sequence Analysis 63

Chapter 5. The emergence and development of Biopark Terneuzen: 83

A process analysis

$\begin{array}{ll}\text { Intermezzo 3: Introduction of event graphs } & 109\end{array}$

Chapter 6. Building capacity for sustainable regional industrial systems: 113 An event sequence analysis of developments in the Sloe Area and Canal Zone

Intermezzo 4: New types of relationships between events 141

$\begin{array}{lll}\text { Chapter 7. The emergence of collaborations } & 147\end{array}$

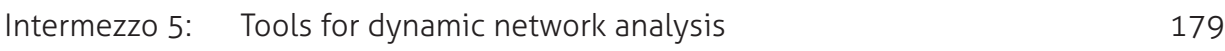

Chapter 8. The network dynamics of collaborative governance: 185

An analysis of sustainable cluster development

Intermezzo 6: Tying everything together 225

$\begin{array}{llr}\text { Chapter 9. Conclusions } & 231\end{array}$

$\begin{array}{ll}\text { References } & 271\end{array}$

Annex 1: $\quad$ Supplementary material to chapter $6 \quad 311$

Annex 2: $\quad$ Supplementary material to chapter $7 \quad 339$ 



\section{ACKNOWLEDGEMENTS}

Writing this $\mathrm{PhD}$ thesis was quite a journey, and there are many people that have helped me see it through to the end. Here, I would like to thank a number of these people.

First I want to thank my promotors, Geert Teisman and Frank Boons. My meetings with Geert were always inspiring and encouraging. Geert knows exactly what to say to point me in the right direction. Especially in the final stages of my PhD project, Geert's advice has been a great help in structuring my thoughts, and putting them on paper. In terms of guidance, there is no one to whom I owe more than I owe to Frank Boons. He made my $\mathrm{PhD}$ project possible, and in the past years he has created countless opportunities for me to grow as a researcher. Frank gave me a lot of freedom in my work, but at the same time he was very closely involved, and always ready to offer me advice when I needed it. His critical feedback helped me more than anything to improve the quality of my work throughout the process. Frank, I can honestly say it is a pleasure and privilege to work with you, and I hope we will continue to work together for many years to come.

The next person I wish to thank is Lasse Gerrits. He was the first person to give me the idea to enter academia, and he made it possible for me to start my work at the Erasmus University Rotterdam as a junior researcher. The energy with which Lasse does his work has been an inspiration to me since I was a student, and I admire the fresh ideas that he and Peter Marks (his partner in crime) come up with. I enjoyed our discussions on ways to systematize qualitative research, and (more importantly) our discussions on making electronic 'music.'

Next, I want to thank the people from the project group Vitaal Sloegebied en Kanaalzone that participated to my workshop on Building blocks for Sustainable Clusters. I especially like to thank Leo Leynse of the province of Zeeland, who was helped to make the workshop possible. I also want to thank Jacco Rentrop, Chris Venderbos, and Alex Crane for receiving me in Moerdijk to discuss the findings of my research. Although my $\mathrm{PhD}$ thesis is mostly based on desk research, it was very valuable to hear the reflections of people that have been closely involved in the developments that I studied.

The Public Administration department of the Erasmus University Rotterdam was a great environment to work in, which I have my former colleagues to thank for. I have had many interesting and enjoyable discussions with people like Jasper Eshuis, Erik-Hans, Arwin van Buuren, Peter Marks, Jurian Edelenbos, and Bonno Pel. I've also had the privilege to be part of a great group of PhD students. Stefan Verweij, Joris van der Voet, Ingmar van Meerkerk and I have known each other since 2004, when we started our first year in the bachelor program of Public Administration. It is a pleasure to see that you are all doing so well in your work. I'm happy that Stefan and I have become close friends. I also want to thank the people in our 'blokje' on the $17^{\text {th }}$ floor of the T-building: Danny Schipper, 
Lieselot Vandenbussche, and Ewald de Bruijn (Stefan was also a proud member of this group). I think it is safe to say that our 'blokje' was the best. My favorite 'drinking buddy' of the department is William Voorberg. I think we've pretty much proven that alcohol is not a necessary ingredient for our conversations to escalate into quasi-philosophical rambling. Then again, it never hurts to gather more evidence. I also would like to specifically mention Iris Korthagen, Ruth Prins, Ruth Post, Shivant Jahgroe, Mark van Ostaijen, Saskia van Broekhoven, Wenting Jiao and Jolien Grandia. I thank you, and all other PhD students, tutors and junior researchers for helping to create the great atmosphere that I experienced during my years in Rotterdam.

I want to thank several people from the Industrial Ecology community. I always look forward to the conferences of the International Society for Industrial Ecology (ISIE), because they are rare opportunities to hang out with people like Graham Aid, Ankit Aggarwal, and Jérémie Joubert. I also thank Yong Geng, who invited me to visit his research group at the Institute of Applied Ecology in Shenyang for three months. It was truly a great experience, and I feel greatly indebted to Yong Geng and his students for hosting me.

One very annoying habit of (some) PhD students is that they tend to 'take their work home.' There are several people that I need to thank for putting up with that. This of course includes those who I sometimes refer to as 'my favorite people:' Machiel Noijen, Stefan Verweij, and Jos van Nistelrooij. Thank you for being such good friends. The people that have had most to suffer from my endless stories about my work are my parents and my brother. I really feel blessed with my family. My parents, Dik and Diny, are always there for me, and they supported me throughout the highs and lows of my PhD life. Visiting my parents in Woudrichem still feels like coming home. My brother has always been an example to me. Martijn, I am very proud of who you are. It is nice to have someone to always look up to.

Sweet Ambra, we first met briefly after I started in my position as a postdoctoral researcher. It took a few months before we started dating, and a few more before you knew how to properly pronounce my name. You're an amazing person, and I enjoy every moment I spend with you. When we are together, I feel happy and at peace. I look forward to all the adventures that we are going to experience together. Somehow, there is one particular moment that sticks in my mind: You were watching television in the living room, and I was doing the dishes in the kitchen. I heard you exclaim "dinosaurus lekker!" Thinking of this moment always brings a smile to my face. 


CHAPTER 1

INTRODUCTION 



\subsection{INDUSTRIAL ECOLOGY AND INDUSTRIAL SYMBIOSIS}

In the nineties we have witnessed the emergence of Industrial Ecology. As the name suggests, researchers in the field have looked at natural ecosystems as models for industrial activity. It promotes the view that industrial systems can reduce their impact on their natural environment, while at the same time improving their economic performance through efficient cycling of material and energy flows (Frosch and Gallopoulos 1989; Lifset and Graedel 2002). The part of this field that is known as Industrial Symbiosis focuses specifically on the improvement of environmental and economic performance of regional industrial systems through the exchange of by-products, and shared use of utilities and services between companies (Van Berkel, Majer, and Stehlik 2007; Chertow, Ashton, and Espinosa 2008). According to its most often cited definition "industrial symbiosis engages traditionally separate entities in a collective approach to competitive advantage involving physical exchange of materials, energy, water, and by-products. The keys to industrial symbiosis are collaboration and the synergistic possibilities offered by geographic proximity" (Chertow 2000, p. 314). Industrial symbiosis is seen as one of the main contributors to the development of eco-industrial systems, i.e., industrial systems that mimic the webs of flows that occur in natural ecosystems ${ }^{1}$. A specific variant of such systems is the Eco-Industrial Park (EIP), where eco-industrial principles are applied within the geographical boundaries of industrial parks (Côté and Cohen-Rosenthal 1998). Although the development of EIPs is often equated to industrial symbiosis, EIP development usually entails other activities as well, such as the implementation of cleaner production techniques and green supply chain management (Lowe, Moran, and Holmes 1996; Shi, Tian, and Chen 2012).

Chertow's (2000) definition of industrial symbiosis highlights the two core themes of this thesis. First, it highlights that industrial symbiosis has a significant social dimension, here summarized in the statement that collaboration is seen as one of the keys to industrial symbiosis. As I discuss in section 1.2, various insights on the social dimension of industrial symbiosis have been developed. However, few attempts have been made to systematize these insights in a more encompassing conceptual framework that allows us to study how the capacity of relevant actors to engage in industrial symbiosis emerges and develops (cf. Boons, Spekkink, and Mouzakitis 2011). One contribution that I seek to make in this thesis is to develop and apply such a framework as an aid in further theoretical advancement. The definition of Chertow (2000) also emphasis that industrial symbiosis is best conceived as a process (Boons, Spekkink, and Mouzakitis 2011; Boons, Spekkink, and Jiao 2014). Although various contributions to the literature on industrial

1. Another term that is frequently used to refer to webs of material and energy exchanges as outcomes of industrial symbiosis is simply 'industrial symbiosis network.' 
symbiosis express this view conceptually (see section 1.3), this has not yet led to the development and/or application of methodological approaches that allow for the systematic investigation of processes (see Paquin and Howard-Grenville 2012; Yu, de Jong, and Dijkema 2014 for exceptions). Another aim that is at the basis of this thesis is to contribute to the development of such a methodological approach. Thus, two research questions are at the basis of this thesis:

1. How does the collective capacity of firms, governments, knowledge institutes and other relevant actors to engage in industrial symbiosis emerge and develop?

2. What can methods, techniques and tools that are dedicated to the systematic and longitudinal investigation of process phenomena contribute to our understanding of industrial symbiosis?

The first research question expresses my view that industrial symbiosis can be understood as a governance problem, i.e., that industrial symbiosis entails an interactive process between firms, governments, knowledge institutes and other relevant actors through which issues of common concern are tackled (Stoker 1998; Kooiman 1999; Kooiman et al. 2008). Thus, to address the social dimension of industrial symbiosis I focus on the emergence and development of the collective capacity of actors in regional industrial systems to coordinate their actions and interactions in the development of industrial symbiosis. I operationalize the development of this capacity as the development of social relationships and shared knowledge, as well as the emergence of shared visions and actors with a central position in their social network (Healey, de Magalhaes, and Madanipour 1999; Healey et al. 2003).

Another characteristic of the perspective used in this thesis is the emphasis that is put on the temporal dimension of industrial symbiosis and capacity building. A major part of the thesis is constituted by an exploration of methods, techniques and tools that can be used for a systematic, longitudinal investigation that takes the temporal dimension of the investigated phenomena seriously. Methodological approaches that have this aim have been in development in several fields of research, including sociology (Abell 1987; Heise 1991; Abbott 2001; Griffin 1992), organization studies (Pettigrew 1990; Langley 1999; Poole et al. 2000; Hernes 2008; Sminia 2009), and political science (Mahoney 2004; Hall 2006; Howlett 2009)2. A central characteristic shared by most of these approaches is that the units of analysis are (sequences of) events, rather than fixed entities with variable attributes (Abbott 1988). In this thesis I build on some of these methodological approaches, but also make contributions to their further development. These contributions are part of a joint effort of a small group of researchers from the Public Administration

2. These are just a few examples. A useful overview of publications on process research methods is published on the website www.processresearchmethods.org. 
department of the Erasmus University. We named this approach Event Sequence Analysis (ESA; Boons, Spekkink, and Jiao 2014).

In the next section I offer a more detailed discussion on the various ways in which the social dimension of industrial symbiosis has been addressed in literature (section 1.2). Section 1.3 explores various ways in which the process dimension has been dealt with in the same literature. In sections 1.4 and 1.5 I outline how I build on this existing material to develop the basis for my own research. In section $1.6 \mathrm{I}$ introduce the outline of my thesis.

\subsection{THE SOCIAL DIMENSION OF INDUSTRIAL SYMBIOSIS}

One of the earliest publications in the emerging field of industrial symbiosis ${ }^{3}$ defines it as "an application of industrial ecology which seeks to optimize the efficiency of material and energy flows through large-scale industrial processes. Fundamental to this approach is the cascading use of energy and the use of industrial byproducts as feedstocks for processes other than the ones that created them" (Gertler 1995, pp. 14-15). This definition reflects the fact that industrial symbiosis is often approached as a technical issue, although it was recognized from an early stage of development that industrial symbiosis has a strong social dimension. Typically, the social dimension of industrial symbiosis refers to the need for firms to interact more extensively than is required for normal business practice. In his further elaboration of the concept, Gertler (1995) argues that "because industrial symbiosis requires interaction and trust among companies that goes well beyond normal business practice, such expanded collaboration is both a component and a necessary precursor of industrial ecosystem development" (Gertler 1995, p. 15). By now there are many publications in the field that address the social dimension of industrial symbiosis, using a variety of concepts (Boons, Spekkink and Mouzakitis 2011). One of the concepts that have been used to capture the social dimension of industrial symbiosis is that of trust, which is seen as a key condition for the willingness of public and private actors to share information, to do business together, and to cooperate and commit themselves to industrial symbiosis (Gibbs 2003; Ashton 2008). Trusting relationships between actors may develop through the activities of champions or brokers (Hewes and Lyons 2008; Paquin and Howard-Grenville 2009), or through frequent interactions that take place between players at industrial parks, which may coincide with other ongoing activities (Boons and Janssen 2004).

3. Although the concept of industrial symbiosis has been used in economic geography as early as the 1947 (Renner 1947), industrial symbiosis emerged as a subfield of industrial ecology in the 1990s, after publication of the seminal article on industrial ecosystems by Frosch and Gallopoulos (1989). Also see Chertow, Ashton and Kuppalli (2004). 
Industrial symbiosis has also been related to (social) learning and innovation. For some, learning processes and innovation are inherent parts of industrial symbiosis (Lambert and Boons 2002; Doménech and Davies 2011). Mirata en Emtairah (2005) see innovation as an outcome to which industrial symbiosis contributes by offering collective problem definitions, by making search and discovery at inter-sectoral interfaces possible, and by learning through inter-organizational collaboration. For Chertow, Ashton and Espinosa (2008) one of the outcomes of industrial symbiosis is collective learning about the economic and environmental management of shared resource management. Similarly, Posch (2010) sees industrial symbiosis as a potential starting point for broader collaborations on sustainable development.

Several scholars in the field of industrial symbiosis have applied the concept of social embeddedness to study the wider social context in which industrial symbiosis takes place, usually referring to the work of Uzzi (1997) and Granovetter (1985; also see Boons and Howard-Grenville 2009b). The concept of social embeddedness expresses the view that economic activities are embedded in (and therefore strongly influenced by) structures of social relationships, which may differ across time and space (Granovetter 1985; Uzzi 1997). One of the first to introduce the concept of embeddedness to the field of industrial symbiosis is Baas (2008), who uses the concept in his argument that industrial symbiosis activities are shaped by the cognitive, structural, cultural, political, spatial and temporal context in which they take place. Doménech and Davies (2011) study the influence of social embeddedness on decision-making processes in the development of industrial symbiosis and Ashton and Bain (2012) study the causal relationships between social embeddedness, social capital (in the spirit of Bourdieu 1986; Nahapiet and Ghoshal 1998) and industrial symbiosis.

Several scholars have discussed the role of coordinating bodies in industrial symbiosis. These may, for example, take the form of "anchor tenants," which are large firms that provide the critical mass for industrial symbiosis to commence (Chertow 2000). The role of coordinating body may also be performed by governmental agencies (Burström and Korhonen 2001), or business associations (Heeres, Vermeulen, and De Walle 2004). Mirata (2004) discusses various activities of coordinating bodies in industrial symbiosis in detail, such as providing informational support, the creation of a supporting institutional setting, and providing guidance on actions that are required to achieve long-term environmental sustainability. Similarly, Paquin and Howard-Grenville (2009; 2012) offer detailed discussions of the activities that brokers undertake to facilitate industrial symbiosis, such as enhancing and intensifying communication among potential partners, and informing them about potential symbiotic exchanges.

In summary, the social dimension of industrial symbiosis has been studied under several guises in the literature on industrial symbiosis. The strategy has usually been to borrow specific concepts from social science literature and apply them in case studies of 
industrial symbiosis. The various insights that have been developed this way have strong parallels with those developed in literature on collaborative planning (Healey 1998; Healey et al. 2003; Innes and Booher 2010), consensus building (Susskind, McKearnan, and Thomas-Larmer 1999; Innes and Booher 1999), and collaborative governance (Bryson, Crosby, and Stone 2006; Ansell and Gash 2008; Emerson, Nabatchi, and Balogh 2012). Typically, scholars in these fields study processes in which a wide range of public and private actors engage in decision-making or management activities that are aimed at achieving a common purpose that the actors could not have attained alone (Bryson, Crosby, and Stone 2006; Ansell and Gash 2008; Emerson, Nabatchi, and Balogh 2012). An almost equivalent interpretation is sometimes given to the role of collaboration in industrial symbiosis (Zhu et al. 2007; Lombardi and Laybourn 2012). A clear link between these literatures and the literature on industrial symbiosis has not yet been made, while making the link provides the opportunity to study the various social aspects to industrial symbiosis in a more integrated way. One of the contributions of this thesis is to act on this opportunity by applying insights from the aforementioned fields to the investigation of industrial symbiosis. Before discussing this in more detail (see section 1.4), the second central theme of the thesis requires further introduction, namely that industrial symbiosis is best understood as a process.

\subsection{INDUSTRIAL SYMBIOSIS AS A PROCESS}

The process dimension of industrial symbiosis is evident in several of its conceptualizations. Interestingly, many of these conceptualizations use a stage-based approach, where the final stage usually represents the maturation of an industrial system into an eco-industrial system. Baas and Boons (2004) conceptualize the process of industrial symbiosis as one in which regional industrial systems go through the stages of regional efficiency, regional learning and sustainable districts. They emphasize the changes in coordination strategies and sustainability visions that occur as a system moves from one stage to the next. Chertow and Ehrenfeld (2012) build on the stage model of Baas and Boons (2004) to develop their own stage-model, which distinguishes between the phases of sprouting, uncovering, and embeddedness and institutionalization. Their model emphasizes that initial symbiotic exchanges may develop "randomly" (i.e., without the explicit intent to engage in industrial symbiosis) and that such "kernels" to symbiosis may be used as a basis for the development larger networks of symbiotic exchanges after they are "uncovered" (also see Chertow 2007). Doménech and Davies (2011) develop a model that distinguishes between the phases of emergence, probation and development and expansion. The model emphasizes the importance of trust building and cooperation. Based on their case studies of the National Industrial Symbiosis Programme in the 
United Kingdom, Paquin and Howard-Grenville (2012) distinguish between three phases of facilitated industrial symbiosis that they label as pre-network development, earlier network development and later network development. They investigate how serendipitous and goal-directed processes interact to influence this evolution, and discuss the predominant activities of facilitators in the different phases.

Several scholars in the field compare industrial symbiosis to the evolution and adaptation of natural ecosystems (Jelinski et al. 1992; Hardy and Graedel 2002). Ehrenfeld and Gertler roughly summarize this process as "moving from linear throughput to closedloop material and energy use" (1997, p. 68). Korhonen and Snäkin (2005) use this idea to distinguish between type I, II and III industrial ecosystems. For them, the process through which the system evolves from one stage to the next entails increases in the roundput of material and energy flows and increases in the diversity of involved actors. Pakarinen et al. (2010) use a similar approach, but focus on the evolution of four different system components (non-renewable resources, emissions to nature, land use and impacts on human health and society) rather than describing the evolution of the system as a whole. Several contributions to the edited volume of Ruth and Davidsdottir (2009) promote evolutionary models that are not stage-based. Ashton (2009) introduces an adapted version of the adaptive cycle of Gunderson and Holling (2002; also see Holling 2001). According to this model, industrial ecosystems can be understood to move through cycles of release, mobilization, exploitation and conservation.

Some authors conceptualize self-organized and planned industrial symbiosis as two distinct dynamics through which eco-industrial systems may come about. Chertow (2007; 2009; also see Baas 2011) offers one of the clearest statements of this view, although a similar distinction (engineering or self-designing) had been introduced earlier (Côté and Cohen-Rosenthal 1998; Cohen-Rosenthal 2000). Roughly, planned industrial symbiosis concerns those developments where a conscious effort is made to locate companies together and engage them industrial symbiosis, whereas in the self-organized model industrial symbiosis builds on existing kernels of cooperation and exchange that were developed without the intention to engage in industrial symbiosis (Chertow 2007). Verguts et al. (2010) add more depth to the distinction between planned and self-organized industrial symbiosis based on insights derived from transition management and organizational change. Costa and Ferrão add a third model to this distinction, which they refer to as the middle-out approach: "In a middle-out approach, agents from governmental, industry, university and other institutions converge in a positive feedback process to create an adequate context that is able to support industrial symbiosis development" (2010, p. 991; also see Paquin and Howard-Grenville 2009).

The observant reader will have noticed that the process dimension of industrial symbiosis is often associated with the social dynamics that industrial symbiosis entails. In my view, these social dynamics, and the long-term nature of industrial symbiosis (Heeres, 
Vermeulen, and de Walle 2004; Gibbs and Deutz 2007; Baas 2011) are inextricably intertwined. More specifically, the relevance of the social dynamics is to be sought primarily in the long-term development of the social context in which by-product exchanges and utility synergies are realized. This is the topic of the next section.

\subsection{INDUSTRIAL SYMBIOSIS AND INSTITUTIONAL CAPACITY BUILDING}

In their analysis of the iconic case of Kalundborg in Denmark, Ehrenfeld and Gertler (1997) find that each of the exchanges was negotiated as an independent business deal and was established for economic motivations. These economic incentives alone were found to be generally sufficient for most of the exchanges (also see Lowe and Evans 1995). Chertow (2007) also observes that individual exchanges are often developed for conventional business reasons, and Desrochers (2000; 2002; 2004) has repeatedly made the argument that pure market coordination is the best approach to the creation of inter-firm recycling linkages (but see Boons 2008). These observations show that the development of individual by-product exchanges and utility synergies does not necessarily presuppose an elaborate collaboration taking place among a large group of actors. They may be relatively common transactions between two or more firms, and perspectives such as Transaction Cost Economics may come a long way in the development of solid explanations for the way that these transactions are governed (Williamson 1985; Ehrenfeld and Gertler 1997; Stift 2011). However, the social dynamics that industrial symbiosis entails are primarily important in understanding the emergence and development of the wider social context in which transactions are realized ${ }^{4}$ (Cohen-Rosenthal 2000). In this regard, it is also important to distinguish between individual by-product exchanges or utility synergies that are developed for entirely disparate purposes, and by-product exchanges and utility synergies that are intentionally developed as building blocks of a larger industrial symbiosis network. In the first case, a network of exchanges may develop as a simple aggregate of individual exchanges. In the second case, the network is the product of a consciously coordinated process through which actors aim to create synergies between the different building blocks of the network. The latter type of development requires actors to shift their focus from autonomous decision-making to the exchange of knowledge, the development of broader visions on sustainability, and the inclusion of new stakeholders (Baas and Boons 2004). This shift of focus may oc-

4. Similarly, in his elaboration of the framework of Transaction Cost Economics, Williamson (1996) distinguishes between the governance dynamics of individual transactions and the slower paced changes that may occur in the wider institutional environment (changes in property rights, contract laws, norms, customs, and the like) that influence the comparative advantages of different governance arrangements. 
cur if actors "uncover" the potential economic and environmental benefits of industrial symbiosis (Chertow 2007).

Based on the foregoing, the perspective developed in this thesis builds on the assumption that the primary level of analysis for the investigation of the social dynamics of industrial symbiosis is that of the regional industrial system, which can be understood "as a more or less stable collection of firms located in proximity to one another, where firms in principle can develop social and material/energy connections as a result of that proximity" (Boons, Spekkink, and Mouzakitis 2011, p. 907). At this level we also find other actors, such as governments, knowledge institutes, and interest groups that may become involved in efforts to increase the sustainability of the regional industrial system ${ }^{5}$ (Boons, Spekkink, and Mouzakitis 2011). It is at this level that coordination for the development of networks of by-product exchanges and utility synergies takes place.

As stated earlier in this chapter, the insights that have been developed on the social dimension of industrial symbiosis have parallels with those developed in fields of research that study collaborative forms of governance. Of the various frameworks that have been introduced in these fields, that of Healey and her colleagues (Healey 1998; Healey, de Magalhaes, and Madanipour 1999; Healey et al. 2003) has particular relevance to the investigation of industrial symbiosis, because it explicitly focuses on the long-term development of a context that is conducive to collaborative governance, whereas other perspectives often focus on a particular collaborative process (e.g. Bryson, Crosby, and Stone 2006; Ansell and Gash 2008; Emerson, Nabatchi, and Balogh 2012). Healey et al. (2003) propose that the capacity of actors to engage in collective action is determined by the qualities of their social relations (relational resources), the knowledge resources that flow around and are developed through these relations (knowledge resources), and the capability of actors to mobilize these resources for joint action (mobilization capacity) (also see the distinction of Innes and Booher 1999 between social capital, intellectual capital and political capital). They suggest that institutional capacity "represents a force which is continually emergent, produced in the interactive contexts of its use" (Healey et al. 2003, p. 63). More specifically, their theory is that institutional capacity is created in consensus-oriented/collaborative interactions (Healey 1998; Healey, de Magalhaes, and Madanipour 1999). Thus, the framework draws attention to the long-term social consequences of the various interactions that actors in a region may engage in, and here lies the potential contribution of this perspective to a better understanding of the social dynamics of industrial symbiosis. The concept of institutional capacity building encompasses many of the concepts that have been introduced to the literature on industrial

5. The exact geographical scale of a regional industrial system may vary a lot between different cases and is best treated as an empirical variable (Boons, Spekkink, and Mouzakitis 2011). 
symbiosis to study its social dimensions (Boons and Spekkink 2012a), and therefore also provides the opportunity for a more systematic investigation of these dimensions.

The concept of institutional capacity building takes a central place in the conceptual framework that was developed in the early stages of the research process (see chapter 3 ). A comprehensive literature study revealed that few attempts have been made to provide an adequate conceptual underpinning for empirical investigations of the emergence and development of industrial symbiosis (see chapter 2). The conceptual framework that is presented in chapter 3 aims to fill this gap. It was designed to serve as a framework for explaining the emergence and development of industrial symbiosis in different places of the world. However, in this thesis the focus of research is specifically on the emergence and development of industrial symbiosis in regional industrial systems in the Netherlands. In the empirical studies that are presented in chapters 5 and 6 the framework was used as the conceptual starting point. One of the purposes of the research presented in these chapters is to confront the framework with empirical observations. The findings of the studies suggest that some aspects of the framework require modification to provide a more accurate representation of the dynamics of institutional capacity building as they are observed in the case studies. The chapters close with a number of suggestions for conceptual refinement, which are used as new starting points in the conceptual section of chapter 7. Some of the implications of the modified conceptual framework are tested in chapters 7 and 8, and in the concluding chapter a more elaborate version of the adapted framework is presented. The adapted framework constitutes one of the main products of this thesis. Another main product of the thesis is a set of methods, tools and techniques for the systematic longitudinal investigation of social processes, which is discussed in more detail in the next section.

\subsection{INTRODUCTION TO EVENT SEOQUENCE ANALYSIS}

As stated earlier in this chapter, one of the aims of the thesis is to make a contribution to the development of a methodological approach that is suitable for the investigation of process phenomena. The methodological sections of the studies presented in chapters 5 to 8 reflect the progress that has been made with the development of ESA during the $\mathrm{PhD}$ project. In chapter 5 the emphasis is on the systematic collection of longitudinal data and the development of event sequence datasets in which the data are stored (cf. Poole et al. 2000). The approach to analysis used in chapter 5 can be understood as a form of visual mapping (Langley 1999). In chapter 6 the analysis is further systematized based on the introduction of event graphs and event tables, which are inspired by the work of Abell (1984; 1987; 1993). The idea of event graphs is further elaborated in the methodological section of chapter 7 . In chapters 7 and 8 a link is also sought between 
the process perspective and a structural perspective by combining the analysis of event sequences with social network analysis (Wasserman and Faust 1994; Scott 2013; see especially Doreian 1979; Borgatti and Everett 1997; Borgatti and Halgin 2011). The various methods that were developed for this thesis, as well as the software tools that have been created as an aid in the use of the methods, are discussed in further detail in chapter 4. In the concluding chapter a discussion is offered on the value of ESA in performing longitudinal research.

\subsection{OUTLINE OF THE DISSERTATION}

In the next chapter a literature review is presented that assesses the extent to which an adequate theoretical underpinning for the empirical investigation of industrial symbiosis is present in the literature on industrial symbiosis. The review was published as part of a journal article; only the review is included in this thesis because its results served as the motivation for the introduction of a new conceptual framework. The new conceptual framework is introduced in chapter 3 . This chapter was originally written for a forthcoming book on international perspectives on industrial ecology. In chapter 4 the methods, techniques, and tools that have been developed and applied throughout the research process are presented. The chapter outlines the methodological starting points of the thesis, but it also includes some of the end-products of the research process. Several of the methods, techniques and tools presented in the chapter were developed in response to methodological challenges that arose during the research project. Chapter 4 is written specifically for this thesis. Chapters 5 to 8 are empirical studies that have been published as journal articles, or that have been submitted for publication as a journal article. As is discussed in the previous section, the empirical studies of chapters 5 and 6 test the implications of the original conceptual framework of this thesis, while chapters 7 and 8 test the implications of a modified version of the framework. The modified framework is presented in detail in the concluding chapter of the thesis (chapter 9). In the same chapter the value of ESA for the longitudinal investigation of industrial symbiosis is discussed, and a number of recommendations for further research and for practice are made. Intermezzos are placed between most of the chapters, the aim of which is to highlight the progressive theoretical and methodological insights that developed throughout the research process. With the exception of chapter 4, the chapters of this thesis are placed in the order that they were written. Before a new chapter was written, the methodological and/or theoretical basis of the research typically expanded. The intermezzos are designed to provide the reader a better understanding into this developmental process, by describing what happened 'in between' the writing of the different chapters. 




\section{CHAPTER2}

\section{LITERATURE REVIEW}

This chapter is published as part of Boons, F. A. A., Spekkink, W. A. H. and Mouzakitis, Y. 2011. The Dynamics of industrial symbiosis: A proposal for a conceptual framework based upon a comprehensive literature review. Journal of Cleaner Production 19: 905-911. This chapter only includes the literature review that is presented in the article. Minor changes to the text have been made to account for the fact that other parts of the original article are not included, and new text has been added to complete the chapter. 


\section{ABSTRACT}

There is increasing evidence that throughout the world, firms, governmental agencies and NGOs are seeking to stimulate industrial symbiosis. This concept and its application have also been the topic of extensive research. In this chapter, a review of the literature on industrial symbiosis is offered to assess the concepts and theoretical insights that have been proposed to aid understanding of the development of industrial symbiosis. The literature review reveals that there have been few attempts to offer an adequate theoretical underpinning for the analysis and explanation of emergence and development of industrial symbiosis. 


\subsection{INTRODUCTION}

While it has become fashionable to talk about the globalization of economic activities and the corresponding rise in importance of the space of flows, such activities require a specific place where they are performed (Castells, 1996). Within the field of industrial ecology, this space of place has been coined industrial symbiosis. Chertow has defined industrial symbiosis as "engaging traditionally separate industries in a collective approach to competitive advantage involving physical exchange of materials, energy, water, and by-products. The keys to industrial symbiosis are collaboration and the synergistic possibilities offered by geographic proximity" (Chertow 2007, p.12). Removing the intentionality from this definition, industrial symbiosis concerns the material and energy flows and transformations that are generated by economic actors within a geographically bound system. Chertow's definition points to the fact that in several countries, firms, NGOs and governmental agencies have sought to make such flows and transformations more sustainable (for overviews see Mouzakitis et al. 2003; Sakr et al. 2009). The aim of this chapter is to assess the extent to which concepts and theoretical insights have been proposed in literature to aid understanding of this phenomenon.

\subsection{CONCEPTUAL APPROACHES IN THE LITERATURE}

For our literature research we have used the ISI Web of Science database and searched for publications that listed 'industrial symbiosis', 'eco-industrial park', or the combination of 'industrial ecology' and 'regional' as a topic. From the resulting 347 items we removed all entries that dealt with topics unrelated to material and energy flows among firms in regional industrial systems. We also excluded conference proceedings for reasons of accessibility. This procedure resulted in a list of 102 publications that were analyzed first for their conceptual background (see Table 2.1; complete references are given by the end of the chapter on pages 33-39).

Based on our assessment we categorized publications in eight categories. Five categories are excluded from our discussion of the literature, because they do not address our primary interest: To develop a theoretical underpinning of the process through which industrial symbiosis comes about. The first category that we excluded covers descriptive publications. This includes case studies, descriptions of policy developments and historical overviews. In some of these publications findings are generalized post hoc by identifying drivers, barriers, strengths or weaknesses to industrial symbiosis. However, these factors fall short of a theoretical framework because their connections remain unexplored. The second excluded category covers the publications which present a model. These are usually developed to aid in the design and evaluation of eco-industrial 
Table 2.1: Number of ISI listed publications in eight categories. The first three categories are included in the discussion on literature in section 2.2. See pages 28-39 for the complete overview of the literature included in the review. The numbers between parentheses correspond with the numbers reported in section 2.3.

\begin{tabular}{lll}
\hline Included & Explanatory conceptual frameworks and theories & $13(1-13)$ \\
& Typologies & $2(14,15)$ \\
& Methodologies & $2(16,17)$ \\
Not Included & Descriptions & $38(18-55)$ \\
& Models & $27(56-82)$ \\
& Normative conceptual frameworks and theories & $11(83-93)$ \\
& Ouantitative evaluations & $6(94-99)$ \\
& Epistemological discussions & $3(100-102)$ \\
\hline
\end{tabular}

parks. Although some of the models also attempt to develop an understanding of the coming about of industrial symbiosis, they are predominantly prescriptive and necessarily limited to only a few parameters and variables (Ostrom 2007a). A third category we excluded from our discussion covers publications that offer conceptual frameworks or theories of a normative nature. These are designed and applied to prescribe how industrial symbiosis should develop but they do not analyses and explain empirical cases of industrial symbiosis developments. The fourth category we excluded covers quantitative analyses of the outcomes of industrial symbiosis developments. Although these are very useful in understanding the outcomes of industrial symbiosis, they do not offer an understanding of the process through which industrial symbiosis comes about. The last category we excluded is that of publications that provide epistemological discussions about the use of nature as an analogy, model or metaphor.

The remaining publications relate to the purpose of developing a theoretical framework for analyzing and explaining the process through which industrial symbiosis comes about. The first category covers publications that offer conceptual frameworks or theories for understanding empirical cases of industrial symbiosis. Korhonen and Snäkin (2005) build their conceptual framework on a model of natural ecosystems. They analyse and explain the evolution of an industrial park from a type I ecosystem into a type III ecosystem, using the concepts of roundput, diversity, and connectance. They argue that increased diversity (of the actors involved) enhances connectance and opens up new possibilities for cooperation, although increasing the number of actors can also lead to conflicting interests, thereby preventing connectance and interdependency. Mirata and Emtairah (2005) discuss industrial symbiosis networks from the perspective of innovation studies. The authors argue that industrial symbiosis networks can contribute to fostering environmental innovation at the local or regional level by stimulating the collective definition of problems, providing inter-sectoral interfaces, and promoting a culture of interorganizational collaboration oriented towards environmental challenges. Lyons (2007) examines the relationship between geographical scale and loop closing 
for heterogeneous wastes. He finds that there is no preferable spatial scale at which loop closing should be organized. According to Lyons, loop closing is dominated by the spatial economic logic of the transactions of the involved firms. Ashton (2009) builds a framework for the analysis of the structure, function and evolution of regional industrial ecosystems by combining perspectives from economic geography and industrial ecology with Holling's theoretical framework of complex systems. The emphasis in Ashton's framework is on successional changes observable in regional industrial ecosystems (exploitation, conservation, release, and mobilization). Patterns of change in regional industrial ecosystems are described for multiple levels of analysis, using the metaphor of ecosystem development and concepts borrowed from literature on economic geography and industrial ecology. The link between industrial ecology and concepts of economic geography has also been explored by Deutz and Lyons (2008), Deutz and Gibbs (2008) and Chertow, Ashton and Espinosa (2008).

There are several publications that draw more attention to the social aspects of industrial symbiosis. Lambert and Boons (2002) describe the sustainable development (including industrial symbiosis) of industrial parks as a social process based on ecological, social, and economic aspects and emphasize the importance of learning processes among social actors. The authors describe two main difficulties in the development towards sustainability. First, it is relatively easy to achieve superficial, short-term social changes, but social actors have a tendency to fall back into their old patterns of behavior on the long term, due to their embeddedness in an institutional context. Second, to ensure system change rather than system optimization, it needs to emerge from the existing system. Thus all system actors need to be involved in the change process. In addition, Lambert and Boons suggest that, in practice, change towards sustainability is particularly difficult to achieve in mixed industrial parks due to divergent interests of the involved actors, a lack of collective organizations, and minimal experience with cooperation. Baas and Boons (2004) develop a social science framework for investigating regional industrial ecology. Central to their analytical framework is a three-phased learning process that can be used to analyze the evolution of industrial ecology initiatives. The phases are called regional efficiency, regional learning, and sustainable industrial district. Each phase is associated with different governance mechanisms through which different types of collective competitive goods are produced. Hewes and Lyons (2008) investigate the role of champions of industrial symbiosis in the establishment of humanistic connections in industrial symbiosis developments. The main focus of the authors is on the concept of trust and its relation to the concepts of community embeddedness and proximity. Posch (2010) investigates whether industrial recycling networks or industrial symbiosis projects can be used as a starting point for broader inter-company cooperation for sustainable development. In his conceptual discussion Posch defines sustainable development as an outcome of sustainability-oriented cooperation between 
human actors and stakeholders. According to Posch sustainable development revolves around the decisions made by particular people in particular organizations and social settings. "How such individuals perceive their concrete situation, their possibilities and their responsibilities, determines whether sustainability networks emerge."

Costa et al. (2010) argue that industrial symbiosis depends on an enabling context which can be described in terms of cognitive, structural, cultural, political, spatial and temporal embeddedness. The authors consider self-organization a more feasible strategy for the development of industrial symbiosis but building on the findings of Mirata (2004) in his assessment of the (National Industrial Symbiosis Programme) NISP in the United Kingdom they argue that coordinating bodies and governmental policies can foster (or pose barriers to) the development of industrial symbiosis by influencing some of the factors that shape the enabling context of industrial symbiosis. The authors focus on the influence of policy development at the supra-national, national, and subnational level. Similarly, Costa and Ferrão (2010, p. 985) suggest that a context favorable to the development of industrial symbiosis "can be shaped through an interactive process wherein the government, industries and other institutions are guided towards aligning their strategies in support of collaborative business strategies in resource management". The authors refer to this process as the middle-out approach.

Another category we include in our discussion covers two publications that offer a typology of different shapes of industrial symbiosis. Based on a taxonomy of eco-industrial parks Chertow (2000) distinguishes 5 material exchange types of which the inter-firm exchanges are identified as industrial symbiosis: Those among firms co-located in a defined eco-industrial park, those among local firms that are not co-located, and those among firms organized 'virtually' across a broader region. In addition, Chertow discusses several tools and approaches for developing eco-industrial parks. She argues that evolutionary approaches are key to the development of eco-industrial parks because cooperation develops over time. Three possible variants are suggested: (1) building on existing types of material or energy exchange, (2) building on pre-existing organizational relationships and networks, and (3) the anchor tenant model. In another publication Chertow (2007) distinguishes between a planned model and a self-organizing model of industrial symbiosis. The former refers to conscious efforts to identify firms from different industries and co-locate them so they can share resources across and among them. The latter refers to industrial ecosystems that emerge from the decisions by private actors motivated to exchange resources for economic reasons. Chertow argues that policy initiatives should be focused on the identification of industrial symbiosis and aid in their further development.

The last category we include in our discussion covers two publications that develop methodologies for analyzing empirical cases of industrial symbiosis. Ashton (2008) discusses the increasing attention given to the social aspects of industrial symbiosis and 
introduces social network analysis as a methodology to study the patterns of relationships, interactions, and social structure that are often emphasized in social theories. She demonstrates the relevance of this methodology in the context of industrial symbiosis by using it to analyze the relation between connectivity among firms and managers in the Barceloneta region of Puerto Rico and the observed industrial symbiosis linkages there. Wright et al. (2009) propose a methodology for translating ecological quantitative analysis techniques to an industrial context. The methodology is demonstrated in the case of Burnside industrial park, using the concepts of connectance and diversity. The demonstrated techniques can potentially aid in gaining an understanding of industrial symbiosis.

This overview shows the richness of the work that has been done in the field of industrial symbiosis. However, it also reveals that there is only a small amount of publications that attempt to offer a theoretical underpinning for the analysis and explanation of empirical cases of industrial symbiosis. In addition, these publications have a very specific focus, as they take one theoretical approach and explore industrial symbiosis through that lens. In our view the field of industrial symbiosis would benefit from a conceptual framework that allows for a more encompassing analysis of industrial symbiosis developments.

\subsection{INSTITUTIONAL CAPACITY BUILDING AS THE BASIS FOR A NEW FRAMEWORK}

In the next chapter a conceptual framework is introduced that specifically addresses dynamics of industrial symbiosis at the level of the regional industrial system ${ }^{6}$. The literature on industrial symbiosis itself offers few building blocks for developing such a framework. Therefore, the framework builds primarily on a concept that has not been applied in the literature on industrial symbiosis before, but that is able to tie together various relevant factors that have been identified in the literature on industrial symbiosis. This is the concept of institutional capacity building, which was first introduced in the literature on collaborative planning (Healey 1998; Healey et al. 1999; Healey et al. 2003; also see Innes and Booher 1999). To specify how the concept of institutional capacity building is able link insights that have been developed in the literature on industrial symbiosis, several factors identified in the literature review provided above are summarized here (also see Boons and Spekkink 2012a):

6. A framework that addresses dynamics at the societal level (or the policy level) was introduced by Jiao and Boons (2014). 
1. Patterns of relationships and interactions between actors (Ashton 2008), which have also been addressed in terms of connectance and interdependency (Korhonen and Snäkin 2005; Wright et al. 2009).

2. The need for an inclusive social learning process (Lambert and Boons 2002), which may be accompanied by the collective definition of problems (Mirata and Emtairah 2005), and the development of a shared strategic vision (Baas and Boons 2004);

3. The role of champions (Hewes and Lyons 2008), anchor tenants (Chertow 2000), or other types of coordinating bodies (Heeres et al. 2004; Mirata 2004).

4. The presence of an enabling context, which can also be shaped by different types of actors (Mirata 2004; Costa and Ferrão 2010).

Institutional capacity can be understood as the capacity of a community of actors to engage in collective action. Healey et al. (2003) distinguish between three dimensions of institutional capacity:

- Relational capacity: A network of relationships, based on trust and mutual recognition;

- Knowledge capacity: Shared knowledge and experience, including shared conceptions of issues, problems and solutions;

- Mobilization capacity: The capacity to mobilize relational capacity and knowledge capacity for joint action.

The analysis of institutional capacity focuses primarily on the interplay of these three dimensions. Rather than representing a stock of assets, institutional capacity "represents a force which is continually emergent, produced in the interactive contexts of its use" (Healey et al. 2003, p. 64). The interplay between the three dimensions is captured in the concept of institutional capacity building. A short summary of this idea is offered here (based on Healey et al. 2003 and Innes and Booher 1999), and the links with factors identified in the literature on industrial symbiosis (summarized above) are clarified by showing their numbers between parentheses.

It is assumed that the process of institutional capacity building starts with the development of relationships between actors (1), based on repeated interactions. Healey (1998), for example, suggests that such relationships may develop through collaborative action. The network of relationships that emerges allows knowledge and experience to flow around, which contributes to the development of shared definitions of problems and solutions (2). The existence of the network of relationships, and the existence of shared definitions of problems and solutions offer key actors a basis to mobilize others for joint action (3). Where institutional capacity is strong, it may be mobilized to influence contextual conditions that are normally outside the sphere of influence of the involved actors (factor 4). One of the most far-reaching effects of institutional capacity building is social learning, which contributes to the identification of new ways in which 
the involved actors can solve common problems. A concrete outcome of social learning is the development of a shared strategic vision that articulates common conceptions of problems and agreed upon strategies to solving these (2).

In the next chapter, the conceptual framework is introduced in more detail. Throughout the empirical chapters of this thesis, the framework is further elaborated, and adapted based on progressive insights derived from empirical studies.

\section{OVERVIEW OF PUBLICATIONS INCLUDED IN LITERATURE REVIEW}

\section{Explanatory conceptual frameworks and theories}

1. Ashton, W. S. 2009. The Structure, Function, and Evolution of a Regional Industrial Ecosystem. Journal of Industrial Ecology 13 (2), 228-246.

2. Baas, L. W. and Boons, F. A. A, 2004. An industrial ecology project in practice: exploring the boundaries of decision-making levels in regional industrial systems. Journal of Cleaner Production 12 (8-10): 1073-1085.

3. Chertow, M. R., Ashton, W. S. and Espinosa, J. C. 2008. Industrial Symbiosis in Puerto Rico: Environmentally Related Agglomeration Economies. Regional Studies 42 (10): 1299-1312.

4. Costa, I. and Ferrão, P. 2010. A case study of industrial symbiosis development using a middleout approach. Journal of Cleaner Production 18 (10-11): 984-992.

5. Costa, I., Massard, G. and Agarwal, A. 2010. Waste management policies for industrial symbiosis development: case studies in European countries. Journal of Cleaner Production 18 (8): 815822.

6. Deutz, P. and Gibbs, D. 2008. Industrial Ecology and Regional Development: Eco-Industrial Development as Cluster Policy. Regional Studies 42 (10): 1313-1328.

7. Deutz, P. and Lyons, D. I. 2008. Editorial: Industrial Symbiosis - An Environmental Perspective on Regional Development. Regional Studies 42 (10): 1295-1298.

8. Hewes, A. K. and Lyons, D. I. 2008. The Humanistic Side of Eco-Industrial Parks: Champions and the Role of Trust. Regional Studies 42 (10): 1329-1342.

9. Korhonen, J. and Snäkin, J. 2005. Analysing the evolution of industrial ecosystems: concepts and application. Ecological Economics 52 (2): 169-186.

10. Lambert, A. J. D. and Boons, F. A. 2002. Eco-industrial parks: stimulating sustainable development in mixed industrial parks. Technovation 22 (8): 471-484.

11. Lyons, D. I. 2007. A spatial analysis of loop closing among recycling, remanufacturing, and waste treatment firms in Texas. Journal of Industrial Ecology 11 (1): 43-54.

12. Mirata, M. and Emtairah, T. 2005. Industrial symbiosis networks and the contribution to environmental innovation: The case of the Landskrona industrial symbiosis programme. Journal of Cleaner Production 13 (10-11): 993-1002.

13. Posch, A. 2010. Industrial Recycling Networks as Starting Points for Broader SustainabilityOriented Cooperation? Journal of Industrial Ecology 14 (2): 242-257.

\section{Typologies}

14. Chertow, M. R. 2000. Industrial symbiosis: Literature and Taxonomy. Annual Review of Energy and the Environment 25: 313-337. 
15. Chertow, M. R., 2007. "Uncovering" industrial symbiosis. Journal of Industrial Ecology 11 (1): 11-30.

\section{Methodologies}

16. Ashton, W. S. 2008. Understanding the organization of industrial ecosystems - A social network approach. Journal of Industrial Ecology 12 (1): 34-51.

17. Wright, R. A., Côté, R. P., Duffy, J. and Brazner, J. 2009. Diversity and Connectance in an Industrial Context: The Case of Burnside Industrial Park. Journal of Industrial Ecology 13 (4): 551-564.

\section{Descriptions}

18. Brent, A. C., Oelofse, S. and Godfrey, L. 2008. Advancing the concepts of industrial ecology in South African institutions. South African Journal of Science 104 (1-2): 9-12.

19. Chiu, A. S. F. and Yong, G. 2004. On the industrial ecology potential in Asian Developing Countries. Journal of Cleaner Production 12 (8-10): 1037-1045.

20. Desrochers, P. 2002. Regional development and inter-industry recycling linkages: some historical perspectives. Entrepreneurship and Regional Development 14 (1): 49-65.

21. Desrochers, P. 2004. Industrial symbiosis: the case for market coordination. Journal of Cleaner Production 12 (8-10): 1099-1110.

22. Desrochers, P. 2009. Does the invisible hand have a green thumb? Incentives, linkages, and the creation of wealth out of industrial waste in Victorian England. Geographical Journal 175 (1): 3-16.

23. Desrochers, P. and Sautet, F. 2008. Entrepreneurial policy: The case of regional specialization vs. spontaneous industrial diversity. Entrepreneurship Theory and Practice 32 (5): 813-832.

24. Elabras Veiga, L. B. and Magrini, A. 2009. Eco-industrial park development in Rio de Janeiro, Brazil: a tool for sustainable development. Journal of Cleaner Production 17 (7): 653-661.

25. Geng, Y. and Côté, R. P. 2003. Environmental Management Systems at the Industrial Park Level in China. Environmental management 31 (6): 784-794.

26. Geng, Y. and Côté, R. P. 2004. Applying industrial ecology in rapidly industrializing Asian countries. International Journal of Sustainable Development \& World Ecology 11 (1): 69-85.

27. Geng, Y. and Doberstein, B. 2008. Developing the circular economy in China: Challenges and opportunities for achieving 'leapfrog development'. International Journal of Sustainable Development and World Ecology 15 (3): 231-239.

28. Geng, Y., Haight, M. and Zhu, O. 2007. Empirical analysis of eco-industrial development in China. Sustainable Development 15 (2): 121-133.

29. Geng, Y., Zhang, P., Côté, R. P. and Fujita, T. 2009. Assessment of the National Eco-Industrial Park Standard for Promoting Industrial Symbiosis in China. Journal of Industrial Ecology 13 (1): 15-26.

30. Geng, Y., Zhang, P., Côté, R. P. and Qi, Y. 2008. Evaluating the applicability of the Chinese ecoindustrial park standard in two industrial zones. International Journal of Sustainable Development \& World Ecology 15 (6): 543-552.

31. Gibbs, D. and Deutz, P. 2007. Reflections on implementing industrial ecology through ecoindustrial park development. Journal of Cleaner Production 15 (17): 1683-1695.

32. Gibbs, D., Deutz, P. and Proctor, A. 2005. Industrial ecology and eco-industrial development: A potential paradigm for local and regional development? Regional Studies 39 (2): 171-183. 
33. Harris, S. 2007. Industrial symbiosis in the Kwinana industrial area (Western Australia). Measurement \& Control 40 (8): 239-244.

34. Heeres, R. R., Vermeulen, W. J. V. and de Walle, F. B. 2004. Eco-industrial park initiatives in the USA and the Netherlands: first lessons. Journal of Cleaner Production 12 (8-10): 985-995.

35. Illsley, B., Jackson, T. and Lynch, B. 2007. Addressing Scottish rural fuel poverty through a regional industrial symbiosis strategy for the Scottish forest industries sector. Geoforum 38 (1): 21-32.

36. Kim, H. 2007. Building an eco-industrial park as a public project in South Korea. The stakeholders' understanding of and involvement in the project. Sustainable Development 15 (6): 357-369.

37. Lin, Y. J., Zhang, Z., Wu, F. and Deng, N.S. 2004. Development of Ecological Industrial Parks in China. Fresenius Environmental Bulletin 13 (7): 600-606.

38. Lowitt, P. C. 2008. Devens Redevelopment - The Emergence of a Successful Eco-Industrial Park in the United States. Journal of Industrial Ecology 12 (4): 497-500.

39. Mirata, M. 2004. Experiences from early stages of a national industrial symbiosis programme in the UK: determinants and coordination challenges. Journal of Cleaner Production 12 (8-10): 967-983.

40. Ometto, A. R., Ramos, P. A. R. and Lombardi, G. 2007. The benefits of a Brazilian agro-industrial symbiosis system and the strategies to make it happen. Journal of Cleaner Production 15 (1314): $1253-1258$.

41. Park, H. and Won, J. 2007. Ulsan Eco-industrial Park: Challenges and Opportunities. Journal of Industrial Ecology 11 (3): 11-13.

42. Phillips, P. S., Barnes, R., Bates, M. P. and Coskeran, T. 2006. A critical appraisal of an UK county waste minimisation programme: The requirement for regional facilitated development of industrial symbiosis/ecology. Resources, Conservation and Recycling 46 (3): 242-264.

43. Shi, H., Chertow, M. R. and Song, Y., 2010. Developing country experience with eco-industrial parks: a case study of the Tianjin Economic-Technological Development Area in China. Journal of Cleaner Production 18 (3): 191-199.

44. Sterr, T. and Ott, T. 2004. The industrial region as a promising unit for eco-industrial development: reflections, practical experience and establishment of innovative instruments to support industrial ecology. Journal of Cleaner Production 12 (8-10): 947-965.

45. Van Beers, D., Bossilkov, A. and Lund, C. 2009. Development of large-scale reuses of inorganic by-products in Australia: The case study of Kwinana, Western Australia. Resources, Conservation and Recycling 53 (7): 365-378.

46. Van Beers, D., Bossilkov, A. and Van Berkel, R. 2008. A regional synergy approach to advance sustainable water use: a case study using Kwinana (Western Australia). Australasian Journal of Environmental Management 15 (3): 149-158.

47. Van Beers, D., Corder, G., Bossilkov, A. and van Berkel, R. 2007. Industrial symbiosis in the Australian minerals industry - The cases of Kwinana and Gladstone. Journal of Industrial Ecology 11 (1): 55-72.

48. Van Berkel, R., Fujita, T., Hashimoto, S. and Geng, Y. 2009. Industrial and urban symbiosis in Japan: Analysis of the Eco-Town program 1997-2006. Journal of Environmental Management 90 (3): 1544-1556.

49. Yang, S. and Feng, N. 2008. A case study of industrial symbiosis: Nanning Sugar Co., Ltd. in China. Resources, Conservation and Recycling 52 (5): 813-820. 
50. Yuan, Z., Bi, J. and Moriguichi, Y. 2006. The Circular Economy: A New Development Strategy in China. Journal of Industrial Ecology 10 (1-2): 4-8.

51. Yuan, Z. and Shi, L. 2009. Improving enterprise competitive advantage with industrial symbiosis: case study of a smeltery in China. Journal of Cleaner Production 17 (14): 1295-1302.

52. Zhang, H., Hara, K., Yabar, H., Yamaguchi, Y., Uwasu, M. and Morioka, T. 2009. Comparative analysis of socio-economic and environmental performances for Chinese EIPs: case studies in Baotou, Suzhou, and Shanghai. Sustainability Science 4 (2): 263-279.

53. Zhang, L., Yuan, Z., Bi, J., Zhang, B. and Liu, B. 2010. Eco-industrial parks: national pilot practices in China. Journal of Cleaner Production 18 (5): 504-509.

54. Zhu, Q. and Côté, R. P. 2004. Integrating green supply chain management into an embryonic eco-industrial development: a case study of the Guitang Group. Journal of Cleaner Production 12 (8-10): 1025-1035.

55. Zhu, O., Lowe, E.A., Wei, Y. and Barnes, D. 2007. Industrial symbiosis in China - A case study of the Guitang Group. Journal of Industrial Ecology 11 (1): 31-42.

\section{Models}

56. Aviso, K. B., Tan, R. R., Culaba, A. B. and Cruz, J. B., Jr. 2010. Bi-level fuzzy optimization approach for water exchange in eco-industrial parks. Process Safety and Environmental Protection 88 (1): 31-40.

57. Baldwin, J. S., Murray, R., Winder, B. and Ridgway, K. 2004. A non-equilibrium thermodynamic model of industrial development: analogy or homology? Journal of Cleaner Production 12 (810): 841-853.

58. Batten, D. F. 2009. Fostering Industrial Symbiosis With Agent-Based Simulation and Participatory Modeling. Journal of Industrial Ecology 13 (2): 197-213.

59. Cao, K., Feng, X. and Wan, H. 2009. Applying agent-based modeling to the evolution of ecoindustrial systems. Ecological Economics 68 (11): 2868-2876.

60. Chae, S. H., Kim, S. H., Yoon, S. and Park, S. 2010. Optimization of a waste heat utilization network in an eco-industrial park. Applied Energy 87 (6): 1978-1988.

61. Chew, I. M. L., Tan, R. R., Foo, D. C. Y. and Chiu, A. S. F. 2009. Game theory approach to the analysis of inter-plant water integration in an eco-industrial park. Journal of Cleaner Production 17 (18): 1611-1619.

62. Fernández, I. and Ruiz, M. C. 2009. Descriptive model and evaluation system to locate sustainable industrial areas. Journal of Cleaner Production 17 (1): 87-100.

63. Fons, S., Achari, G. and Ross, T. 2004. A fuzzy cognitive mapping analysis of the impacts of an eco-industrial park. Journal of Intelligent \& Fuzzy Systems 15 (2): 75-88.

64. Goto, N., Tachibana, J. and Fujie, K. 2005. Environmental management system based on material flow analysis to establish and maintain eco town. Journal of Industrial and Engineering Chemistry 11 (6): 818-825.

65. Karlsson, M. and Wolf, A. 2008. Using an optimization model to evaluate the economic benefits of industrial symbiosis in the forest industry. Journal of Cleaner Production 16 (14): 1536-1544.

66. Kempener, R., Beck, J. and Petrie, J. 2009. Design and Analysis of Bioenergy Networks. Journal of Industrial Ecology 13 (2): 284-305.

67. Kim, S. H., Yoon, S., Chae, S. H. and Park, S. 2010. Economic and environmental optimization of a multi-site utility network for an industrial complex. Journal of environmental management 91 (3): 690-705. 
68. Lim, S. and Park, J. M. 2010. Interfactory and Intrafactory Water Network System To Remodel a Conventional Industrial Park to a Green Eco-industrial Park. Industrial \& Engineering Chemistry Research 49 (3): 1351-1358.

69. Liwarska-Bizukojc, E., Bizukojc, M., Marcinkowski, A. and Doniec, A. 2009. The conceptual model of an eco-industrial park based upon ecological relationships. Journal of Cleaner Production 17 (8): $732-741$.

70. Lovelady, E. M. and El-Halwagi, M. M. 2009. Design and integration of eco-industrial parks for managing water resources. Environmental Progress \& Sustainable Energy 28 (2): 265-272.

71. Niutanen, V. and Korhonen, J. 2003. Industrial ecology flows of agriculture and food industry in Finland: utilizing by-products and wastes. International Journal of Sustainable Development $\&$ World Ecology 10 (2): 133-147.

72. Okkonen, L. 2008. Applying industrial ecosystem indicators: case of Pielinen Karelia, Finland. Clean Technologies and Environmental Policy 10 (4): 327-339.

73. Park, H., Rene, E. R., Choi, S. and Chiu, A. S. F. 2008. Strategies for sustainable development of industrial park in Ulsan, South Korea: From spontaneous evolution to systematic expansion of industrial symbiosis. Journal of environmental management 87 (1): 1-13.

74. Pearce, J. M. 2008. Industrial symbiosis of very large-scale photovoltaic manufacturing. Renewable Energy 33 (5): 1101-1108.

75. Salmi, O. 2007. Eco-efficiency and industrial symbiosis - a counterfactual analysis of a mining community. Journal of Cleaner Production 15 (17): 1696-1705.

76. Sendra, C., Gabarrell, X. and Vicent, T. 2007. Material flow analysis adapted to an industrial area. Journal of Cleaner Production 15 (17): 1706-1715.

77. Singh, A., Lou, H. H., Yaws, C. L., Hopper, J. R. and Pike, R. W., 2007. Environmental impact assessment of different design schemes of an industrial ecosystem. Resources, Conservation and Recycling 51 (2): 294-313.

78. Snäkin, J. and Korhonen, J. 2002. Industrial ecology in the North Karelia Region in Finland - Scenarios for heating energy supply. International Journal of Sustainable Development and World Ecology 9 (1): 9-21.

79. Tiejun, D. 2010. Two quantitative indices for the planning and evaluation of eco-industrial parks. Resources, Conservation and Recycling 54 (7): 442-448.

80. Valero, A., Usón, S., Torres, C. and Valero, A. 2010. Application of Thermoeconomics to Industrial Ecology. Entropy 12 (3): 591-612.

81. Zhang, X., Strømman, A. H., Solli, C. and Hertwich, E. G. 2008. Model-Centered Approach to Early Planning and Design of an Eco-Industrial Park around an Oil Refinery. Environmental science $\&$ technology 42 (13): 4958-4963.

82. Zhao, Y., Shang, J., Chen, C. and Wu, H. 2008. Simulation and evaluation on the eco-industrial system of Changchun economic and technological development zone, China. Environmental monitoring and assessment 139 (1): 339-349.

\section{Normative conceptual frameworks and theories}

83. Adamides, E. D. and Mouzakitis, Y. 2009. Industrial ecosystems as technological niches. Journal of Cleaner Production 17 (2): 172-180.

84. Burström, F. and Korhonen, J. 2001. Municipalities and Industrial Ecology: Reconsidering Municipal Environmental Management. Sustainable Development 9 (1): 36-46. 
85. Carr, A. J. P. 1998. Choctaw Eco-Industrial Park: an ecological approach to industrial land-use planning and design. Landscape and Urban Planning 42 (2-4): 239-257.

86. Geng, Y. and Côté, R. P. 2002. Scavengers and decomposers in an eco-industrial park. International Journal of Sustainable Development and World Ecology 9 (4): 333-340.

87. Haskins, C. 2007. A Systems Engineering Framework for Eco-Industrial Park Formation. Systems Engineering 10 (1): 83-97.

88. Korhonen, J. 2001. Industrial ecosystems - some conditions for success. International Journal of Sustainable Development and World Ecology 8 (1): 29-39.

89. Korhonen, J. 2001. Regional industrial ecology: examples from regional economic systems of forest industry and energy supply in Finland. Journal of environmental management 63 (4): 367-375.

90. Roberts, B. H. 2004. The application of industrial ecology principles and planning guidelines for the development of eco-industrial parks: an Australian case study. Journal of Cleaner Production 12 (8-10): 997-1010.

91. Singhal, S. and Kapur, A. 2002. Industrial estate planning and management in Indian integrated approach towards industrial ecology. Journal of environmental management 66 (1): 19-29.

92. Sopha, B. M., Fet, A. M., Keitsch, M. M. and Haskins, C. 2010. Using systems engineering to create a framework for evaluating industrial symbiosis options. Systems Engineering 13 (2): 149-160.

93. Yang, P. P. and Lay, O. B. 2004. Applying ecosystem concepts to the planning of industrial areas: a case study of Singapore's Jurong Island. Journal of Cleaner Production 12 (8-10): 1011-1023.

\section{Quantitative evaluations}

94. Chertow, M.R. and Lombardi, D.R. 2005. Quantifying economic and environmental benefits of co-located firms. Environmental science \& technology 39 (17): 6535-6541.

95. Eckelman, M. and Chertow M. R. 2009. Quantifying life cycle environmental benefits from the reuse of industrial materials in Pennsylvania. Environmental science \& technology 43 (7): 25502556.

96. Jacobsen, N. B. 2006. Industrial symbiosis in Kalundborg, Denmark - A quantitative assessment of economic and environmental aspects. Journal of Industrial Ecology 10 (1-2), 239-255.

97. Laybourn, P. and Lombardi, D. R. 2007. The role of audited benefits in industrial symbiosis: The UK national industrial symbiosis programme. Measurement \& Control 40 (8): 244-247.

98. Mattila, T. J., Pakarinen, S. and Sokka, L. 2010. Quantifying the Total Environmental Impacts of an Industrial Symbiosis -a Comparison of Process-, Hybrid and Input-Output Life Cycle Assessment. Environmental science \& technology 44 (11): 4309-4314.

99. Van Berkel, R., Fujita, T., Hashimoto, S. and Fujii, M. 2009. Quantitative Assessment of Urban and Industrial Symbiosis in Kawasaki, Japan. Environmental science \& technology 43 (5): 12711281.

\section{Epistemological discussions}

100. Hess, G. 2010. The Ecosystem: Model or Metaphor? Journal of Industrial Ecology 14 (2): 270285.

101. Isenmann, R. 2003. Industrial ecology: shedding more light on its perspective of understanding nature as model. Sustainable Development 11 (3): 143-158. 
102. McManus, P. and Gibbs, D. 2008. Industrial ecosystems? The use of tropes in the literature of industrial ecology and eco-industrial parks. Progress in Human Geography 32 (4): 525-540. 



\section{INTERMEZZZ 1}

\section{DEVELOPING THE CONCEPTUAL FRAMEWORK}


The literature review presented in chapter 2 was published as part of a publication that aims to provide a basic conceptual underpinning for the empirical investigation of industrial symbiosis (Boons, Spekkink and Mouzakitis 2011). This initial framework distinguishes between two levels of analysis, which are the societal level and the level of the regional industrial system. Boons, Spekkink and Mouzakitis (2011) suggest that institutional capacity building is a promising concept to capture the social dynamics that occur at the level of the regional industrial system. In short, institutional capacity can be understood as the capacity to engage in collective action (see chapter 3 ). The conceptual framework that I present in chapter 3 builds on the starting point provided by Boons, Spekkink and Mouzakitis (2011) and it elaborates on the relationship between institutional capacity building and industrial symbiosis.

The framework is the result of several iterations of conceptual development. Figure I1 visualizes one of the earlier versions of the framework, which is reproduced from Boons and Spekkink (2012a). The visualization illustrates some of the initial steps that were taken in the development of the framework. One of these steps was to develop a conceptual link between the dynamics of institutional capacity building and the development of symbiotic exchanges (i.e., by-product exchanges and utility synergies). This link was established by including the concept of opportunity sets in the framework. This concept was derived from the work of Hall and Soskice (2001; also see Spekkink and Boons 2010) and from the work of Elster (2007). It represents the different courses of action that actors perceive to be available to them. The framework assumes that the opportunity set of an actor is shaped by (among other influences) changes in institutional capacity available in the regional industrial system in which the actor is embedded. The central idea behind this link is that the opportunities that actors see for engaging in industrial symbiosis will improve with the development of new or stronger relationships (relational capacity), the creation of a shared knowledge and experience (knowledge capacity), and the increase of their capacity to mobilize for joint action (mobilization capacity). The concept of opportunity sets thus offers a way to link the dynamics of institutional capacity building (at the macro-level) to the actions and interactions that actors engage in (at the micro-level). It is assumed that the decisions of actors are influenced by their opportunity set, although the exact model of choice through which actors reach their decision is not specified in the framework visualized in figure 11. This process will, for example, influence the decision of an actor whether or not to engage in industrial symbiosis.

Another addition that I made to the framework, one which was not yet included in the framework visualized in figure 11 , is an explicit ${ }^{7}$ feedback loop between interactions and institutional capacity. The logic of this feedback loop is that institutional capacity itself

7. The feedback loop itself was already part of the frameworks of Healey et al. (2003) and Innes and Booher (1999), but it was largely left implicit. 


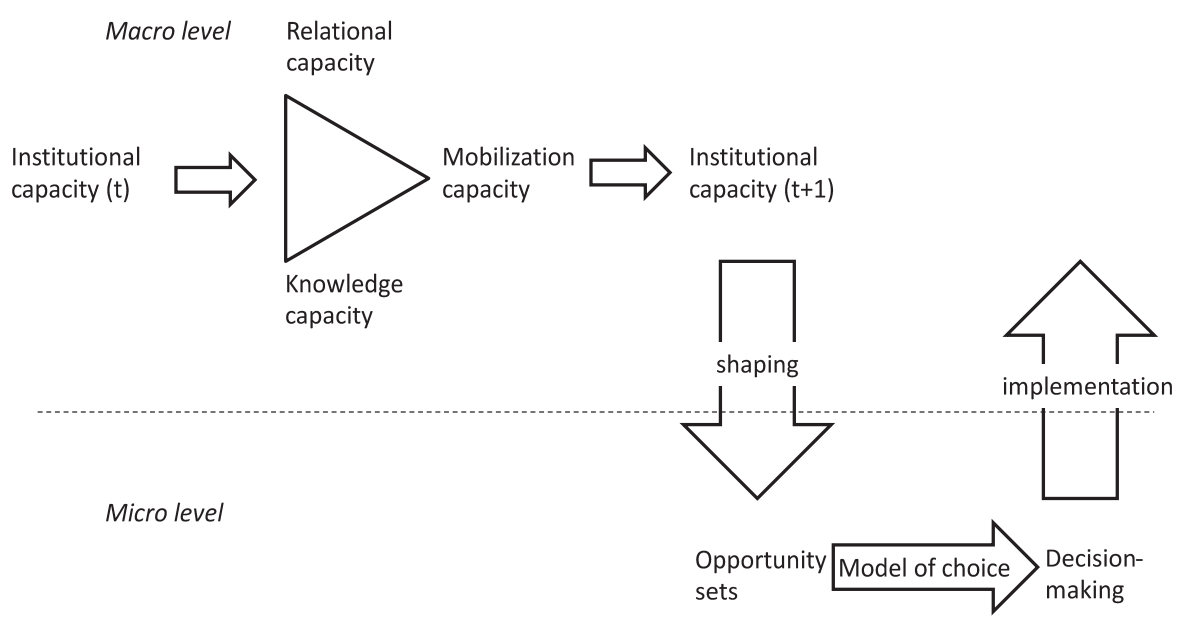

Figure 11: A predecessor of the conceptual framework presented in chapter 3 (from Boons and Spekkink 2012a).

is shaped by interactions between actors that have occurred in the past, based on the development of new or improved relationships (relational capacity), the development and exchange of new knowledge and experience (knowledge capacity), and the development of shared visions, as well as the emergence of actors that are willing to take the lead in joint action (mobilization capacity).

During the research process, it proved to be difficult to empirically investigate the link between changes in institutional capacity and changes in perceived opportunities, because the data required to reconstruct the evolution of opportunity sets often cannot be obtained (in general, it proved to be difficult to reconstruct interactions at the micro-level). The concept of opportunity sets was gradually replaced by the concept of intentional linkages. An intentional linkage exists between two interactions if in one interaction actors intentionally respond to conditions that are outcomes of an earlier interaction (see chapter 4). Although intentional linkages do not provide direct information about the changes in opportunities that are assumed to take place throughout interaction processes, they do offer insight in the way that interactions are influenced by interactions that occurred in the past, and thus are a proxy for the way that relationships and knowledge are carried forward in time.

Chapter 3 was written for an edited volume on international perspectives on industrial ecology. It was thus written as a framework that can be used to compare developments in different countries ${ }^{8}$. However, both case studies included in this thesis concern developments in the Netherlands, and although the framework in chapter 3 builds towards international comparisons, such a comparison is not part of this thesis.

8. For a while, I also had the ambition to make comparisons with developments in other countries, but the investment required in terms of data collection were too great. 



\section{CHAPTER 3}

\section{CONCEPTUAL FRAMEWORK}

This chapter is published as Spekkink, W. A. H. 2015. Varieties of Industrial Symbiosis. In: P. Deutz, D. I. Lyons, B. Jun (Eds.). International Perspectives on Industrial Ecology. 


\section{ABSTRACT}

There has been little academic attention for the different ways in which industrial symbiosis unfolds around the world. In this chapter a conceptual framework is introduced that can be used as a basis for studying varieties of industrial symbiosis. The framework is rooted in the assumption that industrial symbiosis is best understood as a process. It distinguishes three levels of analysis at which dynamics relevant to the emergence and development of industrial symbiosis take place: (1) the project level at which actors prepare and implement symbiotic exchanges and engage in other relevant types of interactions, (2) the regional industrial system at which actors develop the institutional capacity that enables them to coordinate their activities in a collaborative fashion, and (3) the institutional context which shapes the opportunities that actors have for different courses of action in the process of industrial symbiosis. The framework introduces a number of core concepts, as well as examples of social mechanisms that can be linked to the framework. The chapter closes with some methodological suggestions on how to investigate these mechanisms. 


\subsection{INTRODUCTION}

The concept of industrial symbiosis was first introduced into the industrial ecology literature by Lowe and Evans (1995) to depict the web of material and energy exchanges that was developed at Kalundborg in Denmark. While the exchanges among firms in Kalundborg may be interpreted as a form of economic coordination amongst many others, what made them appealing to advocates of industrial ecology was the combination of economic and environmental benefits that resulted from the exchanges. Since the introduction of the concept of industrial symbiosis, numerous efforts have been made to identity other existing occurrences of industrial symbiosis or to plan new ones, which is illustrated by the many case studies presented in the literature on industrial symbiosis (e.g. Eilering \& Vermeulen 2004; Chertow 2007; Deutz \& Gibbs 2008).

An interesting feature of these developments that has received relatively little academic attention is that industrial symbiosis unfolds in very different ways in different places of the world. In the UK, the NISP program emerged as a government funded program for the brokerage of waste streams. Based on regional experiences, the program was extended to cover the whole UK. Many of the symbiotic exchanges concern the exchange of existing waste streams, but over time NISP facilitators have sought to help firms in their network to develop more innovative linkages (Paquin and Howard-Grenville 2012). In the Netherlands the Dutch government has provided subsidies for sustainability projects on industrial parks, which in some cases has led to, or catalyzed, the development of symbiotic exchanges (Boons and Janssen 2004; Boons \& Spekkink 2012a). In contrast, exemplary cases such as Kalundborg and the Rotterdam Harbor area are examples where firms have developed larger networks of symbiotic exchanges without the active stimulation of outside actors (Ehrenfeld and Gertler, 1995; Baas and Boons 2007).

In this chapter I present a conceptual framework of industrial symbiosis that may serve as a basis for explanations for the different ways in which industrial symbiosis unfolds in different places of the world. The conceptual framework is grounded in an understanding of industrial symbiosis as a process. As a consequence, the framework is focused in the first place on identifying and explaining differences in the dynamics through which networks of symbiotic exchanges emerge and develop over time. The structural features of the networks of symbiotic exchanges are understood as outcomes of these dynamics and are of secondary concern. Industrial symbiosis is defined as the process through which firms and other relevant actors within regional industrial systems increase their connectedness in terms of material, energy and information flows, in order to lower the ecological impact of their regional industrial system (Boons, Spekkink and Mouzakitis 2011). The framework distinguishes between dynamics of industrial symbiosis at three levels: (1) the project level at which actors prepare and implement symbiotic exchanges and engage in other relevant types of interactions, (2) the regional industrial system at 
which actors develop the institutional capacity that enables them to coordinate their activities in a collaborative fashion ${ }^{9}$, and (3) the institutional context which is the source of institutional pressures and conditions the opportunities that actors have for different courses of action in the process of industrial symbiosis.

In addition to the conceptual framework, I introduce several mechanisms through which dynamics at the three levels of the framework are connected. These mechanisms are "...frequently occurring and easily recognizable causal patterns that are triggered under generally unknown conditions or with indeterminate consequences" (Elster 2007, p. 36). The purpose of the conceptual framework is to offer a set of concepts relevant to the investigation of the coming about of industrial symbiosis and the purpose of the mechanisms is to link the concepts into partial theories about typical patterns in the emergence and development of industrial symbiosis.

I introduce the conceptual framework in section 3.2. In section 3.3 I identify several mechanisms that link the dynamics at the different levels of the framework together and discuss how these shape the networks of symbiotic exchanges that emerge from them. In section 3.4 I conclude the chapter with a brief discussion on how the mechanisms might be investigated.

\subsection{THE CONCEPTUAL FRAMEWORK}

The framework breaks the process of industrial symbiosis down into dynamics at three different levels: The project level, the regional industrial system, and the institutional context (see figure 3.1). The framework suggests several linkages between the concepts and these are further elaborated in the discussion on mechanisms (section 3.3). The outcome of the process of industrial symbiosis is conceptualized as the emergence and development of a network of symbiotic exchanges in the regional industrial system.

Based on the work of Van Berkel and colleagues (2007) I distinguish between two types of symbiotic exchanges. First, by-product synergies concern the exchange between firms of previously disposed by-products to replace other business inputs. By-products can originate from process operations (e.g. residues, wastes, leftovers) and non-process operations (e.g. maintenance, warehousing, administration, etc.). Second, utility synergies concern the shared use of utility infrastructures for the production of energy carriers, process water and for the joint treatment of wastes and emissions.

9. A regional industrial system is "a more or less stable collection of firms located in proximity to one another, where firms in principle can develop social and material/energy connections as a result of that proximity" (Boons et al. 2011, p. 907). 


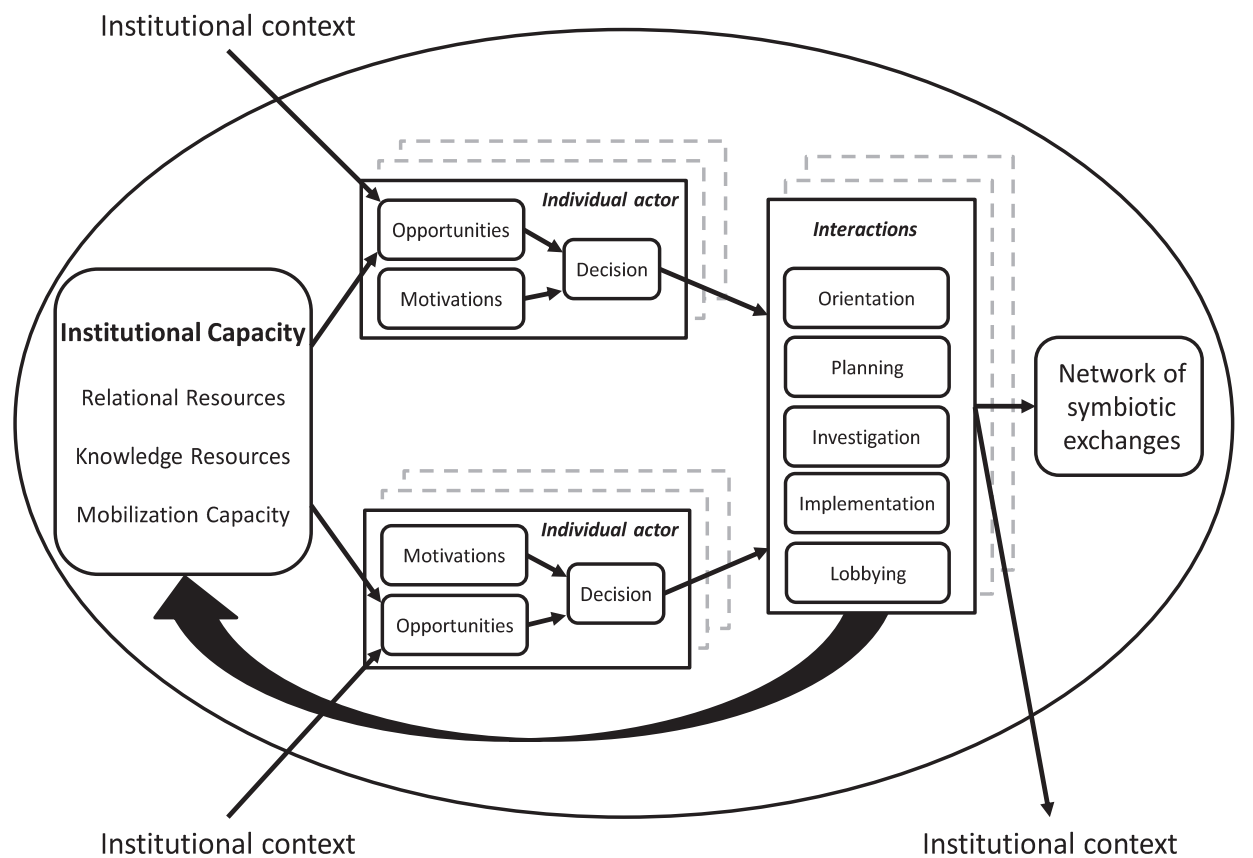

Figure 3.1: The conceptual framework.

I propose that the emergence and development of networks of symbiotic exchanges can be explained, in the first place, by interactions between actors in the regional industrial system. The implementation of symbiotic exchanges is a type of interaction that contributes to the development of the network of symbiotic exchanges directly, but other types of interactions such as orientation on possibilities for symbiotic exchanges, planning of symbiotic exchanges, investigations on the feasibility of symbiotic exchanges, and lobbying for support may also be important parts of the process through which industrial symbiosis comes about. Such interactions are often project-based and their scope does not necessarily cover the entire regional industrial system. Therefore, they are included in the project level of the framework.

The interactions themselves are shaped by the decisions that individual actors involved in the interactions make. I propose that to large extent industrial symbiosis revolves around the decisions made by particular people at particular moments (Posch 2010; Andrews 2000). However, these decisions should not be taken as the ultimate building blocks for explanations of the different ways in which industrial symbiosis comes about. Decisions are shaped by the motivations (i.e., beliefs and desires) and the opportunities of actors. Although decisions should always be understood as a function of both motivations and opportunities, opportunities are of special importance because it is through opportunities that the dynamics at the other levels of the framework influ- 
ence the decisions that actors make. The opportunities that an actor sees for different courses of action are conditioned by the institutional context in which he is embedded and by dynamics of institutional capacity building that unfold at the level of the regional industrial system.

The institutional context represents "...the rules of the game in society [...] that shape human interaction" (North 1990, p.3). It consists of regulatory structures, governmental agencies, laws, courts, professions, cultural norms and etcetera (Scott 1987). There are many ways in which the institutional context of actors conditions the opportunities they see for different actions, ranging from subtle influences, such as taken for granted cultural norms, to palpable influences, such as laws and regulations (Oliver 1997). The institutional context can act to limit the opportunities that actors see for different courses of action, for example, when institutional pressures make the costs of choosing for particular types of exchanges prohibitive. The institutional context may also provide actors with increased opportunities; this can happen when institutions provide the basis for increased trust among actors that enables them to engage in more lengthy and strategic types of exchanges.

The opportunities that actors see for different courses of action are also shaped by dynamics of institutional capacity building at the level of the regional industrial system. Institutional capacity is the capacity of a community of actors to coordinate their actions toward issues of common concern in a collaborative fashion (Healey 1998; Innes and Booher 1999; Healey et al. 2003). Based on the work of Healey and colleagues (2003) I distinguish three dimensions along which institutional capacity develops in a regional industrial system:

- Relational resources: Through repeated interactions actors may develop bonds of trust and mutual recognition, which contributes to the development of stronger personal and professional relationships.

- Knowledge resources: The stronger relationships between actors serve as a basis for the exchange and joint production of knowledge, including shared conceptions of issues, problems and opportunities.

- Mobilization capacity: increases in relational resources and knowledge resources increase the capacity of actors to mobilize for joint initiatives by providing a social network that they can draw upon and by providing shared conceptions around which actors may mobilize (strategic visions). In addition, the mobilization of resources often depends on one or more actors to take initiative in mobilizing others.

Institutional capacity builds up through interactions between the actors in the regional industrial system. These interactions may concern the implementation of symbiotic exchanges themselves, but institutional capacity also builds up through other types of projects in which actors orient themselves on the possibilities for symbiotic exchanges, develop concrete plans for symbiotic exchanges, or investigate the technical, organiza- 
tional and economic feasibility of symbiotic exchanges (e.g., Boons \& Spekkink 2012a). Such interactions at the project level set the stage for future developments by contributing to the development of institutional capacity at the level of the regional industrial system.

\subsection{MECHANISMS OF INDUSTRIAL SYMBIOSIS}

I use a mechanism-based approach to elaborate on the linkages between the concepts introduced in section 3.2. This is an approach in sociology which acknowledges that explanation of social phenomena should not strive towards generic theories, but should consist of understanding why certain social mechanisms operate in specific situations (Stinchcombe 1991; Hedström \& Swedberg 1998; Mayntz 2004; Elster 2007; Gross 2009). This approach leads to the development of multiple (often alternative) partial theories that link two or more concepts of the framework together, rather than one coherent theory that accounts for all concepts and relations.

Based on this approach a process such as the emergence and development of industrial symbiosis can be studied as a concatenation of mechanisms. In doing so, it is important to take into account sequence effects; mechanisms may influence the course of the process as a whole in a path-dependent way and thus the order in which they occur is relevant (cf. Poole et al. 2000).

Based on the conceptual framework a large variety of mechanisms can be identified that may influence the way industrial symbiosis unfolds and, more specifically, the network of symbiotic exchanges that develops throughout the process. My aim is not to provide an exhaustive list of all mechanisms that may be relevant to the development of industrial symbiosis, but to describe a small number of mechanisms that I believe to be central to many examples of industrial symbiosis. Also, to keep the discussion simple and concise, I will restrict my discussion to mechanisms that link dynamics at the level of the institutional context to dynamics at the project level, and mechanisms that link dynamics at the level of the regional industrial system to the project level. Where possible, I clarify the mechanisms by offering empirical examples.

\subsubsection{Mechanisms linking the institutional dynamics to dynamics at the project level}

The first mechanisms I discuss are those that link dynamics at the level of the institutional context to dynamics at the project level. As I discussed in section 3.2, the opportunities that actors see for different courses of action form the conceptual link between the dynamics at these two levels. Here I present two mechanisms that illustrate how the actions of actors are influenced by institutional dynamics that are mediated by oppor- 
tunities. The two mechanisms I discuss here are closely linked to the motivations that an actor may have to engage in symbiotic exchanges. The first mechanism is linked to legitimacy seeking behavior and the second mechanism is linked to behavior driven by conventional business motivations.

In the case of the first mechanism the actions of actors can be understood as responses to different types of institutional pressures that actors face (cf. Oliver 1997). A type of institutional pressure that is easy to grasp is regulatory pressure (i.e., legislative and regulatory requirements). Although regulatory pressures are likely to play a role in any variant of industrial symbiosis, their role is probably most evident in Chinese variants, where regulatory pressures traditionally play an important role in the promotion of eco-industrial developments (Shi and Zhang 2006; Geng and Doberstein 2008). However, legitimacy-seeking behavior often goes beyond simply following governmental regulations. It also involves attempts to meet expectations that are set by the general public (i.e., societal pressures). Ashton (2010) demonstrates how certain changes in the practices of firms on the island of Puerto Rico resulted from a combination of regulatory and societal pressures. In this case societal pressures took the form of expectations with regard to the health impact and environmental impact of the firms' activities.

The opportunities for different courses of action that actors should follow to attain legitimacy are often encoded in the institutional pressures themselves. For example, in support of its circular economy programme the Chinese government published specific guidelines for the development of eco-industrial parks (Yuan et al. 2006; Geng \& Doberstein 2008). Similarly, in the Netherlands the government published a handbook that suggests possible approaches to the sustainable development of industrial parks. Also, actors could only be subsidized for such activities if they performed certain types of projects in a specific order (Boons and Spekkink 2012a).

If industrial symbiosis activities are the consequence of institutional pressures, their results (in terms of the types of symbiotic exchanges that emerge) are likely to reflect those pressures. For example, many of the more than 200 projects that were subsidized by the Dutch stimulation program for sustainable industrial parks (1999-2004) followed the logic prescribed in the handbook that the government had published earlier (Boons and Spekkink 2012a). Differences in the structure of networks of symbiotic exchanges may thus be partly explained by differences in the institutional pressures faced by actors involved in their development.

A mechanism alternative to the one introduced above is based on the observation that many industrial symbiosis initiatives are driven by business motivations, such as cutting costs and resource security (Chertow 2007). With this mechanism the institutional context shapes industrial symbiosis in a different way than it does with initiatives that are driven by legitimacy seeking behavior. Here, the actions of actors can be understood to reflect their attempts to reduce the risks entailed by the symbiotic exchanges they 
engage in, which is the topic of transaction cost economics (Williamson 1975; 1985; 1996; also see Shi 2011). The opportunities that actors have to mitigate the risks of exchanges are determined by the types of economic coordination that are supported by the institutional context in which they are embedded (e.g., contract laws). This type of reasoning is central to the varieties of capitalism approach of Hall and Soskice (2001). The varieties of capitalism approach draws a core distinction between liberal market economies where actors typically rely on hierarchies and competitive market arrangements for coordination, and coordinated market economies where actors typically rely on relational and incomplete contracting for coordination.

Although this distinction is rather idealized (M. Gertler 2010; Peck \& Theodore 2007) it serves well to illustrate that there may be systematic differences in the forms of economic coordination that actors choose for their exchanges. For example, in China some firms have the possibility to set up an intra-firm network of symbiotic exchanges such as in the case of the Guitang Group (Zhu \& Côté 2004; Zhu et al. 2007). Such arrangements do not entail the risks entailed by exchanges between two or more independent firms. In an institutional context where such elaborate intra-firm arrangements are unfeasible, bilaterally dependent actors typically rely on complexes of contracts and alliances such as in the case of Kalundborg (Ehrenfeld \& N. Gertler 1997).

To summarize, the opportunities actors have to mitigate the risks of symbiotic exchanges depend on the institutional context in which they are embedded and, more specifically, the forms of economic coordination it supports. Differences in the structure of different networks of symbiotic exchanges can thus be partially explained by differences in the types of economic coordination available to the actors involved in their development.

Both types of mechanisms discussed above are likely to be at play in the evolution of any network of symbiotic exchanges, and additional mechanisms are conceivable. The development of symbiotic exchanges involves multiple actors that often have more than one motivation for engaging in industrial symbiosis. Also, their motivations may change over time. The fact that different mechanisms can link the institutional context to actor decisions means that empirical research should also focus on the conditions under which one or the other mechanism comes into play.

\subsubsection{Building institutional capacity}

So far I presented mechanisms that explain how the decisions of actors are linked to institutional dynamics by the opportunities that these dynamics generate for different courses of action. As I mentioned in section 3.2, the opportunities that actors see for different course of action are also shaped by dynamics that occur within the boundaries of the regional industrial system. I will now discuss a set of mechanisms that link the dynamics at the level of the regional industrial system to dynamics at the project 
level. I conceptualize the dynamics at the level of the regional industrial system in terms of institutional capacity building (Boons and Spekkink 2012a). Before I introduce the mechanisms that link institutional capacity building to actor behavior, a further explanation of the concept of institutional capacity building is required.

In the process of industrial symbiosis the actions and interactions at the project level are not all directly dedicated to the development of symbiotic exchanges. There are many activities that may precede the actual development of symbiotic exchanges, such as the exploration of possibilities to cooperate, the gathering of knowledge on the economic, organizational and technical feasibility of exchanges, the bargaining of agreements, the development of plans and strategic visions, and etcetera. Examples of such activities can be found in the case of the INES project in the Rotterdam harbor industrial area, as described by Baas and Boons (2007). Long before firms in this area engaged in symbiotic exchanges they were involved in other initiatives concerning environmental performance such as the reduction of Hydro Carbons, the reduction of Chlorine Fluor Carbon implementation and the implementation of environmental management systems. The INES project itself consisted out of 4 phases that together span a period from 1992 to 2002, after which the INES project was included in the ROM-Rijnmond project (Baas and Boons 2007). Throughout the process, the actors engaged in workshops, performed feasibility studies and made attempts to implement symbiotic exchanges.

I propose that such interactions contribute to the development of institutional capacity at the level of the regional industrial system. Through recurring interactions actors develop stronger personal and professional relationships, which contribute to the growth of social networks in the regional industrial system (Deutz and Gibbs, 2008). These social networks also offer actors better opportunities to exchange and jointly produce knowledge, including shared conceptions of problems and solutions. The combination of a growing social network and the development of shared visions around which actors can mobilize offers actors better opportunities to mobilize for collaborative action and engage in new projects together (Healey 1998; Healey et al. 2003; Innes \& Booher 1999).

The development of institutional capacity continuously feeds back on the process of industrial symbiosis by influencing the opportunities that actors see for further interactions. This occurs through at least three mechanisms. First, as the personal and professional relationships between actors strengthen, they are less likely to perceive relational risks in further interactions, including symbiotic exchanges. This mechanism was also observed in the INES-project: "Thanks to the historical development within several programmes the strategic platform could build on the built-up trust between the members of the different organizations and the conditions for successful projects that earlier failed" (Baas and Boons 2007, p. 559). Second, by producing and exchanging knowledge, actors may develop a better view on the feasibility of symbiotic exchanges and identify new possibilities for symbiotic exchanges. In this regard, Baas and Boons (2007) describe 
a learning process that occurred in the INES-project. Finally, the availability of the social network, the development of knowledge, in addition to the presence of key actors and a strategic vision around which to mobilize, increase the opportunities that actors have to actually engage in further joint action. In the INES-project the industrial association Deltalinqs repeatedly played a key role in mobilizing others, and throughout the project multiple strategic platforms were developed, as well as a strategic vision in the later stages of the project, although for these it is less clear to what extent they contributed to further initiatives.

It is important to note that a positive influence of institutional capacity on symbiotic exchanges does not necessarily involve an enlarged opportunity set. Symbiotic exchanges may also become more feasible as a result of a diminished opportunity set, for example by excluding actions such as opportunistic behavior.

As the case of the INES-project illustrates, the development of institutional capacity is a gradual process that may span a period of many years. It may take a very long time before these dynamics result in actual symbiotic exchanges. In addition, institutional capacity may have built up through earlier interactions that were not specifically related to the development of industrial symbiosis. In the literature on industrial symbiosis this is sometimes referred to as shared histories or pre-existing organizational relationships (Eilering \& Vermeulen 2004; Heeres et al. 2004; Gibbs \& Deutz 2007).

One question that remains to be answered is how these dynamics at the level of the regional industrial system may explain differences in the structure of networks of symbiotic exchanges that develop in different places of the world. A simple answer to this question is that structural differences may be explained by the extent that institutional capacity building actually takes place. In this regard Hall and Soskice suggest that collaborative approaches to economic coordination depend on the presence of institutions of deliberation, which they define as "...institutions that encourage the relevant actors to engage in collaborative discussion and to reach agreements which each other" (2001, p. 11). In the Netherlands self-regulation is rather common and business is relatively well organized through business associations. Heeres and colleagues (2004) suggest that these serve as platforms to educate and inform firms of the potential benefits of symbiotic exchanges, and as much needed communication platforms. Because of these factors it is also relatively easy for firms and other relevant actors in the Netherlands to find platforms for collaboration on environmental issues. In China, the presence of organized business is more limited and the repeated interactions of the kind we observe in the Netherlands are far less common. Historically, there has been a stronger role for regulatory approaches to environmental issues in China, although things may be gradually changing in that regard (Shi and Zhang 2006).

Another explanation points for the role that strategic visions may play in the development of networks of symbiotic exchanges. For example, in the Canal Zone of the 
Netherlands (a regional industrial system in the province of Zeeland) firms, governments and knowledge institutes are developing Biopark Terneuzen, which is based on a vision of a bio based cluster that links the chemical process industry to the agricultural industry. The types of exchanges that actors develop throughout the development of this cluster are strongly related to this shared vision. Indeed, such visions also depend on the opportunities generated by situational factors such as the type of industries present in the system, and the geographical features of the system.

\subsubsection{Influencing the institutional context}

Actors may also attempt to influence their institutional context. Boons (2009) suggests that firms may engage in marketing, public relations, and public affairs activities to influence the institutional pressures that they face. These activities can be directed at governmental agencies, politicians, NGOs and the general public. Through these activities, firms aim to align institutional pressures with their own motivations. Innes and Booher (1999) suggest that when actors have developed sufficient institutional capacity they may also work together to influence public action in ways they were unable to do before. In the regional industrial system of the Canal Zone actors involved in the development of symbiotic exchanges have occasionally made attempts to influence public opinion and national policies and regulations with regard to the stimulation of bio based industry.

\subsection{INVESTIGATING MECHANISMS}

In this chapter I introduced a conceptual framework that is grounded in an understanding of industrial symbiosis as a process, and building on this framework I introduced several mechanisms that may explain how different types of symbiotic exchanges may emerge throughout the process.

I propose that a fruitful way to investigate these mechanisms is to undertake a longitudinal research approach in which multiple cases of industrial symbiosis are compared. For this purpose Event Sequence Analysis (ESA) was developed by researchers of the Erasmus University Rotterdam (Boons, Spekkink and Jiao 2014). ESA is a longitudinal research approach that is inspired by methods developed in the Minnesota Innovation Research Program (MIRP) (Van de Ven \& Poole 1990; Poole et al. 2000; Van de Ven et al. 2000) and by theory and methods developed by Abbott (1988; 1990; 2001) and Abell $(1987 ; 1993)$. Using this approach, the actions and interactions of the actors involved in the development of industrial symbiosis are recorded and entered into event sequence datasets as incidents. These incidents are empirical descriptions that include (at least) a description of the action or interaction, the actor(s) involved, the date on which the action or interaction occurred, and the data source. Researchers can code these incidents 
using a coding scheme that is derived from the conceptual or theoretical perspective of the researcher. The coded incidents serve as indicators for theoretical events (Poole et al. 2000). For example, based on the conceptual framework introduced in this chapter one would develop a coding scheme that identifies events related to (changes in) opportunities, motivations, institutional capacity, the institutional context, and etcetera. From the stream of coded incidents one or more sequences of events may be derived that can be analyzed for temporal patterns using a variety of methods, such as phasic analysis, stochastic modeling, event time series analysis (Poole et al. 2000), narrative analysis (Abell 1987), template matching (Langley 1999) and optimal matching (Abbott \& Tsay 2000). The investigation of whole event sequences is a relatively straightforward way to study concatenations of mechanisms. The sequence effects associated with such concatenations can be investigated by comparing sequences across multiple cases. Such investigations should also include an analysis of the conditions under which alternative mechanisms are triggered.

In the introduction I present industrial symbiosis as a process through which actors increase their connectedness in terms of material, energy and information flows. From this perspective industrial symbiosis revolves around change rather than a certain state affairs. A mechanism-based approach, accompanied with ESA, ties in well with a view of industrial symbiosis as a process and is therefore a promising way forward for research on industrial symbiosis. 



\section{INTERMEZZZO 2}

CHANGING THE SCOPE OF THE RESEARCH 
As I discussed in chapter 1 , in this thesis I introduce a number of methods, techniques and tools that were developed as contributions to Event Sequence Analysis (ESA) (Boons, Spekkink and Jiao 2014). To great extent, the contributions that this thesis makes to ESA are the products of an exploratory process, which continues even after finishing the thesis. The adoption of the methods, tools and techniques of ESA was also a major break with my original plans for the PhD project. Initially, I had planned to make an updated version of an existing dataset of 233 projects on sustainable industrial parks in the Netherlands (see Boons and Spekkink 2012a; Pellenbarg 2002). Figure 12 shows a screenshot of one of the interfaces of the dataset, which was developed with the Microsoft Access toolkit. The dataset was produced by Novem, an agency of the ministry of Economic Affairs that was responsible for implementing a subsidy program for the stimulation of sustainable development of industrial parks. The subsidy program was carried out between 1999 and 2004, and in the dataset government officials that monitored the program recorded several details on subsidized projects (e.g., financial details, ambitions of the projects, activities to be carried out, and summary descriptions). In terms of results, the dataset only reports an evaluation of the ambitions of project participants at the start of the projects and at the end of the projects. The aim of the program was to support the start of collaborations, and the actual implementation of, for example, by-product exchanges and utility synergies was not within the scope of the program. Thus, one of the original aims of my PhD project was to make an overview of the current situation at the industrial parks where projects were carried out, such that an assessment of the results of the collaborations subsidized by the program could be made.

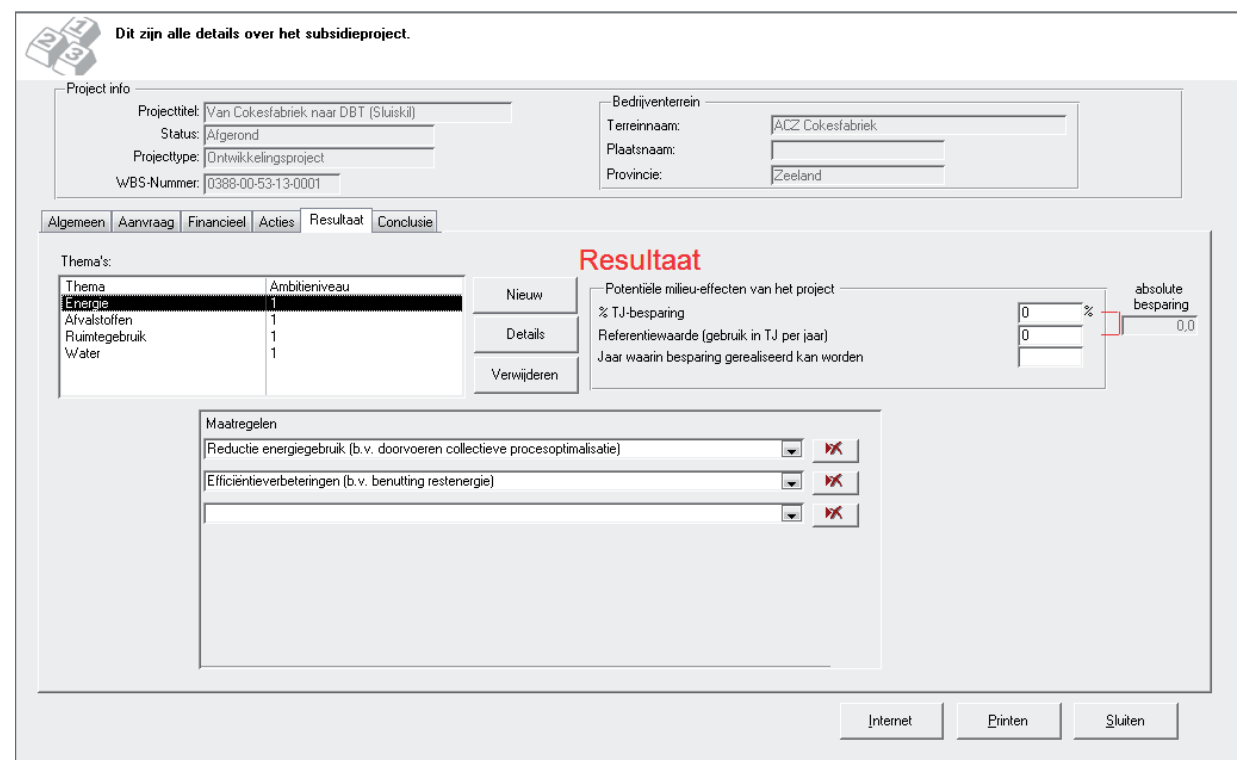

Figure 12: screenshot of Novem dataset. 
After doing some initial desk research it quickly became clear that it was difficult to make a good link between projects that were carried out between 1999 and 2004 and the current situation at the industrial parks. Many years had passed since the projects and a good understanding of the current situation at the industrial parks also required a reconstruction of what had happened during these years. The initial explorations also made clear that a relatively large amount of archival data could be found on relevant developments that had taken place over the years. Therefore, I started looking for ways to make use of this rich data. Around the same time a student from Delft University of Technology was finishing his master thesis on industrial symbiosis (De Valk 2011), in which the functions of innovations systems approach was applied (Hekkert et al. 2007). This approach involves the creation of longitudinal datasets, for which the work of Poole et al. (2000) served as the main source of inspiration. Poole et al. (2000) describe a dataset structure that is suitable for storing longitudinal, primarily qualitative data. Their approach thus offered a way to structure the large amount of data that I found in a meaningful way. Because I had worked quite intensively on the dataset of the Novem subsidy program, I had also developed some experience with the structure of relational datasets and with the tools that Microsoft Access offers to build such datasets. I decided to build my own event sequence dataset structure (see Annex $6^{10}$ ) and to use event sequence datasets as the basis for my empirical investigations.

This decision had major consequences for the scope and direction of my PhD project. First, developing an event sequence dataset for a single case proved to require a major time investment. As a result, I was only able to make two such datasets within the time available to me. Second, Frank Boons and I started exploring methods that would enable us to get the most out of the rich data available in event sequence datasets ${ }^{11}$. Indeed, it was possible for us to build on longitudinal research strategies that had been developed by others, but especially in the later stages of the research process Frank Boons and I felt the need to introduce some innovations of our own. Chapter 3 brings together methods and techniques that have been developed throughout the entire research process. Although they are presented as the methodological basis of this thesis, the reader should realize that in many ways they are also products of my PhD project. The gradual methodological development is also reflected in the empirical chapters that have been included in the thesis (chapters 5 to 8). Each chapter introduces new methods and techniques and/or tools that Frank Boons and I had only developed shortly before the chapter was written. I discuss the development of some of these methods, techniques and tools in other intermezzos.

10. Annex 3 to 7 can only be found online: http://www.wouterspekkink.org/?page_id=206.

11. The development of ESA unfolded as a long sequence of interactions between Frank Boons and myself. 



\section{CHAPTER 4}

METHODS: EVENT SEOQUENCE ANALYSIS 



\subsection{INTRODUCTION}

In chapter 1 the argument is made that industrial symbiosis can be usefully understood as a process, which is, for example, reflected in the fact that conceptualizations of industrial symbiosis often take the form of stage models (Baas and Boons 2004; Chertow and Ehrenfeld 2012; Doménech and Davies 2011; Paquin and Howard-Grenville 2012; Korhonen and Snäkin 2005; Pakarinen et al. 2010). However, with a few important exceptions (Paquin and Howard-Grenville 2012; Yu, de Jong, and Dijkema 2014), little efforts have been made to develop and/or apply methodological approaches that engage with the process dimension of industrial symbiosis. Therefore, the second research question of this thesis was explicitly formulated as a methodological question to steer the research towards the use and development of methods and techniques that are dedicated to a systematic inquiry into process phenomena. Throughout the research process contributions have been made to the development of Event Sequence Analysis (ESA). In this chapter some of the methods and techniques that this thesis has contributed to ESA are discussed in more detail, and the motivations behind various methodological choices are outlined as well.

Several of the methods and techniques introduced in the chapter were developed during the research process to address challenges encountered in operationalizing and visualizing ideas that arose from the different studies performed. Thus, to some extent this chapter can be understood to outline some of the products of this thesis. It also means that several methods and techniques (especially those developed for the identification of intentional and emergent linkages - see sections 4.6 and 4.7) are closely associated with the evolution of the conceptual framework that is at the basis of the thesis.

\subsection{A PROCESS PERSPECTIVE}

The use of any method entails, either implicitly or explicitly, a number of ontological and epistemological assumptions. The aim of this section is to outline a few fundamental assumptions that underlie the methods presented in this chapter. These assumptions are part of what can be understood as a process perspective (see Boons, Spekkink, and Jiao 2014). More specifically, the philosophical starting point that is chosen for this thesis is Whitehead's (1978) idea that the fundamental building blocks of "every thing" are events $^{12}$. Despite its insistence that fundamentally "every thing" exists in an inescap-

12. The term events was chosen here for pragmatic reasons. Whitehead (1978) calls the fundamental building blocks of reality 'actual entities,' sometimes also describing them as 'drops of experience,' and 
able flux, this approach does not deny that things can endure. Whitehead emphasizes that stability emerges from flux in the form of enduring entities. In his view, flux and permanence are two metaphysical lines that cannot be torn apart, and together constitute the complete problem of metaphysics: "In the inescapable flux, there is something that abides; in the overwhelming permanence, there is an element that escapes into flux. Permanence can be snatched only out of flux; and the passing moment can find its adequate intensity only by its submission to permanence" (Whitehead 1978, p. 338) ${ }^{13}$. Thus, one of the fundamental questions that follows from this philosophical position is how stable entities emerge, develop and dissolve over time.

An important epistemological consequence that can be drawn from the ontological starting point summarized above is that it is important take into account the changes that entities undergo over time, because no entity is ever exactly the same from one moment to the next (Whitehead 1978). The concrete implication for the scientific investigation of process phenomena is that we need methods that are capable of making visible the interplay between change and stability. The methodological approach taken in this thesis is based on the assumption that this can be achieved by studying processes as sequences of events. In this approach, one first defines a central subject, which can be any kind of entity, such as an individual person, an organization, a group of organizations, or a machine (Hull 1975). One then defines the events that the central subject makes happen or endures (Poole et al. 2000), as well as the mechanisms that are responsible for the progression in sequences of events (Abbott 1990a). This focus on entities and events largely replaces the model of entities and variable attributes that is currently dominant in the social sciences. The former model has a number of important advantages over the latter (Abbott 1988). A first advantage is that it doesn't require entities to remain fixed over time. Instead it allows entities to change, or dissolve entirely without creating problems in terms of missing data. Second, unlike most approaches that are rooted in the model of entities and attributes, the model of entities and events is sensitive to sequence effects, i.e., the order and duration of events may influence outcomes. Research that is based on the model of entities and events largely revolves around the reconstruction of sequences of events that describe the emergence, development, and/or the dissolution of a central subject. The concrete methods used in this thesis to perform these tasks are outlined in the remaining sections of this chapter.

these are not exactly the same as events. For an accessible discussion on the difference between actual entities and events, see Shaviro (2012).

13. Many alternative versions of process perspectives exist. See Rescher (1996) for an accessible overview. 


\subsection{GENERAL INTRODUCTION TO EVENT SEOUENCE ANALYSIS AND SELECTION OF CASES}

ESA comprises a set of ideas, methods, techniques, and tools that builds on the ontological and epistemological starting points outlined above, as well existing methodological approaches that have been developed in sociology (Abbott 1990a; Abbott 2001; Abell 1987; Abell 1993), and organizational sciences (Poole et al. 2000; Langley 1999). ESA is perhaps best understood as a type of longitudinal case study. ESA is also primarily a qualitative approach to social enquiry. Although it is possible to focus entirely on, for example, abstract patterns of events, one of the principles of ESA is that a full understanding of the way that social processes unfold also requires that events can be further qualified based on information that goes beyond these abstract patterns. The significance of events cannot always be derived from their place in the sequence(s) of which they are part, or their duration; the significance of events must sometimes be determined based on a qualitative understanding of the developments that they represent. In this regard, a useful distinction can be made between the syntactical structure of sequences of events (i.e., the abstract patterns of relationships between events) and the semantic content of sequences of events (i.e., the meaning that can be attributed to them, the substance of events) (Abell 1987; Heise 1993). ESA aims at the analysis of both these dimensions of sequences of events.

ESA entails the collection of large amounts of longitudinal data, which are recorded in event sequence datasets (based on Poole et al. 2000). Once this task has been completed, different avenues for analysis are possible, each requiring a particular approach to the preparation of data. In this thesis two main avenues are chosen: one avenue revolves around the construction and analysis of event networks, and the other avenue revolves around the construction and analysis of networks of actors or issues (see figure 4.1). The steps involved with ESA are further outlined below.

The case studies performed for this thesis are based on what Boons, Spekkink and Jiao (2014) refer to as a backward approach, where the researcher locates an outcome of interest and seeks to uncover the sequences of events that have led to this outcome. The concrete outcome of in-

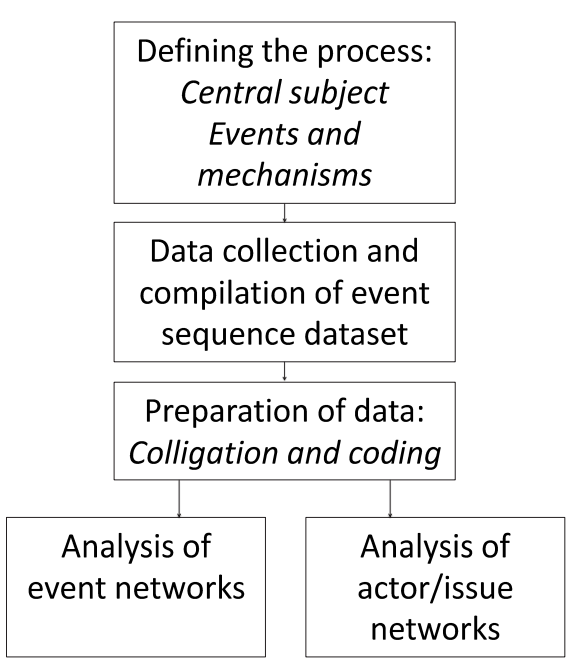

Figure 4.1: Steps in ESA. The definition of the central subject, events and mechanisms is discussed in section 4.2. 
terest to this thesis is the development of networks of by-product exchanges and utility synergies. In the cases that were chosen, networks of by-product exchanges and utility synergies already existed, to some extent, at the time that the research was started. Two cases have been studied for the research presented in this thesis, namely that of the Sloe Area and Canal Zone, and Moerdijk. In both cases the central subject is the community of actors $^{14}$ involved in the development of a network of by-product exchanges and utility synergies in their regional industrial system ${ }^{15}$, and the events focused upon are the actions and interactions through which members of the community develop institutional capacity. More specifically, and based on the conceptual framework of this thesis (see chapter 3), the events include actions and interactions through which actors orient themselves on problems and solutions, develop plans and visions, perform investigations to gather new knowledge or to test the feasibility of plans, engage in lobbying in attempts to influence the behavior of others, and implement plans. The communities that serve as the central subjects of the studies presented in this thesis consist out of various types of actors of which companies and governmental organizations are most actively involved. Figure 4.2 gives an indication of the regions in which the communities are active, although occasionally the actors would be involved in interaction processes that transcend the geographical boundaries of these regions.

The cases were chosen because in both of them the communities had achieved important outcomes in the development of networks of by-product exchanges and utility synergies. By the time that the research was started, in both cases the actors had implemented by-product exchanges and utility synergies that were to serve as components of larger networks. In addition to their similarity in outcomes, the cases are similar in three other important ways: (1) both cases concern developments that have occurred in the Netherlands; (2) both cases concern developments at, or around an industrial port area (see figure 4.2) with establishments of (among others) large industrial companies, which also leads to some similarities in terms of the types of actors involved; (3) in both cases the development of the network of by-product exchanges and utility synergies is still in progress. Because the cases are similar in several important respects, it is difficult to generalize the findings to cases that differ from them on these dimensions. Second, because both cases are chosen based on the achievements that were already made, it is not possible to determine whether the patterns observed in the case studies will always lead to such achievements. This would require further comparisons with cases where attempts to engage in industrial symbiosis are met with failure.

14. Actors are identified at the organizational level.

15. In chapter 6 the central subject is broader, and concerns the community of actors involved in the sustainable development of their regional industrial system. 


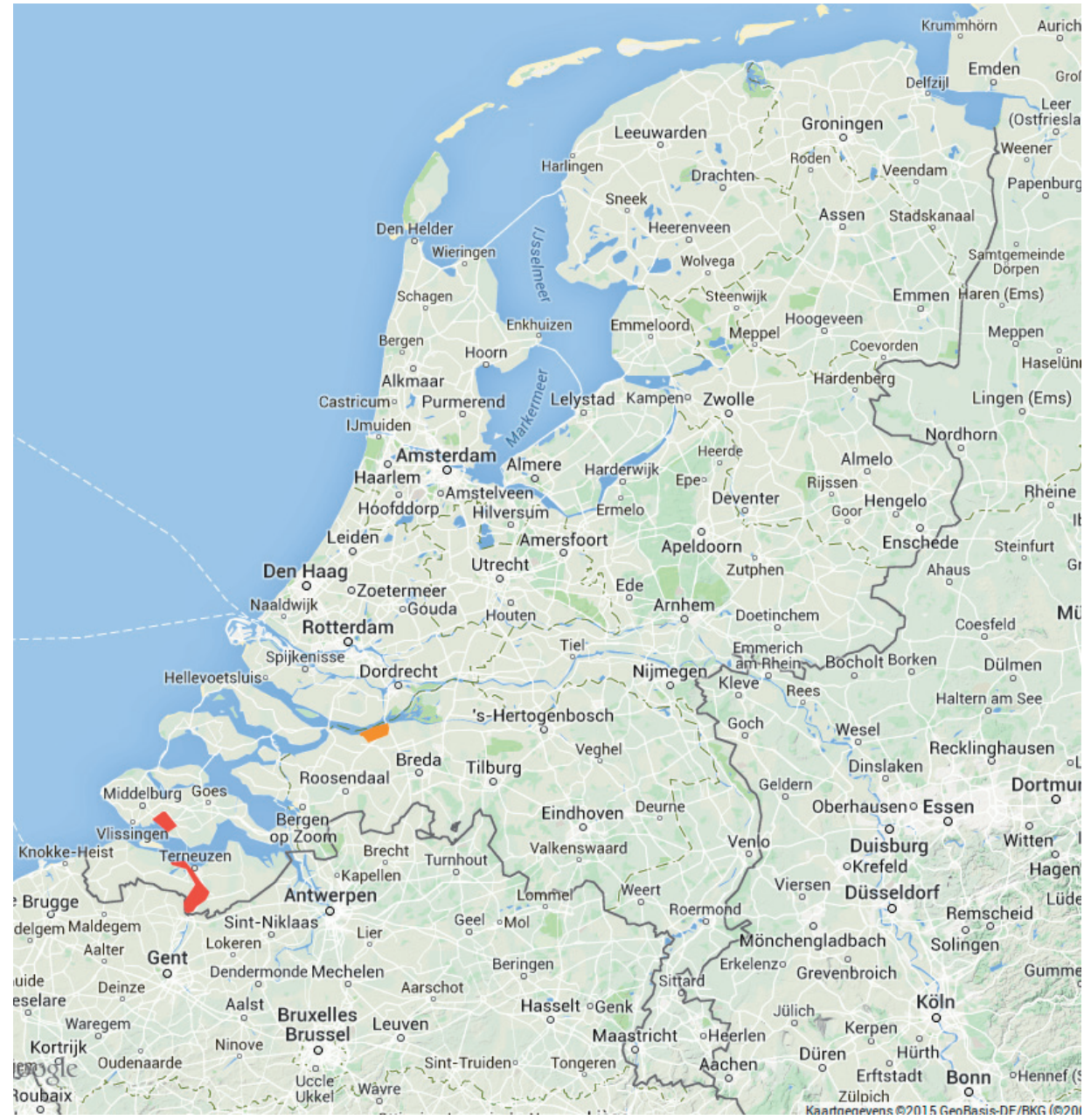

Figure 4.2: Indication of the location of the Sloe Area and Canal Zone (red) and Moerdijk (orange).

\subsection{COLLECTING LONGITUDINAL DATA}

The approach to data collection that is used in ESA is based on the procedures that have been developed for data collection in the Minnesota Innovation Studies (Van de Ven and Poole 1990; Van de Ven, Angle, and Poole 2000; Poole et al. 2000). Van de Ven and Poole (1990) introduce the idea to record empirical data as incidents, which they defined as a qualitative datum, consisting out of a bracketed string of words that captures basic information about an occurrence that happened on a specific date. These incidents are recorded in chronological order in an event sequence dataset. Poole et al. (2000) suggest that incidents can be identified either through direct observation, or through archival research. Direct observation includes participant observation, interviews, and the inves- 
tigation of emerging records and documents (Poole et al. 2000). The benefit of direct observation is that it allows the researcher to study a process as it unfolds, and that, depending on the resources of the researcher, data can be collected at a very detailed level. However, direct observation is impractical or even impossible for the investigation of processes that last more than a few years. Archival research is performed largely after the process has already unfolded. This can be performed through the analysis of documents and records, news archives, and retrospective interviews (Poole et al. 2000). The benefit of archival research is that it is possible to cover longer periods of time. However, a major disadvantage over direct observation is that the researcher must make do with what information has been preserved. For example, it is very difficult to reconstruct informal processes and events based on archival data, because these are less likely to leave behind traces in the form of documents and records. In this regard, it is useful to make distinction between front-stage dynamics and back-stage dynamics, ${ }^{16}$ where the former refer to the more formal dimensions of social processes, that is, the type of events that tend to be recorded in formal documents, reports, and news items, and the latter refer to micro-level dynamics and the informal interactions that leave behind little traces.

The approach to data collection used in this thesis is a form of archival analysis, although no use was made of retrospective interviews. This means that the reconstructions of sequences of events in this thesis only account for front-stage dynamics. At some point in the research process an attempt was made to validate reconstructions of sequences of events through retrospective interviews, but this approach was abandoned as it proved to be difficult to discuss the sequences of events at the level of detail necessary to use the interviews for purposes of validation. A major drawback of retrospective interviews is that the memory of people is far from perfect. To some extent, this problem may be dealt with through various techniques that have been developed in, for example, life course studies (e.g. Clausen 1998) and the learning history approach (Kleiner and Roth 1996), but these entail large time investments. For one of the regions that was considered in the research presented in this thesis (the Sloe Area and Canal Zone of Zeeland) a workshop was organized with the members of the project group Vital Sloe Area and Canal Zone, which includes representatives of government, business, education, and an environmental interest group. One of the activities included in the workshop was to reflect on a rough version of the reconstruction that was made of various sequences of events that occurred in the region. The participants were asked to indicate whether important events were missing. On the question forms that the participants were provided with none of the participants indicated that they were missing something (in many cases the field was left blank), but one participant verbally expressed that, to his memory, the preparations for one of the developments (Biopark Terneuzen) had started a bit earlier than indicated.

16. This distinction was introduced by Professor Frank Boons (Boons and Spekkink 2014). 
An attempt to find archival data on these events was unsuccessful, which supports the proposition that only front-stage dynamics can be accounted for by the approach that was used in this thesis. As a consequence, the analyses provided in this thesis are largely restricted to the more general patterns that have been observed in sequences of events. For example, the order of events is given priority over the exact dates on which the events occurred. In addition, micro-dynamics are left out of consideration.

To systematize the data collection process and to make the process reproducible a data collection protocol was developed in advance. The data collection protocol is included in Annex $3^{17}$. The protocol is designed for searches that are performed on the Web, and for searches that are performed in the LexisNexis database ${ }^{18}$. It offers a detailed description of the steps to be taken in the performance of searches, and how to record the results of the searches. The protocol is accompanied by a dataset for metadata that was developed with Microsoft Access (see Annex 5). In this dataset general information is recorded about all the sources that have been stored to the disk, and it offers an overview and justification of the search terms that were used during the data collection process. For the collection of data on developments in the Sloe Area and Canal Zone two rounds of data collection have been performed. The first took place from 27-1-2011 to 26-4-2012, and the second round took place from 13-12-2012 to 11-9-2013 to also include data on events that have occurred in 2011 and 2012. One round of data collection took place for the case of Moerdijk from 10-9-2012 to 11-10-2013. All the data sources that were collected were assigned a unique identification number and stored to a hard drive.

An event sequence dataset structure was developed using Microsoft Access, following instructions by Poole et al. (2000) (see Annex 6). The dataset structure offers an interface that can be used to make incident descriptions. This interface requires the researcher to provide (1) a qualitative description of the (inter)action to which the incident refers; (2) a date on which the incident occurred, including an indication of its accuracy; and (3) the source of the data. It is also possible to include additional information on the incident (e.g., background information) in a separate field. The dataset structure puts the incidents in chronological order. The dataset structure also offers interfaces for open, as well as closed coding procedures, including the possibility to record a codebook with descriptions that explain the meaning of codes. The data included in the dataset can be exported as an excel-file, which makes it easy to further prepare the data for analysis. All the collected sources were read and incidents were entered into the dataset manually

17. Annex 3 to 7 can only be found online: http://www.wouterspekkink.org/?page_id=206.

18. The LexisNexis database archives newspaper articles. The availability of news items depends on the specifics of the subscription of your organization. The Erasmus University Rotterdam has access to (among others) Dutch national and regional newspapers, usually from around 1990. 
by the researcher. The final dataset for the Sloe Area and Canal Zone includes 1483 incidents. The final dataset for Moerdijk includes 1143 incidents $^{19}$.

\subsection{PREPARING THE EVENT DATA FOR ANALYSIS}

After recording the data, various approaches can be taken to prepare the data for analysis, and each of these approaches entails colligation ${ }^{20}$ of incidents into events, as well as some type of coding procedure. Although different coding procedures are used for different purposes (see below), they all have in common that the codes are used to capture theoretically relevant aspects of the qualitative information provided in the incident descriptions. This approach to coding is similar to coding passages in documents or texts, with the important difference that the relevant passages have already been identified during the compilation of the event sequence dataset.

In the first empirical study that was performed for this thesis (chapter 4), the analysis was based on an approach that combines visual mapping (Langley 1999) with template matching (Poole et al. 2000). The incidents included in the event sequence dataset were coded based on a predetermined coding scheme, which was derived from the conceptual framework at the basis of the study. This coding procedure is based on the one that was developed by Poole et al. (2000) for the Minnesota Innovation studies. The purpose of the procedure is to transform the incidents into indicators of predefined theoretical events. Because the coding categories are known in advance, it is also possible to check for the reliability and accuracy of the coding scheme by having multiple researchers code samples of the dataset, and checking the results for inter-coder reliability. After coding the incidents they were colligated into events, which means that some incidents were grouped together because they are understood to refer to the same event (Abbott 1984). The results were displayed in visual maps, which show the identified events on a timeline, including an interpretation of the relationships between the events. In chapter 4 the theoretical assumptions behind the linkages between events are not yet explicitly discussed, but the type of linkage visualized is a precursor of what is explicitly defined as an intentional linkage in later chapters (see below).

Another approach to coding incidents that was introduced later in the $\mathrm{PhD}$ project bears closer resemblance to qualitative coding procedures (Boeije 2010). Instead of

19. The procedures used for data collection and storage are discussed in more detail in the various empirical chapters of this thesis.

20. The purpose of colligation is to assemble together different pieces of evidence for the occurrence of an event (Abbott 1984; 1990a; 2001). In this thesis, incidents served as indicators for the occurrence of events. In many cases, multiple incidents indicated the occurrence of one event. In the process of colligation, these are grouped together. 
starting with a predefined coding scheme, in this procedure descriptive codes are used to capture the theoretically relevant aspects of the incidents descriptions. After coding the incidents in two rounds, the incidents and their codes are compared to check for completeness and consistency of the codes that were assigned. In the research presented in this thesis this procedure was applied to code incidents along two broad dimensions. The first dimension concerns the actors involved in the incidents, and the second dimension concerns the issues that they addressed in their activities. Issues are defined as the topics on which actors formulate problem and solution definitions, and on which they gather knowledge and experience. The information that is gained from this coding procedure is used in the construction and analysis of network graphs (see section 4.7), as well as the identification of emergent linkages in event graphs (see section 4.6).

A third approach to coding that has been applied in this thesis concerns the identification of intentional linkages between incidents (and events). An intentional linkage between a pair of events indicates that actors involved in the later event of the pair respond to conditions that have been raised in the earlier event. The existence of such a linkage does not imply the necessity or sufficiency of these conditions for the occurrence of the event. Making such statements in a reliable way involves special procedures that are quite demanding, and the conditions for applying these procedures are not met in the research presented in this thesis (cf. Ragin 1987; Willer 1993). What intentional linkages do indicate is that there was an influence from on event on another, that is, that how the event came about would have been different, had the earlier event not occurred. Another way to interpret intentional linkages is that they represent the heritage of events from the past. The assumption behind this interpretation is that issues are carried forward in time by actors participating in the events, and that the intentional paths indicate which lines of heritage were plausible (cf. Abbott 2004). Coding for intentional linkages occurs by indicating for each incident which earlier incidents have contributed to the conditions in which the incident occurred (see figure 4.3).

In the qualitative descriptions of incidents references are often made to incidents that have occurred prior to the incident being described. Such references were used as the primary evidence for the existence of intentional linkages between incidents. In some cases the evidence for the existence of an intentional linkage between two incidents was not found in the descriptions of these incidents themselves, but in one or more other incidents that lie further in the future of sequence of events. In these cases the identification of the intentional linkage was accompanied with memo that indicates where the evidence for the existence of the linkage is to be found. 


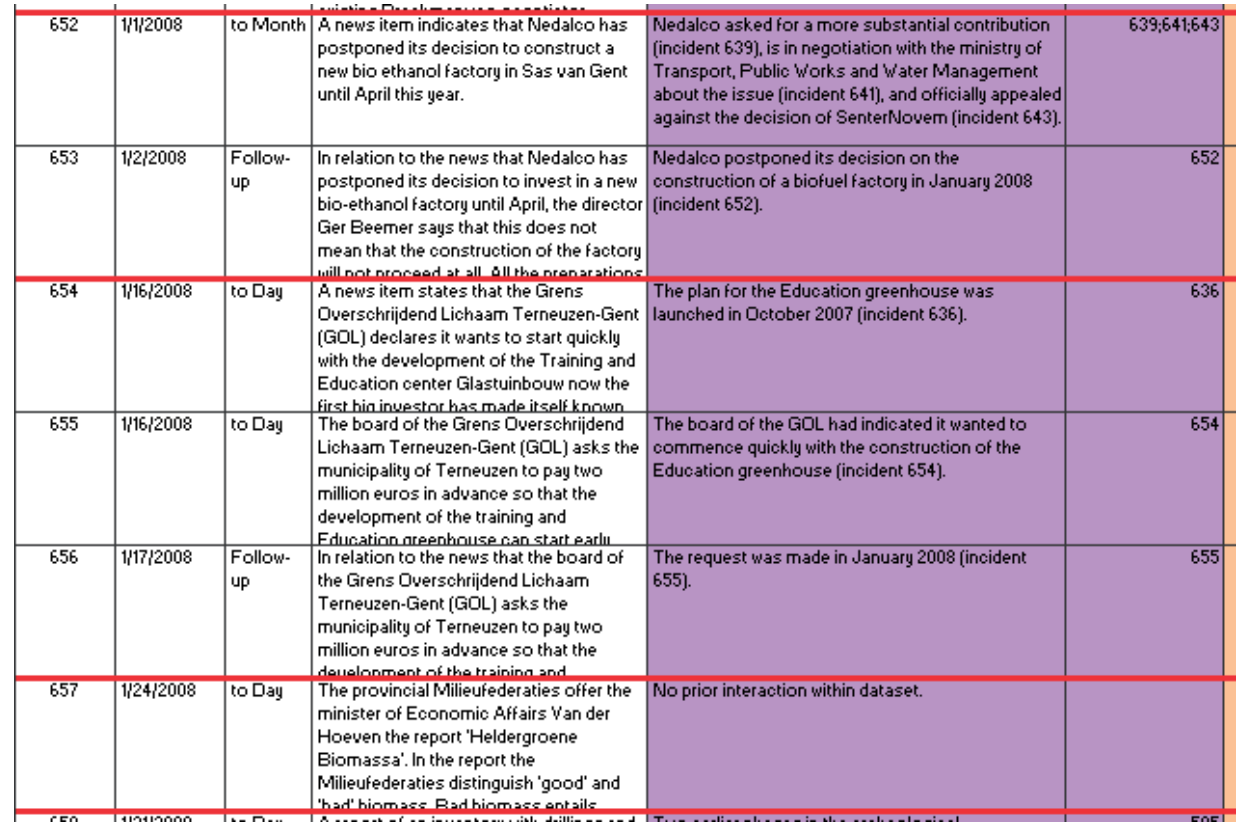

Figure 4.3: Intentional linkages were coded by describing the conditions under which they occurred in a separate column of the event sequence dataset and by including references to the numbers of the incidents in which these conditions arose (the purple columns in the screenshot).

\subsection{EVENT GRAPHS: INTENTIONAL LINKAGES}

After the data have been coded, the resulting information can be used for different types of analysis. If the data are exported to an excel-file, it is possible to retrieve the necessary data by using the program Gephi ${ }^{21}$ (see Annex $6^{22}$ for detailed instructions). In this thesis, Gephi was also used to create the visualizations of the various event graphs and network graphs (see chapters 6 to 8). The intentional linkages between events are visualized as directed, a-cyclic graphs, an approach that is inspired by Abell's $(1987 ; 1993)$ approach to the reconstruction of narratives ${ }^{23}$. In this thesis, the graphs are referred to as event graphs. Events are represented by nodes, which are represented in order of time on the

21. Gephi is an open source program for network visualization. It is also very useful for converting data to various formats. It is available at https://gephi.github.io/. To retrieve the data, a third-party plugin was used (Levallois 2013).

22. Annex 3 to 7 can only be found online: http://www.wouterspekkink.org/?page_id=206.

23. A major difference is the way that linkages between events are interpreted. For Abell (1987; 1993), these linkages represent "paths of social determination." Another difference is that Abell also includes steps in his method to develop abstract narratives from detailed ones, which can be understood as an alternative approach to event colligation. 
horizontal axis, and the intentional linkages between events are represented by arcs (see figure 4.4). The layout of the nodes on the vertical axis has no use other than making parallel subsequences easier to distinguish by giving them separate positions on the vertical axis. The author of this thesis has developed a plugin for Gephi that automates the layout of nodes on both axes (see Annex 7). The event graphs can be accompanied by event tables, in which the more detailed descriptions of the events can be offered, similar to Abell's $(1987 ; 1993)$ narrative tables.

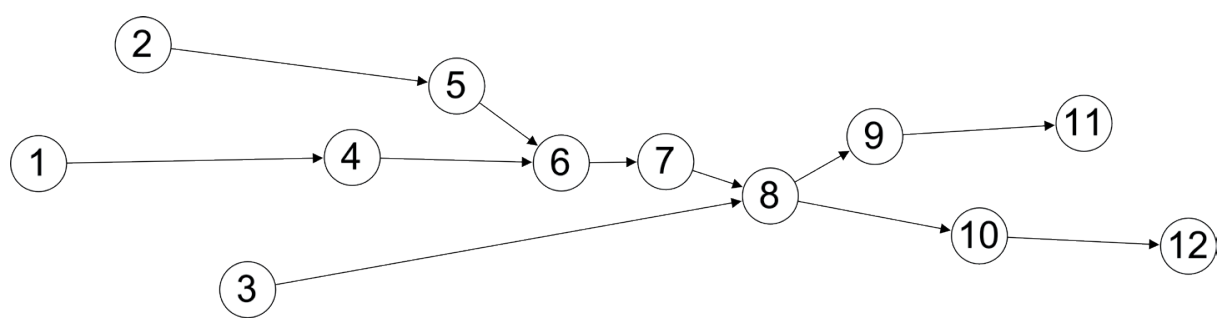

Figure 4.4: Fictional example of an event graph. Nodes represent events and arcs represent intentional linkages. The layout on the horizontal axis represents the order of events. The numbers can be linked to numbers in (for example) an event table that contains detailed descriptions of the events.

A visual inspection of event graphs already offers useful information. For example, the graph in figure 4.2 shows two points of convergence at event 6 and event 8 . At these points, different sequences of events that used to be mutually independent (in terms of intentional linkages) become linked. Event 8 is also a point of divergence, because its descendants constitute two mutually independent sequences of events. Visual inspection also raises issues that may require a further analysis based on a qualitative understanding of the underlying events. One may ask, for example, if the convergence at event 8 would have happened had event 7 not occurred. This can be understood as a form of counterfactual analysis (Hawthorn 1991; Lewis 2001).

It is also possible to apply different methods for network analysis to event graphs, some of which need to be adapted to the study of directed graphs (Wasserman and Faust 1994). One example is to find all ancestors of an event (i.e., all prior events that are directly and/or indirectly linked to the event in question) or all descendants (i.e., all events that follow the event in question and are directly and/or indirectly linked to that event). For small event graphs this can be determined based on visual inspection, but for larger event graphs it is useful to automate the process ${ }^{24}$. The event graphs provided in

24. NetworkX (http://networkx.github.io/) is an open source Python library that provides algorithms for detecting ancestors and descendants of designated events. The author also made a plugin for Gephi that performs the same task: http://www.wouterspekkink.org/?page_id=203. 
chapter 6 were abstracted from the complete dataset of events by first finding the ancestors and descendants of 'focal events,' and then plotting the results separately in event graphs. It is also possible to determine the various paths ${ }^{25}$ that are present in an event graph. An algorithm for detecting such paths is provided as an R-script on the website of the author ${ }^{26}$. Paths are not interpreted directly in this thesis, but their identification is a necessary step in the reconstruction of emergent linkages (see section 4.7). Another analysis of event graphs that was applied in this thesis concerns the detection of subsequences. In this thesis, these subsequences are identified inductively by calculating the modularity of the graph (see chapter 7). Modularity can be understood as a measure of how well a graph can be divided into different communities, based on the patterns of connectivity between different nodes (Newman 2006). The algorithm that was used in this thesis to determine modularity involves assigning nodes (representing events) to different communities in such a way that the modularity of the graph is optimized (Blondel et al. 2008) ${ }^{27}$. Modularity is reported as a number between 0 and 1 , where numbers near 0 indicate low modularity and numbers near 1 indicate high modularity. If modularity is low, this may also mean that the resulting division in communities is 'unstable,' i.e., for many nodes there is a lot of uncertainty as to what community they should be assigned to ${ }^{28}$. In this thesis the resulting communities are interpreted as subsequences. These subsequences have been used primarily as an aid in the qualitative interpretation of the observed patterns of events. For example, the various subsequences detected in chapter 7 largely corresponded with various initiatives that existed before collaborations towards industrial symbiosis, as well as to different projects that were included as part of the collaborations themselves. This can only be determined by a qualitative understanding of the underlying events.

\subsection{EVENT GRAPHS: EMERGENT LINIKAGES}

After coding the datasets for actors and issues, the datasets also provide the information that is necessary to reconstruct emergent linkages. Emergent linkages play a major role in the analysis that is offered in chapter 7 of this thesis. Emergent linkages are similarities that exist between events that are not accounted for by intentional linkages, that is, they

25. Wasserman and Faust (1994) offer an elaborate discussion of paths in graphs.

26. See the website www.wouterspekkink.org.

27. The algorithm of Blonder et al. (2008) to calculate modularity is included in Gephi. This algorithm ignores the direction of the relationships between the nodes.

28. This can be observed by running the algorithm several times. If the division into communities is unstable, different communities will be detected at each run. 
are similarities between events that do not share a historical lineage. More specifically, an emergent linkage exists between a pair of events if the issues addressed by actors in these events are similar, but if the events are not linked by a path of intentional linkages at any length. The underlying assumption is that similarities that exist in the absence of intentional linkages are coincidental, because the similarity cannot be caused by the inheritance by one event from another. In chapter 6 of this thesis emergent linkages are studied to investigate the emergence of common ground for otherwise independent projects.

The reconstruction of emergent linkages proceeds through a number of simple steps. First, the relationships of issues to events are reported in an incidence matrix, where issues are reported in the rows of the matrix, and the events are reported in the columns of the matrix (see table 4.1).

Table 4.1: Fictional incidence matrix.

\begin{tabular}{lcccc}
\hline & Event 1 & Event 2 & Event 3 & Event 4 \\
\hline Reuse & 1 & 0 & 1 & 0 \\
Heat & 0 & 1 & 1 & 0 \\
Employment & 0 & 0 & 0 & 1 \\
\hline
\end{tabular}

$A$ ' 1 ' in any cell indicates that the issue in the corresponding row was addressed in the event in the corresponding column. The incidence matrix provides all information that is required to calculate the similarity of the events. Various approaches can be used to perform the calculations (Borgatti and Halgin 2011), and in this thesis similarities are calculated as correlations between the various column profiles, for which the algorithm implemented in the Ucinet software package was used (Borgatti, Everett, and Freeman 2002). A correlation of ' 1 ' indicates that the column profiles are exactly similar (taking into account both the presence and the absence of issues). A correlation of '- 1 ' indicates that the column profiles are each other's exact opposites, and a correlation of ' 0 ' indicates that the two columns are 'indifferent' to each other (Borgatti and Halgin 2011). If the focus is on the similarity of events, all correlations that are lower than, or equal to ' $O$ ' should be removed from the resulting correlation matrix (which is what Ucinet produces as a result). The correlation matrix then needs to be translated to a list of bilateral relationships between all pairs of events. This can be achieved by opening the matrix in Gephi, and then exporting the edges as an edge list. Because the list will also include similarities between events that are also intentionally linked, these still have to be filtered out. An algorithm that achieves this is offered on the website of the author ${ }^{29}$. This algorithm requires that the paths of intentional linkages are detected first, using the

29. www.wouterspekkink.org 
algorithm that was mentioned in section 4.6. The algorithm for filtering out the unwanted similarities goes through all paths of intentional linkages in order to find out whether the events between which similarities exist feature in one of these paths together. If this is the case, the corresponding similarity relationship is removed from the list. The list that remains after running the algorithm only contains the emergent linkages. These linkages can then be visualized in event graphs (see figure 4.5.)

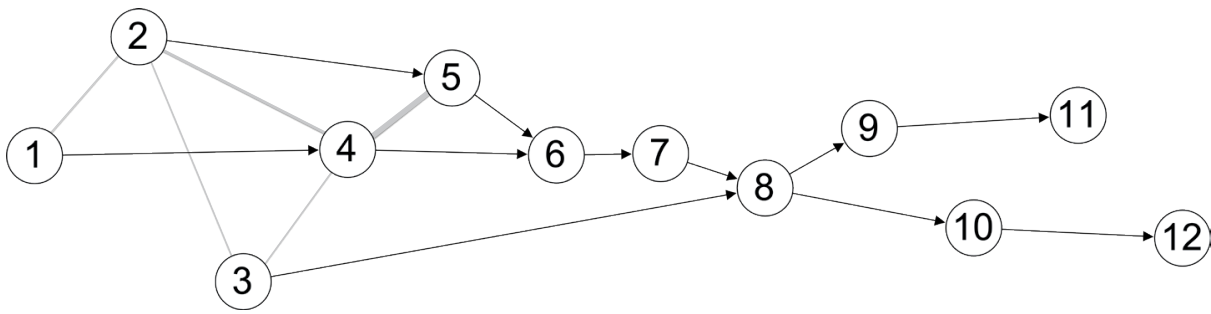

Figure 4.5: Fictional example of an event graph with emergent linkages, represented by the grey edges. The thickness of the edges represents the strength of the similarity.

\subsection{NETWORK GRAPHS: PROCESS AND STRUCTURE}

Healey and her colleagues (Healey, de Magalhaes, and Madanipour 1999; Healey et al. 2003) operationalize the relational dimension of institutional capacity largely in terms of structural characteristics of the networks of social relationships that actors engaged in capacity building form, such as the morphology and integration of the social network. These structural characteristics of the relational dimension are also seen as an important foundation for the extent that the other dimensions of institutional capacity are present within a community. According to Healey et al. (2003), the way that knowledge flows around in a network is determined by the structure of the social relationships. Also, one of the ways in which the mobilization dimension of institutional capacity is operationalized is the 'location of the power to act' in a network (Healey et al. 2003). From this perspective the process of institutional capacity building can be understood to materialize in the changes that occur in these structural characteristics over time. In the first two empirical chapters of this thesis (chapters 5 and 6) no serious attempt is made to engage with the structural dimensions of institutional capacity; in terms of methods the focus is entirely on the identification of patterns of events. Observations on changes in social structures are made in a descriptive way. However, during the research process it became clear that a structural perspective on institutional capacity and institutional capacity building could offer insights that are difficult to develop with an exclusive focus on patterns of events. Therefore the step was made to use methods that engage with 
social structures, and to explore how such methods can be usefully related to methods that are used to study patterns in sequences of events.

One of the issues raised in section 4.2 is that a process perspective does not deny the importance of stable entities, but that it is rooted in the idea that stable entities emerge from processes, i.e., process has primacy over substance. From this perspective, stable entities, such as organizations and networks of relationships can be understood to "emerge from [the] soup of events as lineages, as events that keep happening in the same way" (Abbott 2001, p. 296). This is the position that was explicitly chosen in this thesis as a starting point for exploring the relationship between process and structure. More specifically, social structures were investigated as recurring patterns of interactions. The building blocks for such investigations are already present in the literature on Social Network Analysis (SNA), in the branch of the literature that deals with affiliation networks (chapter 8 in Wasserman and Faust 1994; Borgatti and Everett 1997; Schalk, Torenvlied, and Allen 2010; Borgatti and Halgin 2011; Akkerman and Torenvlied 2011; Scott 2013; Hu, Knox and Kapucu 2014). Similar ideas have been brought forward in qanalysis, an approach originally introduced by Atkin (1974). For example, Doreian (1979) uses q-analysis in a manner very similar to the way that SNA is used in this thesis to study (changes in) social structures. As in most other approaches to SNA, affiliation networks are represented using graph-theoretical concepts. Thus, entities (such as persons, organizations, or events) are represented by nodes, and the relationships between these entities are represented by edges (see figure 4.6). Affiliation networks can also be represented in the form of an incidence matrix (see table 4.2). A special characteristic of affiliation networks is that two different types of nodes are considered. These types are usually referred to as modes, which is why affiliation networks are also referred to as two-mode networks (Borgatti and Everett 1997), and why the graphs that represent such networks

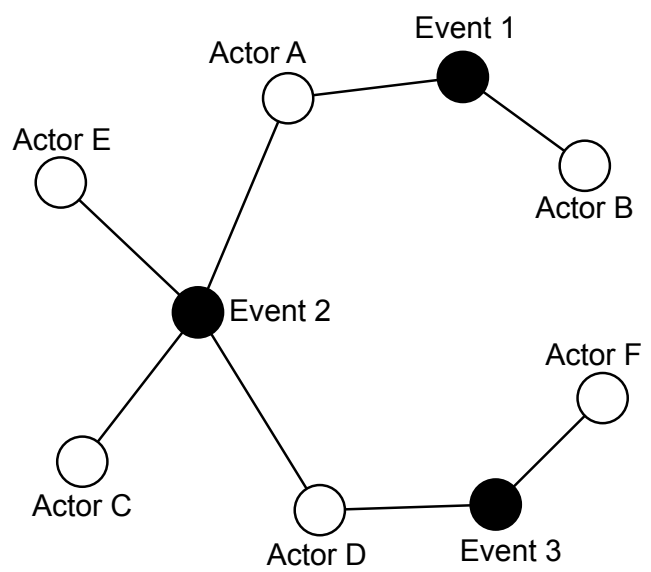

Figure 4.6: Fictional example of an affiliation network. are often called bipartite graphs (two partitions exist).

In SNA affiliation networks are often used to study the joint affiliations of persons to events or organizations. Thus, in these applications the persons constitute one mode, and the organizations/ events constitute a second mode. In affiliation networks relationships never exist between two nodes of the same mode directly. Two nodes of the same mode can only be related indirectly, through their joint 
connectedness to one or more nodes of the other mode. Direct relationships between nodes of the same mode can be approximated by using the incidence matrix to calculate an adjacency matrix. To this end, the incidence matrix needs to be multiplied with a transposed version of itself. The result of this operation is an adjacency matrix, which is a symmetric matrix that shows the relationships among nodes of a single mode (see table 4.3).

Although it is not the case in the example offered in table 4.3, it is possible for an adjacency matrix that is constructed this way to have valued relationships. If two actors jointly participated in two events, then the corresponding cell of the adjacency matrix will report a value of 2 . This information can be used as a measure of the strength of the relationship between the actors. The network represented by the adjacency matrix can also be visualized in a graph (see figure 4.7).

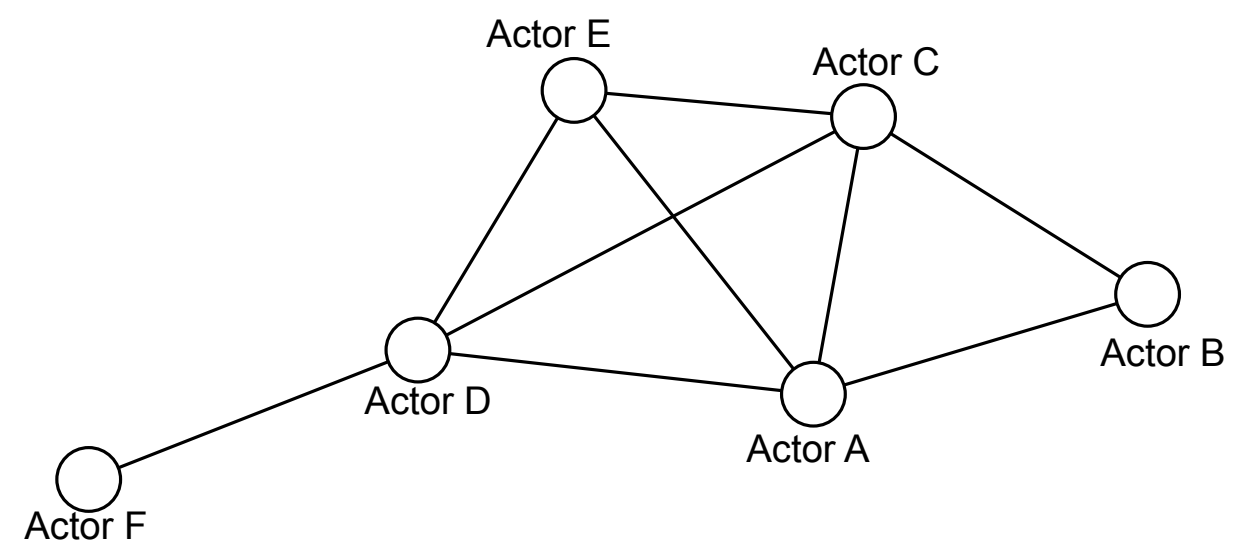

Figure 4.7: Fictional example of one-mode network.

\subsection{ANALYSIS OF NETWORIK DYNAMICS}

Following the steps described in section 4.8, it is possible to reconstruct networks of actors using the information provided in event data, which opens the door to an investigation of the contribution that social processes (represented by sequences of events) make to social structures (represented by actor networks). Because an incidence matrix such as the one illustrated in table 4.2 can represent the events in order of time, it is also possible to reconstruct the network as it exists at different stages of a sequence of events (cf. Doreian 1979). To achieve this, all one has to do is to reconstruct the adjacency matrix for different frames of the incidence matrix. In chapter 8 of this thesis this technique is used to create large amounts of overlapping adjacency matrices. For example, if the complete incidence matrix reports 30 events, and if the research reconstructs overlap- 
ping frames of 10 events $^{30}$, then the first frame will include events 1 to 10 , the second frame will contain events 2 to 11, the third frame will contain event 3 to 12. As a result, each frame differs only in one event from its direct neighbors. An R-script with an algorithm that automates the process of reconstructing these frames from a given incidence matrix is offered on the website of the author ${ }^{31}$. Each frame is represented by a separate adjacency matrix, and all adjacency matrices are included in an array. The R-script can also be used to analyze the adjacency matrices, for which it uses the "igraph" package (Csardi and Nepusz 2006) for R (a package for Social Network Analysis). These results can be converted into time series, using functions that are native to $R$. These time series give insight in the evolution of social networks over time. In this thesis, these time series were analyzed based on a visual inspection of the patterns, an interpretation of which is offered based on the underlying qualitative event data.

Table 4.2: Fictional incidence matrix of affiliation network

\begin{tabular}{lccc}
\hline & Event 1 & Event 2 & Event 3 \\
\hline Actor A & 1 & 1 & 0 \\
Actor B & 1 & 0 & 0 \\
Actor C & 0 & 1 & 0 \\
Actor D & 0 & 1 & 1 \\
Actor E & 0 & 1 & 0 \\
Actor F & 0 & 0 & 1 \\
\hline
\end{tabular}

Table 4.3: Fictional adjacency matrix for one-mode network.

\begin{tabular}{|c|c|c|c|c|c|c|}
\hline & Actor A & Actor B & Actor C & Actor D & Actor $\mathrm{E}$ & Actor $F$ \\
\hline Actor A & - & 1 & 1 & 1 & 1 & 0 \\
\hline Actor B & 1 & - & 0 & 0 & 0 & 0 \\
\hline Actor C & 1 & 0 & - & 1 & 1 & 0 \\
\hline Actor D & 1 & 0 & 1 & - & 1 & 1 \\
\hline Actor E & 1 & 0 & 1 & 1 & - & 0 \\
\hline Actor $F$ & 0 & 0 & 0 & 1 & 0 & - \\
\hline
\end{tabular}

30. See chapter 8 for considerations that come into play when choosing a suitable size for the frame of events.

31. www.wouterspekkink.org; also see the Dynamic Networks Tool. 



\section{CHAPTER 5}

\section{THE EMERGENCE AND DEVELOPMENT OF BIOPARIK TERNEUZEN: A PROCESS ANALYSIS}

This chapter has been published as Spekkink, W. A. H. 2013. Institutional capacity building for industrial symbiosis in the Canal zone of Zeeland in the Netherlands: $a$ process analysis. Journal of Cleaner Production 52(1): 342-355. 


\section{ABSTRACT}

One of the assumptions underlying much of the research on Industrial Symbiosis (IS) that has been performed over the past decades is that, in addition to technical and economic feasibility, collaboration between firms is of central importance to the development of IS. Up till now there has been little systematic research into the process through which firms and other relevant actors build up collaborations for IS. I present Event Sequence Analysis as a research approach that allows for a systematic, longitudinal analysis of process phenomena and I outline the steps to be taken in the application of this approach. I demonstrate the value of the approach by offering a first analysis of how companies in the Canal Zone of Zeeland in the Netherlands build up the institutional capacity that enables them to address the development of IS collaboratively. The analysis reveals that institutional capacity did not build up in a linear way. The generation of institutional capacity enabled the involved actors to engage in increasingly complex by-product synergies and utility synergies. It also enabled the actors to develop a strategic vision in which they articulated the development of a bio-based industrial cluster as a common purpose. This common purpose stimulated the actors to shift their focus from the development of individual synergies to the development of a regional network of such synergies. Event Sequence Analysis proves to be a promising approach to investigating phenomena such as institutional capacity building and the emergence and development of Industrial Symbiosis. 


\subsection{INTRODUCTION}

One of the assumptions underlying a major part of the research that has been performed on Industrial Symbiosis (IS) for more than a decade is that, besides technical and economic factors, social aspects such as inter-firm cooperation and trust are of central importance to the successful development of symbiotic exchanges (Gibbs, 2003; Hewes \& Lyons, 2008; Posch, 2010). The most cited definition of IS refers to collaboration as a key factor: "engaging traditionally separate industries in a collective approach to competitive advantage involving physical exchange of materials, energy, water, and by-products. The keys to industrial symbiosis are collaboration and the synergistic possibilities offered by geographic proximity" (Chertow, 2007, p. 12). The assumption about the importance of collaboration has also spilled over to policy programs that aim to stimulate the development of IS. For example, in the Netherlands the national government sought to disseminate the idea and necessary knowledge for IS in industrial parks through a stimulation program that ran from 1999 to 2004 . The goal of the program was defined as "the realization of sustainable industrial parks, by stimulating the exploration of possibilities for cooperation between firms in the industrial park and between firms and involved governments" (Berenschot, 2004, p. 5).

Although the assumptions on the importance of collaboration and trust for IS have been scrutinized before (e.g., Ashton, 2008; Deutz and Gibbs, 2008; Hewes and Lyons, 2008), there has been little systematic investigation of this relationship from a process perspective. The aim of my own research is to study the actual process through which collaborations conducive to the development of symbiotic exchanges come about. There is a number of studies that conceptualize industrial symbiosis as an evolutionary process, often based on an analogy between industrial systems and natural ecosystems (e.g., Ehrenfeld and Gertler, 1997; Korhonen and Snäkin, 2005; Pakarinen et al. 2010). However, this meta-theoretical perspective does not help us identify the specific mechanisms through which collaborations come about. To identify such mechanisms Boons and colleagues (2011) and Boons and Spekkink (2012a) introduce the concept of institutional capacity building (Healey, 1998; Healey et al., 2003; also see Innes \& Booher, 1999) to the literature on IS. Institutional capacity building provides a useful conceptual basis for investigating IS as a social process. In this article I have two aims. The first aim is to offer insights into the dynamics of institutional capacity building and their influence on the emergence and development of symbiotic exchanges based on an in-depth, longitudinal case study of IS projects in the Canal Zone, a Regional Industrial System (RIS) in Zeeland, the Netherlands. A RIS is "a more or less stable collection of firms located in proximity to one another, where firms in principle can develop social and material/ energy connections as a result of that proximity" (Boons et al., 2011, p. 907). The second aim of this article is to introduce Event Sequence Analysis (ESA) as a research approach 
that allows for a systematic and longitudinal investigation of process phenomena, such as institutional capacity building and the emergence and development of IS. For the past two years researchers of the research cluster Governance of Energy and Material Flows at the Erasmus University Rotterdam have been developing this approach for the longitudinal investigation of governance processes, based on similar approaches that have been developed by others (Abbott, 2001; Langley, 1999; Poole et al., 2000; also see Boons and Spekkink, 2012b). I introduce the approach in this article and I demonstrate its usefulness to research on IS. My central research questions are:

1. How was institutional capacity built in the Canal Zone between 1995 and 2010?

2. How did the dynamics of institutional capacity building influence the emergence and development of symbiotic exchanges in the Canal Zone?

3. How can Event Sequence Analysis be applied for a systematic longitudinal investigation of process phenomena?

In section $5.2 \mathrm{I}$ introduce the conceptual framework that serves as the conceptual basis for my research on institutional capacity building and IS in the Canal Zone. In section 5.3 I introduce the method ESA and discuss the specific methods that I used to collect, organize and analyze data. In section 5.4 I present the results of my analysis and discuss their significance. Finally, in section 5.5 I present my conclusions.

\subsection{CONCEPTUAL FRAMEWORK}

\subsubsection{Institutional capacity building and industrial symbiosis}

My conceptual framework is built around the concept of institutional capacity building (Healey, 1998; Healey et al., 2003). Boons, Spekkink and Mouzakitis (2011) and Boons and Spekkink (2012a) introduced the concept of institutional capacity building to the literature on IS to analyze how firms, governments, knowledge institutes and other relevant actors build relational resources, knowledge resources, and mobilization capacity that allow them to address the development of networks of symbiotic exchanges in a collaborative fashion. The concept of institutional capacity building covers several of the 'social factors' of IS that have been identified in literature (Boons \& Spekkink, 2012a). The concept is based on the understanding that to address issues of common concern in a collaborative fashion there should be a network of actors that trust each other and have some level of mutual understanding (relational resources), that have shared definitions of problems and solutions, possibly codified in plans or even strategic visions (knowledge resources), and that among them there are actors with sufficient power and resources to mobilize others for action (mobilization capacity). Figure 5.1 visualizes the conceptual framework. 


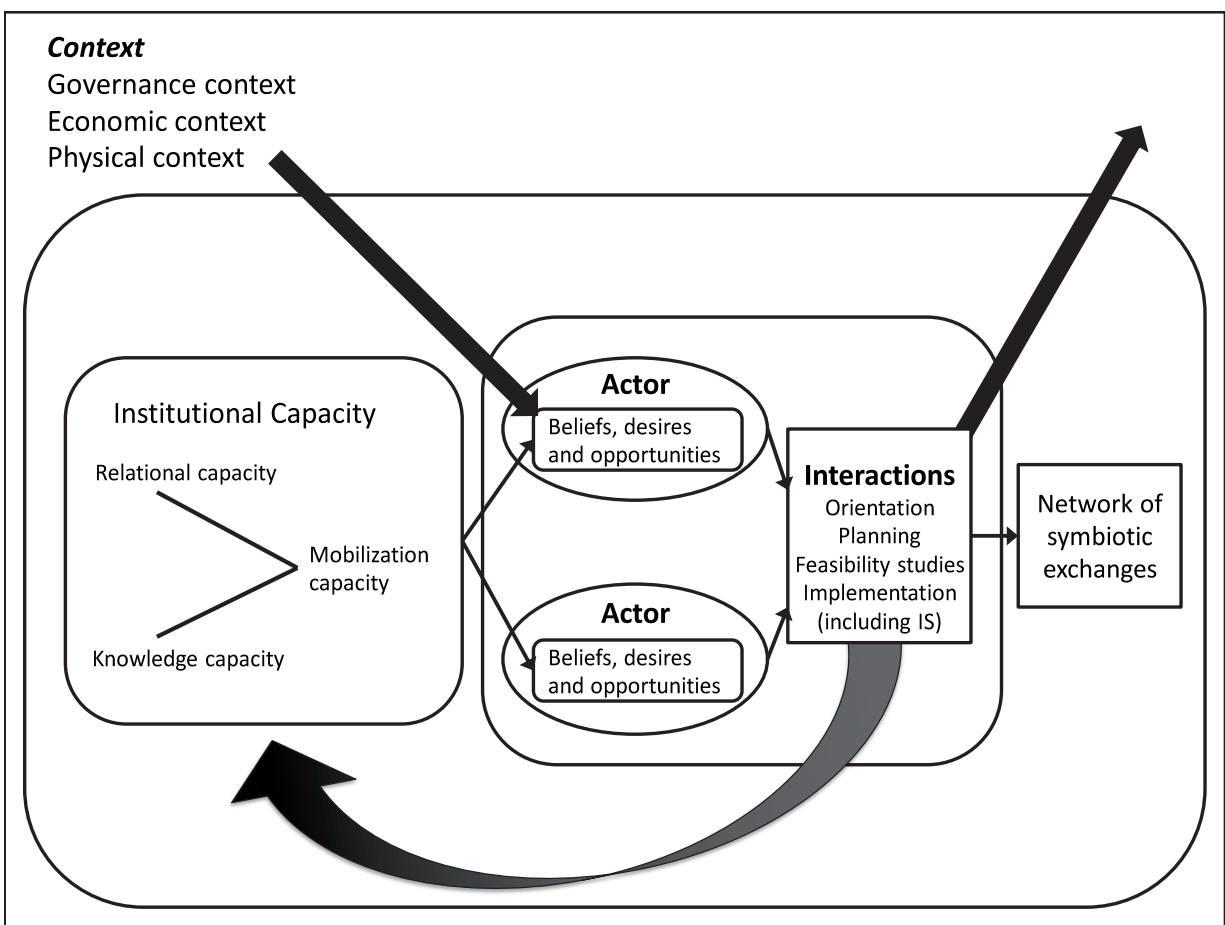

Figure 5.1: Conceptual framework.

In my conceptual framework I distinguish three different levels. First, I distinguish the level of interactions at which I conceptualize the different types of interactions that actors may engage in throughout the process of building institutional capacity. The second level is the level of the RIS, which is the level at which I conceptualize dynamics of institutional capacity building. This is also the level at which a network of symbiotic exchanges may develop. I distinguish two types of symbiotic exchanges in my research project. First, by-product synergies concern the exchange between firms of previously disposed byproducts to replace other business inputs. Second, utility synergies concern the shared use of utility infrastructures for the production of energy carriers, process water and for the joint treatment of waste and emissions (Van Berkel et al., 2007). The third level of the framework is the level of context. The inclusion of this level in the framework is based on the understanding that actors in the regional industrial system are embedded in a context that influences the opportunities they see for different courses of action through policies and regulations (governance context), through geographical and infrastructural restrictions (physical context) and through market developments (economic context).

Although dynamics of institutional capacity are analyzed at the level of the RIS, institutional capacity is generated by dynamics at the level of interactions, i.e., institutional capacity can be understood as the emergent product of interactions between actors. 
Institutional capacity is built through recurring interactions between a growing group of actors. The process of institutional capacity building will typically start with a number of actors that are brought together by key players to meet face to face over a long period of time to orient themselves on an issue of common concern. The recurring interactions allow the actors to strengthen their personal and professional relationships or build new ones (Innes \& Booher, 1999). The actors may also identify and involve additional key players that have the resources and power that are necessary to "get things done." The stronger personal and professional relationships offer a basis for sharing experiences and jointly producing knowledge that aid the actors in the development of plans for dealing with the issue. The actors may also work together to draw on expertise and resources from outside the group (Healey, 1998). After developing plans the actors will typically gather additional knowledge to investigate the feasibility of their plans before the plans are actually implemented. If the plans are found to be feasible, the actors may mobilize the generated capacity in efforts to implement the plans they have developed, such as the development of symbiotic exchanges. Innes and Booher (1999) argue that one of the most far-reaching effects of institutional capacity building is social learning. The involved actors may find new ways of solving common problems or reassess their purposes and goals and come to see their interests and problems as interconnected. This can become concrete in the development of shared strategic visions, which give direction to further interactions between the actors.

As institutional capacity builds up over time, it influences future interactions by shaping the opportunities that actors see for engaging in further interactions (see Boons \& Spekkink, 2012a). Interactions can also affect institutional capacity negatively, for example when actors have negative experiences in working together or when more uncertainty or disagreement about problems and solutions is created. In addition, the opportunities that actors see for future interactions are not only influenced by dynamics of institutional capacity building. The different dimensions of the context in which the actors are embedded also restrict or generate opportunities that actors see for different courses of action. Indeed, provided that sufficient institutional capacity is generated, actors may work together to influence their context in ways that they were unable to do alone (Innes \& Booher, 1999).

The network of by-product synergies and utility synergies that emerges and develops at the level of the RIS can be understood as an outcome of the process of institutional capacity building. The network emerges as actors in the RIS implement by-product synergies and utility synergies and establish further connections between them over time. The stability of the network largely depends on the efforts of actors to sustain symbiotic exchanges. The structure of the network may change when symbiotic exchanges come to an end, when new ones are implemented or when existing exchanges are adapted to changing circumstances. 


\subsubsection{Propositions}

The conceptual framework that I present leads to several expectations on the development of institutional capacity and its influence on the development of networks of byproduct synergies and utility synergies. To make these expectations explicit I developed 5 propositions that I used to focus my analysis. The propositions all address dynamics at the level of the RIS, except for proposition 5. The concept of institutional capacity building suggests that there is a basic logic to the sequence of interactions through which actors build the capacity to address an issue of common concern. My framework predicts that actors are first primarily occupied with orientation. Following initial orientations they engage in the development of plans and after studying the feasibility of their plans they carry out the plans that appear to be feasible. Actors may subsequently orient themselves on the results of implementations and use the knowledge and experience gained for the development of new plans. This could be a first step in the learning process that Innes and Booher (1999) refer to. The above suggests a first simple sequence of events that I expect to observe in the case study, summarized in proposition 1.

Proposition 1: The interactions between actors in the process of institutional capacity building proceed through a cycle of orientation, planning, feasibility studies and implementation.

My next propositions concern developments in the number and range of actors involved in the process of institutional capacity building. The conceptual framework suggests that recurring interactions take place between an expanding group of actors, although the number of involved actors can be expected to stabilize at a certain point when the entry of additional actors no longer contributes significantly to the capacity of actors to deal with issues of common concern. I distinguish two types of growth in actors. First, there can be growth in the total number of actors involved. Second, there can be growth in the range of actors involved in terms of their institutional background (e.g. governmental organizations, firms, business associations, knowledge institutes and environmental organizations). These hypotheses have been brought forward earlier by Baas and Boons (2004).

Proposition 2: The number of actors involved in the process of institutional capacity building will grow throughout the process of institutional capacity building.

Proposition 3: The range of actors involved in the process of institutional capacity building will grow throughout the process of institutional capacity building.

Another aspect of the process of institutional capacity building that is predicted by the framework is related to one of the aspects of the social learning process that Innes and 
Booher (1999) refer to. Based on social learning, actors may begin to see their problems as interconnected, which may become concrete in the development of strategic visions. Thus, in later stages of the process (when enough time has passed for leaning to occur) we may expect actors that were dealing with certain issues autonomously before to start working together, based on shared strategic visions. The importance of strategic visions is also suggested in the work of Baas and Boons (2004).

Proposition 4: In later stages of the process of institutional capacity building actors that acted autonomously before may start working together based on shared strategic visions.

My final proposition concerns the effects of institutional capacity building on IS. The conceptual framework suggests that actors can use the institutional capacity they build up to engage in interactions that require larger investments in terms of people, knowledge, and financial resources. This goes for interactions in general but in this investigation I am specifically interested in the growing ability of actors to engage in more complicated symbiotic exchanges.

Proposition 5: In later stages of the process of institutional capacity building actors engage in symbiotic exchanges that require larger investments in terms of people, knowledge and financial resources as compared to symbiotic exchanges earlier in the process.

\subsection{METHODS}

\subsubsection{Event Sequence Analysis}

ESA is a research approach that offers a set of methods and techniques for the systematic longitudinal investigation of process phenomena (Boons and Spekkink, 2012b). It builds on an ontological and epistemological position that views reality in terms of entities and events and that puts change and creativity in the forefront as fundamental aspects of reality. Processes are seen as fundamental and substances, as outcomes of these processes, are seen as ontologically secondary (Rescher, 1996). This position offers a philosophical basis for methodologies that focus on the analysis of change, where research questions concern how entities emerge, develop and dissolve again. Over the past decades several researchers have advanced methodologies that build explicitly on the philosophical position that process is fundamental to reality, some notable examples being Abbott (1988, 1990, 2001), Abell (1984, 1987) and Poole and colleagues (2000). These approaches have certain advantages over other methodologies when it comes to studying how things change over time. For example, they bring us directly to the sequences of events that constitute change instead of having to base ourselves on varying attributes of entities 
as derivatives of change. In addition, they allow us to study patterns that do not comply with the general linear model that is the basis for many variance-based approaches (Abbott, 1988). In the literature on IS the importance of the process dimension is reflected in several conceptualizations. Baas and Boons (2004) emphasize that over time regional industrial systems go through distinct stages of regional efficiency and regional learning before arriving at the stage of sustainable districts. Chertow and Ehrenfeld (2012) elaborate this conceptualization to distinguish subsequent development stages of sprouting, uncovering, and embeddedness and institutionalization. Ruth and Davidsdottir (2008a, 2008b) bring together work that focuses on the dynamics of industrial ecosystems, including empirical analyses. Paquin and Howard-Grenville (2012) study the evolution of facilitated industrial symbiosis in the National Industrial Symbiosis Programme (NISP).

In ESA a process is defined as a sequence of events that describes how entities emerge, develop and possibly dissolve over time. To define something as a process is to define a central subject as well as the different types of events that the central subject endures or makes happen (Poole et al., 2000). The central subject can be any kind of entity, such as an individual actor, a group of actors, a lineage, a social movement, a machine, (Hull 1975) or a RIS. Events can be understood as the theoretically significant occurrences that the central subject endures or makes happen. The relevant types of events should be identified based on the theoretical or conceptual framework of the researcher. In addition, the theoretical or conceptual framework should specify the mechanisms that link the different types of events together into sequences (Abbott, 1990). Although a set of relevant event types should always be identified beforehand, it is possible that in later stages of the research process additional event types are identified based progressive insights (Vayda, 1983). In doing so, the researcher should always consider the theoretical implications of adding the new event types to prevent inconsistencies.

The central subject is not a fixed entity because it may evolve as a result of the events that it endures. For example, if the central subject is a group of actors, some members of the group may leave and others may be added over time. Such developments are of fundamental importance in ESA because much of its explanatory power resides in its ability to elucidate how the phenomena of interest change over time. In my case study the central subject is the group of actors involved in the sustainable industrial development of the Canal Zone. The theoretically significant events that constitute the process that this group of actors endured, as well as the mechanisms that link these events are defined in terms of institutional capacity building and IS, which I discussed in section 5.2.

After defining a suitable central subject and the relevant types of events, ESA proceeds through the following steps. First, longitudinal data are gathered on the process of interest. In the process of gathering data the definitions of the central subject and types of events serve as guidelines in determining what data are relevant to the investigation. The gathered data are recorded as incidents into a chronologically ordered event sequence da- 


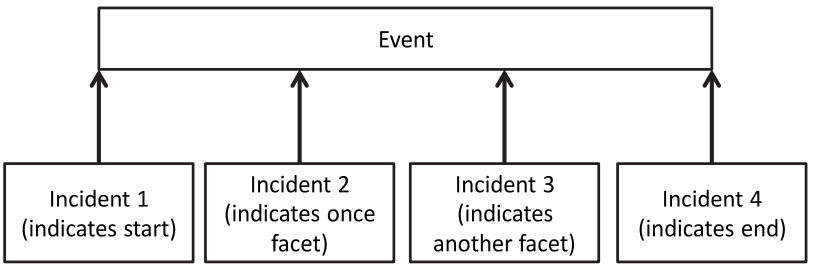

Figure 5.2: Incidents as indicators of events. taset. Incidents are short empirical descriptions of things that happened in a process. In ESA, these descriptions are used as indicators for the occurrence of events. The basic

information that is included in the description of an incident is as follows: 1) the date at which it occurred, 2) the actor(s) or object(s) involved in the incident, 3) the (inter-) action that the actor(s) or object(s) performed and, 4) the source of the information (based on Poole et al., 2000). It is possible to include relevant background information on incidents in a separate field. After the incidents are recorded in the event sequence dataset, they are all separately coded as indicators for different types of events. The codes are based on a coding scheme that the researcher develops based on his theoretical perspective. After all incidents have been coded they have to be colligated into events (Abbott, 1988, 1990); some incidents may be indicators for the same event and have to be grouped together before the researcher can proceed with analysis. The process of colligation also serves to determine the duration of events. For example, some incidents may indicate the start of an event while others indicate its end. In addition, although incidents only describe single actions or interactions, events may entail a wider range of actions or interactions that represent different facets of the event (see figure 5.2).

After the coded data have been prepared the researcher can use different methods for analysis to analyze the data for temporal patterns. Examples of methods for analysis are stochastic modeling, phasic analysis, event time series analysis (Poole et al., 2000), template matching, visual mapping, narrative analysis (Langley, 1999), and optimal matching (Abbott \& Tsay, 2000), although for the different methods for analysis additional preparations are usually required.

\subsubsection{Data collection and processing}

ESA is very data-intensive, as it requires the researcher to collect, process and analyze longitudinal data that can span a long period of time. The data that I gathered for my case study are based on news items, documents and web pages. Although information is presented differently in each of these three types of sources, there was enough overlap for me to be able to triangulate the data from the different sources. For the collection of documents and web pages I searched the Internet using a search protocol that I developed in advance. The documents and web pages I found were created by different stakeholders involved in the developments at the Canal Zone, including firms, governmental organizations, knowledge institutes, business associations, and different types of interest groups. For the collection of news items I used the LexisNexis database, 
which contains news items of Dutch national and regional newspapers that have been published since 1980 . To keep the data collection process manageable and replicable I developed an electronic logbook to keep track of my data collection activities. The logbook involves the use of forms on which I indicate how the searches were performed, including the search engines and the keywords that I used. In addition, the forms record for each source when it was found, where it was found and, depending on the type of the source, some additional relevant details about the origin of the source. I assigned all sources a unique identification number and stored them on a hard drive using the identification numbers as their names. This allowed me to easily navigate through the collected data and to use the identification numbers in the event sequence dataset as references to the sources of the incident descriptions.

After formulating the central subject of my research and identifying initial relevant types of events I started the data collection process on January 27, 2011. The last additions to the raw data were made on April 26, 2012. In the process I collected 252 web pages, 189 documents, and 884 news items, although several news items have been included multiple times because of overlap between different search results. In addition, some sources appeared to be irrelevant to my research and were not included in the final dataset. I created an event sequence dataset using Microsoft Access and throughout the data collection process I entered incident descriptions in the dataset that I derived from the raw data (see figure 5.3). The complete database consists of 1065 chronologically ordered incidents. I performed two interviews with actors involved in the developments at the Canal Zone to check whether my reconstruction of the process corresponds with their experiences. The results of the interviews gave me no cause to revise my reconstruction of the process.

\subsubsection{The coding scheme}

After all the incidents were entered into the event sequence dataset and some necessary corrections were made, I developed a coding scheme and coding procedure based on my

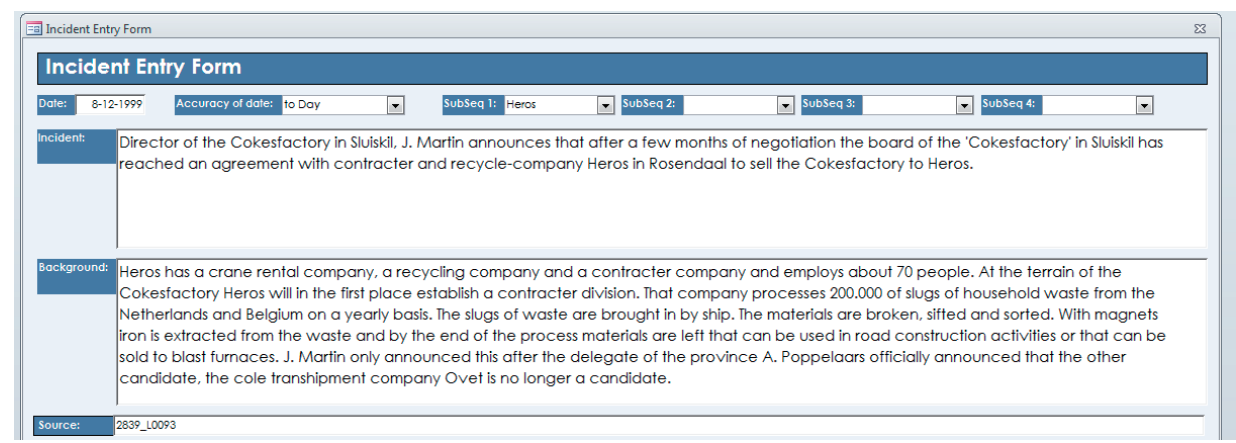

Figure 5.3: Screenshot of incident entry in event sequence dataset. 
conceptual framework. I developed codes for the different types of events suggested by my framework, such as the articulation of beliefs, desires and opportunities, interactions such as orientation, planning, feasibility study, implementation, and contextual influences. Throughout the development and testing of the coding scheme I added a number of other codes to increase the accuracy of the coding scheme and to capture some types of events that were not easily categorized under the existing codes. The additional event types all concern dynamics that fit with the logic of my conceptual framework and thus their addition did not require me to revise the framework. Rather, their addition can be understood as further elaboration of the framework. The most important examples are the establishment of strategic visions, the establishment of declarations by actors of their intent to address an issue of common concern, attempts by actors to influence the opportunities of other actors, the establishment of new organizations in the RIS, and attempts by actors to influence their physical or political context.

To improve the reliability and accuracy of the coding scheme, a colleague and I coded several samples of the dataset which allowed me to check for inter-coder reliability using Scott's $\mathrm{Pi}$ as a measure (Scott, 1955). The last score for inter-coder reliability recorded is 0.66. It is difficult to determine what level of inter-coder reliability is adequate because not much research using this approach has been performed yet. However, Poole and colleagues (2000) suggest that inter-coder reliability is very good from 0.80 . Although the inter-coder reliability could still be improved I propose that a score of 0.66 is adequate for a first analysis. After coding all the incidents I exported the dataset to an excel-file and in the excel-file I colligated the incidents into events by grouping indicators of the same events together. The resulting dataset served as the basis for analysis.

\subsubsection{Data analysis}

For my analysis I used visual mapping, which is discussed by Langley (1999), and a version of template matching that I adapted from the one introduced by Poole et al. (2000). I used visual mapping to give a visual overview of the sequences of events that I analyze in this article and to visualize the interrelationships between some of the sequences of events. For this part of the analysis I first identified IS outcomes that were realized in the Canal Zone. I then reconstructed the sequences of events that preceded these outcomes going back to the events that initiated the IS development and in one case reconstructing the sequence of events that followed the symbiotic exchange. After reconstructing the sequences of events I used template matching to check whether the patterns in the sequences of events matched those suggested by the propositions I derive from my conceptual framework. 


\subsection{RESULTS}

\subsubsection{Introduction to the Canal Zone}

The Canal Zone is situated in the province of Zeeland in the Netherlands. It covers an area around a canal that runs from the Westerschelde River near Terneuzen to the port area of Ghent. The Canal Zone includes a port area that is managed by Zeeland Seaports (Zeeland Seaports became manager of both the ports of Vlissingen and Terneuzen after a merger of two separate port authorities in 1998), a chemical complex of Dow Terneuzen, a greenhouse area and several smaller industrial areas that are situated along the canal. The dominant sectors in the Canal Zone are chemical industry, food industry, metals industry, paper and cartons and storage and transshipment (over 60 companies).

Several companies in the Canal Zone have been making efforts to reduce the environmental impact of their activities for a longer period of time, but broader collaborations between firms to deal with this issue started around 1998. By the end of 2010, several symbiotic exchanges were in progress, while several others were still being prepared. One of the symbiotic exchanges in progress concerns the supply of residual heat and $\mathrm{CO}_{2}$ by a fertilizer producer called Yara to three commercial greenhouses and one education and information greenhouse in the greenhouse area of Terneuzen. A second exchange that was in progress concerns the supply of starch from the agricultural company Cargill to an alcohol factory of Nedalco, which is located on the same terrain. The factory also makes use of the water purification installation of Cargill and is supplied energy and compressed air by its partner company. Another set of symbiotic exchanges in progress was developed at the terrain of the waste processing company Heros. Besides Heros' own facilities, the terrain, which is now named Ecopark Terneuzen, houses a biodiesel plant of the former company Rosendaal Energy (in 2010 the company went bankrupt and by the end of the year negotiations with potential new owners were still in progress), and a biomass power plant of Lijnco Green Energy. The wastewater of both facilities is treated by the wastewater treatment facility of Heros, and Heros also performs several park management activities for the companies on the terrain.

All the exchanges described above are part of a project called Biopark Terneuzen, which aims to concentrate companies in the agricultural sector and the process industry and stimulate the exchange of by-products and waste products between the participating companies. Biopark Terneuzen itself is part of a larger project called Bio Base Europe, an international project funded by the European Union in which parties in Zeeland and Ghent (Belgium) work together to realize the biggest bio based industrial cluster in Europe.

There are also other IS projects besides those bundled in the Biopark Terneuzen initiative. The chemical company Dow Benelux and the port authority Zeeland Seaports joined forces to develop Valuepark Terneuzen and Maintenance Valuepark Terneuzen, where the initiators aim to realize synergies between Dow Benelux and other companies that 
are invited to the terrains. A project group called Vital Sloe Area and Canal Zone, which has been in existence since 2003, has also developed several projects. The project group consists out of firms (including Yara and Dow), governmental organizations, and knowledge institutes, and is very active in promoting sustainable entrepreneurship among companies in the region. I have not included the developments related to Valuepark Terneuzen, Maintenance Valuepark Terneuzen and the project group Vital Sloe Area and Canal Zone in my analysis, because it would require too many words.

In the following sections I analyze the projects related to Biopark Terneuzen in more detail, reconstructing the event sequences that preceded them. The events that constitute these sequences refer to the different types of interactions described in the conceptual framework. To keep the analysis concise I did not explicitly include changes in believes, desires and opportunities in the analysis. After discussing the sequences of events specifically related to the symbiotic exchanges I then discuss their relationship to the process of institutional capacity building as a whole and how dynamics of institutional capacity have influenced the emergence and development of IS.

\subsubsection{The event sequences}

\section{Yara and the Greenhouses}

The first event sequence that I reconstructed is the one preceding the exchange between the fertilizer company Yara and the four greenhouses in the greenhouse area of Terneuzen (see figures 5.4 to 5.6). The first delivery of residual heat was made in November 2009. By that time an organization called $\mathrm{WarmCO}_{2}$ had been established as a joint venture between Zeeland Seaports, Yara, and Visser and Smit Hanab to coordinate the supply of $\mathrm{CO}_{2}$ and residual heat from Yara to the greenhouses. In November 2009 an alderman of Terneuzen symbolically started the first delivery of residual heat to three greenhouse companies: De Westerschelde, Gebroeders van Duijn, and Tomaholic. In June 2010 Yara also started supplying an information and education greenhouse that had been established in the area. The first time that the idea for reusing residual heat and $\mathrm{CO}_{2}$ in greenhouses was discussed was long before the greenhouse area itself had been developed. In 1999 the national government had indicated its interest in developing a greenhouse area in Zeeland. Following that event the province of Zeeland investigated the possibility of developing a greenhouse area at Nieuwdorp, within the municipal boundaries of Borsele, but several actors in the region, including an employer's association, two municipalities and the chamber of commerce lobbied for the establishment of the greenhouse area in the Canal Zone. One of their major arguments was that in the Canal Zone the greenhouses could reuse the residual heat and $\mathrm{CO}_{2}$ of Hydro Agri (renamed to Yara after a demerger). After the plans for Nieuwdorp turned out to be unfeasible, the province of Zeeland indicated that it did not want to investigate any 
other locations. Following that decision, the municipality of Terneuzen started its own investigation in cooperation with Hydro Agri and sometime later both the province of Zeeland and the national government agreed with the development of a greenhouse area in the Canal Zone. The planning procedures for the greenhouse area started in July 2004 and it took until November 2008 before the procedures were completely finished. Before the procedures were finished contracts with three greenhouse companies had already been signed.

During the development of the greenhouse area, in October 2007, the municipalities of Ghent and Terneuzen declared their intent to develop an information and education

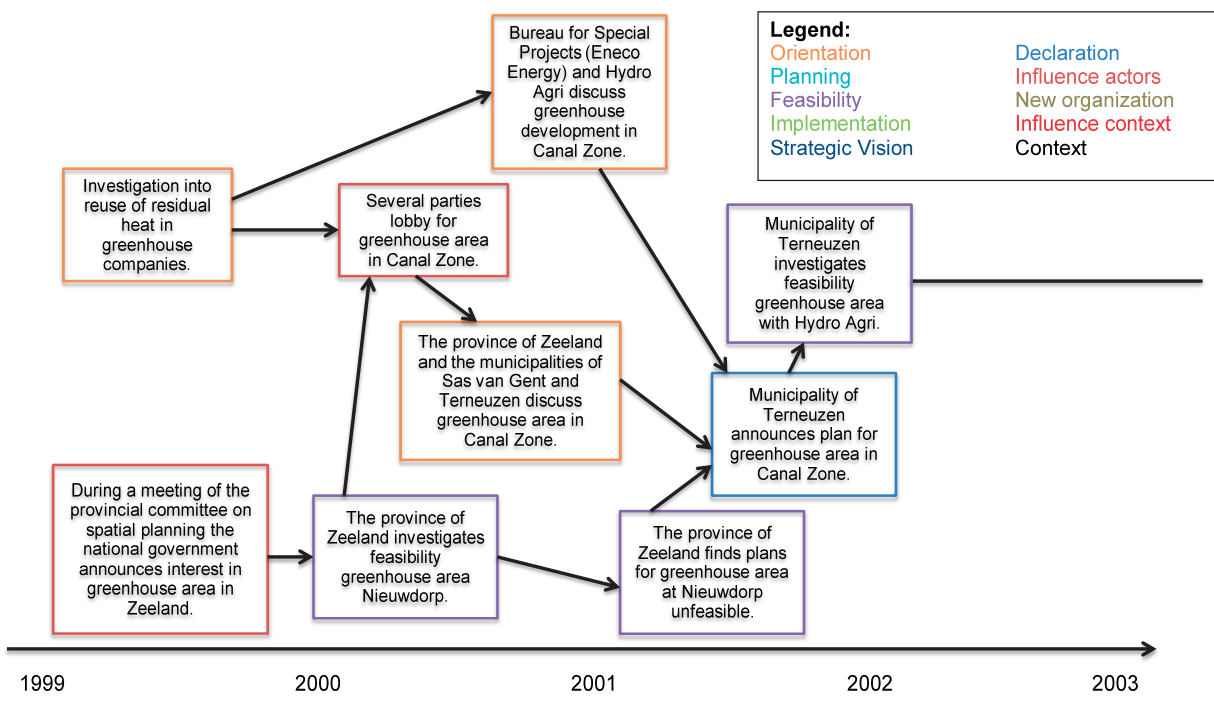

Figure 5.4: Visual map event sequence Yara and Greenhouses (part 1).

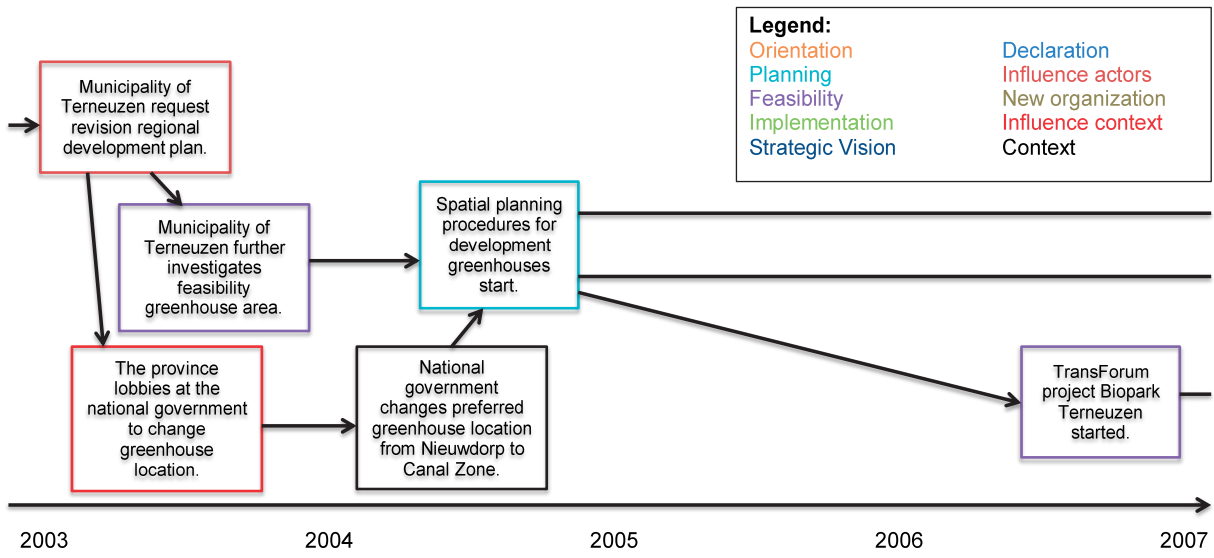

Figure 5.5 Visual map event sequence Yara and Greenhouses (part 2). 


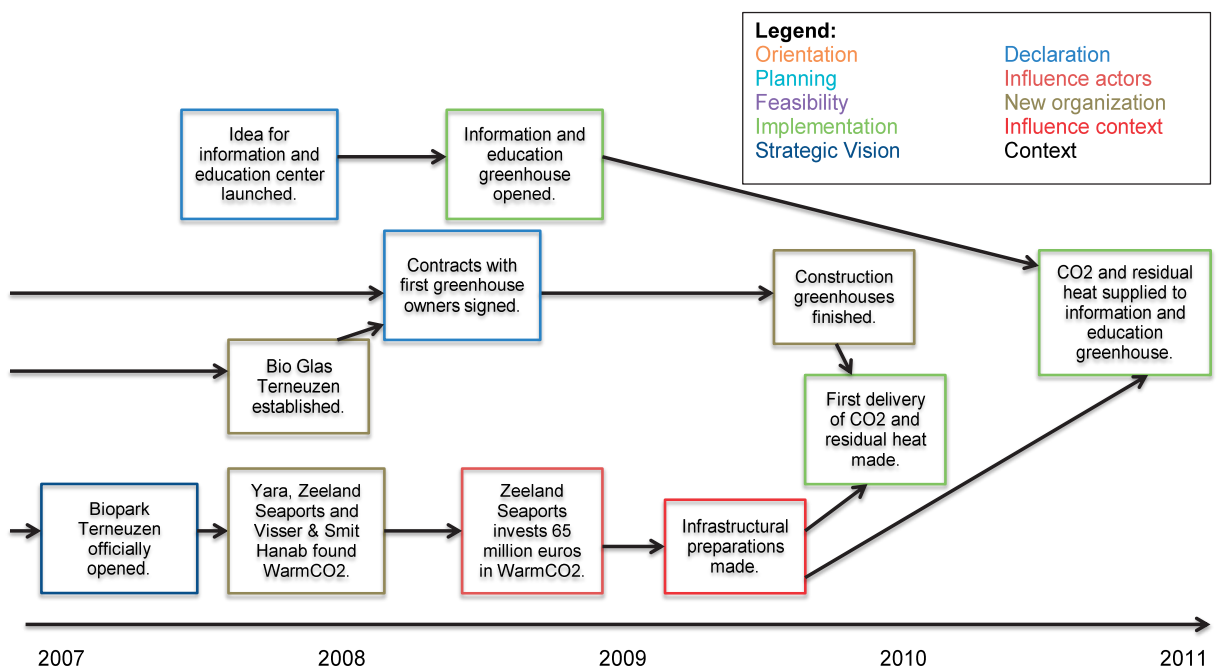

Figure 5.6: Visual map event sequence Yara and Greenhouses (part 3).

greenhouse where people would be re-educated for work in the greenhouse sector. The information and education greenhouse was opened in October 2008 and started using residual heat and $\mathrm{CO}_{2}$ supplied by Yara in 2010 .

When the planning procedures for the greenhouse area were still in progress, several parties involved in its development, namely Zeeland Seaports, Yara, the province of Zeeland and the municipality of Terneuzen participated in a feasibility study of TransForum Agro \& Groen. The original ambition of the study was to develop better establishment factors for firms in the agricultural sector. The firms involved also wanted to link the agricultural companies to the process industry in the region to realize the sustainable use of energy and the reuse of residual streams. The involved actors built on opportunities offered by ongoing developments in the region, one of them being the greenhouse area. The feasibility study was started in May 2006. Besides the parties already mentioned, other participants were Heros, Biomassa Unie, Roosendaal Energy, Ecoservice Europe, Nedalco, Rewin, the municipality of Ghent, the province of Flanders, the universities of Amsterdam, Nijmegen and Wageningen, the Athena Institute, the university of applied sciences Zeeland, the Dutch Research Institute for Transitions, Kortrijk College, Meersma Project Development, Van de Bunt consultancy, Lievens Communicatie, the Southern Association for Agriculture and Horticulture, and TransForum Agro \& Groen. After Biopark Terneuzen was officially opened, Yara, Zeeland Seaports and Visser \& Smit Hanab founded $\mathrm{WarmCO}_{2}$, an organization that would be responsible for coordinating the exchanges between Yara and the greenhouses and for developing the necessary infrastructures. In December 2008 Zeeland Seaports announced that it would invest 65 million in WarmCO to be able to finance the infrastructural adjustments necessary for the exchange between 
Yara and the greenhouses and to be able to guarantee a fixed price to the greenhouse companies for a period of ten years (the total required investment was 80 million). In May 2009 WarmCO $_{2}$ started laying pipelines and in the same period heat exchangers were installed at Yara and at each of the greenhouses.

\section{Nedalco and Cargill}

In October 2005 the alcohol producer Nedalco opens a new alcohol factory on the terrain of Cargill in Sas van Gent (see figure 5.7 and 5.8). The alcohol factory receives starch from Cargill as an input for the production of alcohol and makes use of Cargill's water purification installation. By 2010 Cargill also supplies Nedalco energy and compressed air. The negotiations between Nedalco and Cargill about these exchanges first started early 2003. Nedalco and Cargill were already working together in similar ways at other locations, which may have contributed to a relatively speedy implementation of Nedalco's plans. The construction of the factory started in October 2004 and the factory officially began operations in October 2005. The symbiotic exchanges between Nedalco and Cargill constituted an essential part of the factory's operations from the very beginning. Like the development of the greenhouse area, the cooperation between Nedalco and Cargill was one of the projects that the actors involved in the Biopark Terneuzen initiative built on.

Besides the sequence of events preceding this symbiotic exchange, the reconstruction of the sequence of events also revealed another project by Nedalco that was included in the Biopark Terneuzen initiative. At the time that Nedalco was negotiating with Cargill about the alcohol factory, Nedalco was also negotiating with the municipality of Bergen op Zoom about moving one of Nedalco's factories to another location.

The municipality wanted to use Nedalco's former terrain for the development of housing. Nedalco considered several locations for the establishment of a replacement factory, one of them being Sas van Gent, which is a place located in the Canal Zone. Nedalco also had the ambition to produce bio-ethanol in the factory, based on the ambition to make a substantial contribution to the development of the biofuels market in the Netherlands. This project was included in the Biopark Terneuzen initiative as one of the key components. Like Yara, the factory of Nedalco would supply residual heat and $\mathrm{CO}_{2}$ to the future greenhouses and thereby ensure a steady supply of residual heat and $\mathrm{CO}_{2}$. However, the national government only wanted to endorse a small portion of the subsidy that Nedalco needed to realize its plans. Nedalco postponed its plans for the biofuel factory and negotiated with the national government in an attempt to convince the government to change its decision. However, in September 2008, Cosun, the mother company of Nedalco decides not to develop the bio-ethanol factory in Sas van Gent or anywhere else in the Netherlands. The director of Cosun articulated that this decision was not only influenced by the difficulties in attracting a subsidy but also by the general lack of support by the Dutch government to the development of the bio-fuel industry in the Netherlands. 


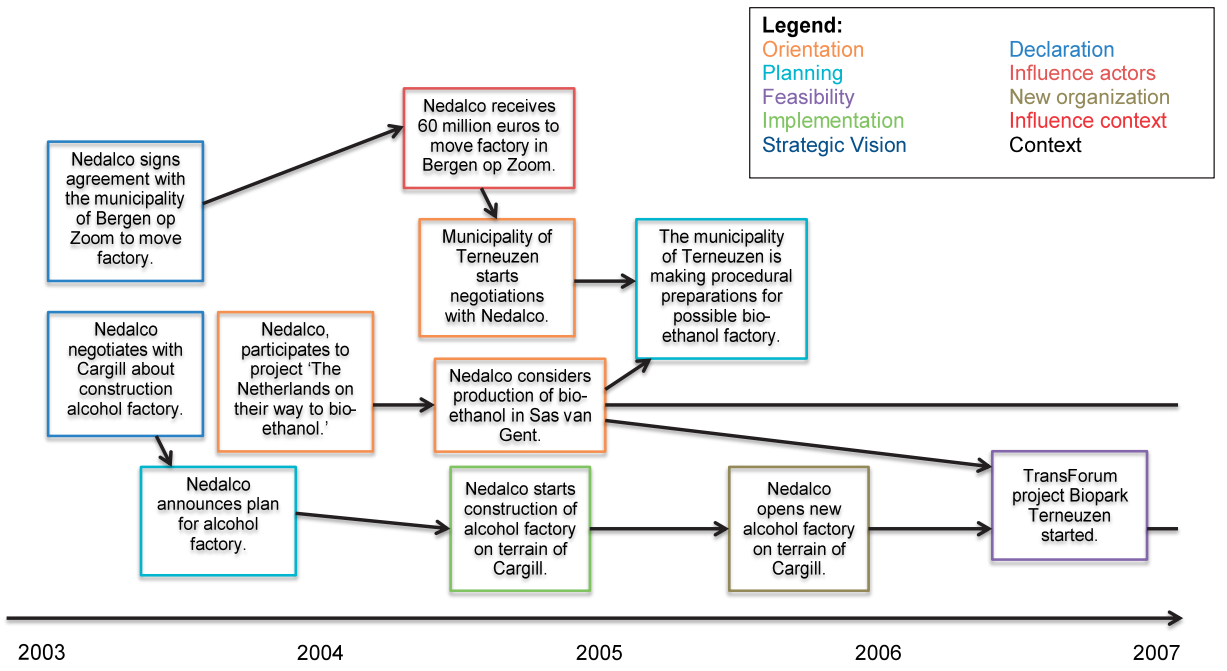

Figure 5.7: Visual map event sequence Nedalco and Cargill (part 1).

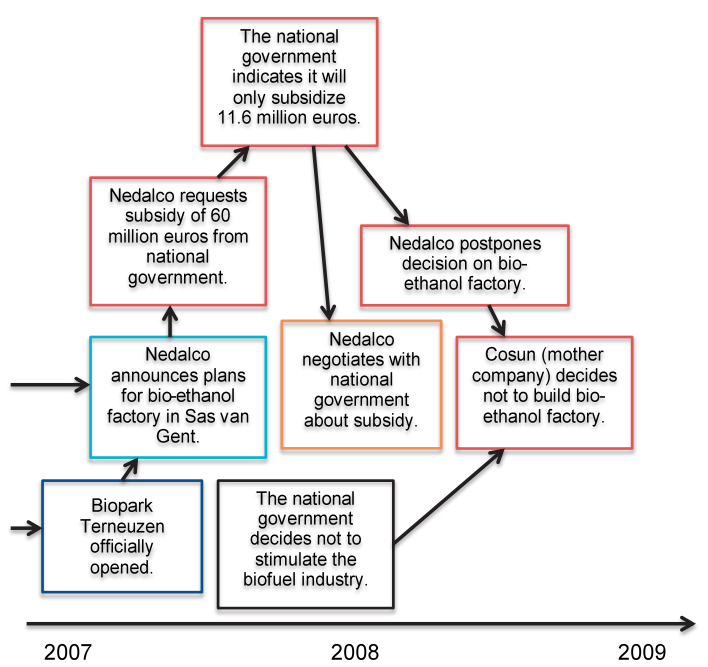

\begin{tabular}{|ll|}
\hline Legend: & \\
Orientation & Declaration \\
Planning & Influence actors \\
Feasibility & New organization \\
Implementation & Influence context \\
Strategic Vision & Context \\
\hline
\end{tabular}

Figure 5.8: Visual map event sequence Nedalco and Cargill (part 2).

\section{Heros and Ecopark Terneuzen}

Heros is involved in several of the projects that are part of Biopark Terneuzen (see figures 5.9 to 5.11). Heros has a terrain called Ecopark Terneuzen where, besides Heros' own facilities, there is a biomass plant and a biofuel factory that both make use of the wastewater treatment facility of Heros. In addition, Heros performs park management activities such as providing repair squads, security personnel and a shared control room for all companies. Heros also explicitly stimulates the companies to start reusing each 
other's residual materials. In April 2010, Lijnco Green Energy started the construction of a biomass plant at the terrain of Heros, a facility that would be included in the network as soon as it were finished. In August 2010 Heros also announced the plan for a second biomass plant. All these projects were developed as part of Biopark Terneuzen and Heros proliferated itself as one of the most activate advocates of the project. There is also some evidence that Heros already treated water of the neighboring company Cargill in December 2003, although no evidence exists that this exchange was still in operation by the time that Biopark Terneuzen was officially opened.

The waste collection and processing company Heros had ambitions to cooperate with other companies since it came to the RIS in 1999. Shortly after purchasing a large piece of land from the former Cokes factory in Sluiskil, Heros announced that it wanted to use the wastewater treatment facility that was left behind to treat the water of neighboring companies. It also negotiated with other companies about establishment on Heros' terrain because the company felt it had more room than it required. This finally led Heros to join forces with Ecoservice Europe to establish a biomass plant (based on a joint venture called Biomassa Unie) and to have Rosendaal Energy build a biofuel factory on the terrain. The plans for using the wastewater treatment facility and the plans for the two new facilities were included in the Biopark Terneuzen initiative. The vision of Biopark Terneuzen became an important guideline for Heros' activities.

Rosendaal Energy got into financial difficulties soon after the national government had decided not to stimulate the biofuel industry in the Netherlands. In the years before this decision, the government planned to raise the obligated percentage of biofuels mixed with traditional fuels from 2.75 to 5.75 percent. However, by October 2008 the government decided to raise the percentage to only 4 percent instead. Combined with the consequences of the economic crisis, this decision caused a lot of problems for certain companies, including Rosendaal Energy. The court of Middelburg finally declared Rosendaal Energy bankrupt in July 2009 and by the end of 2010 the curator was still negotiating with parties about a possible take-over.

An interesting feature of Heros' history in Sluiskil that I have not explicitly added to the visual map is that from 2002 to 2006 Heros had several conflicts with the province about the interpretation of environmental permits and the violation of environmental norms. These conflicts do not seem to have affected the relationship between Heros and the province negatively. The director of Heros articulated multiple times that he understood the position of the province but that his company simply needed a lot of time to clean up the pollution that was left by the former owner of the terrain.

\subsubsection{Institutional capacity building and industrial symbiosis in the Canal Zone}

The overviews of the different sequences of events shows that there is no single starting point for the process of institutional capacity building in the Canal Zone. Until the begin- 
ning of the Biopark Terneuzen initiative, different actors were preparing and carrying out several projects relatively autonomous from each other, although some actors, such as the province of Zeeland and the municipality of Terneuzen, were occasionally involved in each of the projects for varying reasons. Through their interactions the actors involved in the different projects aimed to address different issues, but in the Biopark Terneuzen initiative the development of a bio based industrial cluster became the issue of common concern. The analysis of the different sequences of events also reveals that there is no clear cycle of orientation, planning, feasibility studies and implementation at the level of interactions or at the level of the RIS as a whole. Feasibility studies are sometimes even among the first activities of actors and occur without elaborate orientation or planning. Actors could also orient themselves on new ideas at any point in the process, while

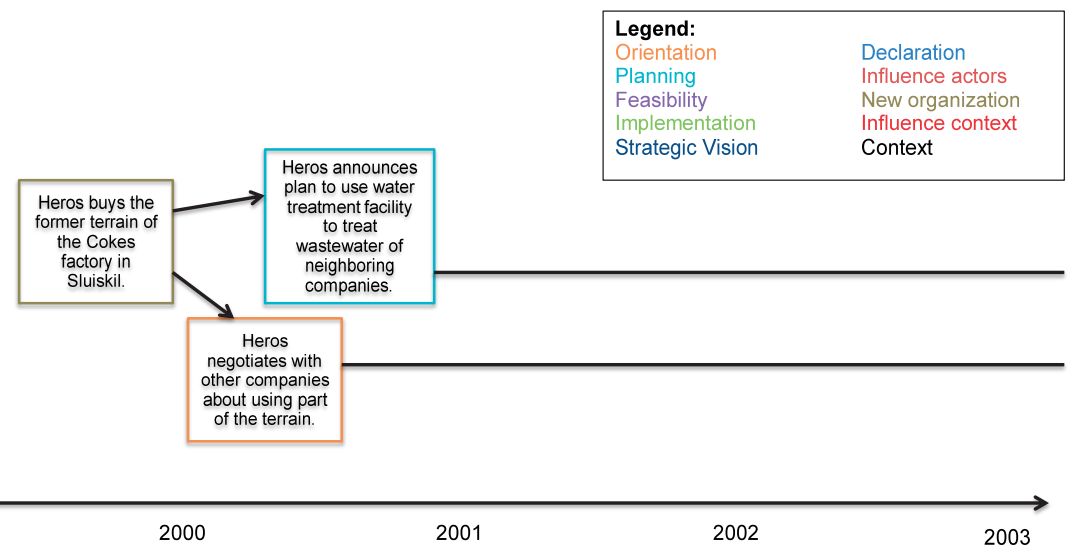

Figure 5.9: Visual map event sequence Heros and Ecopark Terneuzen (part 1).

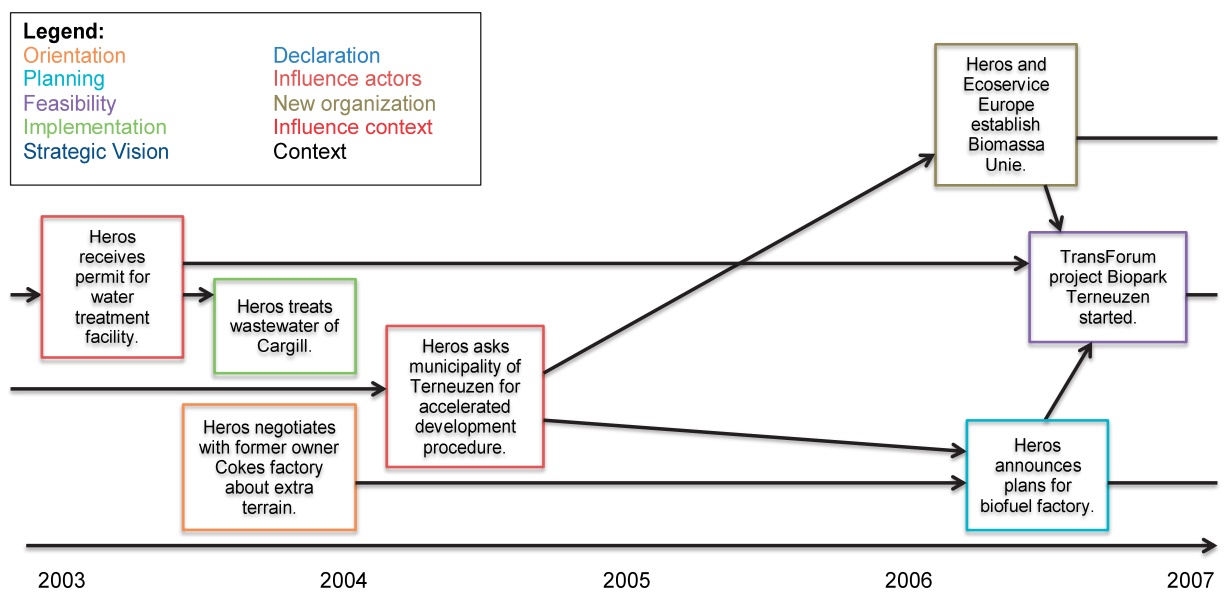

Figure 5.10: Visual map event sequence Heros and Ecopark Terneuzen (part 2). 


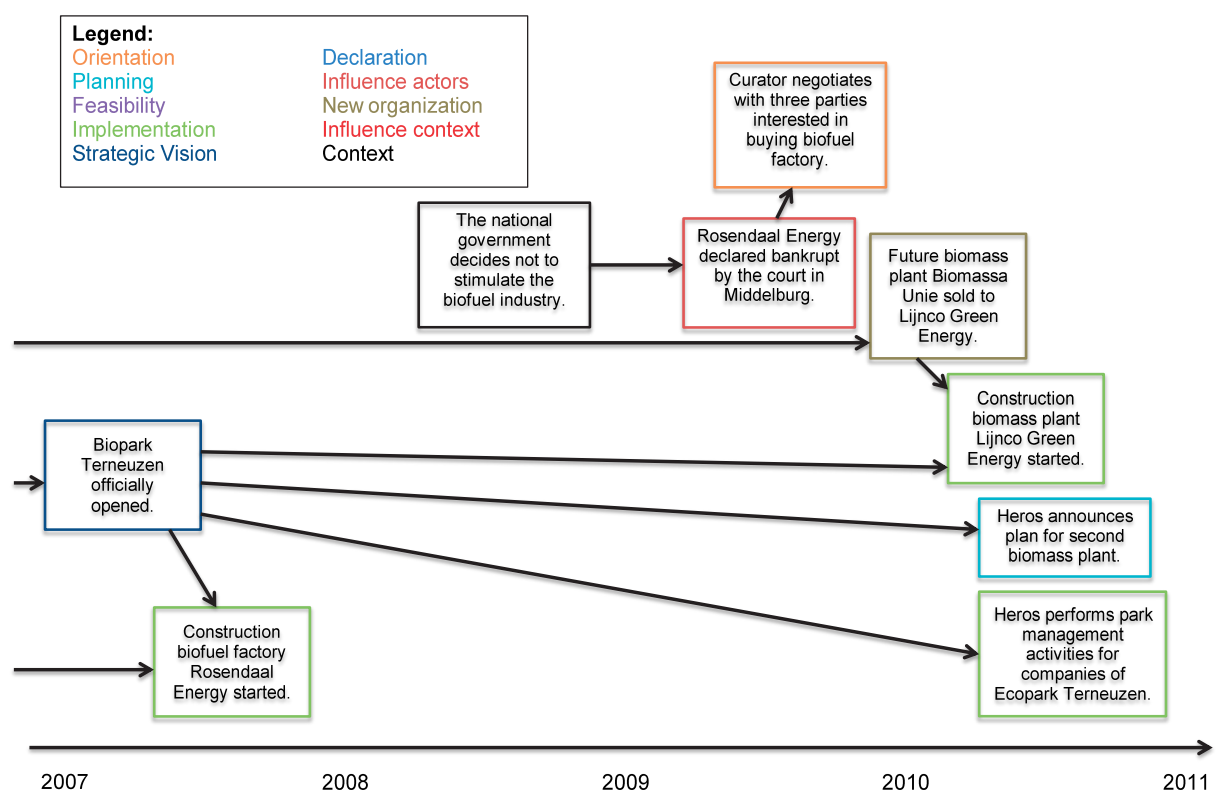

Figure 5.11: Visual map event sequence Heros and Ecopark Terneuzen (part 3).

other projects are still in progress. In summary, the sequence of events through which institutional capacity is built in the case of the Canal Zone does not follow the linear stage-based logic of my conceptual framework but is rather chaotic.

An important contribution of the Biopark Terneuzen initiative is that it gave a strategic purpose to the different projects that the actors were already developing. Although these projects were not connected before they now became part of a joint effort to develop a bio based industrial cluster in the Canal Zone. This also changed the focus of the activities by some actors from a local scale to a regional scale. In addition to bringing together the actors involved in ongoing projects the Biopark Terneuzen initiative also involved actors that were not involved in the projects before. This includes knowledge institutes, consultancy companies and even Belgian governmental organizations. Compared to what is predicted by my conceptual framework there is one subtle difference in the growth of actors in the case of the Canal Zone. The framework suggests a gradual growth in the number and range of actors but in the Canal Zone the involvement of new actors sometimes seems to happen in a rather abrupt way. Especially with the start of the Biopark Terneuzen initiative many actors were brought together at once. Here too, the actual observations seem to reveal a rather chaotic pattern instead of the orderly progression suggested by my own conceptual framework.

The involvement of the knowledge institutes and consultancy companies contributed to the development and dissemination of knowledge about the different projects that the actors were engaged in. From the beginning of the Biopark Terneuzen initiative in 
October 2006 to June 2010 the knowledge institutes and consultancy companies performed several investigations to support the projects included in Biopark Terneuzen, to investigate their feasibility and to disseminate the experiences gained with them. The involvement of the Belgian authorities provided a link to Ghent Bio Valley, an initiative similar to Biopark Terneuzen that is being developed in Belgium.

Based on my current analysis it is difficult to provide hard evidence for the contribution that the buildup of institutional capacity made to the development of symbiotic exchanges. So far, not many exchanges have been developed, making it hard to compare early exchanges with later exchanges. However, to some extent it is possible to compare between the exchanges that have been developed in the different projects. The exchanges between Nedalco and Cargill can be understood to depend the least on the institutional capacity that was build up in the Canal Zone. The exchanges seem to be relatively straightforward business transactions between two companies that have been doing business together before. The symbiotic exchanges that developed between Heros and the other companies in Ecopark Terneuzen are already much more dependent on the development of institutional capacity as they depend on the willingness of the involved parties to work together on a long-term basis. Also, the facilities in Ecopark Terneuzen all depend on the services of Heros, a situation that depends on the involved actors trusting each other. The biomass plant developed by Heros and Ecoservice Europe (Biomassa Unie) also received significant support from the research activities of the Wageningen University. Finally, for the exchange between Yara and the greenhouses the importance of institutional capacity building is the most evident. The development of the greenhouse area itself is the result of the joint efforts of the province of Zeeland, the municipality of Terneuzen, Yara and several other parties that started a lobby to ensure that the greenhouse area would be developed in Terneuzen. The establishment of WarmCO was instrumental in realizing the infrastructural and contractual preparations necessary for the exchange to happen. This organization would not have developed without the strong relationships and the will to work together that developed among the involved actors. The involvement and dedication of Zeeland Seaports was especially important, because without the investment of 65 million euros in the joint venture, $\mathrm{WarmCO}_{2}$ would not have been able to develop the necessary infrastructures so quickly and to offer the greenhouse companies a fixed price for a period of 10 years. The key role that Zeeland Seaports played in Biopark Terneuzen is also emphasized in an evaluative report on the Biopark Terneuzen initiative that was published by Van de Bunt consultancy in March 2009. The report indicates that Zeeland Seaports played the leading role in bringing the different actors together and in supporting the different projects. 


\subsection{DISCUSSION AND CONCLUSIONS}

The analysis presented in the foregoing sections reveals that institutional capacity building is not necessarily the linear and stage-based process that is described in my conceptual framework and in other conceptualizations (Baas \& Boons, 2004; Chertow $\&$ Ehrenfeld, 2012). Although there is no clear order in which the actors built up relational resources, knowledge resources and mobilization capacity, over time the actors did develop a shared vision on the development of a bio based industrial cluster in the region, which provides some evidence of accumulating institutional capacity. It is also clear from the analysis that the development of this vision was instrumental in bringing actors involved in different projects together, and also in bringing in knowledge institutes from outside the RIS. Thus, an initial answer to the first research question is that, although there is no clear order in which institutional capacity was built, institutional capacity accumulated to the point that it became possible to develop a shared vision that acted as a catalyst for the further development of institutional capacity in the Canal Zone. A possible explanation for the chaotic patterns through which institutional capacity was built, is that the process may be understood as what Abbott (1997) refers to as an interactional field. This type of process can be understood as a collection of several individual processes that are inextricably braided. The development of each of these individual processes is contingent on the development of other processes that are part of this collection. In the case of the Canal Zone specifically, we might say that the numerous projects that actors engaged in are such individual processes that determine the course of the process of institutional capacity building as a whole through their interaction.

The idea of institutional capacity building as an interactional field suggests a stronger focus on projects as interrelated subsequences and an analysis of patterns of institutional capacity building in terms of subsequent and parallel projects that create and alter conditions for each other's development. The analysis of such patterns would require a more detailed reconstruction of event sequences based on a more detailed coding scheme, which is one of the next steps in my own research.

The current analysis offers too little evidence for a definite and complete answer to the second research question, although the results do indicate that the different dimensions of institutional capacity building are highly relevant to the development of by-product synergies and utility synergies. Some of these synergies entail significant risks and investments and can only be realized when the involved actors trust each other enough to commit themselves to such deals. Also, insights in the possibilities for and risks associated with certain synergies depend on the knowledge resources that are generated through studies performed by various actors. In addition to being valuable to the development and implementation of individual symbiotic exchanges, the build-up of institutional capacity is vital to the development of a network of such exchanges at the 
level of the RIS. In this regard mobilization capacity is of particular importance. The involvement of actors such as Zeeland Seaports, that are willing to take up a leading role in several projects, is instrumental in establishing connections between different projects and actors. In addition, the development of strategic visions gives the actors in the RIS a common purpose and stimulates them to shift their focus from local developments (the individual projects) to regional developments (the network of by-product synergies and utility synergies).

ESA proves to be promising for the investigation of phenomena such as institutional capacity building and the emergence and development of IS. The approach offers a powerful means to assess temporal patterns that are often suggested in conceptualizations of processes, but that are rarely thoroughly tested. In this regard the approach will also have value beyond research in the field of industrial ecology. Thus ESA has the potential to contribute significantly to the theoretical advancement of the field of IS by confronting theories with empirical evidence. In some regards I have only scratched the surface of what is possible using ESA. One possibility that I already mentioned is to make a stronger distinction between multiple subsequences within one case and study their interrelationships. Another possibility is to perform a multiple case study in which the patterns observed in different cases can be compared among each other. This would also offer opportunities for generalization of the findings beyond the case of the Canal Zone. In addition, to determine the extent to which these findings are relevant beyond the governance context, economic context and physical context of the Netherlands, similar studies will have to be performed in other countries. 




\section{INTERMEZZZO 3}

INTRODUCTION OF EVENT GRAPHS 
The visualizations that I use in chapter 5 to show events and their relationships were my first attempt to abstract patterns from the rich data included in my event sequence datasets in an efficient way. Although I found them to be a good first step, I also felt that their contribution to the analysis was rather limited, and I started looking for ways to systematize the analysis more. Sometime after finishing the article that is at the basis of chapter 5 I got my hands on a second hand version of Abell's Syntax of Social Life (1987). I had already read about Abell's work in several articles by Abbott (2001), but it took me a very long time to find a copy of Abell's book that was also affordable. I discussed Abell's work on narrative graphs extensively with Frank Boons and we made more and more use of graphs as analytical tools. One of the main added values of Abell's work to our own thinking is that Abell roots his methods in graph-theoretical concepts, which opens the door to thinking about processes as a special type of networks, and invites a stronger focus on patterns of relationships between events.

I used Abell's work as a basis for the creation of event graphs, which visualize the events that constitute a process as well as the relationships between the events. The type of event graphs that I use in chapter 6 is a descendant of several other types of event graphs that I experimented with earlier. Figure 13 visualizes one of these earlier versions. It was made 'by hand' in Microsoft PowerPoint. Creating event graphs this way was an extremely tedious (and therefore time-consuming) process. It was also relatively easy to make mistakes when making event graphs this way. For example, it was easy to forget to include one of the many linkages between events in the event graph.

By the time that I was writing the final version of the article that is at the basis of Chapter $6 \mathrm{I}$ had learned how to program software ${ }^{32}$ and I adapted an existing plugin for the Gephi network visualization program to develop a new plugin that automates the creation of event graphs (see Annex 7). In combination with an existing tool for retrieving the necessary data from event sequence datasets (Levallois 2013), the plugin allows for the creation of event graphs with just a few mouse clicks, provided that the necessary data are appropriately recorded in an event sequence dataset. The use of the tool greatly increased the efficiency of my workflow and that of others I worked with.

The introduction of event graphs contributed to an increased focus on the analysis of various types of relationships between events. The relationships that I studied in chapter 5 primarily concern the order in which different types of events (e.g. orientation, planning, and implementation) occurred, but I found that this focus led to relatively few interesting results. The findings of chapter 5 pointed to other relationships between sequences of events that appeared to be more interesting. For example, the analysis had revealed the fragmented nature of the process of institutional capacity building, in the sense that I found multiple historical lineages that led up to the Biopark Terneuzen

32. I discuss this in more detail in Intermezzo 4. 
initiative. To get a better grip on this aspect of the process I needed better methods and techniques to analyze patterns in historical relationships between events. In this regard, the development of event graphs and the introduction of intentional linkages ${ }^{33}$ were of great instrumental value. At a later stage of the research process I also considered other types of relationships between events, based on overlaps of actors and issues involved in events. I discuss this in more detail in intermezzo 4.
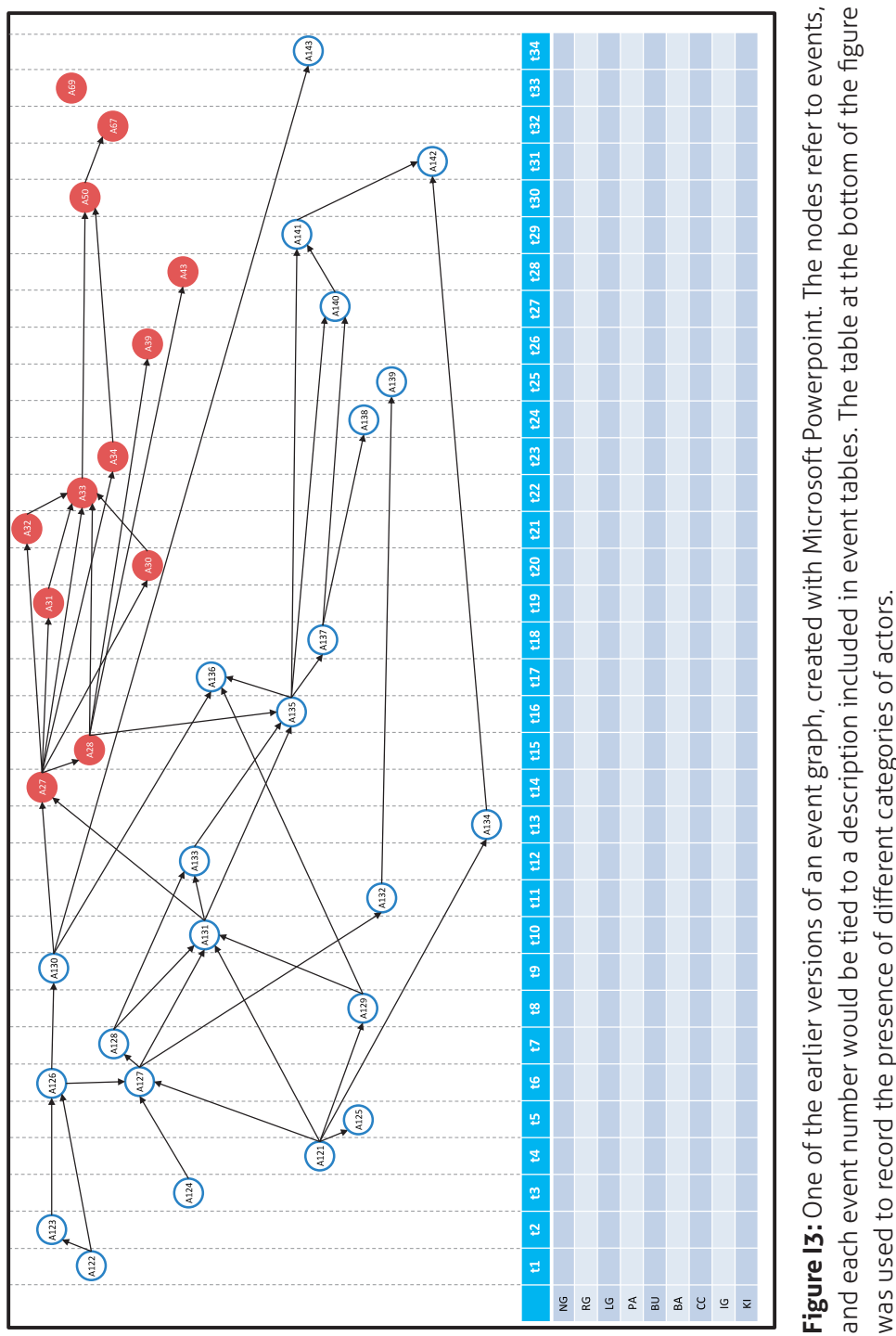

33. The linkages in the event graphs in Chapter 6 are intentional linkages, although I did not explicitly refer to them as intentional linkages at the time I was writing the article that is at the basis of the chapter. 



\section{CHAPTER 6}

\section{BUILDING CAPACITY FOR SUSTAINABLE REGIONAL INDUSTRIAL SYSTEMS: AN EVENT SEQUENCE ANALYSIS OF DEVELOPMENTS IN THE SLOE AREA AND CANAL ZONE}

This chapter is published as Spekkink, W. A. H. 2015. Building capacity for sustainable regional industrial systems: an event sequence analysis of developments in the Sloe Area and Canal Zone. Journal of Cleaner Production 98: 133-144. 


\section{ABSTRACT}

For more than a decade, firms, governmental organizations, knowledge institutes and other relevant actors in the Sloe Area and Canal Zone have been engaged in multiple initiatives dedicated to the sustainable industrial development of their region. In this article, a reconstruction is made of these developments, using Event Sequence Analysis (ESA), to study how actors built and maintained the collaborations that drive these initiatives, and to study the extent to which these initiatives mutually influence each other. The analysis reveals that there are no direct mutual influences between the developments, but that there are indirect influences based on partially overlapping sources of institutional capacity (i.e., the capacity for collective action). Based on the results, several additions are made to existing models of industrial symbiosis that describe the stages through which industrial symbiosis develops. The first addition is the idea that industrial symbiosis can be understood to build on stable intermediate components that develop autonomously from each other. The second addition is that the development of industrial symbiosis itself can be understood as a stable intermediate for more comprehensive developments at a higher system level. The third addition is that the development of industrial symbiosis can be understood to be embedded in a larger social context that influences the opportunities that actors see for collective action towards industrial symbiosis. 


\subsection{INTRODUCTION}

Over the past decade a small collection of by-product exchanges and utility synergies has emerged in the Sloe Area and Canal Zone, an industrial port area in the province of Zeeland in the Netherlands (see figure 6.1 for a map of the region). These symbiotic exchanges are the outcomes of a long-term development in which firms, governmental organizations, knowledge institutes and other relevant actors interacted to develop a bio based industrial cluster in the Canal Zone (Biopark Terneuzen). A detailed description of Biopark Terneuzen is offered in an earlier publication (Spekkink 2013). Biopark Terneuzen is not the only initiative in the region that is dedicated to sustainable development. Another development concerns a joint venture by the port authority Zeeland Seaports and Dow Benelux that is dedicated to clustering firms that specialize in the production and distribution of chemical products (Valuepark Terneuzen). A third development concerns

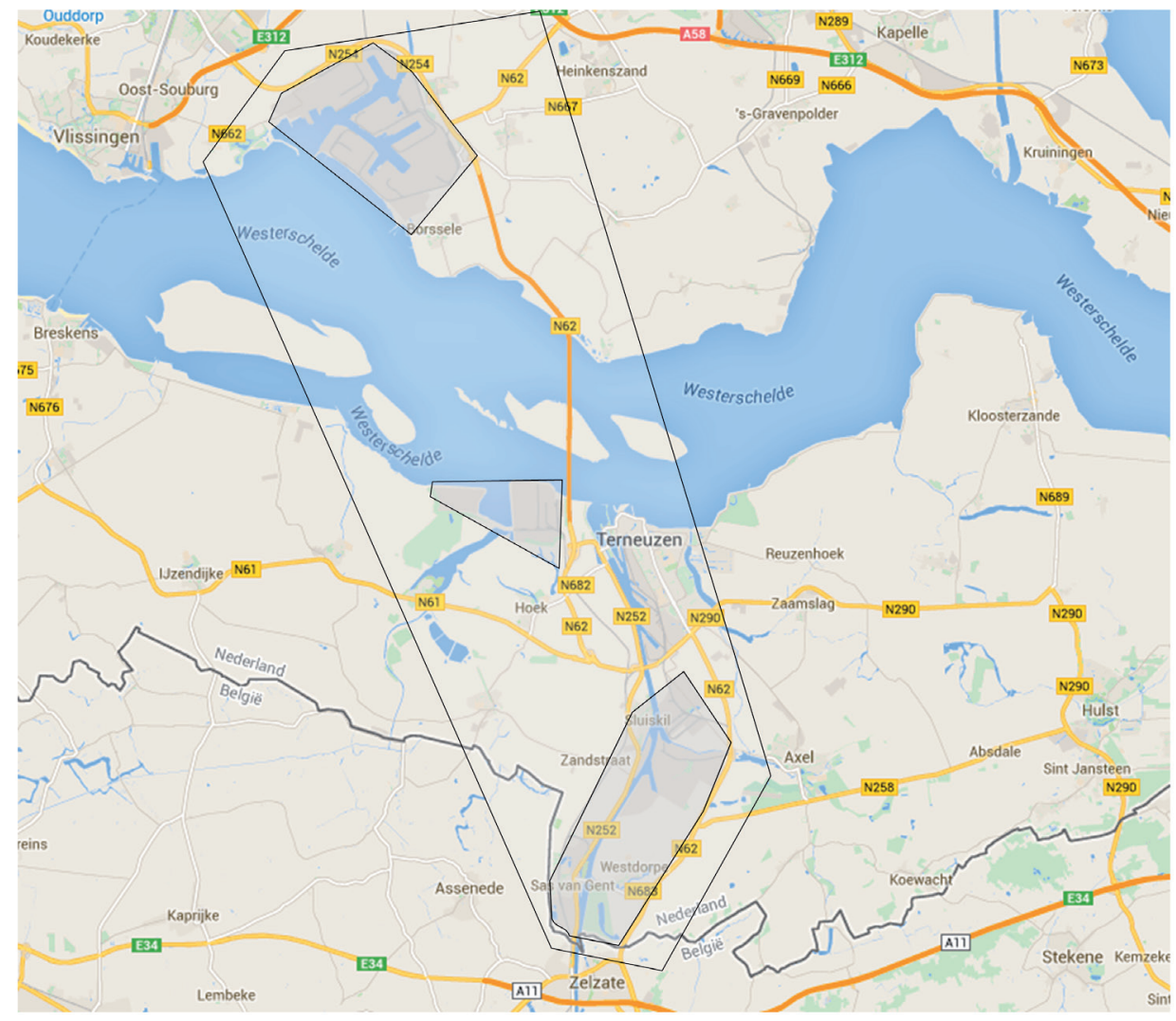

Figure 6.1: The southernmost area is the part of the Canal Zone where Biopark Terneuzen is located. The area in the middle is where the complex of Dow (the right part of the area) and Valuepark Terneuzen (the left part of the area) are located. The uppermost region is the Sloe Area (source: Google Maps). 
the activities of a project group that, among other things, organizes master classes on sustainable entrepreneurship for firms in the region (Vital Sloe Area and Canal Zone). In this article the focus of analysis shifts to the Sloe Area and Canal Zone as a whole, in order to investigate the relationships between the three developments and the implications of these relationships for the sustainable development of the region as a whole. To that end, a reconstruction is made of each development, focusing on the interactions through which the involved actors built and maintained the collaborations that drove the developments. Then an analysis is offered of the extent to which the three developments mutually influenced each other.

The conceptual basis for the reconstructions is a framework that builds on Healey's concept of institutional capacity building (Healey, 1998; Healey et al., 2003). Boons et al. (2011) and Boons and Spekkink (2012a) introduced the concept of institutional capacity building to the literature on industrial symbiosis to investigate how actors build the capacity for collective action towards the development of industrial symbiosis. Collective action is understood here as a more or less coordinated sequence of interactions through which actors work to achieve common goals. Based on the conceptual framework, the focus of the reconstructions offered in this paper will be on activities undertaken by actors in the Sloe Area and Canal Zone to build and mobilize capacity for collective action. The developments under investigation in this article took a long time to unfold and therefore a longitudinal approach to their investigation is fitting. The approach adopted in this investigation is Event Sequence Analysis (ESA) (Spekkink, 2013; Boons, Spekkink and Jiao, 2014). ESA builds on other process-oriented research approaches (Abell, 1987; Abbott, 2001; Langley, 1999; Poole et al., 2000) and is developed by researchers of the research cluster 'Governance of Energy and Material Flows'34 at the Erasmus University of Rotterdam as an approach for the systematic longitudinal investigation of governance processes.

The conceptual basis for the research is introduced in more detail in section 6.2. In section 6.3, ESA is introduced and the approach taken to the collection, organization and analysis of data is elaborated. In section 6.4 the results of the analysis are presented and in section 6.5 the conclusions of the research are presented.

34. The research cluster 'Governance of Energy and Material Flows' is part of the research group 'Governance of Complex Systems' in the Public Administration department of the Erasmus University Rotterdam. 


\subsection{CONCEPTUAL FRAMEWORK}

\subsubsection{Institutional capacity}

The central concept of the conceptual framework (see figure 6.2) is that of institutional capacity building (Healey, 1998; Healey et al. 1999; Healey et al., 2003). Institutional capacity is defined as the capacity of a community of actors to engage in collective action to deal with issues of common concern (Healey et al. 1999).

A community can be defined as "[...] a group of people who interact directly, frequently and in multi-faceted ways" (Bowles \& Gintis, 2002, p. 420). The stance taken in this research is that communities emerge from frequent interactions, which means that the existence (and development) of a community presupposes interactions, instead of the other way around. Following Healey and colleagues (1999), institutional capacity can be broken down into three dimensions:

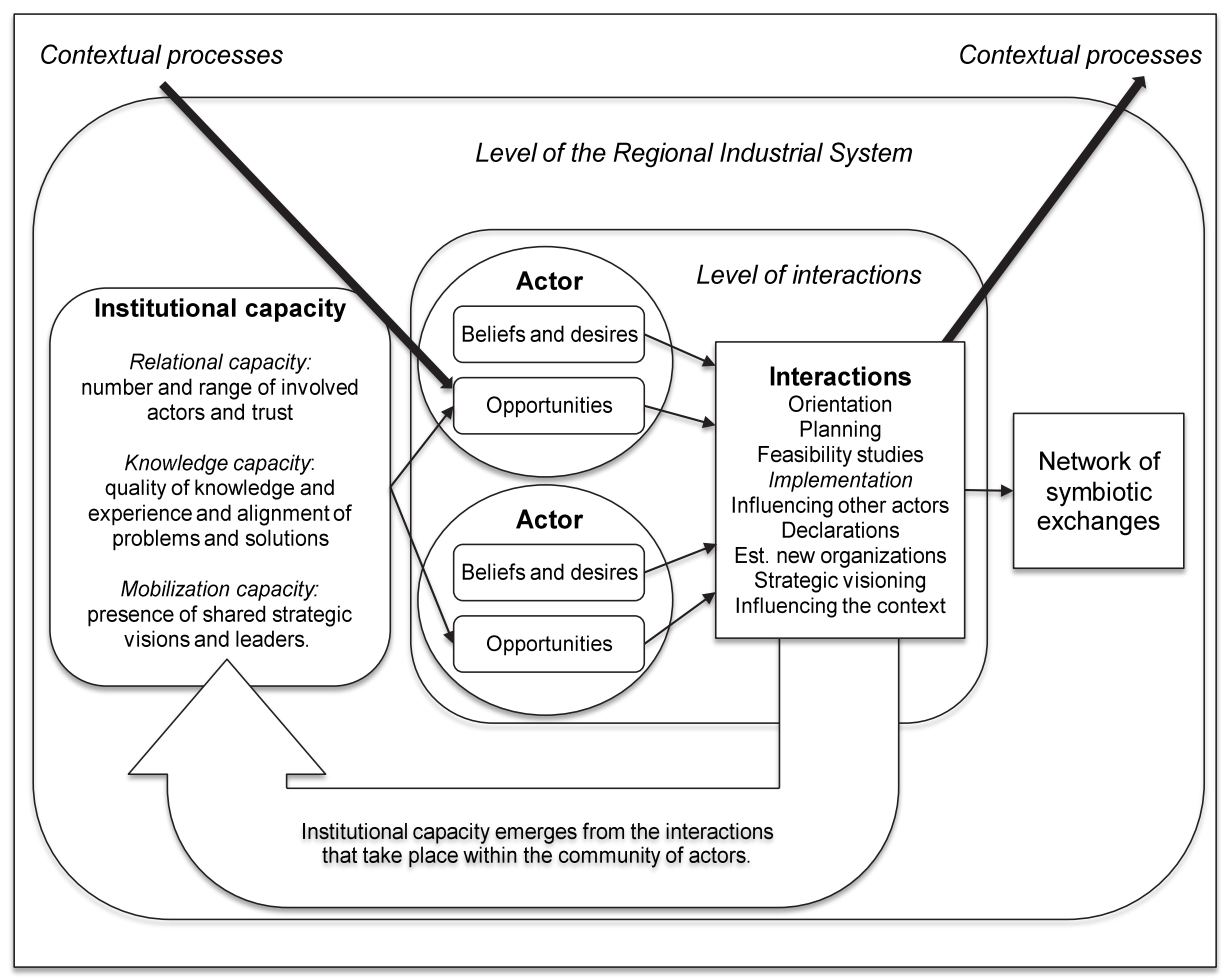

Figure 6.2: Conceptual framework. 
- Relational capacity: Capacity for collective action based on the quality of the relationships of actors, such as the number and range of actors involved in the community as well as the level of trust between them.

- Knowledge capacity: Capacity for collective action based on the quality of the knowledge and experience of the members of the community as well as the alignment of definitions of problems and solutions.

- Mobilization capacity: Capacity for collective action based on the existence of a shared strategic vision and the presence of actors within the community that are willing and able to take the lead.

Institutional capacity is closely linked to the opportunities that individual actors in a community see for engaging in collective action. First, the number and diversity of actors in a community will shape the opportunities that its members see for engaging in interactions that require coordinated efforts of its members. It is difficult to predict under which circumstances this influence will be positive or negative (Gould, 1993; Ostrom, 2007b). A larger, more diverse group of actors will usually have access to a wider range of resources (Oliver \& Marwell, 1988), which is likely to increase the opportunities that actors in the community see for engaging in demanding interactions. However, larger groups can also create severe coordination problems (Poteete \& Ostrom, 2004). The extent that the members of the community see opportunities to engage in demanding interactions is also shaped by the level of trust between them, because trust reduces the risks that actors perceive in cooperative relationships (Ring \& Van der Ven, 1992).

Actors with strong personal and professional relationships are also more likely to share knowledge and experience, and to negotiate conflicting views on problems and solutions (Innes and Booher, 1999). The knowledge and experience that actors gain through interactions can shape the opportunities that they see for different courses of action by shaping their ideas of what courses of action are feasible or not. In addition, the opportunities that actors see for working together will increase if actors are able to align their different definitions of the problems and solutions. This doesn't necessarily mean that the actors converge on a particular set of problems and solution definitions; it is also possible for them to achieve knowledge inclusion (Van Buuren, 2009), which means that the actors develop mutual comprehension and recognition of each other's perceptions of problems and solutions, and their perceptions of which knowledge is valid and relevant.

At the long term, actors may come to see their problems and interests as interrelated, and reassess their individual purposes for them to become more aligned (Innes and Booher, 1999). Such a social learning process can lead to the development of shared strategic visions, in which the actors articulate their common interests and goals. Shared strategic visions influence the opportunities that actors see for collective action because they offer long-term, common frames around which actors can mobilize (Healey et al., 2003). Actors will also see better opportunities for engaging in collective action if there 
are one or more actors that are willing to lead or facilitate the interactions (Elliot, 1999). Leadership is, to some extent, a general requirement for collective action (Ansell $\&$ Gash, 2008). More specifically, the implementation of shared visions depends on sustained leadership by an actor that has made the commitment to see the vision through (Moore, Longo \& Palmer, 1999).

\subsubsection{Institutional capacity building}

The concept of institutional capacity building denotes the process through which a community of actors generates the capacity to engage in collective action. This process manifests itself in the changes that occur in the dimensions discussed above, such as changes in the number and diversity of actors involved, changes in their definitions of problems and solutions, and the establishment of strategic visions. These developments occur at the level of the Regional Industrial System (RIS). A RIS is "a more or less stable collection of firms located in proximity to one another, where firms in principle can develop social and material/energy connections as a result of that proximity" (Boons et al., 2011, p. 907).

To understand how these changes occur, we turn our attention to the lower level interactions that actors engage in, because it is at this level that changes in institutional capacity are brought about. In other words, changes in institutional capacity building at the level of the RIS are conceptualized as the emergent outcomes of dynamics at the level of interactions. The actors in the RIS may interact with each other in various coalitions (i.e., smaller groups of actors within the RIS) and for various motivations (i.e., beliefs and desires). Also, whether or not an actor participates in interactions, depends on the opportunities the actor sees to do so at that moment ${ }^{35}$. The basic types of interactions that are distinguished in the conceptual framework are the following:

1. Orientation: Actors negotiate and explore issues of common concern in an effort to develop initial definitions of problems and solutions.

2. Planning: Actors formulate the concrete steps that have to be taken in order to realize certain solutions.

3. Feasibility study: Actors perform research on the (technical, organizational, or economic) feasibility of certain solutions.

4. Implementation: Actors implement the solutions they have planned. This includes the implementation of by-product exchanges or utility synergies.

5. Influencing other actors: Actors perform activities deliberately aimed at influencing the opportunities that other actors see for different courses of action. This includes lobbying and legal procedures. 
6. Declaration: Actors formally declare their intent to act upon an issue of common concern, possibly involving the signing of formal declarations.

7. Establishing new organizations: Actors establish a new organization within the boundaries of the RIS.

8. Strategic visioning: Actors establish strategic visions in which they articulate their common interests and goals.

9. Influencing the context: Actors perform activities deliberately aimed at influencing their (political, economic, or physical) context. This includes adjustments to infrastructure, and lobbies specifically dedicated to influencing national policies.

Throughout these interactions actors can strengthen existing relationships, or establish new ones. In addition, through interactions actors can exchange knowledge and experience, and learn about each other's definitions of problems and solutions. Thus, by engaging in interactions, actors shape the institutional capacity available to them in the future.

\subsubsection{Mobilizing institutional capacity}

Interactions are not only a source of changes in institutional capacity, they are also the processes through which institutional capacity is mobilized. The logic of the framework is that, in each interaction, actors will act on their motivations and the opportunities they see available to them at that moment. The overarching hypothesis is that, as institutional capacity builds up, actors will be able to engage in increasingly demanding interactions, because of increasing opportunities to do so.

In this regard the implementation of by-product exchanges and utility synergies is especially interesting. By-product exchanges concern the exchange between firms of previously disposed by-products to replace other business inputs. Utility synergies concern the shared use of utility infrastructures for the production of energy carriers, the production of process water, and the joint treatment of wastes and emissions (Van Berkel et al., 2007). Depending on the specifics, such synergies can become very demanding in terms of the investments required and the risks involved (e.g., when a pipeline infrastructure needs to be developed first). Based on the logic of the conceptual framework, we would expect the more demanding symbiotic exchanges to be preceded by long sequences of interactions through which the involved actors generate institutional capacity. Symbiotic exchanges can be developed autonomously from each other, based on independent projects. However, it is possible that, over time, symbiotic exchanges become increasingly interlinked, thereby contributing to the development of a network of symbiotic exchanges at the level of the RIS.

\subsubsection{Contextual processes}

The opportunities that actors see for different courses of action are not shaped by dynamics of institutional capacity building alone. Various events that are not part of 
the process of institutional capacity building may also influence the opportunities that actors see. Examples of such events are changes in policies and regulations, and changes in economic circumstances. Because such events influence the opportunities that actors see, they will also influence the course that the process of institutional capacity building might take. Provided that the actors have generated sufficient institutional capacity, actors in the RIS may work together to influence their context (Innes \& Booher, 1999).

\subsection{METHODS: EVENT SEQUENCE ANALYSIS}

ESA is a collection of methods specifically developed for longitudinal research. It is focused on the reconstruction of sequences of events and on the identification and analysis of temporal patterns (Boons, Spekkink and Jiao, 2014). ESA builds on existing longitudinal methodologies, the primary examples being the work of Abell $(1987 ; 1993$; 2004), Abbott (1988; 1990; 2001), and Poole and colleagues (2000). Their methodologies have been applied to investigate, among other things, professionalization (Abbott, 1991), careers (Abbott and Tsay, 2000), the interactions between the regional headquarter of a company and its subsidiaries (Abell, 1987), and innovation processes (Poole et al., 2000; Van de Ven et al., 2000). In ESA processes are defined as sequences of events that describe how entities emerge, develop and possibly dissolve again over time. An example of a process is the emergence, development and dissolution of a network of symbiotic exchanges. In this process, the establishment of symbiotic exchanges features as one type of event. The focus of the analysis is on the sequences of events that contribute to the conditions under which symbiotic exchanges are established. In addition, the researcher may investigate how symbiotic exchanges themselves contribute to the conditions under which further developments occur. Which other types of events are considered as part of the process depends on the specific theoretical perspective of the researcher. Based on the theoretical perspective chosen in this article the focus is on the events through which actors build and mobilize capacity for collective action. The application of ESA involves at least 4 steps: (1) defining the process, (2) collecting longitudinal data, (3) coding and grouping of data (colligation), and (4) data analysis. These steps, as well as their application in this research, are elaborated below.

\subsubsection{Defining the process}

The first step in ESA is to define the process to be studied. This involves the identification of a central subject, and relevant types of events (Poole et al., 2000). A central subject can be any kind of entity, such as an individual actor, a group of actors, a lineage, a social movement, or a machine (Hull, 1975). Events are theoretically significant changes that the central subject endures or brings about. The specific definition of different types 
of events depends on the conceptual framework of the researcher (Poole et al., 2000). In addition, the framework should specify how the events are linked to each other in sequences (Abbott, 1984).

In the research presented in this article, the central subject is the community of actors involved in the sustainable industrial development of the Sloe Area and Canal Zone. The events concern changes in the capacity for collective action of the actors in the Sloe Area and Canal Zone that are realized through their interactions. The conceptual basis for the definition of these events is offered in section 5.2. The same section discusses how the events are linked in sequences.

\subsubsection{Data collection}

After defining the process to be studied, longitudinal data on the process are gathered. The definitions of the central subject and the relevant types of events serve as guidelines in determining what data are relevant to the research project. The raw data are recorded as brief empirical descriptions of incidents in a chronologically ordered event sequence dataset. Incidents are actions or interactions that occurred during the process of interest. Incidents should be included if there is a reason to believe that they may serve as an indicator for one of the relevant event types, although the final decision on whether or not an incident can be used as an indicator is made in the coding process (see section 2.3). The basic information included in the description of an incident is as follows: (1) the date at which it occurred, (2) the actor(s) or object(s) involved in the incident, (3) the (inter-)action that the actor(s) or object(s) performed, and (4) the source of the information (based on Poole et al., 2000).

The data that were gathered for the research presented in this article are based on news items, different kinds of documents produced by actors in the course of the process, and web pages. For the collection of documents and webpages an Internet search was performed, using the Google search engine. For the collection of news items the LexisNexis database was used, which includes news items from Dutch national and regional newspapers. Searches were made through news items that have appeared since January 1995. The searches were based on a search protocol and a concomitant electronic logbook that were developed in advance. The search protocol offers a set of rules and guidelines for conducting searches and for recording the results of searches. This includes the prescription that in the searches performed for documents and websites 10 pages of search results are to be checked, and that any relevant website (collection of webpages) should be further investigated for other potentially relevant webpages or documents that link to the webpage that was originally found. The protocol also prescribes how the relevant data are to be stored and what information about the performed searches is to be recorded in the electronic logbook. The electronic logbook is used to record who performed the searches, when the data collection process started, when the 
final searches were performed, which search engines were used, which keywords were used (including a justification for the chosen keywords), as well as information on the origin of each source. This information includes the URL of any webpage or document at the time it was found, the host of the website or the publisher of the document, and the date that the website or document was retrieved by the researcher. Each source also has a unique identification number that is used for reference.

All sources that appeared to be relevant on face value were stored to a hard drive ${ }^{36}$, using the unique identification number that was assigned to them as the filename. The face value relevance of the sources was determined by checking the subjects treated in the source. The data collection process for the Sloe Area and Canal Zone was started on January 27, 2011. The last additions to the raw data were made on April 26, 2012. All searches have been performed by the author of this article. In the process 252 webpages, 189 documents, and 884 news items were collected, although several news items have been included multiple times because of overlap between different search results. The raw data were used to construct a dataset built from chronologically ordered incident descriptions. The structure for the dataset was developed using Microsoft Access. The dataset structure includes a user-interface that allows the researcher to input incident descriptions, which are then automatically put in chronological order by the dataset. The original sources of the information in the descriptions are referenced by the unique identification number that was assigned to them in the data collection process. This makes it possible to quickly consult the original sources of the information at any time. The dataset also includes features to accommodate the coding process (described in section 6.3.3 and to export all data (coded or non-coded) to a Microsoft Excel-file. All the sources that were found in the data collection process were read to identify relevant incidents. The dataset that is at the basis of the analysis reported on in this article consists of 1065 incidents. These incidents cover the period from 1995 to 2010.

\subsubsection{Coding and grouping of data}

After the raw data have been translated to incidents in the event sequence dataset, all incidents are separately coded as indicators for events. For this purpose, a user-interface was developed that allows the researcher to assign codes to each incident. The coding process serves to determine whether the incidents in the dataset are valid and reliable indicators for the events of interest to the researcher. The codes used in the coding procedure are based on the conceptual framework of the research project. To ensure the reliability and accuracy of the coding scheme, multiple researchers perform the coding,

36. In the case of news items from the LexisNexis database, all results were stored to the hard drive in documents that include up to 10 news items each. The relevance of the news items was judged in the process of recording incident descriptions in the event sequence dataset. This approach was chosen because, during the data collection process, checking each news item in detail would take too much time. 
which makes it possible to check for inter-coder reliability. For the research reported on in this article, two researchers coded several samples of the dataset and checked for inter-coder reliability after each session, using Scott's Pi as a measure (Scott, 1955). If the inter-coder reliability score proved to be too low, the coding scheme would be adjusted. The last score recorded for inter-coder reliability is 0.66. Craig (1981) proposes that the standards for substantive interpretation of values of kappa developed by Landis and Koch (1977) can also be applied to interpret values of Scott's pi. According to these standards a measure of 0.61-0.80 is substantial.

The coding scheme that was developed for the research presented in this article is outlined in table 6.1. The articulations of beliefs and desires and articulations of opportunities for different courses of action are not treated as types of events in their own right, but as aspects of the other types of events. For example, actors would occasionally articulate their motivations for engaging in a certain interaction (such as orientation). In the compilation of the dataset such an articulation is recorded as a separate incident, in the coding process it is coded as an articulation of beliefs and desires, and in the process of colligation (see below) it is grouped together with the event it refers to. It is possible that multiple incidents in the dataset indicate a single event. To group those incidents together, all coded incidents of the dataset were exported to a Microsoft Excel-file and grouped together manually. This step is usually referred to as colligation (Abbott, 1984).

An important limitation of using archival and secondary sources of data is that it is difficult to assess to what extent the data offer a complete picture of the sequences of events under study. Certain developments may be underreported in news items, and certain interactions that actors engage in leave little traces behind. To verify the reconstructions that were made of the developments in the Sloe Area and Canal Zone, interviews were performed with two people involved in some of the developments.

Only two interviews were performed because it quickly became clear that the interviewers sometimes ended up reminding the respondents of certain developments that had occurred early on in their region. It appeared that the respondents couldn't remember the developments at the level of detail that was required for verification of the reconstructions. As an alternative, a workshop was organized in December 2012, where a reconstruction of the developments in the Sloe Area and Canal Zone was presented to a group of 20 people from business, government, educational institutes and an environmental interest organization, which are all active in the region. All participants were handed a list of questions, including the question whether important events were missing in the reconstruction. None of the participants indicated that something was missing. 
Table 6.1: Coding scheme

\begin{tabular}{ll}
\hline Event type & \multicolumn{1}{c}{ description } \\
\hline Orientation & $\begin{array}{l}\text { actors negotiate and explore issues of common concern in an effort to develop initial } \\
\text { definitions of problems and solutions. }\end{array}$ \\
\hline Planning & actors formulate the concrete steps that have to be taken in order to realize certain solutions. \\
\hline Feasibility study & $\begin{array}{l}\text { actors perform research on the (technical, organizational, or economic) feasibility of certain } \\
\text { solutions. }\end{array}$ \\
\hline Implementation & $\begin{array}{l}\text { actors implement the solutions they have planned. This includes the implementation of by- } \\
\text { product exchanges or utility synergies. }\end{array}$ \\
\hline Being influenced by context & context events that influenced the opportunities that actors see for different courses of action \\
\hline Influence of context & $\begin{array}{l}\text { actors perform activities deliberately aimed at influencing their (political, economic, or } \\
\text { physical) context. This includes adjustments to infrastructure, and lobbies specifically } \\
\text { dedicated to influencing national policies. }\end{array}$ \\
\hline Influence of actors & $\begin{array}{l}\text { actors perform activities deliberately aimed at influencing the opportunities that other } \\
\text { actors see for different courses of action. This includes lobbying and legal procedures. }\end{array}$ \\
\hline Declaration & $\begin{array}{l}\text { actors formally declare their intent to act upon an issue of common concern, possibly } \\
\text { involving the signing of formal declarations. }\end{array}$ \\
\hline Opew Organization & actors establish a new organization within the boundaries of the RIS. \\
\hline Strategic visioning & actors establish strategic visions in which they articulate their common interests and goals. \\
\hline articulations by actors of their beliefs and desires.
\end{tabular}

\subsubsection{Data analysis}

The method used for the analysis of the event sequences is based on the approach to narrative analysis developed by Abell (1987; 1993; 2001; 2004). Abell developed his approach to allow for the development of causal explanations for particular events in terms of those actions which, in context, brought them about (Abell, 1978). Abell (1993, p. 94) assumes that "human actions bring about events (outcomes) in the social world, and one may apparently offer an explanation of the occurrence of those events by pointing to the actions from which they eventuate." The analysis presented in this article is based on the approach developed by Abell, although it differs from it in a few ways. First, in this article the human actions that 'bring about events' are understood as events themselves. In principle it is possible for 'non-human events' to bring about other events as well. Second, Abell tends to focus (primarily) on actions and forbearances (actors forbearing to do something). In this article the focus is on interactions, and forbearances are not included as events.

For all developments analyzed in this article an event table was made (included in Annex 1). The event table lists the events in chronological order, including their type and the conditions under which they occurred. Based on the event tables, event graphs are made to visualize the linkages between the events. A linkage between any pair of events is made if the earlier event can be understood to have contributed to the condi- 
tions under which the later event occurred. Abell (2001) suggests that the most obvious kind of evidence are the accounts given by those involved in the events, or by close observers. He adds that many other possibilities with more or less face validity exist. In this article the links are made if actors (preferably multiple) involved in an event make a clear reference to an earlier event, usually in the form of articulated beliefs, desires or opportunities. The prime focus of the analysis is to find out to what extent and how the different developments have influenced each other. Also, in order to analyze dynamics of institutional capacity building, some qualification of the reconstructed sequences of events is necessary. This is achieved by studying who was involved in what events, by studying the articulations of beliefs and desires by actors (these include definitions of problems and solutions), and by studying articulations of opportunities by actors.

\subsection{RESULTS}

\subsubsection{Introduction to the Sloe Area and Canal Zone}

The Sloe Area and Canal Zone are situated in the province of Zeeland in the Netherlands. They are two port areas where most of the industry in Zeeland is concentrated. Together, the Sloe Area and Canal Zone cover about 4.400 hectares, although most of the industry is concentrated in specific parts of the area. Both port areas are managed by Zeeland Seaports, who became the port authority for the Sloe Area and Canal Zone after the merger of two separate port authorities in 1998. The Sloe area is situated near Vlissingen along the northern banks of the Westerschelde River. This is where most of the industry is concentrated (over 120 companies). The dominant sectors in the Sloe Area are chemical industry, metals industry, electricity production, storage and distribution. The Canal Zone is an area around a canal that runs between the southern banks of the Westerschelde River near Terneuzen and the port area of Ghent in Belgium. The dominant sectors in the Canal Zone are chemical industry, food industry, metals industry, paper and cartons and storage and transshipment (over 60 companies). There is also a greenhouse area in the Canal Zone.

Several firms in the Sloe Area and Canal Zone have been making efforts to reduce the ecological impact of their activities for a longer period of time, but broader collaborations between the firms and other relevant actors to reduce the ecological impact of firms began around 1998. By the end of 2010, several symbiotic exchanges were in progress, and several initiatives were still being prepared. The sequences are discussed in chronological order. 


\subsubsection{The sequences of interactions in the Sloe Area and Canal Zone}

\section{Vital Sloe Area and Canal Zone}

The first development concerns the activities of a project group called Vital Sloe Area and Canal Zone (see figure 6.3). The group was established in January 2003 (event 6), building on two earlier projects that had taken place in the Canal Zone and the Sloe Area (events 1, 2, 3 and 4). The establishment of the project group itself represents the most significant development in terms of relational resources, the conditions for which were, to some extent, already established in the earlier projects. From the outset, the group displays a wide diversity of participants, including firms, governmental organizations, knowledge institutes, consultancy companies and interest groups. After its establishment, the group has remained more or less the same, except for some minor changes in membership. Thus, after 2003, there was little development of relational resources, except for the strengthening of relationships between the existing partners. The project group is repeatedly described by its participants as an incubation chamber for innovative ideas with regard to sustainable entrepreneurship. Sustainable entrepreneurship was chosen as the central theme for the project, based on an investigation into the needs of the companies in the region (event 5). Looking at the event graphs in figure 6.3, we can see that 'the project as an incubation chamber' is quite an apt description.

Throughout its existence, several initiatives were taken by the project group to explore different aspects of sustainable entrepreneurship, which is reflected in the branching structure of the event sequence and in the fact that most events in the sequence are of the orientation type. Examples of the aspects of sustainable entrepreneurship explored by the group are the attempt to stimulate managers of companies to think of the Sloe Area as one whole (events 12, 13 and 35), park management (events 16 and 20), sustainable innovation in the chemical industry (events 23, 32 and 42), residual material exchanges (events 38, 39 and 46) and biodiversity (events 31, 36, 37, 44 and 48). Thus, in terms of knowledge resources there was a lot of development, although only few of the initiatives seem to have triggered longer term developments. In a report published in May 2008 one of the participants to the project group indicated that the initiatives would sometimes lead to commercial spin-offs, implemented outside the context of Vital Sloe Area and Canal Zone, which again reflects that the platform was treated primarily as an incubation chamber.

From the moment that the project became independent (event 33), the project group was also used as a platform to discuss and coordinate initiatives that originate from elsewhere, such as the intended transition to a sustainable chemical sector in Zeeland (events 32 and 42), the Water Loops project of Dow (event 47) and the Residual Heat Use project for companies in the Sloe area (events 38, 39 and 46). Different members of the project group were regularly mobilized for such projects. There is not one particular 
Chapter 6

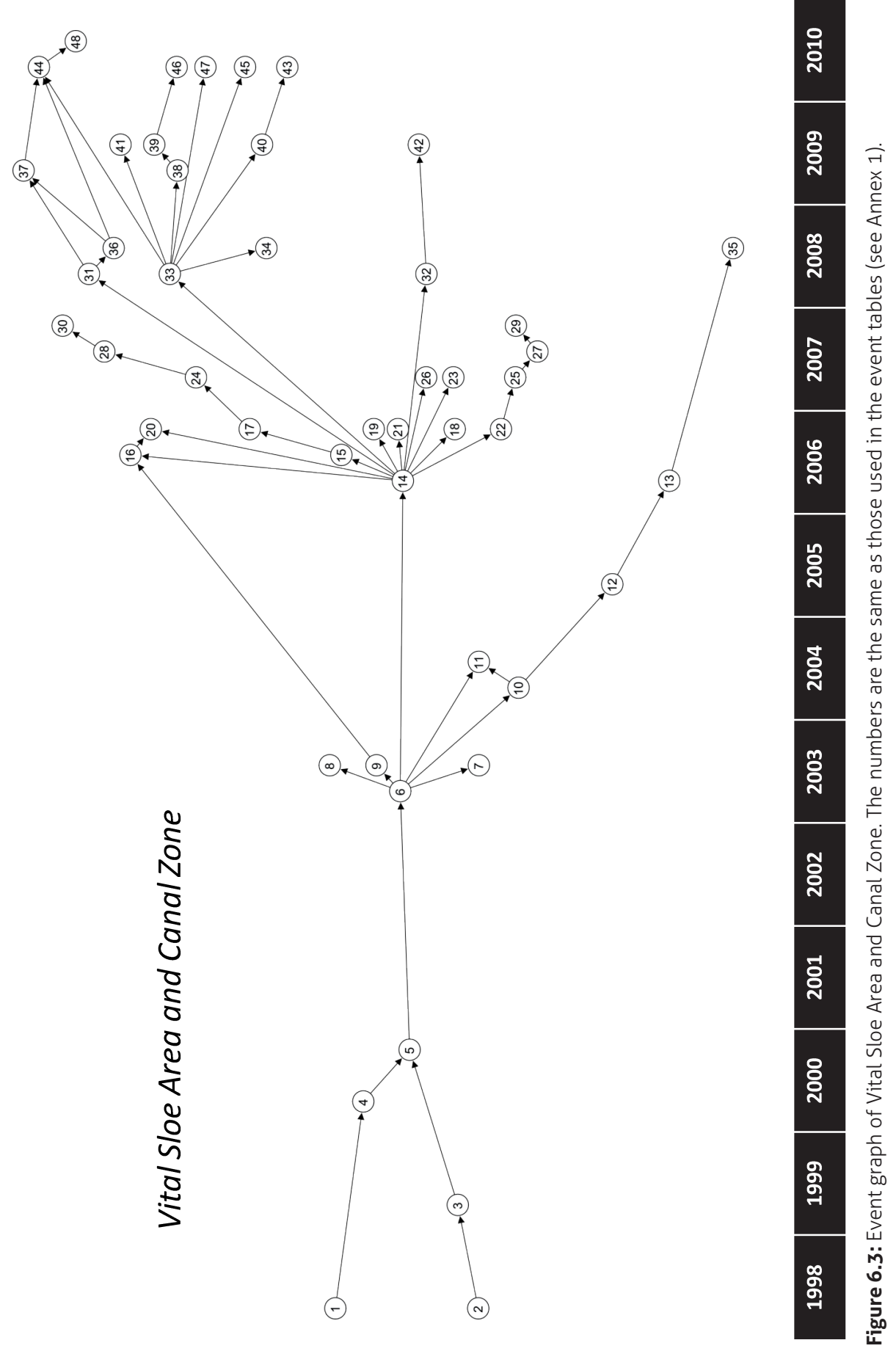

128 
leader that stands out in these initiatives; different actors took the lead in different cases. The common ground for all the initiatives was the group's general focus on sustainable entrepreneurship. To some extent this theme can be understood to have served as a strategic vision, although there is no evidence that the participants themselves perceived sustainable entrepreneurship as such.

\section{Biopark Terneuzen}

The development of Biopark Terneuzen can be broken down into three subsequences that unfold more or less autonomously in their initial stages, but become intertwined as soon as the vision of Biopark Terneuzen is introduced (also see Spekkink, 2013). One of these subsequences concerns the development of a greenhouse area, including the initiative to have the fertilizer producer Yara supply residual heat and $\mathrm{CO}_{2}$ to the greenhouses (the $\mathrm{WarmCO}_{2}$ project) (see figure 6.4).

Event 50 to 62 describe the development of the greenhouse area itself. This includes actions that actors in the region took to make sure that the greenhouse area would be located in the Canal Zone (see event 52 especially). Interestingly, one of the main arguments used by the lobbying actors was that there would be a possibility to have Yara supply the greenhouses with residual heat and $\mathrm{CO}_{2}$. This idea can be traced back to a project that was performed earlier in which such possibilities were investigated (event 49). The development of the greenhouse area is rich in lobbying events and feasibility studies (events 50,51,52,55,57, 58 and 60). This indicates a significant development in terms of knowledge resources, as multiple actors successfully convinced the province of Zeeland (and indirectly the national government) to implement their preferred solution.

At about the same time that the discussion on the greenhouse area in Zeeland started, Heros, a waste collection and processing company, purchased a terrain in Sluiskil (in the Canal Zone) (see figure 6.5). The process that follows is maybe best described as one in which Heros is looking to exploit the business opportunities that its new terrain offers.

This finally led to plans for the development of a biomass plant (event 90) and an alcohol factory (event 91) at the terrain of Heros. Developments that could have been of (negative) influence on the relationship between Heros and the province of Zeeland, concern those that describe the conflicts that Heros had with the province about several permits (events 77, 78, 79, 80, 81, 84, 86, 88 and 89). However, based on several commentaries that the director of Heros made during these conflicts, it is clear that the company still experienced the interactions with the civil servants of the province as positive. As the leader of a company heavily involved with environmental issues, the director understood the actions of the province, although he found that the province sometimes exaggerated in the measures it took against Heros. During the activities of Heros that took place in the context of Biopark Terneuzen no reference was made to the conflicts, which is why linkages between these developments are absent in the event graph. 


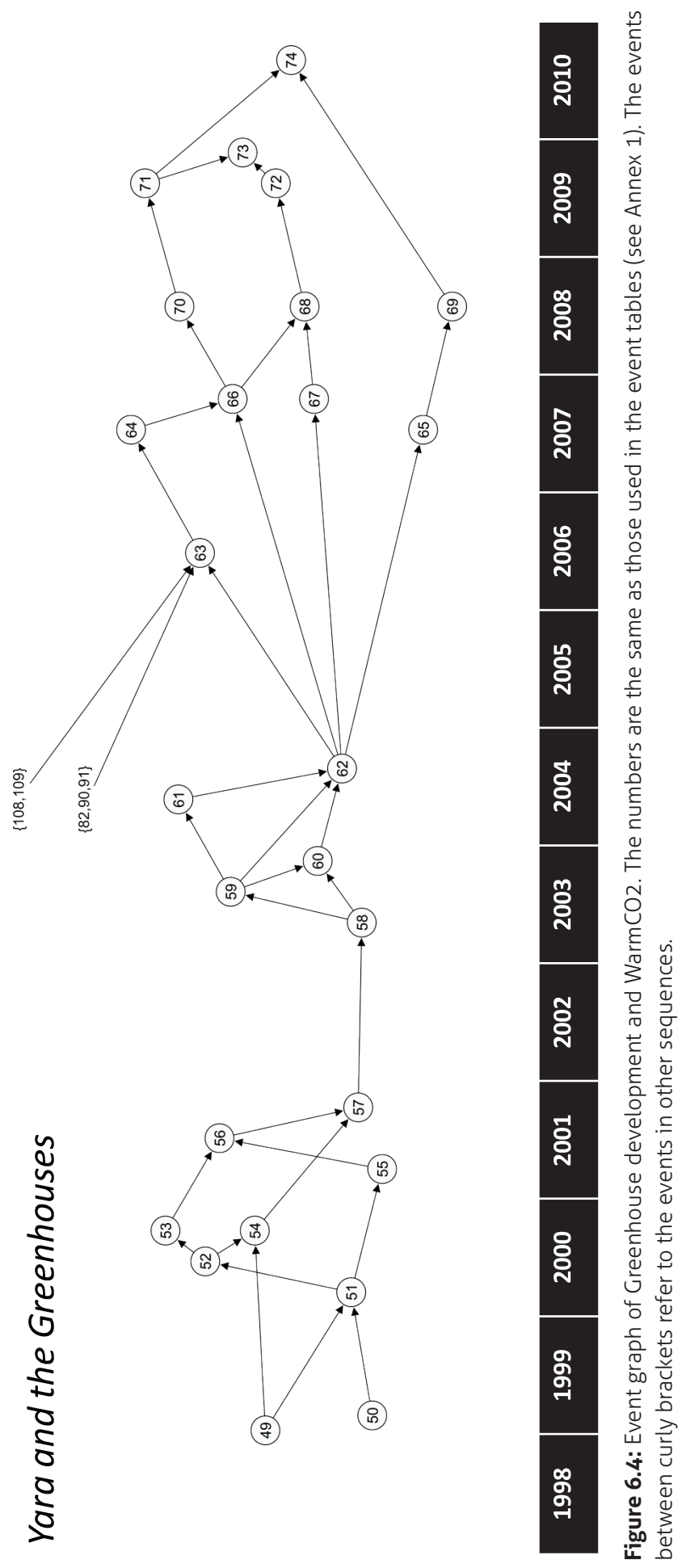



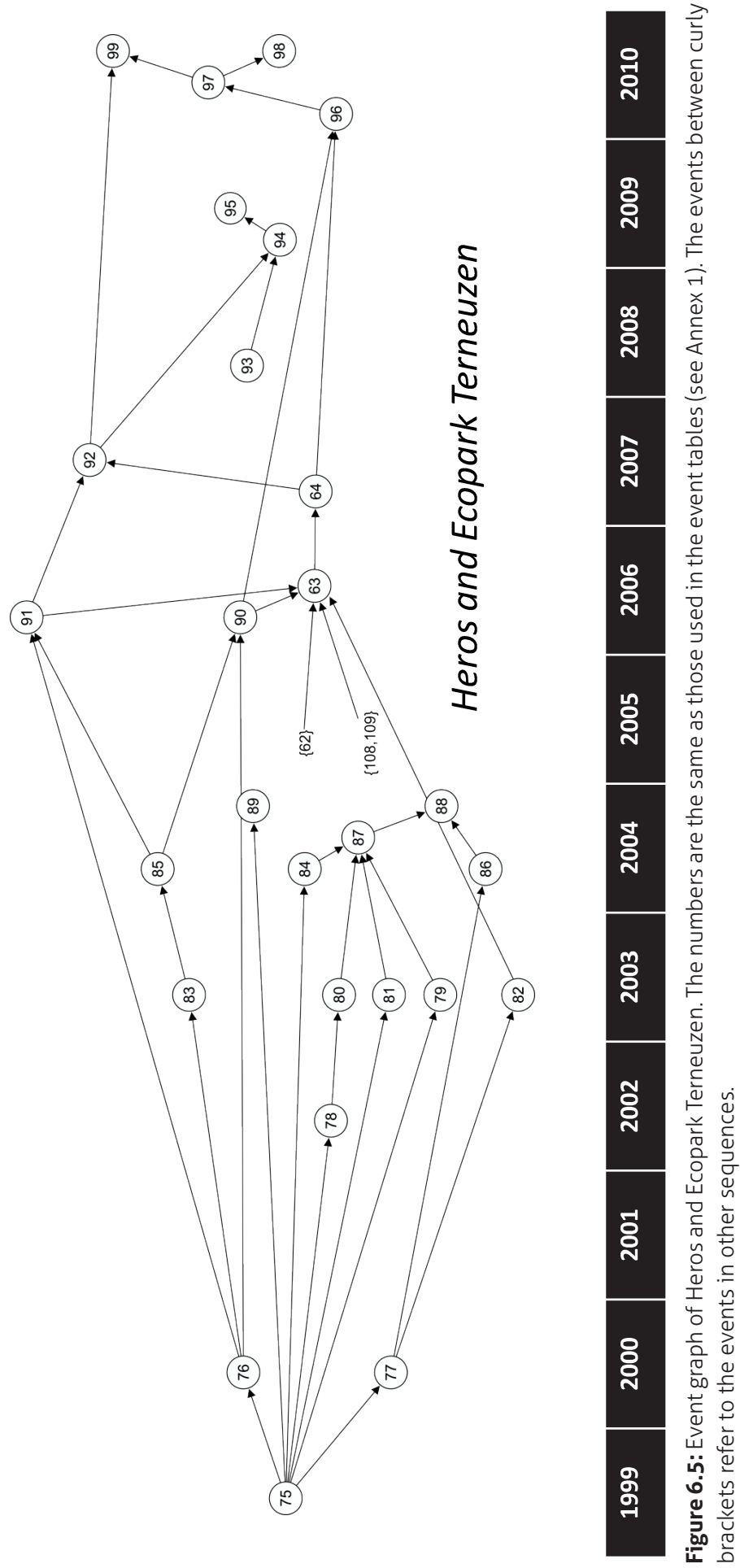
In 2003 Nedalco and Cerestar (a daughter company of Cargill) started negotiations on what would become the first symbiotic exchange to be realized in the Sloe Area and Canal Zone in the investigated period (events 100 and 102) (see figure 6.6). This initiative, combined with other interactions that Nedalco engaged in at about the same time (event 101, 103 and 104) also led to several follow-up initiatives that Nedalco wanted to realize in the Canal Zone, including the establishment of a biofuel factory (event 110). This initiative was never realized, because Nedalco didn't receive the requested support from the national government (events 111, 112, 113, 114 and 115). The symbiotic exchanges between Nedalco and Cerestar (event 109) were not preceded by a lengthy process of institutional capacity building. These exchanges are best understood as more or less conventional business arrangements, based on similar arrangements that Nedalco and Cargill had developed at other locations.

In their beginning stages the three subsequences had relatively little to do with collective action, with the exception of several events in the greenhouse development. At the time, there wasn't a clear underlying common purpose that he actors were working towards. However, in all three developments the conditions were created for collective action at a later stage.

When Nedalco started participating in the project "The Netherlands on the road to ethanol" (event 103), representatives of the municipality of Terneuzen started talking about opportunities to develop an agrocluster, or an agro-chemical cluster in the Canal

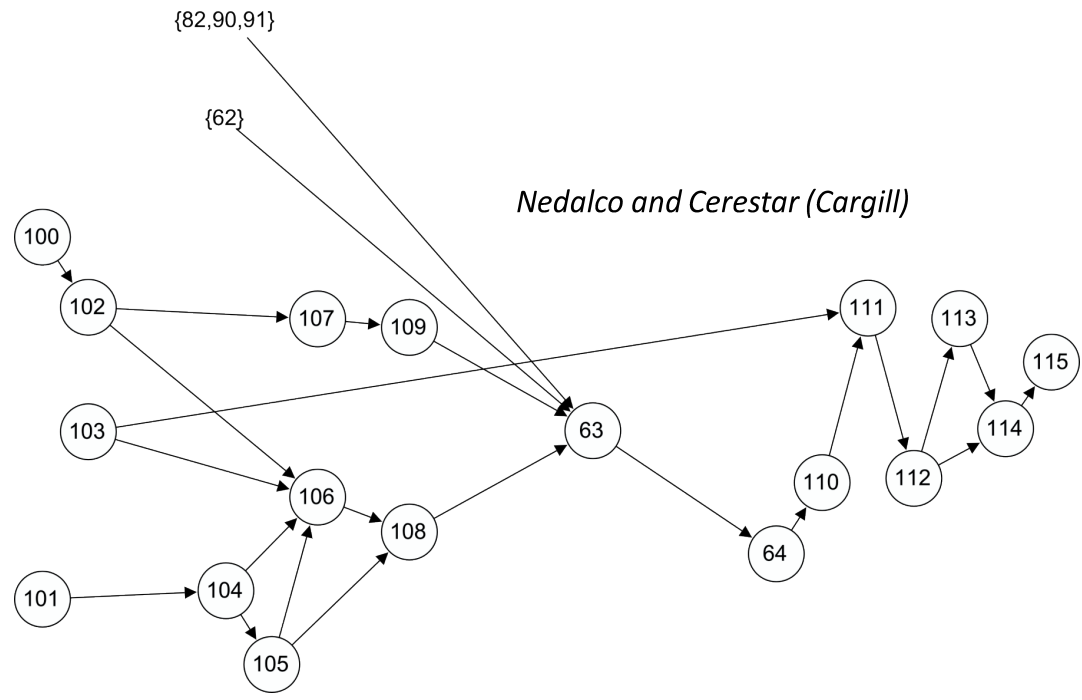

Figure 6.6: Event graph of Nedalco and Cargill. The numbers are the same as those used in the event tables (see Annex 1). The events between curly brackets refer to the events in other sequences. 
Zone, which could give the region a leading role in the transition to biofuels. For example, the mayor of Terneuzen explicitly urged to act on the opportunities provided by the presence of companies such as Dow, Nedalco and Cerestar and the favorable geographical conditions of the Canal Zone, by including them in regional development visions. Such a vision was established in the Biopark Terneuzen project (events 63 and 64).

In this project, the three subsequences that had developed more or less autonomously thus far, were united under one overarching vision. Biopark Terneuzen not only brought together the actors involved in the three subsequences into a larger network, but also introduced a number of other actors that were involved for the duration of the Biopark Terneuzen project. This includes several universities that supported the initiatives included in the Biopark Terneuzen project with research (the final report was delivered in June 2009). The vision of Biopark Terneuzen transformed how the involved actors approached the development of the greenhouse area, the development of Nedalco's biofuel factory, and the developments at Heros' terrain. Instead of being isolated initiatives, they were now thought of as parts of a larger (future) cluster. For example, part of the plans was for the biofuel factory of Nedalco to supply $\mathrm{CO}_{2}$ to the greenhouses that were to be constructed in the Canal Zone, and the biomass plant of Heros would use by-products from the greenhouses as input for energy production. This made the development of the greenhouse area into the centerpiece of Biopark Terneuzen. Although the actors involved in Biopark Terneuzen were not constantly working together, they were working towards a common goal. This makes the Biopark Terneuzen development a very clear example of how a shared strategic vision is used to mobilize the capacity that a community has for collective action.

The development of Biopark Terneuzen has had several setbacks. The biofuel factory of Nedalco was never realized, and the first owner of the biofuel factory at the terrain of Heros went bankrupt (events 94 and 95), partly as the result of the decision by the national government to no longer support the development of biofuels (event 93). However, the supply of residual heat and $\mathrm{CO}_{2}$ to the greenhouses was realized through the WarmCO$_{2}$ joint venture (events $66,70,71,73$, and 74), primarily thanks to a large investment made by Zeeland Seaports (event 70).

\section{Valuepark Terneuzen and Maintenance Valuepark Terneuzen}

In 2002 Dow Benelux and Zeeland Seaports started a joint venture (event 117), dedicated to the maintenance and development of Valuepark Terneuzen, a new site next to the existing complex of Dow (see figure 6.7). The sequence of events that follows largely describes how the partners attract several companies to the new site. Part of the sequence shows the beginning of what could be called an agglomeration effect (Gordon and McCann, 2000), as the establishment of the company Oiltanking (events 118, 122 and 127) subsequently leads to the attraction of Biofueling (event 128), which itself leads 


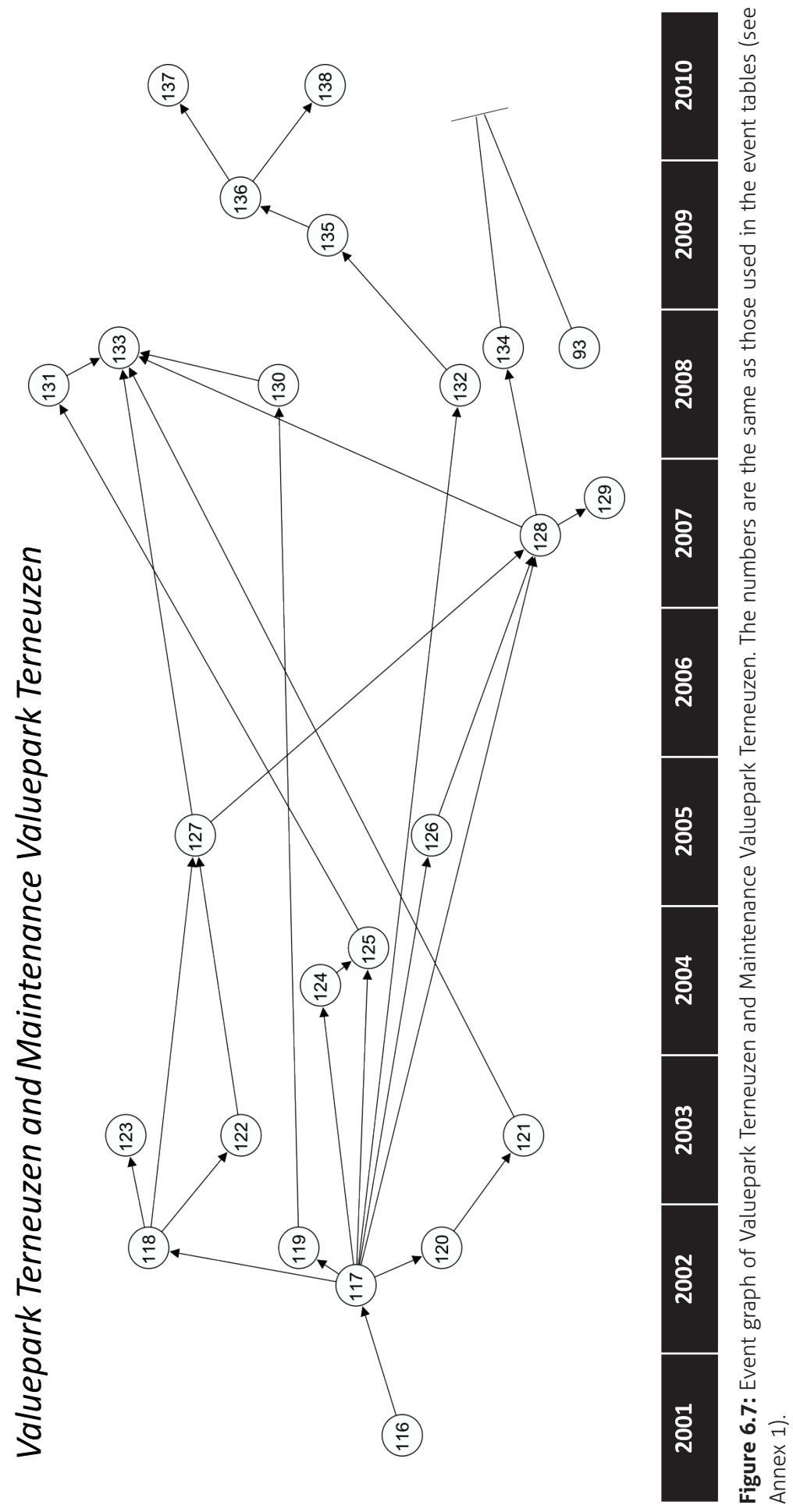


to the attraction of the company SGS (event 129). Although the partners of Valuepark Terneuzen aimed to attract both chemical production and distribution companies, they only succeeded in attracting companies of the latter type (events 118, 122, 127, 119, $120,121,124,125,130$ and 131); SGS and Biofueling are exceptions). Therefore, the partners decided in 2008 to reserve the remaining land for production companies (event 133). The partners developed plans for an additional park, also next to the Dow complex, where they wanted to concentrate maintenance companies (including knowledge institutes) for the process industry (events 132, 135 and 136). Although the project is based on the same organizational platform, it is considered a separate project by the partners. The sequence of events concerning Valuepark Terneuzen and Maintenance Valuepark Terneuzen is primarily characterized by declarations (in this case agreements) and the establishment of new actors in the park.

This is a significant development in terms of relational capacity, although it is difficult to say to what extent the activities of the companies amount to something that can be called collective action. The main focus is on the creation of economies of scale and increasing the economic and environmental efficiency of logistical activities. Dow is also open to other types of synergies and to joint research and development, but for such activities the establishment of additional production companies is required.

\subsubsection{Interactions between the three developments}

As can be seen in the reconstructions of the three developments, there is no interaction between them in terms of direct linkages between events. In the Vital Sloe Area and Canal Zone project, subtle references were sometimes made to the other developments. For example, the project Residual Stream Couplings was partly inspired by the desire to develop a bio based economy in the southwestern Netherlands, a discussion to which Biopark Terneuzen made a significant contribution. However, there is no clear evidence of direct mutual influences in this regard. The only aspect in which the three developments are clearly interconnected, is that several actors are involved in two, or all three of the developments, such as Zeeland Seaports, the province of Zeeland, the municipality of Terneuzen, Dow, Yara, the University of Applied Sciences of Zeeland, and the Southern Association for Agriculture and Horticulture.

There is no reason to assume that institutional capacity developed in one development is only available within that development. In that sense institutional capacity building has no clear boundaries (cf. Innes and Booher, 1999). Because there is a certain overlap in the actors involved in the three developments, there can be indirect influences between the developments in the sense that institutional capacity built in one is also mobilized in another. For example, Yara and Zeeland Seaports joined forces in the joint venture $\mathrm{WarmCO}_{2}$, even though there is little evidence of earlier interactions between the two within the same sequence of events. However, Yara and Zeeland Seaports inter- 
acted quite regularly in the project Vital Sloe Area and Canal Zone, which gave them good opportunities to maintain and strengthen their relationship, and to exchange their visions on problems and solutions. Thus, even though the two developments unfold more or less autonomously from each other, they contribute to, and are subsequently influenced by overlapping sources of institutional capacity (see figure 6.8).

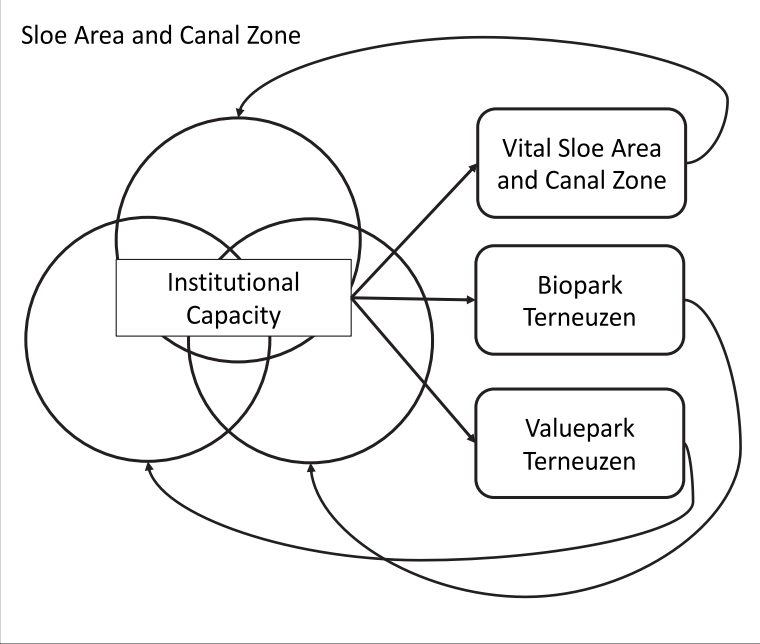

Figure 6.8: The three autonomous developments in the Sloe Area and Canal Zone contribute to, and are influenced by more or less the same sources of institutional capacity.

\subsection{CONCLUSION}

The reconstruction of the event sequences clearly demonstrates that the three developments are driven by very different underlying logics. The project Vital Sloe Area and Canal Zone is driven by a logic of exploration, as the involved actors are continuously exploring different ways to give meaning to the concept of sustainable entrepreneurship. Biopark Terneuzen stands out because it emerged as an entanglement of three more or less autonomous initiatives. The initiative is driven by a logic that is at the heart of the concept of industrial symbiosis, namely the development of a cluster, where firms exchange by-products, and share utilities in order to realize economic and environmental benefits that the participants could not have realized by themselves (Chertow, 2000).

Valuepark Terneuzen is driven by a logic of (orchestrated) agglomeration, as Zeeland Seaports and Dow attract new companies to the site, in order to realize economies of scale and more efficient logistics. The reconstruction reveals no evidence of direct interactions between the three developments, but there is indirect influence between the developments because of (partially) common sources of institutional capacity. Only Biopark Terneuzen contributes directly to the development of a network of symbiotic exchanges, but some aspects of the context that make this development possible are also shaped by the other two developments.

To some extent the indirect influence between the three developments in the Sloe Area and Canal Zone is a reproduction of the pattern observed at the level of the 
Biopark Terneuzen initiative. There, the three initiatives were also driven by different actor coalitions, with a limited overlap in actors involved. Although there was little to no interaction between the three initiatives at first, they each made (unique) contributions to the conditions that made the Biopark Terneuzen initiative possible at the long term. Also, each initiative was driven by a distinct logic, like the three developments at the level of the Sloe Area and Canal Zone. We may ask whether there can be something similar to the Biopark Terneuzen initiative at the level of the Sloe Area and Canal Zone as a whole: An event, or sequence of events that links the three developments in the region together, based on an overarching vision that changes the approach that actors take to the further shaping of the developments. These patterns bear close resemblance to Herbert Simon's (1962) view on the development of complex systems. Simon argues that "[...] complex systems will evolve from simple systems much more rapidly if there are stable intermediate forms than if there are not" (Simon 1962, p. 473). From this perspective, the three subsequences of Biopark Terneuzen can be understood to have produced the stable intermediates for Biopark Terneuzen. At a higher level, Valuepark Terneuzen, Biopark Terneuzen and Vital Sloe Area and Canal Zone may once produce the stable intermediates for an even more comprehensive system at the level of the RIS. This system would combine the qualities of all three developments and give them a new, overarching meaning. This possibility is also suggested by Posch (2005; 2010), who suggests that networks of symbiotic exchanges can serve as the starting point for broader sustainability-oriented cooperation within regions.

This conceptualization of dynamics can be seen as an elaboration of existing models of the evolution of industrial symbiosis. Baas and Boons (2004) emphasize that, over time, regional industrial systems go through distinct stages of regional efficiency and regional learning before arriving at the stage of sustainable districts. Chertow and Ehrenfeld (2012) elaborate this conceptualization to distinguish subsequent development stages of sprouting, uncovering, and embeddedness and institutionalization. In the case of Biopark Terneuzen, the years from 2000 to 2005 could be usefully described as a stage of regional efficiency or sprouting, as actors were developing the intermediate components for Biopark Terneuzen. The Biopark Terneuzen project itself (2006-2007) can be understood as a stage of regional learning, or uncovering, as actors start to see the larger potential of their activities, and the number of actors involved is broadened. The period after the official introduction of the Biopark Terneuzen concept in 2007 can be understood as the stage of sustainable industrial district, or embeddedness and institutionalization, where actors act based on shared strategic visions. What we can add to these models based on the findings presented in this article is the notion of stable intermediate components. These are built in the stage of regional efficiency or sprouting, they are assembled in the stage of regional learning or uncovering, and this makes possible the continued existence of the assembly of components as a whole in the stage of 
sustainable industrial district, or embeddedness and institutionalization (see figure 6.9). Another addition is the idea that the assembly (e.g., Biopark Terneuzen) is itself a possible intermediate for even greater assemblies, such as broader sustainability-oriented cooperation at the regional level (Posch 2005; 2010).

Finally, we add the understanding that the development of industrial symbiosis is embedded in, and therefore shaped by a larger social context (cf. Boons and HowardGrenville 2009a). This larger social context is shaped by multiple developments, of which industrial symbiosis is just one. Even though we can give a useful description of the development of industrial symbiosis in isolation, to understand why actors involved in its development see opportunities to engage in collective action towards industrial symbiosis, we may sometimes need to broaden the scope of analysis to include the other developments that contribute to the conditions under which collective action becomes possible.

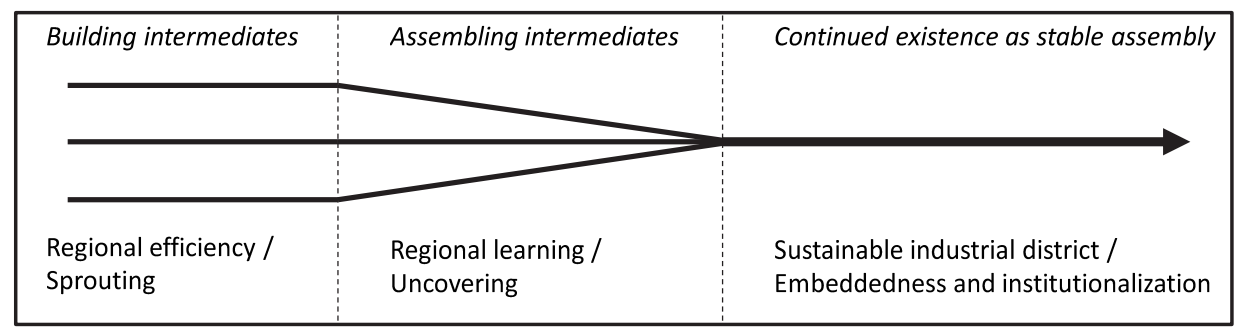

Figure 6.9. Adapted model of the development of industrial symbiosis. 




\section{INTERMEZZZ 4}

NEW TYPES OF RELATIONSHIPS

BETWEEN EVENTS 
The conclusions of chapter 6 represent my first attempt to modify my conceptualization of the process of institutional capacity building. In the conclusions I present the basis for a model of the process of institutional capacity building that is elaborated in much more detail in chapter 7. In many ways the new model is also an attempt to come to grips with some of the findings that were already produced in the analysis of chapter 5 , such as the fragmented nature of the process of institutional capacity building and the abrupt changes that occurred in the constellation of actors involved in the emergence and development of industrial symbiosis.

The model presented in the conclusions of chapter 6 provides the basic skeleton for theoretical advancements made in chapters 7 and 8 . One important question that the model in the conclusions of chapter 6 does not explicitly address yet is what causes different subsequences to grow together into larger assemblies. After working with the qualitative data on my cases for a long period of time I expected that answers to this question could be found in other types of relationships between events. In the analysis that is presented in chapter $5 \mathrm{I}$ had already found that some of the subsequences had overlaps of actors. In addition, based on my qualitative understanding of the cases I knew that the different subsequences that were later assembled together were often quite similar in terms of the types of issues that they addressed, and I had the impression that these similarities made it interesting for actors to tie different developments together. Thus, I already knew that relationships between events other than intentional linkages were important in the process of institutional capacity building too, but I had not yet developed a systematic approach to investigating these other types of relationships.

To find ways to fill this gap in my work I started reading more into the literature on social network analysis. What primarily drew my attention to this literature was the explicit focus on the relationships between entities rather than (for example) the attributes of entities. The explicit focus on the investigation of relationships fitted very well with the challenges that I faced at the time. I started experimenting with social network analysis tools to visualize the relationships between events, actors, and issues. Figure 14 shows the outcomes of experiments that I didn't include in my thesis.

For example, I experimented with the creation of hypergraphs because they offer an efficient way to visualize the relationships of actors to events. However, an analysis of hypergraphs that goes further than visual inspection proved to be difficult, and the visualizations themselves become increasingly difficult to interpret when larger collections of events are considered. I also experimented with a combination of multidimensional scaling analysis and cluster analysis. I developed a procedure (based on scripts of Rcode) in which events are placed in an n-dimensional space ${ }^{37}$ in such a way that their distances in that space are proportional to their dissimilarities (in terms of actors and/

37. The appropriate number of dimensions depends on the fit of the configuration. 
or issues). Through a cluster analysis I identified groups of events in this space that are relatively similar to each other. My aim with this technique was to identify different types of events inductively, based on an interpretation of the dimensions of the space created in the analysis and the location of the clusters of events in this space. The visualization offered in figure 14 is based on an analysis that uses only three dimensions. However, I typically could get a configuration with a good fit only with at least 6 dimensions, which made an interpretation of the results very difficult. Also, I have not yet developed a good approach to the validation of the interpretation of the dimensions.

In addition to experimenting with the aforementioned techniques I experimented with the representation of the relationships between events, actors and issues as multimode networks. The benefits of using such networks are that they are relatively easy to reconstruct and visualize, and that they can be converted to one-mode networks that can be analyzed with more or less conventional techniques of social network analysis. The techniques that I apply in chapter 7 to study the relationships between different subsequences in the process of institutional capacity building ultimately derive from this approach. For the investigation of relationships between subsequences that are based on overlaps of actors I used rather conventional social network analysis methods, such as an analysis of betweenness centrality and clique analysis. I introduced the concept of emergent linkages to study the relationships between events that are based on similarities of the issues that are addressed in the events. The introduction of emergent linkages gave me a way to show that historically independent subsequences can still be similar in
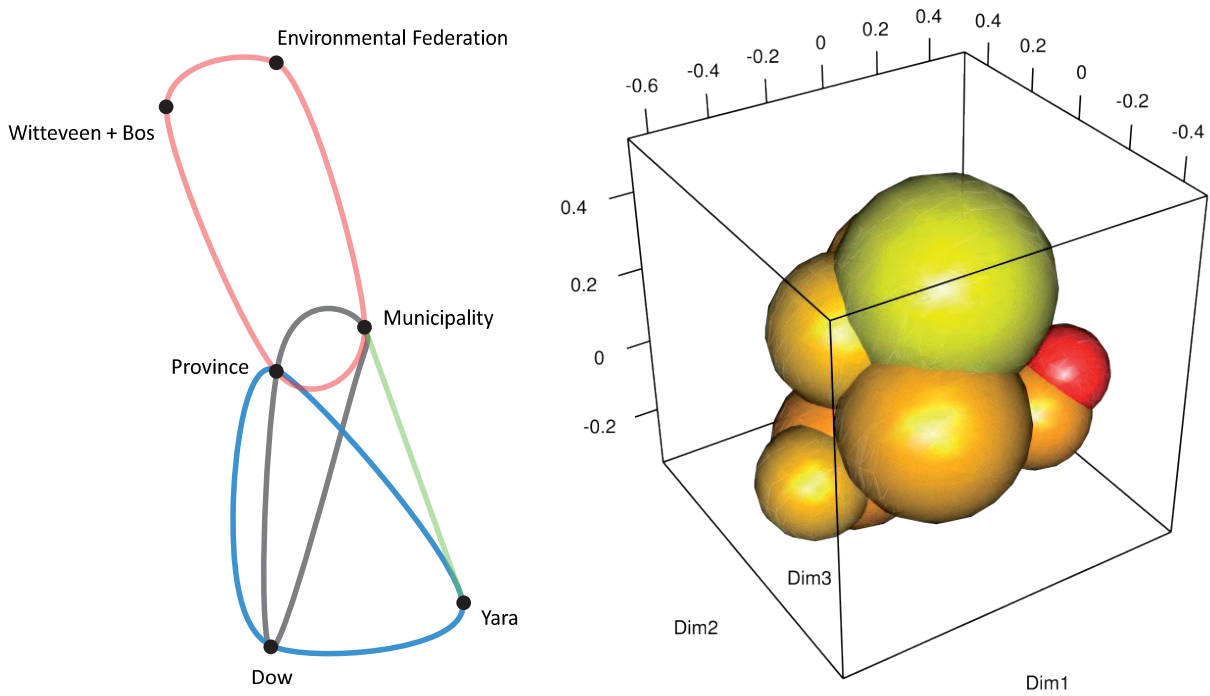

Figure 14: The picture on the left shows a hypergraph visualization of involvement of actors (the nodes) in events (the edges with different colors). The picture on the right shows a visualization of clusters of events, based on their dissimilarities. 
terms of the issues that are addressed in them. This idea became the basis for the concept of an emergent common ground, and I used emergent linkages as an operationalization of this concept. The introduction of these types of relationships between events was a vital step in the further elaboration of my modified conceptualization of the process of institutional capacity building. The modified conceptualization is discussed in greater detail in the conclusions of this thesis (chapter 9). 




\section{CHAPTER 7}

\section{THE EMERGENCE OF COLLABORATIONS}

This chapter has been accepted for publication as Spekkink, W. A. H. and Boons, F. A. A. (in press) The Emergence of Collaborations. Journal of Public Administration Research 


\section{ABSTRACT}

In the literature on collaborative governance it is often assumed that collaborative capacity, i.e., the ability of actors to coordinate their activities around public issues is generated during the collaborative process itself. In this article we show that collaborative capacity can already emerge before the start of collaborations, in the form of a common ground and the bridging position that some actors attain through their involvement in different projects that build up to the collaboration. We introduce a conceptual framework that captures these dimensions of collaborative capacity and we present findings on two case studies to test several propositions, using an approach called event sequence analysis. We find that in both cases a common ground develops before the start of collaborations and strongly influences the aims that are chosen during the collaborations themselves. We also find that actors that attain a bridging position before the collaboration play an important role in assembling building blocks for collaboration together. Our findings have relevance primarily for regional collaborations that involve large numbers of professional organizations. 


\subsection{INTRODUCTION}

The concept of collaborative governance has attracted the attention of a wide range of researchers and practitioners in the field of Public Administration. Induced by environmental turbulence and the failure of single sectors to address increasingly complex public problems (Bryson, Crosby, and Stone 2006), arrangements that bring together actors across sectoral boundaries have emerged in practice to such an extent that they have become an object of study. Currently, there are at least three comprehensive frameworks that aim to integrate the various insights gained on collaborative governance (Ansell and Gash 2008; Bryson, Crosby, and Stone 2006; Emerson, Nabatchi, and Balogh 2012). These frameworks seek to provide an explanation for the differential success of collaborative arrangements. Each framework identifies conditions or qualities that contribute to successful collaboration, such as mutual trust and understanding, leadership, knowledge resources, commitment, and so on. These can be understood as different dimensions of collaborative capacity, that is, the capacity of a group of actors to coordinate activities in a collaborative fashion with the aim of tackling public issues. The various dimensions of collaborative capacity are typically assumed to come about during the collaborative process, as intermediate outcomes of the interactions between the collaborating actors. There is little to no attention for the development of collaborative capacity before the start of the collaborative process. The legacy of previous cooperative or conflictual encounters is taken in consideration in the form of initial conditions (e.g., initial level of trust), but process-oriented studies on the development of collaborative capacity before the start of a collaborative process are lacking.

In this article, we explore the possibility that some dimensions of collaborative capacity develop prior to the collaborative process itself. We describe a mechanism in which the basic building blocks for collaborations are developed in smaller scale projects that are antecedent to collaborations and that unfold in relative autonomy from each other. Instead of capturing these prior influences in terms of initial conditions, we demonstrate the value of taking a dynamical view on these antecedents, and we reveal that the impact that they have on the course of the collaborative process is far greater than is suggested by models that focus on the development of collaborative capacity during the collaborative process itself. Our central research questions are as follows:

1. How do initiatives antecedent to collaborative governance processes contribute to the development of collaborative capacity?

2. What is the influence of these antecedents on the course of the collaborative process itself?

In the next section, we develop the conceptual basis for our investigation, including a set of implications in the form of propositions. We test these propositions in two case studies of collaborative governance processes in the Netherlands. Both cases concern 
collaborations between public and private parties, aimed at the development of sustainable industrial clusters, where companies exchange by-products and share utilities. These initiatives are driven by multiple public purposes, including the reduction of environmental pressures, innovation of the regional economy and the improvement of employment opportunities. As our cases concern two highly similar collaborative processes in the Netherlands, further research on other types of collaborations is required to assess the generalizability of our conceptual argument and our empirical findings. We therefore close the article with suggestions for further research.

\subsection{CONCEPTUAL FRAMEWORK}

\subsubsection{Introduction}

In the literature on collaborative governance, it is usually assumed that collaborative capacity develops largely through direct interactions, based on which actors develop bonds of trust, mutual understanding, and commitment (Ansell and Gash 2008; Bryson, Crosby, and Stone 2006; Emerson, Nabatchi, and Balogh 2012; Susskind, McKearnan, and Thomas-Larmer 1999). At the same time, it is recognized that collaborations usually take place in a context where existing networks and previous collaborations or conflicts influence the initial conditions (Bryson, Crosby, and Stone 2006), starting conditions (Ansell and Gash 2008), or system context (Emerson, Nabatchi, and Balogh 2012) of collaborations. However, little attention is paid to the developmental processes through which these initial conditions come about. Collaborative capacity is usually understood to develop primarily during the collaborative process itself, based on the creation of new ties between actors. We suggest a complementary perspective on the creation of collaborative capacity, based on the idea that collaborations are not necessarily built 'from scratch,' but that they may be assembled from existing, smaller scale projects. Our perspective suggests that some dimensions of collaborative capacity can be drawn from these existing projects, including the common ground that emerges between them, as well as actors that have attained a bridging position between parts of their social network before the start of collaboration. We outline this perspective below.

\subsubsection{The emergence of modular systems}

We draw inspiration from Simon's $(1962,1973,2002)$ theory of the development of nearly decomposable systems. One of its central claims is that complex systems are more likely to emerge if they are built from stable subassemblies, rather than from a large number of elementary components that all have to "fall into place" at once (Heylighen 1989). As a consequence, complex systems often have a modular structure (Cilliers 2001), where stable subassemblies assume a new role as components of the larger system. Instead of 
being completely dissolved into the larger whole, these modules largely retain their own identities. The short-run behavior of any module is approximately independent of that of the other modules, and in the long run, the modules only depend on each other in an aggregate way (Simon 1962; Weick 1976). Our conceptual thinking on the emergence of collaborations was influenced primarily by Simon's account of how complex, nearly decomposable systems come about. The argument that complex systems are difficult to create 'from scratch' has relevance to the investigation of collaborations because the structure of collaborations can also be highly complex (Bryson, Crosby, and Stone 2006; Huxham and Vangen 2000a), especially if the number of participating actors and (as a result) the number of possible relationships increases (Provan and Kenis 2008). Based on the theory of Simon, we suggest that complex collaborations may build up through the assemblage of existing building blocks. Such building blocks consist of smaller projects in which actors coordinate activities to achieve joint goals ${ }^{38}$. These smaller projects may themselves be characterized as (smaller) collaborations, but it is not necessary that the projects are of a collaborative nature. We conceptualize such projects as sequences of intentionally linked events (Van de Ven and Poole 1995). Thus, these building blocks can be understood as subgroups of events. Relatively little attention is paid to the emergence of these building blocks and to the way that they can be assembled into collaborations. One exception is offered by Bardach (2001), who introduces "Craftsmanship Theory." Bardach (2001) envisions individual people as the "raw materials" out of which "craftsmen" may fashion interagency collaborations. This happens in a process that Bardach refers to as "platforming." Bardach compares the process to the building of a house, "with many builders acting independently, but taking account of one another" (Bardach 2001, p. 152). He identifies 10 intermediate building blocks, each representing a different type of collaborative capacity (Bardach 1998). Bardach assumes that the building blocks for collaboration are created intentionally. In our view, this assumption is problematic because it requires the collaboration to be present from an early stage in the form of a blueprint. As an alternative, we suggest that the building blocks of collaborations are often projects that were developed independently from each other. Borrowing Bardach's metaphor, this means that the builders do not take account of one another.

Proposition 1: The building blocks of collaborations develop independently from each other.

If the building blocks develop independently from each other, the question is how they become connected. Here, we see an important role for a dimension of collaborative capacity that does not depend on frequent and direct interactions between actors. 


\subsubsection{Common ground as collaborative capacity}

Boons and Berends (2001) suggest that in the coordination of interorganizational arrangements, a lack of tight coupling between the organizations can be compensated by shared values and beliefs. In the development of collaborations, we see a similar role for common ground. In our definition of the concept, common ground exists if actors involved in different projects address similar issues. Such similarities between large numbers of actors are often attributed to the existence of weak ties (Granovetter 1983). However, we hypothesize that common ground may also develop coincidentally, as actors involved in the different building blocks happen to be working on similar issues at the same time. This may occur even if social ties between the involved actors are entirely absent. We see this emergent overlap as an important dimension of collaborative capacity because it creates a common ground for projects that are otherwise independent. As a result of this emergent common ground, the projects become potential building blocks for collaboration.

Proposition 2: Initiatives antecedent to collaborations become potential building blocks for collaboration by developing a common ground.

The development of a common ground by itself is not sufficient for a collaboration to emerge from the building blocks. The building blocks have to be actively assembled, which requires that some actors involved in the building blocks become aware of the common ground. We suggest that this is most likely to happen if there are actors that are involved in more than one building block. These actors can be understood to have a bridging position, and their involvement in multiple building blocks gives them access to information about these building blocks (Burt 2000, 2001). As result, the act of assembling building blocks into collaborations is likely to be carried out by actors that have attained this position. Here, we see a clear link with facilitative leadership in collaborative governance processes, which is seen as "important for bringing stakeholders together and getting them to engage each other in a collaborative spirit" (Ansell and Gash 2008, p. 554; also see Bryson, Crosby, and Stone 2006; Huxham and Vangen 2000b). We see the existence of actors with a bridging position as a second dimension of collaborative capacity.

Proposition 3: Collaborations are started by actors with a bridging position that respond to the existence of a common ground between otherwise independent building blocks.

The first three propositions deal with the emergence of building blocks and their assemblage into a collaborative process. We now turn to propositions about the collaborative process itself. 


\subsubsection{The modular system in action}

We have defined building blocks as sequences of intentionally linked events in which small groups of actors coordinate their activities to achieve joint goals. Once the collaborative process has commenced, these building blocks are still visible in two ways: First the groups of actors that were active in the building blocks are co-opted into the collaboration in which they function as working groups (Huxham 2000). As a result, the actor network that forms in the collaboration is characterized by the existence of several cohesive subgroups, which are "subsets of actors among whom there are relatively strong, direct, intense, frequent or positive ties" (Wasserman and Faust 1994, p. 249). Second, the building blocks are still visible as identifiable subsequences of events that correspond to the activities of the various working groups. Huxham observes that "working groups operate with varying degrees of autonomy relative to the collaboration" (Huxham 2000, p. 343). The working groups will attend primarily to their own tasks and respond only occasionally to the activities of other working groups. The activities of the various working groups can thus be characterized as parallel sequences of intentionally linked events, where only occasionally there are intentional linkages between these parallel subsequences. This idea reflects Simon's (1962) notion of short-term independence between the different modules of a system.

Proposition 4: During the collaborative process the building blocks are still present as cohesive subgroups within the actor network that emerges from the collaboration.

Proposition 5: During the collaborative process the building blocks are still present as subsequences of intentionally linked events.

To summarize and conclude our conceptual discussion we formulate a proposition that captures the overarching argument that follows from our discussion. When collaborations emerge as an assemblage of building blocks, they build on the common ground that was created by those building blocks. This common ground embodies a dimension of collaborative capacity that was created before the collaborative process commences.

Proposition 6: The generation of collaborative capacity starts already before the collaborative process is initiated. 


\subsection{METHODS}

\subsubsection{Introduction}

The methods that we apply to test our propositions are inspired by longitudinal research approaches developed in sociology (Abbott 2001; Abell 1987) and organizational research (Langley 1999; Poole et al. 2000) and can be understood as a type of longitudinal case study. The central defining characteristic of our approach is that sequences of events serve as the basis for all our analyses (Boons, Spekkink, and Jiao 2014). Data are collected and recorded in event sequence datasets in which events are listed in chronological order, represented by one or more qualitative descriptions of actions and interactions. In our research, events refer to actions and interactions that actors engage in before and during collaborative governance processes. An event may, for example, concern a meeting (sometimes several) in which actors discuss problems and the possible solutions for them, the signing of declarations of intent or cooperation, the presentation of a plan or vision, engagement in a research project (or the presentation of its results), and activities undertaken to implement plans, such as the construction of a new facility, or the start of an exchange between businesses. Occasionally, an event may refer to something that happened in the context of the collaborative process, such as decisions by the national government to change policies.

\subsubsection{Data collection}

The two processes we analyze in this study are longitudinal case studies that cover the period of 1997 to 2012. Both case studies are captured in event sequence datasets that we developed in the spirit of Poole and colleagues (2000). We recorded our data as chronologically ordered, brief qualitative descriptions of actions and interactions. We refer to these descriptions as incidents. Each incident has a time stamp, and for each incident, we recorded the source of the data (see below). For both cases, we also made a second type of dataset in which we recorded metadata on each of our sources. The metadata include the date on which a source was found, the URL address of the source at that time, the host of the website or the publicist of the document, and usually a very brief summary of the contents of the source. Each source is given a unique identification number that is used as a reference in the event sequence dataset. The dataset with metadata also records information about the keywords that we used in our searches and a justification of those keywords. To create the event sequence dataset, we read through all the collected documents, web pages and news items, and when relevant information was found, we manually entered this information in the event sequence dataset by writing an incident description. Incidents were later grouped together if they could be understood to refer to the same event. Typically, incidents that are grouped together concern multiple observations (from different sources) of the same interaction. 
Our sources of data include web pages, various types of documents produced by the actors involved in the developments of interest (e.g., plans, study reports, visions, meeting agendas and reports, and etcetera), and newspaper articles. For the collection of web pages and documents, we performed searches with the Google search engine, and for the collection of newspaper articles, we made use of the LexisNexis dataset, which in this case includes Dutch national and regional newspapers that have been published since 1990. Prior to the data collection process, we developed a protocol, which consists out of a number of rules that we followed during data collection ${ }^{39}$. For our initial searches, we used general search terms (e.g., the name of the case of interest). The data that we found in this way provided us with new leads, which we translated into new search terms that were used in follow-up searches. We continued this process until we found that our searches did not uncover any previously unknown developments that we deemed relevant to the case of interest. We recorded the keywords that we used in our metadataset, accompanied by a justification of their use.

The data collection process for the developments in Zeeland started January 27, 2011, and ended April 26, 2012. An additional round of data collection was performed from December 13, 2012, to September 11, 2013. In total, 368 web pages, 250 documents, and 1,134 news items were collected, although there is overlap in the news items that were found throughout different searches. In addition, not all of the collected sources proved to be relevant, and some of them have not contributed to the compilation of the event sequence dataset. The data collection process for Moerdijk started September 10, 2012, and the last data were added on October 11, 2013. In total, 171 web pages were collected, 143 documents, and 1,620 news items (again, with overlap). In this article, we focus on two collaborations that occurred in the investigated regions, which are Biopark Terneuzen in Zeeland and Sustainable Connections in Moerdijk. Our datasets cover additional developments that we do not include in the analysis presented in this article. These are other interaction processes that we collected data on, but of which we later found that they are not directly related to the collaborative processes of interest to the study presented here ${ }^{40}$. The total number of events considered for the analysis of Biopark Terneuzen is 219. For Sustainable Connections, the total number of events is 196.

\subsubsection{Analysis}

To prepare our event data for analysis, we use qualitative coding procedures to code for theoretically relevant aspects of our event data (Boeije 2010). Based on the information

39. An example rule is that for each web search (using the Google search engine) we checked the first 10 pages of search results.

40. Thus, in our data collection process we started with a very broad scope, based on the philosophy that it would be better to include sequences of events that would later turn out not to be directly related to the specific processes of interest, rather than finding out later that crucial sequences of events are missing. 
provided in the coded event data, we develop two types of graphs on which we base our analysis. The first type is an event graph, which is similar to Abell's $(1984,1987)$ narrative graphs. The event graph gives three types of information:

1. The order of events (visualized as nodes) indicated by their distribution on a horizontal axis;

2. intentional linkages between events (visualized as arcs)—an intentional linkage exists between two events if the actors that participate in one event intentionally respond to conditions that are created in the other event (see figure 7.1) (Van de Ven and Poole 1995);

3. emergent linkages between events (visualized as edges)_an emergent linkage is present between two events if (a) the events are not connected by a path of intentional linkages, and (b) the events are similar in the sense that they address the same issue(s).

By definition, an emergent linkage cannot exist between two events if the same events are somehow connected by a path of intentional linkages. Our reason for defining emergent linkages in this way is that, in the case of emergent linkages, we are primarily interested in similarities between events that are unintended. When events are intentionally linked, their similarity is most likely to be the result of 'inheritance'. For

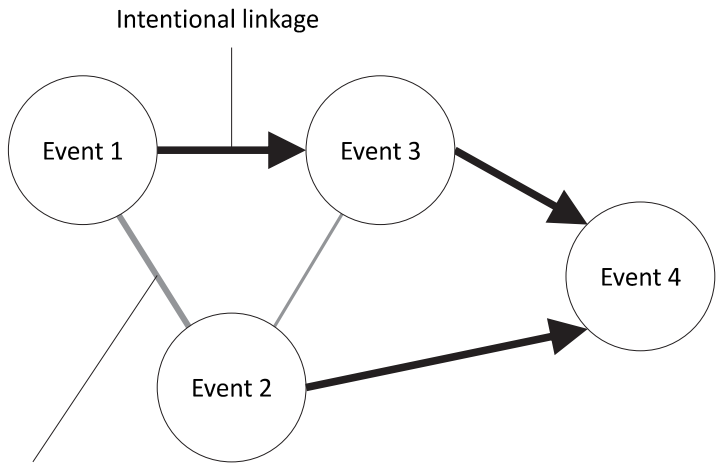

Emergent linkage

Figure 7.1: Intentional (arcs) and emergent (edges) linkages between events represented in a graph. The thickness of the edge represents the strength of event similarity. example, if a plan is developed (event A), which is implemented at a later point in the sequence (event B), the similarity of the issues that events $A$ and $B$ address is intentional. However, if two events concern the independent development of plans that happen to address the same issues, then we consider the similarity of the two events to be emergent.

The second type of graph is a two-mode graph, which we use to visualize the relationships of actors and issues to building blocks of the collaboration, as well as to the various subsequences that exist during the collaboration itself. In addition to analyzing these two graphs, we perform analyses of the networks of actors, and the networks of issues that form before and during the collaborative process. We do not visualize these networks, but we report our measurements in tables. 
Table 7.1 offers an overview of our propositions, and it shows for each proposition which type of analysis is used and which patterns we expect to observe if our propositions hold. In the remainder of this section, we explain the techniques that we used in our analysis in more detail.

Table 7.1: Summary of propositions and indicative patterns used to evaluate the propositions.

\begin{tabular}{|c|c|c|}
\hline Proposition & $\begin{array}{l}\text { Graph/ } \\
\text { Network }\end{array}$ & Indicative Pattern \\
\hline $\begin{array}{l}\text { Proposition 1: The building blocks of } \\
\text { collaborations develop independently from } \\
\text { each other. }\end{array}$ & Event graph & $\begin{array}{l}\text { Several subsequences exist before the collaboration and } \\
\text { intentional linkages between them are absent until they } \\
\text { converge on the collaborative process. }\end{array}$ \\
\hline \multirow{3}{*}{$\begin{array}{l}\text { Proposition 2: Initiatives antecedent to } \\
\text { collaborations become potential building } \\
\text { blocks for collaboration by developing a } \\
\text { common ground. }\end{array}$} & Event graph & $\begin{array}{l}\text { Emergent linkages exist between subsequences before } \\
\text { they converge on the collaborative process. }\end{array}$ \\
\hline & $\begin{array}{l}\text { Two-mode } \\
\text { graph }\end{array}$ & $\begin{array}{l}\text { There are one or more issues that have relationships to all } \\
\text { subsequences that converge on the collaborative process. }\end{array}$ \\
\hline & Issue network & $\begin{array}{l}\text { The issues that are addressed during the collaborative } \\
\text { process have a high closeness centrality before the } \\
\text { process starts. }\end{array}$ \\
\hline \multirow{2}{*}{$\begin{array}{l}\text { Proposition 3: Collaborations are started by } \\
\text { actors with a bridging role that respond to } \\
\text { the existence of a common ground between } \\
\text { otherwise independent building blocks. }\end{array}$} & $\begin{array}{l}\text { Two-mode } \\
\text { graph }\end{array}$ & $\begin{array}{l}\text { The actors that initiate the collaboration are related } \\
\text { to more than one subsequences that precede the } \\
\text { collaborative process. }\end{array}$ \\
\hline & Actor network & $\begin{array}{l}\text { The actors that initiate the collaboration have a high } \\
\text { betweenness centrality before the collaborative process } \\
\text { starts. }\end{array}$ \\
\hline $\begin{array}{l}\text { Proposition 5: During the collaborative } \\
\text { process the building blocks are still present } \\
\text { as cohesive subgroups within the actor } \\
\text { network that emerges from the collaboration. }\end{array}$ & Actor network & $\begin{array}{l}\text { Several distinct subgroups with high valued relationships } \\
\text { exist at the same time. }\end{array}$ \\
\hline $\begin{array}{l}\text { Proposition 5: During the collaborative } \\
\text { process the building blocks are still visible as } \\
\text { subsequences of events. }\end{array}$ & Event graph & $\begin{array}{l}\text { Several subsequences exist during the collaboration, with } \\
\text { more intentional linkages within the subsequences, than } \\
\text { between the subsequences. }\end{array}$ \\
\hline $\begin{array}{l}\text { Proposition 6: The generation of } \\
\text { collaborative capacity starts already before } \\
\text { the collaborative process is initiated. }\end{array}$ & Multiple & $\begin{array}{l}\text { For this proposition to be supported, the indicative } \\
\text { patterns associated with propositions } 2 \text { and } 3 \text { have to } \\
\text { hold. }\end{array}$ \\
\hline
\end{tabular}

\section{Event Graphs}

The first type of linkages between events that we visualize in event graphs is the intentional linkage. We identified intentional linkages through qualitative coding of our event descriptions, where we checked for references made in the descriptions to earlier events. For example, if we find an event where a feasibility study is performed on a plan that was developed in an earlier event, then we draw an intentional linkage between these two events.

In our conceptual discussion, we defined building blocks as intentionally linked sequences of events. We visualize these building blocks as subsequences in the event graph, using shaded fields to indicate which events belong to the same building block. To 
identify these building blocks, we took the following steps: We first perform an analysis of the modularity of our event graph, using an algorithm that reports a number between 0 and 1 , which is a measure of how well the graph can be divided into different groups of nodes, based on their patterns of interconnection (Blondel et al. 2008; Newman 2006). The algorithm also partitions the nodes into the different groups that have been identified. Applying this algorithm gives us first indications of (1) the extent that distinguishable building blocks do indeed exist (based on the measure of modularity), and (2) which events belong to the same building block (based on the resulting partitions). We take the results of the algorithm as the starting point for our next step, which is our qualitative assessment of the existence of different building blocks, based on our interpretation of the underlying event data. For example, some groups of events identified by the modularity algorithm can be interpreted as different phases in the development of the same building block and can therefore be grouped together. Also, based on our qualitative interpretation of the events, we sometimes moved events to another building block than was suggested by the results of the modularity algorithm. In Tables A7.1, A7.2, A7.4, and A7.5 (Annex 2), we report all events that we moved to another building block.

We used the exact same procedure to identify and visualize the projects that developed after the formal start of the collaborative process. Once the building blocks have been identified, it is also possible to assess the extent to which interactions between these building blocks exist, based on the number of intentional linkages that exist between them.

The second type of linkages that we consider are emergent linkages. To reconstruct emergent linkages, we identified the issues addressed in events through qualitative coding of the event descriptions. We stayed close to the data; no attempt was made to abstract our codes to more general theoretical categories, and we only coded for issues that were explicitly mentioned in the descriptions. We coded each dataset twice in order to remove any inconsistencies that were created in the first round of coding. The similarities themselves were calculated from an incidence matrix (see figure 7.2). The similarities between events were identified by calculating the correlations between all the column profiles of the incidence matrix in Ucinet, which uses Pearson's product-moment correlation. The algorithm in Ucinet produces a correlation matrix. The correlation matrix in figure 7.3 is based on the incidence matrix of figure 7.2. Positive correlations indicate similar column profiles (a correlation of 1 means that they are exactly the same), whereas negative correlations indicate dissimilar column profiles (a correlation of -1 means that they are exact opposites). A correlation of 0 means that knowing the issues addressed in one event does not help us at all in guessing what the relationship of the other event to these issues might be (Hanneman and Riddle 2005). In this study, our focus is only on similarities because similarities are our indicators for emergent linkages. Therefore, we filtered out all negative correlations from our visualization of the emergent linkages. This filtering 


\begin{tabular}{|c|c|c|c|}
\hline & Event 1 & Event 2 & Event 3 \\
\hline Environment & 1 & 0 & 1 \\
\hline Reuse & 1 & 1 & 1 \\
\hline Heat & 1 & 0 & 0 \\
\hline Water & 0 & 1 & 1 \\
\hline
\end{tabular}

Figure 7.2: Fictional example of incidence matrix.

\begin{tabular}{|c|c|c|c|}
\hline & Event 1 & Event 2 & Event 3 \\
\hline Event 1 & 1.00 & -0.577 & -0.333 \\
\hline Event 2 & -0.577 & 1.000 & 0.577 \\
\hline Event 3 & -0.333 & 0.577 & 1.00 \\
\hline
\end{tabular}

Figure 7.3: Correlation matrix based on incidence matrix in figure 6.2. can be done in Gephi, which is the software that we used to produce our visualizations. In Gephi, a filter can be set up to only show edges (the correlations are visualized as edges) that have a positive value attached to them. The similarities are visualized as edges in the event graphs (see figure 7.1), where the strength of the correlation between two events determines the thickness of the edge.

\section{Two-mode network graphs}

The second type of graph included in our analysis is a two-mode graph, also known as a bipartite graph. In a two-mode graph, the nodes are partitioned into two types that are called modes. In our case, one mode represents the subsequences that we identified in our event graphs, and the second mode represents actors and issues. The relationships in the graph visualize the participation of actors and issues in different subsequences. These graphs offer a quick overview of the actors and issues that are common to different subsequences, as well as the actors and issues that are unique to a particular subsequence. We use the two-mode graphs to get a more specific overview of the issues and actors that different building blocks in the process that we investigate have in common. This allows us to study the emergent linkages that are visualized in the event graphs in more detail; the event graphs only indicate that events address similar issues, and the two-mode graph indicates which specific issues this concerns.

\section{Analysis of actor networks}

Parts of our conceptual discussion concern the structure of the actor network that exists before and during the collaborative process. We identify actors by studying the descriptions of the events and adding codes for each actor that is reported to be involved. We then reconstruct the actor network by examining which actors jointly participated in events. The strength of the relationships between two actors is determined by the number of times that they were involved in the same events. Thus, the networks that we reconstruct are one-mode networks based on joint affiliations (Borgatti and Halgin 2011), and we use measures for one-mode networks to perform our analyses of our actor networks. 
One specific characteristic of the structure that we investigate is the extent to which there are actors with a bridging position, that is, a position where they connect different parts of the actor network. Bridging actors can be identified visually, based on an inspection of the relationships between actors and subsequences that we show in our two-mode graphs. However, to strengthen our analysis, we also calculate the betweenness centrality for all actors in the network that exists before the collaboration ${ }^{41}$. If actors are in a bridging position, then their betweenness centrality will be relatively high (Burt 2000; Freeman 1978). We report our measures of betweenness centrality in tables, and we normalize our measures by making them proportional to the theoretical maximum (Freeman 1978; Wasserman and Faust 1994). Another relevant characteristic of the actor network is the existence of cohesive subgroups during the collaborative process. In this study, we define subgroups as maximally connected subgraphs that include at least three nodes (Wasserman and Faust 1994). To study the existence of cohesive subgroups, we use a method that is developed especially for networks that are the result of joint affiliations (Doreian 1969; Wasserman and Faust 1994). Because the relationships in the network are valued, it is possible to identify subgroups at different levels of $c$, where $c$ represents the number of events in which the actors participated. Thus, a subgroup that exists at a level $c=5$ is a subgroup of actors that have jointly participated in at least five events. In a subgroup, all actors have to be connected to each other. We only consider subgroups with least three members. Also, because we are interested in subgroups that occur relatively often, we focus specifically on subgroups that exist at higher levels of $c$.

\section{Analysis of issue networks}

In the two-mode graphs, we are able to show the common ground that is created by different building blocks through a visualization of the relationships between building blocks and issues. To strengthen our analysis of the common ground, we also study which issues are the most central before the collaborative process starts. To this end, we first reconstruct an issue network as a one-mode network. Similarly to the actor network, issues in the issue network are linked if they appeared together in an event. After reconstructing the issue network, we examine which issues are the most central by calculating their closeness centrality. Closeness centrality is high for issues that are relatively closely connected to all other issues (Freeman 1978).

41. For our calculations of centrality, we used the 'sna' package that isavailable for R (Butts 2014). 


\subsection{CASE STUDIES}

\subsubsection{Introduction}

In our discussion of the findings from our case studies we focus on the broader patterns that are relevant for testing our propositions. More detailed descriptions of the subsequences can be found in Annex 2. In this section we offer a brief introduction to our cases, followed by a presentation of our findings.

\subsubsection{Biopark Terneuzen}

Biopark Terneuzen is an initiative that was formally started in the Canal Zone of Zeeland in February 2007. In this initiative several governmental organizations (the port authority Zeeland Seaports, the province of Zeeland, and the municipality of Terneuzen), companies and knowledge institutes work together to link agricultural and industrial activities in order to improve the environmental and economic performance of the involved companies and the region as a whole (including the creation of employment opportunities). The emphasis of the project is on the development of residual material exchanges between companies, the primary example being the supply of residual heat and $\mathrm{CO}_{2}$ from a fertilizer company (Yara) to greenhouses in a greenhouse area that was in development at the time that Biopark Terneuzen was started. Other projects included in the initiative were a by-product exchange between Nedalco and Cerestar (already implemented before the start Biopark Terneuzen), the construction of three biofuel factories (Heros/Rosendaal Energy, Nedalco, and Biofueling), a biomass plant (Heros/Ecoservice Europe), and the shared use of a water treatment installation (Heros).

The formal start of Biopark Terneuzen was preceded by a couple of meetings in which a wide diversity of actors was brought together in the context of a TransForum ${ }^{42}$ project that explored the feasibility of Biopark Terneuzen. By 2012 the supply of residual heat and $\mathrm{CO}_{2}$ from the fertilizer company to four greenhouses had been realized. A joint venture called $\mathrm{WarmCO}_{2}$ had been established to develop the pipeline infrastructure for this and to govern the contracts. The biomass plant that was included in the plan was under construction and plans for a second biomass plant had been made. The plans for two of the biofuel factories (Nedalco and Biofueling) had been cancelled after it became clear in 2008 that the national government would not support biofuel production. A third biofuel plant (Rosendaal Energy) had already been constructed, but the company went bankrupt, due to the changing stance of the national government towards biofuels and due to the economic crisis. The company was taken over by Electrawind Biofuels in 2012.

42. TransForum was a government-funded innovation program in which governments, companies, knowledge institutes and societal organizations cooperated to stimulate innovative projects. 


\subsubsection{Sustainable Connections}

Sustainable Connections started in April 2009 at the industrial park of Moerdijk. It is a collaboration between governmental organizations (the port authority of Moerdijk, the province of Noord-Brabant, the municipality of Moerdijk, the department of waterways and public works, and the water authority Brabantse Delta), and the Business and Industry Circle Moerdijk (BIM). Sustainable Connections largely revolves around the construction of a pipeline infrastructure that makes possible the circulation of energy (primarily in the form of heat), $\mathrm{CO}_{2}$ and water at the industrial park. The project partners formulated several concrete ambitions, such as the development of an infrastructure for the exchange of heat between companies at the industrial park, the improvement of permit procedures, the supply of residual heat and $\mathrm{CO}_{2}$ to greenhouses in the nearby Spiepolder, the improvement of employment opportunities and improvement of communication with the direct environment. By 2012 steps had been made in several of these concrete ambitions. Part of the infrastructure for the exchange of heat had been realized, largely thanks to a private initiative on which the collaborating partners could build. The partners experimented with new permit procedures to speed up the permit process. For the improved communication with the direct environment a Neighbors council had already been set up in another context (before the Sustainable Connections initiative started). The supply of residual heat and $\mathrm{CO}_{2}$ to the Spiepolder had not yet been realized, but was still on the agenda by the end of 2012. In addition, there were plans to supply residual heat to a second industrial park (for logistical companies) that was to be developed near the existing one. The Sustainable Connections initiative is still in progress. In 2011 the collaborating partners signed a renewed agreement for the period of 2011-2015 and another initiative for sustainable development in the region (Sustainable Port and Industry Area) was integrated in the Sustainable Connections initiative. This second initiative dealt primarily with communication with the environment (e.g. registration of complaints from neighboring residents), monitoring of the environmental performance of the industrial park (an environmental monitoring report was published on a yearly basis), and the exchange of knowledge and the optimization of water loops at the industrial park.

\subsubsection{The building blocks of the collaborations}

The event graphs that visualize the antecedents of Biopark Terneuzen and Sustainable Connections are shown in figure 7.4. In the event graph for Biopark Terneuzen, events $246,254,279$, and 286 are not included in any building block because events 246, 254, and 279 are meetings that are part of the official preparations for Biopark Terneuzen, and event 286 is the formal start of the collaboration itself. We interpret these events as part of the collaborative process (see figure 4.7) and not as part of one of the building blocks that developed before the collaborative process. In the event graph for Sustain- 
able Connections, the event that marks the start of the Sustainable Connections collaboration (event 321) is not included in any of the building blocks for the same reason. As explained in the methods section, some events were reassigned to another building block based on our qualitative interpretation of the events. For example, event 281 was originally included in a building block that represents the development of an alcohol factory of Nedalco, but based on our qualitative information on event 281, we know it concerns a decision to put the development plan for the greenhouse area in display. We therefore reassigned it to the corresponding building block (building block 1-A).

The event graphs in figure 7.4 show that both collaborations were preceded by multiple, largely independent subsequences of events. These subsequences are public and private projects that are driven by various actor constellations, and for various purposes. Not all of these building blocks were necessarily included in the collaborative processes that followed. In the case of Biopark Terneuzen, the plans for the biofuel plant, which were introduced as part of Valuepark Terneuzen (subsequence 1-C), were eventually withdrawn. In the case of Sustainable Connections, the development of the chicken manure incineration plant (subsequence 2-A) was repeatedly linked to potential residual material exchanges, but it was never included in the collaborative process. The development of the asbestos processing facility (subsequence $2-\mathrm{H}$ ) was eventually cancelled. Finally, while the Neighbors Council (subsequence 2-G) became one of the major communication channels for the collaborating parties in Sustainable Connections, it never became a fully integrated part of the collaboration.

Figure 7.5 shows the same sequences of events but with the emergent linkages. The event graphs in figure 5 show that the building blocks addressed similar issues from their early stages, indicating that a common ground was already developing before intentional linkages between the various subsequences existed. What types of issues constitute this common ground cannot be read from the event graphs themselves, but more details on this are offered in the two- mode graphs of figure 7.6, which show the involvement of actors and issues in the different building blocks.

In figure 7.6 issues that the building blocks have in common are situated in the middle area of the graph. Issues that are unique to building blocks are situated on the outside. In the case of Biopark Terneuzen, examples of issues that are part of the common ground are Reuse (161), Use of Space (172), Infrastructure (142), Logistics (146), Employment (129), Economy (127), and Environment (131). In the case of Moerdijk, examples of issues that are part of the common ground are Reuse (I144), Heat (I114), Environment (I99), Water (I159), Permits (I135), and Logistics (I122). Based on the qualitative descriptions of the events, we know that these issues do not arise because of an overarching plan, but they arise independently, as part of the plans that actors develop in the different initiatives. In all events, multiple issues are connected to each other. For example, Reuse is often tied to the ambition of actors to reduce their impact on the Environment. Also, Reuse is usually 

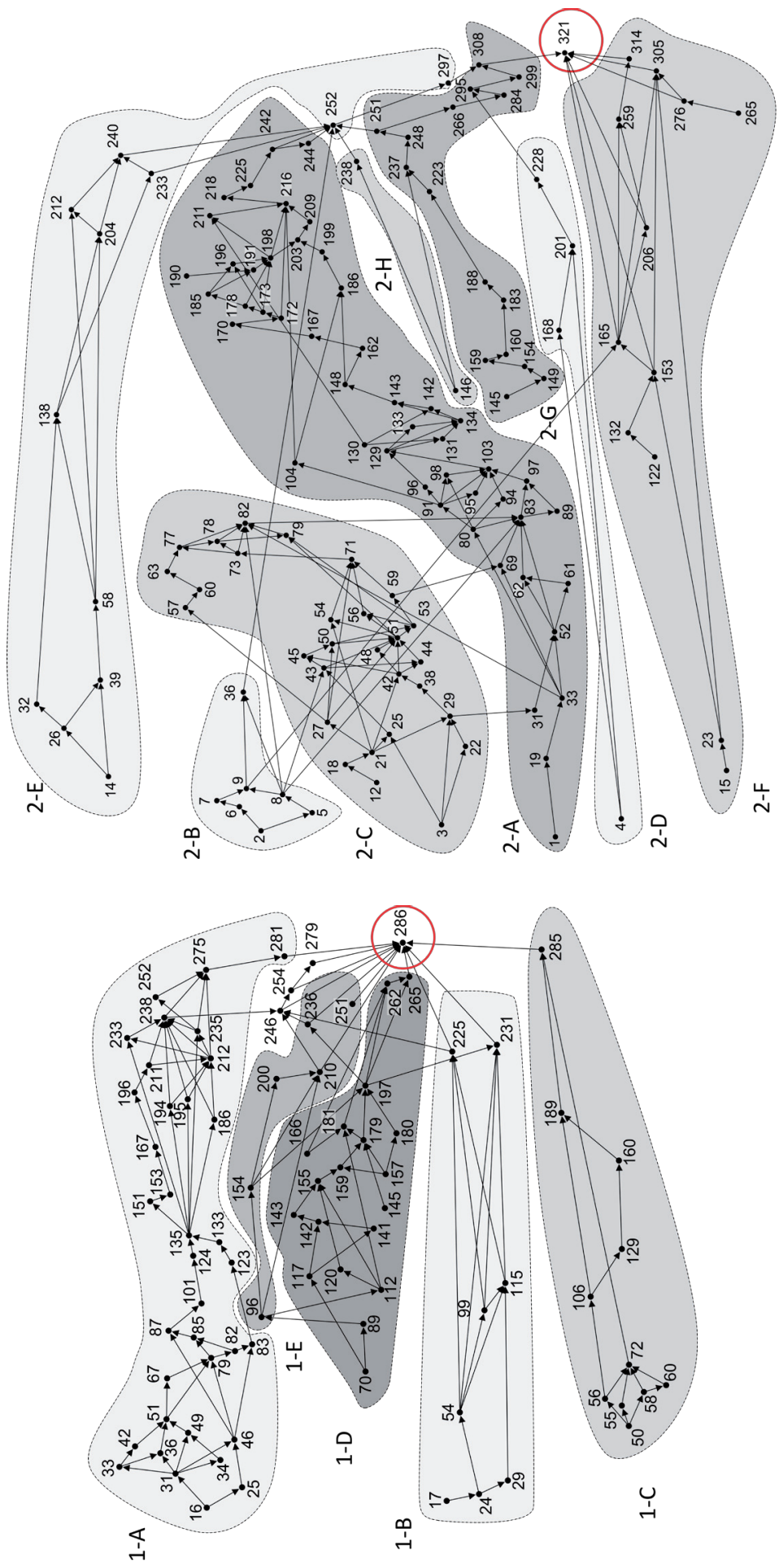

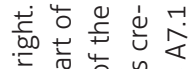
요요

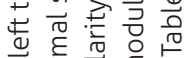

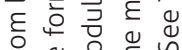
일워

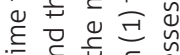

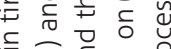

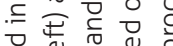
บ 옥 는 ปั

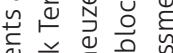
ब

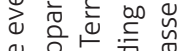
\& 음든

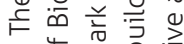

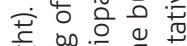

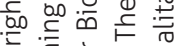

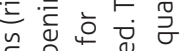
气ั 은

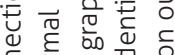
है

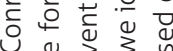

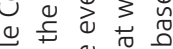

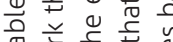

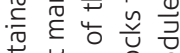
苛茂응

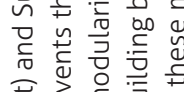
ङ

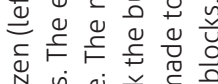
N

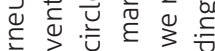
む)

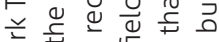
T.

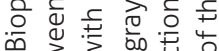

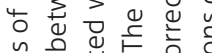

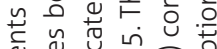
离

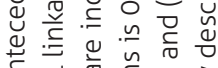
品

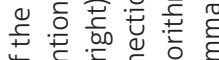

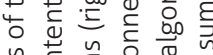
जั

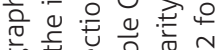
50.

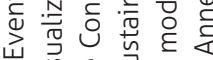
山.

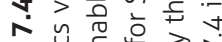

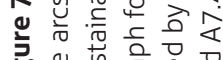

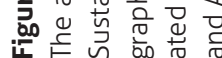




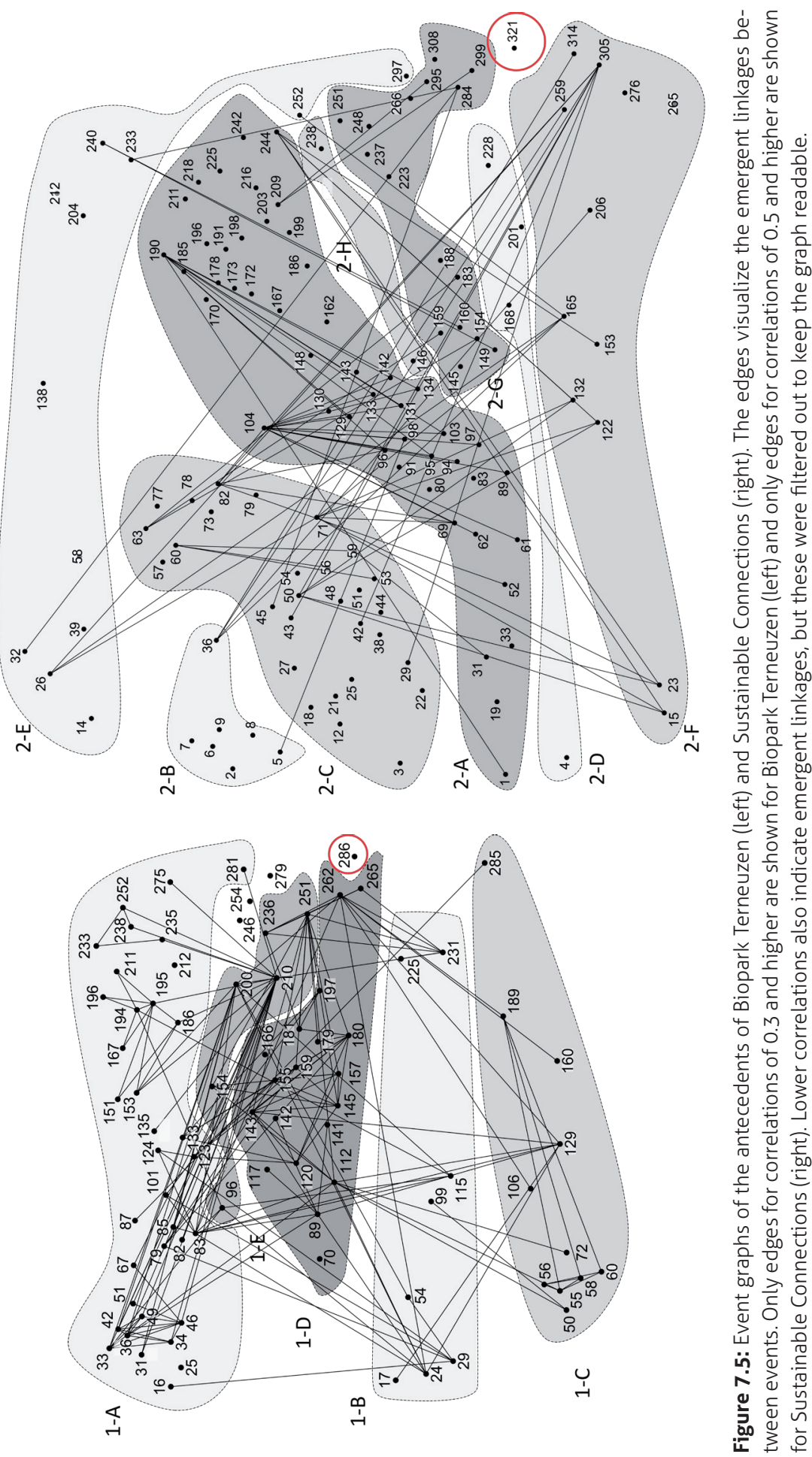


tied to different kinds of material and energy flows, such as Heat, Water, and $\mathrm{CO}_{2}$. Through these connections, networks of issues are formed. We reconstructed these networks (as one-mode networks) to examine the issues that are most closely connected to other issues, using closeness centrality as our measure. Table 7.2 shows the top ten most central issues for Biopark Terneuzen, and table 3 shows them for Sustainable Connections. Both tables also indicate in which building blocks these central issues are featured. Many of the most central issues in tables 7.2 and 7.3 are also issues that feature in most of the building blocks, that is, they are part of the common ground. The most central issues are also the issues that are typically included as central aims of the collaborations. This includes the issues Reuse, Infrastructure, Employment, Greenhouses, Biofuels, and $\mathrm{CO}_{2}$ for the case of Biopark Terneuzen and Energy, Reuse, Heat, $\mathrm{CO}_{2}$, Permits, and Water for the case of Sustainable Connections (see Introduction to the cases for an overview of the

Table 7.2. Top ten most central issues in building blocks for Biopark Terneuzen. The capitalized letters refer to subsequences.

\begin{tabular}{|c|c|c|c|c|c|c|c|}
\hline Name & Label & Closeness Centrality & 1-A & 1-B & $1-C$ & 1-D & $1-\mathrm{E}$ \\
\hline Reuse & 161 & 0.84 & $x$ & $x$ & & $x$ & $x$ \\
\hline Use of Space & 172 & 0.79 & $x$ & $x$ & $x$ & $x$ & \\
\hline Infrastructure & 142 & 0.78 & $x$ & $x$ & $x$ & $x$ & \\
\hline Employment & 129 & 0.73 & $x$ & $x$ & & $x$ & $x$ \\
\hline Environment & 131 & 0.70 & $x$ & $x$ & $x$ & & $x$ \\
\hline Greenhouses & 139 & 0.70 & $x$ & & & & $x$ \\
\hline Logistics & 146 & 0.68 & $x$ & & $x$ & $x$ & \\
\hline Regional Economy & 156 & 0.68 & $x$ & & $x$ & $x$ & $x$ \\
\hline Biofuels & 19 & 0.67 & & $x$ & $x$ & $x$ & $x$ \\
\hline $\mathrm{CO}_{2}$ & 117 & 0.67 & $x$ & & & & $x$ \\
\hline
\end{tabular}

Table 7.3. The most central issues in the building blocks for Sustainable Connections. The capitalized letters refer to subsequences.

\begin{tabular}{|c|c|c|c|c|c|c|c|c|c|c|}
\hline Name & Label & Closeness Centrality & $2-A$ & $2-B$ & $2-C$ & 2-D & $2-E$ & $2-F$ & $2-G$ & $2-\mathrm{H}$ \\
\hline Energy & 197 & 0.89 & $x$ & $x$ & $x$ & $x$ & $x$ & $x$ & & \\
\hline Reuse & 1144 & 0.85 & $x$ & $x$ & $x$ & $x$ & $x$ & $x$ & $x$ & $x$ \\
\hline Environment & 199 & 0.84 & $x$ & $x$ & $x$ & & $x$ & $x$ & $x$ & \\
\hline Heat & |114 & 0.82 & $x$ & $x$ & $x$ & $x$ & $x$ & $x$ & & \\
\hline $\mathrm{CO}_{2}$ & 187 & 0.78 & $x$ & & $x$ & $x$ & $x$ & $x$ & & \\
\hline Permits & 1135 & 0.76 & $x$ & $x$ & & $x$ & & $x$ & & $x$ \\
\hline Wastes & 1158 & 0.75 & $x$ & $x$ & $x$ & $x$ & $x$ & $x$ & & \\
\hline Sustainability & 149 & 0.73 & $x$ & $x$ & $x$ & & $x$ & $x$ & & \\
\hline Water & 1159 & 0.73 & $x$ & $x$ & $x$ & & $x$ & $x$ & & \\
\hline Use of Space & 1155 & 0.71 & $x$ & & & & $x$ & $x$ & & \\
\hline
\end{tabular}




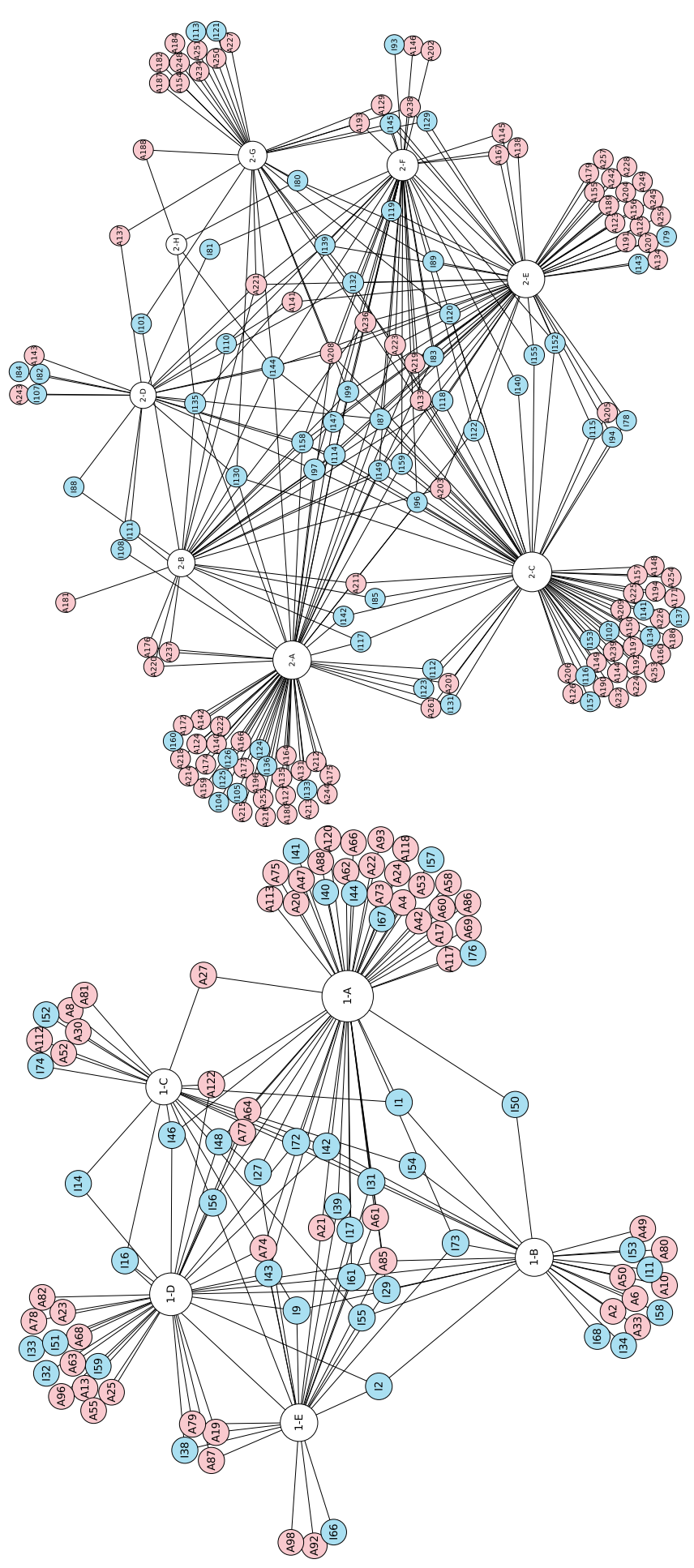

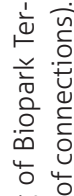

$\stackrel{\infty}{\subseteq}$

号 है

है

는

$\stackrel{\square}{\rightleftarrows}$

는

จ

ํํ

음

مै

$\frac{\pi}{\frac{7}{2}} \frac{0}{8}$

这

产

兵

$\subseteq \stackrel{1}{n}$

a n

जै

它

든

号

苋.

पू पे

듷

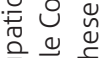

은 훙

동

空 气

空

a 4 范

起节京

袺 $\frac{n}{0}$

$\approx$ है

흔후

总焉

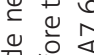

둥 प

है

文

焉这

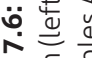

o $\frac{1}{0}$

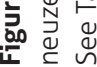




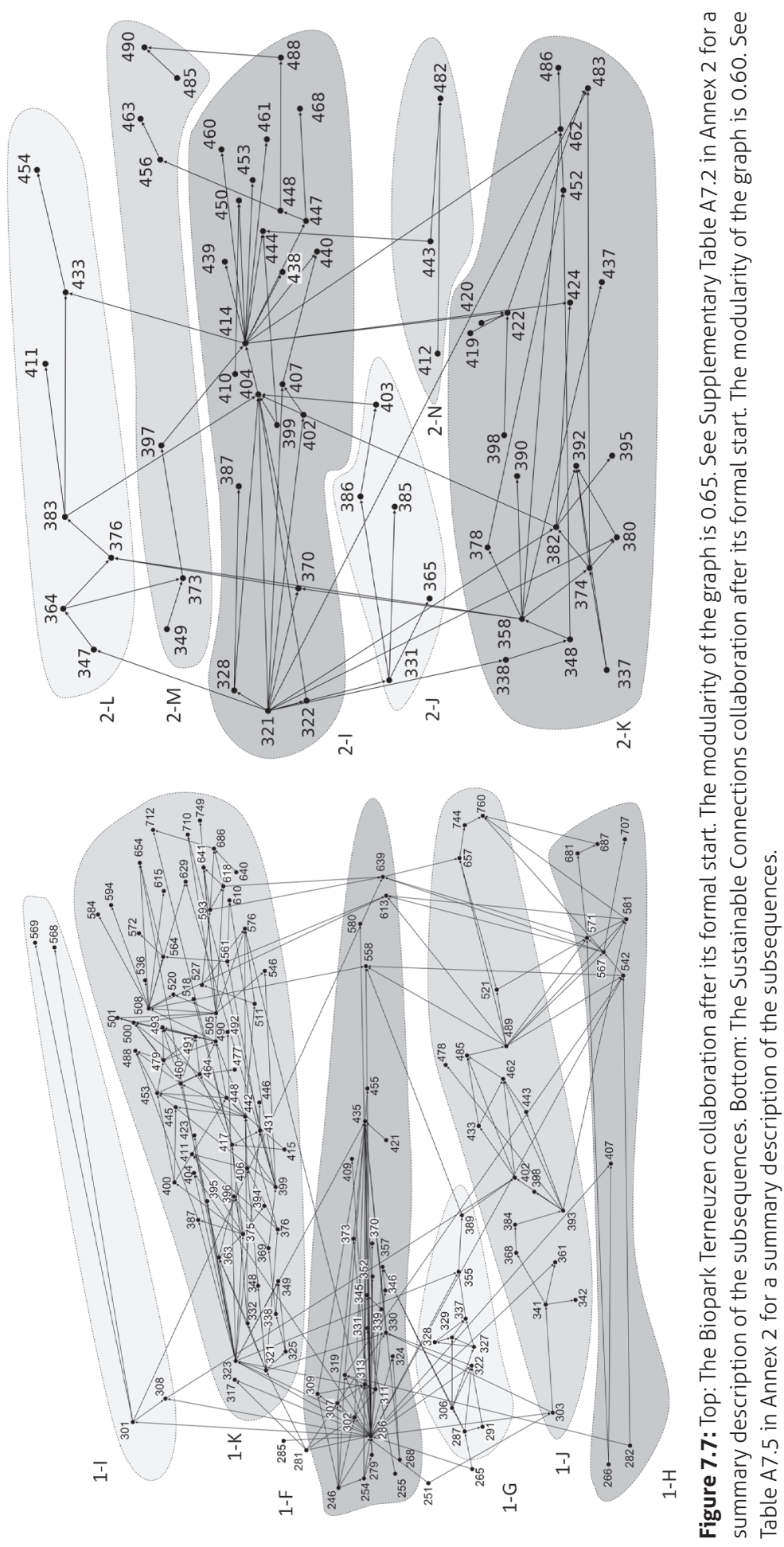




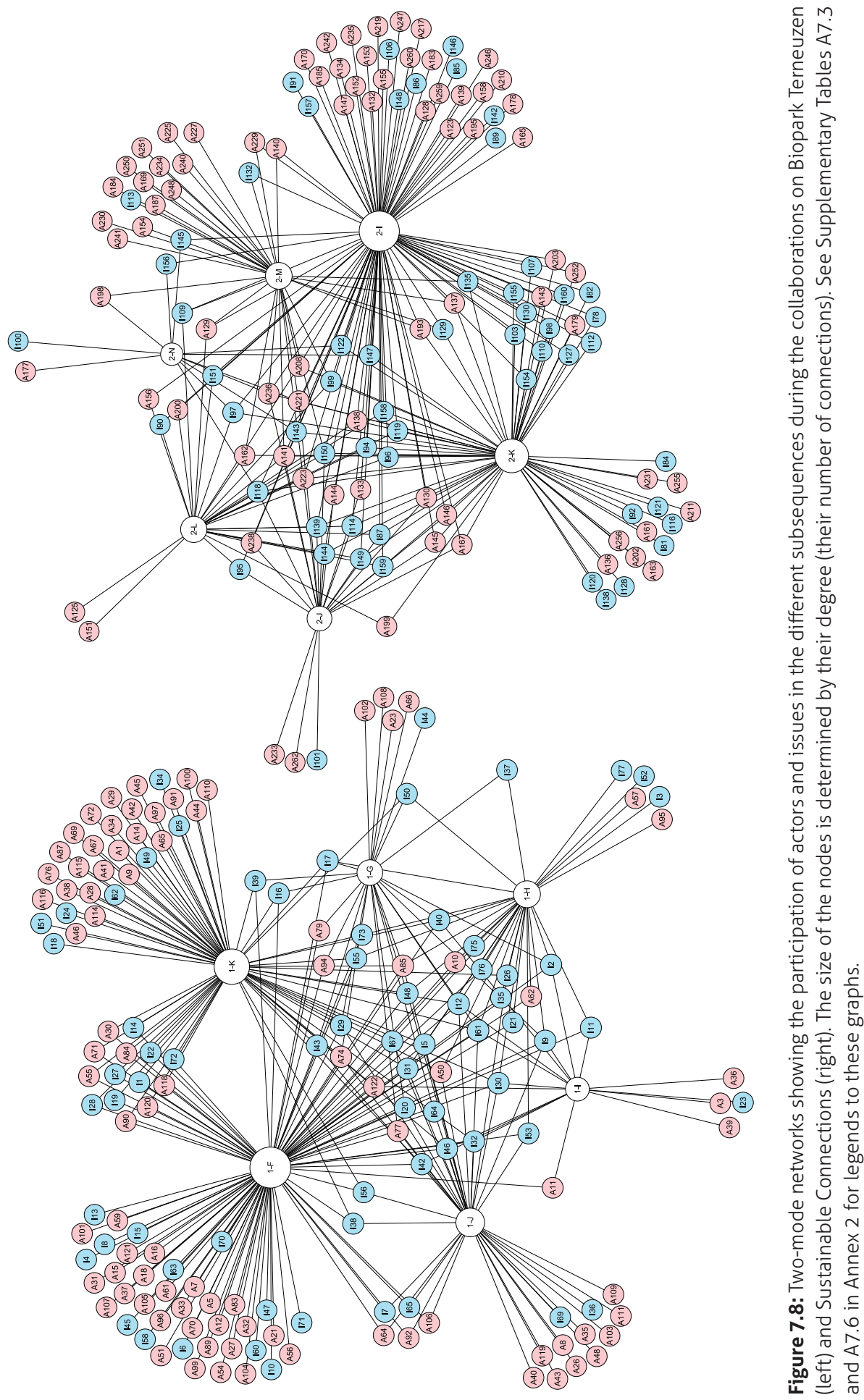


aims). This is a strong indication that the collaborations build on issues that are central to the common ground that has developed.

Table 7.4. Most central actors in history of Biopark Terneuzen. The capitalized letters refer to the subsequences in the event graphs.

\begin{tabular}{|c|c|c|c|c|c|c|c|}
\hline Name & Label & $\begin{array}{c}\text { Betweenness } \\
\text { Centrality }\end{array}$ & $1-A$ & 1-B & $1-\mathrm{C}$ & $1-D$ & $1-E$ \\
\hline Province of Zeeland & A85 & 0.41 & $x$ & $x$ & & $x$ & $x$ \\
\hline Zeeland Seaports & A122 & 0.27 & $x$ & & $x$ & $x$ & \\
\hline Municipality of Terneuzen & A74 & 0.16 & $x$ & & & $x$ & $x$ \\
\hline Rabobank & A87 & 0.15 & & & & $x$ & $x$ \\
\hline Ministry of Housing, Spatial Development and the Environment & A64 & 0.14 & $x$ & & & $x$ & \\
\hline Nedalco & A79 & 0.13 & & & & $x$ & $x$ \\
\hline Delta & $\mathrm{A} 27$ & 0.13 & $x$ & & $x$ & & \\
\hline ACZC & $\mathrm{A} 2$ & 0.11 & & $x$ & & & \\
\hline Heros & A50 & 0.08 & & $x$ & & & \\
\hline Circle of Employers & $\mathrm{A} 21$ & 0.06 & $x$ & & & & \\
\hline
\end{tabular}

\subsubsection{The bridging actors}

For both cases, we reconstructed the actor networks as they existed before the start of the collaborations. Figure 7.6 already reveals that most actors tend to be active in only one building block, but that there are some actors that are involved in multiple building blocks and can act as a bridge between them because of their position. In tables 7.4 and 7.5 , we report the top ten most central actors in our cases. In both cases, we find that the actors with a relatively high betweenness centrality are public actors.

In the case of Biopark Terneuzen, the three most central actors are also the actors that our sources report as the initiators of the Biopark Terneuzen collaboration. In the case of Sustainable Connections, four of the six initiators are among the most central actors (the province, the municipality, the port authority, and the water authority) but only the province and the municipality seem to have a modest bridging role. The most central actors are also affiliated to most of the subsequences that lead up to the collaborations. With some exceptions, the bridging actors that initiate the collaborations are typically only loosely involved in the development of the building blocks themselves. Exceptions include the greenhouse development in the case of Biopark Terneuzen and the development of a second industrial park in the case of Sustainable Connections. In the other building blocks, the bridging actors are typically involved because of their administrative responsibilities in the region.

These findings support our propositions on the antecedents of collaborations. Proposition 1 is supported because the event graphs reveal that independent subsequences do exist before the collaborations start, which indicates the presence of multiple build- 
Table 7.5. Most central actors in history of Sustainable Connections. The capitalized letters refer to the subsequences in the event graphs.

\begin{tabular}{|c|c|c|c|c|c|c|c|c|c|}
\hline Name & Label & $\begin{array}{c}\text { Betweenness } \\
\text { Centrality }\end{array}$ & $2-A$ & 2-B & $2-\mathrm{C}$ & $2-D$ & $2-E$ & $2-F$ & $2-\mathrm{G} 2-\mathrm{H}$ \\
\hline Province of Noord-Brabant & A223 & 0.28 & $x$ & & $x$ & & $x$ & $x$ & $x$ \\
\hline Municipality of Moerdijk & A208 & 0.27 & $x$ & & $x$ & $x$ & $x$ & $x$ & $x$ \\
\hline DEP & A166 & 0.19 & $x$ & & & & & & \\
\hline Coatex & A56 & 0.07 & & & & & $x$ & & \\
\hline Wuppermann Staal & A259 & 0.07 & & & & & $x$ & & \\
\hline Southern Association of Agriculture and Horticulture & A261 & 0.07 & $x$ & & $x$ & & & & \\
\hline Port authority of Moerdijk & A221 & 0.07 & & $x$ & & $x$ & $x$ & $x$ & $x$ \\
\hline Water authority & A257 & 0.06 & & & $x$ & & & & \\
\hline AZN & A133 & 0.04 & & $x$ & $x$ & & $x$ & $x$ & \\
\hline Shell & A236 & 0.04 & & $x$ & $x$ & & $x$ & $x$ & $x$ \\
\hline
\end{tabular}

ing blocks. Although intentional linkages between the building blocks are largely absent, we have seen that emergent linkages between the building blocks do exist, indicating that the building blocks developed a common ground, which is support for proposition 2. The issues that are most central in this common ground are also good predictors of the aims that are chosen at the start of the collaborations, which supports our expectation that the initiators of the collaborations responded to the development of a common ground. Thereby the common ground that emerges before the collaboration has a strong influence on the contents of the collaboration itself. This strengthens the support for proposition 2. Proposition 3 is supported because the actors that have a bridging position before the start of the collaborations are also among the actors that initiated the collaborations.

\subsubsection{The collaborative process}

Figure 7.7 shows the event graphs of the collaborative processes as they occurred in our cases (the events in figure 7.7 follow the events visualized in figure 7.4). Thus, they capture the events that occurred after the collaborations had formally begun. In the event graph that visualizes the collaborative process in the case of Biopark Terneuzen, events $251,265,281$, and 285 are not included in any of the collaborative projects because these are events that are part of the building blocks that are visualized in figure 7.4. The events are also included in figure 7.7 to show that, in addition to being linked via event 286 (the formal start of the collaboration), there are direct intentional linkages between some of the building blocks and the collaborative projects.

As mentioned before, the collaborative processes are initiated by bridging actors, and in response to the common ground that has emerged through the development of the different building blocks. A visual inspection of the event graphs reveals that multiple 
subsequences still exist, but that there are now more intentional linkages between the different subsequences. As a result of the increased connections between the subsequences, the modularity of these graphs is also lower compared with the event graphs of the antecedents to the collaborations (figure 7.4). The subsequences of the collaborative process to some extent reflect the building blocks that existed before the collaboration (also see Tables A7.2 and A7.5 in Annex 2). For example, a major project in the Biopark Terneuzen collaboration revolves around the development of residual heat and $\mathrm{CO}_{2}$ exchanges between Yara and the greenhouses that established in the newly developed greenhouse area (subsequence 1-K). Subsequence 1-G and 1-J represent the development of the biofuel factory of Nedalco and the biofuel factory on the terrain of Heros, respectively. Subsequence $1-\mathrm{H}$ represents the development of biomass plants on the terrain of Heros. Subsequence $1-F$ includes research projects that were carried out as part of the collaboration, as well as other events that relate to the Biopark Terneuzen collaboration in general. Subsequence 1-I refers to changes that Zeeland Seaports made in its acquisition strategy after the start of Biopark Terneuzen. In the case of Sustainable Connections, the main project is the development of a heat exchange infrastructure (subsequence $2-K)$, which builds primarily on the initiative of Bewa to exchange heat with its neighbors (subsequence 2-D), and in which a link is also made to the development of a second industrial park in Moerdijk (subsequence 2-C). Subsequence 2-] represents a project on the optimization of water loops, which was addressed earlier in subsequence $2-F$, The events in subsequence $2-M$ are meetings of the Neighbors council, which was never a fully integrated part of the collaborative process but in which developments in the collaboration were discussed occasionally. Subsequences 2-I includes developments that relate to the Sustainable Connections collaboration more in general, and subse-

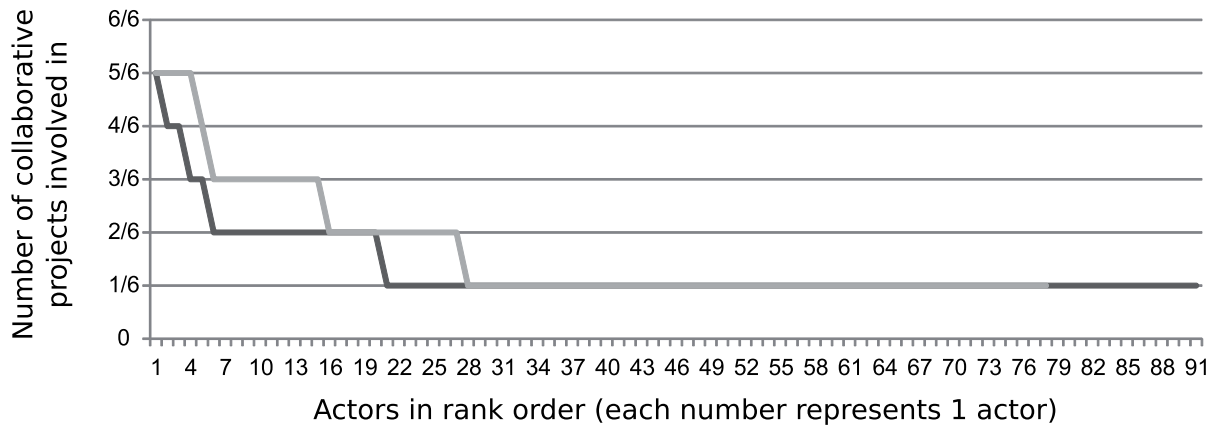

Figure 7.9: Ratio of involvement of actors in collaborative projects for Biopark Terneuzen (dark grey) and Sustainable Connections (light grey). The ratio was calculated for each actor by dividing the number of collaborative projects the actor is involved in by the total number of collaborative projects in the collaboration (six for both cases). 
Table 7.6: Subgroups at three highest c levels in Biopark Terneuzen.

\begin{tabular}{lll}
\hline \multicolumn{1}{c}{ c level } & Subgroups \\
\hline 7 & 1. & Zeeland Seaports, Municipality of Terneuzen, Province of Zeeland, \\
\hline 6 & 1. & Zeeland Seaports, Municipality of Terneuzen, Province of Zeeland, University of Wageningen \\
& 2. & Zeeland Seaports, Municipality of Terneuzen, Yara \\
& 3. & Zeeland Seaports, TransForum, University of Wageningen \\
\hline 5 & 1. & Zeeland Seaports, Municipality of Terneuzen, Province of Zeeland, TransForum, University of Wageningen, Yara \\
& 2. & Municipality of Terneuzen, Province of Zeeland, Nedalco \\
3. & Zeeland Seaports, TransForum, University of Nijmegen \\
4. & TransForum, University of Nijmegen, Van de Bunt Consultancy \\
\hline
\end{tabular}

Table 7.7: Subgroups at three highest c levels in Sustainable Connections.

\begin{tabular}{lll}
\hline \multicolumn{2}{l}{ clevel } & Subgroups \\
\hline 16 & 1. & Municipality of Moerdijk, Port of Moerdijk, Province of Noord-Brabant \\
\hline 12 & 1. & Municipality of Moerdijk, Port of Moerdijk, Province of Noord-Brabant \\
& 2. & Brabantse Delta, Department of Waterways and Public Works, Province of Noord-Brabant \\
\hline 11 & 1. & Brabantse Delta, Department of Waterways and Public Works, Port of Moerdijk, Province of Noord-Brabant \\
& 2. & Brabant Water, Port of Moerdijk, Province of Noord-Brabant \\
& 3. & Municipality of Moerdijk, Port of Moerdijk, Province of Noord-Brabant \\
4. & BMD Consultancy, Port of Moerdijk, Province of Noord-Brabant \\
\hline
\end{tabular}

quences 2-L and 2-N are newly conceived projects on the identification of frontrunners in business (2-L) and residual material exchanges between Shell and Erca (2-N).

Figure 7.8 shows the two-mode graphs for the collaborative processes to illustrate the involvement of actors and issues in the various subsequences. The figure shows that relatively many actors are involved in only one or two of the projects that are implemented during the collaboration. Compared with the period antecedent to the collaboration (the development of the building blocks), the ratio of actors involved in more than one subsequence increases only slightly. For Biopark Terneuzen, this ratio changes from 0.20 $(11 / 56)$ to 0.22 (20/91), and for Sustainable Connections, it changes from 0.23 (23/99) to $0.35(27 / 78)$. The line graphs in figure 7.9 reveals that a relatively small amount of the actors is involved in half (or more) of the collaborative projects. Figure 7 has revealed that the collaborative processes are of a modular nature (multiple subsequences with short-term independence exist), and the ratio of involvement of actors in collaborative projects also suggests that most actors tend to work in only one or two distinct collaborative projects, which reflects the modular nature of the collaborative process.

We also performed a subgroup analysis for the actor networks that were formed during the collaborative processes, which also takes into account the frequency of involvement of actors in the collaborative process.

The subgroups that occur most often are reported in tables 7.6 and 7.7. In both our cases the subgroup that meets most often is formed by the municipality, the province 
and the port authority. One or two of these public actors also feature in almost all of the other subgroups that we identified, which indicates that they have a more structural involvement in the collaborative process than the other actors. The analysis also shows that the various subgroups overlap. As a result of this overlap, the actor network has a core of actors (the overlapping subgroups) that are involved in the collaborative process on a more structural basis. Around this core, there is a periphery of actors that are involved on a more incidental basis.

Our propositions on the collaborative process are supported by our findings. Proposition 4 is partially supported by our findings. Even during the collaborative process, most actors tend to work on only one or two projects at the same time. We were able to identify several subgroups, but these subgroups are overlapping rather than being completely distinct, which is caused by the continued presence of bridging actors during the collaborative process. This contributes to the development of an actor network with core-periphery structure rather than a distinctly modular structure. Proposition 5 is supported because several subsequences of events do still exist during the collaborative process. Although there are occasional interactions between these subsequences, they are largely independent at the short term. Finally, our overarching proposition (6) is also supported by our findings. It is clear that several building blocks existed before the collaboration and that these building blocks developed a common ground. The importance of the common ground as a dimension of collaborative capacity is supported by the fact that the most central issues of this common ground also reflect the aims that are chosen at the start of the collaborations.

\subsection{CONCLUSIONS AND DISCUSSION}

Our main finding is that collaborations can be assembled from building blocks and that these building blocks already make a strong contribution to the development of collaborative capacity before the collaborative process itself starts. In this case, it specifically concerns two dimensions of collaborative capacity: A common ground that emerges because the actors involved in the various building blocks address the same issues at more or less the same time, and the existence of actors in a bridging position, that is, actors that are in a good position to assemble the various building blocks into a collaboration. Interestingly, in both our cases the bridging actors appear to be public organizations. There is nothing in our conceptual discussion that suggests that this is a necessary condition for collaborations to develop. However, a possible explanation for the observation is that public organizations usually face a greater multiplicity of objectives compared with private organizations (Rainey 2009; Rainey, Backoff, and Levine 1976). As a consequence, public organizations may be more likely to get involved in a greater diversity of 
building blocks and find themselves in a position where they can act as a bridge between these building blocks. This also leads to an interesting role division between public and private actors in the emergence and development of the collaborations. Private actors are primarily responsible for the development of the different building blocks (with some exceptions), but the public actors that act as bridges are responsible for assembling the building blocks into collaborations. In our view, common ground and the bridging actors should be seen as two dimensions of collaborative capacity that are complementary to other dimensions of collaborative capacity that may be created primarily during the collaborative process itself, such as bonds of trust, mutual understanding, and commitment (Ansell and Gash 2008; Emerson, Nabatchi, and Balogh 2012; Vangen and Huxham 2003). The common ground and the presence of bridging actors can be understood to offer an initial basis on which stronger personal and professional relationships can build.

Although the collaborations that we studied were assembled from various building blocks, we did not find that this leads to a modular structure of the actor networks. Instead, we find that the networks are characterized by overlapping subgroups and that the public actors feature in most of these subgroups, forming a stable core. The subgroups are also relatively small, compared with the number of actors that are involved throughout the entire collaborative process. Most of the other actors are involved only occasionally. Thus, in addition to the stable core, the actor networks have a large fluid periphery. This may be understood as a way of coping with the complexity of governing collaborations. As Provan and Kenis (2008) suggest, this complexity increases quickly as the number of actors and relationships increases. The actors in our cases appear to solve this problem by maintaining a relatively small group of actors that meet frequently, and by only occasionally involving additional actors, for specific purposes. This points to another dimension of collaborative capacity that we did not address explicitly in our conceptual discussion and which revolves around the capability to involve the right actors, at the right time.

In our cases, the common ground that emerged before the collaborations influenced the aims that were chosen for the collaborations themselves and thereby had an influence on the course that the collaborative processes took at their start. In our view, this influence of the building blocks is underestimated by recently developed frameworks on collaborative governance. Although Bryson, Crosby and Stone (2006) suggest that a problem definition may already be present at the outset, other frameworks assume that the course of the collaborative process is determined primarily during the collaborative process itself (Ansell and Gash 2008; Emerson, Nabatchi, and Balogh 2012). We do not deny the importance of developing shared visions during the collaborative process, but we emphasize that these shared visions are to some extent an articulation of a common ground that has already emerged before actors engage in a visioning process. Thus, visions do not only function as forward-looking devices. They also offer means to 
consolidate the common ground that has already emerged, thereby providing a bridge between the building blocks for collaboration, and the collaboration itself.

In this article, we focused on two highly similar cases of collaboration that occurred in the Netherlands. Further research is required to assess the extent to which the conceptual arguments and findings presented in this paper are generalizable to other types of collaborations. The collaborations that we investigated occur at a regional level and involve mainly professional organizations, whereas many collaborative processes investigated in the literature on Public Administration are characterized by a strong involvement of citizens (Ghose 2005; Sirianni 2009; Vigoda 2002). Also, as Agranoff and McGuire (1998) observe, the composition and size of collaborative networks may depend on the specific characteristics of the collaborations. Thus, it is important to assess the extent to which our findings also hold in cases of collaborations among a relatively small number of actors. Finally, collaborative governance processes are often started specifically to deal with situations characterized by conflict (Ansell and Gash 2008; Gray 1989). Further research is necessary to assess how our conclusions apply in such conditions. However, we expect that many regional collaborations will exhibit the qualities of those that we investigated in this article. We suggest that a good understanding of the building blocks of those collaborations is vital in the development of a good understanding of the collaborations themselves. 




\section{INTERMIE720.5}

\section{TOOLS FOR DYNAMIC NETWORK ANALYSIS}


In the literature on institutional capacity building and collaborative governance the development of dense networks of social relationships is typically assumed to be the starting point of building capacity for collective action. Chapter 7 introduces alternative mechanisms for capacity building and illustrates their workings in two case studies. The alternative mechanisms do not take the development of dense social networks as their starting point, but show that relationships can be built on a common ground that may develop before intensive interactions between actors take place. However, other than that the analysis in chapter 7 has relatively little to say about the relational dynamics of collaborative processes. Because relational capacity takes such an important place in the original conceptualizations of institutional capacity and collaborative governance I decided that I should investigate the relational dynamics in my cases more explicitly. For this purpose I developed tools that can be used for the dynamic analysis of social networks ${ }^{43}$.

In the period in which I had written chapters 5,6 and 7 of this thesis I had also taught myself how to program software in $\mathrm{C}++, \mathrm{R}$ and, to some extent, Java. I picked up programming during a 3-month stay in China as a way of keeping my mind occupied during the evening hours. By the end of my stay in China I could write command-line tools to perform rather silly tasks, such as removing all the interpunctions of an input sentence. However, I further improved my programming skills by applying them for the development of several tools that I have used throughout my PhD project, including the tool for the automated creation of event graphs (chapter 6), and the algorithm for the identification of paths in event graphs (chapter 7). I spent many nearly sleepless nights debugging my own programs, a strangely addictive activity that was occasionally accompanied by verbal abuse of my computers. By the time that I started working on chapter 7 I was able to write programs capable of performing relatively complex tasks. In the meantime I had also improved my understanding of different branches of mathematics related to the methods I was using, of which matrix algebra is the most important example. I used the skills that I thus acquired to write several software tools that can be used to harness event sequence data for the dynamic analysis of social networks. Figure I5 shows a small fragment of my biggest program so far. It concerns a tool (with a graphical user interface) that can be used as a companion to the Gephi visualization program. It converts incidence matrices with event data ${ }^{44}$ into dynamic network data that can be visualized with Gephi. Ironically, the role that the program has played in my analyses of network dynamics has left few traces in the products that result from the analyses (see chapter 8). I typically use the program to visualize networks of relationships as they existed at different points of

43. Here too the ideas underlying the methods used were developed in interaction with Frank Boons.

44. Events are reported in chronological order in the columns of the matrix. The actors and/or issues involved in the events are reported in the rows of the matrix. 
time, but because of their dynamic nature the visualizations are difficult to include in reports on the analyses performed. However, the visualizations were of central importance as aids in my interpretation of the patterns of relational dynamics that I identified with the help of other tools that I created.

These other tools are functions that I wrote for $R^{45}$ that can be used to create time series of various metrics typical to social network analysis. The time series give clues about the evolution of the structure of the social network under investigation. Such time series take a central place in the study that is presented in chapter 8 , in which the relationship between the dynamics of collaborative governance processes and evolution

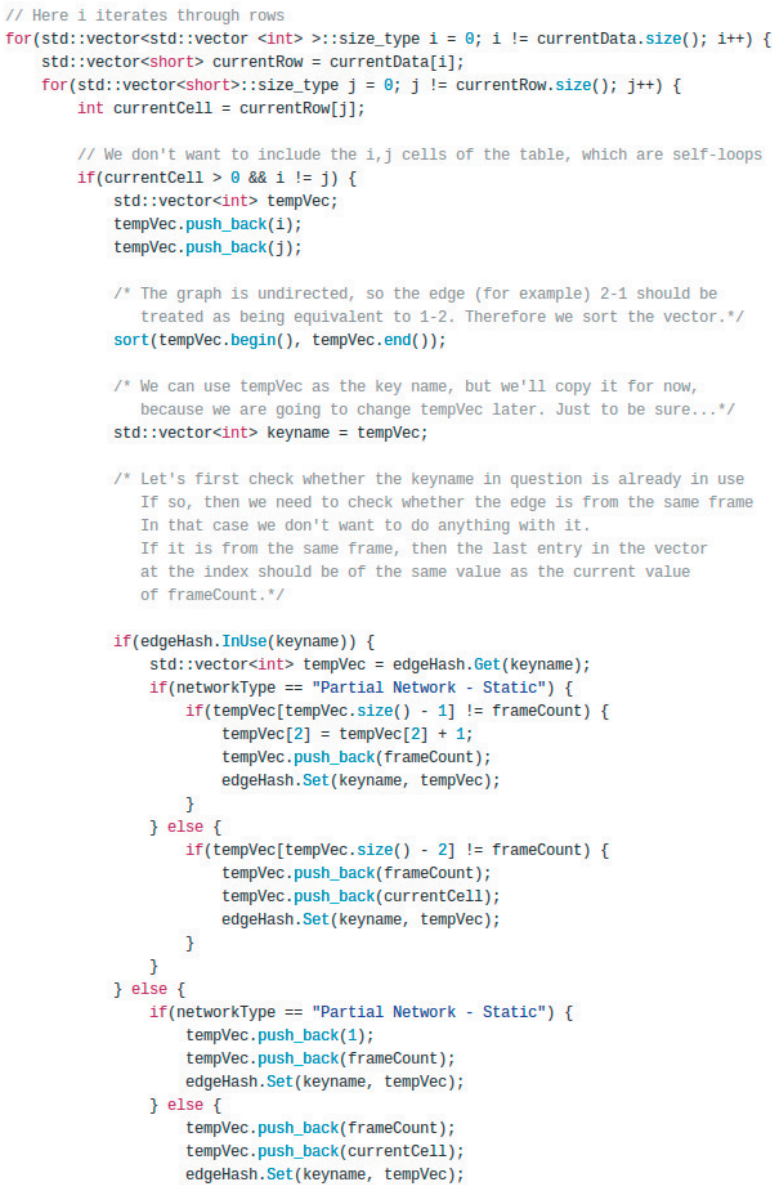

Figure 15: Fragment of source code for the Dynamic Networks tool (see http://www.wouterspekkink. org/?page_id=87)

45. Writing the functions in $R$ allowed me to integrate functionalities of existing packages for $R$ (see the methods section of chapter 8 ). 
of collaborative network structures is investigated. For example, the tools enabled me to critically assess assumptions that existing models of collaborative governance processes make about relationship building.

Chapter 8 is the last chapter included in my thesis before the presentation of my conclusions and recommendations. In the conclusions I present a modified conceptual framework that draws on the lessons learned from the various case studies, and that attempts to capture the most important characteristics of the process of institutional capacity building as I have come to understand it. Although the modified framework is one of the end-products of my thesis, I primarily see it as a basis for new studies on processes of institutional capacity building in a variety of contexts. This will also help to determine to what extent the lessons derived from the case studies of this thesis can be generalized to cases of emergence and development of industrial symbiosis in other contexts, or to types of collaborations other than industrial symbiosis. In the conclusions I also reflect on the value of ESA for the investigation of social processes. As I stated in the second intermezzo, the development of ESA continues after finishing the thesis, as I (and the others that I have worked with on ESA) believe that there is still a lot of untapped potential. My hope is that the work presented in this thesis can convince other researchers to adopt ESA (or a similar approach), such that we have a stronger basis for further improvements and enrichments of the approach. 




\section{CHAPTER:}

\section{THE NETWORK DYNAMICS OF COLLABORATIVE GOVERNANCE: AN ANALYSIS OF SUSTAINABLE CLUSTER DEVELOPMENT}

This chapter is an edited version of a manuscript that was submitted as Spekkink, W. A. H. and Boons, F. A. A. The network dynamics of collaborative governance: An analysis of sustainable cluster development. 


\section{ABSTRACT}

Several integrative frameworks on collaborative governance have been introduced in the literature on Public Administration. The frameworks include (among other things) models of the collaborative governance process. These 'process models' have implications for the evolution of collaborative network structures. For example, the process models typically imply that collaborating partners establish new relationships and strengthen existing ones, by building trust, mutual understanding, and commitment. In this paper we investigate what this implies for the evolution of collaborative network structures. We offer a conceptual discussion on the implications of the models, we derive several propositions from this discussion, and we test these propositions in a longitudinal study of two cases of collaborative governance in the Netherlands. Our findings show that in both our cases actors typically work in parallel projects, although collective meetings may take place in the initial stages of the collaborative process. In the case of Biopark Terneuzen working in parallel leads to a low-density collaborative network that is sometimes highly modular. In the case of Sustainable Connections density increases over time as a result of relatively high overlap of the groups of actors that are involved in parallel projects. Governmental organizations play an important role as bridging actors during various stages of the collaborative process, by being involved in relatively many projects at the same time. Our findings also reveal that the group of actors that is involved in the collaborative process on a structural basis is relatively small, and that many actors are involved on an incidental basis. This incidental involvement of actors is not yet explicitly taken into account in process models of collaborative governance. 


\subsection{INTRODUCTION}

In the literature on Public Administration there is ample attention for emergent forms of cross-boundary governance that have come to be known under the header of collaborative governance (Emerson, Nabatchi, and Balogh 2012). In collaborative governance, actors are brought together from public, private and civic spheres to engage in decision-making and/or management activities aimed at achieving a public purpose that the involved actors could not have attained alone (Bryson, Crosby, and Stone 2006; Ansell and Gash 2008; Emerson, Nabatchi, and Balogh 2012; Huxham 2000; Huxham and Vangen 2005). Currently, there are at least three frameworks that integrate numerous insights gained on collaborative governance (Bryson, Crosby and Stone 2006; Ansell and Gash 2008; Emerson, Nabatchi and Balogh 2012). Each of these integrative frameworks includes, among other things, a model of the collaborative process, the purpose of which is to capture the dynamics of the collaborative governance process. These models typically emphasize repeated interactions through which actors build trust, mutual understanding and commitment (also see Innes and Booher 1999; Agranoff and McGuire 2001; Vangen and Huxham 2003a; Imperial 2005; Ansell and Gash 2008). In the remainder of this paper, we will refer to this model as the 'process model' of collaborative governance.

Although the process model is designed to capture the dynamics of the collaborative governance process, it also has theoretical implications for the structure of relationships between collaborating partners that we can expect to emerge, because the process is expected to lead to the development of new relationships, or the strengthening of existing ones (Innes and Booher 1999; 2003) ${ }^{46}$. This structure of relationships is more commonly referred to as the collaborative network, which is an object of study in itself in the literature on public administration (e.g., Agranoff and McGuire 2001; Booher and Innes 2002; Agranoff and McGuire, 2003; Keast, Mandell, Brown and Woodcock 2004; Imperial 2005; Kenis and Provan 2006; Provan and Kenis 2008; Weber and Khademiam 2008; Head 2008). Collaborative networks are defined as "organizational arrangements for solving problems that cannot be achieved, or achieved easily, by single organizations" (Agranoff and McGuire 2001, p. 296; also see Agranoff and McGuire, 2003; Booher and Innes 2002; Kenis and Provan 2006; Provan and Kenis 2008). Thus, collaborative networks are formed when people (and the organizations that they represent) realize that they need to work together if they wish to achieve common goals (Keast, Mandell, Brown and Woodcock 2004). There is a close association between this understanding of the nature of collaborative networks and the process model of collaborative governance

46. Although it is possible that the collaborating partners (or subsets thereof) have a history of collaboration or conflict, the integrative frameworks of collaborative governance appear to assume that (most) relationships need to be built anew. 
that we introduced earlier: Collaborative networks refer to the relational structures that are formed to achieve common goals that actors cannot achieve alone, and the process model can be understood to model the dynamics through which these relationships are formed.

To our knowledge, an explicit link between the process model of collaborative governance and the evolution of collaborative networks has not been made so far. In this paper we seek to explore this link. To that end, we first offer a more detailed conceptual discussion on the process model of collaborative governance and its implications for the evolution of collaborative network structures. We summarize these implications in a set of propositions that we then confront with empirical observations on two cases of collaborative governance: The Biopark Terneuzen collaboration in the Canal Zone of the province of Zeeland, and the Sustainable Connections collaboration in Moerdijk, in the province of Noord-Brabant (both regions are located in the Netherlands). Both cases concern regional collaborations on sustainable industrial cluster development, the aim of which is to improve the environmental and economic performance of the regions in which they take place. Our study is guided by the following research question: How do the dynamics of collaborative governance processes shape the structure of collaborative networks?

Our research question makes clear that we are looking at changes over time. Therefore, the empirical part of our study is of a longitudinal nature. The data that we have on our cases consist out of chronologically ordered, qualitative descriptions of interactions that occurred before and during the collaborative processes. This includes interactions such as negotiation on problems and solutions, development or exchange of knowledge and experience, development and presentation of plans, and the implementation of plans. For both cases we have qualitative data on the occurrence of such interactions, spanning a period of around 10 years. To approximate the relational structures that emerge from the interactions we study which actors are jointly involved in interactions. This approach is based on the idea that joint affiliations to events provide the opportunity for relationships to form (Feld 1981; Borgatti and Everett 1997; Borgatti and Halgin 2011). It also corresponds well with the idea that collaborative network structures emerge from the dynamics of the collaborative governance process.

The methods that we use to reconstruct network dynamics are similar to those used by Doreian (1979). In his approach, the participation of actors in events is recorded in an incidence matrix, where the rows represent actors, and the columns represent the events to which the actors participated, in their chronological order. A ' 1 ' in a given cell $_{i j}$

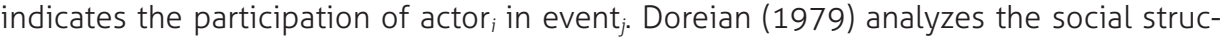
ture that emerges from the participation of actors in events by performing a q-analysis (see Atkin 1974) on increasingly large chunks of the incidence matrix. The same type of matrix is at the basis of the analyses presented in this article. We use social network 
analysis instead of q-analysis, although the type of insights developed are largely the same (Doreian 1979; Freeman 1980). We create descriptive time series of different characteristics of our networks by studying overlapping 'frames' of our incidence matrix that each represent our networks in different stages of their overall process. We use these descriptive time series as guides in our interpretation of the cases, which is primarily of a qualitative nature.

As our cases concern two highly similar collaborations in the Netherlands, our empirical findings are generalizable only to limited extent. Further research on other types of collaborations is needed to assess the generalizability of our empirical findings. In the next section we offer our conceptual discussion. After that, we provide a more detailed description of the methods that we used in our investigation. We then present our case studies, and we conclude with a discussion of the implications of our findings.

\subsection{COLLABORATIVE GOVERNANCE AND COLLABORATIVE NETWORIKS}

In our introduction we briefly introduced the process model that features in several integrative frameworks of collaborative governance (Bryson, Crosby and Stone 2006; Ansell and Gash 2008; Emerson, Nabatchi and Balogh 2012). We also suggested that the process model has implications for the evolution of collaborative network structures. In this section we discuss these implications in more detail.

\subsubsection{The setting of the collaborative governance process: Collective vs. distributed}

A fundamental assumption of the process model is that actors develop trust, mutual understanding and commitment through repeated face-to-face interactions (Innes and Booher 1999; Booher and Innes 2002; Thomson and Perry 2006; Ansell and Gash 2008). However, there is disagreement among the architects of the different frameworks on the setting in which these interactions take place. Ansell and Gash (2008, p. 545) suggest that the forum in which collaboration takes place "is formally organized and meets collectively." It should be noted here that this is also a matter of definition for Ansell and Gash (2008): In order to ensure that we are comparing apples with apples, the authors have come up with a definition of collaborative governance that is more restrictive than those used by other authors in the field, and the emphasis on collective meetings is part of that definition. In contrast to the suggestions of Ansell and Gash (2008), Emerson, Nabatchi and Balogh (2012) suggest that meetings may take place among different groups of actors at different times. Also, they suggest that face-to-face dialogue is advantageous at the outset, but not always essential, especially when shared objectives and values surface quickly, whereas Ansell and Gash (2008) suggest that face-to-face 
dialogue is continuous throughout the process (which is also emphasized by the cyclical nature of their process model). Bryson, Crosby and Stone (2006) are less explicit on who is involved at what time, although their proposition that the structure of the collaboration is likely to change over time due to ambiguity of membership (also see Vangen and Huxham 2003a; Innes and Booher 1999) suggests that their view is more or less in line with that of Emerson, Nabatchi and Balogh (2012).

To some extent, whether or not meetings will take place in a collective setting will also depend on the size of the involved group of actors. The larger the group is, the more time consuming and resource intensive the organization of collective meetings becomes (Imperial 2005; Provan and Kenis 2008). In that case a polycentric approach, where different groups of actors are involved to target specific problems, is much more efficient (Imperial 2005). For similar reasons, collaborative networks are often characterized by the existence of working groups that are established to tackle specific problems, and where the members of these groups interact primarily among each other (Vangen and Huxham 2003a; Bodin and Crona 2009).

The constellations in which actors meet during the collaborative process will have several consequences for the evolution of the collaborative network that emerges from the process. A first structural feature that we can assess is that of modularity (Blondel et al. 2008). A more technical explanation of the concept of modularity is offered in our section on methods, but an intuitive explanation is as follows: Networks with high modularity have easily distinguishable communities, which are subgraphs of nodes that are more strongly connected among themselves than they are connected with other nodes in the overall network. Networks that lack this community structure have low modularity. A collaborative network that emerges from collective meetings can be expected to have low modularity, because the network as a whole will resemble one large community. A collaborative network that emerges from meetings between different actors at different times should have high modularity, because the different groups form distinguishable communities within the overall network. The discussion so far can be summarized in two opposing propositions, where the first builds on the perspective of Ansell and Gash (2008) and the second builds on the perspective of Bryson, Crosby and Stone (2006), and Emerson, Nabatchi and Balogh (2012).

Proposition 1a: The actors involved in the collaborative process engage in collective meetings, leading to collaborative network structure with low modularity.

Proposition 1b: Different groups of collaborating actors meet each other at different times, leading to a collaborative network structure with high modularity. 


\subsubsection{The density of relationships in the collaborative network structure}

The process models of Ansell and Gash (2008) on the one hand and that of Bryson, Crosby and Stone (2006) and Emerson, Nabatchi and Balogh (2012) on the other hand also have implications for the density of the collaborative networks that we can expect to emerge. Because actors meet collectively in the model of Ansell and Gash (2008), we expect the emergence of a densely connected collaborative network. Bryson, Crosby and Stone (2006) and Emerson, Nabatchi and Balogh (2006) suggest that actors may meet in different groups, at different times, and thus the type of collaborative network we expect to emerge has a low density of relationships, because not all actors are directly connected with each other. The distinction between densely connected collaborative networks on the one hand and distributed collaborative networks on the other hand has strong parallels with the distinction that Ahuja (2000) and Burt (2000; 2001) make between two different perspectives on social capital. In Coleman's (1988) understanding of the concept, social capital derives primarily from the density of a network: Social capital increases as the density of relationships increases. In Burt's (1992) understanding of the concept, social capital derives primarily from brokerage opportunities created by networks with so-called structural holes, that is, networks that are characterized by the existence of groups that may be densely connected internally, but that are only loosely connected among each other. From this perspective, networks that are characterized by low density may actually be richer in social capital than densely connected networks.

The type of network structure that we would expect to emerge from the cyclical process envisioned by Ansell and Gash (2008) corresponds closely with Coleman 's (1988) perspective on social capital. Here, relationships of trust, mutual understanding and commitment play a role analogous to that of social capital, and the assumption is that a dense network of these relationships is required for collaborative action to be successful. The process models of Bryson, Crosby and Stone (2006) and Emerson, Nabatchi and Balogh (2012) have a stronger parallel with Burt's (1992) understanding of the network structure of social capital. This perspective puts more emphasis on the role of actors that are located 'in between' the different groups of actors involved in the collaborative process, and that thereby have better access to the information and resources held by the different groups. Before we address the role of these actors in more detail, we introduce two opposing propositions on the density of the network that we can expect to emerge from the collaborative governance process, based on the perspectives outlined above:

Proposition 2a: The collaborative network structure that emerges from the collaborative governance process is characterized by a high density of relationships.

Proposition 2b: The collaborative network structure that emerges from the collaborative governance process is characterized by a low density of relationships. 


\subsubsection{The role of leaders}

There are similarities between Burt's (1992) perspective on social capital, and the perspectives of Bryson, Crosby and Stone (2006) and Emerson, Nabatchi and Balogh (2012) on collaborative governance, but to limited extent. In Burt's (1992) theory, actors use their privileged access to the information and resources of others primarily for their own strategic purposes. In the context of collaborative governance, actors are typically assumed to be driven by common interests. We would therefore expect actors to use their privileged position to advance these common interests. To some extent the frameworks of collaborative governance foresee this role in the form of leadership. Emerson, Nabatchi and Balogh (2007, p. 9) define a leader as an actor "who is in a position to initiate and help secure resources and support" and who possesses "a commitment to collaborative problem solving [and] a willingness not to advocate for a particular solution." A relevant leadership role identified by Bryson, Crosby and Stone (2006, p. 46) in this regard is that of "conveners, who are often recognized as boundary-spanning leaders with credibility in multiple arenas touched by the problem." Other leadership roles are identified by Bryson, Crosby and Stone (2006), including sponsors and champions, and Ansell and Gash (2008) emphasize the importance of facilitative leadership in bringing parties to the table and steering them through the collaborative process.

In the context of this discussion we make a distinction between the facilitation of collective forums (which is the leadership role envisioned by Ansell and Gash [2008]), and the boundary-spanning activities of leaders that maintain a position in between the different groups of actors involved in the collaborative process. As we discuss further in our section on methods, the latter position should lead to a relatively high betweenness centrality (Freeman, 1978) of the leaders, while this betweenness centrality should negligible for the facilitators of collective forums. We summarize this discussion in two opposing propositions:

Proposition 3a: In the collaborative process, leaders act as facilitators of collective forums.

Proposition 3b: In the collaborative process, leaders act as bridges between different groups of collaborating actors.

The tests of our propositions are based on an inspection of descriptive time series of basic social network measures, accompanied by further interpretations that are based on an inspection of the underlying qualitative event data. This approach, and our reasons for choosing it, are discussed in more detail in the next section. 


\subsection{METHODS}

The methods that we use in this article were developed as part of a broader program that we coined Event Sequence Analysis (Boons, Spekkink, and Jiao 2014). Our approach involves the collection of large amounts of data (in the form of news items, documents and web pages) that are recorded as incidents in an event sequence dataset (Poole et al. 2000). Incidents are brief qualitative descriptions of actions or interactions performed by actors. These descriptions are time-stamped, such that they can be put in chronological order. The data in the event sequence dataset are coded to identify, for example, the actors involved in various interactions and the issues that they interact on. The coded data can be used as input for different types of analysis (see Langley 1999; Poole et al. 2000; Abell 1987). In this article, we use the coded data as input for Social Network Analysis (Wasserman and Faust 1994; Knoke and Yang 2008; Scott and Carrington 2011; Scott 2013). For this study we use event data on two collaborative processes that take place in the Netherlands: Biopark Terneuzen in the Canal Zone of Zeeland, and Sustainable Connections in Moerdijk. A more detailed introduction of these cases is offered in the discussion of our results. In the remainder of this section we describe the steps we took in our approach from data collection to analysis.

\subsubsection{Data collection}

The data that are at the basis of this study were collected using a protocol that we developed in advance. We recorded relevant data in event sequence datasets, and we developed separate datasets for the two cases included in this study. The datasets include data on other interaction processes as well, because during the data collection process our scope was broader than the collaborative processes alone. The reason for this is that the boundaries of the collaborative processes were not known to us before we started our study. We identified several other interaction processes in the regions under investigation of which it was not immediately clear how strongly they related to the focal collaborations. Our broad scope in the collection of data and the construction of the datasets to some extent serves as a safeguard to ensure that developments relevant to the collaboration are not excluded unnecessarily. After building the datasets we identified the events that relate specifically to the collaborations of interest to us (or the interactions building up to these collaborations), and we included only these events in our analysis.

Based on our data collection protocol we performed searches of the LexisNexis database in order to find relevant news items on our cases ${ }^{47}$. We also performed searches on

47. In this case the dataset contains news items from Dutch national and regional newspapers that have appeared since 1990 (for some newspapers the first year included is 1995). 
the Web to find relevant documents and web pages. Because we use archival sources, our data only capture formal interactions that have occurred in the investigated collaborative processes. As a consequence, the influence of informal interactions on the collaborative processes cannot be considered in our analyses. In the process of data collection we developed a second type of dataset in which we recorded details about the searches that we performed, as well as metadata on each of the sources that we used, such as the URL address from which we retrieved the source, and the date that the source was found.

As discussed above, we compiled two event sequence datasets based on the data that we found. For the event sequence dataset that includes the Biopark Terneuzen collaboration we collected 368 web pages, 250 documents and 1134 news items. There is some overlap in the news items that we found, because the results of some of our searches in the LexisNexis database sometimes included news items that we also found in other searches. For the event sequence dataset that includes the Sustainable Connections collaboration we collected 172 Web pages, 143 documents, and 1620 news items (again, with overlap). In addition, not all sources necessarily proved to be useful when compiling the event sequence dataset.

\subsubsection{Coding}

We coded all the incidents in our event sequence datasets to indicate which actors were involved in them. Actors were identified at the organizational level because more detailed information was often missing. We grouped incidents that refer to the same interaction together, and we refer to the grouped incidents as events (the datasets include events that consist out of one incident). Here, events are defined as theoretically relevant interactions that actors engaged in during the collaborative process. This includes the orientation on issues of common concern, the development and exchange of knowledge on these issues, the development of solutions (including visions), and attempts to implement these solutions. For the construction of our descriptive time series (see section 8.3.3) we are specifically interested in interactions between actors, and therefore excluded events where only one actor could be identified.

As discussed before, the event sequence datasets include events from our focal collaborations, as well as other interaction processes. The event sequence dataset that includes the Biopark Terneuzen collaboration has 781 events in total, but for the study presented here we identified 130 events that relate specifically to the Biopark Terneuzen collaboration. The event sequence dataset that includes the Sustainable Connections collaboration has 490 events in total, but for the study presented here we identified 155 events that relate specifically to the Sustainable Connections collaboration. We also counted the numbers of actors that were involved in both collaborations, which is 113 for Biopark Terneuzen and 129 for Sustainable Connections. In both cases, many actors feature in only one or two events (see figures 8.1 and 8.2). Also, for some events 
it was not possible to identify all the involved actors because not all actors are always mentioned by name.

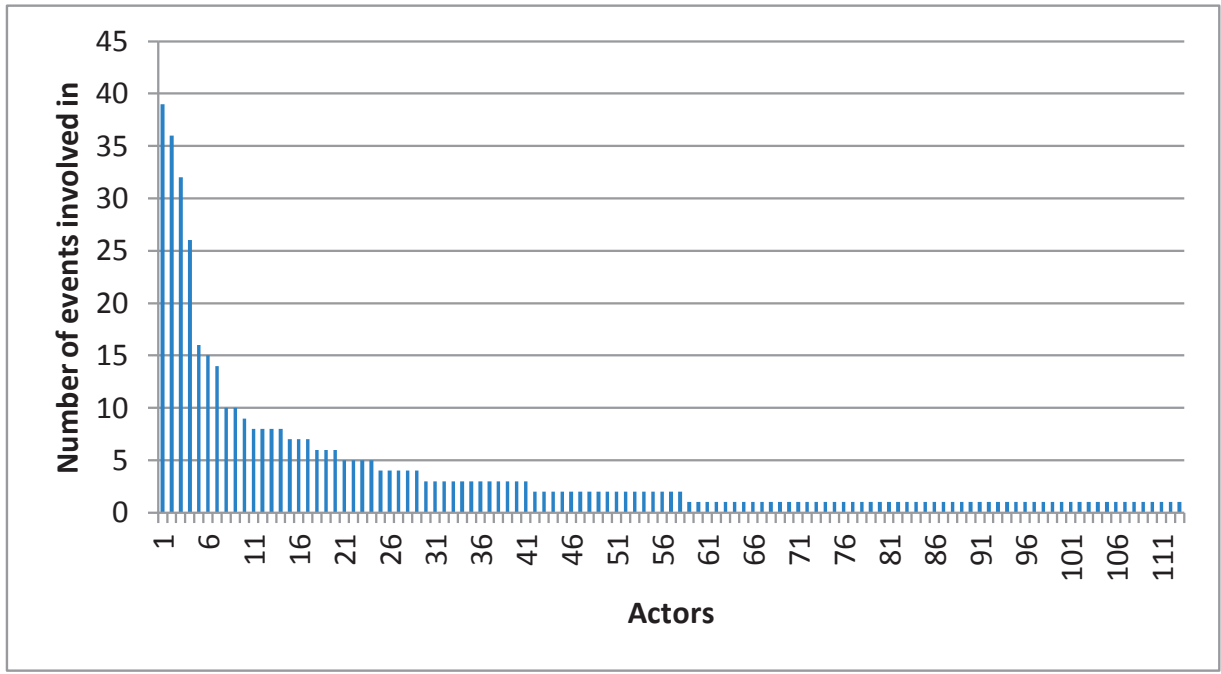

Figure 8.1: Actors and the number of events they are involved in for the case of Biopark Terneuzen. The actors on the horizontal axis are ordered by the frequency of their appearance.

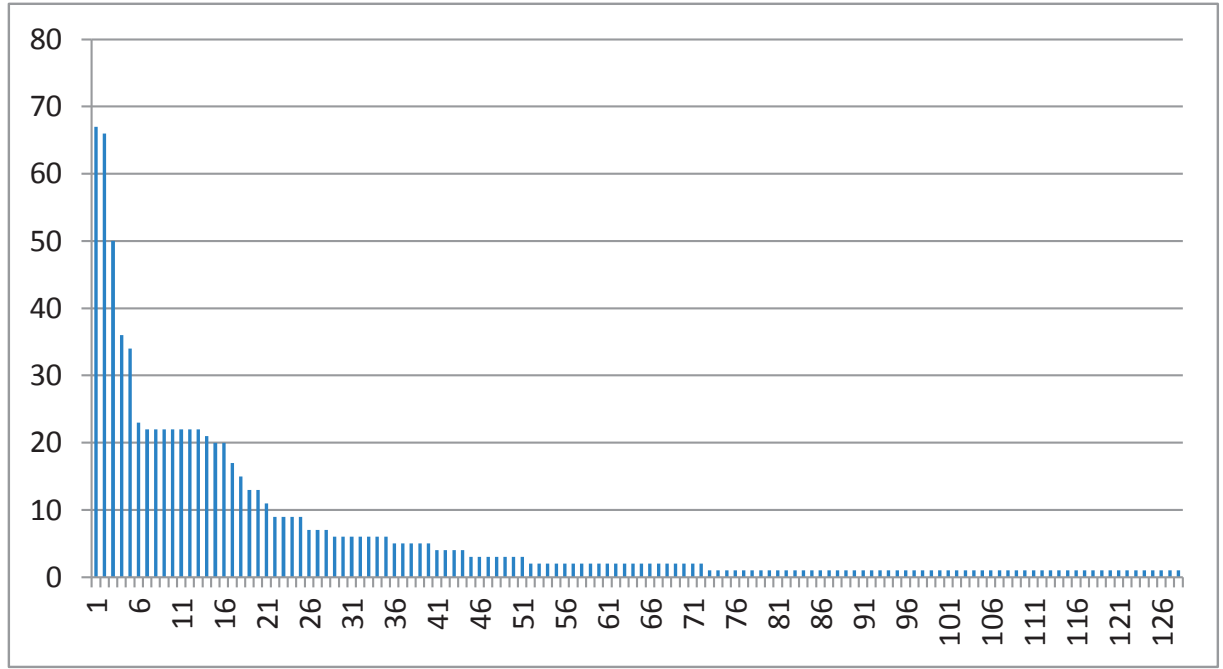

Figure 8.2: Actors and the number of events they are involved in for the case of Sustainable Connections. The actors on the horizontal axis are ordered by the frequency of their appearance.

\subsubsection{Reconstruction of networks}

The idea that interaction processes influence the shape of network structures has strong affinities with the branch of Social Network Analysis that deals with affiliation networks 
(Borgatti and Halgin 2011). Affiliation networks have two separate classes of nodes, where relationships exist only between nodes of a different class (Latapy, Magnien, and Vecchio 2008). Usually, this type of network is used to describe the relationships of people or organizations to events. Examples include the participation of woman to social events (Davis, Gardner, and Gardner 1941; Borgatti and Everett 1997), the membership of directors to company boards (Robins and Alexander 2004), the participation of actors to movies (Watts and Strogatz 1998), the contribution of authors to scientific papers (Newman 2001), the affiliations of PABO colleges to various cooperative networks, joint programs and formal institutions (Schalk, Torenvlied and Allen 2010), the shared environmental contacts of nursing colleges (Akkerman and Torenvlied 2011), and the affiliation of organizations to local emergency support functions in the aftermath of the Boston Marathon Bombings (Hu, Knox and Kapucu 2014).

Although techniques have been developed to analyze the structure of affiliation networks directly (Wasserman and Faust 1994; Borgatti and Everett 1997; Faust 1997), affiliation data are often converted to one-mode data before analysis. The joint affiliations of actors are then used to approximate the direct relationships that exist among them (Borgatti and Everett 1997; Borgatti and Halgin 2011). The reasoning behind this is that joint affiliations of actors are opportunities for them to develop a relationship (Feld 1981; Borgatti and Halgin 2011). Affiliation networks are typically represented by incidence matrices that indicate which actors participated in which events. In an incidence matrix the rows represent actors and the columns represent events (see table 8.1). An incidence matrix can be converted into an adjacency matrix by multiplying it with a transposed version of itself (see Borgatti and Everett 1997). The resulting adjacency matrix represents a one-mode network of actors ${ }^{48}$ (see table 8.2). Unlike the incidence matrix, the adjacency matrix is symmetric; the actors are reported in the rows as well as the columns. The values in the cells of the matrix indicated the number of times that actors participated in the same event.

\subsubsection{Reconstructing network dynamics}

To reconstruct a collaborative network for different moments in a collaborative process we divide the incidence matrix that records the events of the collaborative process in a large collection of overlapping frames. In our case, the size of each frame is 15 events. We experimented how different frame sizes influence the patterns that are visible in the time series. We found that choosing larger frame sizes tends to smooth out the time series, resembling the effect of moving averages in time series: Broader trends in the

48. It is also possible to reconstruct the adjacency matrix for the other mode included in the incidence matrix by multiplying a transposed version of the matrix with the original version (in that order). The result would be a one-mode network of events. In this article we only consider the network of actors. 
Table 8.1: Fictional example of incidence matrix. A ' 1 ' indicates the participation of an actor in an event. The events in the columns are in chronological order.

\begin{tabular}{cccccc}
\hline & Event 1 & Event 2 & Event 3 & Event 4 & Event 5 \\
\hline Actor A & 0 & 1 & 0 & 1 & 1 \\
Actor B & 1 & 1 & 1 & 1 & 0 \\
Actor C & 0 & 0 & 1 & 0 & 0 \\
\hline
\end{tabular}

Table 8.2: Adjacency matrix constructed from the fictional incidence matrix of table 2. The diagonal is disregarded because it only represents the number of times that an actor featured in an event.

\begin{tabular}{cccc}
\hline & Actor A & Actor B & Actor C \\
\hline Actor A & - & 2 & 0 \\
Actor B & 2 & - & 1 \\
Actor C & 0 & 1 & - \\
\hline
\end{tabular}

time series are maintained with larger frame sizes, but smaller changes become invisible as the frame size increases. We also found that smaller frame sizes tend to inflate the measurements for each frame. We decided to use a frame size of 15 because we found that with this frame size we were able to identity broader trends in the time series, while remaining sensitive to relatively short-term changes. An additional reason to choose a frame size of 15 is that is this frame size is close to the size of a similar dataset (14 events) that has been used in network analysis before by Doreian (1979), Borgatti and Everett (1997), and Borgatti and Halgin (2011). Thus, the first frame includes events 1 to 15, the second frame includes events 2 to 16, the third frame includes events 3 to 17 , and so on. Each frame is converted to a separate adjacency matrix, and the adjacency matrices are then used to calculate various network measures.

Based on our conceptual discussion we focus on three basic network measures, which are modularity, density, and betweenness centrality. In addition, we measure the total number of actors involved in the network, as it provides us with basic information about the evolution of the collaborative network structures over time. Modularity is a measure of community structure in networks, that is, how well a network can be divided in different groups based on the patterns of relationships between the nodes of the network. For our measurement of modularity we used an algorithm that puts each node of a network in a community of its own, and then re-assigns nodes to other communities until it achieves the highest possible measure of modularity (Blondel et al. 2008). In this paper we applied the method of Blondel et al. (2008), as implemented in the 'igraph' package for R (Csardi and Nepusz 2006). We also used the 'igraph' package for the calculation of density and betweenness centrality. Density measures how many of the potential relationships in a network are present, ranging from 0 (no relationships are present) to 1 (all potential relationships are present) (Wassermann and Faust 1994). To 
study the role of leadership in collaborative networks we use betweenness centrality as our measure (Freeman 1978). Betweenness centrality is typically high for actors if many of the shortest paths in a network pass through their position. It thus provides a measure of the extent that they serve as a linking pin between different parts of the network.

We wrote a number of functions in $\mathrm{R}$ to extract the overlapping frames from incidence matrices and to automate the analysis of larger collections of adjacency matrices ${ }^{49}$. One of the functions produces an adjacency matrix for each frame. We then make measurements of each adjacency matrix using the igraph package and record the measurements in time series. The patterns in the time series are inspected visually and our interpretations of the patterns are supported by our interpretation of the underlying sequences of events. We also inspected numerous plots of the network as it existed during different stages of its development in order to get a visual impression of the network structures that are behind the patterns observed in the time series. These plots are not included in the article.

In addition to our longitudinal analyses of network size, modularity, density, and centrality we also perform an analysis of the core-periphery structure of the networks in our cases. There is no immediate reason to do so based on our conceptual discussion, but figures 8.1 and 8.2 reveal that there are relatively many actors that are involved in events of the collaborative process only sporadically, while a small set of actors is involved on a more structural basis. We perform the core-periphery analysis to determine the extent to which this leads to a collaborative network structure where there is a core group of frequently interacting actors and a peripheral group of actors who are involved only on an incidental basis. For this analysis we use an algorithm in Ucinet that calculates continuous core-periphery scores (also known as coreness) for each actor in the network and then suggests a partition between core and periphery based on these scores ${ }^{50}$ (Borgatti, Everett, and Freeman 2002; Borgatti, Everett and Johnson 2013). For this analysis we do not make a distinction between different frames over time, but we use an adjacency matrix that aggregates all interactions for the entire process as an input.

Other approaches to the longitudinal investigation of network dynamics exist. Typically, these involve the development of statistical models that model latent network dynamics that occur as a result of opportunities and constraints created by the (past) network structure itself, or as a result of micro-level behavior of the actors that are members of the network (Doreian and Stokman 1997; Snijders 2011; Stadtfeld and Geyer-Schulz 2011). The implications of the models are tested through an analysis of empirical observations at two or more points in time. A drawback of this approach is that

49. These functions are available at http://www.wouterspekkink.org/?page_id=163

50. We use the MINRES algorithm, because it excludes the diagonal of the matrix in the calculation of coreness. In our networks, the diagonal has no relevant meaning. 
the network dynamics themselves are not empirically observed; empirical observations are limited to the network measurements that are performed at different points in time. Our own approach allows for an empirical reconstruction of the actual network dynamics. However, the time series thus produced are purely descriptive. Also, our approach depends on the availability of archival data, which raises certain limitations for the level of detail at which a process can be reconstructed, and the consistency with which actors could be identified. A great deal of uncertainty thus surrounds the time series, and it is difficult to give a measure of this uncertainty. Therefore, we use the time series primarily as diagnostic tools that put the focus on various parts of the process where it is interesting to take a closer look at the underlying qualitative event data. Our interpretation of the patterns therefore depends mostly on our qualitative observations, although the time series provide us with useful starting points. This makes it impossible to identify the mechanisms underlying the observed dynamics with the same rigor that is achieved through statistical modeling. However, the analysis might provide insights that are useful as input for future studies in which statistical models of network dynamics are used to study the mechanisms underlying processes similar to those studied in this paper.

Table 8.3 summarizes the propositions that follow from our conceptual discussion, and outlines the empirical patterns that we associate with the different propositions.

Table 8.3. Summary of propositions and associated empirical patterns.

\begin{tabular}{|c|c|}
\hline Propositions & Empirical patterns \\
\hline $\begin{array}{l}\text { Proposition 1a: The actors involved in the collaborative } \\
\text { process engage in collective meetings, leading to } \\
\text { collaborative network structure with low modularity. }\end{array}$ & $\begin{array}{l}\text { The time series of the network measures show a low level } \\
\text { of modularity. }\end{array}$ \\
\hline $\begin{array}{l}\text { Proposition } 1 b \text { : Different groups of collaborating actors } \\
\text { meet each other at different times, leading to a collaborative } \\
\text { network structure with high modularity. }\end{array}$ & $\begin{array}{l}\text { The time series of the network measures show a high level } \\
\text { of modularity. }\end{array}$ \\
\hline $\begin{array}{l}\text { Proposition } 2 a \text { : The collaborative network structure that } \\
\text { emerges from the collaborative governance process is } \\
\text { characterized by a high density of relationships. }\end{array}$ & $\begin{array}{l}\text { The time series of the network measures show a } \\
\text { consistently high level of network density. }\end{array}$ \\
\hline $\begin{array}{l}\text { Proposition } 2 b \text { : The collaborative network structure that } \\
\text { emerges from the collaborative governance process is } \\
\text { characterized by a low density of relationships. }\end{array}$ & $\begin{array}{l}\text { The time series of the network measures show a } \\
\text { consistently low level of network density. }\end{array}$ \\
\hline $\begin{array}{l}\text { Proposition } 3 a \text { : In the collaborative process, leaders act as } \\
\text { facilitators of collective forums. }\end{array}$ & $\begin{array}{l}\text { The time series of the network measures show no } \\
\text { differences in the betweenness centrality of actors } \\
\text { identified to act as leaders in the collaborative process and } \\
\text { other actors. }\end{array}$ \\
\hline $\begin{array}{l}\text { Proposition } 3 b \text { : In the collaborative process, leaders act as } \\
\text { bridges between different groups of collaborating actors. }\end{array}$ & $\begin{array}{l}\text { The time series of the network measures show a high level } \\
\text { of betweenness centrality of actors that are identified to act } \\
\text { as leaders in the collaborative process. }\end{array}$ \\
\hline
\end{tabular}




\subsection{THE CASE STUDIES}

\subsubsection{Biopark Terneuzen - Overview of the collaborative process}

Figure 8.3 offers a rough overview of the Biopark Terneuzen collaboration and its antecedents. Biopark Terneuzen was officially opened during a public event in February 2007. The collaboration aims to realize residual material exchanges between several companies in the Canal Zone. Before the formal opening of Biopark Terneuzen in 2007, several collective meetings had taken place through which public and private actors involved in the initiative developed their vision of what Biopark Terneuzen should become.

The vision was not developed from scratch; several of the plans included in the overarching vision had already been in development for some time, although these plans had not been explicitly brought together before the start of the Biopark Terneuzen collaboration. One of the developments that was incorporated in the collaboration concerns the development of a greenhouse area, the official planning procedures for which had commenced in 2004, following several years of negotiation on the size and location of

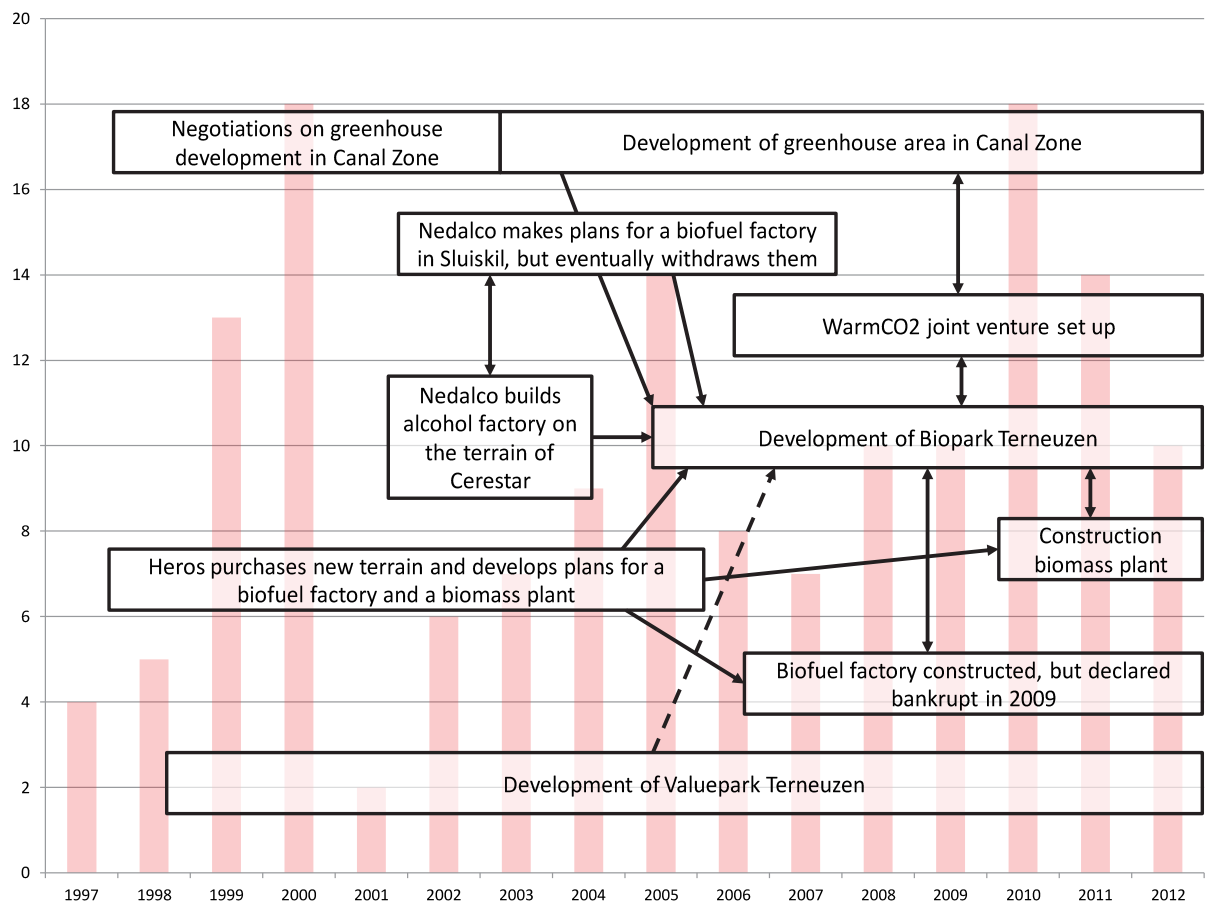

Figure 8.3: Summarizing overview of developments in the Biopark Terneuzen collaboration. Arrows indicate which developments are historically related. Double-headed arrows indicate mutual influences. The dashed arrow symbolizes that Valuepark Terneuzen and Biopark Terneuzen remained largely independent developments (see description in section 8.4.1). The bar chart plotted in the background shows the number of observed events for each year. 
the greenhouse area. Part of the plans was to have industry in the region supply the greenhouse area with residual heat and $\mathrm{CO}_{2}$. The plans were included as a central part of the Biopark Terneuzen collaboration, and during the collaborative process a joint venture called $\mathrm{WarmCO}_{2}$ was set up by the port authority Zeeland Seaports, the fertilizer producer Yara (the company that would supply the residual heat and $\mathrm{CO}_{2}$ ), and the construction company Visser \& Smit Hanab to develop the necessary pipeline infrastructure and govern the contracts required for the exchanges. The first part of the pipeline infrastructure had been realized in 2009, and by then 3 commercial greenhouses had been attracted to the area. The exchanges were implemented in the same year.

Another development that was incorporated into the Biopark Terneuzen collaboration concerns the development of an industrial terrain that the waste collection and processing company Heros purchased by the end of 1999. The terrain offered more room than Heros required for its own activities, and the company started exploring other uses for the space that it didn't use. By 2006, Heros, in collaboration with other companies, had developed plans for the construction of a biofuel factory and a biomass plant on its terrain. Both plans were incorporated in the Biopark Terneuzen collaboration, and both facilities were constructed (by other companies). The company that constructed the biofuel factory (Roosendaal Energy) went bankrupt in 2009, partly as a consequence of the economic crisis and partly due to the fact that the national government decided in 2008 not to support biofuel production in the Netherlands. Another company restarted the biofuel factory in 2012

Another company that wanted to construct a biofuel factory in the region is Nedalco. The same company also constructed an alcohol factory on the terrain of Cerestar (a company owned by Cargill). The alcohol factory uses several residual materials produced by the production facilities of Cerestar. The existing exchanges between Nedalco and Cargill, as well as the plans for the biofuel factory were included in the Biopark Terneuzen collaboration. The plans for the biofuel plant were eventually withdrawn, because Nedalco wasn't satisfied with the amount of subsidies that it received for the development of the plant. This was a major setback for the collaboration, as the biofuel factory was to serve as one of the suppliers of $\mathrm{CO}_{2}$ to the greenhouse area.

In 2001 the port authority Zeeland Seaports and the chemical company Dow Benelux started a joint venture to develop a new complex near the existing complex of Dow, where chemical production companies and logistical companies would be concentrated. The initiative was developed independently from Biopark Terneuzen. However, one of the companies interested in establishing in the new park had plans for a biofuel factory, which was considered as a potential contribution to the Biopark Terneuzen initiative. However, the company finally decided not to construct the biofuel factory, largely for the same reasons that led Nedalco to withdraw its plans. 
By the end of the study period (2012) Biopark Terneuzen was still in development. By then the collaborating partners had hoped to have attracted more greenhouses, but, partly as a result of the economic crisis, acquisition activities were met with little success. In the next section we present our findings on the network dynamics that emerged from the Biopark Terneuzen collaboration. The reader should note that $x$-axes of the time series presented in the next section are not based on calendar data, but on the order of the occurrence of events. The number of events observed in each year varies, and as a result the exact period of time covered by each frame of the time series varies as well.

\subsubsection{Biopark Terneuzen - Network dynamics}

Figure 8.4 visualizes the number of actors involved in the collaborative network of Biopark Terneuzen throughout time. The mean number of actors involved for the entire time series is about 28 actors. The highest number of actors in the network is 40 (in frames 46 and 85) and the minimum number of actors is 18 (in frames 28 and 29). In the time series there is one temporary increase that stands out in particular, which occurs from frame 33 and lasts until frame 58. The frames that lie within this range include the collective meetings that are organized to develop the vision for Biopark Terneuzen, which took place before the collaboration formally started. As discussed in the previous section, the Biopark Terneuzen collaboration builds on developments that were already in progress in the region. The actors involved in these developments used to work more or less independently, but in the collective meetings they are brought together. Additional actors were involved in the collective meetings as well to support the process with knowledge resources. This included consultancy companies as well as several knowledge institutes. Many of these actors are not directly involved in the implementation of the plans for Biopark Terneuzen itself, which explains why the number of actors in the network gradually decreases after the formal opening of Biopark Terneuzen, when a start

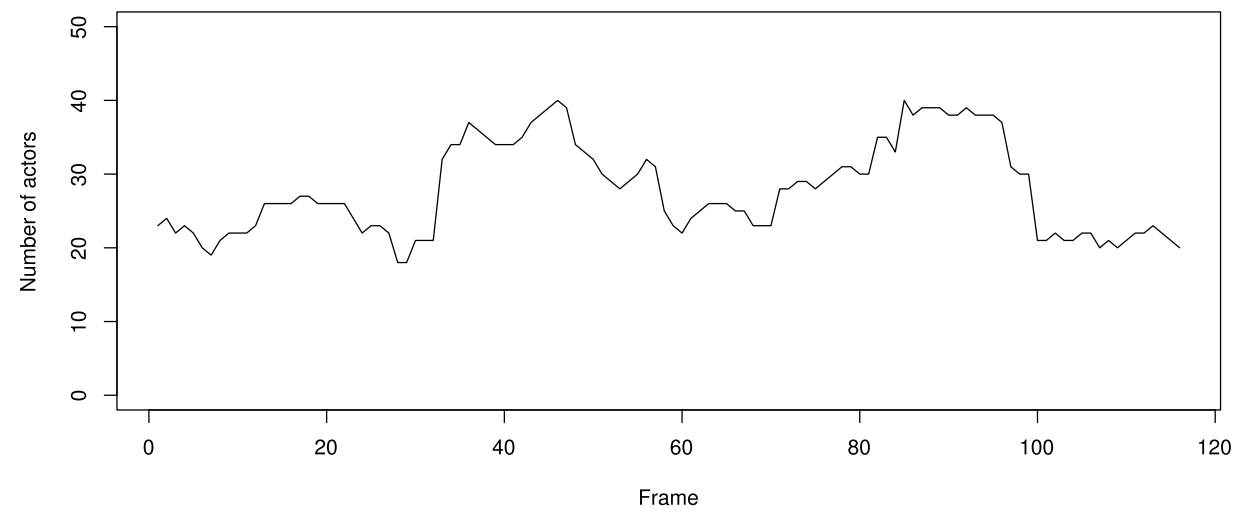

Figure 8.4: Time series of number of actors in the Biopark Terneuzen collaboration. 
is made with the actual implementation of the plans. The implementation of plans is pursued through projects that occur largely in parallel.

Another increase in the number of actors in the network starts at around frame 71 , and ends at frame 96 . The increase is partly the result of the fact that the collaborating partners involve additional actors from outside the initial group of collaborating partners. The additional actors are involved because the success of some of the projects depends partly on the cooperation and the resources of actors outside the initial group of collaborating partners. The increase that starts at frame 71 is also partly the result of the start of an interregional collaboration called Biobase Europe, for which Biopark Terneuzen is used as a building block, alongside a similar initiative that was being developed in Flanders (BioValley Ghent). This interregional collaboration involves actors affiliated to Biopark Terneuzen, as well as actors affiliated to the Flemish initiative.

After frame 96 the number of actors drops. At this stage, some of the projects included in the Biopark Terneuzen collaboration are finished and others have failed. Nedalco had withdrawn its plans for a biofuel factory, and the biofuel factory on the terrain of Heros went bankrupt. At this stage, most activity occurs in the development of the greenhouse area and the associated pipeline infrastructure. The infrastructure for the supply of residual heat and $\mathrm{CO}_{2}$ from Yara to the greenhouse area is completed and officially put into use, and the focus of the activities shifts to attracting additional greenhouses to the greenhouse area. With the reduced number of projects occurring in this period, the number of active actors in the network is also relatively low compared to the period before frame 96.

Figure 8.5 shows the time series of modularity for the Biopark Terneuzen collaboration. The mean value for modularity is 0.35 . The highest observed value of modularity is 0.70 at frame 65 , and the lowest observed value for modularity is 0.06 at frame 43 . The pattern in the time series of modularity largely follows the storyline outlined above. Before the formal start of the Biopark Terneuzen collaboration actors work on parallel projects in groups that exist largely in parallel. At this point, modularity is moderately high. The low level of modularity that lasts from frames 33 to 57 corresponds with the collective meetings in which the initial group of collaborating partners develop their vision for Biopark Terneuzen. Modularity decreases from frame 82, primarily as the result of the international collaboration that starts around this time, which involves actors that are also involved in projects of Biopark Terneuzen. The modularity remains low as the number of parallel projects increases near the end of the observation period. It suddenly increases near the end, as Heros starts a new project for a second biomass plant on its terrain, and the bankrupt biofuel factory on the terrain of Heros is taken over. The start of these new developments, in addition to the continuation of projects related to the greenhouse area contributes to the increased modularity. 


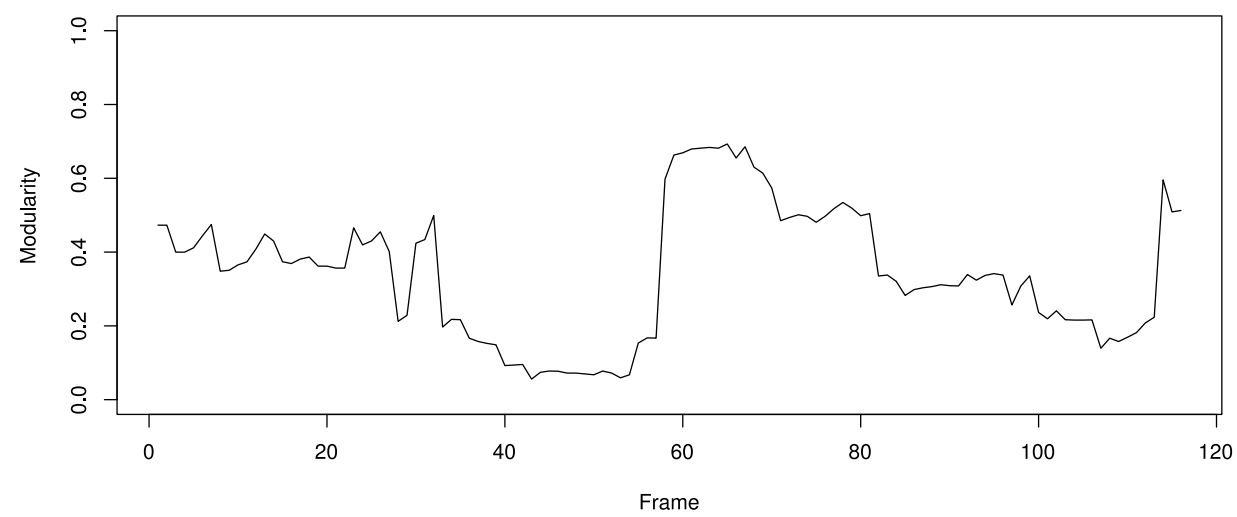

Figure 8.5: Time series of modularity in Biopark Terneuzen collaboration.

Figure 8.6 shows the development in the density of the collaborative network. The mean density is 0.24 . The highest observed value of density is 0.50 at frame 53 . The lowest observed value is 0.09 at frame 70 . During frames 41 to 66 there is a temporary increase of density, which relates to the collective meetings that were organized in preparation of the Biopark Terneuzen initiative. As soon as actors start working on the implementation of projects, density drops again, which corresponds with the observations made above on the number of involved actors and the modularity of the network. By the end of the process (from frame 115 to frame 129) density increases temporarily, which relates to the reduced number of projects occurring at the time. Density decreases again at the end, for the same reasons that the modularity of the network increases at the same time: Heros starts with the development of a second biomass plant and the biofuel factory that went bankrupt is taken over by a company that is new to the network. Because these developments occur largely in parallel to the development of the greenhouse area, density is relatively low at this stage of the observed period.

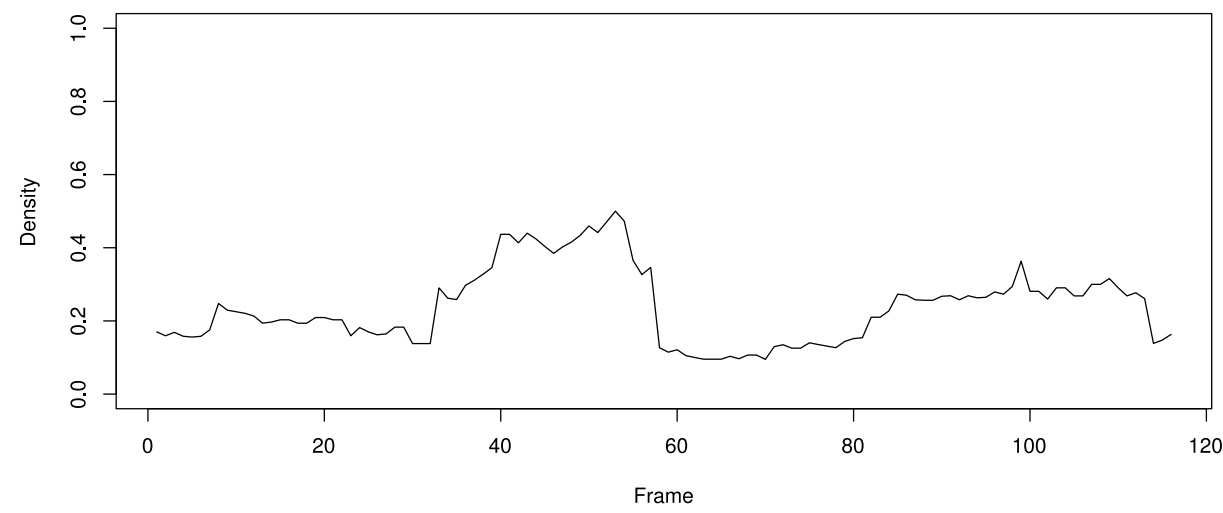

Figure 8.6: Time series of density in the Biopark Terneuzen collaboration. 


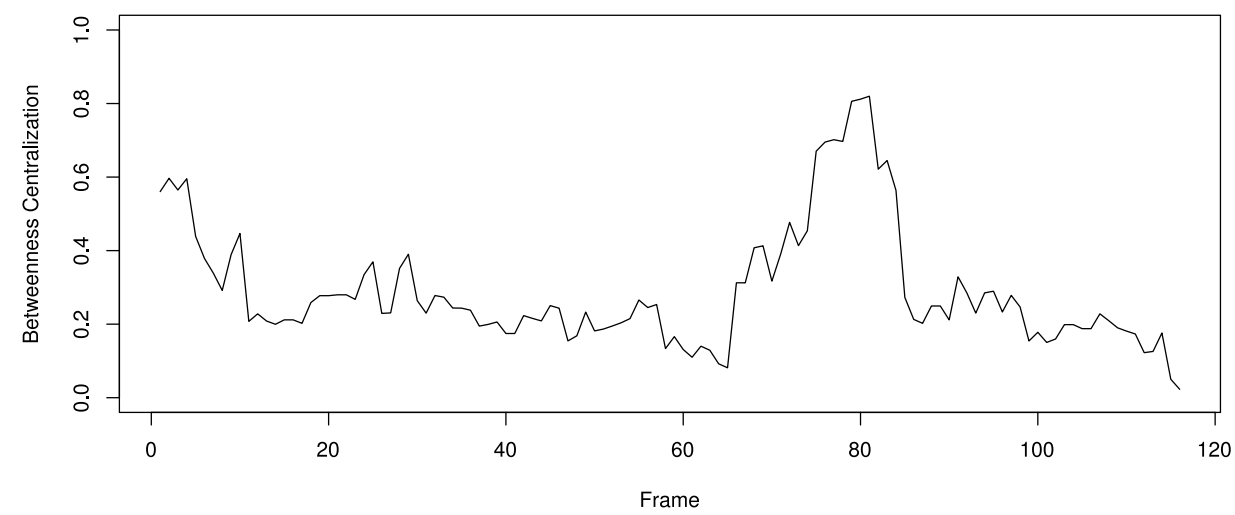

Figure 8.7: Time series of betweenness centralization in the Biopark Terneuzen collaboration.

Figure 8.7 shows the time series for the betweenness centralization of the network. The mean value for betweenness centralization is 0.29 . The maximum observed value is 0.82 at frame 81 and the minimum observed value is 0.02 at frame 116 . Most of the time the value of betweenness centrality is modest, but it is high for the first few frames, and for frames 75 to 84. To determine which actors are central in these periods we also made time series for the betweenness centrality of individual actors. We then calculated which actors have the highest mean score on betweenness centrality (see table 8.4). Figures 8.8 to 8.12 show the time series for the top 5 actors.

The time series reveal that the port authority Zeeland Seaports (figure 8.8) and the province of Zeeland (figure 8.10) score relatively high on betweenness centrality in the early stages of development. This concerns the phase in the process where the collective meetings on Biopark Terneuzen have not yet taken place, and where the various projects that are eventually incorporated into the Biopark Terneuzen collaboration are developing independently from each other. Zeeland Seaports and the province of Zeeland typically play a role in multiple of these developments at the same time, whereas other actors are usually involved in just one development. The province and the port authority thus served as a bridge between the different groups of actors that were working on the different projects. From our qualitative event data it is also clear that both actors played

Table 8.4: Top five actors for betweenness centrality in Biopark Terneuzen collaboration.

\begin{tabular}{lc}
\hline Name of actor & Mean betweenness centralization \\
\hline Zeeland Seaports & 0.18 \\
Municipality of Terneuzen & 0.15 \\
Province of Zeeland & 0.11 \\
Nedalco & 0.11 \\
WarmCO2 & 0.06 \\
\hline
\end{tabular}


an important role in bringing the different actors together for the Biopark Terneuzen collaboration. The patterns in their betweenness centrality suggest that they were able to play this role because they were in a good position to broker the relationships between the different groups of actors that were active in the region.

Zeeland Seaports and the Municipality of Terneuzen were typically active in multiple of the projects that were carried out in parallel to implement the plans for Biopark Terneuzen. As a result, they also occasionally acted as bridges between the different groups of actors during the implementation phase of the collaborative process. The increase in the betweenness centrality of the municipality from frame 75 to frame 84 occurs in a period where relatively many of these developments unfold at the same time. The municipality of Terneuzen played a role in most of these developments, which causes the municipality's score on betweenness centrality to be especially high at this stage.

The betweenness centrality of Nedalco is relatively high in two stages of the observed period. In the period before the formal start of Biopark Terneuzen Nedalco is negotiating with the municipality of Bergen op Zoom in the province of Noord-Brabant about relocating its establishment in Bergen op Zoom to a new location, while also engaging in projects to explore opportunities for biofuel production, for which Sas van Gent in the Canal Zone was considered as one of the locations.

In relation to both these activities Nedalco is negotiating with actors inside and outside the Canal Zone. As a result, Nedalco acts as a bridge between these actors. The relatively high level of centrality in the period during the collaboration can be explained in a similar way. Here, Nedalco is negotiating with several actors affiliated to the national government to gain support for its planned biofuel factory. Again, Nedalco acts as a bridge between actors inside the Canal Zone and outside the Canal Zone in this period. The fact that the betweenness centrality of Nedalco suddenly flats out reflects Nedalco's decision to withdraw from the collaboration.

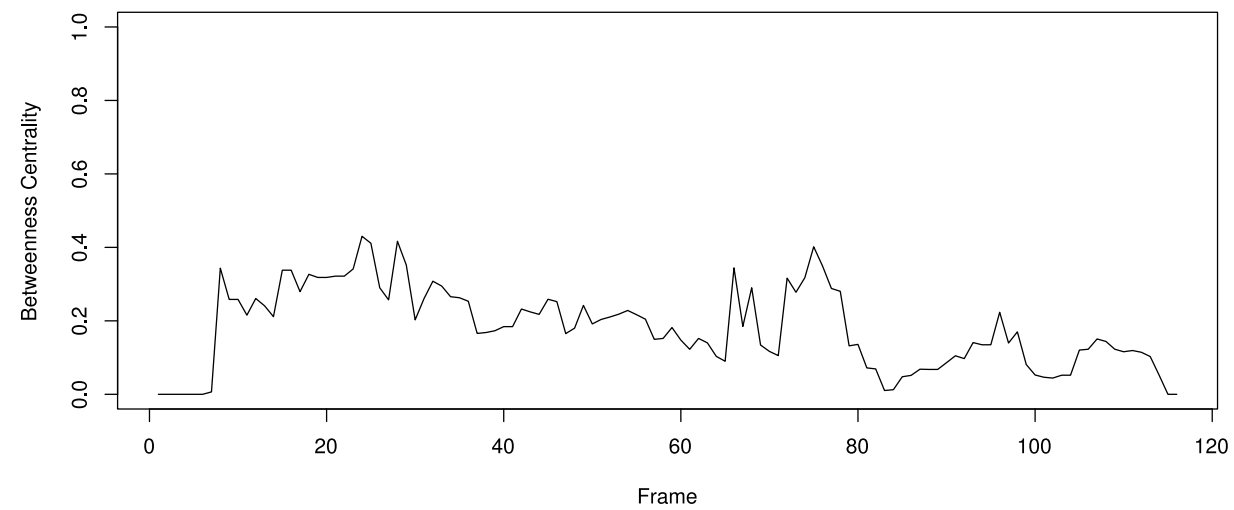

Figure 8.8: Time series of betweenness centrality for Zeeland Seaports. 


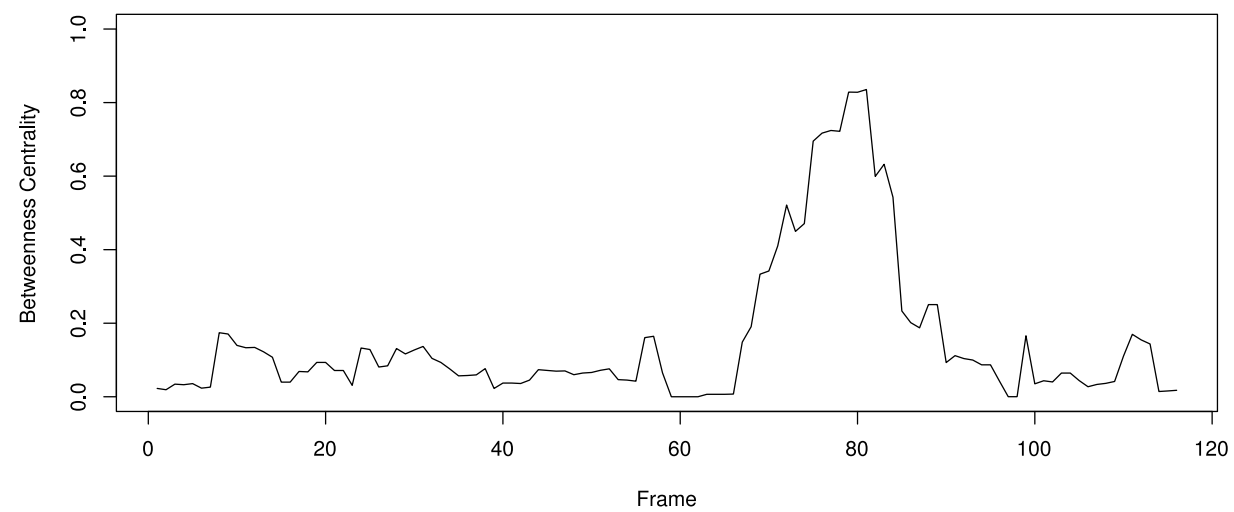

Figure 8.9: Time series of betweenness centrality for Municipality of Terneuzen.

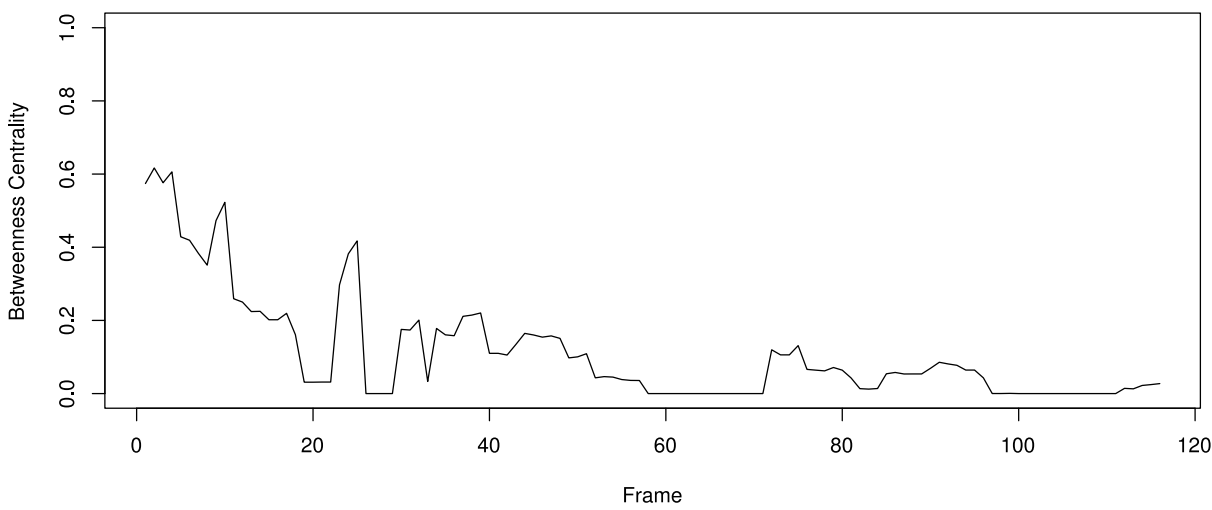

Figure 8.10: Time series of betweenness centrality for Province of Zeeland.

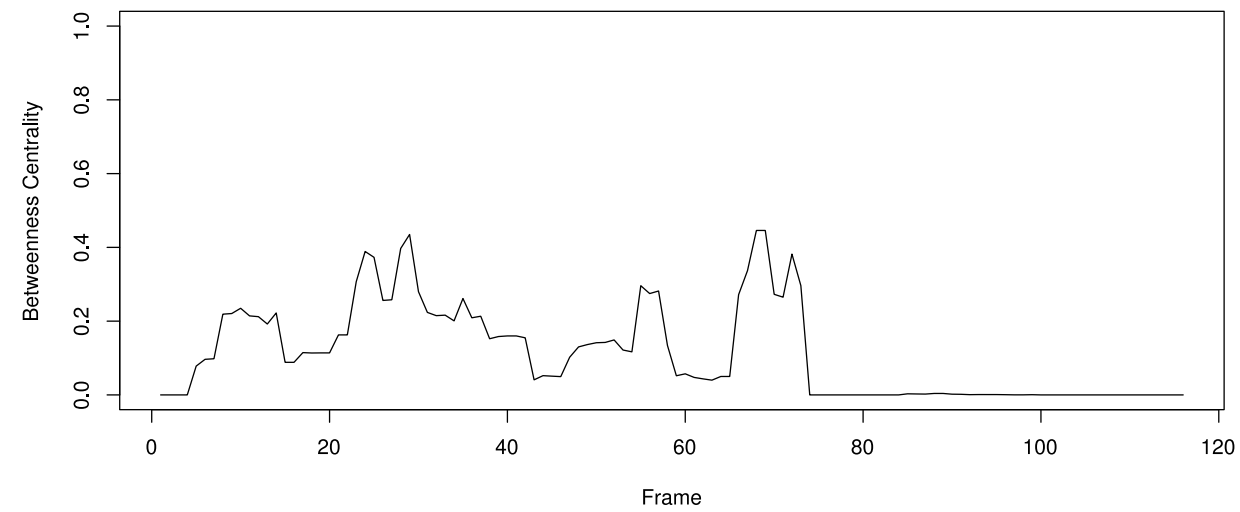

Figure 8.11: Time series of betweenness centrality for Nedalco 
Warm $\mathrm{CO}_{2}$ is the joint venture that was set up by Zeeland Seaports, Yara, and Visser 8 Smit Hanab to develop the pipeline infrastructure for the distribution of $\mathrm{CO}_{2}$ and heat from Yara to the greenhouses. Overall, the betweenness centrality of the organization is modest, but it reaches values of around 0.3 a few times in the later stages of the process (figure 8.12), which is caused by the central role that the organization plays in activities that are carried out for the development of the greenhouse area and the associated exchange infrastructure.

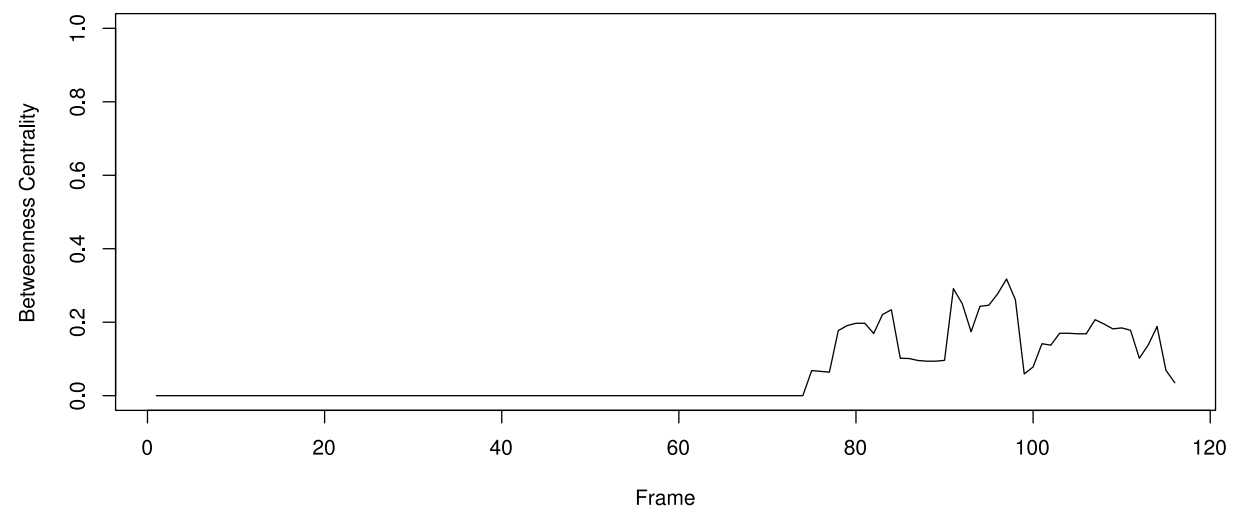

Figure 8.12: Time series of betweenness centrality for WarmCO2.

The various time series of betweenness centrality show that different actors act as a bridge between parts of the network in different stages of development. The patterns of betweenness centrality of for the governmental organizations are especially interesting, because they reflect the role that these organizations play in as a bridge between different groups of actors involved in different projects. The governmental actors thus serve as a source of continuity in the collaborative process and a source of coherence in the collaborative network.

Table 8.5 shows a list of 8 actors that are part of the core of the collaborative network according to the core-periphery analysis (with a concentration of 0.856). All these actors are part of the initial group of collaborating partners that were also involved in the collective meetings that took place to develop a vision for Biopark Terneuzen. Many of these also played an important role in the implementation of plans that were included in this vision. The central role that the governmental organizations play in the collaborative network is confirmed by their relatively high scores on coreness. The analysis indicates that the core of the network is small, and that most actors are involved only on an incidental basis. Thus, the collaborative network that emerged from the Biopark Terneuzen collaboration is transitory. 
Table 8.5: Actors that are part of the core of the collaborative network of Biopark Terneuzen.

\begin{tabular}{ll}
\hline Name & Coreness \\
\hline Municipality of Terneuzen & 0.429 \\
Zeeland Seaports & 0.397 \\
Province of Zeeland & 0.379 \\
Nedalco & 0.278 \\
Yara & 0.257 \\
University of Wageningen & 0.230 \\
TransForum & 0.204 \\
Heros & 0.177 \\
University of Nijmegen & 0.164 \\
Van de Bunt Consultancy & 0.164 \\
Ecoservice Europe & 0.159 \\
\hline
\end{tabular}

\subsubsection{Biopark Terneuzen - Discussion of results}

If we confront our findings with the propositions derived from our conceptual discussion, the analysis of the case of Biopark Terneuzen reveals a mixed story. Several collective meetings did indeed take place, which also entails a low modularity of the network (proposition 1a) and a relatively high level of network density (proposition 2a) for the period in which these meetings took place. However, this period is relatively short. Most activities took place in groups that existed in parallel, sometimes leading to high levels of modularity (proposition 1a) and low density (proposition 2b). Also, in periods where modularity is low and density is high, betweenness centralization is also low (proposition $3 a)$, whereas in periods where modularity is high and density is low higher values of betweenness centralization are observed. This can be accounted for by the patterns in betweenness centrality scores of a small number of actors (proposition 3b). Thus the process models of Ansell and Gash (2008) on the one hand and Bryson, Crosby and Stone (2006) and Emerson, Nabatchi and Balogh (2012) on the other hand both have value for understanding what happened in the case of Biopark Terneuzen, depending on the specific stage of the process that is observed. If we look at the overall picture, then the perspective of Emerson, Nabatchi and Balogh (2012) comes closest to what we observe in the case of Biopark Terneuzen. In the initial stages of the collaborative process, face-to-face interactions among a larger group of actors takes place to develop a shared vision. Once the vision is in place, the continuation of face-to-face interactions does not seem to be necessary.

An aspect of the process that came up, but that neither of the models addresses in detail, is that many actors become involved in the collaborative process on an incidental basis. These actors are typically involved because their cooperation or support is required to realize some of the plans of the collaborating partners. These actors do not 
become part of the core group of collaborating partners, which remains relatively small. The incidental nature of their interactions raises questions about the extent that these actors form relationships of trust, mutual understanding and commitment with the core group of collaborating partners. Establishing such relationships among the core group of collaborating partners may be necessary, but the results of our analysis suggest that the collaborative process also involves the establishment of relationships with actors outside this core group, and that these are of a much shorter duration. These shorter term relationships are also likely to be driven by mechanisms other than building trust, mutual understanding and commitment.

\subsubsection{Sustainable Connections - Overview of the process}

The Sustainable Connections collaboration formally started in April 2009 when a steering group formed by the province of Noord-Brabant, the municipality of Moerdijk, the Business and Industry Circle of Moerdijk (a business association), the Department of Waterways and Public Works in South Holland, the water authority Brabantse Delta, and the port authority of Moerdijk signed a declaration of intent. Among the aims of the collaboration are the development of a pipeline infrastructure for the exchange of residual heat between companies, optimization of water loops at the industrial park of Moerdijk, improvement of the reachability of the industrial park of Moerdijk, improvement of employment opportunities, improvement of permitting procedures, and the stimulation of sustainable entrepreneurship among companies of the industrial park of Moerdijk.

Several projects have been carried out as part of the collaboration to realize these ambitions. This includes a conference on mobility, a project aimed to identify and award frontrunners in sustainable entrepreneurship, an experiment with more streamlined permitting, a project to explore the feasibility of water loop optimization, and several projects related to the development of a heat exchange network. The main achievement so far has been the realization of one part of the heat exchange network, where a company named Bewa supplies residual heat to its neighbors Bolsius and DCS.

Although the Sustainable Connections initiative was formally started in 2009, it builds on several earlier developments that occurred in the region (see figure 8.13). In fact, the collaboration itself can be understood as a continuation of a collaboration that has been in development since 1997. In that year a steering group was formed (the constellation of which is similar to that of Sustainable Connections) with the aim to stimulate sustainable development and safety at the industrial park of Moerdijk. One of the main activities of the group is the yearly publication of environmental monitoring reports, the first of which appeared in 1999. In 2005 it was decided that the group needed a more explicit vision on the sustainable development of the industrial park, in order to have a more effective impact. A master plan was developed and in 2007 the group was renamed to Sustainable Port and Industry Area Moerdijk (SPIA). The group continued the environ- 
mental monitoring activities, but also formulated more explicit goals on the sustainable development of the industrial park.

In the period of 2007 and 2008 the actors involved in SPIA made an inventory of residual material exchanges that had been implemented at the industrial park, and a similar inventory was made in an investigation on residual material exchanges in Western Brabant, which was commissioned by the province of Noord-Brabant. Several exchanges that were implemented since the late nineties were identified and several potential new exchanges were identified as well, including the exchange of heat between Bewa, Bolsius and DCS, for which these companies had already developed a business case themselves. In cooperation with public and private actors at the industrial park of Moerdijk, the province of Noord-Brabant decided to start a 'Proeftuin' project (a type of pilot project) to stimulate the further development of residual material exchanges between companies of Moerdijk. It was very explicitly decided to use the SPIA as a platform for the new project, because this would allow the project to build on the relationships that have historically developed between the collaborating parties of SPIA.

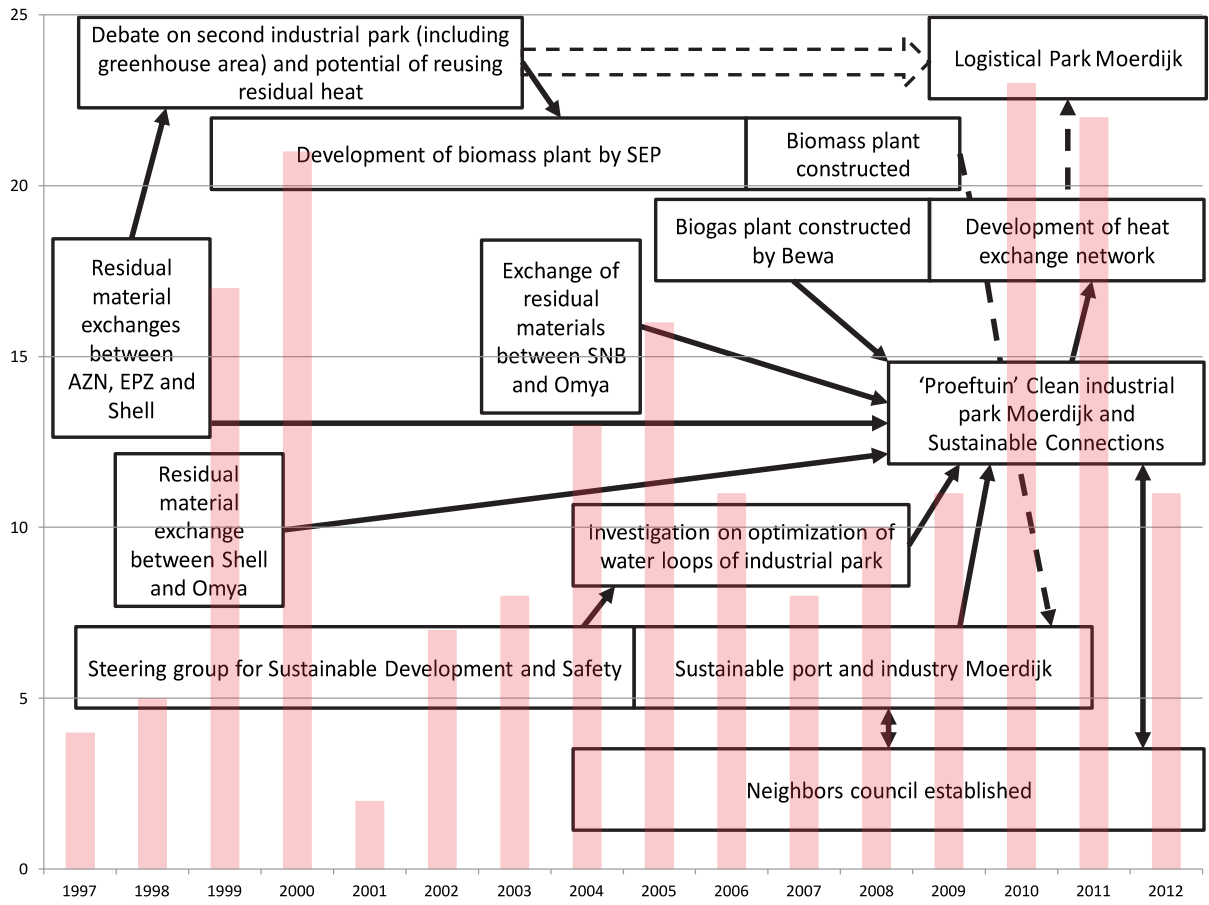

Figure 8.13: Summarizing overview of Sustainable Connections collaboration. Arrows indicate which developments are historically related. Dashed arrows symbolize loose connections. Doubleheaded arrows indicate mutual influences. The bar chart plotted in the background shows the number of observed events for each year. 
The heat exchange between Bewa, DCS and Bolsius (not yet realized at the time) was picked up as the first pilot project, and was realized in November 2009. After realizing this network, the collaborating parties also started working on the expansion of the infrastructure. Other projects were included in the collaboration as well, such as an exploration of possibilities to optimize water loops at the industrial park, which had been an ambition of the earlier incarnations of the steering group for a long time. Sustainable Connections and SPIA existed alongside each other as two separate projects for a while, but in 2011 it was decided to integrate them and to continue the Sustainable Connections collaboration.

A closely related development concerns the establishment of the so-called Neighbors Council. The council was established by the port authority of Moerdijk (based on the suggestion of Shell) in order to improve the communication between companies of the industrial park of Moerdijk and residents from the neighboring villages. The council discusses many developments that occur at and around the industrial park, as well as the results of the environmental reports that are published each year. Although the Neighbors Council is not an integrated part of the Sustainable Connections collaboration, the actors involved in both SPIA and Sustainable Connections see the Neighbors council as one of their main platforms for communication with the direct environment, and use meetings of the council to discuss developments in the collaboration with citizens.

More loosely related developments include the development of a second industrial park (initially the plans included a greenhouse area as well) at Moerdijk and the development of a biomass plant by a farmers' cooperation called Sustainable Energy Production (SEP). The plans for the second industrial park have caused a lot of debate over the years, and not all events recorded for this process are included in this case study. The events that have been included concern events where the involved actors discussed the possibility to have companies in the new industrial park reuse the residual heat of companies in the existing industrial park. The industrial park has not yet been developed, but by 2012 there were concrete plans to create the park as Logistical Park Moerdijk. The collaborating parties of Sustainable Connections also formulated the ambition to expand their heat exchange network to Logistical Park Moerdijk, as well as a nearby greenhouse area (Spiepolder).

The biomass plant of SEP was constructed as a solution to a surplus of poultry manure in the Netherlands. The development has taken place more or less independent from the other developments, although occasionally the involved actors discussed or explored the possibility to develop residual material exchanges with other companies in the industrial park. These ideas were also included in the inventory that SPIA made of potential residual material exchanges at Moerdijk, identifying the project of SEP as a potential building block for the Sustainable Connections collaboration. However, for reasons unknown to us the project was not integrated into the Sustainable Connections initiative. 
In the next section we present our findings on the network dynamics that emerged from the developments described above.

\subsubsection{Sustainable Connections - Network dynamics}

Figure 8.14 shows the time series for the number of actors involved in the collaborative network of Sustainable Connections. The mean number of actors in the network is 31 . The minimum number of actors observed is 16 , at frame 34 , and the maximum number of actors observed is 49 , at frame 118 . The number of actors starts relatively high (in the period before the formal start of the Sustainable Connections collaboration), as several developments occur at the same time, including the implementation of some of the early symbiotic exchanges, the establishment of the SPIA steering group, the discussion on the development of the second industrial park and greenhouse area, and the discussion on the development of SEP's biomass plant. The number of actors decreases gradually as the exchanges are implemented and the number of actors involved in other developments (primarily the discussion on the second industrial park and the biomass plant of SEP) decreases somewhat. From frame 41 an increase of actors in the network occurs, which is caused by the establishment of the Neighbors Council. From that point on, the number of actors involved in the network shows an overall growing trend. This trend is created by several developments, but in the later stages of the process the increases can be attributed primarily to actors being involved in activities related to the Sustainable Connections collaboration (which formally starts at frame 91), such as projects for the development of the heat exchange infrastructure, the water loops optimization project, and the frontrunners project. The initial group of collaborating actors successfully involves other companies in some of its activities, and additional actors are also attracted to aid in the practical implementation of projects.

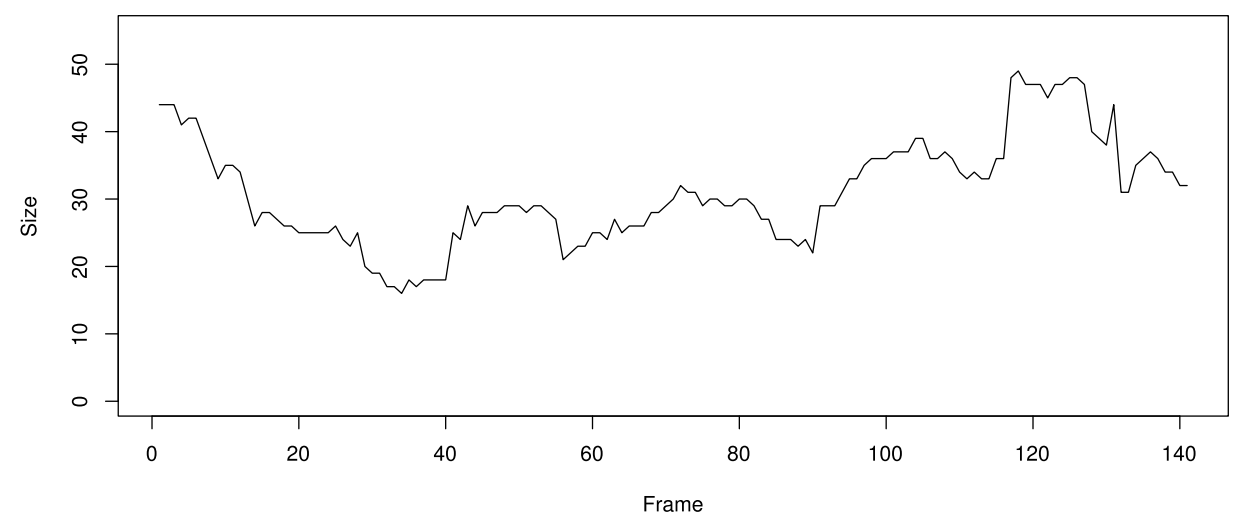

Figure 8.14: Time series of number of actors in the Sustainable Connections collaboration. 
Figure 8.15 shows the time series for the modularity of the network in the Sustainable Connections collaboration. The mean value for modularity is 0.31 . The highest observed value is 0.5 , at frames 74,75 and 76 . The lowest observed value is 0.11 , at frame 58 . The modularity of the network generally fluctuates around its mean value, making it difficult to observe clear trends. There are several points at which relatively low modularity is observed, which are around frame 14, around frame 58, around frame 90, and around frame 140. We could not find a clear substantive reason for the low point at frame 14 . The low points at frames 58, 90 and 140 all occur in periods where meetings of the Neighbors Council occur, and in which companies of the industrial park and the municipality and port authority of Moerdijk also participate. Other activities occur in parallel to these meetings, but these typically involve the same public and private organizations that also attend the meetings of the Neighbors Council (excluding the citizen organizations). Thus, the network that exists in these periods forms a relatively strongly integrated whole.

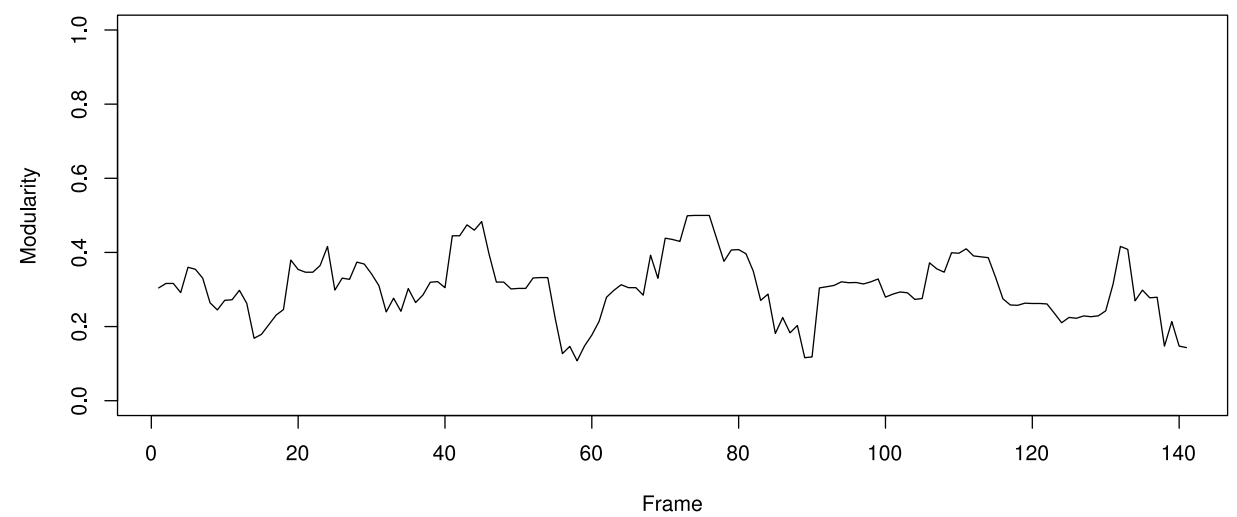

Figure 8.15: Time series of modularity in Sustainable Connections collaboration.

The points where modularity is relatively high occur at stages in the process where multiple activities unfold in parallel, carried out by different groups of actors. Before the start of the collaboration (frame 91) this primarily concerns activities related to the plans for a second industrial park, the biomass plant of SEP, the Neighbors Council, the SPIA group, as well as some privately organized initiatives for the establishment of residual material exchanges. After the start of the collaboration it concerns parallel projects of the collaboration, including different projects related to the development of the heat exchange network, improvement of water loops, environmental monitoring (a continuation of activities carried out by the SPIA group), and meetings on the identification of frontrunners. At the same time, meetings of the Neighbors Council also continue to take place, and most of its members typically feature together as a separate community in the network structure. They maintain this position because they are not involved in projects 
directly related to the Sustainable Connections collaboration; they are only informed about these projects from time to time.

Figure 8.16 shows the time series for the density of the network. The mean density of the network is 0.32 . The lowest value observed is 0.18 at frames 39 and 40 , and the highest value observed is 0.60 at frames 91,92 and 93 (the period around to the formal start of the collaboration). A temporary peak is reached at frames 58 and 59 , which relates to the establishment of the Neighbors council.

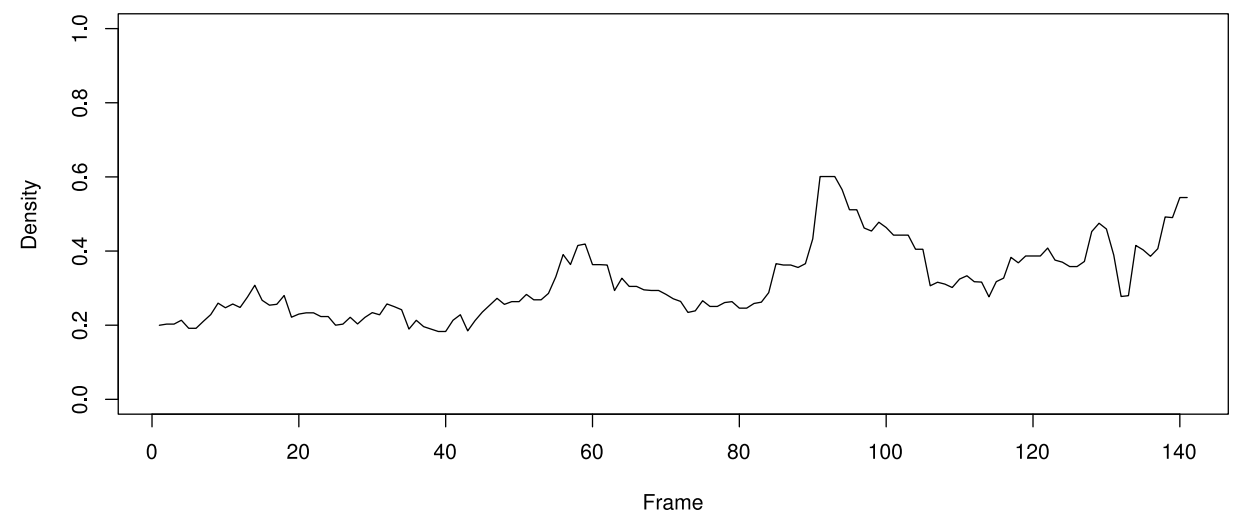

Figure 8.16: Time series of density in Sustainable Connections collaboration.

The peaks in density that occur in the later stages coincide with the start of the Sustainable Connections collaboration (around frame 91) and the implementation of the projects associated to the collaboration. Overall, the density of the network shows a slightly increasing trend, and compared with the period before the start of the collaboration it remains relatively high in the period after the formal start of the collaboration. Even though several projects occur in parallel in the Sustainable Connections collaboration, the overlap between the actors involved in these projects is somewhat greater than was observed in the case of Biopark Terneuzen, which may explain why density generally increases rather than decreases during the implementation of projects.

Figure 8.17 shows the time series for the betweenness centralization of the collaborative network of Sustainable Connections. The mean centralization is 0.27 . The lowest observed value of centralization is 0.05 at frame 63 . The highest observed value is 0.68 at frame 27 . To study which actors are responsible for these patterns, we applied the same strategy as in the case of Biopark Terneuzen, by first calculating the mean scores on betweenness centrality for all actors. Table 8.6 shows the top five actors that result from this calculation. The time series of betweenness centrality for the top five most central actors are visualized in figure 8.18 to 8.22 . 


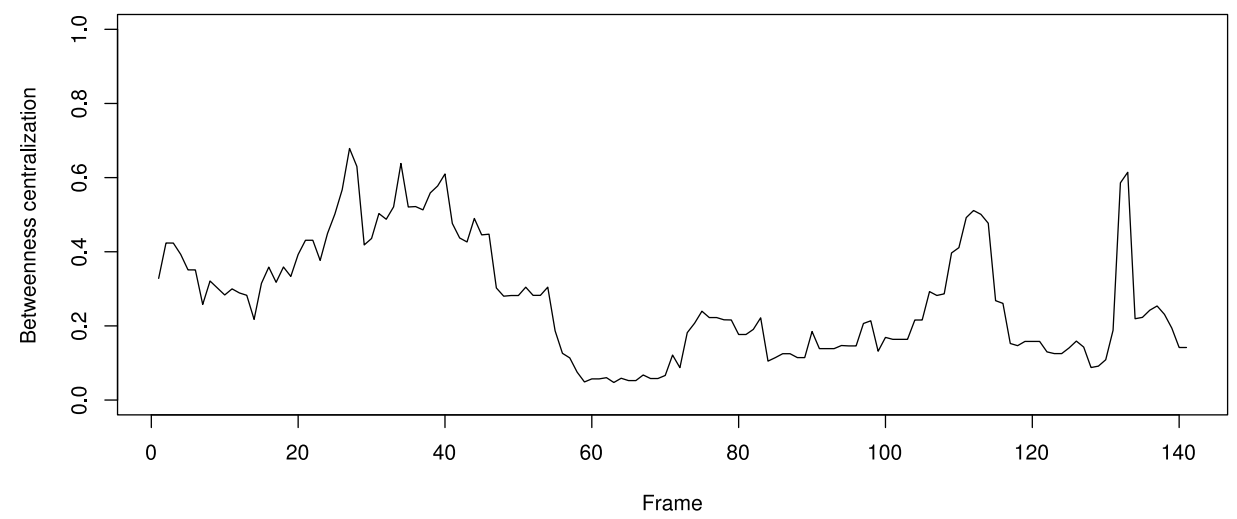

Figure 8.17: Time series of betweenness centralization for Sustainable Connections collaboration.

Table 8.6: Top five actors for betweenness centrality in Sustainable Connections collaboration.

\begin{tabular}{lc}
\hline Name of actor & Mean betweenness centralization \\
\hline Province of Noord-Brabant & 0.14 \\
Port authority of Moerdijk & 0.11 \\
Municipality of Moerdijk & 0.11 \\
SEP & 0.08 \\
Shell & 0.05 \\
\hline
\end{tabular}

Figure 8.18 shows the province of Noord-Brabant had a position of relatively high betweenness centrality primarily in the earlier stages of the process. This is caused by the fact that the province of Noord-Brabant has a role in most of the developments that take place at this stage, including the debate on the second industrial park and, occasionally, the development of the biomass plant of SEP. The province to some extent retains its central position during the collaborative process, but betweenness centrality is more modest here.

Although the port authority of Moerdijk was involved in several projects that occurred before the start of the collaborative process, it has a position of low betweenness centrality in this period. This is caused by the fact that the port authority was not heavily involved in the discussions on the second industrial park or in the development of the biomass plant at Moerdijk (figure 8.19). However, the authority was involved in setting up the Neighbors council and the various sustainability collaborations that have existed throughout the process. Thus, the port authority takes a position of relatively high betweenness centrality in these developments.

The municipality of Moerdijk also played a role in several developments that occurred in the early stages of development, and like the province, the municipality has a position of relatively high betweenness centrality here (see figure 8.20). The municipality of 


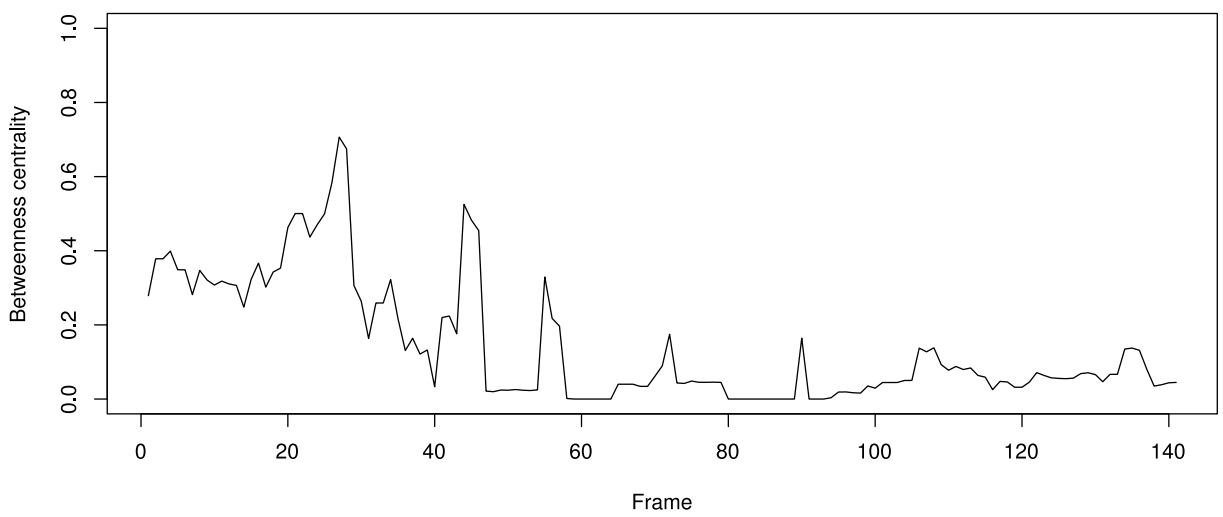

Figure 8.18: Time series of betweenness centrality for the province of Noord-Brabant.

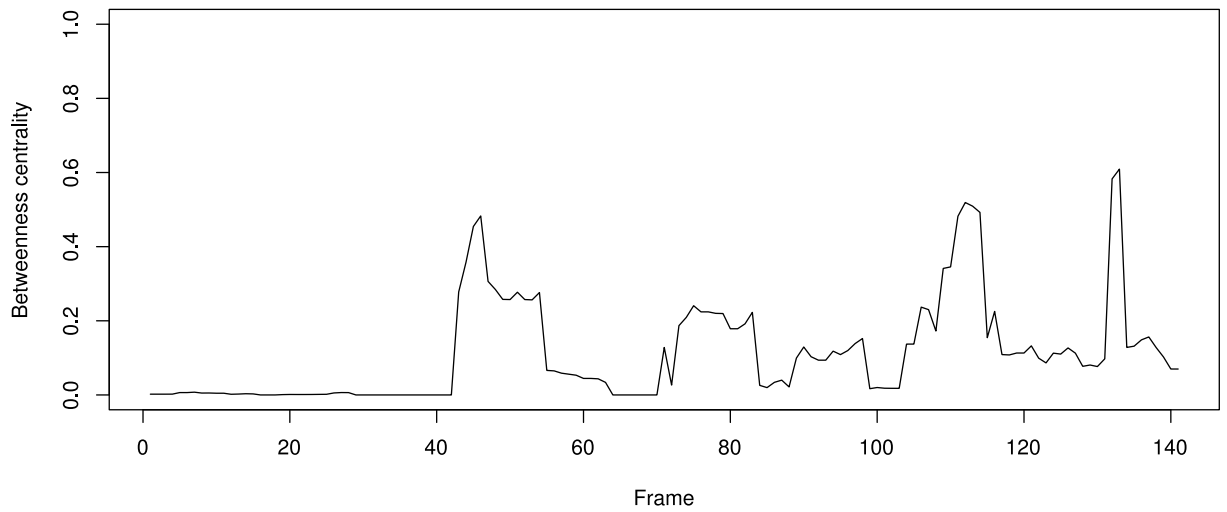

Figure 8.19: Time series for betweenness centrality for the port authority of Moerdijk.

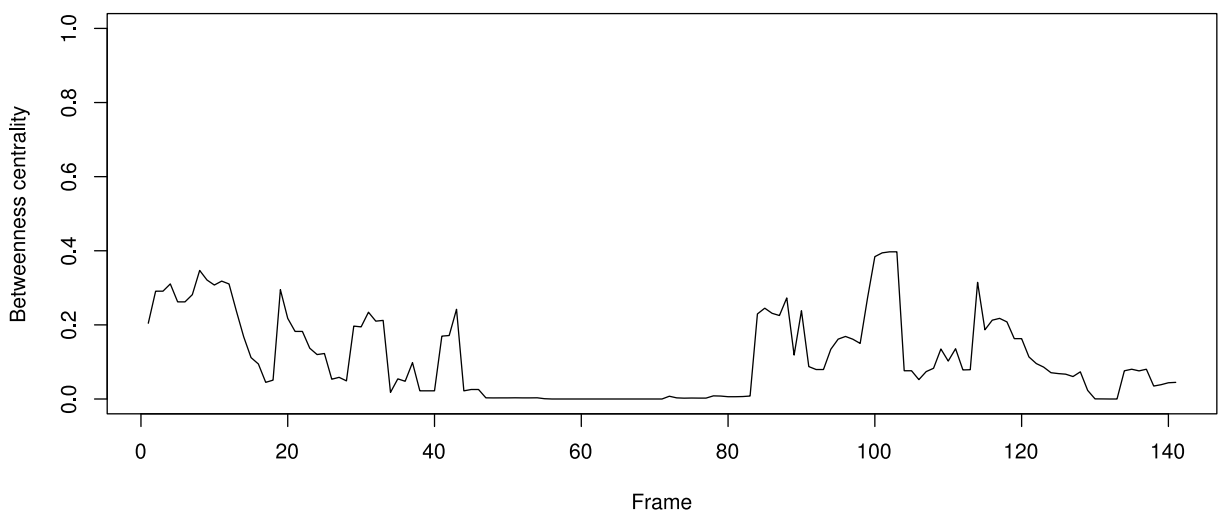

Figure 8.20: Time series of betweenness centrality for the municipality of Moerdijk. 
Moerdijk is also one of the core parties of the Sustainable Connections collaboration, which explains its relatively high betweenness centrality in the later stages of development. Betweenness centrality is slightly higher here than that of the province, which is primarily the result of events where the municipality attends meetings of the Neighbors Council, while simultaneously being involved in the Sustainable Connections projects. Thus, here the municipality is one of the actors that acts as a bridge between these two platforms.

The betweenness centrality of SEP is relatively high for a certain period of time (see figure 8.21) because the organization often served as the primary link between actors in the industrial park of Moerdijk and the other actors involved in the development of the biomass plant of SEP. The fact that betweenness centrality of the organization flats out reflects that the organization never became involved in the Sustainable Connections collaboration, and therefore disappears from the process.

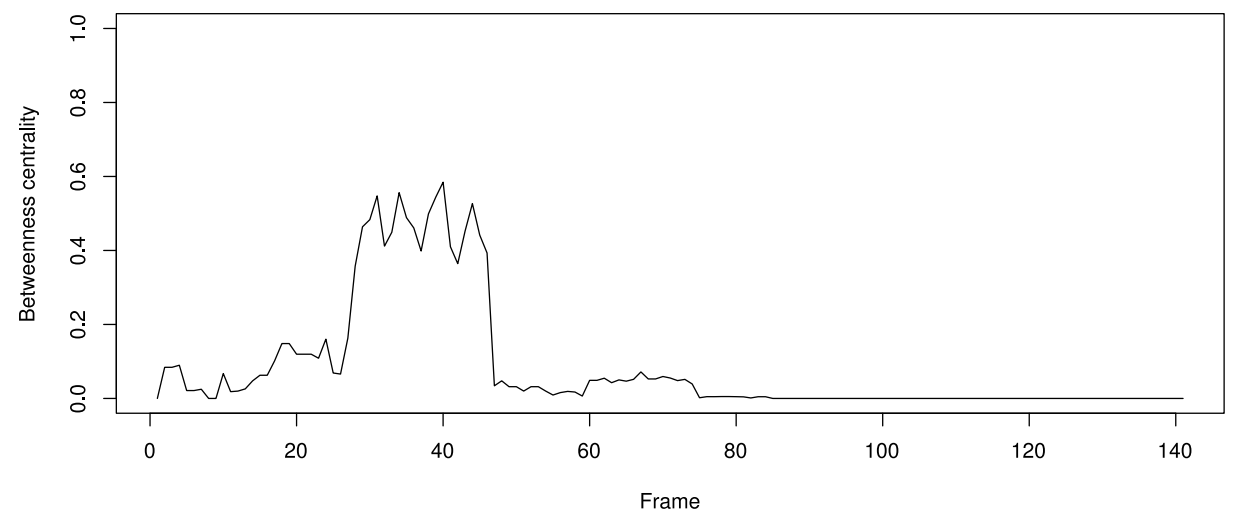

Figure 8.21: Time series of betweenness centrality for SEP.

Figure 8.22 shows that the betweenness centrality of Shell is quite modest. The peak in the early stages of development is the result of Shell's involvement in the implementation of several residual material exchanges. The peaks in the later stages of development occur because Shell is an active participant to projects of the Sustainable Connections collaboration, as well as the Neighborhood Council. In fact, the very idea to establish such a council originates from Shell. Like the municipality of Terneuzen, Shell acts as a bridge between the two platforms.

Table 8.7 shows a list 15 actors that are part of the core of the collaborative network according to the core-periphery analysis (concentration $=0.899$ ). The constitution of the core has clearly been influenced by the relatively strong presence of the Neighbors council throughout the process. As in the case of Biopark Terneuzen, the governmental organizations score relatively high on coreness. Somewhat surprisingly, the steering 
group associated with the various collaborative platforms that have been set up are not included in the core that results from the analysis, although in terms of coreness their scores are close to that of the 12 that are included in the core.

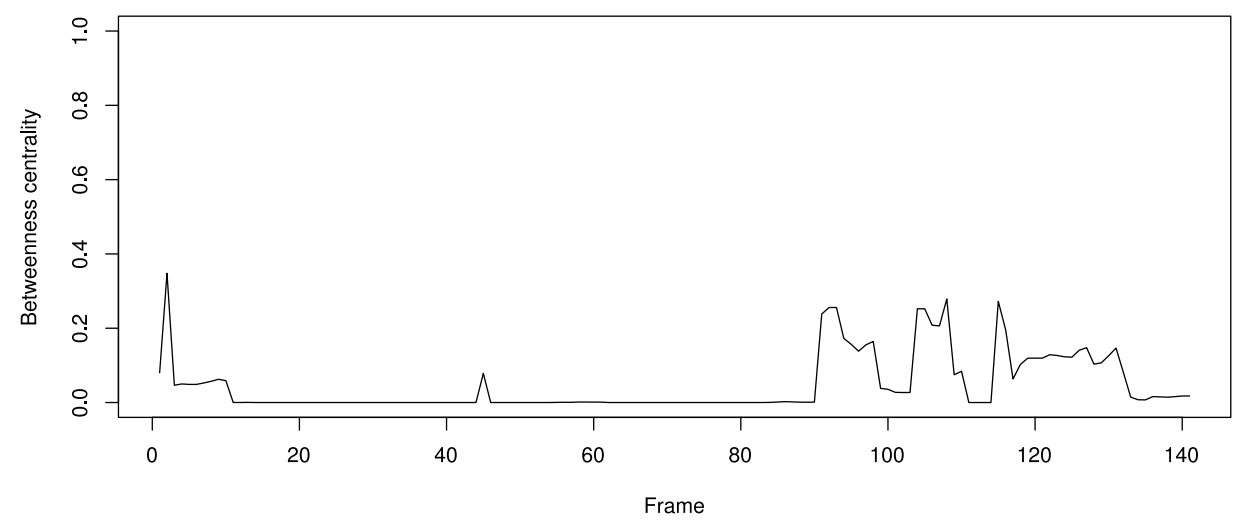

Figure 8.22: Time series of betweenness centrality for Shell.

Table 8.7: Actors that are part of the core of the collaborative network of Sustainable Connections.

\begin{tabular}{ll}
\hline Name & Coreness \\
\hline Port of Moerdijk & 0.447 \\
Province of Noord-Brabant & 0.340 \\
Shell & 0.296 \\
Municipality of Moerdijk & 0.272 \\
ATM & 0.230 \\
Kolb & 0.213 \\
Village Council of Zevenbergen & 0.212 \\
Foundation for the Maintenance of the Environment of Moerdijk & 0.212 \\
Heart of Moerdijk & 0.212 \\
City Council Klundert & 0.212 \\
Chairman Neighbors Council (independent) & 0.199 \\
Residents of Strijen & 0.190 \\
Department Waterways and Public Works & 0.166 \\
BMD Consultancy & 0.156 \\
Business and Industry Circle Moerdijk & 0.142 \\
\hline
\end{tabular}

\subsubsection{Sustainable Connections - Discussion of results}

As in the case of Biopark Terneuzen, the Sustainable Connections collaboration takes place through parallel projects. Collective meetings were not found in the same frequency as in the case of Biopark Terneuzen. Some exceptions are the event where the declaration 
of cooperation is signed, as well as meetings of the Neighbors Council where partners of the Sustainable Connections collaboration also participate. Different groups of actors tend to be involved in different activities, although the overlap of these groups is much greater than that observed in the case of Biopark Terneuzen. As a result, the patterns in modularity and density are not as pronounced as in the case of Biopark Terneuzen. Modularity fluctuates around its mean value of 0.31 , sometimes reaching modest heights in the range 0.40-0.50. Density shows an increasing trend, and reaches its highest values after the collaboration formally commences. These patterns in the timer series do not provide clear support for either of the perspectives outlined in the conceptual discussion. Even though activities take place in different platforms (proposition 1b), the overlap of actors involved in these activities contributes to the emergence of a core group of collaborating partners that form an increasingly dense network (proposition 2a). Some of the leading actors do occasionally have a position of relatively high betweenness centrality during the collaborative process (proposition 3b), although this often boils down to acting as a bridge between the group of collaborating actors, and the Neighbors Council, which is not an integrated part of the collaboration itself.

As in the case of Biopark Terneuzen we observe a relatively small group of frequently interacting actors, and a larger group of actors that is involved on an incidental basis. Thus, the results on both cases presented in this paper reveal something that is not yet explicit in the process models outlined in the conceptual discussion: The collaborative governance process entails the establishment of relatively many relationships that are of short duration. The process models do not yet account for the mechanisms through which these relationships come about and dissolve.

\subsection{CONCLUSIONS}

In this article we explored the way that collaborative governance processes shape the structure of collaborative networks, based on an empirical investigation of network dynamics in two cases. We found some notable differences between the two processes and their dynamics. First, the Sustainable Connections collaboration is more integrated as the result of a stronger overlap of actors that are involved in different projects. This may be caused by the fact that Sustainable Connections builds more explicitly on earlier collaborations, such as SPIA. In other words, in the case of Sustainable Connections the collaborating partners may have built on collaborative relationships that had already been more institutionalized. The Biopark Terneuzen more explicitly brought together actors that had not interacted with each other before. These actors met in a number of collective meetings, causing the network to become more integrated and dense for some time. Overall, collective meetings are rare in both cases. Projects typically take place in 
parallel, although the overlap of actors involved in different projects is greater in the case of Sustainable Connections.

There are also interesting similarities between the two cases. Both collaborations build on networks and ideas that have been developed in earlier developments. In this dynamic, the role of public organizations as bridging actors is especially interesting. They are among the few organizations that have a role in various projects that occur before the start of collaboration, and are therefore in the best position to bring different actors together for collaboration. To some extent, their bridging role remains important during the collaboration, as multiple collaborative projects can take place in parallel, and bridging actors may be needed to tie the different groups involved in these projects together. Governmental organizations are therefore important for the continuity and the coherence of the collaborative processes (cf. Head 2008).

In our conceptual discussion we distinguished between two process models of collaborative governance, with different implications for the evolution of collaborative network structures. The model of Ansell and Gash (2008) implies the emergence of a dense, highly connected network. The model of Bryson, Crosby and Stone (2006) and Emerson, Nabatchi and Balogh (2012) implies the emergence of a more distributed network, where different communities in the network emerge as a result of different groups of actors meeting at different times. In the case of Biopark Terneuzen we find some elements of the first perspective, but these are restricted to the beginning stages of the collaborative process, and the patterns clearly lean more towards what is implied by the model of Bryson, Crosby and Stone (2006), and Emerson Nabatchi and Balogh (2012). The results are more ambiguous in the case of Sustainable Connections, which is caused by the fact that a relatively dense network is formed in the collaboration, even though the involved actors do not continuously participate in collective forums. Thus, a dense network may still emerge from activities that take place in multiple forums if the overlap of actors involved in these forums is great.

Both of the process models emphasize the long-term development of ties based on increased trust, mutual understanding, and commitment. However, our analysis reveals that many actors are involved in the collaborative process for a brief period of time. This is something that neither of the process models explicitly accounts for. The process models are based on the assumption that successful collaboration depends primarily on the capacity of actors to develop long-term ties, but our results suggest that there should also be attention for the role that short-term ties can have in the success of collaboration. For example, our results suggest that, for the success of various projects, the collaborating partners rely on the cooperation and/or resources of actors that are not themselves an integrated part of the collaborative network.

The literature on collaborative governance processes and collaborative networks would benefit from more longitudinal studies of network dynamics. In this article we in- 
troduced an approach to reconstructs network dynamics from event data, as descriptive time series. The main benefit of our approach is that network dynamics are empirically observed rather than modeled. However, our approach also has serious limitations. The main limitation is that our approach relies on the availability of archival data. The availability of data on developments that have occurred years ago is quite limited, which means that the level of detail at which these developments can be reconstructed is equally limited. Also, certain groups of actors may meet informally, but these meetings typically leave behind little traces, which makes it difficult to reconstruct them as events. Thus, our methods are only capable to offer a coarse-grained view of collaborative networks and their dynamics, with a focus on broader patterns rather than the micro-dynamics of collaborative interaction processes. In that sense, it would be interesting to combine our approach with more detailed investigations of the micro-dynamics that occur within specific periods of time. Despite its limitations, our approach makes possible a dynamic view on the collaborative governance process and the way it shapes collaborative network structures. Such an approach is valuable in the investigation of networks that change shape frequently, of which collaborative networks are clearly examples. 




\section{INTERMEZZZO 6}

TYING EVERYTHING TOGETHER 
In the next chapter I present the conclusions of my research as well as a number of recommendations that follow from the conclusions. In this last intermezzo I look back to and summarize the various analyses that were performed in the preceding chapters, and I articulate how they build up to the conclusions of my thesis.

The analyses presented in chapters 5 and 6 served to test the implications of the conceptual framework introduced in chapter 3, with a focus on the mechanisms through which institutional capacity builds up. This was achieved through an in-depth case study of Biopark Terneuzen (chapter 4) as well as several more or less closely related developments that occurred in the Sloe Area and Canal Zone (chapter 5). As ESA was still in its early stages of development, the analyses remained somewhat descriptive. However, they did offer insight in the actual workings of mechanisms of institutional capacity building. In my view, the most important finding of these analyses is that it is difficult (and perhaps not useful) to describe the process of institutional capacity building as an orderly progression of different types of events (orientation, planning, research, and implementation). This is primarily caused by the fact that institutional capacity builds up in a fragmented, or distributed way, through different streams of events that occur in parallel and more or less independent from each other (in their early stages), but that are later brought together once broader collaboration commences. As is suggested in the conclusions of chapter 6 , this dynamic of different streams of events coming together can be usefully conceptualized as a process of assembling. In my view, this perspective has great appeal, because it opens the door to an understanding of collaboration as a complex process that can come about more easily if it builds on stable intermediates. Also, based on this perspective, I started referring to the different streams of events as building blocks for collaboration.

The task that I took up in chapters 7 and 8 is to develop the idea of institutional capacity building as a process of assembling further. The main challenge that I saw in elaborating the idea of institutional capacity building as a process of assembling was to identify the mechanisms that cause different building blocks to come together (i.e., the assembling itself). To this end, a theory on the emergence of collaborations as assemblages is introduced in chapter 7 . The core logic of the theory is that collaborations can be assembled from building blocks if:

1. The actors involved in those building blocks develop a common ground, meaning that they develop knowledge, experience, and conceptions of problems and solutions on overlapping issues.

2. some actors are involved in multiple building blocks, thereby attaining a position in which they can act as a bridge between the building blocks, and

3. the development of a common ground is recognized by these bridging actors, after which they bring other actors involved in the different building blocks together for collaboration. 
To test this theory, I studied three different types of networks. The first type of network is the network of events, which is visualized in event graphs. The network of events can be understood to represent the syntax ${ }^{51}$ of this process of institutional capacity building, i.e., the way that different building blocks (as streams of events) eventually converge, marking the start of a broader collaborative process. By visualizing the process of institutional capacity building as a network of events, I was able to make the idea of converging streams of events more tangible. To study the contents of the process I introduced two other types of networks. First, I introduced a social network that describes the relationships between actors based on their joint participation in events. Introducing this network allowed me to study the relational dimension of institutional capacity building more closely by investigating how the structure of the social network of actors associated with the collaborative process changed over time. Studying the social network also offers insight into one aspect of mobilization capacity, which is the bridging position (i.e., a position with high betweenness centrality in the language of Social Network Analysis) that some actors can take in the social network. The third type of network that I introduced is a two-mode network that describes the relationships between issues and events. Introducing this network allowed me to study the overlap of issues addressed in different parts of the overall process. This became my main approach to studying the knowledge dimension of institutional capacity building, using the issues around which actors develop knowledge and experience as proxies for knowledge itself.

In chapter 7 I studied the development of a common ground based on the investigation of the event network and the two-mode network of issues and events. First, the different streams of events that represent different building blocks were identified in the network of events (building blocks were represented by intentionally connected groups of events). Second, the existence of overlapping issues between these different building blocks was confirmed by visualizing the emergent linkages between the events that constitute the different building blocks. Then I studied the overlap of issues addressed in these different building blocks more closely by examining the two-mode network of issues and (aggregated) events. The analysis confirms that, to some extent, the same issues were addressed in different building blocks, signaling the emergence of a common ground. The analysis also revealed that issues that are part of this common ground also feature prominently in the visions that are at the basis of the broader collaboration that is assembled from the building blocks, pointing to an important link between the common ground and shared visions (an aspect of mobilization capacity). The link between common ground and shared visions is discussed in more detail in the concluding chapter of this thesis. 
In chapter 7 I used more or less conventional Social Network Analysis techniques to study the relational dimension of the process of institutional capacity building, while in chapter 8 a more detailed analysis is offered based on Dynamic Social Network Analysis. For the analysis of the social networks in chapter 7 I first identified two phases in the process of institutional capacity building, based on an analysis of the network of events. The first phase is the process up to the point where different building blocks converge on a broader collaboration, and the second phase is the process from that same point. For both phases I reconstructed the actor network separately. The analysis of the actor network as it existed in the first phase revealed the presence of bridging actors, as was predicted by the theory of collaborations as assemblages. The analysis also pointed out that these actors are typically public organizations. Although this empirical finding was not predicted by the theory, it does point for a division of roles between public and private actors in the process of institutional capacity building: Private actors play a major role in the development of building blocks, while public actors play a major role in bringing the different building blocks together. The role of bridging actors is investigated in more detail in chapter 8 , by looking how prominent the bridging position of different actors is over time. Here, the analysis revealed that different actors may take a bridging position in different stages of the overall process. Also, contrary to my initial expectations, this bridging role does not disappear once the collaborative process has commenced; during the collaborative process the bridging actors can still be important in tying together the different groups of actors involved in the collaboration.

Another expectation that follows from the theory, and that is related primarily to the relational dimension of institutional capacity, is that the different groups of actors associated with the building blocks before the start of collaboration would still exist as cohesive subgroups in the network after the start of collaboration. However, the analysis of the actor network as it existed during the collaboration pointed out that the network is instead characterized by the existence of a relatively small core of actors that are active frequently in the process, and a larger periphery of actors that feature in the process on a more incidental basis (see chapter 7). This feature of the process of institutional capacity building is also examined more closely in chapter 8 . There, it is shown that the mobilization of actors for collaboration does not necessarily lead to a long-term increase of the size and density of the social network associated with the collaboration. Instead, there is a relatively small core group of actors that exists more or less continuously during the collaborative process, while additional actors are attracted only occasionally because they can bring specific capabilities and resources into the process. In chapter 7 this structure of the social network during the collaborative process was uncovered based on the analysis of the existence of cohesive subgroups in the network. It was found that these subgroups do exist, but that there is a strong overlap between them. In other words, actors in the network do occasionally jointly participate in events in relatively 
small groups, but because membership between these small groups overlaps, at the long term they aggregate into the stable core of the social network. Based on these findings, an analysis of the coreness of actors in the network was performed in chapter 8, allowing for a more precise assessment of the comparative sizes of the core and periphery of the actor network. In this analysis, the findings on the stable core and fluid periphery of the social network were replicated. In the concluding chapter of this thesis, the relevance of the distinction between the stable core and the fluid periphery in the actor network is discussed in more detail.

These findings have helped me to identify the mechanisms behind the emergence and development of institutional capacity in the cases that I have investigated, and they have also changed my understanding of the three dimensions of institutional capacity and how they are related to each other in time. Therefore, I start the concluding chapter of my thesis with the introduction of an adapted version of the conceptual framework of institutional capacity building. The adapted framework isn't a complete overhaul of the original framework. Instead, the operationalization of the three dimensions of institutional capacity is altered, and a more specific account is offered of the mechanisms through which they are built. I also used the modified version of the conceptual framework to structure the presentation of other conclusions that follow from my thesis. 



\section{CHAPTER 9}

\section{CONCLUSIONS}





\subsection{INTRODUCTION}

In this chapter the conclusions that follow from the research in this thesis are presented. Two research questions are at the basis of this thesis:

1. How does the collective capacity of firms, governments, knowledge institutes and other relevant actors to engage in industrial symbiosis emerge and develop?

2. What can methods, techniques and tools that are dedicated to the systematic and longitudinal investigation of process phenomena contribute to our understanding of industrial symbiosis?

The conclusions with regard to the first research question are presented in section 9.2 and with regard to the second question in section 9.3. The chapter closes with a number of recommendations for research and practice in section 9.4 .

\subsection{BUILDING INSTITUTIONAL CAPACITY FOR INDUSTRIAL SYMBIOSIS}

\subsubsection{Industrial symbiosis and institutional capacity building}

The variant of industrial symbiosis that is studied in this thesis is a collaborative process through which public and private actors in regional industrial systems ${ }^{52}$ develop a network of symbiotic exchanges, that is, a network of by-product exchanges and shared utilities through which firms seek economic and environmental benefits. This collaborative process does not start from scratch, but it builds on earlier (and typically smaller) developments in the regional system, which can be understood to serve as its building blocks. These building blocks are projects that are started for disparate purposes, and they are not originally designed to serve as building blocks for a comprehensive collaborative process. Nonetheless, they provide the raw materials for collaboration in the form of small groups of actors, and the knowledge, experience and plans that these actors have developed in their own projects. The development of the building blocks on the one hand and the collaborative process that is assembled from these building blocks on the other hand can be understood as two distinct phases of a larger process, which can be understood as the emergence (first phase) and development (second phase) of industrial symbiosis (see the box with the thick border in figure 9.1).

The transition from the first phase to the second phase of the process occurs when the building blocks are actively brought together, and assembled into collaboration on industrial symbiosis. During this transition the actors involved in the different build-

52. A regional industrial system is "a more or less stable collection of firms located in proximity to one another, where firms in principle can develop social and material/energy connections as a result of that proximity" (Boons, Spekkink, and Mouzakitis 2011, p. 907). 


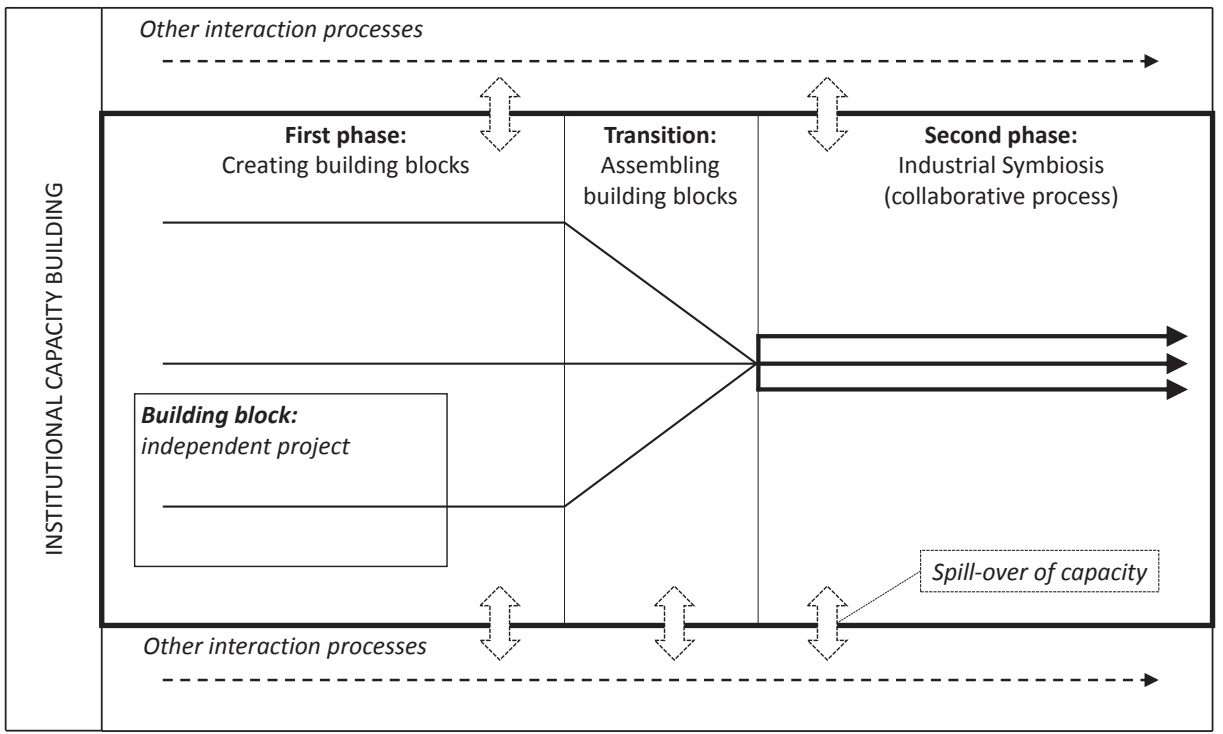

Figure 9.1: Overview of the different processes that have been studied. The box with the thick border contains the emergence and development of industrial symbiosis, which was the main focus of research.

ing blocks are mobilized for collective action, and a shared vision of the network of by-product exchanges and utility synergies is developed. In the collaborative process that commences as a result of this transition a deliberate attempt is made to realize the envisioned network of by-product exchanges and utility synergies. To achieve this, the collaborating partners work together in parallel, closely related implementation projects. Neither phase in the emergence and development of industrial symbiosis is characterized by a single, linear stream of events. Instead, the process as a whole is modular and compounded, where multiple streams of events exist alongside each other (see Tsvetkova and Gustafsson 2012 for a similar view). In the first phase of the process the multiple streams of events represent the emerging building blocks for collaboration. In the second phase the multiple streams represent the different implementation projects that are carried out as part of the collaborative process. Even though the implementation projects are much more intertwined than the building blocks for collaboration, they never become fully integrated into one whole (see figure 9.2).

Throughout the emergence and development of industrial symbiosis the involved community of actors builds and mobilizes institutional capacity: The capacity to coordinate actions around collective goals (Healey 1998; Healey, de Magalhaes, and Madanipour 1999; Healey et al. 2003; Innes and Booher 1999). In section 9.2.2 a detailed conceptual discussion is offered of the different types of institutional capacity that are created. The emergence and development of industrial symbiosis is not the only process that 


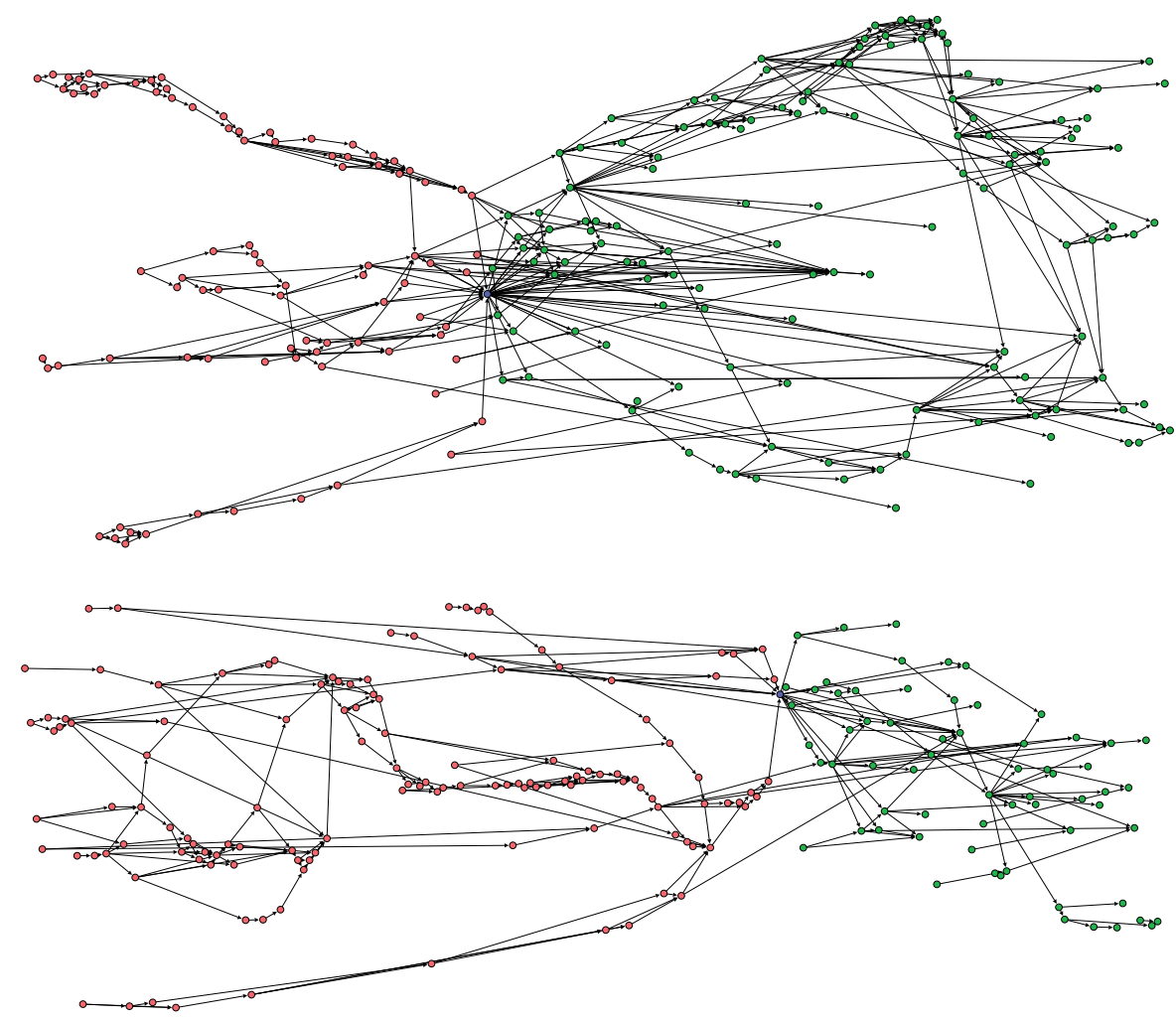

Figure 9.2: Event graphs of two collaborations on industrial symbiosis and the development of their building blocks. The nodes represent events and the arcs represent intentional linkages (see section 9.2.4). The Event Graph at the top represents the development of Biopark Terneuzen. The Event Graph at the bottom represents the development of Sustainable Connections. The blue nodes represent the formal opening of Biopark Terneuzen (top) and the signing of the declaration of intent for the Sustainable Connections collaboration (bottom). The red nodes are ancestors of these events and represent the development of building blocks for the collaborations. The green nodes are descendants of the same events and represent the collaboration on industrial symbiosis itself.

contributes to the creation of institutional capacity in regional industrial systems. Other interaction processes occur in parallel and can provide a positive bedding for industrial symbiosis (cf. Baas 2008; Boons and Howard-Grenville 2009a).

These other interaction processes do not directly contribute to the emergence and development of industrial symbiosis, but they do provide additional opportunities for actors to develop relationships and exchange knowledge and experience on issues that are relevant to the collaboration on industrial symbiosis (see figure 9.1). Thus, spill-overs of capacity occur between the different interaction processes in regional industrial systems, and these spill-overs have to be taken into account in order to gain a more complete picture of the institutional capacity that builds up in a region. The interac- 
tion processes that occur in parallel to the emergence and development of industrial symbiosis are discussed in section 9.2 .10 of this chapter.

All interaction processes in this thesis are defined as sequences of events. In this thesis events are understood as actions and interactions through which actors explore problems and solutions, develop and negotiate plans and visions, perform studies, and work on the implementation of plans and visions. These events provide actors with opportunities to develop relationships with others and to exchange knowledge and experience on different issues, and they can thereby contribute to the development of institutional capacity. A focus on processes as sequences of events creates the possibility to reconstruct how the relationships between actors and the issues that they address evolve over time. It allows for a dynamic view of institutional capacity building that would be impossible to achieve with perspectives that do not explicitly take into account a time dimension. The advantages of a process perspective are discussed in more detail in section 9.3.

The conclusions presented here are the result of an inquiry into the emergence and development of industrial symbiosis and not its outcomes, which is an evolving network of by-product exchanges and utility synergies. Two such networks were identified at the beginning of the research process, namely the network that is in development in the Biopark Terneuzen collaboration in Zeeland and the network that is in development in the Sustainable Connections collaboration at Moerdijk. The research presented in this thesis aims to develop an improved understanding of the contributions that the building and mobilization of institutional capacity has made to the emergence of the networks. As mentioned at the beginning of this chapter, the processes that are reconstructed in this thesis are a particular variant of industrial symbiosis. Other variants of industrial symbiosis exist. Desrochers $(2000 ; 2002 ; 2004)$ has repeatedly made the claim that market coordination may be sufficient for networks of by-product exchanges to emerge and develop (but see Boons 2008). The National industrial symbiosis Programme (NISP) in the United Kingdom achieves the development of networks of symbiotic exchanges through an approach that relies more heavily on facilitation than long-term collaboration (Paquin and Howard-Grenville 2009; Mirata 2004; Jensen et al. 2011), although the type of networks that emerge from this approach look different from those investigated in this thesis (Stift 2011). Developments in China have demonstrated that much can be achieved through a planned approach to industrial symbiosis (Geng et al. 2008; Yu, C. 2014), although the extent to which the Chinese approach is indeed characterized by planning is sometimes exaggerated (Shi, Tian, and Chen 2012; Jiao and Boons 2014). Thus, the conclusions presented in this chapter are generalizable to a limited set of examples of industrial symbiosis. One of the major research tasks for scholars in the field of industrial symbiosis in the coming years is to engage in comparative projects, based on which typologies of industrial symbiosis can be developed and refined. This should also 
lead to an improved understanding of the conditions under which varieties of industrial symbiosis tend to emerge and develop.

\subsubsection{Institutional capacity Building revisited}

Three dimensions of capacity building, based on the work of Healey and colleagues (Healey 1998; Healey, de Magalhaes, and Madanipour 1999; Healey et al. 2003) and Innes and Booher (1999), are distinguished in this thesis: relational capacity, knowledge capacity, and mobilization capacity. In the original work on institutional capacity collaborative processes are believed to be its primary source: By engaging in repeated quality interactions the collaborating partners develop relationships of trust and mutual understanding, and exchange knowledge and experience on various problems and solutions (Healey 1998; Innes and Booher 1999). The same view exists in the literature on collaborative governance (Vangen and Huxham 2003a; Bryson, Crosby, and Stone 2006; Ansell and Gash 2008; Emerson, Nabatchi, and Balogh 2012). The research presented in this thesis has revealed that institutional capacity building already starts before the collaborative process itself commences. Institutional capacity is already created during the emergence of building blocks for collaboration, and the start of the collaborative process entails the mobilization of this capacity. In contrast with what the original framework of institutional capacity building suggests, it was found that the development of institutional capacity does not start with the building of relationships, but with the emergence of a common ground. This common ground emerges if actors develop knowledge and experience on shared issues, even though they work independently. The common ground becomes the basis for joint action, after which the development of new and stronger relationships becomes more prevalent. The original framework on institutional capacity building does not provide an adequate conceptual underpinning for these dynamics. Therefore, a modified conceptualization of the process of institutional capacity building is presented here. The modified framework preserves the analytical distinction between relational capacity, knowledge capacity and mobilization capacity of Healey and colleagues (Healey 1998; Healey, de Magalhaes, and Madanipour 1999; Healey et al. 2003) and Innes and Booher (1999). However, the three dimensions of institutional capacity and their relationships are operationalized in an innovative way. The new framework is presented in the remainder of this section.

\section{Knowledge capacity}

In the original conceptualization offered by Healey et al. (2003), knowledge capacity is defined as the formalized, tacit, and experiential knowledge that flows around and is developed through social relationships. It thus presupposes the existence of a network of social relationships that can be understood to serve as 'the backcloth' of knowledge production. The modified conceptualization of knowledge capacity offered here does 
not presuppose the existence of such a network. Instead, it acknowledges that actors may independently develop knowledge with regard to similar issues. The similarity of issues on which the actors develop knowledge contributes to the emergence of a common ground, even when the activities of the involved actors are not otherwise connected. The notion of emergence is emphasized because common ground as it is understood here is not developed intentionally, i.e., as a result of the coordination of activities between actors involved in different projects. Instead, the commonalities between the projects exist even in the absence of coordination. This coincidence can occur if the actors involved in independent projects draw on the same sources of inspiration for their activities. These common sources of inspiration are issues that are becoming increasingly salient around the world, of which reuse of waste products, and biofuel production are good examples. Whatever the exact origins of the similarities between projects, the most important implication of the idea of an emergent common ground is that it is not the end-product of some carefully coordinated program with an underlying blueprint. By developing common ground, independently initiated projects become building blocks for collaboration. As building blocks they provide the 'raw material' for collaborative processes in the form of (1) the groups of actors that are formed in the projects, and (2) the knowledge, experience and plans that the actors have developed with regard to the issues that they have in common. In this regard it may even be beneficial for knowledge to be developed independently, because it decreases the chances that the knowledge that different actors contribute is redundant (cf. Rogers en Shoemaker 1971; Burt 1992).

Common ground creates the initial basis for collaboration on industrial symbiosis. An indicator for the emergence of a common ground is the development of emergent linkages between the events from which different projects are made up. Emergent linkages exist between otherwise independent projects if the same issues are addressed in the events that constitute the different projects (see figure 9.3).

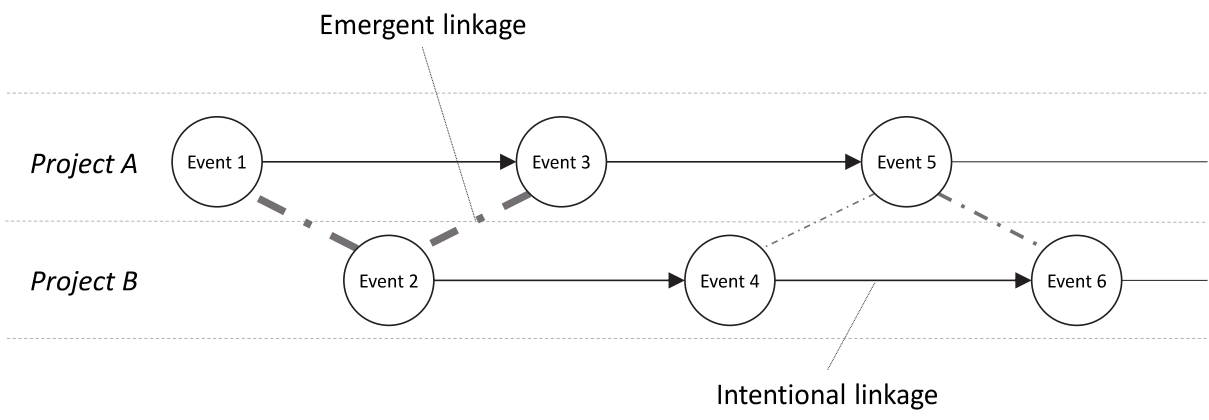

Figure 9.3: Intentional linkages (arrows) and emergent linkages (dashed lines). The thickness of the lines indicates the strength of similarity. Emergent linkages cannot exist between events that are on the same intentional path. 
Emergent linkages are distinguished from intentional linkages, which exist between two events if actors involved in one event consciously respond to conditions created in the other (earlier) event. By definition, emergent linkages can never overlap with intentional linkages, because if two events are connected by a path of intentional linkages, then an emergent linkage cannot exist between them. Using this simple typology of linkages, projects can be defined as intentionally linked sequences of events, and common ground can be measured as the number and strength of emergent linkages that exist between different projects. Both types of linkages can be reconstructed and analyzed by creating event graphs (see section 9.3.2). Qualitative indicators for common ground also exist, and can be used to identify the specific issues that projects have in common (see figure 9.4). The emergence of building blocks and the role of common ground in this process are discussed in more detail in section 9.2.3.

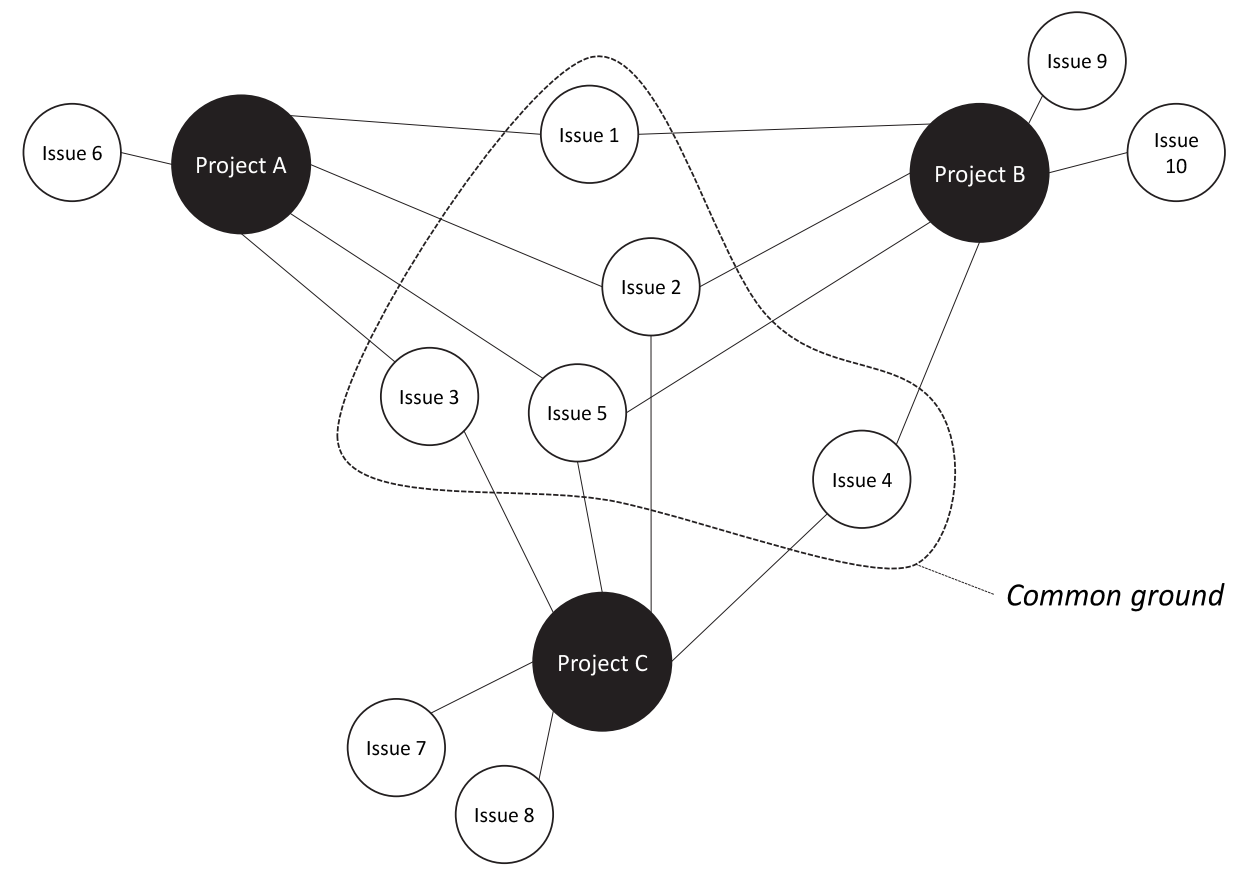

Figure 9.4: Qualitative indicators of common ground. The issues that are related to multiple projects constitute a common ground for the projects.

\section{Mobilization capacity}

In the original conceptualization of Healey et al. (2003) mobilization capacity (the capacity to engage in collective action) presupposes the existence of a social network (relational capacity) and the availability of symbolic frames around which actors can mobilize (knowledge capacity). In the modified conceptualization offered here relational 
capacity is understood primarily as an indirect outcome of mobilization rather than an aspect of it. Certain relationships will already be in place, but mobilization is required precisely because the relationships are still relatively sparse. In the modified conceptualization mobilization capacity is represented by (1) the presence of bridging actors before the start of collaborations on industrial symbiosis, and (2) the shared visions that are developed (a) to articulate the common ground that actors have developed and (b) to envision what the involved actors want to achieve through their collaboration. Bridging actors attain their position through their participation in multiple building blocks for collaboration, i.e., they are part of the overlap between the building blocks. To some extent, their position can be understood to be an emergent property, because it is not necessary for actors to consciously choose to become a bridging actor. Thus, being a bridging actor is not an intrinsic quality of actors, but a relational quality that depends on the position of actors in their wider network. When actors participate in multiple building blocks, they have the opportunity to regularly interact and exchange knowledge with the actors involved in different building blocks. Based on their knowledge of the different building blocks, they are also more likely than others to become aware that a common ground has emerged. They are therefore in the best position to act on this common ground, and bring actors and issues from the different building blocks together for a collaborative process. One hypothesis that follows from the findings of this thesis is that this act of mobilization is necessary to assemble collaborations from building blocks.

A useful indicator for the presence of bridging actors in a social network is the betweenness centralization of that network. It is also possible to identify the specific actors that have a bridging position by studying the betweenness centrality of individual actors in the network (Freeman 1978; Wasserman and Faust 1994). Betweenness centrality is typically high for actors that bridge structural holes in their network (Burt 2000; 2001), that is, when they connect different parts of a network that would otherwise be unconnected (see figure 9.5). It is possible to study changes in betweenness centralization and betweenness centrality by measuring them for different phases in interaction processes or by performing a dynamic analysis of the networks of interest (see section 9.3.4).

Visions are also an aspect of mobilization capacity. They can be understood to act as a bridge between the building blocks for collaboration and the collaborative process itself. This is achieved in two ways. First, actors use shared visions to articulate the common ground that has brought about the building blocks for collaborations. This is how actors recognize that the common ground exists and that a basis for collaboration is already present. Second, in shared visions actors articulate what it is that they want to achieve in the future by building on the common ground. More specifically, in the case of industrial symbiosis, the building blocks offer the potential for a network of by-product exchanges and utility synergies, but at that state of the process it is still 'only' a future ambition that has not yet been realized. Thus, the visions that are developed in this way consolidate the 


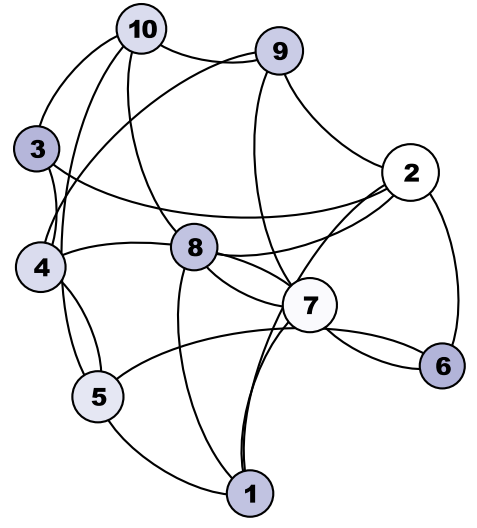

Relatively low betweenness centralization

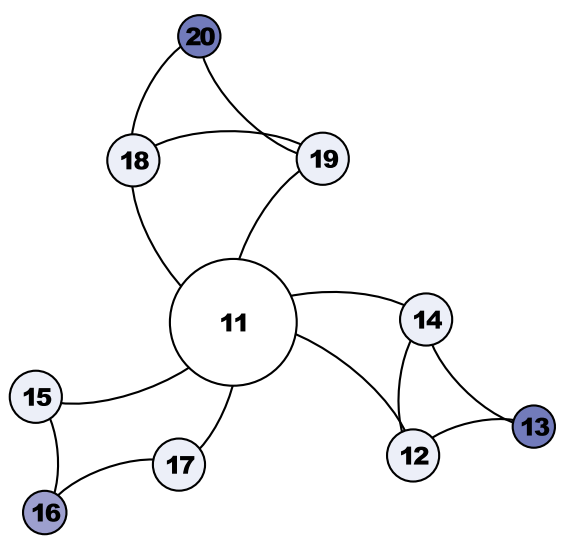

Relatively high betweenness centralization

Figure 9.5: Networks with relatively low betweenness centralization (left) en relatively high betweenness centralization (right). In the second situation, actor 11 is an actor with high betweenness centrality. The size of the nodes is proportional to betweenness centralization.

common ground, but also offer a future-oriented perspective. The existence of shared visions can be assessed qualitatively, by identifying events in which larger groups of actors develop or publish such visions. Usually, actors will codify their visions in documents. The role of bridging actors and visions in assembling building blocks for collaborations is discussed in more detail in sections 9.2.4 and 9.2.5.

\section{Relational capacity}

The relational dimension of the renewed conceptualization of institutional capacity is similar to that of the original framework of Healey et al. (2003). As in the original framework, it deals with the structure of the relationships (i.e., the social networks) that actors develop based on their interactions. However, in the modified conceptualization that is offered here relational capacity is understood to develop primarily during the collaborative process itself, that is, after mobilization for collaboration has taken place; before that point, the social relationships between the actors are relatively sparse. Also, new actors may be introduced during the collaborative process. The modified understanding of relational capacity is also a dynamic one, with an emphasis on the extent to which different parts of the social network endure over time. More specifically, a distinction is made between a stable core of actors that meet relatively frequently throughout the collaborative process, and a fluid periphery of actors that are involved in the collaborative process only occasionally. The stable core allows the collaborating partners to coordinate their efforts, and it acts as a source of continuity in the collaborative process. The fluid periphery represents the capability of the collaborating actors to draw 
on the resources and capabilities of a large number of other actors without the need to continuously uphold relationships with those actors. One indicator that can be used to investigate the existence of stable cores in a social network is the existence of frequently occurring subgroups. Subgroups are "subsets of actors among whom there are relatively strong, direct, intense, frequent or positive ties" (Wasserman and Faust 1994, p. 249). If a social network is reconstructed from event sequences it is possible to investigate how often a given subgroup occurs over time (Doreian 1969; Wasserman and Faust 1994) ${ }^{53}$, which allows for a distinction between groups of actors that interact on a structural basis and groups of actors that interact only occasionally. More direct measurements of core-periphery structures in social networks also exist (see Borgatti, Everett and Johnson 2013), although these assume that only one core exists in the social network, which may not necessarily be the case. The emergence and development of relational capacity in collaborations on industrial symbiosis is discussed in more detail in section 9.2.6.

Figure 9.6 summarizes the altered conceptual framework as a phase model. A separate visualization is made for the two phases that are distinguished in the process of institutional capacity building: The phase in which the building blocks for collaboration emerge, and the phase in which collaboration for industrial symbiosis has taken off. In the first phase institutional capacity emerges from largely independent sequences of interactions, in the form of a common ground and the presence of bridging actors (1). This happens under the conditions that the parallel sequences of interactions address similar issues and a few actors are involved in multiple sequences of interactions at the same time. If the bridging actors become aware of the emergent common ground, they mobilize other actors in their network for collaboration, after which a shared vision is developed to articulate the common ground of the actors, and to envision the network of symbiotic exchanges that the actors want to create (2). These acts of mobilization trigger the second phase of the process (3), in which the sequences of interactions become intertwined, and where the shared vision serves as a bond between the collaborating partners (4). The intertwined patterns of interactions contribute to the emergence of a social network with a stable core and a fluid periphery (5), which allows actors to coordinate the collaboration, while at the same time having access to the resources of actors outside of the core community. In both phases of the process, the sequences of interactions are susceptible to the political, economic, and physical context of the process of capacity building for better or worse (6). Also, spill-over effects between different developments within the regional industrial system (including developments that occur in parallel to the collaborations - see section 9.2.10) contribute to institutional capac-

53. Social networks that are reconstructed from event sequences have valued relationships between the actors, based on the number of times that they jointly participated in events. There are approaches to the analysis of subgroups that take valued relationships into account to offer an indication of how frequently the members of the subgroup have interacted with each other. 


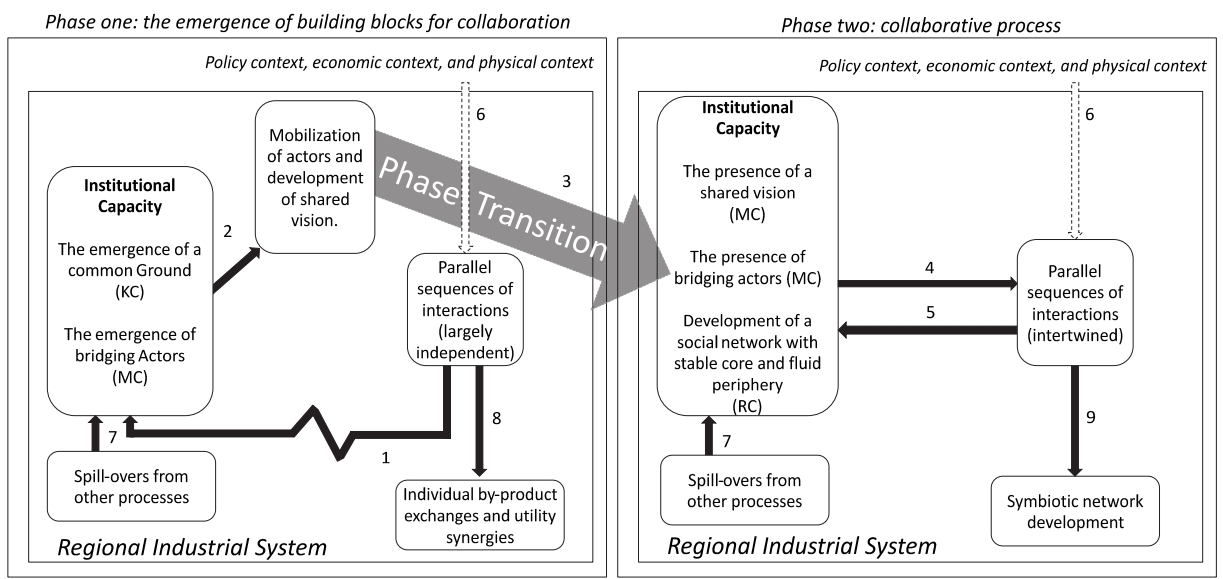

Figure 9.6: Summary of the modified conceptual framework. $\mathrm{KC}=$ Knowledge Capacity, $\mathrm{MC}=$ Mobilization Capacity, RC = Relational Capacity.

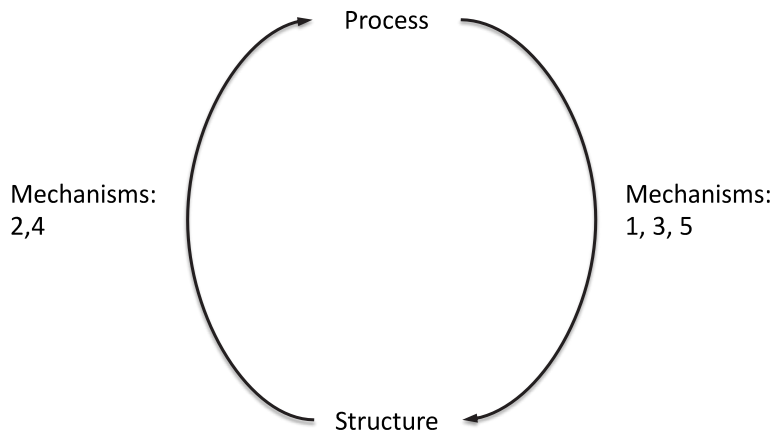

Figure 9.7: Relationships of mechanisms to process and structure.

ity that can be used in the collaboration on industrial symbiosis (7). In the first phase of the process, a network of symbiotic exchanges is not yet in development, although individual by-product exchanges and utility synergies may already be implemented (8). The development of a larger symbiotic network takes off in the second phase (9). Some of the mechanisms outlined in the foregoing describe how processes shape relational structures, and other mechanisms describe how relational structures shape processes. The relational structures embody the institutional capacity available in the regional industrial system, and the processes embody the sequences of interactions that influence, and are influenced by these structures. Figure 9.7 offers an overview of the relationships between the mechanisms, process and structure.

In the renewed understanding of institutional capacity that is presented here, institutional capacity building does not simply refer to the accumulation of resources (e.g., 
relationships and knowledge). Instead, it refers to the emergence of network qualities such as common ground and bridging actors that together create conditions for the start of a collaborative process. In the transition from the first phase of institutional capacity building to the next, these qualities are transformed.

The bridging actors become part of the stable core of the social network that exists in the second phase, and the common ground is transformed into a vision that guides the activities that are carried out in the collaborative process. Thus, institutional capacity building is understood in the first place as a process of qualitative change rather than quantitative change. The conclusions that are presented in the following sections offer a more detailed view of several aspects of the process of institutional capacity building, based on the empirical findings of this thesis.

The adapted version of the conceptual framework does not constitute a complete overhaul of the framework as it is presented in chapter 3. However, the temporal dimension of the process of institutional capacity building is made much more explicit: Where the original framework only identifies a feedback loop between interactions and institutional capacity (emphasizing quantitative change), in the adapted version of the framework a phase-based model is introduced that specifies the qualitative changes that occur in the process of institutional capacity building. Also, instead of assuming that institutional capacity is created through collaboration (Healey 1998), the adapted version of the framework shows that the emergence of the collaboration itself (the events that occur before the start of collaboration) can be a vital part of the process of institutional capacity building. The phase based model also specifies the role that different dimensions of institutional capacity play in the different stages of development. This has also led to a new understanding of the way that the different dimensions of institutional capacity depend on each other. The original framework suggests that the development of knowledge capacity depends mostly on the development of relational capacity, and that mobilization capacity depends on the development of both other types of capacity. In the adapted version of the framework, mobilization capacity depends primarily on knowledge capacity, and the development of relational capacity is understood to occur as a result of mobilization. In short, the adapted version of the framework puts greater emphasis on the mobilizing force of common ground, and it shows how this common ground may emergence in the absence of a dense social network.

One element of the original framework that has been removed from the adapted version of the framework concerns the dynamics that occur at the level of individual decision-makers (e.g., the interaction of opportunities and motivation). This is partly the result of the fact that dynamics never became an explicit focus of the investigation; $A$ thorough investigation of this aspect of the process requires a stronger focus on microlevel dynamics, for which a different kind of data is required. 


\subsubsection{The emergence of common ground}

In the conceptualization of institutional capacity building that is originally offered by Healey and colleagues (Healey 1998; Healey, de Magalhaes, and Madanipour 1999; Healey et al. 2003) the development of knowledge capacity is understood to build on relational capacity. Concretely, it is thought that knowledge resources "flow around and are developed through [social] relations" (Healey et al. 2003, p. 65). The understanding that is offered of collaborative processes in the literature on collaborative governance is similar, where shared understanding is understood to build on repeated interactions between the collaborating partners (Ansell and Gash 2008; Emerson, Nabatchi, and Balogh 2012). One of the conclusions of this thesis is that this sequence of events can occur the other way around; knowledge capacity, in the form of a common ground, can emerge first and provide a basis for the development of relational capacity in the form of the stable core and fluid periphery, which is the relational structure that emerges from the intertwined interaction processes during the collaborative process (see figure 9.8). The emergence of a common ground also explains how building blocks for collaboration on industrial symbiosis are created.

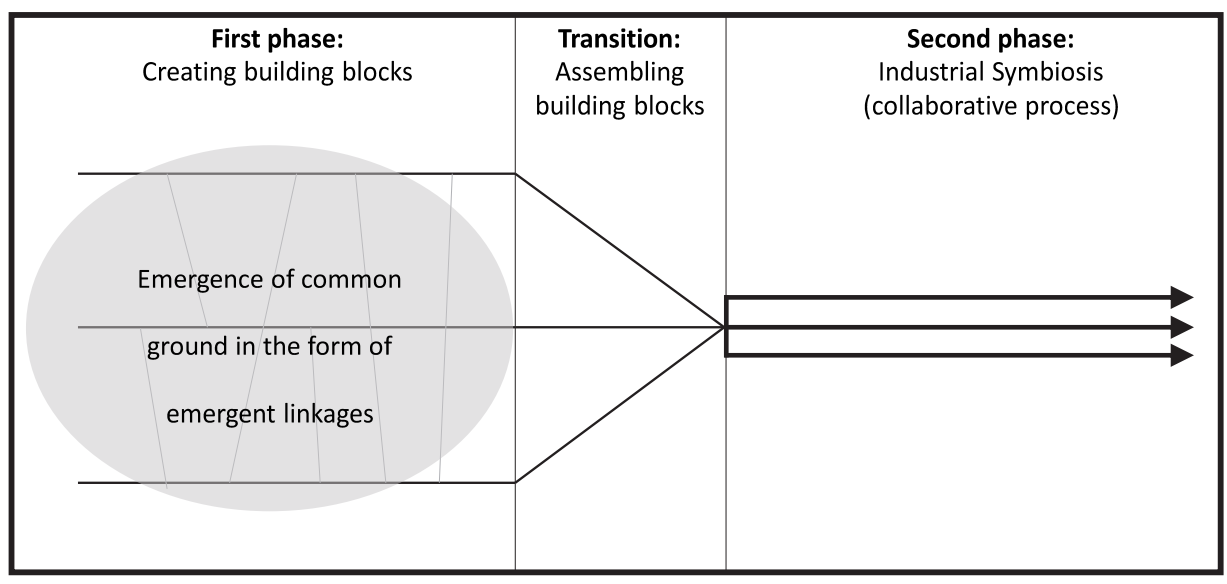

Figure 9.8: Emergence of common ground in the development of industrial symbiosis before the collaborative process takes off.

As is discussed in section 9.2.2 the multiple, independent streams of events that exist before the start of a collaboration represent different projects that actors in a regional industrial system engage in. Examples that have been found in this thesis are projects for the development of production facilities, projects for the (re)development of industrial complexes, projects for the development of greenhouse areas, projects for the development of individual by-product exchanges or utility synergies, but also earlier collaborations. These projects are not consciously designed as building blocks for the 
collaboration that is assembled from them; no blueprint of the collaboration is present in the period in which the actors develop these projects, and it is not necessary for the actors involved in the projects to have the intention to collaborate with actors involved in other projects. However, even in the absence of the intention to create linkages between the different projects, linkages can develop between the projects emergently, as a result of the similarity of the issues addressed in the projects. To make this idea tangible, a distinction between intentional linkages between events and emergent linkages between events was introduced in this thesis. Intentional linkages between events are created by actors that purposefully respond to conditions raised in earlier events (cf. Van de Ven and Poole 1995; Boons, Spekkink, and Jiao 2014). The different streams of events that are visualized in figure 9.1 are sequences of intentionally linked events. Emergent linkages between events are created by the similarity of the issues that are addressed by the actors that participate in events, and can exist only in the absence of an intentional path to connect these events. The absence of an intentional path between two emergently linked events is emphasized to distinguish 'coincidental' similarities between events from similarities that are the result of issues that later events in a sequence inherit from earlier events in the sequence ${ }^{54}$. Emergent linkages are used in this thesis as an indicator of common ground. Thus, common ground as it is defined in this thesis is not the result of active coordination of activities. Instead, it is their coincidental by-product.

Other characteristics of projects may be important in the emergence of common ground as well. A particular characteristic of the building blocks studied in this thesis is that they all have prominent physical and geographical dimensions. The projects usually involve (plans for) the creation of some physical entity, as the earlier mentioned examples of building blocks illustrate. These entities are also usually geographical proximate to each other. Geographical proximity is often posed as a highly influential condition in the development of networks of symbiotic exchanges between firms (Chertow 2007; Jensen et al. 2011; Sterr and Ott 2004).

The clear presence of physical and geographical dimensions in the building blocks for collaboration may be specific to the context of industrial symbiosis, where such dimensions are more prominent than in many other forms of collaboration. Another factor that may be related to geographical proximity is the common culture of actors in a regional industrial system. Rogers and Schoemaker (1971) argue that actors with similar beliefs, culture and values are more likely to exchange information than actors that are dissimilar in these respects (also see Boons and Berends 2001). The development of shared beliefs, culture and values can be facilitated by geographical proximity (Lenartowicz and Roth

54. For example, if actors first develop a plan to create a biofuel factory, and later decide to investigate the feasibility of that plan, then there will be an intentional linkage between the events. The issues addressed in the events will be similar (e.g., biofuel production), but this similarity can be understood as a result of the intentional linkage, and it is certainly not a 'coincidence'. 
1999). In this way, geographical proximity may create an initial basis for the development of common ground. Finally, the geographical proximity of building blocks increases the likelihood that there is an overlap of actors between the building blocks, which increases the chances that the common ground of building blocks is recognized (see section 9.2.4). The relationships between geographical proximity and common ground require further research. It would be especially interesting to investigate the antecedents of other types of collaborations, where the physical and geographical dimensions are less emphasized than with industrial symbiosis. This should offer us further insight in the extent that building blocks for collaboration can also be something more tacit.

The development of common ground as it is described here is not generalizable to all collaborative processes involving governments, firms and knowledge institutes. A particular characteristic of the collaborative processes investigated in this thesis is that they are started to enrich activities that are already in progress in a region. Many other collaborative processes are started in response to a situation that is characterized by conflicts (Ansell and Gash 2008; Gray 1989). In such situations it is more likely that a common ground needs to be actively developed during the collaborative process itself. The findings of this thesis have little to say about that type of collaboration.

The emergence of a common ground does not by itself lead to the start of a collaborative process; the building blocks for collaboration have to be actively assembled. It is in the process of assembling building blocks that mobilization capacity starts to play a more prominent role, in the form of the presence of bridging actors and the development of visions. This is the topic of sections 9.2.4 and 9.2.5.

\subsubsection{Bridging actors}

The development of a common ground is a necessary prerequisite for capacity building, but will not contribute to the development of a collaborative process if actors do not become aware of its existence. It is not self-evident that this happens, because common ground (as it is defined in this thesis) is not created consciously. Actors can work separately on the same ambitions for a longer period, without thinking about the added value of collaborative action. For actors to become aware of the common ground, they need to have knowledge of the various building blocks that are available in their region. This awareness provides them with the opportunity to observe the similarities that exist between the building blocks and the possibilities to mobilize the associated actor coalitions for collective action. Crucial for increased awareness are actors with affiliations to multiple building blocks. By being affiliated to multiple building blocks they can fulfill the role of bridges: Not only can they gather knowledge and experience on the different building blocks, they can also mediate the relationships between the other actors that are involved in the different building blocks (cf. Burt 2000; Burt 2001). In the terminology of social network analysis, these are the actors that have a high "betweenness centrality" 
in their network (Freeman 1978; Wasserman and Faust 1994). An actor with substantial betweenness centrality can link various parts of his social network. In this thesis the actors in this position are mainly public actors. Even though the implementation of many projects depends primarily on the activities of private actors, public actors are usually responsible for linking these activities together. A possible explanation for this public betweenness in public-private networks is the greater multiplicity of objectives that public organizations are usually faced with, compared with private organizations (Rainey, Backoff, and Levine 1976; Rainey 2009). Because public organizations face a greater multiplicity of objectives, they are more likely to find themselves in a position where they act as a bridge between different projects. This finding has particular relevance for the distinction between self-organized and planned industrial symbiosis that is sometimes made in the literature (Côté and Cohen-Rosenthal 1998; Cohen-Rosenthal 2000; Chertow 2007; Chertow 2009; Baas 2011). Planned industrial symbiosis is usually assumed to entail top-down interventions by public organizations, while self-organized industrial symbiosis refers to by-product exchanges and utility synergies that develop spontaneously, as a result of private initiatives. Costa and Ferrão (2010) and Paquin and Howard-Grenville (2012) have nuanced the discussion by showing that the emergence and development of industrial symbiosis often depends on the interplay of public and private interventions. The findings of this thesis add to this discussion by showing the different roles that public and private actors may have in the process: Private actors are usually responsible for the practical implementation of activities related to industrial symbiosis, but public actors are important in linking the different activities of private actors together, thereby making sure that the various activities do indeed amount to a form of collective action.

In this thesis actors are defined at the organizational level. One aspect of bridging actors that requires further investigation concerns the specific activities that the representatives of bridging actors perform at the micro-level. In literature, individuals that act as a bridge between organizational boundaries are often referred to as boundary spanners, and these individuals are usually ascribed special skills that are required to fulfill their role successfully (Tushman and Scanlan 1981; Van Meerkerk and Edelenbos 2014). In earlier studies of industrial symbiosis, boundary spanners (or champions) were found to play an important role in "uncovering" the potential of industrial symbiosis and in mediating the relationships between different stakeholders (Hewes and Lyons 2008; Chertow and Ehrenfeld 2012). More research is required to clarify the link between the particular skills and activities of these individuals, and the bridging position of the organizations that they represent in the process of institutional capacity building.

A hypothesis that follows from the findings of this thesis is that the assembling of building blocks into a collaboration is a conscious act of mobilization that is necessary 
for the collaborative process to commence ${ }^{55}$. Without this act, the institutional capacity that is embodied in the common ground will remain unutilized. Bridging actors are in a position to mobilize others for collaboration. However, they have to be aware of the mobilization opportunities that they have. They also need to have the will to take the responsibility that their position entails. In the cases investigated in this thesis the bridging actors were indeed among the actors that brought different building blocks together to initiate collaborations on industrial symbiosis. The act of assembling the building blocks into a collaboration is the start of a transition to the second phase of institutional capacity building, as described in section 9.2.1. It is marked by the convergence of the streams of events that represent the building blocks for collaboration (see figure 9.9).

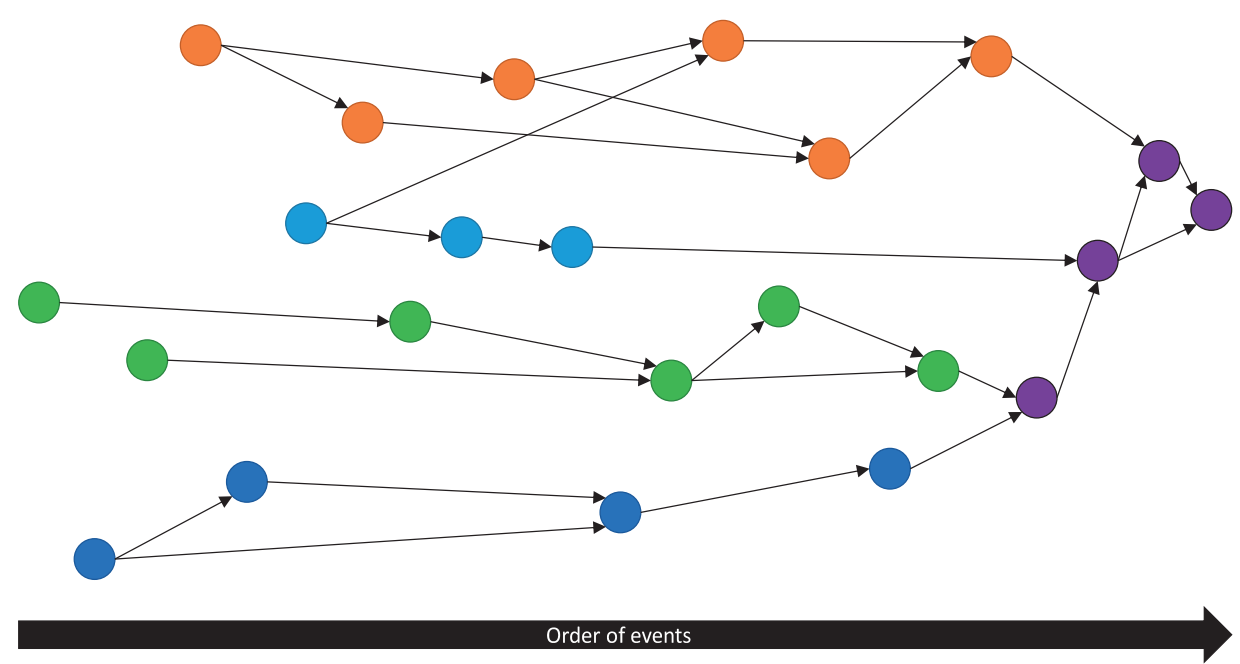

Figure 9.9: Assemblage of building blocks for collaboration. The different colors (excluding the purple nodes) represent different building blocks for collaborations. The purple nodes represent events where the different building blocks converge.

The assemblage of the building blocks may take place through one or more events in which the involved actors actively respond to the conditions that have been created in the different building blocks, that is, the building blocks become intentionally linked. Whether or not the hypothesis on the necessity of mobilization by bridging actors holds requires further investigation, where successful cases (common ground was utilized) and unsuccessful cases (common ground was not utilized) are compared. The investigation

55. The dynamic described here bears close resemblance to what Chertow (2007) described as "uncovering symbiosis" (also see Chertow and Ehrenfeld 2012). 
should focus on the conditions under which common ground is utilized, and include the presence of bridging actors as one of the possible conditions.

Bridging actors are important both before and during the collaborative process. Before the collaborative process they act as mobilizing agents. During the collaborative process they bridge the ties between the different groups of actors that are involved in the collaboration. Thus, during the collaborative process bridging actors are still important for maintaining the continuity and coherence of the collaborative process. However, different actors may take up this role at different points of the process. For example, in the cases investigated in this thesis the provincial governments typically served as the main bridging actor in the early stages of development, but during the collaborative process this role was sometimes taken over by a municipality or port authority. Public organizations typically facilitate the emergence and development of industrial symbiosis, but usually leave the details of the practical implementation of plans to the actors to whom those plans directly concern. In the literature on collaborative governance this role for public actors is usually described in terms of facilitative leadership, which "is widely seen as a critical ingredient in bringing parties to the table and for steering them through the rough patches of the collaborative process" (Ansell and Gash 2008, p. 554).

As mentioned before, in this thesis all actors have been defined at the organizational level. This is a necessary abstraction and a consequence of the type of data used. However, in practice different people can represent that same organization in different projects. It is unclear how reasonable it is to assume that knowledge on all these projects is shared among the various people that represent the same organization, and this question is especially important for organizations that have a bridging role before the start of collaborations. If knowledge doesn't flow around in such organizations easily, it is possible that the link between different building blocks is not made. Such dynamics at the organizational level and their link to inter-organizational relationships in collaborations for industrial symbiosis require further investigation (but see Huxham and Vangen 2000a). Such an investigation could focus on the networks of information exchange that exist within and across the boundaries of organizations that have been confirmed to have a bridging position. This could offer further insights in the extent that knowledge and experience of the various developments in which representatives of the organization are involved are shared among its members. It could also offer further insight in the extent that networks of information exchange of the various members of the organization overlap, which would make information exchange within the organization partially redundant.

\subsubsection{Visions as bridges between past achievements and future ambitions}

Another crucial step in the transition from the emergence of building blocks for collaboration to the collaborative process itself is the development of a shared vision, which 
is an explicit statement of what the actors want to achieve with their collaboration. The shared vision develops during the assemblage of building blocks and articulates how the different building blocks are related. Shared visions are not just future-oriented devices. The findings of this thesis suggest that shared visions are valuable 'instruments' to make the common ground that emerges before the start of collaborations explicit and meaningful for a variety of actors. Because common ground is emergent, it can be understood as a form of tacit knowledge, i.e., it is not yet codified (Lawson and Lorenz 1999; Howells 2002). Shared visions can mobilize this tacit knowledge by codifying it (e.g., in documents), thereby making it explicit and accessible. In this way, the shared vision consolidates the capacity that is embodied by the common ground (see figure 9.10). In addition to consolidating common ground, shared visions articulate what the involved actors want to achieve in the future. In the case of industrial symbiosis this concerns the creation of a network of by-product exchanges and utility synergies from the building blocks that are already in place. Such networks are more than a simple aggregate of the building blocks, because there is an explicit focus on the synergetic effects that can be achieved by bringing them together.

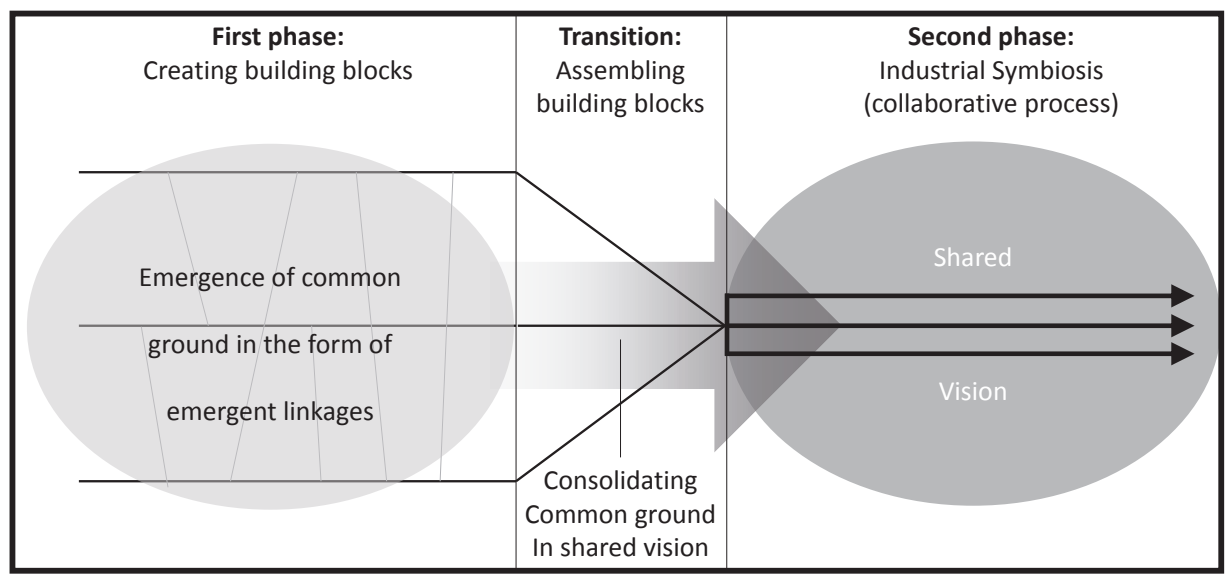

Figure 9.10: Shared visions and the consolidation of common ground.

In collaborations on industrial symbiosis shared visions help actors to shift their attention from the implementation of individual projects to the contribution that these projects make to the development of larger networks of by-product exchanges and utility synergies. Once a shared vision is established, actors will refer to it during the implementation of their activities. This also reduces the need for the actors to continuously coordinate their activities. In that respect, shared visions play a role during the collaboration that is similar to the role of common ground before the collaboration, by creating a bond between actors that does not depend on frequent face-to-face interactions. An important 
difference between shared visions and common ground is that shared visions are products of conscious design, whereas common ground is not. Common ground already exists long before actors become aware of it and start talking about it. Once the actors do start talking about (possibly codifying it in documents) the common ground becomes explicit. By adding the new elements that they want to build on the common ground (the future ambitions), the actors gradually transform common ground into a shared vision.

Anchoring shared visions in common ground also ensures that the shared ambitions that they express do not replace the ambitions that collaborating actors had in their individual projects, but enrich them. Instead of replacing the original ambitions of actors, shared visions can tie the ambitions of various actors together at a higher level of abstraction. A hypothesis that follows from this observation is that in this situation the involved actors are more likely to see value in the collaboration, thereby making it easier for these actors to be mobilized for joint action. This hypothesis should be tested by comparing collaborations where shared visions build on common ground with collaborations where shared visions are not anchored in common ground, i.e., where common ground still needs to be actively developed during the collaborative process itself.

It is important to reiterate here that not all collaborations can build on a common ground that is developed before the start of the collaborative process itself. The special role that common ground plays in the collaborations discussed here also has consequences for the role of shared visions. Shared visions can only fulfill the double role described here if there is indeed a common ground to build on. The process of visioning was not investigated in detail in this thesis, primarily because this would require a stronger focus on micro-dynamics. In this regard, it would be interesting to explore the links that can be made to theoretical perspectives in which there is an explicit focus on the process of visioning, such as transition management (Rotmans, Kemp, and Van Asselt 2001; Loorbach 2007; Loorbach 2010) and backcasting (Dreborg 1996; Quist, Thissen, and Vergragt 2011).

\subsubsection{The relational dimension: the stable core and the fluid periphery}

During the collaborative process the relational dimension of institutional capacity becomes more salient. The start of the collaborative process typically entails an increase in the intensity of interactions between actors, and additional actors may become involved. However, the group of actors that interacts on a structural, long-term basis is relatively small. These actors function as a stable core in the social network that emerges from the collaborative process. Other actors are involved on an incidental basis. In the social network these actors form a fluid periphery around the stable core. The stable core consists out of the public actors that had a bridging position before the collaboration, private actors that had an important role in the building blocks that have been assembled into the collaboration, but also 'new' actors that are attracted specifically to introduce quali- 
ties and resources that were not present in the original community (e.g., universities and consultants).

The stable core of social networks is not a fully integrated group of actors. Instead, the stable core is an assembly of a small number of overlapping subgroups. These subgroups are active in the various projects that are carried out within the collaborative process. In the collaborative process these projects exist as parallel sub-processes (see figure 9.1). The associated subgroups overlap with each other because some actors participate in several projects at the same time. As a result, the modular structure of the collaborative process is not directly visible in the social network that emerges from the collaborative process. Subgroups that meet frequently usually include two or more public actors, in addition to one or two other actors that are active in specific projects within the collaborative process. Thus, in the stable core of the network the public actors have a prominent presence, which is another indication of their importance to the continuity and coherence of the collaborative process.

The stable core and fluid periphery of networks are two distinct manifestations of relational capacity. First, the stable core is a source of continuity of the social network, and it allows for the coordination between actors that are involved in different projects of the collaboration. The small size of the stable core reduces the complications of coordination (cf. Provan and Kenis 2008). The fluid periphery represents the capacity of the actors to attract the resources and capabilities of other actors and utilize these in the collaborative process (cf. Innes and Booher 1999). For example, the national government may occasionally get involved to provide financial or regulatory support, knowledge institutes sometimes get involved to temporarily support projects with research, consultants and engineering bureaus are usually attracted because of their experience with different types of planning procedures, or their expertise in project and process management.

The reconstructions of social networks in this thesis are based on joint participation of actors in events. This is not a direct measurement of relationships, but of opportunities that actors have to develop relationships (Feld 1981; Borgatti and Everett 1997; Borgatti and Halgin 2011). To develop further insights into the social networks that emerge it will be interesting to compare the patterns observed in this thesis with patterns observed through types of network analysis that enquire into relationships (as perceived by the involved actors) more directly. For example, the social networks may be reconstructed by performing surveys in which actors are asked to specify various types of relationships (e.g., formal contact, informal contact, exchange relationship) that they have with others in the region. This will also make it easier to make an assessment of the quality of the relationships, which was not possible to do with the methods applied in this thesis. However, a drawback of such an approach is that the time window within which the uncovered network exists is not made explicit. 


\subsubsection{Modularity and the resilience of collaborations}

In section 9.2.1 the modular nature of collaborations on industrial symbiosis is highlighted. The modular quality of collaborative processes expresses itself in several interconnected streams of events. Each stream represents a project that is carried out as part of the collaboration. The modular nature of the collaborations highlights the fact that the assemblage of building blocks into a collaborative process does not lead to a complete integration of the building blocks. This corresponds with Simon's (1962; 1973; 2002) theory that modular systems are characterized by short-term independence of their modules. An important advantage of such systems is that they can often endure even if one of their modules fails to endure.

This advantage is most easily illustrated through a specific example. At the formal opening of Biopark Terneuzen one of the plans included in the collaboration was to have the biofuel factory of Nedalco (which was not yet built) supply residual heat and $\mathrm{CO}_{2}$ to the greenhouse area. However, before the biofuel factory could be realized the national government changed its stance towards biofuels, and decided to no longer stimulate biofuel production. Nedalco decided to cancel its plans for the biofuel factory, which means that this part of Biopark Terneuzen failed to develop. However, the continuity of the Biopark Terneuzen collaboration did not depend entirely on this particular project, and the collaboration has continued despite of Nedalco's decision not to construct the biofuel factory. This example demonstrates the capability of a modularly structured collaboration to survive when one of its modules is lost due to contextual influences. It suggests that the modular nature of the collaborations described in this thesis also provides them with a certain resilience (cf. Tsvetkova and Gustafsson 2012). The link between modularly structured systems and the resilience of such systems has also been discussed in other contexts (e.g., Ash and Newth 2007; Levin and Lubchenco 2008; Viana et al. 2009; Guimerà et al. 2010). To improve our understanding of the relationship between the modular nature of collaborations and their resilience, further research is required. Ideally, this research would involve an investigation of multiple cases where collaborations of a modular nature had to endure different types of external perturbations. Questions that may be addressed in this research are how many setbacks (i.e., loss of modules) a collaboration can endure without coming to a halt, whether there exists a prioritization of modules (some modules are more important to the resilience of the collaboration than others), and how the loss of some modules affects the ambitions that actors have with their collaboration.

\subsubsection{Unused building blocks}

Although the research of this thesis addressed the question how projects can become building blocks for collaboration, it did not specifically address the criteria that determine whether a building block is used in a collaboration or not. Not all building blocks 
identified in the cases of Biopark Terneuzen and Sustainable Connections have been used. The findings suggest a few criteria that influence whether a building block is assembled into a collaboration or not, although this matter requires further investigation to determine to what extent these criteria hold across different cases. The first criterion has been discussed extensively in this chapter, namely that a project can only be considered a building block for collaboration if it has a common ground with other projects, that is, if it addresses issues that are similar to those addressed in other projects. One question that invites further investigation is what the size and quality of common ground must be. As is discussed earlier in this chapter, common ground can be understood as an emergent and tacit form of knowledge, and it is not necessarily something that actors are aware of. It is likely that actors more easily become aware of common ground if the number of overlapping issues is greater and if the issues that are part of the common ground are specific rather than broad ${ }^{56}$. A second, strongly related criterion is that there must also be some overlap between the building blocks in terms of actors. A central hypothesis that follows from the research in this thesis is that the assemblage of building blocks into collaborations will not happen without this second type of overlap (see section 9.2.4). Here we may also ask how large the overlap of actors should be and how closely these actors should be involved in different building blocks. In the cases studied in this thesis public actors were sometimes only involved in building blocks because of permit procedures. Such a superficial involvement in a building block may be insufficient for the building block to be recognized by bridging actors as a potential contributor to a collaborative process. For both criteria there is also a question of timing. As time passes, the actors involved in a given building block may shift their attention to other issues, which may cause the overlap of issues with other building blocks to disappear (i.e., it stops being a building block). Also, bridging actors may only be involved in a building block for a limited time period, which may be too short for them to recognize the overlap that exists with other building blocks. A third possible criterion is that the actors involved in the building blocks should also be motivated to become involved in a collaboration. This criterion was already addressed in the context of shared visions (see section 9.2.5). There, the hypothesis was raised that if a vision is anchored in common ground, then it is more likely the actors will see the collaboration as an enrichment of their original project(s), and are therefore more likely to get involved in the collaboration. All of the criteria outlined here require further research, based on a comparative research design. The start of a collaborative process can be used as an outcome variable, and the differ-

56. For example, Sustainability has become a 'catchall' issue, while Reuse of residual materials refers to a much narrower set of problems, solutions, and practices. Intuitively, the latter issue seems much more specific than the former issue. In this thesis measures for creating a rank order of issue specificity have not been developed. 
ent criteria outlined here can be included in the study as possible conditions for that outcome to occur.

\subsubsection{Collaborations as building blocks}

There is evidence that the collaborations for industrial symbiosis themselves can serve as building blocks for larger scale initiatives, which leads to hierarchies of collaborations (Huxham and Vangen 2000a). For example, Biopark Terneuzen has been included as a building block in Biobase Europe, a collaboration between actors from the province of Zeeland and the province of Flanders, in which Bio-Valley Ghent (a collaboration in Belgium that is similar to Biopark Terneuzen) features as a second building block. Biopark Terneuzen has also been included as a building block in an initiative called Biobased Delta, which started as a collaboration between actors from the province of Zeeland and the province of Noord-Brabant. Here, a second building block concerns activities related to biobased economy that have occurred primarily at and around Bergen op Zoom in Noord-Brabant. Although the larger scale collaborations such as Biobase Europe and Biobased Delta have not been investigated in detail, it seems that here too common ground provides a basis for broader collaboration. The role of bridging actors is less obvious, as there is no clear evidence of actors that were closely involved in all the collaborations that are included in these larger scale collaborations. However, direct involvement may be less important here because collaborations such as Biopark Terneuzen and Bio-Valley Ghent attract a lot of attention, which makes it relatively easy to have knowledge of these developments and become aware of their common ground without being directly involved.

These examples show that the dynamics observed in collaborations for industrial symbiosis, in which multiple building blocks are first created independently and are later assembled together, are not unique to the level of regional industrial systems. The dynamic is reproduced at higher system levels, which indicates that more complex systems can be built by using the collaborations themselves as building blocks. This resonates with the suggestion of Posch (2010) that industrial symbiosis can serve as the basis for broader sustainability-oriented collaboration.

\subsubsection{Capacity building at the regional level}

The previous conclusions are all based on patterns of capacity building that are observed when one draws a boundary around the collaboration for industrial symbiosis (including its predecessors) itself. However, as discussed in section 9.2.1, this boundary should not be perceived as closed. Other developments that take place in parallel to the collaborations for industrial symbiosis also make contributions to institutional capacity that is available in the wider region. By taking these other developments into account, we gain a fuller understanding of the origins of the institutional capacity that is mobilized 
in collaborations on industrial symbiosis. Taking the other developments into account also makes the idea that institutional capacity building has no clear boundaries concrete (Innes and Booher 1999; Huxham and Vangen 2000a).

The primary way in which developments that occur in the context of collaborations for industrial symbiosis can make a contribution to institutional capacity is by offering additional opportunities for actors to develop relationships and to exchange knowledge and experience on various issues. In this regard, the developments that are particularly interesting are those where platforms for discussion are established where actors from various backgrounds meet regularly, in more or less stable constellations, and over long periods of time. In the Sloe Area and Canal Zone such a platform was created in the project Vital Sloe Area and Canal Zone. At Moerdijk, a platform called the Neighbors Council was created. These platforms contribute to the institutionalization of relationships between the actors that participate to them. In addition, the discussion platforms make contributions to the knowledge capacity that is available in the region by facilitating discussion on various issues. Although the discussion platforms cover a broader range of issues, occasionally discussions will be dedicated to issues that are addressed in the collaborations for industrial symbiosis as well. Thus, both in terms of relational capacity and knowledge capacity there are spill-over effects between the different developments.

\subsection{THE VALUE OF EVENT SEQUUENCE ANALYSIS TO THE STUDY OF PROCESSES}

\subsubsection{The value of a process perspective}

A major part of this thesis is dedicated to the development of methods, techniques and tools that can be used to systematically investigate social processes ${ }^{57}$. These methods, techniques and tools are part of a larger project called Event Sequence Analysis (ESA) (Boons, Spekkink, and Jiao 2014). ESA has made several instrumental contributions to the research presented in this thesis that have made possible the development of insights that would have been difficult to obtain otherwise. A general contribution of ESA has been to shape the 'frame of thought' through which various problems have been addressed throughout the research process. This frame of thought was briefly discussed in chapter 4 of this thesis, and it can be summarized in the statement that 'process has primacy over substance.' Rather than taking stable entities as the point of departure, we ask how stable entities are capable of emerging and enduring in a reality where change is 'the normal state of affairs' (Abbott 2001). Thus, the methods that are used in search for answers to research questions should be capable of capturing change, as

57. The methods and tools presented in this section have been developed in collaboration with professor Frank Boons. 
well as the stable entities that emerge amidst change. In this thesis, the general answer to these challenges has been to build all analyses on the reconstruction of processes as sequences of events. In this approach the events themselves capture development and change (Abbott 1990b; Poole et al. 2000; also see Whitehead 1978). At the same time, it is possible to reconstruct stable entities from sequences of events by focusing on recurrent patterns, that is, "events that keep happening in the same way" (Abbott 2001, p. 296). This is how an approach based on the study of sequences of events distinguishes itself from other approaches: Stable entities are not assumed, but they are discovered. In the following sections, a discussion is offered of the various ways in which this approach has helped to achieve research results that otherwise would not have been achieved ${ }^{58}$.

\subsubsection{Event graphs, intentional linkages and emergent linkages}

One of the most important instruments used in this thesis is the event graph (see figure 9.11). A major advantage of event graphs is that they can offer a complete overview (albeit an abstract one) of the process under investigation. Event graphs incorporate the time dimension of processes by laying out the events in order of time from left to right. This enables the investigation of order effects, which is one of the ways in which the time dimension of social processes can be taken into account. An important order effect that has been revealed in this thesis is that the emergence of common ground precedes the formal start of a collaborative process. In the event graph in figure 9.11 this order effect has been made explicit. This crucial observation can only be made if order effects are indeed taken into account. Otherwise the emergence of common ground is easily mistaken as an outcome or aspect of the collaborative process rather than its predecessor.

One of the primary purposes of event graphs is to facilitate the analysis of relationships between events. In this thesis, two types of relationships between events are distinguished: Intentional linkages and emergent linkages (see section 9.2.3). The analysis of intentional linkages has made it possible to reconstruct and visualize the 'syntax' of the process (Abell 1987). Several of the conclusions presented in this chapter build on the observation that the emergence and development of industrial symbiosis is a modular and compounded process, where multiple streams of events exist at the same time. An event graph based on intentional linkages offers a powerful way to make that observation explicit through visualization. Emergent linkages were introduced to capture the idea that the projects of actors can be linked unintentionally, that is, without conscious coordination across the different projects. The combined use of event graphs and emergent linkages has made it possible to develop indicators for emergent phenom-

58. Several software tools and algorithms have been developed to facilitate the tasks discussed in this section of the chapter. This includes tools for the creation of event graphs, the calculation of directed paths in event graphs, and the dynamic analysis of social networks that are reconstructed from event data. The tools are freely available on the personal website of the author (www.wouterspekkink.org). 


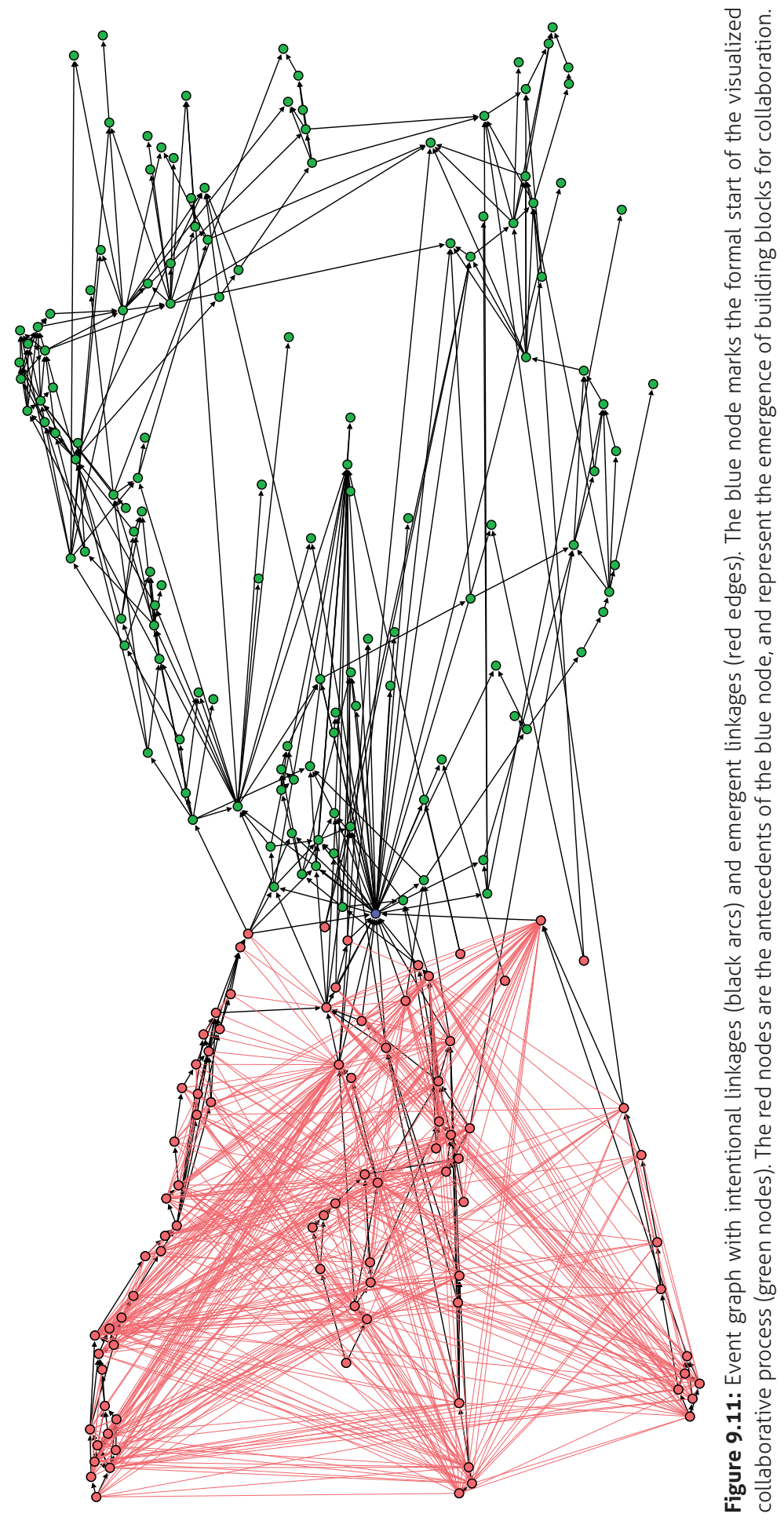


ena, such as the common ground that actors develop as a by-product of their "private" projects. Without these tools, it would have been difficult to go beyond description and provide additional evidence that an emergent common ground actually exists.

Another advantage of event graphs is that it allows for the use of methods for network analysis to analyze sequences of events. A limited set of such methods has already been used in this thesis. First, calculations of modularity (Newman 2006; Blondel et al. 2008) were performed to identify subsequences in the event graphs. These subsequences were used as indicators for (1) the existence of different building blocks before the start of collaborations, and (2) the existence of parallel projects after the start of collaborations. By identifying subsequences, it is possible to create a simpler overview of the complete sequence of events by breaking it up in large chunks. This allows the researcher to simplify the analysis of the process, and it also opens the door to other possibilities, such as comparisons between the different subsequences of a larger process. Potentially, this could lead to the identification of returning episodes in a process. Possibilities for the comparative analysis of subsequences have not been explored in this thesis. Second, an algorithm for the reconstruction of directed paths in event graphs was created (see chapter 4 in Wasserman and Faust 1994 for a detailed discussion of paths). In essence, the reconstruction of these paths provides another way to break up the event graph in different chunks. However, depending on the complexity of the event graph, the number of possible paths quickly becomes very large, which means that the reconstruction of paths can make the analysis more complicated instead of making it simpler. In this thesis, the reconstruction of directed paths in event graphs was only used as an intermediary step in the reconstruction of emergent linkages between events ${ }^{59}$. Third, in directed, acyclic graphs (of which event graphs with intentional linkages are examples) it is possible to find all the ancestors and/or descendants of a given node ${ }^{60}$. This technique was used to reconstruct the sequences of events that led up to the formal start of collaborative processes (ancestors) and the sequences of events that constitute the collaborative processes themselves (descendants). The event graphs that are visualized in figures 9.2 and 9.11 are a result of this process. The identification of ancestors and descendants of events offers another way to simplify the analysis of a process. The datasets that were developed for the two cases of this thesis include hundreds of events, which makes it difficult to create an overview of the different historical lineages that are contained in the datasets. By identifying the ancestors and descendants of particular 'focal events' it is possible to automatically distill various historical lineages from the complete dataset.

59. As explained earlier in this chapter, emergent linkages cannot exist between two events that are on the same path of intentional linkages. To rule out the non-emergent linkages, the paths of intentional linkages first need to be known.

60. For this purpose, the NetworkX library for python was used (http://networkx.github.io/). A plugin for Gephi that performs the same task is now also available: http://www.wouterspekkink.org/?page_id=203. 
What the different methods discussed here have in common is that they are structural approaches to the analysis the event graph as 'a network of events.' By simplifying the rich information that is available in event data they help the researcher to develop an overview of processes that would otherwise be difficult to obtain, and thereby facilitate the discovery of patterns in the data.

\subsubsection{Reconstructing social networks from event data}

One of the themes addressed in section 9.3.1 is the emergence of stable entities from events. In this thesis the idea was made tangible by using sequences of events as the input for the reconstruction of social networks. The social networks thus reconstructed are known in the literature as affiliation networks, which were invented to capture the affiliation of actors (e.g., people or organizations) to events (e.g., parties or membership to organizations) (Borgatti and Everett 1997; Borgatti and Halgin 2011). Because of the focus on affiliations of actors to events, the study of affiliation networks has a natural affinity with the study of event sequences. If the researcher identifies the actors that are involved in the events that make up a sequence, it becomes possible to represent this information as an affiliation network. An added advantage of this approach is that the events have an order in time. As a consequence, it is possible to reconstruct affiliation networks for different parts of an event sequence, which can then be compared to investigate whether certain network structures recur over time (see figure 9.12).

Thus, by using event sequences as input for the reconstruction of affiliation networks, it becomes possible to study the emergence, development and dissolution of stable enti-

Actors and their participation in events

The network of actors for all 6 events

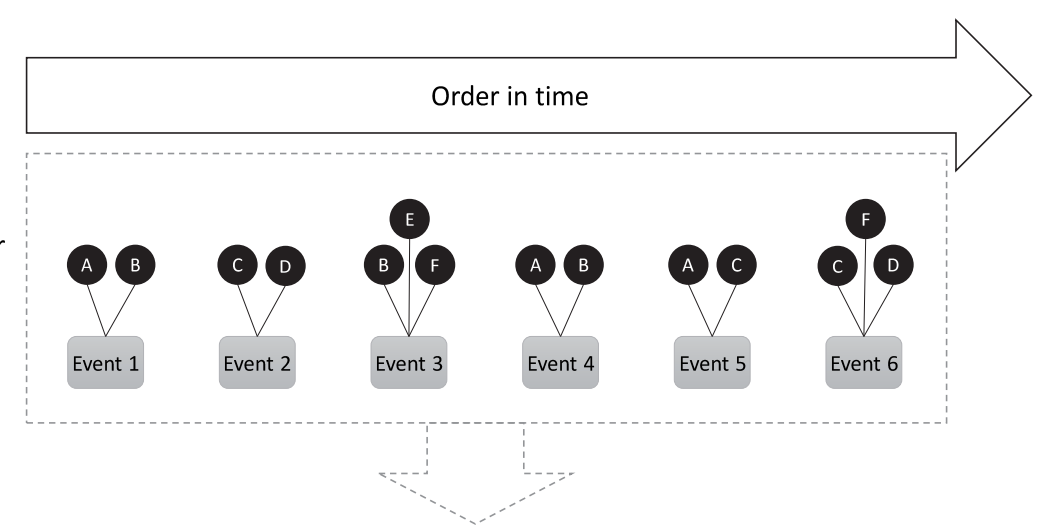

all 6 events

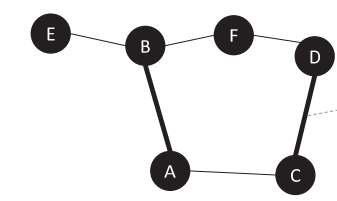

Thicker edges indicate patterns that occurred twice

Figure 9.12: Schematic overview of the reconstruction of social networks from sequences of events 
ties as enduring network structures. The application of this approach in this thesis has led to the discovery of the stable core and the fluid periphery in the social networks that emerge from interaction processes. The notion of stable core embodies the elements that endure in the social networks, while the fluid periphery embodies the elements that are not stable. The identification of these qualities of social networks can only occur through methods that are capable of capturing both stability and change, which is something that most conventional methods for social network analysis are not capable of. The use of event data for the reconstruction of social networks also creates possibilities for the analysis of network dynamics, which is the topic of the next section.

\subsubsection{Event data and network dynamics}

As was mentioned in section 9.3.3, one of the advantages of using event sequences as the input for the reconstruction of social networks is that the events are ordered in time. As a result, the time dimension can to be taken into account in network analysis. Existing approaches to dynamic analysis of social networks typically depend on comparative statics, and sophisticated statistical models that aim to capture the latent change that is assumed to take place between the moments of observation (Snijders 2001; Bunt, Wittek, and Klepper 2005; Doreian and Stokman 1997). A major advantage of using sequences of events as the basis for dynamic network analysis is that changes are observed, rather than assumed, although the detail of the observations depends on the quality of the data.

In this thesis a new approach to the analysis of social network dynamics was explored ${ }^{61}$, which reconstructs network dynamics by making measurements of network structures for overlapping parts of the event sequence (see figure 9.13). This approach to the dynamic analysis of networks was used to investigate network dynamics in collaborations on industrial symbiosis. With the time series that were generated in this way it was possible to analyze long-term trends in the structural characteristics of the social networks that emerge from interaction processes in the system (see figure 9.14 for an example of a time series).

The approach has several important limitations. First, currently it can only be used to study networks that are based on affiliations of actors to events. For the investigation of other types of networks (e.g., networks with directed relationships) a different approach is required. Second, currently the time points in the time series are only in order of occurrence, and the actual length of time that passes between each time point is not taken into account. This raises limitations for the type of analyses that can be performed on the resulting time series.

61. A similar approach was already developed earlier by Doreian (1979). An analysis of network dynamics based on event streams was also used by Stadtfeld and Geyer-Schulz (2011) 


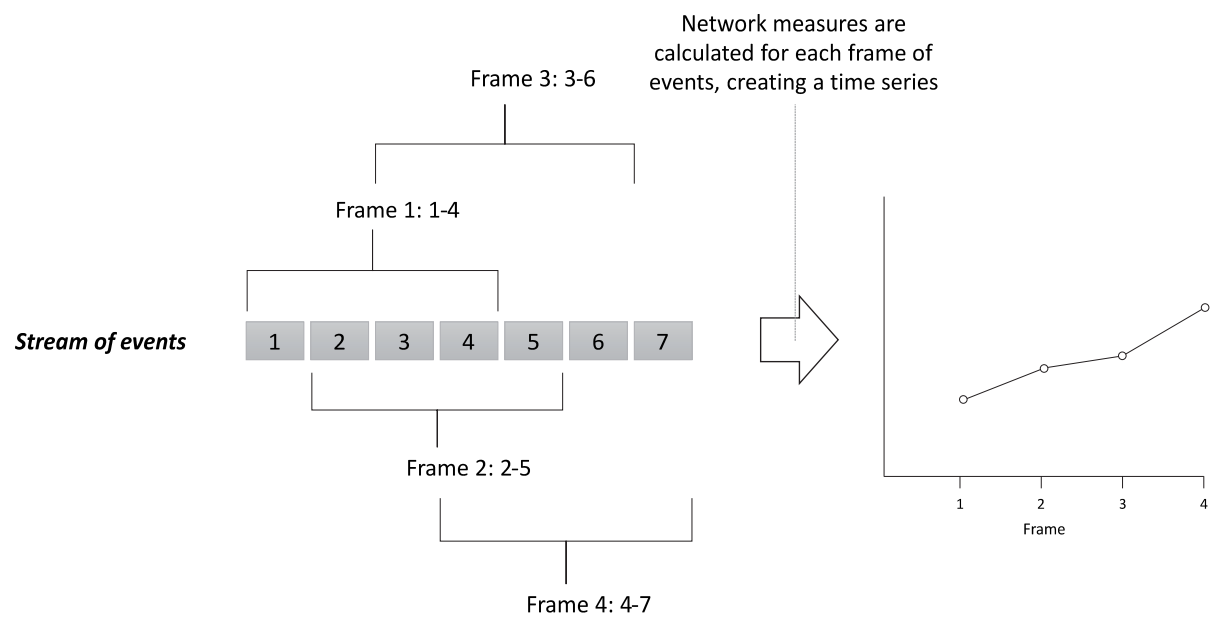

Figure 9.13: Time series of network measures are created by making measurements for overlapping parts of a sequence of events.

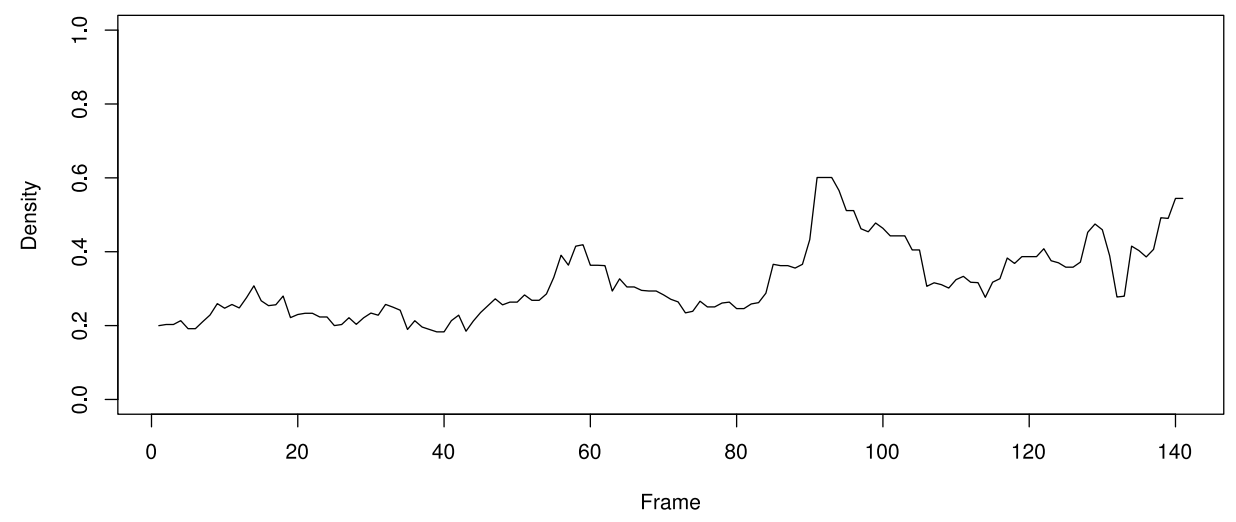

Figure 9.14: Example of time series, showing the changes in network density in the case of Sustainable Connections.

\subsubsection{Comparing processes}

As the reader may have noticed, several of the suggestions for further research that are made in section 9.2 point to the need for comparative research. ESA itself has not been designed for comparative research, and is best understood as a case study approach. Although it is possible to use ESA for multiple case studies that can then be compared among each other (which is the approach used in this thesis), due to the amount of time that must be invested in the reconstruction and analysis of a single case ESA is not suitable for medium- $N$ (e.g., Qualitative Comparative Analysis) or large- $N$ comparisons. 
Two main avenues for comparative research on processes are suggested here. First, an approach that is very similar to ESA in its basic principles is sequence analysis (Abbott and Tsay 2000; Brzinsky-Fay and Kohler 2010; Blanchard, Bühlmann, and Gauthier 2014). In this approach one typically starts with a large number of simple, unitary sequences of events (or states) that are analyzed for their (dis)similarities. Usually, similarity is based primarily on the extent that sequences exhibit the same order of events. A cluster analysis can then be performed to derive a basic categorization of the investigated sequences. Advantages of this approach are that it explicitly takes into account the time dimension of processes, and that it allows one to consider a relatively large amount of processes at the same time. Disadvantages of the approach are that it is primarily useful for categorization of sequences (which is only a first step in the explanation of outcomes), and that it typically cannot handle multi-stranded processes (but see Gauthier et al. 2010). Another possible avenue for comparative research on processes is the application of Oualitative Comparative Analysis (OCA) (Rihoux and Ragin 2009; Schneider and Wagemann 2012). This is a set-theoretic and qualitative approach to comparative analysis. In essence, in QCA one investigates which configurations of (theoretically derived) conditions lead (or do not lead) to some outcome of interest. The cases that are included in the analysis represent configurations of conditions that are empirically observed. Several of the suggestions for further research in section 8.2 are based on hypotheses about conditions that may or may not influence various outcomes in the emergence and development of industrial symbiosis (e.g., the conditions that determine whether a given building block is assembled into a collaboration or not). OCA is a promising approach for testing such hypotheses. Advantages of OCA are that it delivers useful results with a medium sized $N$, and that its configurational approach enables the researcher to lay bare relatively complex causal structures. Disadvantages of the approach are that it does not take into account the time dimension of processes (Verweij and Gerrits 2013), and that it is fundamentally a deterministic approach, and therefore is to some extent at odds with the process perspective, which emphasizes creativity and novelty.

Using ESA in combination with a comparative approach is a promising way forward in the study of processes. In this combination, ESA's main strength is its ability to reveal temporal patterns that would go unnoticed with approaches that are time-agnostic. Comparative approaches can then be used to determine to what extent these temporal patterns hold across different cases and/or contexts. The combination can also be made the other way around. After one identifies conditions that are relevant to some outcome of interest through a comparative approach, ESA may help to determine how these conditions are temporally situated. 


\subsection{RECOMMENDATIONS}

In this section some of the recommendations for further research that have been made throughout the chapter are summarized in section 9.4.1. In addition, a number of recommendations for practitioners in the field of industrial symbiosis are presented in section 9.4.2.

\subsubsection{Recommendations for further research}

Several recommendations for further research have been made throughout the chapter that urge for more comparative research on industrial symbiosis. First of all, comparative research may help us identify different types of industrial symbiosis and the contexts in which they emerge. The type of industrial symbiosis investigated in this thesis is one which features collaboration between large numbers of actors. Currently, there is not a clear overview of the different contexts in which this type of industrial symbiosis is likely to emerge. Comparative studies on industrial symbiosis may help to create such an overview.

Comparative research is also required to test some of the hypotheses that have been stated in the conclusions of this thesis. One set of such hypotheses is related to the role of geographical proximity in the emergence of building blocks for collaboration. Further research on this matter could focus on the relative importance of cultural and physical aspects of geographical proximity, and on how these aspects influence the likelihood that actors working in independent projects will discover a common ground. Another hypothesis that may be tested through comparative research concerns the necessity of mobilization of different actor coalitions by actors in a bridging position for the transition from the first to the second phase of industrial symbiosis to happen. Testing this hypothesis requires the comparison of cases where a common ground has developed, but where in some cases the act of mobilization by bridging actors has taken place, while in others it has not. A related topic concerns the extent to which the visions that are at the basis of collaborations are historically rooted in the common ground that actors develop before the collaborative process. With regard to this issue, an interesting avenue for further research would be to determine how such visions compare to visions that are not clearly rooted in common ground in terms of their mobilizing force (i.e., the extent to which they motivate actors to become involved in collaborations) and the feasibility of their ambitions (i.e., the extent to which the involved actors are able to realize the ambitions embodied by the vision). Another set of hypotheses that can be tested through comparative research concerns the different conditions that determine whether or not building blocks for collaboration are actually utilized. Here, different configurations of such conditions can be identified after which one may investigate whether or not these configurations lead to the outcome of interest (inclusion in a collaborative 
process). The different cases to be compared concern building blocks for collaboration. Finally, comparative research is required to further explore the relationship between the modularity of collaborative processes and the extent that they are resilient to external perturbations.

Other suggestions for further research that have been made throughout this chapter require the researcher to zoom in on specific aspects of the emergence and development of industrial symbiosis. One example concerns the role of individual representatives of organizations with a bridging role in the emergence and development of industrial symbiosis. Here, further research could focus on how the role that bridging organizations have in the emergence in development of industrial symbiosis (and other types of collaborations) translates to the activities of specific individuals in these organizations. More specifically, further research could focus on the level of coordination that is required within such organizations in order for such organizations to be able to effectively mediate the relationships between different projects and actor constellations. This question is especially interesting for situations in which different people represent the same organization in different projects. More generally, it will be useful to develop a stronger link between dynamics of institutional capacity building at the level of the regional industrial system to the opportunities that actors see for different courses of action at the micro-level. This link was introduced in the original version of the conceptual framework presented in chapter 3. However, it proved to be too difficult to reliably investigate this link based on the approach taken in this thesis. Nonetheless, how the development of institutional capacity influences the opportunities that individuals see to, for example, engage in symbiotic exchanges remains an important question.

In this thesis some attention has paid to the relationship between industrial symbiosis and other types of interaction processes that occur in regional industrial system. Several insights on this relationship have been developed in this thesis, but further research on this matter is required. Research on industrial symbiosis tends to focus entirely on the process of industrial symbiosis itself, but this thesis has provided some evidence that there can be synergies between industrial symbiosis and other types of interaction processes that occur in regional industrial systems. This thesis has provided some preliminary evidence that the different types of interaction processes that occur in regional industrial systems can be mutually reinforcing. Further research could focus more specifically on the co-evolution of different interaction processes to determine under what conditions these processes can create positive bedding for each other.

A final recommendation for further research concerns the question what happens after the collaboration on industrial symbiosis has commenced. This issue points at a limitation of the phase model of industrial symbiosis that is introduced earlier in this chapter: It doesn't clarify what happens after the second phase of the process. It is not possible to offer insights in this matter based on the findings of this thesis, because both of the 
cases that were studied concern processes that are still in progress. Further research may clarify what will happen after the collaborative process ends and what this means for the development of institutional capacity in the regional industrial system. In this regard it will be interesting to explore parallels with Nooteboom's (1999) cycle of learning and with Holling's (2001) adaptive cycle. From the perspective of both these models the second phase of industrial symbiosis may be understood as a phase of exploitation that is inevitably followed by a phase of reorganization in which the structures that have been created in earlier phases are (partially) broken down again, creating opportunities for the development of novel structures.

\subsubsection{Recommendations for practitioners of industrial symbiosis}

Based on the findings of this thesis a few recommendations can be made specifically to practitioners in the field of industrial symbiosis. First, one of the major findings of this thesis is that the emergence and development of industrial symbiosis can be understood as a creative process in which existing building blocks are assembled into new wholes. This means that actors that have the ambition to engage in industrial symbiosis do not necessarily have to start 'from scratch.' Building blocks may already be present in a variety of forms, and the trick is to recognize these building blocks at a point in time where the larger whole that they potentially form is not yet clearly envisioned. The recognition of building blocks for collaboration requires actors to be relatively well connected to different sustainability-oriented projects that are carried out within their region, and it requires them to be sensitive to the commonalities that might exist between these projects. This thesis has revealed that (local and regional) public organizations are often in a position where they have a relatively good overview of the potential building blocks in their region. For public organizations this means that they should be aware of this special position and of the particular opportunities (or responsibilities) that his creates for them. For private organizations it means that public organizations should be among the first partners to address when they have the ambition to engage in industrial symbiosis (if their ambition goes beyond the development of individual symbiotic exchanges). A general recommendation to public organizations with the ambition to stimulate industrial symbiosis is that it is important to build on, and harness the activities that private actors are already developing in their region, rather than attempting to develop industrial symbiosis in a strictly top-down fashion. This can be achieved by identifying the common ground of the various activities that occur in the region, and articulating this common ground in shared visions. By doing so, the institutional capacity that is already available in the region is consolidated, which makes it possible to effectively mobilize this capacity for the collaboration. Thus, visions should not just be used to guide future behavior; they should also be used to provide a strong foundation for the collaborative process at its start. Finally, it is important that public actors recognize their importance 
to the continuity and coherence of collaborative processes once it has started. They are typically in a position where they can tie the different groups of actors involved in the collaboration together. It is uncertain how long the collaborative network can survive if the public actors step out of this role. 




$$
\text { RAFARENCAES }
$$



A

Abbott, A. 1984. "Event Sequence and Event Duration: Colligation and Measurement [in Medicine]." Historical Methods 17 (4): 192-204.

Abbott, A. 1988. "Transcending General Linear Reality." Sociological Theory 6 (2): 169-86. Abbott, A. 1990a. A Primer on Sequence Methods. Organization Science 1(4): 375-392.

Abbott, A. 1990b. "Conceptions of Time and Events in Social Science Methods: Causal and Narrative Approaches." Historical Methods 23 (4): 140-150.

Abbott A. 1991. The Order of Professionalization: An Empirical Analysis. Work and Occupations 18 (4), 355-384.

Abbott, A. 1997. Of Time and Space: The Contemporary Relevance of the Chicago School. Social Forces 75(4), 1149-1182.

Abbott, A. 2001. Time Matters: On Theory and Method. Chicago: University of Chicago Press.

Abbot, A. 2004, The Historicality of Individuals. Presidential Address, SSHA. Retrieved from http://escholarship.org/uc/ item/Ozj4d90d.pdf.

Abbott, A. and Tsay, A. 2000. Sequence Analysis and Optimal Matching Methods in Sociology. Sociological Methods \& Research 29(1): 3-33.

Abell, P. 1984. Comparative Narratives: Some Rules for the Study of Action. Journal for the Theory of Social Behaviour 14 (3) 309-331.

Abell, P. 1987. The Syntax of Social Life: The Theory and Method of Comparative Narratives. Oxford: Clarendon.

Abell, P. 1993. Some Aspects of Narrative Method. The Journal of Mathematical Sociology $18(2-3): 93-134$.

Abell, P. 2001. Causality and Low-Frequency Complex Events: The role of Comparative Narratives. Sociological Methods \& Research 30 (1): 57-80.
Abell, P. 2004. Narrative Explanation: An alternative to Variable-centered explanation? Annual Review of Sociology 30: 287-310.

Agranoff, R. 2006. Inside Collaborative Networks: Ten Lessons for Public Managers. Public Administration Review, 66(s1): 56-65.

Agranoff, R. and McGuire, M. 1998. The Intergovernmental Context of Local Economic Development. State \& Local Government Review 30 (3): 150-64.

Agranoff, R. and McGuire, M. 2001. Big Questions in Public Network Management Research. Journal of Public Administration Research and Theory, 11(3): 295-326.

Agranoff, R., and McGuire, M. 2003. Collaborative Public Management: New Strategies for Local Governments. Washington DC: Georgetown University Press.

Ahuja, G. 2000. Collaboration Networks, Structural Holes, and Innovation: A Longitudinal Study. Administrative Science Quarterly, 45(3): 425-455.

Akkerman, A. and Torenvlied, R. 2011. Managing The Environment. Public Management Review, 13(1): 159-174.

Andrews, C.J. 2000. Building a micro foundation for industrial ecology. Journal of Industrial Ecology, 4(3): 35-52.

Ansell, C. and Gash, A. 2008. Collaborative Governance in Theory and Practice. Journal of Public Administration Research and Theory 18 (4): 543-571.

Ash, J., and Newth, D. 2007. Optimizing Complex Networks for Resilience against Cascading Failure. Physica A: Statistical Mechanics and Its Applications 380: 673-683.

Ashton, W. S. 2008. Understanding the Organization of Industrial Ecosystems. Journal of Industrial Ecology 12 (1): 34-51.

Ashton, W. S. 2009. The Structure, Function, and Evolution of a Regional Industrial Ecosystem. Journal of Industrial Ecology 13 (2): 228-246.

Ashton, W. S. 2010. Managing Performance Expectations of Industrial Symbiosis. Busi- 
ness Strategy and the Environment 20(5): 297-309.

Ashton, W. S. and Ariana C. B. 2012. Assessing the 'Short Mental Distance' in Eco-Industrial Networks. Journal of Industrial Ecology 16 (1): 70-82.

Atkin, R. H. 1974. Mathematical Structure in Human Affairs. London: Heinemann Educational Books Limited.

\section{B}

Baas, L. W. 2008. Industrial Symbiosis in the Rotterdam Harbour and Industry Complex: Reflections on the Interconnection of the Techno-Sphere with the Social System. Business Strategy and the Environment 17 (5): 330-340.

Baas, L. W. 2011. Planning and Uncovering Industrial Symbiosis: Comparing the Rotterdam and Östergötland Regions. Business Strategy and the Environment 20 (7): 428-40.

Baas, L. W. and Boons, F. A. A. 2004. An Industrial Ecology Project in Practice: Exploring the Boundaries of Decision-Making Levels in Regional Industrial Systems. Journal of Cleaner Production 12 (8-10): 1073-1085.

Baas, L. W. and Boons, F. A. A. 2007. The introduction and dissemination of the industrial symbiosis projects in the Rotterdam Harbour and Industry Complex. International Journal of Environmental Technology and Management 7(5): 551-577.

Bardach, E. 1998. Getting Agencies to Work Together: The Practice and Theory of Managerial Craftsmanship. Washtington, D.C.: Brookings Institution Press.

Bardach, E. 2001. Developmental Dynamics: Interagency Collaboration as an Emergent Phenomenon. Journal of Public Administration Research and Theory 11 (2): 149-164.

Berenschot, 2004. Evaluatie van de beleidsinstrumenten voor bedrijventerreinen: StiREA, TIPP en DBT [Evaluation of policy instru- ments for industrial parks: StiREA, TIPP, and $D B T]$. Ministerie van Economische Zaken.

Blanchard, P., Bühlmann, F. and Gauthier, J. A. 2014. Advances in Sequence Analysis Theory, Method, Applications. Cham: Springer.

Blondel, V. D, Guillaume, J. L., Lambiotte, R.and Lefebvre, E.. 2008. Fast Unfolding of Communities in Large Networks. Journal of Statistical Mechanics: Theory and Experiment (10).

Bodin, Ö. and Crona, B. L. 2009. The Role of Social Networks in Natural Resource Governance: What Relational Patterns Make a Difference? Global Environmental Change 19 (3): 366-374.

Boeije, H. 2010. Analysis in Qualitative Research. Thousand Oaks: SAGE.

Booher, D. and Innes, J. (2002). Network power in collaborative planning. Journal of Planning Education and Research, 21(3): 221-236.

Boons, F. A. A. 2008. History's Lessons: A Critical Assessment of the Desrochers Papers. Journal of Industrial Ecology 12 (2): 148-158.

Boons, F. A. A. 2009. Creating ecological value: An evolutionary approach to business strategies and the natural environment, Cheltenham: Edward Elgar Publishing.

Boons, F. .A. A. and Berends, M. 2001. Stretching the Boundary: The Possibilities of Flexibility as an Organizational Capability in Industrial Ecology. Business Strategy and the Environment 10 (2): 115-124.

Boons, F. A. A. and Howard-Grenville, J. (eds.) 2009a. The Social Embeddedness of Industrial Ecology. Edward Elgar Publishing.

Boons, F. A. A. and Howard-Grenville, J. 2009b. Introducing the social embeddedness of industrial ecology. In: F.A.A. Boons and J. Howard-Grenville (Eds.), The social embeddedness of industrial ecology. Cheltenham: Edward Elgar, pp. 3-27.

Boons, F. A. A., and Janssen, M. A. 2004. The Myth of Kalundborg: Social Dilemmas in Stimulating Eco-Industrial Parks. In J. C. J. M. Van den Bergh and M. A. Janssen (eds.). 
Economics of Industrial Ecology: Materials, Structural Change, and Spatial Scales. Cambridge: MIT Press, pp. 337-55.

Boons, F. A. A. and Spekkink, W. A. H. 2012 a. Levels of Institutional Capacity and Actor Expectations about Industrial Symbiosis: Evidence from the Dutch Stimulation Program 1999-2004. Journal of Industrial Ecology 16(1): 61-69.

Boons, F. A. A., and Spekkink, W. A. H. 2012b. Governance as process. Paper presented at the IPA conference, Tilburg 5-7 July 2012.

Boons, F. A. A., and Spekkink, W. A. H. 2014. Dynamiek in beleid: proces en gemeenschap. Presentation.

Boons, F. A. A., Spekkink, W. A. H. and Jiao, W. 2014. A Process Perspective on Industrial Symbiosis. Journal of Industrial Ecology 18 (3): $341-355$.

Boons, F. A. A., Spekkink, W. A. H. and Mouzakitis, Y. 2011. The Dynamics of Industrial Symbiosis: A Proposal for a Conceptual Framework Based upon a Comprehensive Literature Review. Journal of Cleaner Production 19 (9-10): 905 -911.

Borgatti, S. P. and Everett, M. G. 1997. Network Analysis of 2-Mode Data. Social Networks 19 (3): 243-269.

Borgatti, S. P., Everett, M. G. and Freeman, L. C. 2002. Ucinet for Windows: Software for Social Network Analysis. Harvard, MA: Analytic Technologies.

Borgatti, S. P., Everett, M. G. and Johnson, J. C. 2013. Analyzing Social Networks. Thousand Oaks: Sage.

Borgatti, S. P. and Foster, P. C. 2003. The Network Paradigm in Organizational Research: A Review and Typology. Journal of Management 29 (6): $991-1013$.

Borgatti, S. P. and Halgin, D. S. 2011. Analyzing Affiliation Networks. In J. Scott and P. J. Carrington (Eds.), The SAGE Handbook of Social Network Analysis. Thousand Oaks: Sage, pp. 417-433.
Borgatti, S. P. and Lopez-Kidwell, V. 2011. Network Theory. In: J. Scott and P. J. Carrington (Eds.). The SAGE Handbook of Social Network Analysis. Thousand Oaks: Sage, pp. 40-54.

Bourdieu, P. 1986. The Forms of Capital. In J. Richardson (Ed.), Handbook of Theory and Research for the Sociology of Education. New York: Greenwood, pp. 241-258.

Bowles, S. and Gintis, H. 2002. Social Capital and Community Governance. The Economic Journal 112 (483): 419-436.

Bryson, J. M., Crosby, B. C. and Stone, M. M. 2006. The Design and Implementation of Cross-Sector Collaborations: Propositions from the Literature. Public Administration Review 66: 44-55.

Brzinsky-Fay, C. and Kohler, U. 2010. New Developments in Sequence Analysis. Sociological Methods \& Research 38 (3): 359-364.

Burström, F. and Korhonen, J. 2001. Municipalities and Industrial Ecology: Reconsidering Municipal Environmental Management. Sustainable Development 9 (1): 36-46.

Burt, R. S. 1992. Structural holes: The social structure of competition. Cambridge, MA: Harvard University Press.

Burt, R. S. 2000. The Network Structure of Social Capital. Research in Organizational Behavior 22: 345-423.

Burt, R. S. 2001. Structural Holes versus Network Closure as Social Capital. In: N. Lin, K. Cook and R. S. Burt (Eds.). Social Capital: Theory and Research. New Jersey: Transaction Publishers, pp. 31-56.

\section{C}

Castells, M. 1996. The Rise of the Network Society. Blackwell Publishers: Malden.

Chertow, M. R. 2000. Industrial Symbiosis: Literature and Taxonomy. Annual Review of Energy and the Environment 25 (1): 313-337. 
Chertow, M. R. 2007. 'Uncovering' Industrial Symbiosis. Journal of Industrial Ecology 11 (1): 11-30.

Chertow, M. R. 2009. Dynamics of Geographically Based Industrial Ecosystems. In: M. Ruth and B. Davidsdottir (Eds.) Dynamics of Regions and Networks in Industrial Ecosystems. Cheltenham: Edward Elgar Publishing, pp. 6-27.

Chertow, M. R., Ashton W. S. and Espinosa, J. C. 2008. Industrial Symbiosis in Puerto Rico: Environmentally Related Agglomeration Economies. Regional Studies 42 (10): 1299-1312.

Chertow, M. R., Ashton, W. S. and Kuppalli, R. 2004. The Industrial Symbiosis Research Symposium at Yale: Advancing the Study of Industry and Environment. Yale School of Forestry \& Environmental Studies.

Chertow, M. R. and Ehrenfeld, J. 2012. Organizing Self-Organizing Systems. Journal of Industrial Ecology 16 (1): 13-27.

Cilliers, Paul. 2001. Boundaries, Hierarchies and Networks in Complex Systems. International Journal of Innovation Management 5 (2): 135-147.

Clausen, J. A. 1998. Life Reviews and Life Stories. In: J. Z. Giele and G. H. Elder (Eds.). Methods of Life Course Research. Thousand Oaks: SAGE, pp. 189-212.

Cohen-Rosenthal, E. 2000. A Walk on the Human Side of Industrial Ecology. American Behavioral Scientist 44 (2): 245 -264.

Coleman, J. S. 1988. Social Capital in the Creation of Human Capital. The American Journal of Sociology, 94, S95-S120.

Costa, I. and Ferrão, P. 2010. A Case Study of Industrial Symbiosis Development Using a Middle-out Approach. Journal of Cleaner Production 18 (10-11): 984-992.

Côté, R. P. and Cohen-Rosenthal, E. 1998. Designing Eco-Industrial Parks: A Synthesis of Some Experiences. Journal of Cleaner Production 6 (3-4): 181-188.
Craig, R. T. 1981. Generalization of Scott's Index of Intercoder Agreement. Public Opinion Quarterly 45: 260-264.

Csardi, G. and Nepusz, T. 2006. The igraph software package for complex network research. InterJournal, Complex Sys (1695).

D

Davis, A., Gardner, B. B. and Gardner, M. R. 1941. Deep South: A Social Anthropological Study of Caste and Class. Chicago: University of Chicago Press.

Desrochers, P. 2000. Market Processes and the Closing of 'Industrial Loops': A Historical Reappraisal. Journal of Industrial Ecology 4 (1): 29-43.

Desrochers, P. 2002. Industrial Ecology and the Rediscovery of Inter-firm Recycling Linkages: Historical Evidence and Policy Implications. Industrial and Corporate Change 11 (5): 1031-1057.

Desrochers, P. 2004. Industrial Symbiosis: The Case for Market Coordination. Journal of Cleaner Production, 12 (8-10): 1099-1110.

Deutz, P. and Gibbs, D. 2008. Industrial ecology and regional development: Eco-industrial development as cluster policy. Regional Studies 42 (10) 1313-1328.

Deutz, P. and Lyons, D. I. 2008. Editorial: Industrial symbiosis-an environmental perspective on regional developmnt. Regional Studies 42 (10): 1295-1298.

De Valk, E. 2011. A Functions of Innovation System approach to analysing Eco-Industrial Park development. Master thesis, Delft: TU Delft.

Doménech, T., and Davies, M. 2011. The Role of Embeddedness in Industrial Symbiosis Networks: Phases in the Evolution of Industrial Symbiosis Networks. Business Strategy and the Environment 20 (5): 281-296. 
Doreian, P. 1969. A Note on the Detection of Cliques in Valued Graphs. Sociometry 32 (2): 237-242.

Doreian, P. 1979. On the Evolution of Group and Network Structure. Social Networks 2 (3): 235-252.

Doreian, P. 2002. Event Sequences as Generators of Social Network Evolution. Social Networks 24 (2): 93-119.

Doreian, P. and Stokman, F. 1997. Evolution of Social Networks: Processes and Principles. In: P. Doreian and F. Stokman (Eds.). Evolution of Social Networks. Amsterdam: Routledge, pp. 233-250.

Dreborg, K. H. 1996. Essence of Backcasting. Futures 28 (9): 813-828.

\section{E}

Ehrenfeld, J. R. and Gertler, N. 1997. Industrial Ecology in Practice: The Evolution of Interdependence at Kalundborg. Journal of Industrial Ecology 1 (1): 67-79.

Eilering, J. A. M. and Vermeulen, W. J. V., 2004. Eco-industrial parks: toward industrial symbiosis and utility sharing in practice. Progress in Industrial Ecology 1(1-2): 245270.

Elliot, M. L. P. 1999. The Role of Facilitators, Mediators and Other Consensus Building Practitioners. In: L. Susskind, S. McKearnan, ]. Thomas-Larmer (Eds.). The consensus building handbook. Thousand Oaks: Sage Publications, pp. 199-240.

Elster, J. 2007. Explaining social behavior: more nuts and bolts for the social sciences. Cambridge: Cambridge University Press.

Emerson, K., Nabatchi, T. and Balogh, S. 2012. An Integrative Framework for Collaborative Governance. Journal of Public Administration Research and Theory 22 (1): 1-29.
$\mathbf{F}$

Faust, K. 1997. Centrality in Affiliation Networks. Social Networks 19 (2): 157-191.

Feld, S. L. 1981. The Focused Organization of Social Ties. American Journal of Sociology 86 (5): 1015-1035.

Fine, G. A. and Kleinman, S. 1979. Rethinking Subculture: An Interactionist Analysis. American Journal of Sociology 85 (1): 1-20.

Freeman, L.C. 1978. Centrality in Social Networks Conceptual Clarification. Social Networks 1 (3): 215-239.

Freeman, L.C. 1980. Q-Analysis and the Structure of Friendship Networks. International Journal of Man-Machine Studies 12: 367-378.

Frosch, R. A. and Gallopoulos, N. E. 1989. Strategies for Manufacturing. Scientific American 261 (3): 144-152.

\section{G}

Gauthier, J. A., Widmer, E. D., Bucher, P. and Notredame, C. 2010. Multichannel Sequence Analysis Applied to Social Science Data. Sociological Methodology 40 (1): 1-38.

Geng, Y. and Doberstein, B. 2008. Developing the circular economy in China: Challenges and opportunities for achieving 'leapfrog development'. International Journal of Sustainable Development and World Ecology 15(3):231-239.

Geng, Y., Zhang, P., Côté, R. P. and Oii, Y. 2008. Evaluating the Applicability of the Chinese Eco-Industrial Park Standard in Two Industrial Zones. International Journal of Sustainable Development \& World Ecology 15 (6): 543-552.

Gertler, M., 2010. Rules of the Game: The Place of Institutions in Regional Economic Change. Regional Studies, 44(1): 1-15.

Gertler, N. 1995. Industry Ecosystems: Developing Sustainable Industrial Structures. Thesis, Massachusetts Institute of Technology. 
Ghose, R. 2005. The Complexities of Citizen Participation through Collaborative Governance. Space and Polity 9 (1): 61-75.

Gibbs, D. 2003. Trust and Networking in InterFirm Relations: The Case of Eco-Industrial Development. Local Economy 18 (3): 222-236.

Gibbs, D. and Deutz, P. 2007. Reflections on Implementing Industrial Ecology through Eco-Industrial Park Development. Journal of Cleaner Production 15 (17): 1683-1695.

Gordon, I. R. and McCann, P. 2000. Industrial Clusters: Complexes, Agglomeration and/ or Social Networks? Urban Studies 37 (3): 513-532.

Gould, R. V. 1993. Collective action and network structure. American Sociological Review 58 (2): 182-196.

Granovetter, M. 1983. The Strength of Weak Ties: A Network Theory Revisited. Sociological Theory 1 (1): 201-233.

Granovetter, M. 1985. Economic Action and Social Structure: The Problem of Embeddedness. The American Journal of Sociology 91 (3): 481-510.

Gray, B. 1985. Conditions Facilitating Interorganizational Collaboration. Human Relations 38 (10): 911-36.

Gray, B. 1989. Collaborating: Finding Common Ground for Multiparty Problems. San Francisco: Jossey-Bass.

Griffin, L. J. 1992. Temporality, Events, and Explanation in Historical Sociology An Introduction. Sociological Methods \& Research 20 (4): 403-427.

Gross, N. 2009. A Pragmatist Theory of Social Mechanisms. American Sociological Review, 74(3): 358 -379.

Guimerà, R., Stouffer, D. B. Sales-Pardo, M. Leicht, E. A., Newman, M. E. J. and Amaral, L. A. N. 2010. Origin of Compartmentalization in Food Webs. Ecology 91 (10): 2941-2951.

Gunderson, L., H. and Holling, C.S.. 2001. Panarchy: Understanding Transformations in Human and Natural Systems. Washington: Island Press.

\section{H}

Hall, P. A. 2006. Systematic Process Analysis: When and How to Use It. European Management Review 3 (1): 24-31.

Hall, P. A. and Soskice, D. 2001. An Introduction to Varieties of Capitalism. In P. A. Hall and D. Soskice (Eds.). Varieties of capitalism: the institutional foundations of comparative advantage. Oxford: Oxford University Press, pp. 1-68.

Hanneman, R. A., and Riddle, M. 2005. Introduction to Social Network Methods. Riverside: University of California.

Hardy, C. and Graedel, T. E. 2002. Industrial Ecosystems as Food Webs. Journal of Industrial Ecology 6 (1): 29-38.

Hawthorn, Geoffrey. 1991. Plausible Worlds: Possibility and Understanding in History and the Social Sciences. Cambridge University Press.

Head, B. W. 2008. Assessing network-based collaborations. Public Management Review 10(6): 733-749.

Healey, P. 1998. Building Institutional Capacity through Collaborative Approaches to Urban Planning. Environment and Planning A 30 (9): 1531-1546.

Healey, P., De Magalhaes, C. and Madanipour, A. 1999. Institutional Capacity Building, Urban Planning and Urban Regeneration Projects. FUTURA - Journal of the Finnish Society for Future Studies 18 (3): 117-137.

Healey, P., DeMagalhaes, C., Madanipour, A. and Pendlebury, J. 2003. Place, Identity and Local Politics: Analysing Initiatives in Deliberative Governance. In: M. A. Hajer and H. Wagenaar (Eds.). Deliberative Policy Analysis: Understanding Governance in the Network Society. Cambridge: Cambridge University Press, pp. 60-87.

Hedström, P. and Swedberg, R. (Eds.). 1998. Social mechanisms: an analytical approach to social theory. Cambridge: Cambridge University Press. 
Heeres, R. R., Vermeulen, W. J. V. and De Walle, F. B. 2004. Eco-Industrial Park Initiatives in the USA and the Netherlands: First Lessons. Journal of Cleaner Production 12 (8-10): 985-995.

Heise, D. R. 1991. Event Structure Analysis: A Qualitative Model of Quantitative Research. In: N. G. Fielding and R. M. Lee (Eds.). Using Computers in Qualitative Research. London: Sage Publications, pp. 136-163.

Heise, D. R. 1993. Narratives without Meaning? The Journal of Mathematical Sociology 18 (2-3): 183-189.

Hekkert, M. P., Suurs, R. A. A., Negro, S. O., Kuhlmann, S. and Smits, R. E. H. M. 2007. Functions of innovation systems: A new approach for analysing technological change. Technological Forecasting and Social Change, 74(4): 413-432.

Hernes, T. 2008. Understanding Organization as Process: Theory for a Tangled World. London: Routledge.

Hewes, A. K. and Lyons, D. I. 2008. The Humanistic Side of Eco-Industrial Parks: Champions and the Role of Trust. Regional Studies 42 (10): 1329-1342

Heylighen, F. 1989. Self-Organization, Emergence and the Architecture of Complexity. In: Proceedings of the 1st European Conference on Systems Science, Paris, pp. 23-32.

Holling, C. S. 2001. Understanding the Complexity of Economic, Ecological, and Social Systems. Ecosystems 4 (5): 390-405.

Howells, J. R. L. 2002. Tacit Knowledge, Innovation and Economic Geography. Urban Studies 39 (5-6): 871-884.

Howlett, M. 2009. Process Sequencing Policy Dynamics: Beyond Homeostasis and Path Dependency. Journal of Public Policy 29 (3): 241-262.

Hu, O., Knox, C. C., and Kapucu, N. 2014. What Have We Learned since September 11, 2001? A Network Study of the Boston Marathon Bombings Response. Public Administration Review 74(6): 698-712.
Hull, D. L. 1975. Central Subjects and Historical Narratives. History and Theory 14 (3): 253-274.

Huxham, C. 2000. The Challenge of Collaborative Governance. Public Management: An International Journal of Research and Theory 2 (3): 337-358.

Huxham, C. 2003. Theorizing Collaboration Practice. Public Management Review 5 (3): 401-423.

Huxham, C. and Vangen, S. 2000a. Ambiguity, Complexity and Dynamics in the Membership of Collaboration. Human Relations 53 (6): 771-806.

Huxham, C. and Vangen, S. 2000b. Leadership in the Shaping and Implementation of Collaboration Agendas: How Things Happen in a (Not Quite) Joined-up World. The Academy of Management Journal 43 (6): 1159-1175.

Huxham, C. and Vangen, S. (2005). Managing to Collaborate: The Theory and Practice of Collaborative Advantage. London: Routledge.

\section{I}

Imperial, M. T. 2005. Using Collaboration as a Governance Strategy: Lessons From Six Watershed Management Programs. Administration \& Society 37(3): 281-320.

Innes, J. E., and Booher, D. E. 1999. Consensus Building and Complex Adaptive Systems: A Framework for Evaluating Collaborative Planning. Journal of the American Planning Association 65 (4): 412-423.

Innes, J. E. and Booher, D. E. 2003. Collaborative Policy Making: Governance through Dialogue. In: M. A. Hajer and H. Wagenaar (Eds.). Deliberative Policy Analysis: Understanding Governance in the Network Society. Cambridge: Cambridge University Press, pp. 60-87.

Innes, J. E. and Booher, D. E. 2010. Planning with Complexity: An Introduction to Collabora- 
tive Rationality for Public Policy. New York: Routledge.

\section{J}

Jelinski, L. W., Graedel, T. E. , Laudise, R. A., McCall, D. W. and Patel, C. K. 1992. Industrial Ecology: Concepts and Approaches. Proceedings of the National Academy of Sciences 89 (3): 793-797.

Jensen, P. D., Basson, L., Hellawell, E. E., Bailey, M. R. and Leach, M. 2011. Quantifying 'geographic Proximity': Experiences from the United Kingdom's National Industrial Symbiosis Programme. Resources, Conservation and Recycling 55 (7): 703-712.

Jiao, W, and Boons, F. A. A. 2014. Toward a Research Agenda for Policy Intervention and Facilitation to Enhance Industrial Symbiosis Based on a Comprehensive Literature Review. Journal of Cleaner Production 67: 14-25.

\section{K}

Keast, R., Mandell, M. P., Brown, K. and Woolcock, G. 2004. Network Structures: Working Differently and Changing Expectations. Public Administration Review 64(3): 363-371.

Kenis, P., and Provan, K. G. 2006. The Control of Public Networks. International Public Management Journal 9(3): 227-247.

Kleiner, A., and Roth, G. 1996. Field Manual for a Learning Historian: Version 4.0, October 28, 1996. MIT-COL and Reflection Learning Associates.

Klijn, E. H., and Koppenjan, J. F. M. . 2000. Public Management and Policy Networks. Public Management: An International Journal of Research and Theory 2 (2): 135-158.

Knoke, D., and Yang, S. 2008. Social Network Analysis. Thousand Oaks: SAGE.

Kooiman, J. 1999. Social-Political Governance. Public Management: An International Journal of Research and Theory 1 (1): 67-92.
Kooiman, J., Bavinck, R., Chuenpagdee, R., Mahon, R. and Pullin, R. 2008. Interactive Governance and Governability: An Introduction. Journal of Transdisciplinary Environmental Studies 7 (1): 1-11.

Korhonen, J. and Snäkin, J. P. 2005. Analysing the Evolution of Industrial Ecosystems: Concepts and Application. Ecological Economics 52 (2): 169-186.

\section{$\mathbf{L}$}

Lambert, A. J. D. and Boons, F. A. A. 2002. EcoIndustrial Parks: Stimulating Sustainable Development in Mixed Industrial Parks. Technovation 22 (8): 471-484.

Landis, R. J. and Koch, G. 1977. The Measurement of Observer Agreement for Categorical Data. Biometrics 33 (1): 159-174.

Langley, A. 1999. Strategies for Theorizing from Process Data. The Academy of Management Review 24 (4): 691-710.

Latapy, M., Magnien, C. and Del Vecchio, N. 2008. Basic Notions for the Analysis of Large Two-Mode Networks. Social Networks 30 (1): 31-48.

Lawson, C. and Lorenz, E. 1999. Collective Learning, Tacit Knowledge and Regional Innovative Capacity. Regional Studies 33 (4): 305-317.

Lenartowicz, T. and Kendall R. 1999. A Framework for Culture Assessment. Journal of International Business Studies 30 (4): 781-798.

Levallois, C. 2013. Excel / Csv Converter to Network (software).

Levin, S. A. and Lubchenco, J. 2008. Resilience, Robustness, and Marine Ecosystem-Based Management. BioScience 58 (1): 27-32.

Lewis, D. K. 2001. Counterfactuals. Mass: Blackwell Publishers.

Lifset, R, and Graedel, T. E. 2002. Industrial Ecology: Goals and Definitions. In: R. U. Ayres and L. Ayres (Eds.). A Handbook of 
Industrial Ecology. Cheltenham: Edward Elgar Publishing, pp. 3-15.

Lombardi, D. R. and Laybourn, P. 2012. Redefining Industrial Symbiosis. Journal of Industrial Ecology 16 (1): 28-37.

Loorbach, D. 2007. Transition Management: New Mode of Governance for Sustainable Development. Utrecht: International Books. Loorbach, D. 2010. Transition Management for Sustainable Development: A Prescriptive, Complexity-Based Governance Framework. Governance 23 (1): 161-183.

Lowe, E. A., and Evans, L. K. 1995. Industrial Ecology and Industrial Ecosystems. Journal of Cleaner Production 3 (1-2): 47-53.

Lowe, E. A., Moran, S. R. and Holmes, D. B. 1996. Fieldbook for the Development of Eco-Industrial Parks. Final Report. Oakland: Indigo Development.

Lyons, D. I. 2007. A spatial analysis of loop closing among recycling, remanufacturing, and waste treatment firms in Texas. Journal of Industrial Ecology 11 (1): 43-54.

\section{M}

Mahoney, J. 2004. Comparative-Historical Methodology. Annual Review of Sociology 30 (1): 81-101.

Mayntz, R. 2004. Mechanisms in the Analysis of Social Macro-Phenomena. Philosophy of the Social Sciences 34(2): 237-259.

McGuire, M. 2006. Collaborative public management: Assessing what we know and how we know it. Public Administration Review 66(1): 33-43.

Mirata, M. 2004. Experiences from Early Stages of a National Industrial Symbiosis Programme in the UK: Determinants and Coordination Challenges. Journal of Cleaner Production 12 (8-10): 967-983.

Mirata, M. and Emtairah, T. 2005. Industrial Symbiosis Networks and the Contribution to Environmental Innovation: The Case of the Landskrona Industrial Symbiosis
Programme. Journal of Cleaner Production 13 (10-11): 993-1002.

Moore, C. M., Longo, G. and Palmer, P. 1999. Visioning. In: L. Susskind, S. McKearnan, and J. Thomas-Larmer (Eds.). The consensus building handbook. Thousand Oaks: SAGE,pp. 557-590.

Mouzakitis, Y., Adamides, E. and Goutos, S. 2003. Sustainability and industrial estates: the emergence of eco-industrial parks. Environmental Research, Engineering and Management 4 (26): 85-91.

\section{$\mathbf{N}$}

Nahapiet, J. and Ghoshal, S. 1998. Social Capital, Intellectual Capital, and the Organizational Advantage. Academy of Management Review 23 (2): 242-266.

Newman, M. E. J. 2001. Scientific Collaboration Networks. Network Construction and Fundamental Results. Physical Review 64(1).

Newman, M. E. J. 2006. Modularity and Community Structure in Networks. Proceedings of the National Academy of Sciences 103 (23): 8577-8582.

Nooteboom, B. 1999. Innovation, Learning and Industrial Organisation. Cambridge Journal of Economics 23 (2): 127-150.

North, D.C. 1990. Institutions, institutional change, and economic performance, Cambridge: Cambridge University Press.

\section{0}

Oliver, C. 1991. Strategic Responses to Institutional Processes. The Academy of Management Review 16(1): 145-179.

Oliver, P. E. and Marwell, G. 1988. The Paradox of Group Size in Collective Action: A Theory of the Critical Mass II. American Sociological Review 53 (1): 1-8.

Ostrom, E. 2007. Institutional rational choice: an assessment of the institutional analysis and development framework. In: P. A. 
Sabatier (Ed.). Theories of the Policy Process Boulder: Westview Press, pp. 21-64.

Ostrom, E. 2007b. Collective Action and Local Development Processes. Sociologica 3: 1-32.

\section{P}

Pakarinen, S., Mattila, T. Melanen, M. Nissinen, A. and Sokka, L. 2010. Sustainability and Industrial symbiosis-The Evolution of a Finnish Forest Industry Complex. Resources, Conservation and Recycling 54 (12): 1393-1404.

Paquin, R. L. and Howard-Grenville, J. 2009. Facilitating Regional Industrial Symbiosis: Network Growth in the UK's National Industrial Symbiosis Programme. In F. A. A. Boons and J. A. Howard-Grenville (Eds.). The Social Embeddedness of Industrial Ecology. Cheltenham: Edward Elgar Publishing, pp. 103-127.

Paquin, R. L. and Howard-Grenville, J. 2012. The Evolution of Facilitated Industrial Symbiosis. Journal of Industrial Ecology 16 (1): 83-93.

Peck, J. and Theodore, N. 2007. Variegated capitalism. Progress in Human Geography 31(6): $731-772$.

Pellenbarg, P. H. 2002. Sustainable Business Sites in the Netherlands: A Survey of Policies and Experiences. Journal of Environmental Planning and Management 45 (1): 59-84.

Pettigrew, Andrew M. 1990. Longitudinal Field Research on Change: Theory and Practice. Organization Science 1 (3): 267-292.

Poole, M. S., Van de Ven, A. H., Dooley, K. J. and Holmes, M. E. 2000. Organizational Change and Innovation Processes: Theory and Methods for Research. New York: Oxford University Press.

Posch, A. 2005. From "Industrial Symbiosis" to "Sustainability Networks". In: L.M. Hilty, E.K. Seifert and R. Treibert (Eds.). Informa- tion systems for sustainable development. London: Idea Group Publishing, pp. 229242.

Posch, A. 2010. Industrial Recycling Networks as Starting Points for Broader SustainabilityOriented Cooperation? Journal of Industrial Ecology 14 (2): 242-257.

Poteete, A. R. and Ostrom, E. 2004. Heterogeneity, group size and collective action: The role of institutions in forest management. Development and Change 35 (3): 435-461.

Provan, K. G. and Kenis, P. 2008. Modes of Network Governance: Structure, Management, and Effectiveness. Journal of Public Administration Research and Theory 18 (2): 229-252.

Quist, J., Thissen, W. and Vergragt, P. J. 2011. The Impact and Spin-off of Participatory Backcasting: From Vision to Niche. Technological Forecasting and Social Change 78 (5): 883-897.

\section{$\mathbf{R}$}

Ragin, C. C. 1987. The Comparative Method: Moving beyond Qualitative and Quantitative Strategies. Berkeley: University of California Press.

Rainey, H. G., Backoff, R. W. and Levine, C. H. 1976. Comparing Public and Private Organizations. Public Administration Review 36 (2): 233-244.

Rainey, H. G. 2009. Understanding and Managing Public Organizations. San Francisco: Jossey-Bass.

Rescher, N. 1996. Process Metaphysics: An Introduction to Process Philosophy. Albany: State University of New York Press.

Renner, G. T. 1947. Geography of Industrial Localization. Economic Geography 23(3): 167-189. 
Rihoux, B., and Ragin, C. C. (ds.). 2009. Configurational Comparative Methods: Qualitative Comparative Analysis (OCA) and Related Techniques. London: Sage.

Ring, P. S., and Van der Ven, A. 1992. Structuring cooperative relations between organizations. Strategic Management Journal 13: 483-498.

Robins, G. and Alexander, M. 2004. Small Worlds Among Interlocking Directors: Network Structure and Distance in Bipartite Graphs. Computational \& Mathematical Organization Theory 10 (1): 69-94.

Rogers, E. M. and Shoemaker, F. F. 1971. Communication of Innovations: A Cross-Cultural Approach. Free Press.

Rotmans, J., Kemp, R. and Van Asselt, M. 2001. More Evolution than Revolution: Transition Management in Public Policy. Foresight 3 (1): 15-31.

Ruth, M. and Davidsdottir, B. (eEds.). 2009. The Dynamics of Regions and Networks in Industrial Ecosystems. Cheltenham: Edward Elgar Publishing.

\section{S}

Sakr, D., Baas, L., El-Haggar, S. and Huisingh, D., 2009. Critical success and limiting factors for eco-industrial parks. Paper Presented at the 15th ISDRS Conference, 5-8 July, Utrecht, the Netherlands.

Schalk, J., Torevlied, R., and Allen, J. (2010). Network Embeddedness and Organizational Performance: The strength of strong ties in Dutch Higher Education. Journal of Public Administration Research and Theory 20(3):629-653.

Schneider, C. O. and Wagemann, C. 2012. SetTheoretic Methods for the Social Sciences: A Guide to Qualitative Comparative Analysis. Strategies for Social Inquiry. Cambridge: Cambridge University Press.

Scott, J. 2013. Social Network Analysis: A Handbook. Thousand Oaks: SAGE.
Scott, J. and Carrington, P. J. (Eds.). 2011. The SAGE handbook of social network analysis. Thousand Oaks: SAGE.

Scott, W. A. 1955. Reliability of content analysis: the case of nominal scale coding. Public Opinion Quarterly (19): 321-325.

Scott, W. R. 1987. The Adolescence of Institutional Theory. Administrative Science Quarterly 32(4): 493-511.

Selin, S. and Chevez, D. 1995. Developing a Collaborative Model for Environmental Planning and Management. Environmental Management 19 (2): 189-195.

Shaviro, S. 2012. Without Criteria: Kant, Whitehead, Deleuze, and Aesthetics. Cambridge: MIT Press.

Shi, H. 2011. Industrial Symbiosis From The Perspectives of Transaction Cost Economics and Institutional Theory. Charleston: UMI Dissertation Publisher.

Shi, H., Jinping T. and Lujun C. 2012. China's Quest for Eco-Industrial Parks, Part I. Journal of Industrial Ecology 16 (1): 8-10.

Shi, H., Tian, J. and Chen, L. 2012. China's Quest for Eco-Industrial Parks, Part II. Journal of Industrial Ecology 16 (3): 290-292.

Shi, H. Chertow, M. R. and Song, Y. 2010. Developing country experience with ecoindustrial parks: a case study of the Tianjin Economic-Technological Development Area in China. Journal of Cleaner Production 18(3): 191-199.

Shi, H. and Zhang, L. 2006. China's environmental governance of rapid industrialization. Environmental Politics 15(2): 271-292.

Simon, H. A. 1962. The Architecture of Complexity. Proceedings of the American Philosophical Society 106 (6): 467-482.

Simon, H. A. 1973. The Organization of Complex Systems. In H. H. Pattee (Ed.). Hierarchy Theory: The Challenge of Complex Systems. New York: George Braziller, pp. 1-27.

Simon, H. A. 2002. Near Decomposability and the Speed of Evolution. Industrial and Corporate Change 11 (3): 587-599. 
Sirianni, Carmen. 2009. Investing in Democracy: Engaging Citizens in Collaborative Governance. Washington, D.C.: Brookings Institution Press.

Sminia, H. 2009. Process Research in Strategy Formation: Theory, Methodology and Relevance. International Journal of Management Reviews 11: 97-125.

Snijders, T. A. B. 2011. Network Dynamics. In: J. Scott and P. J. Carrington (Eds.). The SAGE Handbook of Social Network Analysis. Thousand Oaks: SAGE, pp. 501-513.

Spekkink, W. A. H. 2013. Institutional Capacity Building for Industrial Symbiosis in the Canal Zone of Zeeland in the Netherlands: a process analysis. Journal of Cleaner Production 52 (1): 342-355.

Spekkink, W. A. H. 2015. Building Capacity for Sustainable Regional Industrial Systems: An Event Sequence Analysis of Developments in the Sloe Area and Canal Zone. Journal of Cleaner Production 98: 133-144.

Spekkink, W. A. H. and Boons, F. A. A. 2010. A varities of capitalism approach to EIP development. Paper presented at The 16th Annual International Sustainable Development Research Conference, Hong Kong, 30 May - 1 June 2010.

Spekkink, W. A. H. and Boons, F. A. A., 2011. The governance of industrial symbiosis. Paper presented at the ISIE 6th International conference on industrial Ecology, Berkeley, 7-10 June.

Stadtfeld, C. and Geyer-Schulz, A. 2011. Analyzing Event Stream Dynamics in Two-Mode Networks: An Exploratory Analysis of Private Communication in a Question and Answer Community. Social Networks 33 (4): 258-272.

Sterr, T. and Ott, T. 2004. The Industrial Region as a Promising Unit for Eco-Industrial Development-reflections, Practical Experience and Establishment of Innovative Instruments to Support Industrial Ecology. Journal of Cleaner Production 12 (8-10): 947-965.
Stift, N. 2011. Implementing Industrial Symbiosis: Organizational Structures. Master thesis, Delft: TU Delft.

Stinchcombe, A.L. 1991. The Conditions of Fruitfulness of Theorizing About Mechanisms in Social Science. Philosophy of the Social Sciences 21(3): 367 -388.

Stoker, G. 1998. Governance as Theory: Five Propositions. International Social Science Journal 50 (155): 17-28.

Susskind, L. and Cruikshank, J. 1987. Breaking the Impasse: Consensual Approaches to Resolving Public Disputes. New York: Basic Books.

Susskind, L., McKearnan, S. and Thomas-Larmer, J. (Eds.). 1999. The Consensus Building Handbook: A Comprehensive Guide to Reaching Agreement. Thousand Oaks: SAGE.

\section{T}

Thomson, A. M. and Perry, J. L. 2006. Collaboration Processes: Inside the Black Box." Public Administration Review 66: 20-32.

Tsvetkova, A. and Gustafsson, M. 2012. Business Models for Industrial Ecosystems: A Modular Approach. Journal of Cleaner Production 29-30: 246-254.

Tushman, M. L. and Scanlan, T. J. 1981. Boundary Spanning Individuals: Their Role in Information Transfer and Their Antecedents. The Academy of Management Journal 24 (2): 289-305.

\section{U}

Uzzi, B. 1997. Social Structure and Competition in Interfirm Networks: The Paradox of Embeddedness. Administrative Science Quarterly 42 (1): 35-67. 


\section{V}

Van Berkel, R., Majer, J. and Stehlik, D. 2007. Regional Resource Synergies for Sustainable Development in Heavy Industrial Areas: An Overview of Opportunities and Experiences. Perth: Curtain University of Technology - Centre of Excellence in Cleaner Production.

Van Buuren, A. 2009. Knowledge for Governance, Governance of Knowledge: Inclusive Knowledge Management in Collaborative Governance Processes. International Public Management Journal 12 (2): 208-235.

Van de Bunt, G. G., Wittek, R. P. M. and De Klepper, M. C. 2005. The Evolution of IntraOrganizational Trust Networks The Case of a German Paper Factory: An Empirical Test of Six Trust Mechanisms. International Sociology 20 (3): 339-369.

Van de Ven, A. H. and Poole, M. S. 1990. Methods for Studying Innovation Development in the Minnesota Innovation Research Program. Organization Science 1(3): 313-335.

Van de Ven, A. H. and Poole, M. S. 1995. Explaining Development and Change in Organizations. The Academy of Management Review 20 (3): 510-540.

Van de Ven, A. H., Angle, H. L. and Poole, M. S. (Eds.), 2000. Research on the management of innovation: the Minnesota studies. Oxford: Oxford University Press.

Van Meerkerk, I. and Edelenbos, J. 2014. The Effects of Boundary Spanners on Trust and Performance of Urban Governance Networks: Findings from Survey Research on Urban Development Projects in the Netherlands. Policy Sciences 47 (1): 3-24.

Vangen, S. and Huxham, C. 2003a. Nurturing Collaborative Relations Building Trust in Interorganizational Collaboration. The Journal of Applied Behavioral Science 39 (1): $5-31$.

Vangen, S. and Huxham, C. 2003b. Enacting Leadership for Collaborative Advantage: Dilemmas of Ideology and Pragmatism in the Activities of Partnership Managers. British Journal of Management, 14(s1), S61-S76.

Vayda, A. 1983. Progressive Contextualization: Methods for Research in Human Ecology. Human Ecology 11 (3): 265-281.

Verguts, V., Dessein, J. , Lauwers, L. Werkman, R. A. and Termeer, C. J. A. M. 2010. Understanding Eco-Industrial Development Processes through Multiple Change Perspectives. In Proceedings of International Workshop on "System Innovations, Knowledge Regimes, and Design Practices towards Sustainable Agriculture, pp. 16-18.

Verweij, S. and Gerrits, L. M. 2013. Understanding and Researching Complexity with Qualitative Comparative Analysis: Evaluating Transportation Infrastructure Projects. Evaluation 19 (1): 40-55.

Viana, M. P., Tanck, E., Beletti, M. E. and Da Fontoura Costa, L. 2009. Modularity and Robustness of Bone Networks. Molecular Biosystems 5 (3): 255-261.

Vigoda, E. 2002. From Responsiveness to Collaboration: Governance, Citizens, and the Next Generation of Public Administration. Public Administration Review 62 (5): 527-540.

\section{W}

Wasserman, S. and Faust, K. 1994. Social Network Analysis: Methods and Applications. Cambridge: Cambridge University Press.

Watts, D. J. and Strogatz, S. H. 1998. Collective Dynamics of 'small-World' Networks. Nature 393 (6684): 440-442.

Weber, E. P., Lovrich, N. P., and Gaffney, M. 2005. Collaboration, Enforcement, and Endangered Species: A Framework for Assessing Collaborative Problem-Solving Capacity. Society \& Natural Resources 18(8): 677-698. 
Weick, K. E. 1976. Educational Organizations as Loosely Coupled Systems. Administrative Science Quarterly 21 (1): 1-19.

Whitehead, Alfred North. 1978. Process and Reality, an Essay in Cosmology. Edited by David R. G. and D. W. Sherburne. New York: Free Press.

Willer, D. 1993. A Critique of Abell's 'paths of Social Determination.' The Journal of Mathematical Sociology 18 (2-3): 191-201.

Williamson, O. E. 1975. Markets and hierarchies, analysis and antitrust implications: a study in the economics of internal organization. New York: Free Press.

Williamson, O. E. 1985. The Economic Institutions of Capitalism: Firms, Markets, Relational Contracting. New York: Free Press.

Williamson, O. E. 1996. The mechanisms of governance. New York: Oxford University Press.

Wright, R. A., Côté, R. P., Duffy, J. and Brazner, J.2009. Diversity and connectance in an industrial context the case of Burnside industrial park. Journal of Industrial Ecology 13 (4): 551-564.

\section{$Y$}

Yu, C. 2014. Eco-Transformation of Industrial Parks in China. Thesis, Delft: Next Generation Infrastructures Foundation.

Yu, C., De Jong, M. and Dijkema, G. P. J. 2014. Process Analysis of Eco-Industrial Park Development - the Case of Tianjin, China. Journal of Cleaner Production 64: 464-477.

Yuan, Z., Bi, J. and Moriguichi, Y. 2006. The Circular Economy: A New Development Strategy in China. Journal of Industrial Ecology 10(1-2): 4-8.

\section{Z}

Zhu, O. and Côté, R. P. 2004. Integrating green supply chain management into an embryonic eco-industrial development: a case study of the Guitang Group. Journal of Cleaner Production 12(8-10): 1025-1035.

Zhu, O.., Lowe, E. A. Wei, Y. and Barnes, D. 2007. Industrial Symbiosis in China: A Case Study of the Guitang Group. Journal of Industrial Ecology 11 (1): 31-42. 


SUMIMARY 



\section{MOTIVATION, RESEARCH AIMS AND RELEVANCE OF THE RESEARCH}

Industrial symbiosis is a process in which firms in regional industrial systems engage in the exchange of by-products and sharing of utilities and services in order to improve their environmental performance as well as their competitive advantages.

Industrial symbiosis has an important technical dimension. From an early stage in the development of the concept it was recognized that it also has a prominent social dimension. To capture this social dimension concepts from the social sciences have been introduced to the field. This thesis makes one of the first attempts to bring several such concepts together in an integrated conceptual framework. Such a conceptual framework contributes to theorization on industrial symbiosis.

In this thesis the development of industrial symbiosis is understood as a governance challenge, putting the focus on the interaction processes between firms, governments, knowledge institutes and other relevant actors in which issues of common concern are taken up. Thus, in this thesis the social dimension of industrial symbiosis refers specifically to the capacity of actors to coordinate their actions and interactions towards industrial symbiosis.

The purpose of the conceptual framework developed in this thesis is to make the way in which this capacity develops tangible, which also makes it amenable to steering. The framework was developed in five steps:

1. Based on existing, relevant theoretical insights an initial version of the framework was developed;

2. The implications of the initial framework were tested in empirical studies;

3. The theoretical lessons from the empirical studies are used to adapt the conceptual framework;

4. The adapted framework is tested in new empirical studies;

5. The adapted framework is presented in the conclusions.

The process was steered with the following substantive research question:

\section{How does the collective capacity of firms, governments, knowledge institutes and other relevant actors to engage in industrial symbiosis emerge and develop?}

As the starting point for the initial conceptual framework the concept of institutional capacity building from the literature on collaborative planning is used. The concept engages with several social factors that have been marked as important in the literature, such as the occurrence of a learning process, de presence of a strategic vision, the diversity and interconnectedness of involved actors, the existence and nurturing of trust between actors, the presence of key actors that can take the lead, and the presence of an enabling context, usually referring to policies and regulations. The strength of the concept of institutional capacity building is that it indicates how these factors are related to each other. The concept focuses on the long-term development of a social context that 
enables collaboration on industrial symbiosis. Three dimensions of institutional capacity can be distinguished:

1. The qualities of the social relationships between actors (relational capacity);

2. The knowledge resources that flow around and are developed through these relationships (knowledge capacity);

3. The ability of actors to mobilize the first two forms of capacity for joint action (mobilization capacity).

The starting point is that these three dimensions of institutional capacity emerge from interactions between actors in regional industrial systems. In this thesis the theoretical expectations that follow from the framework are tested with empirical observations on two cases of collaboration on industrial symbiosis: Biopark Terneuzen in the Canal Zone of Zeeland and Sustainable Connections in Moerdijk. The results of this test are used to refine the conceptual framework. The adapted version of the framework is presented in the conclusions (also see section 3.1).

The thesis also has an aim that is primarily methodological. There are few studies that apply methods, techniques or tools that explicitly take into account the temporal dimension of industrial symbiosis. Research approaches for longitudinal research have been developed in fields such as sociology, organization studies and political science. The methodological aim of this thesis is to assess what methods, techniques and tools derived from these research approaches can contribute to our understanding of industrial symbiosis as a process. To this end, the following methodological research question was formulated:

\section{What can methods, techniques and tools that are dedicated to the systematic and longitudinal investigation of process phenomena contribute to our understanding of industrial symbiosis?}

This thesis explores existing methods, techniques and tools for longitudinal research and contributes to the further development of methods, techniques and tools in the form of a new approach. The new approach is called Event Sequence Analysis (ESA). Its development was started in collaboration with other researchers from the department of Public Administration of the Erasmus University Rotterdam.

Part 2 of this summary gives an overview of the steps that were taken to answer the two research questions and describes the structure of the thesis. Section 3 offers an overview of the results and conclusions of the thesis.

\section{STRUCTURE OF THE THESIS}

This thesis is built primarily from a book chapter and 4 articles. These were written as standalone publications and therefore have some overlap and testify to progressive 
insight and changes in the chosen approach. In addition, a literature review is included in the thesis (chapter 2), based on part of a standalone publication.

The book chapter (chapter 3 in this thesis) introduces a conceptual framework that serves as the initial conceptual basis of the thesis. The four articles (chapters 5 to 8 in this thesis) include empirical studies that have been performed to test the implications of the various versions of the conceptual framework. An introductory chapter 1 , a chapter on methods (chapter 4), and a concluding chapter (chapter 9) complete the thesis. 6 intermezzos between the chapters explain the theoretical and methodological choices that have been made during the research process. They offer further insight in the way that the research process unfolded.

To assess the extent to which an adequate theoretical underpinning for the empirical investigation of industrial symbiosis is available a literature review was performed. Several publications provide a theoretical underpinning, but a conceptual framework that enables a more encompassing analysis of the emergence and development of industrial symbiosis is missing. Chapter 3 introduces such a framework. The framework describes the evolution of industrial symbiosis at three levels: the project, the regional industrial system, and the institutional context. In addition, several mechanisms are presented that link the dynamics at the three levels, including mechanisms of institutional capacity building. The conceptual framework is the conceptual basis of the articles presented in chapters 5 and 6 . In chapter 5 several propositions that follow from the framework are confronted with empirical observations from the case of Biopark Terneuzen in the Canal Zone. In chapter 6 the scope of the empirical investigation is broadened to include other interaction processes in the Sloe Area and Canal Zone of Zeeland.

Based on the theoretical lessons of the first empirical studies (chapter 5 and 6) a new theoretical model of institutional capacity building is developed (chapter 7 ). In chapter 7 the implications of the new model are tested. For this a strategy similar to the one used in chapter 5 is followed: Several propositions are derived from the model and confronted with empirical observations from two case studies. The first case study concerns Biopark Terneuzen in the Canal Zone (the dataset on this study was expanded in the meantime) and the second case study concerns Sustainable Connections in Moerdijk. Further tests of the implications of the new model are performed in the empirical study that is presented in chapter 8, for which an innovative approach to dynamic network analysis is used.

In the concluding chapter (chapter 9) the results of all the empirical studies (chapters 5 to 8 ) are tied together. Based on the theoretical lessons from the studies an adapted version of the conceptual framework of institutional capacity building is presented. The adapted framework also serves to structure the answer to the first research question of this thesis. In addition, the concluding chapter discusses the added value of the various methods, techniques and tools for longitudinal research that have been developed and applied. In each of the empirical studies further improvements were made in the 
methods, techniques and tools of ESA. The concluding chapter reflects on these methodological advancements, and discusses their contribution to the developed insights on industrial symbiosis. The concluding chapter closes with a number of recommendations for research and practice.

\section{RESULTS AND CONCLUSIONS}

This section summarizes the results and conclusions of the research. Section 3.1 addresses the results and conclusions with regard to the first research question and section 3.2 addresses the results and conclusions with regard to the second research question.

\subsection{Results and conclusions on institutional capacity building}

The empirical study in chapter 5 confronts implications of the initial conceptual framework with empirical observations on the case of Biopark Terneuzen in the Canal Zone. For this study an event sequence dataset of the case was created, which includes events from 1999 to 2010. The sequences of events included in the dataset are presented and patterns in the sequences are compared to patterns implied by the conceptual framework.

The study reveals that institutional capacity does not build up through the orderly, unilinear sequence of interactions that is assumed by the initial framework. Institutional capacity is found to build up in fragmented ways, through different streams of events that occur in parallel, and that represent different projects that unfold largely independent from each other (events in one project do not evoke explicit responses by actors involved in other projects). Changes in relational resources were found to be more abrupt than predicted by the framework as well. The biggest change in relational capacity occurs at the point where the different streams of events come together and become intertwined. The coming together of the different streams of events is boosted by the shared vision on Biopark Terneuzen. The vision stimulates actors to bring their independent projects together in a joint effort to develop industrial symbiosis. The study also points at the key role of the port authority in bringing different actors together and in supporting projects.

The empirical study presented in chapter 6 places the emergence and development of Biopark Terneuzen in the context of other interaction processes in the region of the Sloe Area and Canal Zone:

1. The development of Valuepark Terneuzen;

2. The development of the project group Vital Sloe Area and Canal Zone.

The study reveals that each interaction process is driven by its own logic (i.e., dominated by different types of events). As a result they each make a different contribution to the development of institutional capacity. The study points out that the three interaction processes do not clearly influence each other directly, but do constitute overlapping 
sources of institutional capacity in the region: Institutional capacity developed in one process can be mobilized in another process. The study emphasizes the compounded nature of the Biopark Terneuzen collaboration. This observation is linked to Herbert Simon's theory of complex systems as stable assemblies: The three streams of events that lead up to the start of the Biopark Terneuzen collaboration are stable intermediates that are later assembled into a collaborative process. This idea is linked to existing phase models of industrial symbiosis, and a new phase model is presented.

The model with which chapter 6 ends is elaborated in chapter 7. Its implications are formulated as propositions. These are confronted with empirical observations on the case of Biopark Terneuzen (the dataset now also includes events in 2011 and 2012), and observations on the case of Sustainable Connections in Moerdijk for which a new event sequence dataset was developed. The study shows that collaborative processes can be assembled from projects that serve as building blocks. The capacity of actors to collaborate emerges before they actively interact with each other (an insight that has received little attention in the literature on collaborative governance): Because actors in the independent projects address the same issues at more or less the same time, a common ground emerges. This common ground influences the aims that are formulated at the start of the collaborative process. The presence of a few bridging actors (actors that are involved in multiple building blocks) ensures that the common ground of the building blocks is recognized and that it is mobilized. In both cases public organizations have the role of bridging actors. After the collaboration starts, an actor network develops with a small stable core of actors that collaborate on a structural basis, and a larger, more fluid periphery of actors that are involved on an incidental basis.

The relational dynamics in the described processes are studied in greater detail in chapter 8 . The same cases are analyzed using an innovative approach to dynamic network analysis. The main purpose of the study is to test the implications that process models of collaborative governance processes have for collaborative network structures.. The study shows that most actors do not interact with each other directly, but that their relationships are mediated by actors (typically public actors) that act as a bridge between different parts of the network. Bridging actors are vital to the continuity and the coherence of the collaboration. Although collective meetings of the collaborating partners are possible, these are relatively rare. The study confirms the observation in chapter 7 that the collaborative network consists out of a small stable core of actors that meet on a structural basis and a larger fluid periphery of actors that are involved on an incidental basis.

All findings are drawn together in the concluding chapter to develop an adapted conceptual framework. The core of the framework is a two-phases model. The first phase covers the emergence of building blocks for collaboration and the second phase covers the collaborative process that is assembled from the building blocks. In the first phase 
common ground (a form of knowledge capacity) emerges from parallel sequences of interactions that unfold largely independent from each other. An important conclusion in this regard is that in this case the emergence of institutional capacity begins at the development of knowledge capacity (the common ground) and not with the development of relational capacity as assumed in the original framework. Common ground serves as the basis for the development of a social network.

In addition to the emergence of common ground, the first phase of the process is characterized by the emergence of bridging actors (a form of mobilization capacity) from the interaction processes. These actors attain their bridging position through involvement in multiple (and parallel) interaction processes. A second conclusion of this thesis is that the bridging actors play a major role in bringing building blocks for collaboration together by mobilizing the actors involved in these building blocks and by taking the lead in the development of a shared vision that serves as the basis for the collaborative process that follows. The shared vision (a second form of mobilization capacity) is used to articulate and consolidate the common ground that has emerged on the one hand, and to envision the industrial symbiosis network that can be created in the future by building on this common ground on the other hand. Shared visions thus act as a bridge between the past achievements and the future ambitions of the involved actors.

The mobilization that results from actions by the bridging actors triggers the second phase of the process. In this phase parallel sequences of interactions continue to exist, but they are more strongly intertwined. The parallel sequences of interactions are projects carried out by different groups of actors. The shared vision serves as a bond between the collaborating partners. In addition, bridging actors continue to be important for connecting the different parts of the social network that emerges from the collaboration. This network has a small stable core of actors that collaborate on a structural basis, and a larger fluid periphery of actors that are involved on an incidental basis. The stable core (a form of relational capacity) makes possible coordination of the collaborative process, and the fluid periphery (a second form of relational capacity) represents the ability of the collaborating partners to attract the resources and capabilities of other actors and utilize these in episodes of the collaborative process.

Throughout the process, the sequences of interactions can be influenced by the political, economic and physical context, and institutional capacity can spill over from other interaction processes that occur in the regional system. In the first phase of the process, individual symbiotic exchanges may be developed as outcomes of individual projects. In the second phase the development of a wider network of by-product exchanges and utility synergies may develop. Once the collaborative process has taken off, it can itself become a building block for even more encompassing collaborations. An example of this is the Biobase Europe collaboration, an international collaboration in which Biopark Terneuzen is a building block in addition to Bio-Valley Ghent (a similar collaboration developed in Belgium). 


\subsection{Results and conclusions on event sequence analysis}

ESA has played a major role in making possible the findings. When chapter 5 of the thesis was written ESA was still in an early stage of development and the most important instrument was the event sequence dataset, in which event data are stored in chronological order. After creating the dataset, the data can be coded in various ways, which opens the door to analysis.

A major analytical tool of ESA is the event graph that visualizes processes as networks of events. In chapter 6 the event graphs make their entry. Event graphs offer the possibility to use network analysis methods to analyze processes. They made it possible to uncover the syntax of the process of institutional capacity building, i.e., how building blocks initially develop as parallel, independent sequences of events and eventually converge (marking the start of a collaborative process) and then become intertwined. Thus, the event graphs make the multi-stranded and compounded nature of institutional capacity building more tangible. In addition, the event graphs are of central importance in revealing and visualizing how common ground can emerge from independent projects that unfold before the start of collaboration.

The event data that were recorded in the event sequence datasets served as the basis for the reconstruction of social networks in chapters 7 and 8 . The reconstruction of social networks was achieved by identifying the actors that are involved in the different events, and by subsequently translating this information into two-mode networks that represent the affiliations of actors to events. Such two-mode networks can then be translated to one-mode networks that represent the direct relationships between actors based on their joint involvement in events. The networks have a temporal dimension because they are reconstructed from chronologically ordered data. This makes it possible, for example, to reconstruct networks for different stages of the process under investigation. In the last empirical chapter of the thesis (chapter 8), this approach is taken one step further to develop an innovative approach to dynamic network analysis. This approach creates time series of network measures that serve as indicators of the evolution of the network during collaboration. The network dynamics uncovered in this way are subsequently explained based on a qualitative analysis of the underlying event data. The reconstruction of the social networks from event data led to the discovery of the stable core and fluid periphery in the social networks that emerge from the process of institutional capacity building (chapter 7). In addition, the reconstruction of the social networks provided evidence for the importance of bridging actors in the process.

ESA is still in development. There are many possibilities to further improve the methods, techniques and tools of ESA. ESA proves to be a useful research approach that enables researchers to uncover temporal patterns that will go unnoticed with approaches that do not explicitly take into account the temporal dimension of social phenomena. 

SUMMMARYIN DUTCH 



\section{AANLEIDING, DOELSTELLINGEN EN RELEVANTIE VAN HET ONDERZOEK}

Industriële symbiose is een proces warin bedrijven in regionale industriële systemen deelnemen aan de uitwisseling van bijproducten en het delen van utiliteiten en diensten om daarmee verbeterde milieuprestaties en concurrentievoordelen te behalen.

Industriële symbiose heeft een belangrijke technische dimensie. In de ontwikkeling van het concept werd al snel erkend dat het ook een prominente sociale dimensie heeft. Om de sociale dimensie te vangen zijn concepten geïntroduceerd afkomstig uit de sociale wetenschappen. Dit proefschrift doet een van de eerste pogingen om verschillende van deze concepten samen te brengen in een geïntegreerd conceptueel raamwerk. Zo'n conceptueel raamwerk draagt bij aan de theorievorming over industriële symbiose.

Dit proefschrift beschouwt de ontwikkeling van industriële symbiose als een governance-uitdaging en richt zich op de interactieprocessen tussen bedrijven, overheden, kennisinstellingen en andere relevante partijen waarin kwesties van gemeenschappelijk belang worden opgepakt. De sociale dimensie van industriële symbiose verwijst zo specifiek naar de capaciteit van actoren om hun acties en interacties te coördineren richting industriële symbiose.

Doel van het ontwikkelde conceptueel raamwerk is om de wijze waarop deze, vaak onzichtbare, capaciteit zich ontwikkelt zichtbaar te maken en daarmee ook vatbaar voor sturing. Het raamwerk is in vijf stappen tot stand gekomen:

1. Op basis van bestaande, relevante theoretische inzichten is een initiële versie van het raamwerk ontwikkeld;

2. De implicaties van het initiële raamwerk zijn getest in empirische studies

3. De theoretische lessen uit de empirische studies zijn gebruikt om het conceptuele raamwerk aan te passen;

4. Het aangepaste raamwerk is getest in empirische studies;

5. Het aangepaste raamwerk is gepresenteerd in de conclusies.

Het proces is gestuurd met de volgende inhoudelijke onderzoeksvraag:

\section{Hoe emergeert en ontwikkelt de collectieve capaciteit van bedrijven, overheden en kennisinstellingen om aan industriële symbiose deel te nemen?}

Als uitgangspunt voor het initiële conceptuele raamwerk is het concept van institutionele capaciteitsopbouw uit de literatuur over collaboratieve planning genomen. Het concept speelt in op verschillende sociale factoren die in de literatuur over industriële symbiose als belangrijk worden aangewezen, zoals het plaatsvinden van een leerproces, de aanwezigheid van een strategische visie, de diversiteit en onderlinge verbondenheid van betrokken actoren, het bestaan en kweken van vertrouwen tussen actoren, de aanwezigheid van sleutelactoren die de leiding kunnen nemen, en de aanwezigheid van een stimulerende context, waarbij voornamelijk wordt verwezen naar beleid en regelgeving. De kracht van het concept van institutionele capaciteitsopbouw is dat het aangeeft hoe 
deze factoren met elkaar zijn verbonden. Het concept focust op de lange termijn ontwikkeling van een sociale context die samenwerken aan industriële symbiose stimuleert. Er zijn drie dimensies van institutionele capaciteit onderscheiden:

1. De kwaliteit van de sociale banden tussen actoren (relationele capaciteit);

2. De kennismiddelen die worden ontwikkeld en gedeeld via de sociale banden (kenniscapaciteit)

3. Het vermogen van actoren om de eerste twee vormen van capaciteit te mobiliseren voor gezamenlijke actie (mobilisatiecapaciteit).

Uitgangspunt is dat deze drie dimensies van institutionele capaciteit emergeren uit interacties tussen actoren in regionale industriële systemen. In dit proefschrift worden de theoretische implicaties van het raamwerk getest met empirische bevindingen uit twee casussen van samenwerken aan industriële symbiose: Biopark Terneuzen in de Kanaalzone van Zeeland en Duurzame Verbindingen in Moerdijk. De resultaten van deze test zijn gebruikt om het conceptuele raamwerk te verfijnen. De aangepaste versie van het raamwerk wordt gepresenteerd in de conclusies (zie ook paragraaf 3.1).

Het proefschrift heeft ook een vooral methodische doelstelling. Er zijn weinig studies die methoden, technieken en tools toepassen die expliciet rekening houden met de temporele dimensie van industriële symbiose. Benaderingen voor longitudinaal onderzoek zijn ontwikkeld in onderzoeksvelden als sociologie, organisatiewetenschappen en politieke wetenschappen. Het methodische doel van dit proefschrift is om vast te stellen wat dergelijke benaderingen kunnen bijdragen aan ons begrip van industriële symbiose. Daartoe is de volgende, methodische onderzoeksvraag geformuleerd:

\section{Wat kunnen methoden, technieken en tools voor systematisch en longitudinaal on- derzoek naar procesfenomenen bijdragen aan ons begrip van industriële symbiose?}

Dit proefschrift verkent methoden, technieken en tools voor longitudinaal onderzoek, voortbouwend op bestaande benaderingen, en levert een bijdrage aan verdere ontwikkeling van methoden, technieken en tools in de vorm van een nieuwe benadering. De nieuwe benadering heet Event Sequence Analysis (ESA). De ontwikkeling ervan is in gang gezet samen met onderzoekers van de afdeling Bestuurskunde aan de Erasmus Universiteit Rotterdam.

Deel 2 van deze samenvatting geeft een overzicht van de stappen die zijn gezet om de twee onderzoeksvragen te beantwoorden en schetst de structuur van het proefschrift. Deel 3 bevat de resultaten en conclusies van het proefschrift.

\section{STRUCTUUR VAN HET PROEFSCHRIFT}

Dit proefschrift is grotendeels opgebouwd uit een boekhoofdstuk en 4 artikelen. Ze zijn geschreven als op zichzelf staande publicaties en bevatten dus enige overlap en ook 
een zekere evolutie van benadering en inzicht. Aanvullend is een literatuurdiscussie opgenomen (hoofdstuk 2), gebaseerd op een deel van een op zichzelf staande publicatie.

Het boekhoofdstuk (hoofdstuk 3 in het proefschrift) introduceert een conceptueel raamwerk dat dient als de initiële conceptuele basis van het proefschrift. De vier artikelen (hoofdstukken 5 tot en met 8) bevatten empirische studies, uitgevoerd om de implicaties van verschillende versies van het conceptuele raamwerk te testen. Een inleidend hoofdstuk 1, een hoofdstuk over methoden (hoofdstuk 4) en een conclusiehoofdstuk (hoofdstuk 9) completeren het proefschrift. 6 intermezzo's tussen de hoofdstukken lichten de verschillende theoretische en methodologische keuzes die in het onderzoeksproces zijn gemaakt toe. Ze bieden aanvullende inzichten in hoe het onderzoeksproces zich heeft ontvouwd.

Om vast te stellen of er adequate theoretische onderbouwingen voor empirisch onderzoek naar industriële symbiose beschikbaar zijn, is een literatuurstudie uitgevoerd. Verschillende publicaties bieden theoretische onderbouwing. Wat evenwel ontbreekt, is een conceptueel raamwerk dat een meeromvattende analyse van de emergentie en ontwikkeling van industriële symbiose mogelijk maakt. Hoofdstuk 3 introduceert zo'n conceptueel raamwerk. De evolutie van industriële symbiose wordt daarin op drie niveaus beschreven: project, regionaal industrieel systeem en institutionele context. Daarnaast worden mechanismen aangedragen die de dynamiek van industriële symbiose op de verschillende niveaus verbindt, waaronder mechanismen van opbouw van institutionele capaciteit. Het conceptuele raamwerk vormt de basis voor de artikelen die worden gepresenteerd in hoofdstukken 5 en 6 . In hoofdstuk 5 worden proposities, volgend uit het raamwerk, geformuleerd en geconfronteerd met empirische observaties uit de casus Biopark Terneuzen in de Kanaalzone. Hoofdstuk 6 verbreedt de scope van het onderzoek zodanig dat ook andere interactieprocessen in het Sloegebied en de Kanaalzone in ogenschouw worden genomen.

Op basis van de theoretische lessen uit de eerste empirische studies (hoofdstuk 5 en 6) is een nieuw model van opbouw van institutionele capaciteit ontwikkeld (hoofdstuk 7). In hoofdstuk 7 worden de implicaties van het nieuwe model vervolgens getest. Daarbij is een strategie gevolgd, vergelijkbaar met die uit hoofdstuk 5: Verschillende proposities worden afgeleid van het model en geconfronteerd met empirische bevindingen uit twee casusstudies. De eerste casus betreft Biopark Terneuzen in de Kanaalzone (in de tussentijd is de onderliggende dataset voor deze studie uitgebreid), en de tweede casus betreft Duurzame Verbindingen in Moerdijk. Verdere tests van de implicaties van het nieuwe model worden uitgevoerd in de empirische studie die is opgenomen in hoofdstuk 8 , waarbij een innovatieve benadering van dynamische netwerkanalyse wordt gebruikt.

Het conclusiehoofdstuk (hoofdstuk 9) verbindt de resultaten uit alle empirische studies (hoofdstukken 5 tot en met 8) met elkaar. Op basis van de theoretische lessen uit de studies wordt een aangepaste versie van het conceptueel raamwerk van institutionele 
capaciteitsopbouw gepresenteerd. Het aangepaste raamwerk wordt gebruikt om de presentatie van de conclusies aangaande de eerste onderzoeksvraag van het proefschrift te structureren. Daarnaast is in het conclusiehoofdstuk een discussie opgenomen over de meerwaarde van de methoden, technieken en tools die zijn ontwikkeld en toegepast. In elk van de empirische studies zijn stappen gezet in de ontwikkeling van ESA. Het conclusiehoofdstuk reflecteert op deze methodologische vooruitgang en de bijdrage die is geleverd aan de inzichten in industriële symbiose. Het sluit af met aanbevelingen voor onderzoek en aan de praktijkwereld.

\section{RESULTATEN EN CONCLUSIES}

Dit deel vat de resultaten en conclusies van het onderzoek samen. Paragraaf 3.1 gaat in op de inhoudelijke onderzoeksvraag en paragraaf 3.2. op de methodische onderzoeksvraag.

\subsection{Resultaten en conclusies over opbouw van institutionele capaciteit}

De empirische studie in hoofdstuk 5 confronteert implicaties van het initiële conceptuele raamwerk met empirische observaties uit de casus Biopark Terneuzen in de Kanaalzone. Voor de studie is een event sequence dataset samengesteld waarin gebeurtenissen van 1999 tot en met 2010 zijn vastgelegd. De sequenties van gebeurtenissen in de dataset worden gepresenteerd en patronen in de sequenties worden vergeleken met patronen die het conceptueel raamwerk impliceert.

De studie brengt aan het licht dat institutionele capaciteit niet wordt opgebouwd in een ordelijke, lineaire sequentie van interacties, zoals aangenomen in het conceptuele raamwerk. Institutionele capaciteit blijkt op gefragmenteerde manieren tot stand te komen, in verschillende stromen van gebeurtenissen die zich parallel aan elkaar ontvouwen en die verschillende projecten vertegenwoordigen die grotendeels onafhankelijk van elkaar worden uitgevoerd (actoren die zijn betrokken in een project reageren niet expliciet op gebeurtenissen die zich voordoen in andere projecten). Veranderingen in relationele middelen vinden op een meer abrupte manier plaats dan voorspeld door het raamwerk. De grootste verandering in relationele capaciteit vindt plaats op het punt waar verschillende stromen van gebeurtenissen bij elkaar komen en met elkaar verknoopt raken. Het bij elkaar komen van stromen van gebeurtenissen wordt aangejaagd door de gedeelde visie op Biopark Terneuzen. De visie zet partijen aan om onafhankelijke projecten gezamenlijk in te zetten ten gunste van industriële symbiose. De studie wijst ook op de sleutelrol van de havenautoriteit in het bij elkaar brengen van actoren en het ondersteunen van projecten. 
De empirische studie in hoofdstuk 6 plaatst Biopark Terneuzen in de context van andere interactieprocessen in het Sloegebied en de Kanaalzone:

1. De ontwikkeling van Valuepark Terneuzen;

2. De ontwikkeling van de projectgroep Vitaal Sloegebied en Kanaalzone.

Een bevinding is dat de drie interactieprocessen worden gedreven door eigen logica (de processen worden gedomineerd door verschillende typen gebeurtenissen). Als resultaat daarvan dragen ze op eigen wijze bij aan de ontwikkeling van institutionele capaciteit. De studie wijst uit dat de drie interactieprocessen elkaar niet aanwijsbaar op een directe manier beïnvloeden, maar wel overlappende bronnen van institutionele capaciteit in de regio vormen: Institutionele capaciteit opgebouwd in één interactieproces kan worden gemobiliseerd in een ander proces. De studie benadrukt de samengestelde aard van de Biopark Terneuzen samenwerking. Deze observatie wordt verbonden aan de theorie van Herbert Simon over complexe systemen als stabiele assemblages: De drie stromen van gebeurtenissen die aanzetten tot de Biopark Terneuzen samenwerking zijn stabiele tussenproducten die later worden geassembleerd in samenwerking. Dit idee wordt verbonden aan bestaande fasemodellen van industriële symbiose, en een nieuw fasemodel wordt gepresenteerd.

Het model, waar hoofdstuk 6 mee eindigt, wordt in hoofdstuk 7 uitgewerkt. De implicaties ervan worden geformuleerd als proposities. Deze worden geconfronteerd met empirische observaties uit de casus Biopark Terneuzen (de dataset van deze casus is tussentijds uitgebreid met gebeurtenissen uit 2011 en 2012), en observaties uit de casus Duurzame Verbindingen in Moerdijk, waarvoor een nieuwe event sequence dataset is aangelegd. De studie laat zien dat samenwerking kan worden geassembleerd uit projecten die als bouwstenen fungeren. De capaciteit van actoren om samen te werken emergeert al voordat zij actief met elkaar interacteren (een inzicht dat wordt onderbelicht in de literatuur over collaborative governance): Omdat actoren in de onafhankelijke projecten zich min of meer tegelijkertijd met vergelijkbare kwesties bezighouden, ontwikkelt zich een gemeenschappelijke grond. Deze beïnvloedt de doelen die worden geformuleerd bij de start van samenwerking. De aanwezigheid van enkele brugactoren (actoren betrokken in meerdere bouwstenen) maakt dat de gemeenschappelijke grond van de bouwstenen wordt herkend en gemobiliseerd. In beide casussen vervullen publieke organisaties de rol van brugactor. Nadat de samenwerking start, ontwikkelt zich een actornetwerk met een kleine, stabiele kern van actoren die op een structurele basis samenwerken en een grotere, meer vloeibare periferie van actoren die op incidentele basis zijn betrokken.

De relationele dynamiek in de beschreven processen wordt in detail bestudeerd in hoofdstuk 8. Dezelfde casussen zijn geanalyseerd met een dynamische netwerkanalyse. Hoofddoel is om de implicaties van procesmodellen van samenwerkingsprocessen voor de structuur van samenwerkingsnetwerken te testen. De studie laat zien dat de meeste actoren niet direct met elkaar interacteren, maar dat hun relaties worden gemedieerd 
door actoren (meestal publieke actoren) die fungeren als brug tussen delen van het netwerk. Brugactoren zijn cruciaal voor de continuïteit en coherentie van de samenwerking. Het is mogelijk dat de partners elkaar in collectieve bijeenkomsten ontmoeten, maar deze gebeurtenissen zijn vrij zeldzaam. De studie bevestigt de bevinding uit hoofdstuk 7 dat het netwerk van samenwerkende actoren bestaat uit een kleine, stabiele kern van actoren die elkaar op structurele basis ontmoeten, en een grotere fluïde periferie van actoren die op incidentele basis zijn betrokken.

Alle bevindingen worden in het conclusiehoofdstuk met elkaar verbonden tot een aangepaste versie van het conceptueel raamwerk. Kern van dat raamwerk is een tweefasenmodel. De eerste fase beslaat de emergentie van bouwstenen voor samenwerking en de tweede beslaat het samenwerkingsproces dat van bouwstenen wordt geassembleerd. In de eerste fase emergeert een gemeenschappelijke grond (een vorm van kenniscapaciteit) uit parallelle sequenties van interacties die zich grotendeels onafhankelijk van elkaar ontvouwen. Een belangrijke conclusie van het onderzoek in dit verband is dat de emergentie van institutionele capaciteit begint bij de ontwikkeling van kenniscapaciteit (gemeenschappelijke grond) en niet met de ontwikkeling van relationele capaciteit, zoals aangenomen in het oorspronkelijke raamwerk. Gemeenschappelijke grond dient juist als basis voor de ontwikkeling van een sociaal netwerk.

Naast de emergentie van gemeenschappelijke grond wordt de eerste fase van het proces gekenmerkt door de emergentie van brugactoren (een vorm van mobilisatiecapaciteit) uit interactieprocessen. Deze actoren verkrijgen hun positie door betrokkenheid in meerdere parallelle interactieprocessen. Een tweede conclusie is dat de brugactoren een belangrijke rol spelen in het bij elkaar brengen van bouwstenen voor samenwerking door actoren die zijn gelieerd aan de bouwstenen te mobiliseren en door een leidende rol te spelen in de ontwikkeling van een gedeelde visie die als basis dient voor het daaropvolgende samenwerkingsproces. De gedeelde visie (een tweede vorm van mobilisatiecapaciteit) wordt gebruikt om enerzijds de gemeenschappelijke grond die is ontstaan te articuleren en consolideren en anderzijds een toekomstperspectief te bieden op de ontwikkeling van een netwerk van symbiotische uitwisselingen. De gedeelde visie fungeert daarmee als een brug tussen in het verleden behaalde resultaten en de ambities die actoren hebben voor de toekomst.

De mobilisatie die plaatsvindt door handelingen van brugactoren luidt de tweede fase in. Daarin blijven parallel sequenties van interacties bestaan, maar die zijn sterker met elkaar verweven. De parallelle sequenties zijn projecten die verschillende groepen actoren uitvoeren als onderdelen van hun samenwerking. De gedeelde visie dient als bindmiddel voor samenwerking. Daarnaast blijven brugactoren belangrijk voor het leggen van verbindingen tussen delen van het sociale netwerk dat uit de samenwerking emergeert. Dit netwerk heeft een stabiele kern van actoren die structureel samenwerken en een grotere fluïde periferie van actoren die op incidentele basis zijn betrokken. De stabiele kern 
(een vorm van relationele capaciteit) maakt coördinatie van het samenwerkingsproces mogelijk en de fluïde periferie (een tweede vorm van relationele capaciteit) is een uiting van het vermogen van de samenwerkende partners om middelen en capaciteiten van andere actoren aan te trekken en deze in te zetten in episodes van samenwerking.

Gedurende het proces worden de sequenties van interactie beïnvloed door de politieke, economische en fysieke context, en kan de institutionele capaciteit overvloeien vanuit andere interactieprocessen die zich ontvouwen in het regionale industriële systeem. In de eerste fase van het proces is het mogelijk dat individuele symbiotische uitwisselingen ontstaan als uitkomsten van onafhankelijke projecten. In de tweede fase kan zich een breder netwerk van symbiotische uitwisselingen ontwikkelen. Wanneer de samenwerking gestart is, kan het zelf als bouwsteen fungeren voor meeromvattende samenwerking. Een voorbeeld is de internationale samenwerking Biobase Europe, waarin Biopark Terneuzen een bouwsteen is naast Bio-Valley Ghent (een vergelijkbaar initiatief ontwikkeld in België).

\subsection{Resultaten en conclusies over event sequence analysis}

ESA heeft een belangrijke rol gespeeld in het mogelijk maken van de bevindingen. Op het moment dat hoofdstuk 5 van het proefschrift is geschreven stond ESA in de kinderschoenen en was het belangrijkste instrument de event sequence dataset, warin data over gebeurtenissen in chronologische volgorde staan opgeslagen. Na het maken van de dataset is het mogelijk om de data op verschillende manieren te coderen, waarmee de deur wordt geopend naar analyse.

Een belangrijke analytische tool die onderdeel uitmaakt van ESA is de event graph, dat processen visualiseert als netwerken van gebeurtenissen. In hoofdstuk 6 doen event graphs hun intrede. Event graphs bieden de mogelijkheid om netwerkanalyse in te zetten voor het analyseren van processen. Daarmee is het mogelijk de syntax van het proces van emergentie en ontwikkeling van institutionele capaciteit bloot te leggen, d.w.z. hoe de bouwstenen voor samenwerking zich ontwikkelen als parallelle, onafhankelijke sequenties van gebeurtenissen en uiteindelijk convergeren in een samenwerkingsproces waarin ze met elkaar raken verweven. De event graphs maken de meersporige en samengestelde aard van het proces daarmee beter tastbaar. Daarnaast zijn event graphs van belang in het ontdekken en visualiseren van de manier waarop gemeenschappelijke grond emergeert uit onafhankelijke projecten die voorafgaand aan samenwerkingsprocessen worden uitgevoerd.

De data over gebeurtenissen die zijn opgenomen in de event sequence datasets hebben als basis gediend voor de reconstructie van sociale netwerken in hoofdstukken 7 en 8 . De reconstructies van sociale netwerken zijn gemaakt door eerst te identificeren welke actoren in welke gebeurtenissen zijn betrokken om deze informatie vervolgens te vertalen naar zogenaamde two-mode netwerken waarin de betrokkenheid van actoren 
bij gebeurtenissen wordt gevisualiseerd. De two-mode netwerken worden vervolgens vertaald naar one-mode netwerken waarin de directe relaties tussen actoren worden gevisualiseerd op basis van hun gezamenlijke betrokkenheid in gebeurtenissen. Deze netwerken hebben een temporele dimensie omdat ze worden gereconstrueerd uit chronologisch geordende data. Zo is het bijvoorbeeld mogelijk om met deze benadering sociale netwerken te reconstrueren voor verschillende episodes in het bestudeerde proces. In het laatste empirische hoofdstuk van het proefschrift (hoofdstuk 8) wordt deze benadering nog een stap verder gebracht om een vorm van dynamische netwerkanalyse te ontwikkelen. De benadering maakt tijdsreeksen van netwerkeigenschappen. Deze dienen als indicatoren voor de ontwikkeling van het netwerk gedurende het proces. De netwerkdynamiek die in de tijdsreeksen wordt blootgelegd wordt vervolgens verklaard op basis van een kwalitatieve analyse van de data over de onderliggende gebeurtenissen. De reconstructie van de sociale netwerken op basis van data uit de event sequence datasets hebben onder andere geleid tot de ontdekking van de stabiele kern en de fluïde periferie van de sociale netwerken die emergeren uit de opbouw van institutionele capaciteit (hoofdstuk 7). Daarnaast heeft de reconstructie van sociale netwerken bewijs opgeleverd voor het belang van de aanwezigheid van brugactoren in het proces.

ESA is in ontwikkeling. Er zijn veel mogelijkheden om de methoden, technieken en tools van ESA te verbeteren. ESA blijkt een bruikbare benadering die onderzoekers in staat stelt temporele patronen bloot te leggen die worden gemist als gebruik wordt gemaakt van methoden die niet expliciet de temporele dimensie van sociale verschijnselen in ogenschouw nemen. 




\section{ANNEX 1}

\section{SUPPLEMENTARY MATERIAL TO CHAPTER 6}




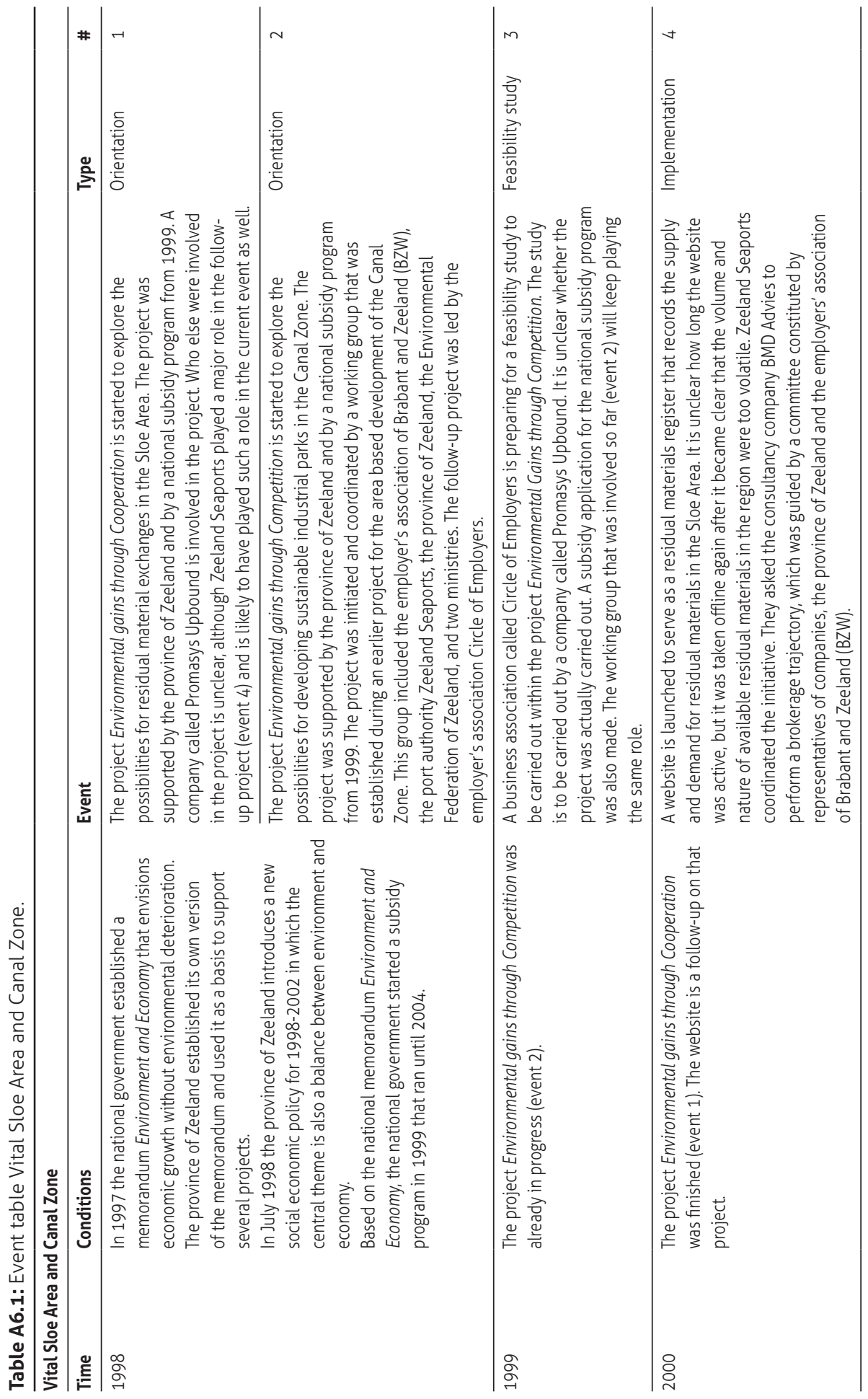




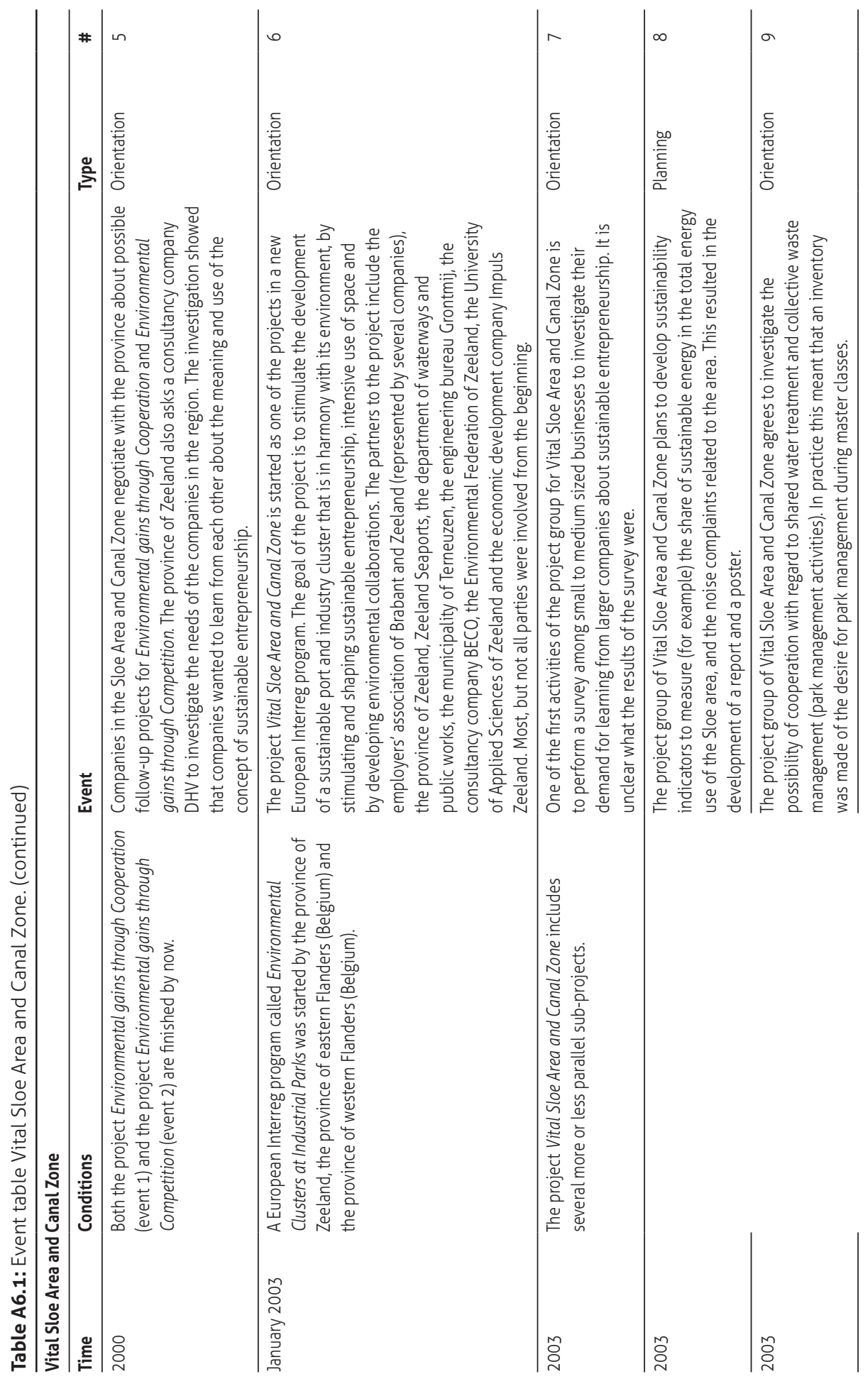


|\#| 울
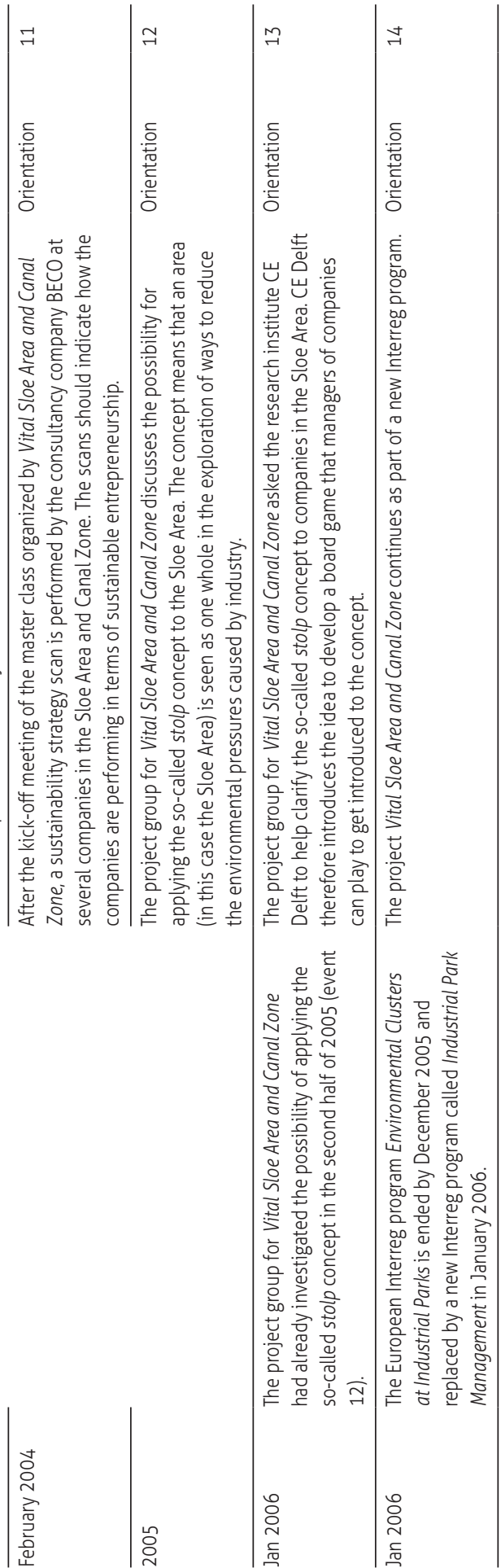

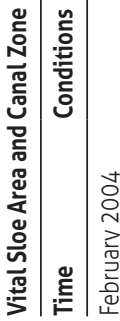
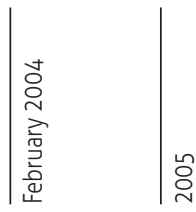

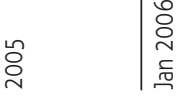

空 


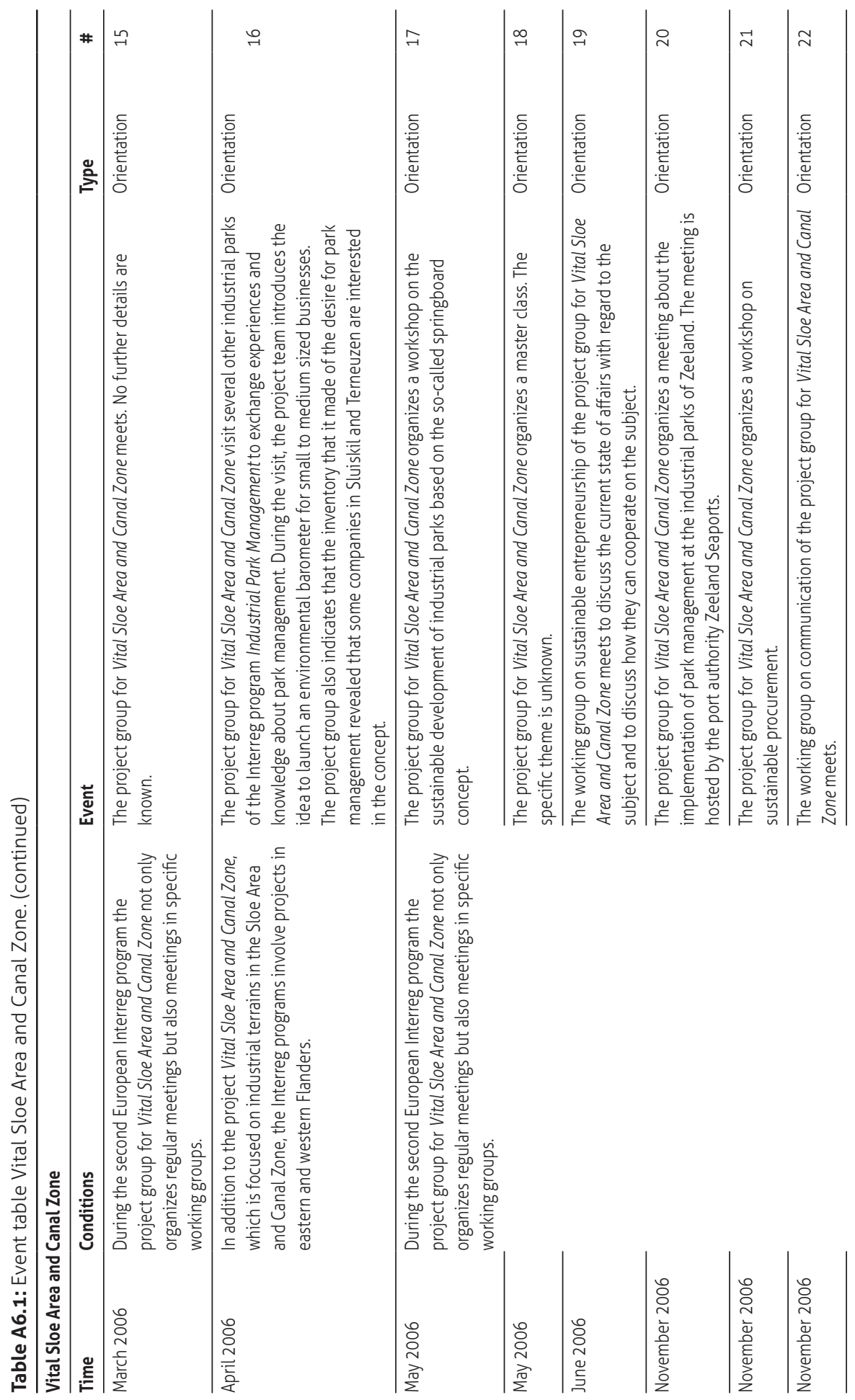




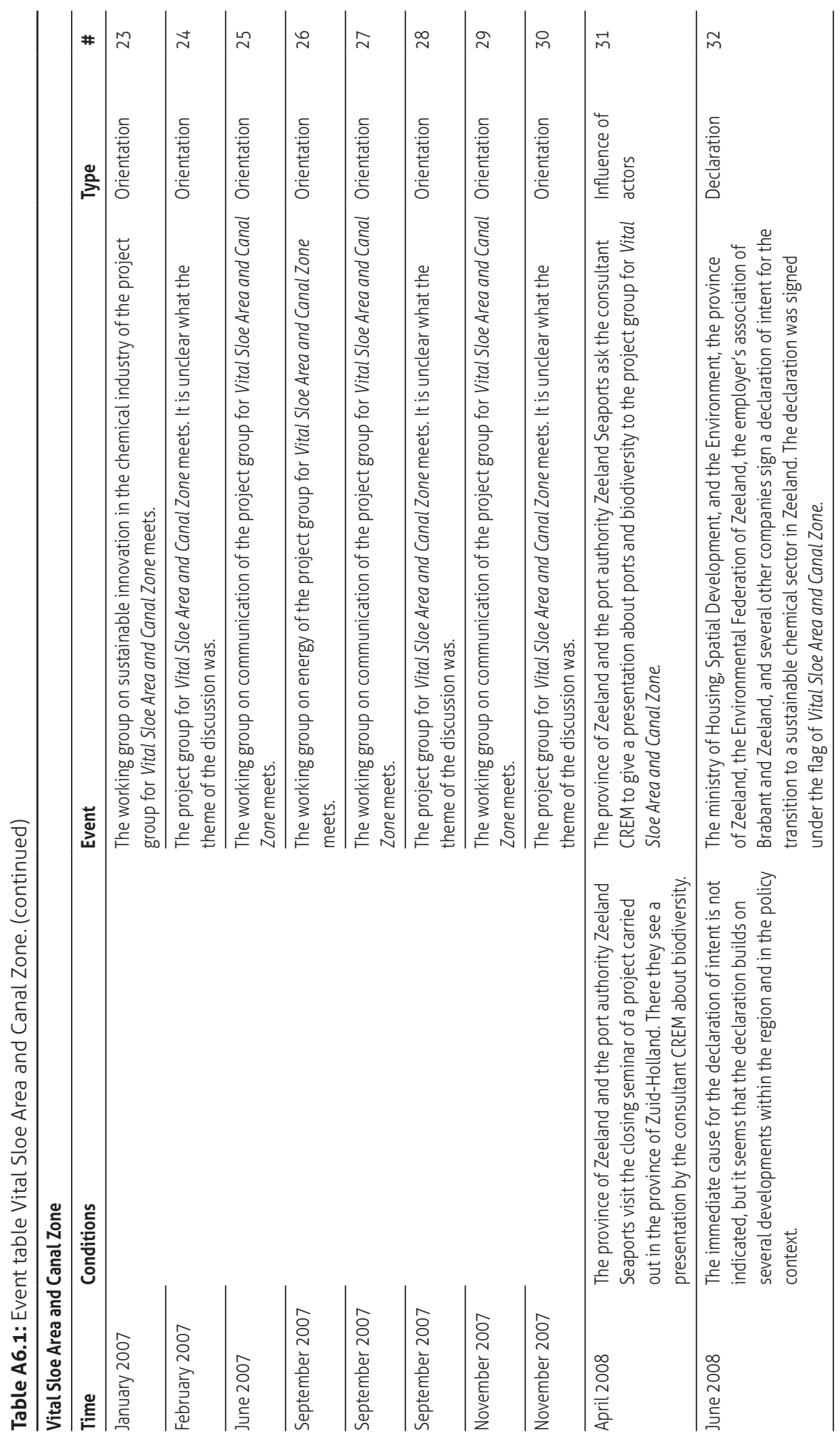




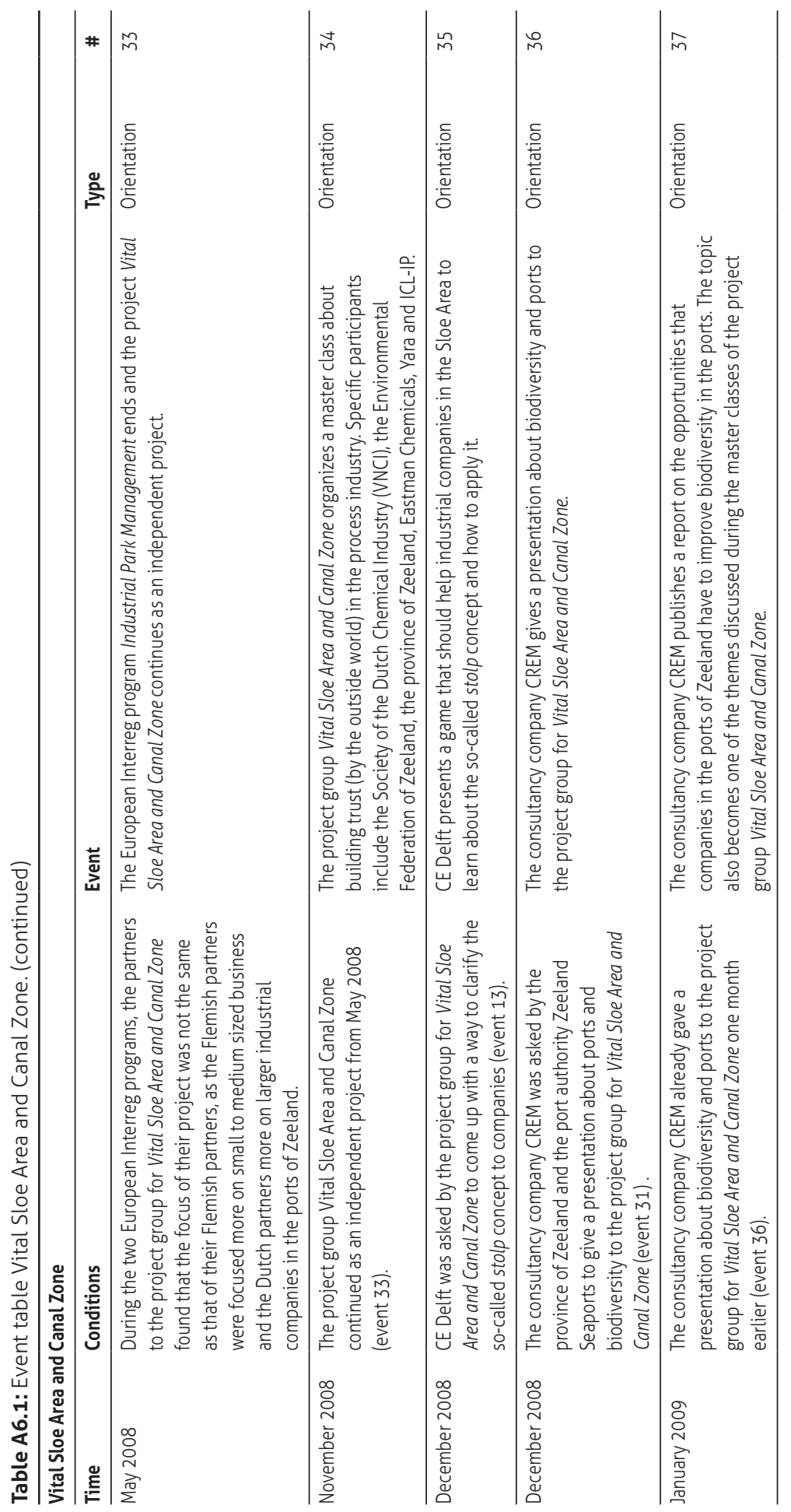




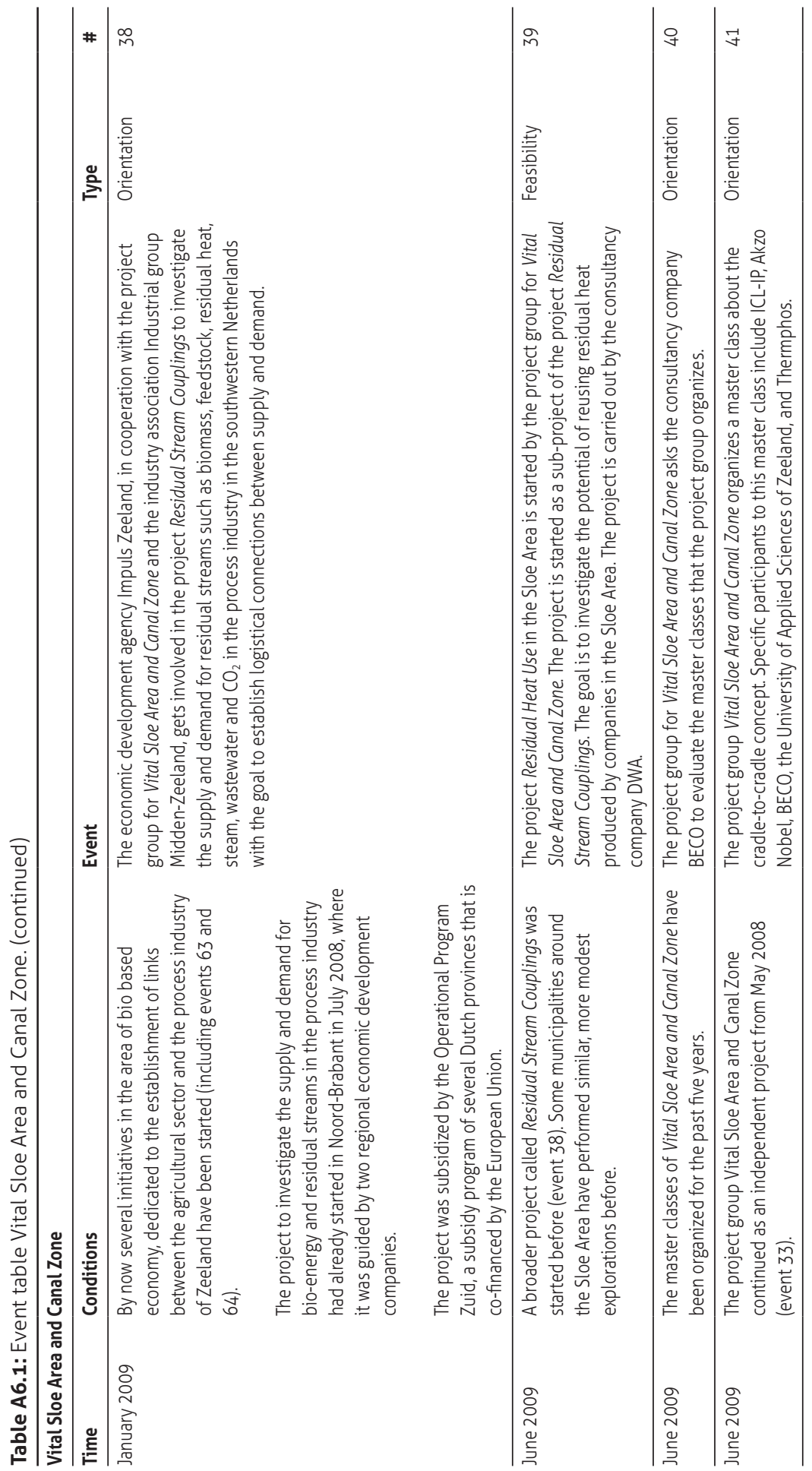




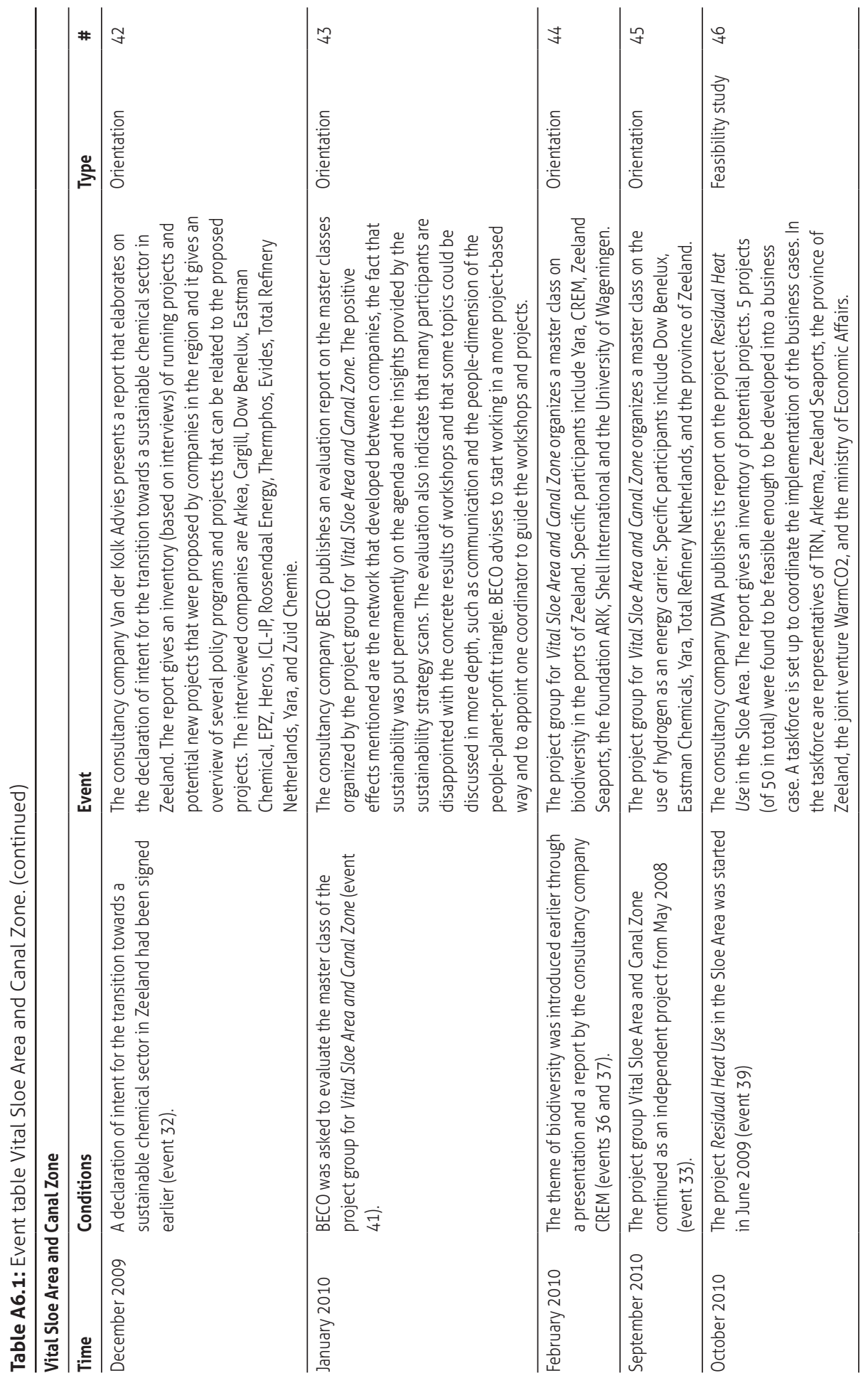




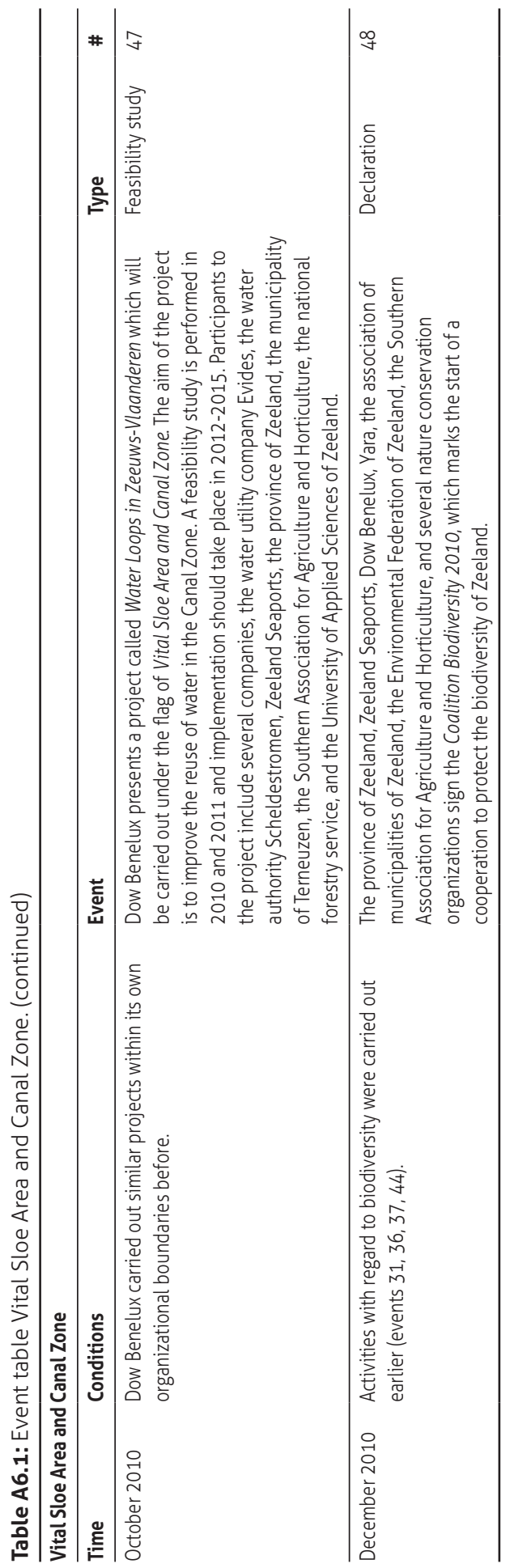




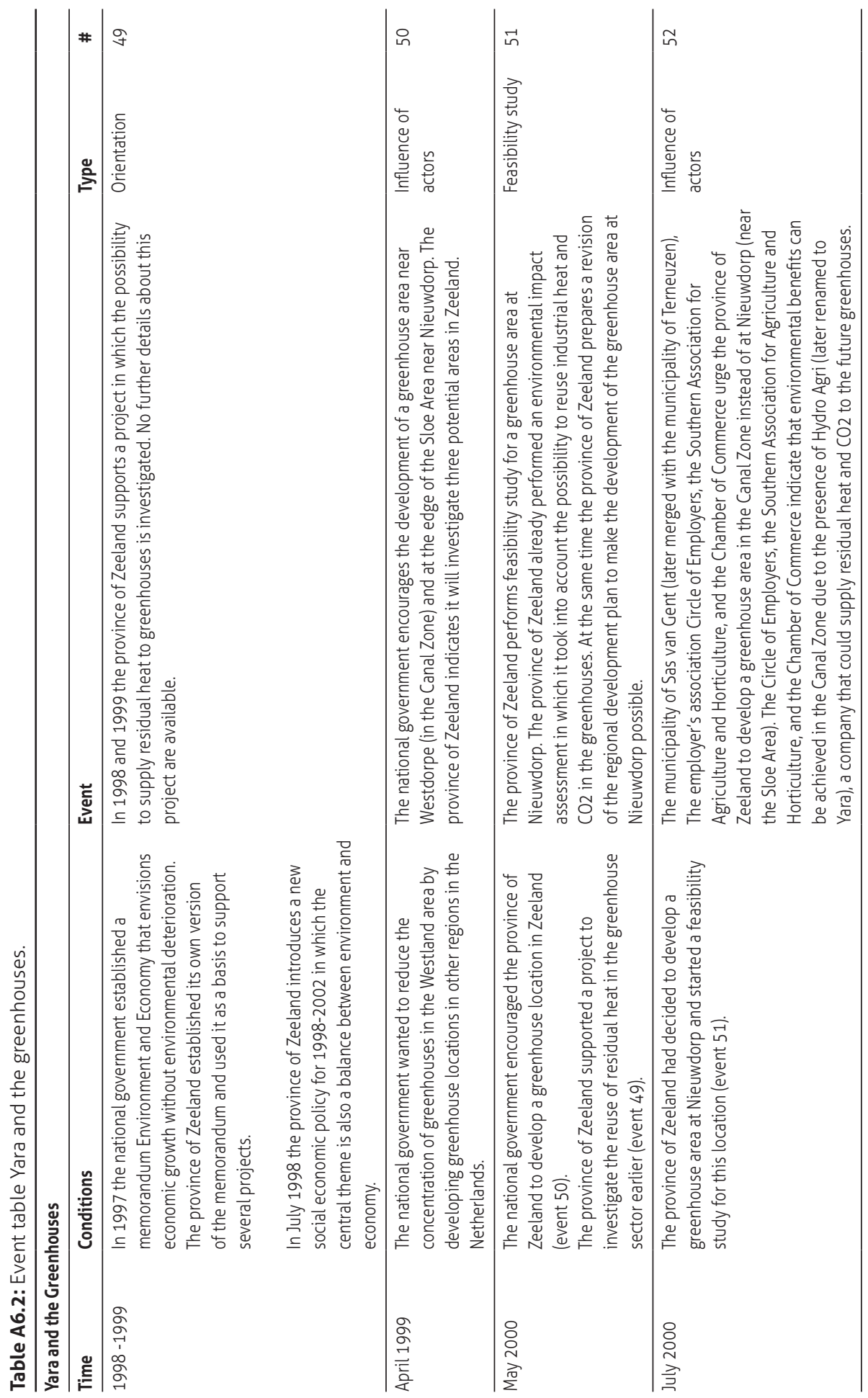




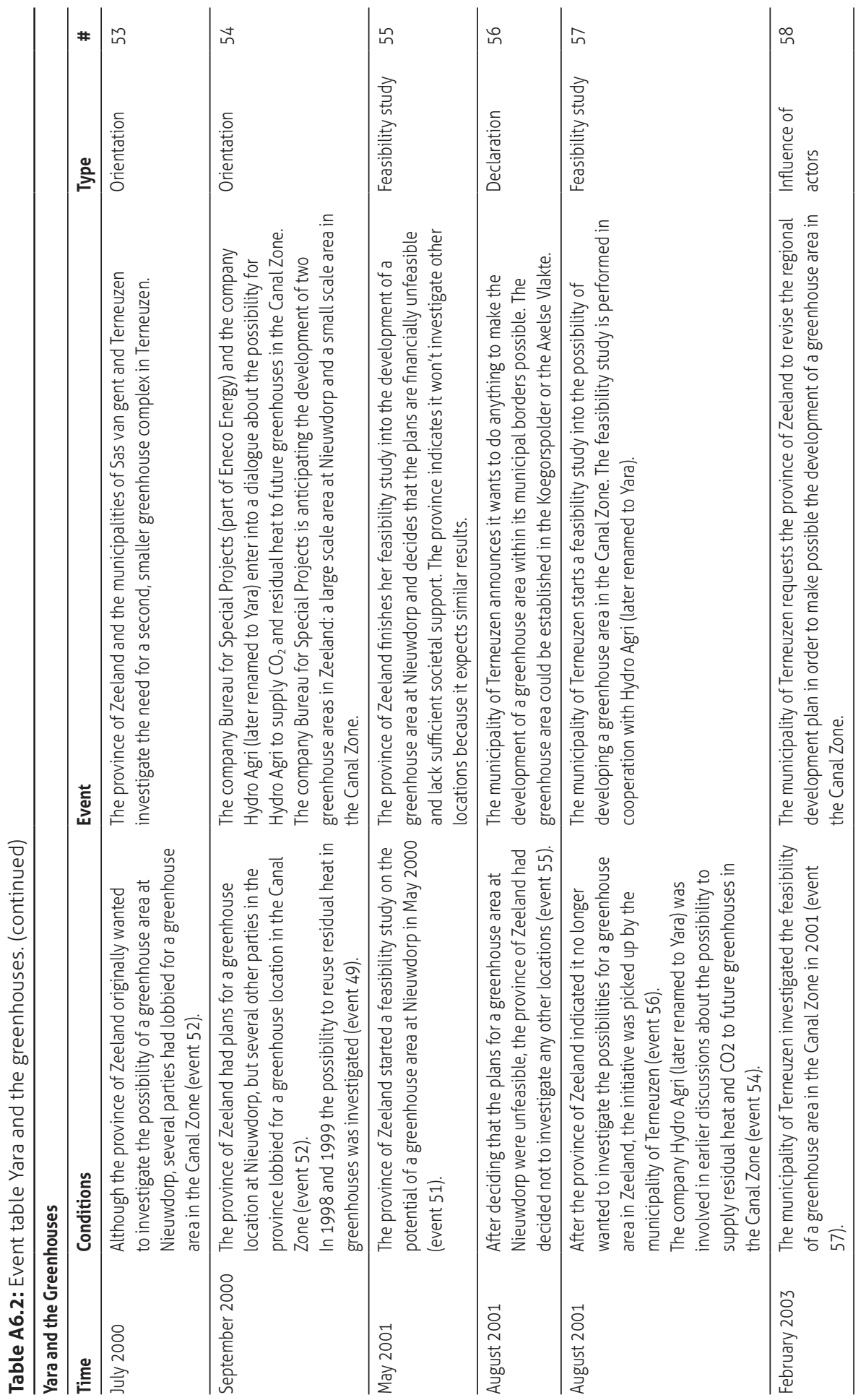




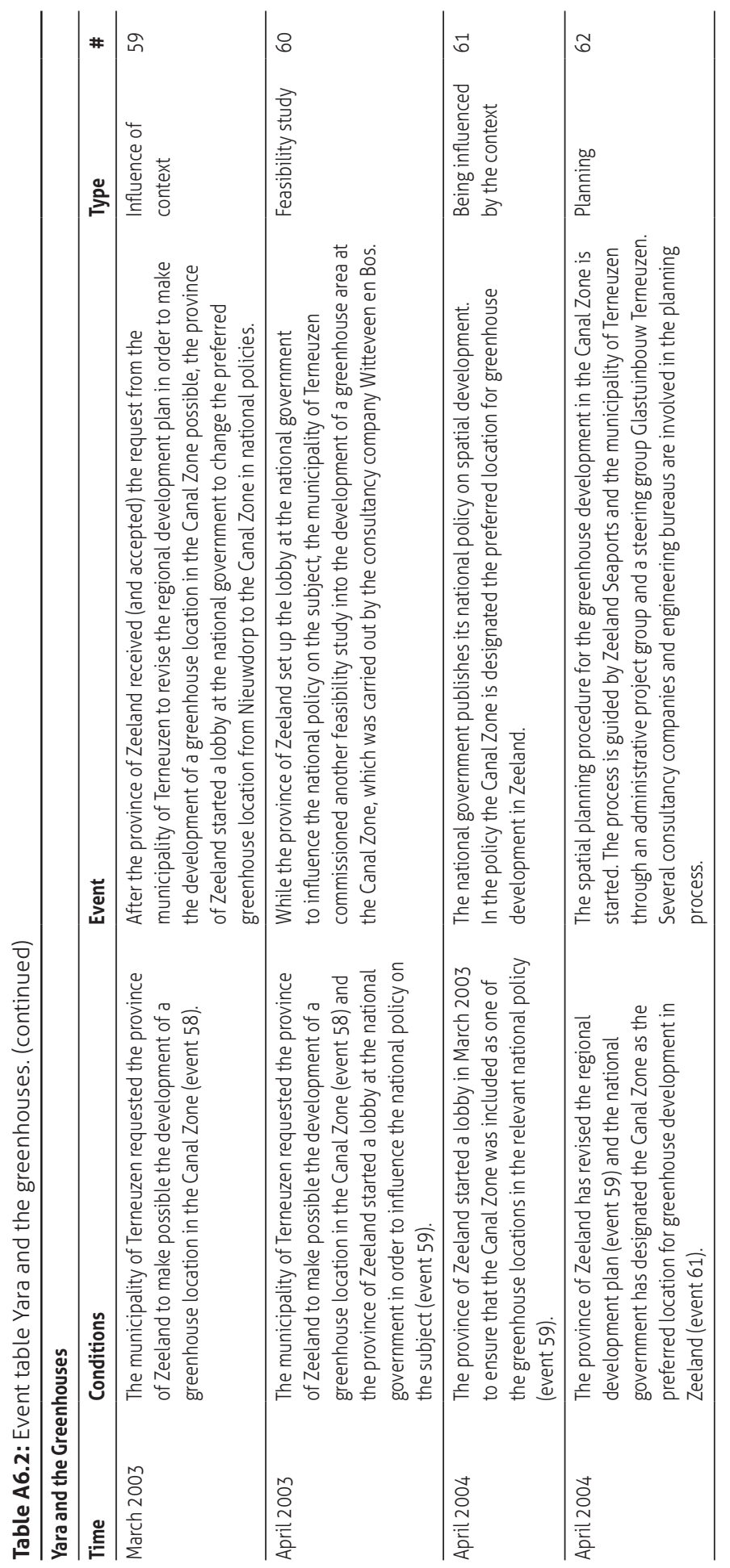




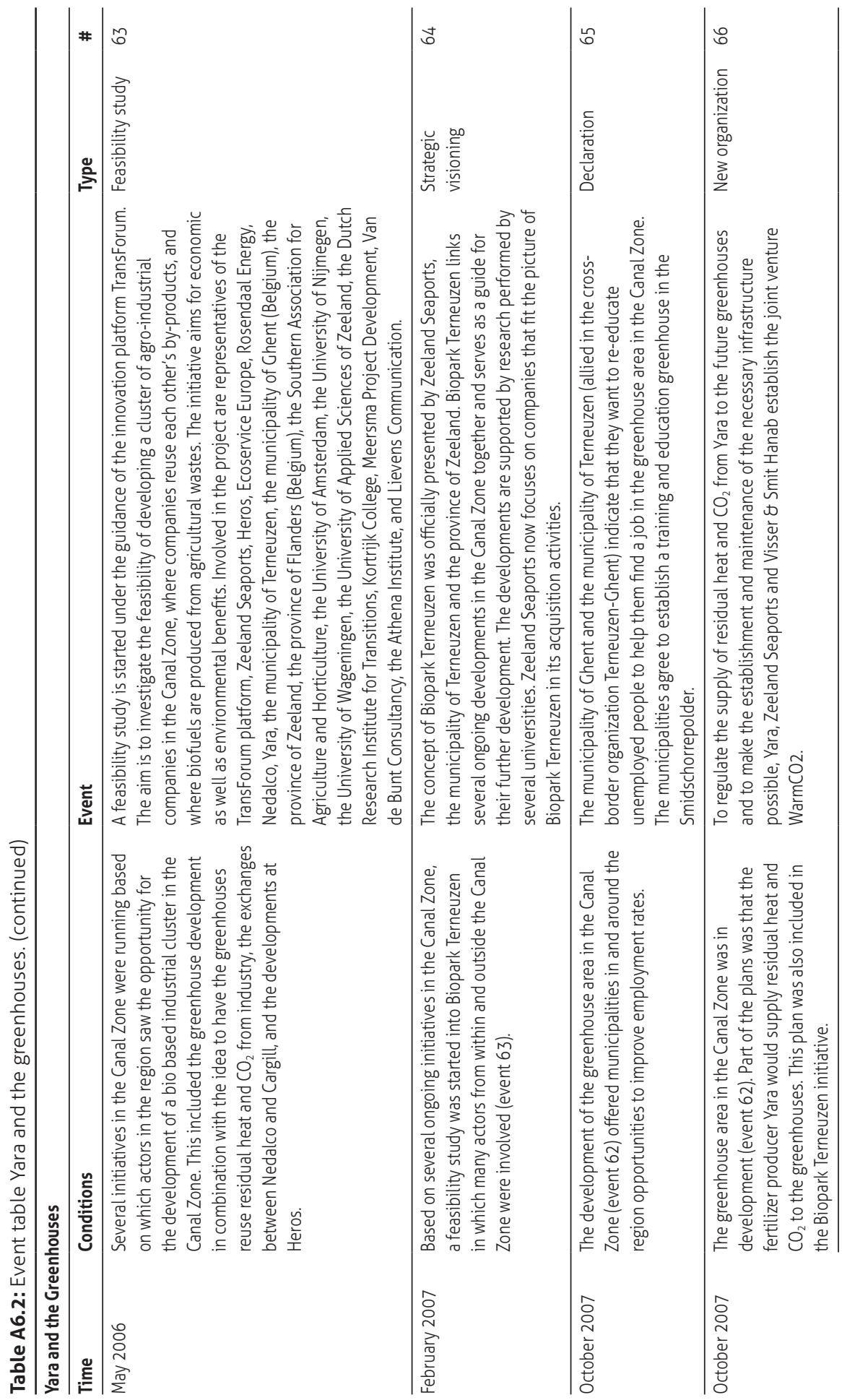




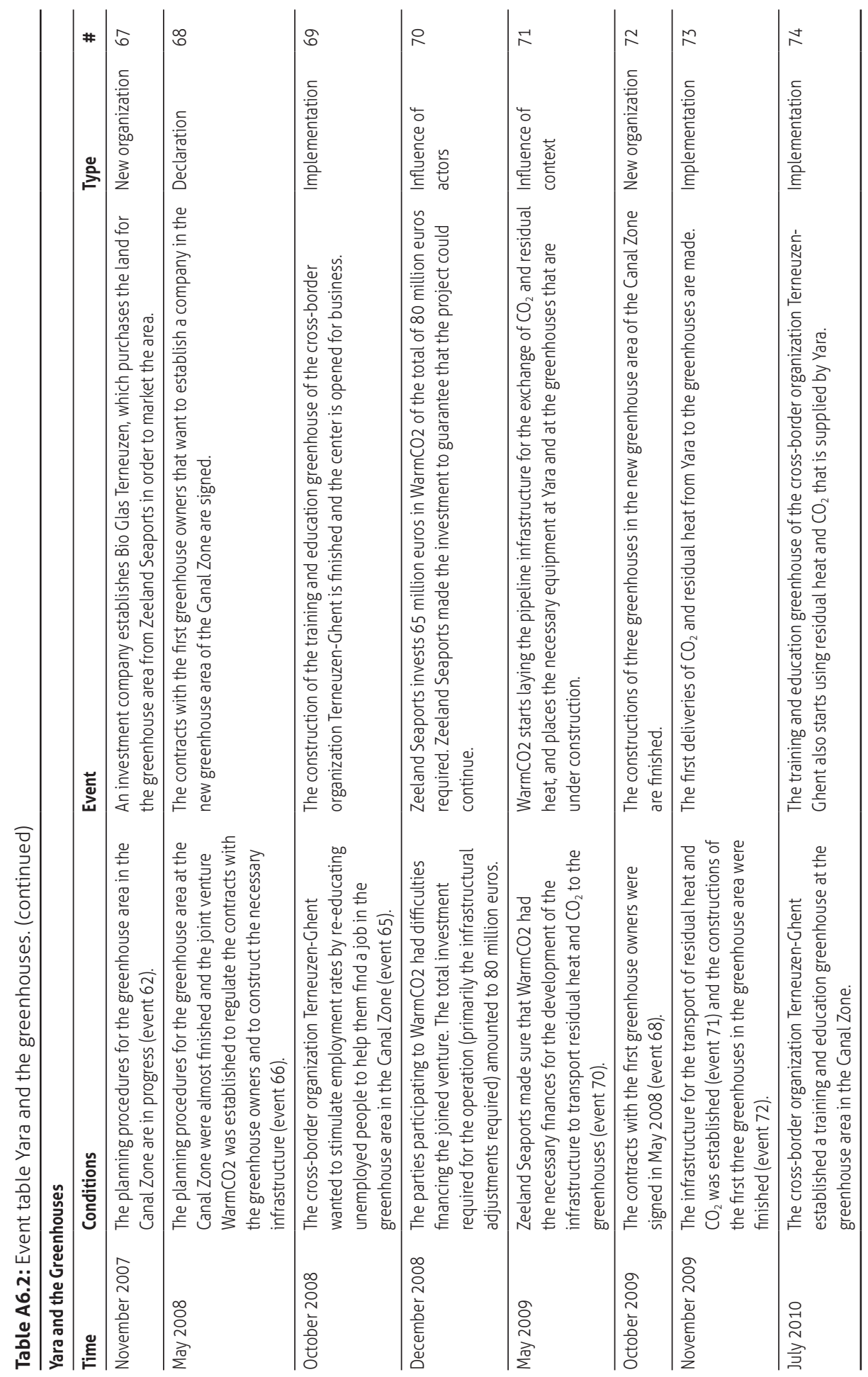




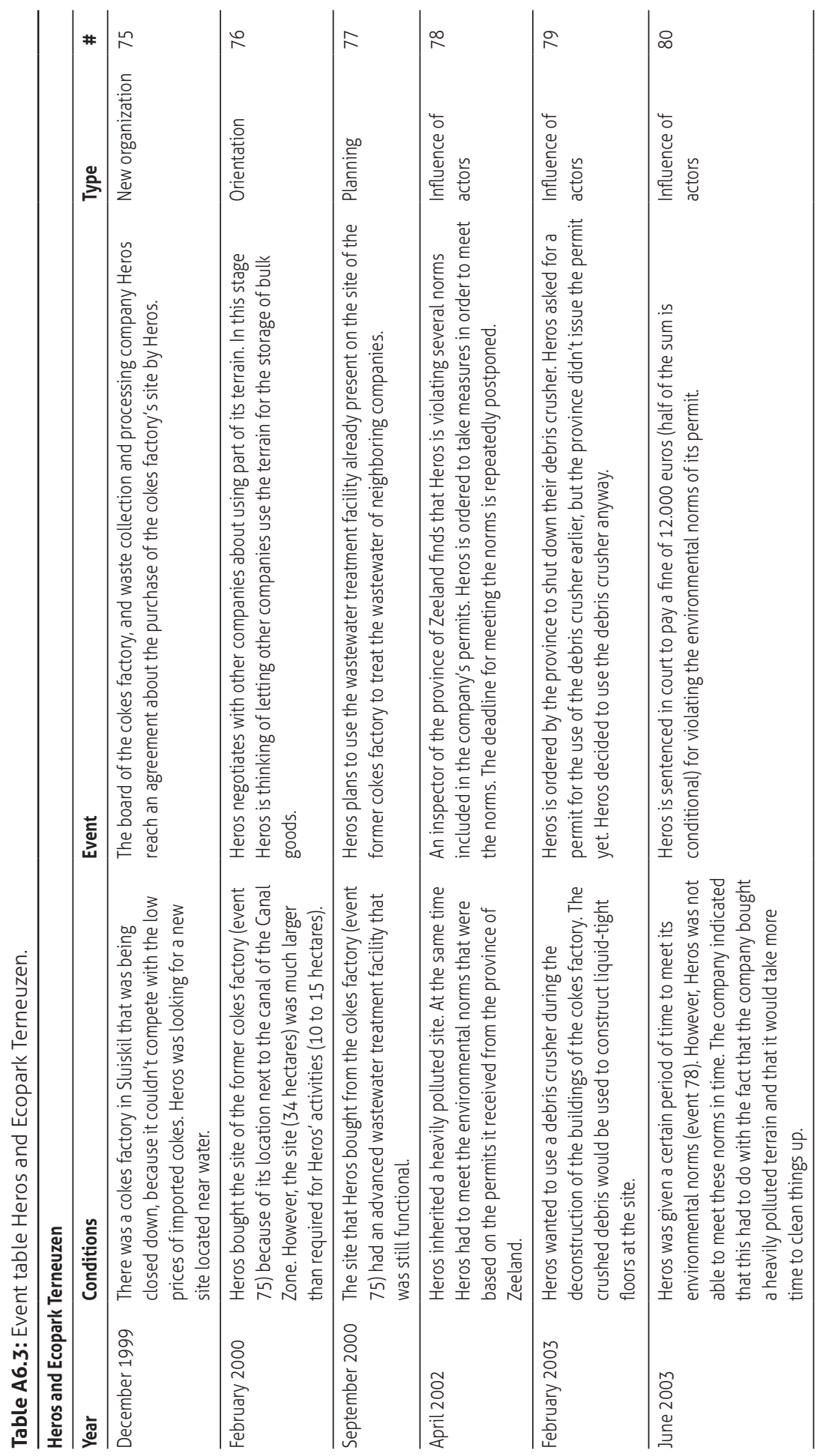




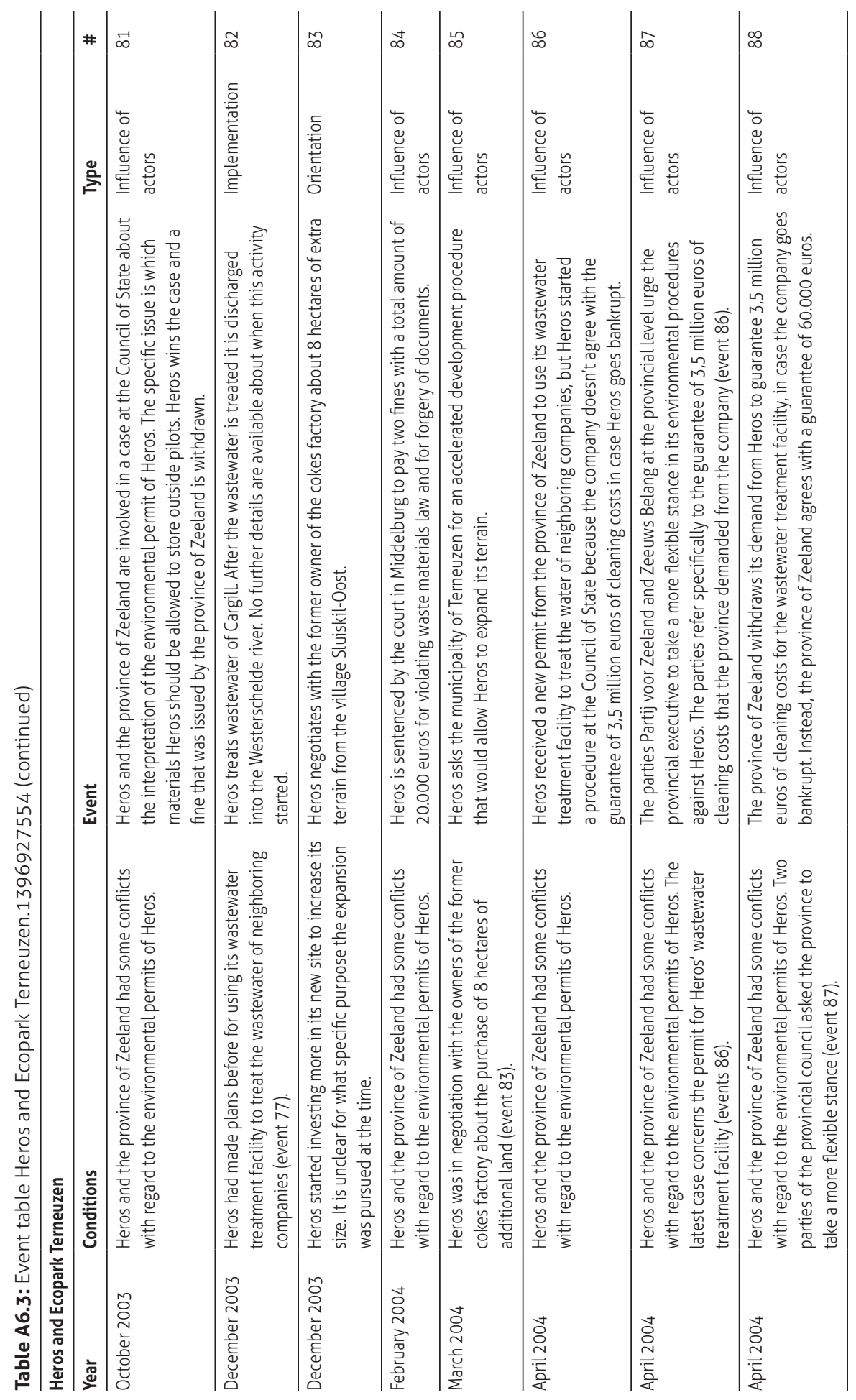




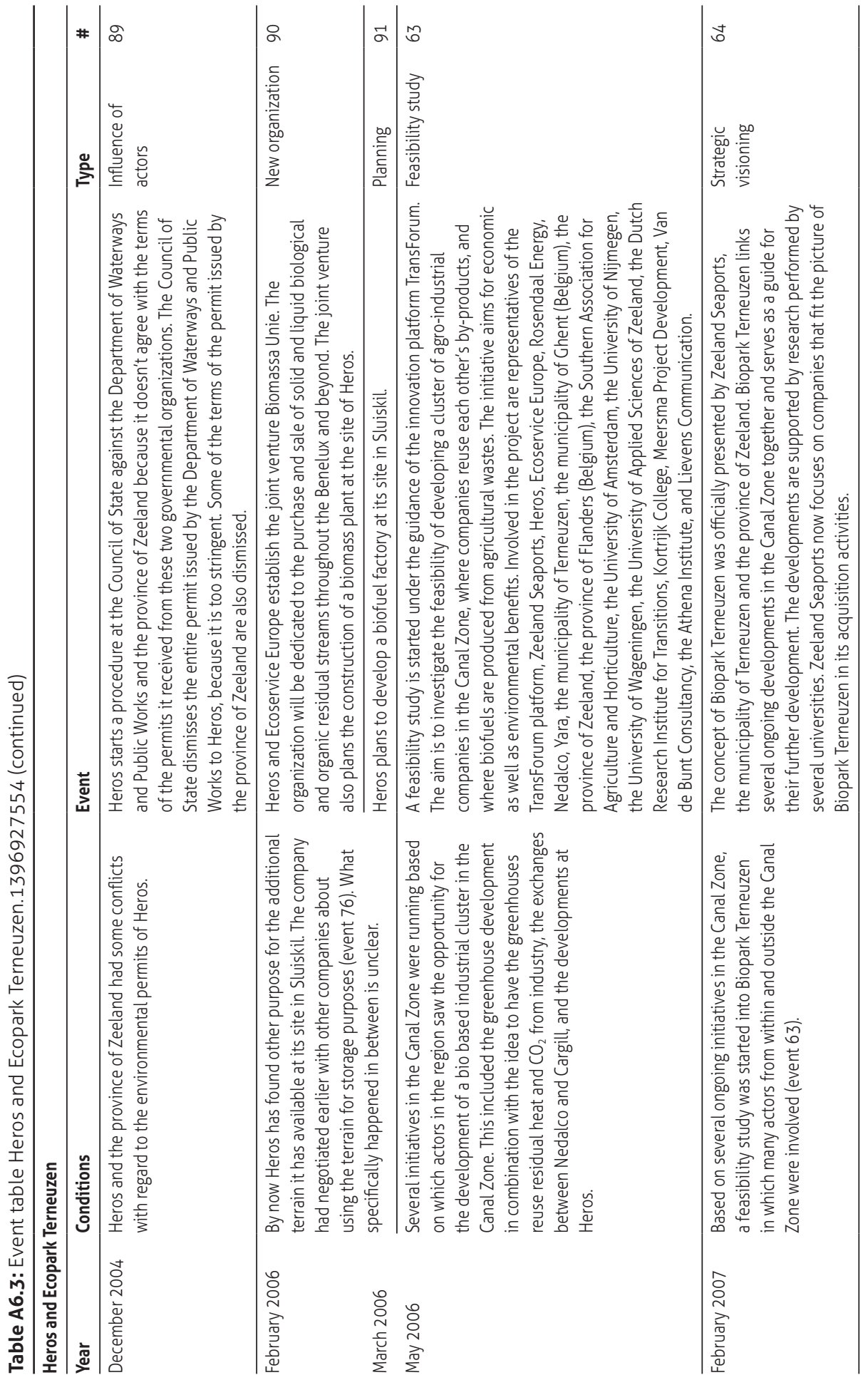




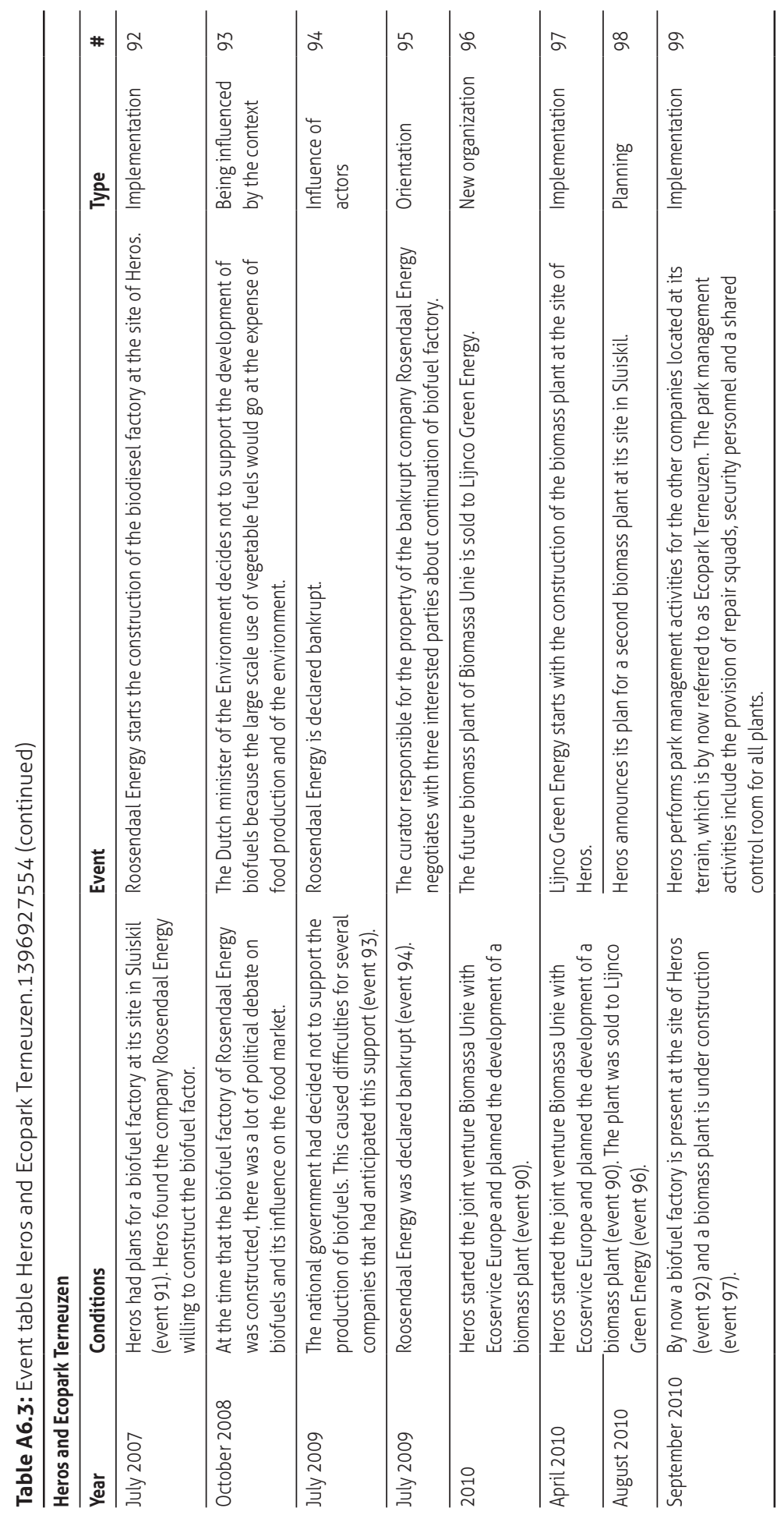




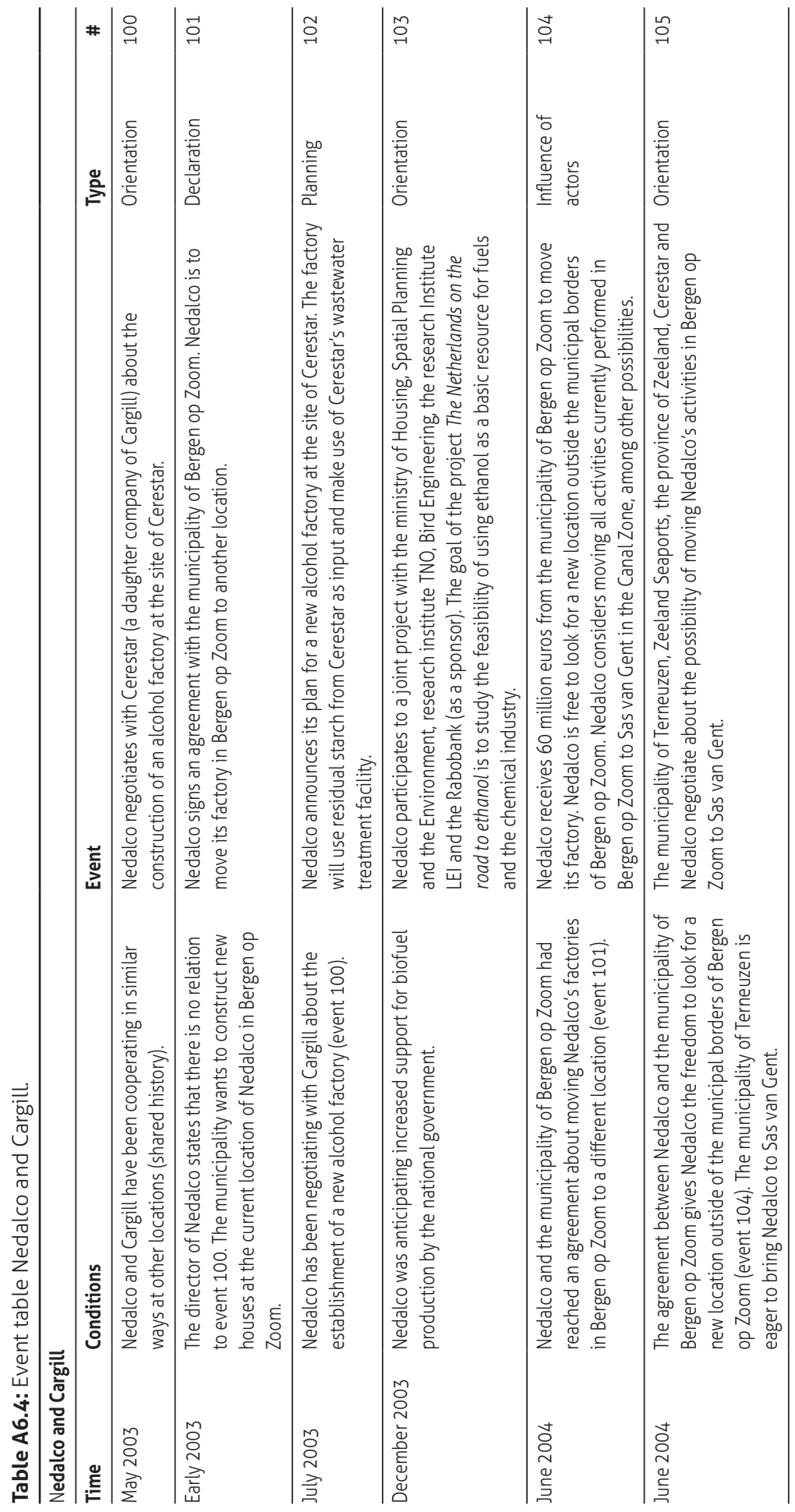




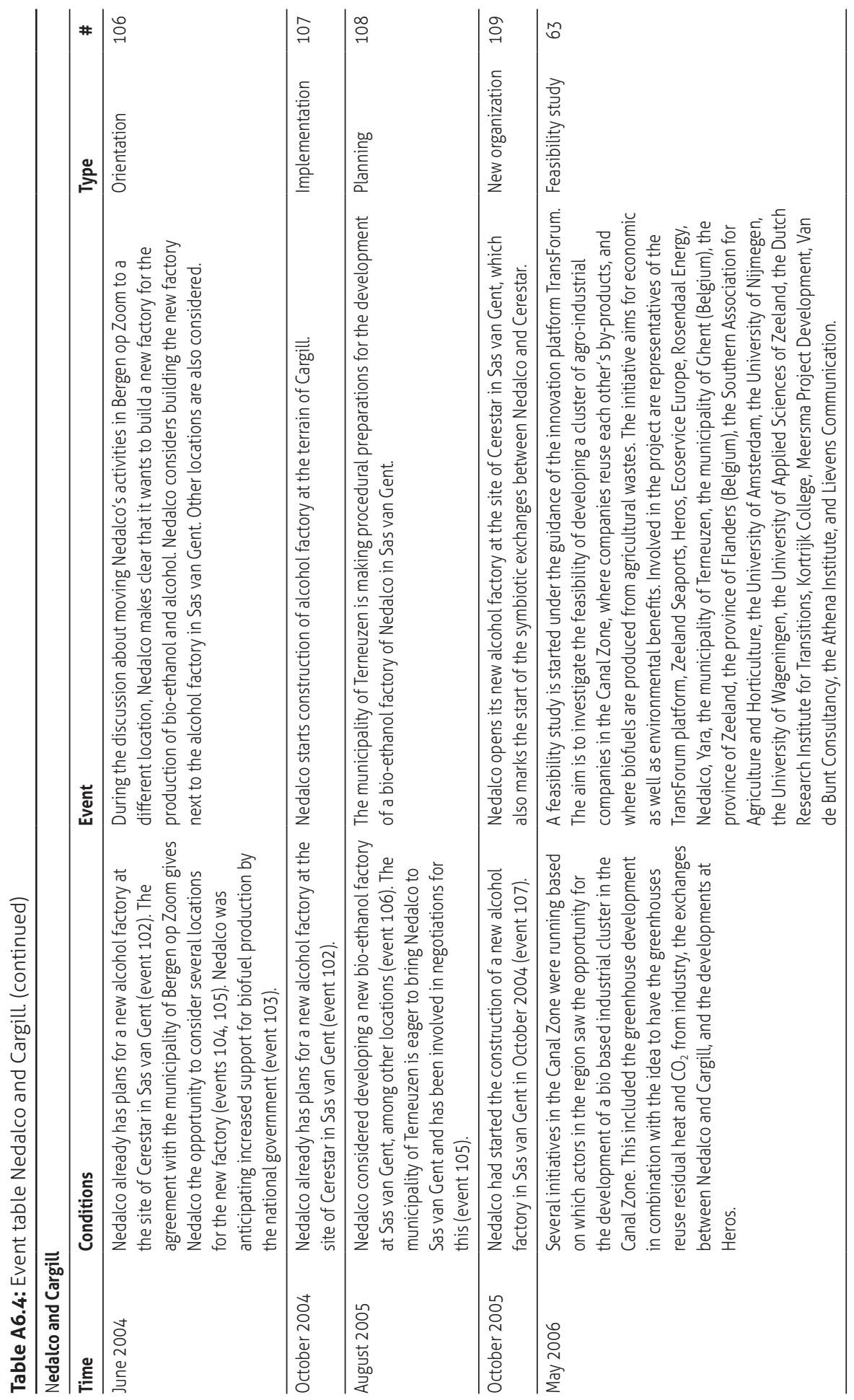




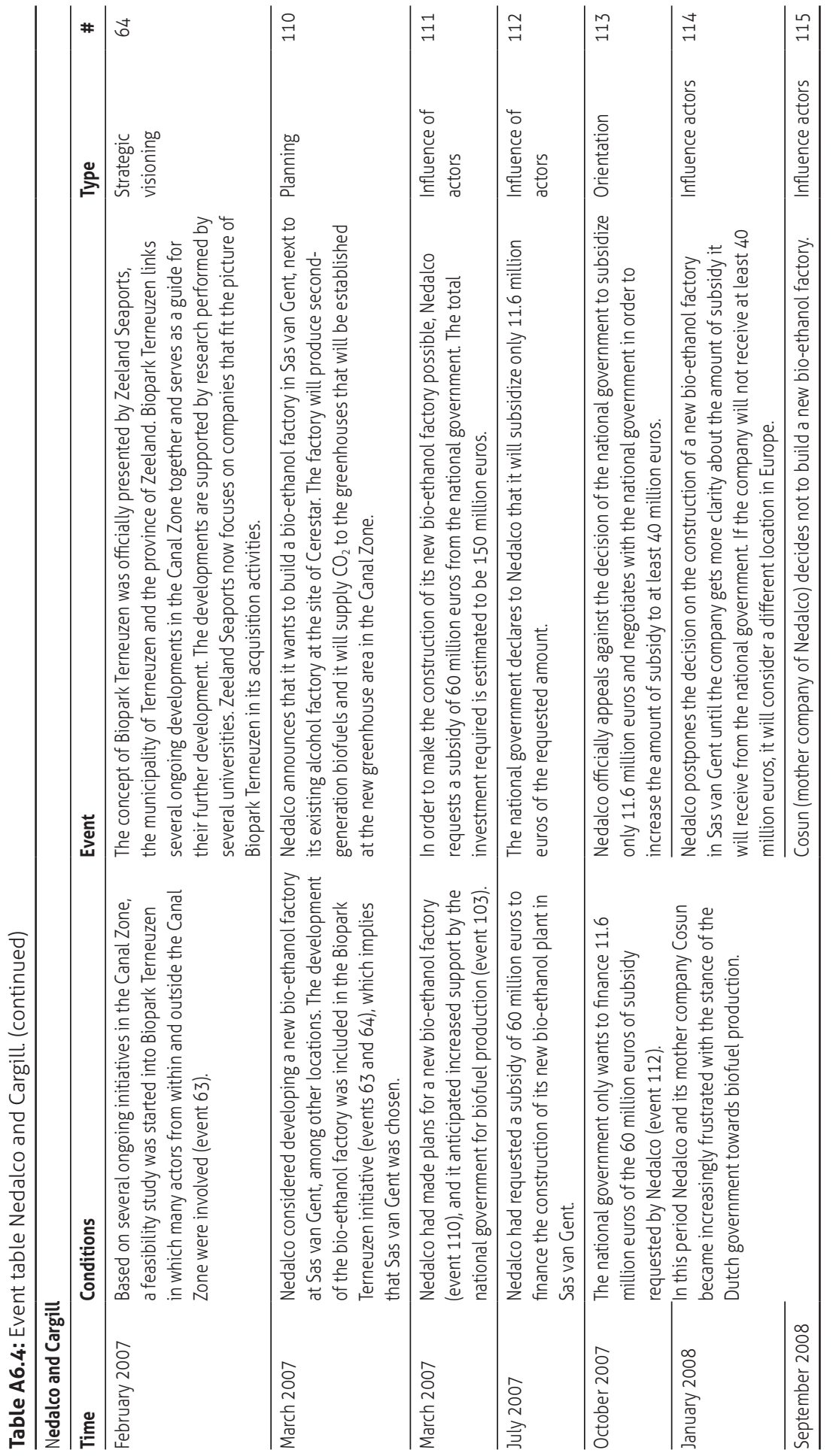




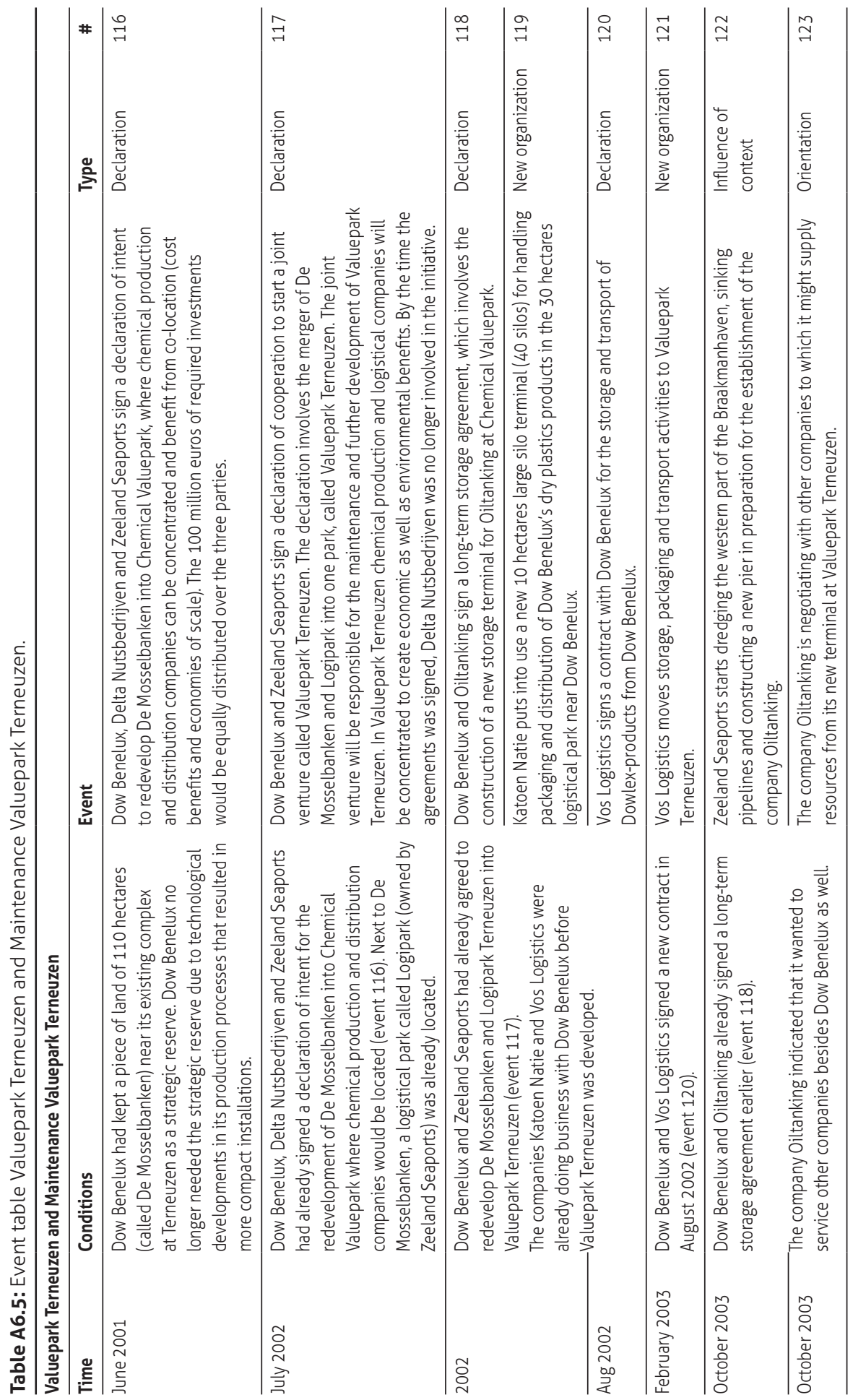




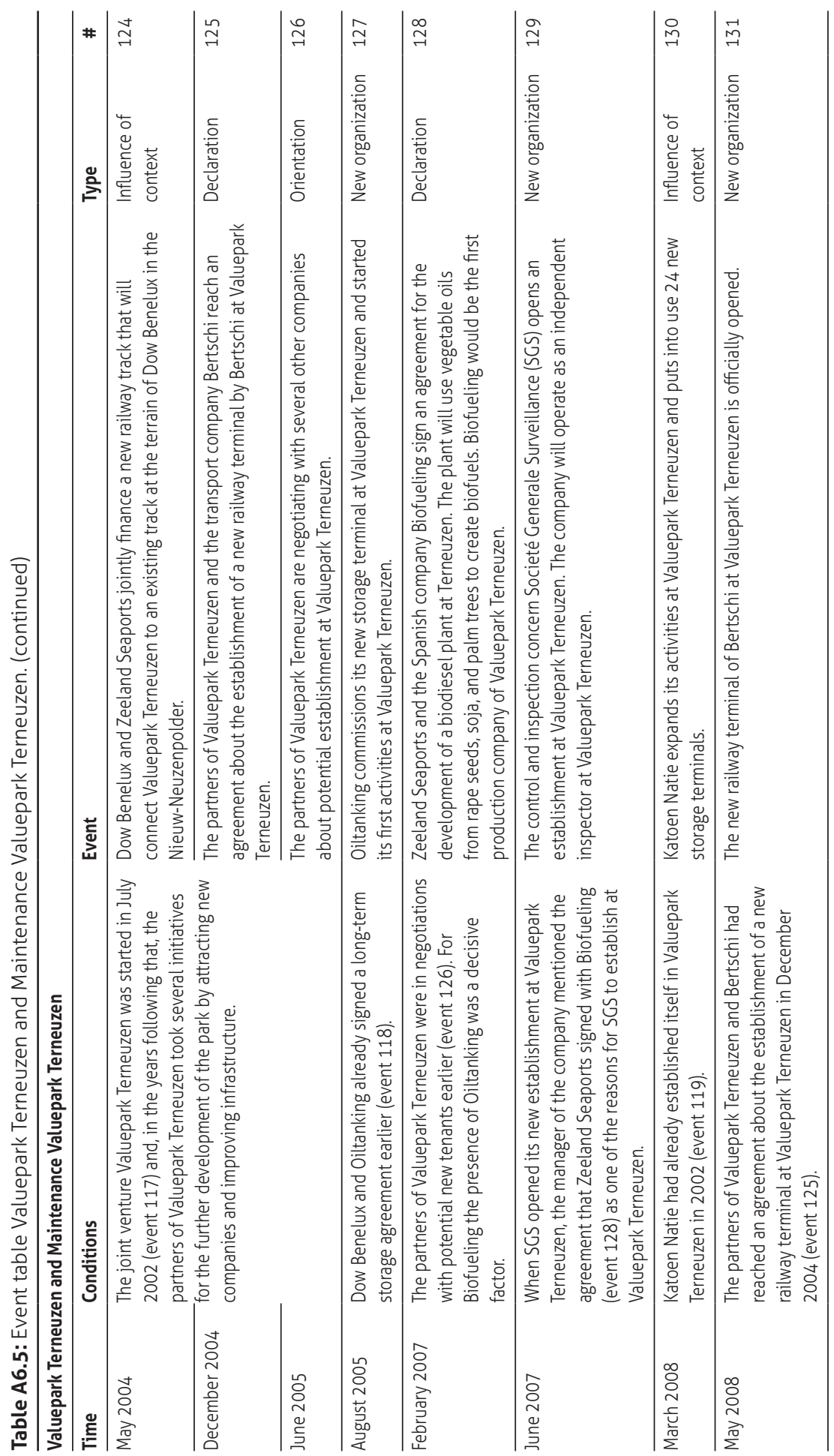




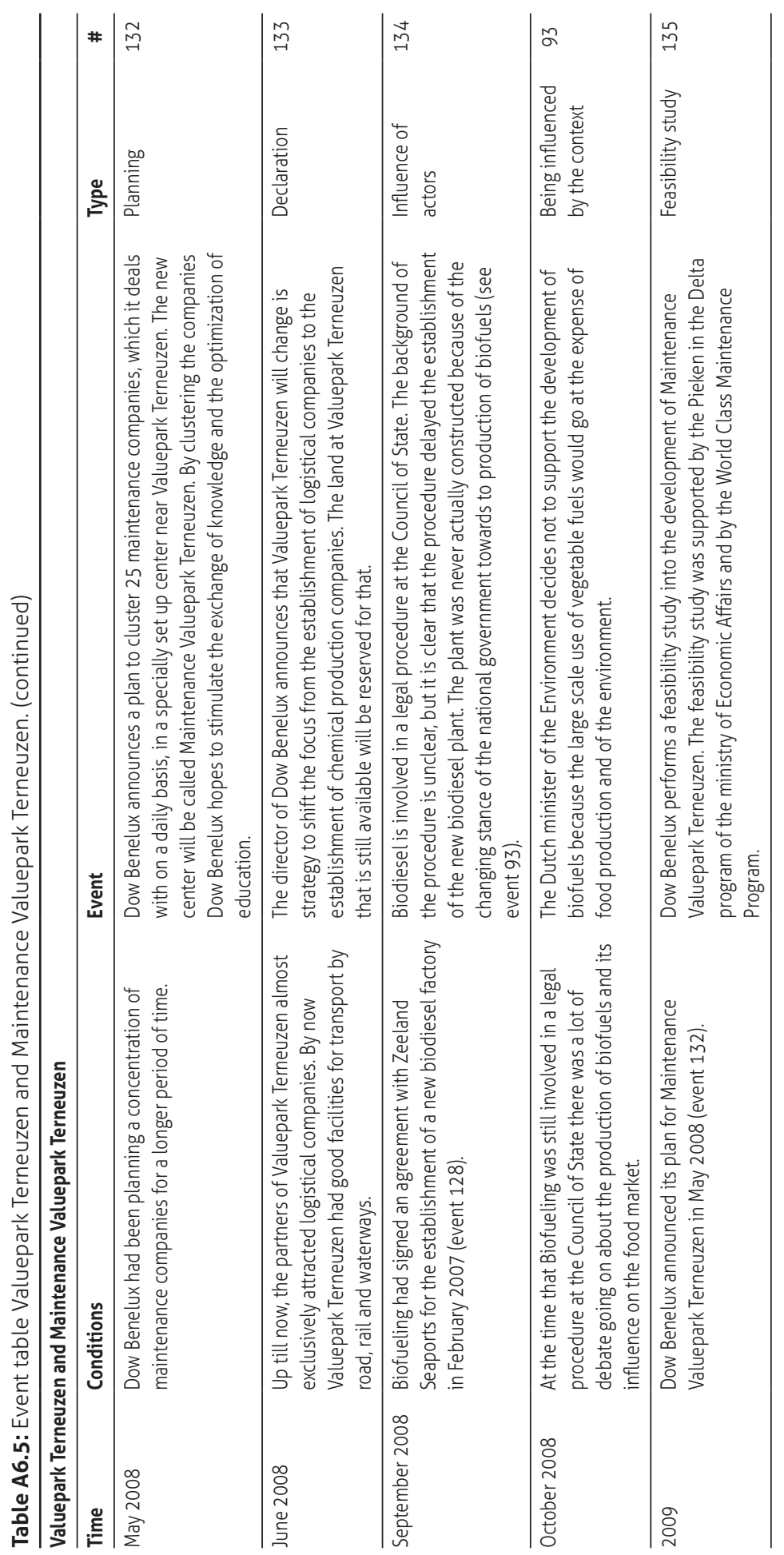




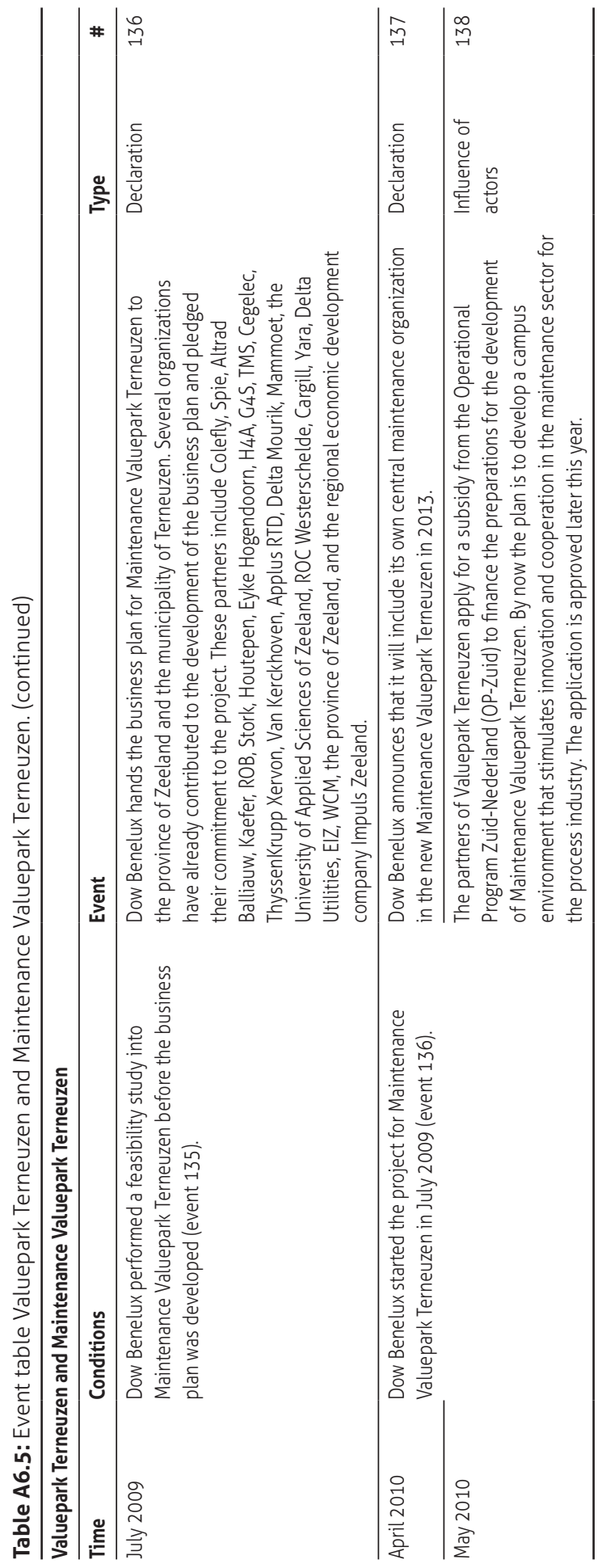






\section{ANNEX 2}

\section{SUPPLEMENTARY MATERIAL TO CHAPTER 7}



This annex includes tables with summary descriptions of the collaborative processes studied in the article on the emergence of collaborations (tables A7.1, A7.2, A7.4 and A7.5), as well as legends to the various network graphs that appear in the article (tables A7.3 and A7.6).

The tables with summary description describe the various subsequences in the investigated processes as they are visualized in the grey fields of the event graphs. These subsequences were identified in two steps:

1. A modularity algorithm was run to identify groups of events in the event graphs based on their patterns of linkages. These groups are referred to as modules.

2. A qualitative assessment was then made of each module to assess whether all events are grouped appropriately, and changes in the grouping of events in subsequences were made accordingly. Any discrepancies between the results of the modularity algorithm and the qualitative assessment were recorded.

The tables with summary descriptions report the modules that were originally identified by the modularity algorithm, as well as the discrepancies recorded during the qualitative assessment in separate columns. Thus the tables with summary descriptions have the following columns:

1. Subsequence: Reports the label of the subsequence

2. Summary description: Offers a summary of the subsequence in the form of a qualitative description.

3. Modules: Reports the module(s) identified by the modularity algorithm, which were used as a basis for the identification of the subsequences.

4. Discrepancies: Reports the discrepancies between the modules identified by the modularity algorithm and our qualitative interpretation of the subsequences. These discrepancies concern events that we decided to group differently based on our qualitative analysis of the event data.

The number of discrepancies found in the different tables are as follows:

- Table A7.1: 5 out of 84 events.

- Table A7.2: 22 out of 144 events

- Table A7.4: 15 out of 131 events

- Table A7.5: 9 out of 66 events Annex 2 
Table A7.1: Summary descriptions of building blocks of Biopark Terneuzen.

\begin{tabular}{|c|c|c|c|}
\hline Subsequence & Summary Description & Modules & Discrepancies \\
\hline \multirow[t]{2}{*}{$1-A$} & $\begin{array}{l}\text { A greenhouse area is planned in Zeeland around 1999. A } \\
\text { successful lobby takes place to make sure it will be located } \\
\text { in the Canal Zone. There are already plans to have the } \\
\text { fertilizer producer Yara supply the greenhouses with residual } \\
\text { heat and } \mathrm{CO}_{2} \text {. In } 2004 \text { it is finally decided to start the } \\
\text { development of the area. }\end{array}$ & $\begin{array}{l}1: 16,25,31,33,34 \\
36,42,46,49,51,67 \\
79,82,83,85,87 \\
101,123,124,133\end{array}$ & $\begin{array}{l}\text { Events added } \\
\text { based on } \\
\text { qualitative } \\
\text { interpretation: } \\
281\end{array}$ \\
\hline & $\begin{array}{l}\text { The official planning procedures for the development of the } \\
\text { greenhouse area start in 2004. A global development plan is } \\
\text { established in } 2006 \text {. }\end{array}$ & $\begin{array}{l}2: 135,151,153,167 \\
186,194,195,196 \\
211,212,233,235 \\
238,252,275\end{array}$ & \\
\hline $1-B$ & $\begin{array}{l}\text { Heros buys the terrain of a former cokes factory in Sluiskil in } \\
\text { 1999. At the long term, Heros develops plans for a biomass } \\
\text { plant (in a joint venture with Ecoservice Europe that is called } \\
\text { Biomassa Unie), as well as a biofuel factory (to be developed } \\
\text { by Roosendaal Energy) at its terrain. }\end{array}$ & $\begin{array}{l}\text { 1: } 17,24,29,54,99 \\
115,225,231\end{array}$ & \\
\hline $1-C$ & $\begin{array}{l}\text { Dow Benelux and Zeeland Seaports engaged in a joint } \\
\text { venture in } 2001 \text { to develop Valuepark Terneuzen, a complex } \\
\text { where chemical production companies and logistics } \\
\text { companies would be concentrated. In } 2007 \text { Zeeland } \\
\text { Seaports signs an agreement with the Spanish company } \\
\text { Biofueling for the establishment of a biofuel factory (event } \\
\text { 285). }\end{array}$ & $\begin{array}{l}1: 50,55,56,58,60 \\
72,106,129,160 \\
189,285\end{array}$ & \\
\hline $1-D$ & $\begin{array}{l}\text { Nedalco needs to relocate some of its facilities in Bergen } \\
\text { op Zoom (province of Noord-Brabant). Sas van Gent in } \\
\text { the Canal Zone is one of the locations considered for the } \\
\text { establishment of new facilities, because Nedalco is also } \\
\text { constructing an alcohol factory there (see subsequence E). } \\
\text { Nedalco develops plans to construct a bio-ethanol plant. }\end{array}$ & $\begin{array}{l}1: 70,89.112,117 \\
120,141,142,143 \\
145,155,157,159 \\
166,179,180,181 \\
197,262,265\end{array}$ & \\
\hline $1-E$ & $\begin{array}{l}\text { Nedalco engages in a cooperation with Cerestar (a daughter } \\
\text { of Cargill) in } 2003 \text { to develop an alcohol factory on the } \\
\text { terrain of Cerestar). The factory uses residual materials from } \\
\text { the plant of Cerestar. The alcohol factory is opened in } 2005 .\end{array}$ & $\begin{array}{l}1: 96,154,200,210 \\
236, \underline{246}, 251, \underline{254} \\
\underline{279}, \underline{281}, \underline{286}\end{array}$ & $\begin{array}{l}\text { Events removed } \\
\text { based on } \\
\text { qualitative } \\
\text { interpretation: } \\
246,254,279 \\
281,286\end{array}$ \\
\hline
\end{tabular}


Table A7.2: Summary descriptions of projects that are part of Biopark Terneuzen.

\begin{tabular}{|c|c|c|c|}
\hline Subsequence & Summary Description & Modules & Discrepancies \\
\hline $1-\mathrm{F}$ & $\begin{array}{l}\text { The TransForum feasibility study into Biopark Terneuzen } \\
\text { takes place in } 2006 \text { and 2007. Biopark Terneuzen is formally } \\
\text { opened in February 2007, while some of the studies are } \\
\text { still in progress. During the Biopark Terneuzen initiative } \\
\text { several knowledge institutes published research reports on } \\
\text { different aspects of the initiative, including the greenhouse } \\
\text { development, knowledge diffusion, the biomass plant, and } \\
\text { the Biopark Terneuzen cluster as a whole. The feasibility } \\
\text { study was officially closed in September 2007. The initiative } \\
\text { was promoted by the collaborating partners in several } \\
\text { ways. Biopark Terneuzen is also used as a basis for other } \\
\text { initiatives. This includes a cooperation between the province } \\
\text { of Zeeland and the province of Flanders in Belgium, where a } \\
\text { cluster similar to Biopark Terneuzen is in development. The } \\
\text { cooperation, called Biobase Europe, is an attempt to turn the } \\
\text { region as a whole into the top European region for biobased } \\
\text { economic development. }\end{array}$ & $\begin{array}{l}1: 246,251,254,255 \\
268,279,281,285 \\
286,302, \underline{303}, 307 \\
309,311,313,317 \\
319,324,330,331 \\
339,345,352,370 \\
373,409,421,435 \\
455,580\end{array}$ & $\begin{array}{l}\text { Events added } \\
\text { based on } \\
\text { qualitative } \\
\text { interpretation: } \\
346,357,558 \text {, } \\
613,639 \\
\text { Events removed } \\
\text { based on } \\
\text { qualitative } \\
\text { interpretation: } \\
251,281,285 \text {, } \\
303,317\end{array}$ \\
\hline $1-G$ & $\begin{array}{l}\text { Nedalco requested a subsidy for the development of its } \\
\text { biofuel factory in Sas van Gent, but the subsidy it receives } \\
\text { is too low according to the company. Also, in } 2008 \text { the } \\
\text { national government decides not to support biofuel } \\
\text { production because it would compete with food production. } \\
\text { These factors finally lead to the decision of Nedalco not to } \\
\text { construct the biofuel factory. }\end{array}$ & $\begin{array}{l}1: 265,287,291,306, \\
322,327,328,329 \\
337,346,357\end{array}$ & $\begin{array}{l}\text { Events added } \\
\text { based on } \\
\text { qualitative } \\
\text { interpretation: } \\
355,389 \\
\text { Events removed } \\
\text { based on } \\
\text { qualitative } \\
\text { interpretation: } \\
265,346,357\end{array}$ \\
\hline $1-\mathrm{H}$ & $\begin{array}{l}\text { A start is made with the construction of the biomass plant } \\
\text { at the terrain of Heros in 2010, by a company called Lijnco } \\
\text { Green Energy. Heros also announces that there are plans for } \\
\text { a second biomass plant. These plans are developed in } 2011 \\
\text { by an engineering and consultancy bureau called Taken. The } \\
\text { worked out plans were auctioned in } 2012 \text {. }\end{array}$ & $\begin{array}{l}1: 266,282,407, \underline{489} \\
521,542,558,567 \\
571,581,613,639 \\
\underline{657}, 681,687,707 \\
\underline{744}, 760\end{array}$ & $\begin{array}{l}\text { Events removed } \\
\text { based on } \\
\text { qualitative } \\
\text { interpretation: } \\
489,521558 \\
613,639,657 \\
744,760\end{array}$ \\
\hline $1-1$ & $\begin{array}{l}\text { The Biopark Terneuzen initiative also influenced the } \\
\text { acquisition strategy of Zeeland Seaports in the development } \\
\text { of an area called the Axelse Vlakte, where the port authority } \\
\text { tried to attract companies that would fit the Biopark } \\
\text { Terneuzen picture. Contracts are signed with two such } \\
\text { companies. }\end{array}$ & - & $\begin{array}{l}\text { This was not } \\
\text { identified as a } \\
\text { separate module } \\
\text { by the modularity } \\
\text { algorithm. but } \\
\text { we interpret } \\
\text { events } 301,308 \text {, } \\
568 \text { and } 569 \text { as } \\
\text { constituting a } \\
\text { separate project. }\end{array}$ \\
\hline
\end{tabular}


Table A7.2: Summary descriptions of projects that are part of Biopark Terneuzen. (continued)

\begin{tabular}{|c|c|c|c|}
\hline Subsequence & Summary Description & Modules & Discrepancies \\
\hline 1-] & $\begin{array}{l}\text { The construction of the biofuel plant of Roosendaal Energy } \\
\text { started operation in October 2008. In October } 2008 \text { the } \\
\text { national government also decides not to support biofuel } \\
\text { production in the Netherlands, because biofuels would } \\
\text { compete too much with food production. According to the } \\
\text { director of Roosendaal Energy, this decision by the national } \\
\text { government, combined with the consequences of the } \\
\text { economic crisis, are the cause of the financial problems that } \\
\text { the company ran into. In July } 2009 \text { Roosendaal Energy, the } \\
\text { company that developed biofuel factory on the terrain of } \\
\text { Heros, was declared bankrupt. The plant started operation } \\
\text { again in August 2012, after the plant was taken over by a } \\
\text { company called Electrawinds Bio Fuel. }\end{array}$ & $\begin{array}{l}1: 301,308,341,342 \\
355,361,368,384 \\
389,393,398,402 \\
433,443,462,478 \\
485,568, \underline{569}\end{array}$ & $\begin{array}{l}\text { Events added } \\
\text { based on } \\
\text { qualitative } \\
\text { interpretation: } \\
303,489,521 \\
657,744,760 \\
\text { Events removed } \\
\text { based on } \\
\text { qualitative } \\
\text { interpretation: } \\
301,308,355 \\
389,568,569\end{array}$ \\
\hline \multirow[t]{3}{*}{$1-K$} & $\begin{array}{l}\text { In } 2007 \text { the development of the greenhouse area is in full } \\
\text { progress. A company called Bioglas Terneuzen is made } \\
\text { responsible for acquisition activities, and Zeeland Seaports, } \\
\text { Yara, and Visser \& Smit Hanab engage in a joint venture } \\
\text { called WarmCO2 that is responsible for the construction } \\
\text { of the pipeline infrastructure for the distribution of } \mathrm{CO}_{2} \\
\text { and residual heat to the greenhouses. The organization } \\
\text { also governed the contracts. The development plan for the } \\
\text { greenhouse area is approved in } 2008 \text {. The municipalities } \\
\text { of Terneuzen and Ghent decide to also establish an } \\
\text { education greenhouse, where unemployed people would be } \\
\text { reeducated for work in the greenhouse sector. }\end{array}$ & $\begin{array}{l}\text { 1: 321, 323, 325, 332, } \\
338,348,349,363 \\
369,375,376,387 \\
394,395,396,404 \\
406,411,415,417 \\
423,492,518,712\end{array}$ & $\begin{array}{l}\text { Event added } \\
\text { based on } \\
\text { qualitative } \\
\text { interpretation: } \\
317\end{array}$ \\
\hline & $\begin{array}{l}\text { Both WarmCO2 and Bioglas Terneuzen engage in acquisition } \\
\text { activities, but it is repeatedly reported that developments } \\
\text { are slow. By October } 2009 \text { three greenhouses (in addition } \\
\text { to the education greenhouse) had been constructed and the } \\
\text { exchange of residual heat and } \mathrm{CO}_{2} \text { through the WarmCO2 } \\
\text { initiative was implemented in November 2009. In May } 2009 \\
\text { it was reported that the education greenhouse would also } \\
\text { make use of the infrastructure, and by December } 2010 \text { the } \\
\text { exchanges with this greenhouse were also realized. }\end{array}$ & $\begin{array}{l}2: 399,431,446,505, \\
508,511,520,527 \\
536,546,561,564 \\
572,576,584,593 \\
594,610,615,618 \\
629,640,641,654 \\
686,710,749\end{array}$ & \\
\hline & $\begin{array}{l}\text { In } 2009 \text { contracts with the first greenhouse owners are } \\
\text { signed. Meanwhile WarmCO2 starts developing the pipeline } \\
\text { infrastructure for the exchange of } \mathrm{CO}_{2} \text { and residual heat, and } \\
\text { the infrastructure is finished in October } 2009 \text {. }\end{array}$ & $\begin{array}{l}3: 400,442,445,448 \\
453,460,464,477 \\
479,488,490,491 \\
493,500,501\end{array}$ & \\
\hline
\end{tabular}


Table A7.3: List of actors and issues for Biopark Terneuzen.

\begin{tabular}{|c|c|c|}
\hline Label & Name & Type \\
\hline A1 & ABN Amro & Bank \\
\hline$A 2$ & ACZC & Company \\
\hline$A 3$ & Alpha Calcit & Company \\
\hline $\mathrm{A} 4$ & Archeo Media & Consultant \\
\hline A5 & Athena Institute & Knowledge Institute \\
\hline A6 & AVR & Company (utilities) \\
\hline A7 & Biobase Europe & Foundation \\
\hline A8 & Biofueling & Company \\
\hline A9 & BioGlas Terneuzen & Company \\
\hline A10 & Biomassa Unie & Company \\
\hline A11 & Biopark Terneuzen & Foundation \\
\hline A12 & Ghent Bio-Economy Valley & $\begin{array}{l}\text { Public-Private } \\
\text { Partnership }\end{array}$ \\
\hline A13 & Bird Engineering & Consultant \\
\hline A14 & Blakowi Groene Kracht & Company \\
\hline A15 & Blonk Milieuadvies & Consultant \\
\hline A16 & Brabantse Ontwikkelingsmaatschappij & Regional Development \\
\hline A17 & Bureau Bijzondere Projecten & Company \\
\hline A18 & Cargill & Company \\
\hline A19 & Cerestar & Company \\
\hline A20 & Chamber of Commerce & Chamber of Commerce \\
\hline $\mathrm{A} 21$ & Circle of Employers & Business Association \\
\hline $\mathrm{A} 22$ & Committee of Environmental Impact Assessments & Independent Committee \\
\hline $\mathrm{A} 23$ & Cosun & Company \\
\hline $\mathrm{A} 24$ & Council of ministers & National government \\
\hline A 25 & CSM & Company \\
\hline A26 & Curator & Curator \\
\hline $\mathrm{A} 27$ & Delta & Company (utilities) \\
\hline $\mathrm{A} 28$ & Dethon & Company \\
\hline A29 & De Westerschelde & Company \\
\hline A30 & Dow & Company \\
\hline A31 & Dutch Research Institute for Transitions & Knowledge Institute \\
\hline A32 & Ecorys & Consultant \\
\hline A33 & Ecoservice Europe & Company \\
\hline A34 & Education Greenhouse & Company (public) \\
\hline A35 & Electrawinds Biofuel & Company \\
\hline A36 & Energy@Work & Company \\
\hline A37 & Environmental Federations of the Netherlands & Interest Organization \\
\hline A38 & Esbro & Company \\
\hline
\end{tabular}


Table A7.3: List of actors and issues for Biopark Terneuzen. (continued)

\begin{tabular}{|c|c|c|}
\hline Label & Name & Type \\
\hline A39 & ESV & Company \\
\hline $\mathrm{A} 40$ & Fortis Lease & Bank \\
\hline A41 & Gebroeders Van Duijn & Company \\
\hline A42 & Glastuinbouw Terneuzen & Company \\
\hline A43 & Goes on Green & Company \\
\hline A44 & Grensoverschrijdend Lichaam Terneuzen-Ghent & Municipal Cooperation \\
\hline A45 & Greenpartners & Company \\
\hline A46 & Groen College Goes & Knowledge Institute \\
\hline A47 & Grontmij & Consultant \\
\hline A48 & Gulf Oil & Company \\
\hline A49 & Heidemij & Company \\
\hline A50 & Heros & Company \\
\hline A51 & University of Applied Sciences Zeeland & Knowledge Institute \\
\hline A52 & Katoen Natie & Company \\
\hline $\mathrm{A} 53$ & Stichting Houdt Koegerspolder Leefbaar & Interest Organization \\
\hline A54 & Kortrijk College & Knowledge Institute \\
\hline A55 & LEl & Knowledge Institute \\
\hline A56 & Lievens Communicatie & Consultant \\
\hline A57 & Lijnco Green Energy & Company \\
\hline A58 & Organization for Agriculture and Horticulture (LTO) & Interest organization \\
\hline A59 & Meersma Project Development & Company \\
\hline A60 & Metrum & Consultant \\
\hline A61 & Ministry of Agriculture & Ministry \\
\hline A62 & Ministry of Economic Affairs & Ministry \\
\hline A63 & Ministry of Finance & Ministry \\
\hline A64 & Ministry of Houing, Spatial Development, and the Environment & Ministry \\
\hline A65 & Ministry of Social Affairs & Ministry \\
\hline A66 & Ministry of Transport and Public Works & Ministry \\
\hline A67 & Municipality of Assenede & Municipal government \\
\hline A68 & Municipality of Bergen op Zoom & Municipal government \\
\hline A69 & Municipality of Borsele & Municipal government \\
\hline A70 & Municipality of Breda & Municipal government \\
\hline A71 & Municipality of Ghent & Municipal government \\
\hline A72 & Municipality of Goes & Municipal government \\
\hline A73 & Municipality of Sas van Gent & Municipal government \\
\hline A74 & Municipality of Terneuzen & Municipal government \\
\hline A75 & Municipal Works Rotterdam & Engineering Bureau \\
\hline A76 & Municipality of Zelzate & Municipal government \\
\hline A77 & National Government (not further specified) & National government \\
\hline
\end{tabular}


Table A7.3: List of actors and issues for Biopark Terneuzen. (continued)

\begin{tabular}{|c|c|c|}
\hline Label & Name & Type \\
\hline A78 & National Parliament & National Parliament \\
\hline A79 & Nedalco & Company \\
\hline A80 & Novem & Governmental agency \\
\hline A81 & Oiltanking & Company \\
\hline$\overline{A 82}$ & Platform Bio Ethanol & Interest Organization \\
\hline$\overline{A 83}$ & Province of Noord-Brabant & Provincial government \\
\hline A84 & Province of Flanders & Provincial government \\
\hline A85 & Province of Zeeland & Provincial government \\
\hline A86 & PvdA(province) & Political party \\
\hline A87 & Rabobank & Bank \\
\hline A88 & Residents of Nieuwdorp & Civilians \\
\hline A89 & Rewin & Regional Development \\
\hline$\overline{A 90}$ & ROC De Westerschelde & Knowledge Institute \\
\hline$\overline{A 91}$ & Roos and De Rijck & Company \\
\hline A92 & Rosendaal Energy & Company \\
\hline A93 & RPA Zeeland & Regional Development \\
\hline A94 & SenterNovem & Governmental agency \\
\hline A95 & Taken & Company \\
\hline A96 & TNO & Knowledge Institute \\
\hline A97 & Tomaholic & Company \\
\hline A98 & Topsy Baits & Company \\
\hline A99 & TransForum & Innovation Platform \\
\hline $\mathrm{A} 100$ & Umbrella organization for greenhouses & Umbrella organization \\
\hline A101 & University of Amsterdan & Knowledge Institute \\
\hline A102 & University of Delft & Knowledge Institute \\
\hline $\mathrm{A} 103$ & University of Eindhoven & Knowledge Institute \\
\hline$\overline{\mathrm{A} 104}$ & University of Ghent & Knowledge Institute \\
\hline A105 & University of Nijmegen & Knowledge Institute \\
\hline A106 & University of Wageningen & Knowledge Institute \\
\hline $\bar{A} 107$ & Van de Bunt Consultancy & Consultant \\
\hline A108 & Village Council Sas van Gent & Interest Organization \\
\hline A109 & Village Council Sluiskil & Interest Organization \\
\hline$\overline{A 110}$ & Visser \& Smit Hanab & Company \\
\hline $\mathrm{A} 111$ & VNBI & Interest Organization \\
\hline A112 & Vos Logistics & Company \\
\hline $\bar{A} 113$ & Vrom Inspectie & Governmental agency \\
\hline $\bar{A} 114$ & WarmCO2 & Company (PPP) \\
\hline A115 & Warmte Netwerk & Interest Organization \\
\hline $\mathrm{A} 116$ & Water Authority & Water authority \\
\hline
\end{tabular}


Table A7.3: List of actors and issues for Biopark Terneuzen. (continued)

\begin{tabular}{|c|c|c|}
\hline Label & Name & Type \\
\hline A117 & Witteveen + Bos & Consultant \\
\hline A118 & Yara & Company \\
\hline A119 & Yard Capital & Company \\
\hline A120 & Southern Organization for Agriculture and Horticulture (ZLTO) & Interest Organization \\
\hline A121 & Environmental Federation of Zeeland & Interest Organization \\
\hline A122 & Zeeland Seaports & Port authority \\
\hline 11 & Acquisition & - \\
\hline 12 & Agriculture & - \\
\hline 13 & Algae & - \\
\hline 14 & Aquaculture & - \\
\hline 15 & Biobased Economy & - \\
\hline 16 & Biobased products & - \\
\hline 17 & Biobase Europe & - \\
\hline 18 & Bio-energy & - \\
\hline 19 & Biofuels & - \\
\hline 110 & Biogas & - \\
\hline 111 & Biomass & - \\
\hline 112 & Biopark Terneuzen & - \\
\hline 113 & Bioplastics & - \\
\hline 114 & Chemical Industry & - \\
\hline 115 & Closing Loops & - \\
\hline 116 & Clustering & - \\
\hline 117 & $\mathrm{CO} 2$ & - \\
\hline 118 & Cogeneration & - \\
\hline 19 & Communication & - \\
\hline 120 & Competition food and biofuels & - \\
\hline 121 & Cradle-2-Cradle & - \\
\hline 122 & Cross-border Cooperation & - \\
\hline 23 & Cross-port Cooperation & - \\
\hline 124 & CSR & - \\
\hline 125 & Demography & - \\
\hline 126 & Economic Crisis & - \\
\hline 127 & Economy & - \\
\hline 128 & Education & - \\
\hline 129 & Employment & - \\
\hline 130 & Energy & - \\
\hline 131 & Environment & - \\
\hline 132 & European Support & - \\
\hline 133 & Environmental Regulations & - \\
\hline
\end{tabular}


Table A7.3: List of actors and issues for Biopark Terneuzen. (continued)

\begin{tabular}{|c|c|c|}
\hline Label & Name & Type \\
\hline 134 & Expansion & - \\
\hline 135 & Facilitation & - \\
\hline 136 & Fats & - \\
\hline 137 & Food & - \\
\hline 138 & Fossil & - \\
\hline 139 & Greenhouses & - \\
\hline 140 & Heat & - \\
\hline 141 & Housing & - \\
\hline 142 & Infrastructure & - \\
\hline 443 & Knowledge \& Innovation & - \\
\hline 144 & Livability & - \\
\hline 45 & Livestock & - \\
\hline 146 & Logistics & - \\
\hline 147 & Manure & - \\
\hline 148 & National Support & - \\
\hline 149 & Nature & - \\
\hline 150 & Nuisance & - \\
\hline 151 & Organizational Structure & - \\
\hline 152 & Park Management & - \\
\hline 153 & Permits & - \\
\hline 154 & Redevelopment & - \\
\hline 155 & Regional Cooperation & - \\
\hline 156 & Regional Economy & - \\
\hline 157 & Regional Support & - \\
\hline 158 & Regulations & - \\
\hline 159 & Relocation & - \\
\hline 160 & Renewables & - \\
\hline 161 & Reuse & - \\
\hline 162 & Safety & - \\
\hline 163 & Seaweed & - \\
\hline 164 & Second generation biofuels & - \\
\hline 165 & Smart Links & - \\
\hline 166 & Steam & - \\
\hline 167 & Sustainability & - \\
\hline 168 & Sustainable Industrial Parks & - \\
\hline 169 & Take-over & - \\
\hline 170 & Third Generation & - \\
\hline 171 & Triple Helix & - \\
\hline 172 & Use of Space & - \\
\hline
\end{tabular}


Table A7.3: List of actors and issues for Biopark Terneuzen. (continued)

\begin{tabular}{|c|c|c|}
\hline Label & Name & Type \\
\hline 173 & Utility Sharing & - \\
\hline 174 & Valuepark Terneuzen & - \\
\hline 175 & Wastes & - \\
\hline 176 & Water & - \\
\hline 177 & Wood & - \\
\hline
\end{tabular}

Table A7.4: Summary descriptions of building blocks of Sustainable Connections.

\begin{tabular}{|c|c|c|c|}
\hline $\begin{array}{l}\text { Building } \\
\text { block }\end{array}$ & Summary Description & Modules & Discrepancies \\
\hline \multirow[t]{3}{*}{$2-A$} & $\begin{array}{l}\text { As a solution to a poultry manure surplus in the Netherlands, } \\
\text { a foundation is established by poultry farmers in } 1998 \text { that } \\
\text { is to develop a plant that will incinerate manure to generate } \\
\text { energy. The foundation is called Duurzame Energieproductie } \\
\text { Pluimveehouderij (DEP). Moerdijk is chosen as the location } \\
\text { for the plant. Environmental groups litigate against the } \\
\text { environmental permits of the plant, based on the argument } \\
\text { that nothing is done with residual heat, or with the mineral- } \\
\text { rich ashes that remain after the incineration process. DEP } \\
\text { engages in contracts with companies in the phosphor } \\
\text { industry to ensure the reuse of ashes. The organization } \\
\text { also explores the possibility of supplying residual heat to a } \\
\text { greenhouse area that was being planned at Moerdijk (see } \\
\text { building block 2-C). }\end{array}$ & $\begin{array}{l}1: 1,19,31,33,52,61 \\
62,69,80,83,89,91 \\
94,95,96,97,98,103\end{array}$ & $\begin{array}{l}\text { Events added } \\
\text { based on } \\
\text { qualitative } \\
\text { interpretation: } \\
225,242,244\end{array}$ \\
\hline & $\begin{array}{l}\text { Between } 2002 \text { and } 2006 \text { DEP made several efforts to find } \\
\text { financial partners for the development of the manure } \\
\text { incineration plant. The foundation also engaged in contracts } \\
\text { with poultry farmers for the supply of manure. By } 2006 \\
\text { DEP had found its financial partners, and had successfully } \\
\text { contracted enough poultry farmers. The construction of the } \\
\text { plant started in February 2006. In } 2006 \text { DEP is turned into a } \\
\text { cooperation. }\end{array}$ & $\begin{array}{l}2: 104,148,162,167 \\
170,172,173,178 \\
185,186,190,191 \\
196,198,199,203 \\
209,211,216,218\end{array}$ & \\
\hline & $\begin{array}{l}\text { In the years before the construction of the manure } \\
\text { incineration plant began, DEP had to make several efforts } \\
\text { to ensure sufficient supply of manure by contracting } \\
\text { poultry farmers. DEP was aided in this effort by several } \\
\text { other organizations. The construction of the plant had to be } \\
\text { postponed several times. }\end{array}$ & $\begin{array}{l}3: 129,130,131,133 \\
134,142,143\end{array}$ & \\
\hline $2-B$ & $\begin{array}{l}\text { In } 1990 \text { plans are announced for the construction of a waste } \\
\text { incineration plant at Moerdijk. The incineration plant was } \\
\text { to be combined with a co-generation plant that would be } \\
\text { constructed next to it. Both plants are finished by } 1997 \text { and } \\
\text { the exchanges between the plants are implemented. }\end{array}$ & $1: 2,5,6,7,8,9,36$ & \\
\hline
\end{tabular}


Table A7.4: Summary descriptions of building blocks of Sustainable Connections. (continued)

\begin{tabular}{|c|c|c|c|}
\hline $\begin{array}{l}\text { Building } \\
\text { block }\end{array}$ & Summary Description & Modules & Discrepancies \\
\hline \multirow[t]{2}{*}{$2-C$} & $\begin{array}{l}\text { In } 1991 \text { the national government and the province of } \\
\text { Noord-Brabant were talking about the development of } \\
\text { a greenhouse area in Noord-Brabant in order to reduce } \\
\text { the pressure on the Westland area. In } 1999 \text { the province } \\
\text { announced that one of the possible locations for the } \\
\text { greenhouse development would be Moerdijk. In } 1997 \text { and } \\
1998 \text { the province of Noord-Brabant also develops a plan for } \\
\text { a second industrial park at Moerdijk. The two plans quickly } \\
\text { become intertwined, and the idea is conceived to develop } \\
\text { the industrial park and the greenhouse area at the same } \\
\text { location. One of the motivations for this development is } \\
\text { that the greenhouses would be able to use residual heat } \\
\text { and } \mathrm{CO}_{2} \text { from companies at the new industrial park. A lot of } \\
\text { debate takes place on the size of both developments, and } \\
\text { locally there is a lot of resistance against the plans (primarily } \\
\text { against the industrial park). }\end{array}$ & $\begin{array}{l}1: 3,12,18,21,22,25 \\
27,29,38,42,43,44 \\
45,48,50,51,53,54 \\
56,59,71\end{array}$ & \\
\hline & $\begin{array}{l}\text { In } 2000 \text { discussions on the development of a second } \\
\text { industrial park at Moerdijk and the greenhouse area are still } \\
\text { in progress. The discussions largely revolve on the size of } \\
\text { the area that is reserved for both plans. A greenhouse area } \\
\text { near Moerdijk remains one of the preferred locations of the } \\
\text { national government and the province of Noord-Brabant, } \\
\text { because of the possibility to reuse heat emitted by Shell, the } \\
\text { waste incineration plant at Moerdijk (see subsequence 2-B), } \\
\text { and the manure incineration plant (see subsequence 2-A). }\end{array}$ & $\begin{array}{l}2: 57,60,63,73,77 \\
78,79,82\end{array}$ & \\
\hline $2-D$ & $\begin{array}{l}\text { The company Bewa, which specializes in the reuse of food } \\
\text { residuals, is established at Moerdijk in 1992. In } 2005 \text { the } \\
\text { company starts developing a Biogas plant (the plant also } \\
\text { uses food residuals as feedstock), after several years of } \\
\text { permit procedures. The plant starts operation in } 2006 \text {. }\end{array}$ & $\begin{array}{l}1: 4,168,201,228, \\
\underline{266}, \underline{284}, \underline{295}, \underline{297} \\
\underline{299}, \underline{308}\end{array}$ & $\begin{array}{l}\text { Events removed } \\
\text { based on } \\
\text { qualitative } \\
\text { interpretation: } \\
266,284,295 \text {, } \\
297,299,308\end{array}$ \\
\hline $2-E$ & $\begin{array}{l}\text { In } 1997 \text { a cooperation between public and private parties } \\
\text { at the industrial park of Moerdijk is started to coordinate } \\
\text { environmental and safety issues. The group is called Stuur- } \\
\text { en Coördinatiegroep Milieu en Veiligheid Moerdijk (SCMVM). } \\
\text { Two years later a report on the environmental burdens } \\
\text { caused at the industrial park of Moerdijk is published by the } \\
\text { research institute TNO, and it is decided that the SCMVM } \\
\text { will start monitoring the environmental performance of } \\
\text { the industrial park. In } 2006 \text { the group decides to develop a } \\
\text { master plan for the industrial park, called Duurzaam Haven- } \\
\text { en Industrieterrein Moerdijk (DHM). The port authority, the } \\
\text { municipality of Moerdijk, the province of Noord-Brabant, } \\
\text { the department of waterways and public works Zuid- } \\
\text { Holland, and the water authority Brabantse Delta start the } \\
\text { cooperation DHM, named after the master plan on which the } \\
\text { cooperation is based, in } 2007 \text {. }\end{array}$ & $\begin{array}{l}1: 14,26,32,39,58 \\
138, \underline{146}, 204,212 \\
\underline{225}, 233, \underline{237}, \underline{238} \\
240, \underline{242}, \underline{244}, \underline{248} \\
\underline{251}, 252\end{array}$ & $\begin{array}{l}\text { Events added } \\
\text { based on } \\
\text { qualitative } \\
\text { interpretation: } \\
297 \\
\text { Events removed } \\
\text { based on } \\
\text { qualitative } \\
\text { interpretation: } \\
146,225,237 \text {, } \\
238,242,244 \text {, } \\
248,251\end{array}$ \\
\hline
\end{tabular}


Table A7.4: Summary descriptions of building blocks of Sustainable Connections. (continued)

\begin{tabular}{|c|c|c|c|}
\hline $\begin{array}{l}\text { Building } \\
\text { block }\end{array}$ & Summary Description & Modules & Discrepancies \\
\hline $2-\mathrm{F}$ & $\begin{array}{l}\text { In } 1998 \text { facilities are established at Moerdijk that allow Shell } \\
\text { to supply } \mathrm{CO}_{2} \text { to Omya and the exchange is implemented } \\
\text { in } 1999 \text {. In } 2003 \text { Omya starts looking for additional sources } \\
\text { of } \mathrm{CO}_{2} \text {. Slibverwerking Noord-Brabant (SNB) is found as } \\
\text { a potential partner and the exchange between the two } \\
\text { companies is implemented in } 2004 \text {. In August } 2004 \text { the port } \\
\text { authority of Moerdijk and the Business and Industry Circle } \\
\text { of Moerdijk (BIM) decide that they want to stimulate the } \\
\text { reuse of residual materials at the industrial park. They use } \\
\text { exchanges between Shell, Essent and Kolb, and the exchange } \\
\text { between Omya and SNB as example. In } 2006 \text { the province } \\
\text { of Noord-Brabant and the company Brabant water decide to } \\
\text { study the possibility to reuse wastewater at the industrial } \\
\text { park of Moerdijk. A similar idea is developed by AZN and SNB } \\
\text { in } 2008 \text {. In the same year the province of Noord-Brabant } \\
\text { starts a program called Proeftuin Schoon Bedrijventerrein } \\
\text { Moerdijk, which aims at the sustainable development of } \\
\text { the industrial park. The province and the port authority of } \\
\text { Moerdijk also made an inventory of potential symbiotic } \\
\text { exchanges at the industrial park in order to make better } \\
\text { informed decisions on the location of new companies. }\end{array}$ & $\begin{array}{l}1: 15,23,122,132 \\
153,165,206,259 \\
265,276,305,314 \\
\underline{321}\end{array}$ & $\begin{array}{l}\text { Events removed } \\
\text { based on } \\
\text { qualitative } \\
\text { interpretation: } \\
321\end{array}$ \\
\hline $2-G$ & $\begin{array}{l}\text { Shell announces in } 2004 \text { that it wants to establish a } \\
\text { Neighbors Council at Moerdijk, in order to improve } \\
\text { communication with residents around the industrial park. It } \\
\text { was decided that the Neighbors Council should also involve } \\
\text { other companies at the industrial park, as well as the port } \\
\text { authority, and invitations are sent to several citizen groups. } \\
\text { The first meeting takes place in April 2004. An independent } \\
\text { chairman is chosen in the second meeting, after which } \\
\text { meetings take place regularly. The council discusses various } \\
\text { developments that occur in the region, including those } \\
\text { reported in other building blocks. }\end{array}$ & $\begin{array}{l}1: 145,149,154,159 \\
160,183,188,223\end{array}$ & $\begin{array}{l}\text { Events added } \\
\text { based on } \\
\text { qualitative } \\
\text { interpretation: } \\
237,248,251, \\
266,284,295, \\
299,308\end{array}$ \\
\hline $2-\mathrm{H}$ & $\begin{array}{l}\text { In March } 2004 \text { the company Heijmans receives a permit for } \\
\text { the construction of an asbestos processing facility that is to } \\
\text { be constructed at the industrial park of Moerdijk. The plans } \\
\text { are discussed by the Neighbors Council around the time that } \\
\text { the company publicly announces the plans. The plans are } \\
\text { eventually withdrawn. }\end{array}$ & - & $\begin{array}{l}\text { This building } \\
\text { block (146, } \\
\text { 238) was not } \\
\text { identified as a } \\
\text { separate module } \\
\text { by the modularity } \\
\text { algorithm (likely } \\
\text { due to the small } \\
\text { number of } \\
\text { events), but we } \\
\text { interpret this as } \\
\text { an independent } \\
\text { building block. }\end{array}$ \\
\hline
\end{tabular}


Table A7.5: Summary descriptions of projects that are part of Sustainable Connections.

\begin{tabular}{|c|c|c|c|}
\hline Subsequence & Summary Description & Modules & Discrepancies \\
\hline \multirow[t]{3}{*}{$2-1$} & $\begin{array}{l}\text { The declaration of intent for Sustainable Connections } \\
\text { was signed in April 2009. In the same month a starting } \\
\text { conference for a new approach to the reachability of the } \\
\text { industrial park of Moerdijk was organized, which is one of } \\
\text { the themes in the Sustainable Connections initiative. In May } \\
2009 \text { the province of Noord-Brabant and the municipality } \\
\text { of Moerdijk start an initiative that allows companies to } \\
\text { apply for their permits in one location and a year later } \\
\text { the legislation on permits is also changed to make permit } \\
\text { processes easier. In } 2010 \text { the port authority publishes an } \\
\text { evaluation of the Sustainable Connections initiative and the } \\
\text { DHM initiative. }\end{array}$ & $\begin{array}{l}1: 321,322,328,370 \\
387,402,404,407 \\
440\end{array}$ & $\begin{array}{l}\text { Events added } \\
\text { based on } \\
\text { qualitative } \\
\text { interpretation: } \\
399,444 \\
\text { Events removed } \\
\text { based on } \\
\text { qualitative } \\
\text { interpretation: } \\
424,456,463 \text {, } \\
485,490\end{array}$ \\
\hline & $\begin{array}{l}\text { The parties to Sustainable Connections and DHM decide to } \\
\text { continue their cooperation in 2011. A new declaration of } \\
\text { intent for Sustainable Connections was signed, and the DHM } \\
\text { initiative was integrated in the Sustainable Connections } \\
\text { initiative. }\end{array}$ & $\begin{array}{l}\text { 2: 410, 414, 424, 438, } \\
439,450,453,460 \\
461\end{array}$ & \\
\hline & $\begin{array}{l}\text { After DHM was integrated into the Sustainable Connections } \\
\text { initiative, the publication of the environmental monitoring } \\
\text { reports also became an integrated part of the project } \\
\text { as a whole. In October } 2011 \text { the parties to Sustainable } \\
\text { Connections establish a new multiannual program. There } \\
\text { was also a discussion on the possibility to add educational } \\
\text { organizations to the project group, but it was decided not to } \\
\text { do that for the time being. }\end{array}$ & $\begin{array}{l}3: 447,448,456,463 \\
468,485,488, \underline{490}\end{array}$ & \\
\hline 2-] & $\begin{array}{l}\text { A project group of Sustainable Connections that focuses } \\
\text { on water reuse starts an exploratory study, which reached } \\
\text { its final phase in May } 2010 \text {. Participants to the project } \\
\text { organized educational events on the theme for young } \\
\text { people. In October } 2010 \text { the project group publishes a } \\
\text { report with recommendations. }\end{array}$ & $\begin{array}{l}\text { 1: } 331,365,385,386 \\
403\end{array}$ & \\
\hline
\end{tabular}


Table A7.5: Summary descriptions of projects that are part of Sustainable Connections. (continued)

\begin{tabular}{|c|c|c|c|}
\hline Subsequence & Summary Description & Modules & Discrepancies \\
\hline \multirow[t]{3}{*}{$2-K$} & $\begin{array}{l}\text { The main project of Sustainable Connections revolves } \\
\text { around the development of a pipeline infrastructure for the } \\
\text { exchange of energy, heat, water, and residual streams. The } \\
\text { first part of a heat network was under development as a pilot } \\
\text { in September 2009, based on an ongoing initiative by Bewa, } \\
\text { who supplies heat to is neighbors DCS and Bolsius. DCS later } \\
\text { established a pipeline under its terrain which allowed Bewa } \\
\text { to receive feedstocks from the docks. In November } 2011 \\
\text { DCS and Bewa were expanding their cooperation again. DCS } \\
\text { would now have its dock heated with residual heat of Bewa. }\end{array}$ & $\begin{array}{l}1: 338,348,358,378 \\
390,437,452,462 \\
486\end{array}$ & \multirow[t]{3}{*}{$\begin{array}{l}\text { Events added } \\
\text { based on } \\
\text { qualitative } \\
\text { interpretation: } \\
424\end{array}$} \\
\hline & $\begin{array}{l}\text { The municipality of Moerdijk, the province of Noord- } \\
\text { Brabant and the national government sign an administrative } \\
\text { agreement to realize nine plans that are bundled in a } \\
\text { program called Moerdijk Meer Mogelijk. This includes the } \\
\text { development of a second industrial park that is named } \\
\text { Logistical Park Moerdijk. In } 2010 \text { a feasibility study is } \\
\text { performed in order to investigate whether the heat net that } \\
\text { was established between Bewa, DCS and Bolsius can also } \\
\text { be established elsewhere in the industrial park of Moerdijk. } \\
\text { One of the ideas is to have the heat net branch out to the } \\
\text { newly planned Logistical Park Moerdijk. During an excursion } \\
\text { to the WarmCO2 initiative in Zeeland, representatives of } \\
\text { the project Sustainable Connections, the province of Noord- } \\
\text { Brabant, and the municipality of Moerdijk sign an agreement } \\
\text { of cooperation on the development of an infrastructure } \\
\text { and an exploitation company for the exchange of residual } \\
\text { materials. In August } 2010 \text { the existing heat network was } \\
\text { being expanded. An exploitation company was to be } \\
\text { established and an infrastructure for the exchange of steam } \\
\text { between Kolb and Bertschi was being developed. }\end{array}$ & $\begin{array}{l}\text { 2: } 337,374,380,382 \\
392,395\end{array}$ & \\
\hline & $\begin{array}{l}\text { In the later stages of the development of the heat } \\
\text { infrastructure, there were plans to eventually expand the } \\
\text { heat infrastructure to Logistical Park Moerdijk as well as } \\
\text { greenhouses in the Spiepolder. }\end{array}$ & $\begin{array}{l}\text { 3: } 398,419,420,422 \\
483\end{array}$ & \\
\hline $2-L$ & $\begin{array}{l}\text { The Business and Industry Circle of Moerdijk (BIM) started } \\
\text { an initiative in } 2009 \text { that is dedicated to the concept } \\
\text { of frontrunners (in sustainable development). The first } \\
\text { companies to be proclaimed frontrunners are DCS and } \\
\text { SNB, because of the residual material exchanges that the } \\
\text { companies had established. The BIM then called for new } \\
\text { nominees. Among the new nominees are ATM Martens en } \\
\text { van Oord, and the Markland College. }\end{array}$ & $\begin{array}{l}1: 347,349,364,373, \\
376,383,397,411 \\
433,454\end{array}$ & $\begin{array}{l}\text { Events removed } \\
\text { based on } \\
\text { qualitative } \\
\text { interpretation: } \\
349,373,397\end{array}$ \\
\hline
\end{tabular}


Table A7.5: Summary descriptions of projects that are part of Sustainable Connections. (continued)

\begin{tabular}{|c|c|c|c|}
\hline Subsequence & Summary Description & Modules & Discrepancies \\
\hline $2-M$ & $\begin{array}{l}\text { The Neighbors Council never became a fully integrated part } \\
\text { of the Sustainable Connections collaboration. However, it } \\
\text { was used as one of the main communication channels to } \\
\text { the social environment of the collaborating parties. More } \\
\text { meetings took place than those included in the event } \\
\text { graph, but those included in the event graph are specifically } \\
\text { meetings where developments related to Sustainable } \\
\text { Connections were discussed. }\end{array}$ & - & $\begin{array}{l}\text { These events } \\
\text { (349, 373, 397, } \\
456,463,485, \\
490) \text { were not } \\
\text { identified by } \\
\text { the modularity } \\
\text { algorithm as } \\
\text { a separate } \\
\text { project, but } \\
\text { they all concern } \\
\text { meetings of the } \\
\text { Neighborhood } \\
\text { Council. }\end{array}$ \\
\hline $2-\mathrm{N}$ & $\begin{array}{l}\text { In January } 2011 \text { it was announced that a company called } \\
\text { Erca would be established next to Shell and that Shell would } \\
\text { supply the company with ethylene oxide through a pipeline. } \\
\text { Another pipeline infrastructure was established by the port } \\
\text { authority that would be used by Shell to transport steam } \\
\text { to LyondellBasell. Both pipelines were developed as one } \\
\text { integrated infrastructure. }\end{array}$ & $\begin{array}{l}\text { 1: } 399,412,443,444 \\
482\end{array}$ & $\begin{array}{l}\text { Events removed } \\
\text { based on } \\
\text { qualitative } \\
\text { interpretation: } \\
399,444\end{array}$ \\
\hline
\end{tabular}

Table A7.5: List of actors and issues for Sustainable Connections.

\begin{tabular}{lll}
\hline Label & Name & Type \\
\hline A123 & A \& G Milieutechniek & Company \\
\hline A125 & ABAB & Company \\
\hline A126 & Accreditation Committee & Other \\
\hline A127 & Agro Limburg & Interest organization \\
\hline A128 & Ardagh Glas & Business association \\
\hline A129 & ATM & Company \\
\hline A130 & Attero & Company \\
\hline A131 & Austrian Energy & Company \\
\hline A132 & Avans Hogeschool & Company \\
\hline A133 & AZN & Knowledge Institute \\
\hline A134 & Basell & Company \\
\hline A135 & Berscherming Van Dieren & Company \\
\hline A136 & Bertschi & Interest organization \\
\hline A137 & Bewa & Company \\
\hline A138 & Business and Industry Circle Moerdijk & Company \\
\hline A139 & BizWorld & Business Association \\
\hline A140 & BMC Moerdijk & Other \\
\hline
\end{tabular}




\begin{tabular}{|c|c|c|}
\hline A142 & Environmental Federation of Brabant & Interest organization \\
\hline A143 & Bolsius & Company \\
\hline A144 & Economic Development Agency of Brabant & Economic development \\
\hline A145 & Brabantse Delta & Water authority \\
\hline$\overline{A 146}$ & Brabant Water & Company (utilities) \\
\hline A147 & BRAMM & Company \\
\hline A148 & BZW & Business Association \\
\hline A149 & CDA Noord-Brabant & Political party (provincial) \\
\hline A150 & CDA Moerdijk & Political party (municipal) \\
\hline A151 & CDS & Company \\
\hline A152 & CHC Kreko Group & Company \\
\hline$\overline{A 153}$ & Chemie Pack & Company \\
\hline A154 & City Council Klundert & Interest organization \\
\hline A155 & CNC Grondstoffen & Company \\
\hline$\overline{A 156}$ & Coatex & Company \\
\hline A157 & Chamber of Commerce & Chamber of Commerce \\
\hline A158 & Combined Cargo Terminals & Company \\
\hline A159 & Council of State & Council of State \\
\hline A160 & D66 Noord-Brabant & Political party (provincial) \\
\hline$\overline{A 161}$ & DBV & Consultant \\
\hline A162 & DCS & Company \\
\hline A163 & Deloitte & Company \\
\hline A164 & Delta & Company (utilities) \\
\hline A165 & Delta Marine Terminals & Company \\
\hline A166 & DEP & Foundation/Cooperation \\
\hline A167 & Department of Waterways and Public Works & Government agency \\
\hline A168 & Deege Coating Moerdijk & Company \\
\hline A169 & DSV Solutions & Company \\
\hline A170 & Dura Vermeer & Company \\
\hline A171 & Dutch Economic Institute & Other \\
\hline A172 & Dutch Investment Bank & Bank \\
\hline $\bar{A} 173$ & Eneco & Company \\
\hline A174 & Energy Systems & Company \\
\hline A175 & EPR & Company \\
\hline A176 & EPZ & Company \\
\hline$\overline{\mathrm{A} 177}$ & Erca & Company \\
\hline A178 & ESPO & Company \\
\hline A179 & Essent & Company \\
\hline A180 & European Committee & European Committee \\
\hline A181 & European Investment Bank & Bank \\
\hline$\overline{\mathrm{A} 182}$ & Fire Department & Fire department \\
\hline
\end{tabular}




\begin{tabular}{|c|c|c|}
\hline A183 & GCA & Company \\
\hline A184 & GGD & Health organization \\
\hline A185 & Greenbrothers & Company \\
\hline A186 & Grontmij & Consultant \\
\hline A187 & Hart van Moerdijk & Interest organization \\
\hline A188 & Heijmans & Company \\
\hline A189 & Hoogheemraadschap & Water authority \\
\hline A190 & Independent Party Moerdijk & Political party (municipal) \\
\hline A191 & Inspection Environmental Hygiene & Public agency \\
\hline A192 & KNV & Consultant \\
\hline A193 & Kolb & Company \\
\hline A194 & Kolpron & Consultant \\
\hline A195 & Koninklijk Nederlands Vervoer & Business association \\
\hline A196 & LEI & Knowledge institute \\
\hline A197 & Association for Agriculture and Horticulture & Interest organization \\
\hline A198 & Lyondell Basell & Company \\
\hline A199 & Markland College & Knowledge institute \\
\hline A200 & Martens \& Van Oord & Company \\
\hline A201 & Ministry of Agriculture Nature and Fishery & National government \\
\hline A202 & Ministry of Economic Affairs & National government \\
\hline A203 & Ministry of Housing, Spatial Development and the Environment & National government \\
\hline $\mathrm{A} 204$ & Ministry of Social Affairs & National government \\
\hline A205 & Ministry of Waterways and Public Works & National government \\
\hline A206 & Municipality of Breda & Municipal government \\
\hline A207 & Municipality of Drimmelen & Municipal government \\
\hline A208 & Municipality of Moerdijk & Municipal government \\
\hline A209 & Municipality of Zevenbergen & Municipal government \\
\hline $\mathrm{A} 210$ & Namascor & Municipal government \\
\hline A211 & National Government (not further specified) & National government \\
\hline A212 & Nature \& Environment & Interest organization \\
\hline $\mathrm{A} 213$ & NCB & Other \\
\hline A214 & NIV Capital & Other \\
\hline $\mathrm{A} 215$ & NOP & Business association \\
\hline A216 & Novem & Governmental agency \\
\hline A217 & NUON & Company \\
\hline A218 & NVP & Business association \\
\hline A219 & Omya & Company \\
\hline A220 & Pnem & Company \\
\hline $\mathrm{A} 221$ & Port authority of Moerdijk & Port authority \\
\hline A222 & Poultry Farmers & Farmers \\
\hline$A 223$ & Province of Noord-Brabant & Provincial government \\
\hline
\end{tabular}


Annex 2

\begin{tabular}{|c|c|c|}
\hline A224 & PvdA Noord-Brabant & Political party (provincial) \\
\hline A225 & PvdA Moerdijk & Political Party (municipal) \\
\hline A226 & Residents of Moerdijk & Civilians \\
\hline A227 & Residents of Strijen & Civilians \\
\hline A228 & Rexam Glas & Company \\
\hline A229 & Ritchie Bros & Company \\
\hline A230 & RMD & Consultant \\
\hline A231 & RDM Campus & Other \\
\hline A232 & Royal Commissioner of Noord-Brabant & Government \\
\hline A233 & RWZI Bath & Company (utilities) \\
\hline$\overline{A 234}$ & SBBM & Interest organization \\
\hline A235 & Schutz & Company \\
\hline A236 & Shell & Company \\
\hline A237 & Siemens & Company \\
\hline A238 & SNB & Company \\
\hline A239 & Foundation Moerdijkse Hoek & Foundation \\
\hline A240 & Strijen & Civilians \\
\hline A241 & Strijenas & Civilians \\
\hline A242 & Tetrapak & Company \\
\hline A243 & Neighboring company of Bewa & Company \\
\hline A244 & Thermphos & Company \\
\hline A245 & TNO & Research institute \\
\hline A246 & Urgenda & Interest organization \\
\hline A247 & Van Gansewinkel & Company \\
\hline A248 & Van Wouwe & Chair Neighbors Council \\
\hline A249 & Vereniging Milieugroep Moerdijk & Interest organization \\
\hline A250 & Village Council Zevenbergen & Interest organization \\
\hline A251 & Village Council Zevenbergschen Hoek & Interest organization \\
\hline A252 & Visser Smit Hanab & Company \\
\hline A253 & VVD Noord-Brabant & Political party (provincial) \\
\hline A254 & VVD Moerdijk & Political party (municipal) \\
\hline A255 & VVD Netherlands & Political party (national) \\
\hline A256 & WarmCO2 & Company (joint venture) \\
\hline A257 & Water Authority & Water authority \\
\hline A258 & Witteveen + Bos & Consultant \\
\hline A259 & Wuppermann Staal & Company \\
\hline A260 & ZHD Staal Terminal & Company \\
\hline A261 & Southern Association of Agriculture and Horticulture & Interest organization \\
\hline A262 & ZWAZI & \\
\hline 178 & Acquisition & \\
\hline 179 & Air & \\
\hline
\end{tabular}




\begin{tabular}{|c|c|}
\hline 180 & Asbestos \\
\hline 181 & Biofuels \\
\hline 182 & Biogas \\
\hline 183 & Biomass \\
\hline 184 & BSE \\
\hline 185 & Chemicallndustry \\
\hline 186 & Clustering \\
\hline 187 & $\mathrm{CO} 2$ \\
\hline 188 & Cogeneration \\
\hline 189 & Communication \\
\hline 190 & CSR \\
\hline 191 & Demography \\
\hline 192 & Dioxine \\
\hline 193 & EconomicCrisis \\
\hline 194 & Economy \\
\hline 195 & Education \\
\hline 196 & Employment \\
\hline 197 & Energy \\
\hline 198 & EnergyWeb \\
\hline 199 & Environment \\
\hline 100 & Ethylene \\
\hline 101 & European Support \\
\hline 102 & Expansion Industrial Area \\
\hline 103 & Exploitation Company \\
\hline 104 & Farming Rights \\
\hline 105 & Feathers \\
\hline 106 & Fire ChemiePack \\
\hline 107 & Food \\
\hline 108 & Fossil \\
\hline 109 & Frontrunners \\
\hline 1110 & Gas \\
\hline $\mid 111$ & Green Energy \\
\hline 1112 & Greenhouses \\
\hline 113 & Health \\
\hline 114 & Heat \\
\hline 1115 & Heavy Industry \\
\hline 116 & Housing \\
\hline 117 & Incineration \\
\hline 118 & Infrastructure \\
\hline 119 & Knowledge \& Innovation \\
\hline 1120 & Livability \\
\hline
\end{tabular}


Annex 2

\begin{tabular}{|c|c|}
\hline 1121 & Logistical Park Moerdijk \\
\hline 1122 & Logistics \\
\hline 1123 & Manure \\
\hline 1124 & Manure Contribution \\
\hline 125 & Manure Quality \\
\hline 1126 & Manure Surplus \\
\hline 1127 & Mobility \\
\hline |128 & Moerdijk Meer Mogelijk \\
\hline 1129 & Monitoring \\
\hline 1130 & National Support \\
\hline 131 & Nature \\
\hline 1132 & Nuisance \\
\hline 1133 & Organizational Structure \\
\hline 1334 & Park Management \\
\hline 135 & Permits \\
\hline 136 & Phosphate \\
\hline 137 & Pollution \\
\hline 1138 & Redevelopment \\
\hline 1139 & Regional Cooperation \\
\hline 140 & Regional Economy \\
\hline 141 & Regional Governance \\
\hline 1142 & Regulations \\
\hline 1143 & Relocation \\
\hline 1144 & Reuse \\
\hline 1145 & Safety \\
\hline 146 & Society \\
\hline 1147 & Steam \\
\hline 1148 & Strategic Vision Port \\
\hline 149 & Sustainability \\
\hline 1150 & Sustainable Connections \\
\hline 151 & Sustainable Entrepreneurship \\
\hline 1152 & Sustainable Industrial Parks \\
\hline 1153 & Sustainable Innovative Industrial Park \\
\hline 1154 & Triple Helix \\
\hline 1155 & Use of Space \\
\hline 1156 & Utility Center \\
\hline 157 & Utility Sharing \\
\hline 158 & Wastes \\
\hline 1159 & Water \\
\hline 160 & Wind \\
\hline
\end{tabular}


